Universitat Politècnica de València

Departamento de Máquinas y Motores Térmicos

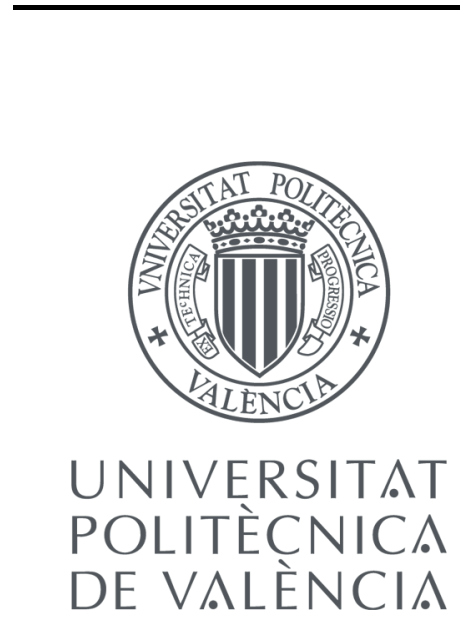

\title{
ANALYSIS OF THE POTENTIAL OF SI LEAN COMBUSTION AND CAI COMBUSTION IN A TWO-STROKE SPARK-ASSISTED GASOLINE ENGINE
}

Doctoral THEsis

Presented by:

Jorge Valero Marco

Directed by:

Dr. J. Javier López

Valencia, February 2020 



\section{Doctoral THEsis}

\section{ANALYSIS OF THE POTENTIAL OF SI LEAN COMBUSTION AND CAI COMBUSTION IN A TWO-STROKE SPARK-ASSISTED GASOLINE \\ ENGINE}

Presented by: Jorge Valero Marco

Directed by: Dr. J. Javier López

Tribunal:

President: Dr. José GALINDO

Secretary: Dr. Francisco V. TINAUT

Vocal: Dr. Hua ZHAO

External Evaluators:

Dr. Hua ZHAO

Dr. Per TUNESTÅL

Dr. Andrés MELGAR

Valencia, February 2020 



\section{Resumen}

Los motores de combustión interna viven un momento en el que deben ser más limpios y eficientes de lo que han sido hasta la fecha. Este cambio viene dado por el endurecimiento global y continuado de las normativas anticontaminación vinculadas a su comercialización, que tratan de establecer el camino para proteger la salud de las personas que conviven con éstos, y avanzar hacia unos modelos más sostenibles de uso de las energías disponibles.

Enmarcado en este contexto, el trabajo de investigación desarrollado en esta tesis se ha centrado en continuar avanzando en el camino para la mejora de los motores de encendido provocado. Para este fin se ha empleado un motor prototipo de dos tiempos con la idea de estudiar la combustión por encendido provocado en mezclas pobres (lean $S I$ ) y la combustión mediante el autoencendido controlado de la mezcla $(C A I)$. De esta forma la operación tradicional en condiciones estequiométricas de este tipo de motores es reemplazada, en busca de una mejora en la eficiencia energética, y una reducción, al mismo tiempo, de las emisiones contaminantes.

Este trabajo se ha abordado desde un punto de vista principalmente experimental. En primer lugar se ha trabajado sobre el motor, operando los diferentes modos de combustión, fijando las estrategias de operación, y obteniendo gran cantidad de datos sobre el funcionamiento del motor en las diferentes regiones del mapa motor. Y, en segundo lugar, estos datos han sido analizados y estudiados en detalle para detectar los potenciales y las debilidades de cada modo de combustión aplicado a las diferentes condiciones de funcionamiento del motor.

La combinación de estos dos trabajos ha servido para obtener gran cantidad de datos sobre las eficiencias alcanzables y los valores de emisiones obtenidos en cada modo de operación. $\mathrm{Y}$, adicionalmente, se ha estudiado también la influencia de la recirculación de gases quemados en el motor $(E G R)$ sobre la combustión, como estrategia para reducir las emisiones y controlar la combustión a altas cargas en ambos modos de operación.

En cuanto a la parte analítica del trabajo, se han detectado diversos problemas. En primer lugar, lidiar con la alta variabilidad de la combustión en este motor, y en segundo lugar, el acople de dos modos de combustión totalmente diferentes. Esto ha generado la necesidad de analizar los datos obtenidos de forma que nos den algo más de información sobre la forma en que se ha desarrollado la combustión. Para dar solución a estos dos aspectos, se ha planteado un punto de vista diferente a la hora de afrontar el diagnóstico de la combustión (análisis ciclo a ciclo) y se ha propuesto una metodología de análisis de la combustión que nos permita estudiar, desde un punto de vista más detallado, la forma en que se ha desarrollado la combustión, y tratar de diferenciar así los diferentes eventos de combustión que se desarrollan en el motor.

Todo este trabajo ha dado sus frutos en forma de la definición de las estrategias para operar el motor en su totalidad mediante la combinación de los modos lean SI y CAI. Esta solución, en comparación con los motores actuales Euro VI, ha presentado unos valores de eficiencia superiores cumpliendo con los límites establecidos de emisiones, mostrando de esta forma un elevado potencial de estos modos de 
combustión aplicados a los motores de encendido provocado, así como una posibilidad real de implementación en los vehículos venideros. 


\section{Resum}

Els motors de combustió interna alternatius es troben a un moment en el que deuen ser mes nets i eficients que mai. Aquest canvi ve motivat per l'augment de l'exigència de les normatives reguladores d'emissions contaminants vinculades a la seua comercialització, que tracten d'establir el camí per a protegir la salut de les persones que conviuen amb aquests, i avançar cap a uns models mes sostenibles d'aprofitament de les energies disponibles.

Dins d'aquest context, el treball d'investigació realitzat en aquesta tesi, ha girat al voltant de la millora dels motors d'encesa provocada. Per a aquesta finalitat, s'ha emprat un prototip de motor de dos temps amb l'idea d'estudiar la combustió per encesa provocada amb dosatges pobres (lean SI) i la combustió mitjançant una autoencesa provocada per les condicions termodinàmiques de la cambra de combustió $(C A I)$. D'aquesta manera l'operació tradicional en condicions estequiomètriques d'aquest tipus de motors és substituïda, buscant una millora en l'eficiència energètica i una reducció al mateix temps de les emissions contaminants.

Aquest treball s'ha abordat des d'un punt de vista fonamentalment experimental. En primer lloc s'ha treballat sobre el motor, operant els diferents modes de combustió, fixant les estratègies d'operació, i obtenint gran quantitat de dades sobre el funcionament del motor en les diferents regions del seu mapa d'operació. I en segon lloc, aquestes dades han sigut analitzades i estudiades en detall per a detectar els potencials i les debilitats de cada mode de combustió aplicat a les diferents condicions de funcionament del motor.

La combinació d'aquests dos treballs ha servit per a obtindre gran quantitat de dades sobre les eficiències assolibles $\mathrm{i}$ els valors d'emissions obtinguts en cada mode d'operació. I, a més, s'ha estudiat la influència de la recirculació de gasos d'escapament al motor $(E G R)$ sobre la combustió, com a estratègia per a reduir les emissions contaminants i controlar la combustió a altes càrregues en els dos modes de combustió.

Quant a la part analítica del treball, s'han detectat diversos problemes. En primer lloc, tractar amb l'alta variabilitat de la combustió en aquest motor, i en segon lloc, l'acoblament de dos modes de combustió totalment diferents. Açò ha generat la necessitat d'analitzar les dades obtingudes de forma que ens donen més informació sobre la forma en que s'ha desenvolupat la combustió. Per a donar solució a aquests dos aspectes, s'ha plantejat un punt de vista diferent a l'hora de realitzar el diagnòstic de la combustió (un anàlisis cicle a cicle) i s'ha proposat una metodologia d'anàlisi de la combustió que permeta estudiar, des d'un punt de vista més detallat, la forma en que s'ha desenvolupat la combustió, i tractar de diferenciar així, les diferents combustions al motor.

Tot aquest treball ha donat uns resultats en forma de la definició de les estratègies per a operar el motor en la seva totalitat mitjançant la combinació dels modes de combustió lean SI i CAI. Aquesta solució, en comparació amb els actuals motors Euro VI, ha ofert uns valors d'eficiència superiors, acomplint amb les limitacions establertes d'emissions, mostrant d'aquesta manera un elevat potencial d'aquests modes aplicats 
als motors d'encesa provocada, així com una possibilitat real d'implantació en els vehicles que estan per vindre. 


\begin{abstract}
Internal combustion engines are in a situation in which they must be cleaner and more efficient than they have ever been. This change is motivated by the global and continuous evolution of the emissions regulations linked to their commercialization, which try to establish the path to protect the human health, and move towards more sustainable energetic models.

Framed in this context, the research work developed in this $\mathrm{PhD}$ thesis has focused on the way to continue improving the spark ignition engines. To this end, a prototype two-stroke engine has been used, with the idea of studying the Spark Ignited combustion in lean conditions (lean SI) and the Controlled Auto-Ignition combustion $(C A I)$. In this way, the traditional $S I$ operation in stoichiometric conditions of this type of engines is replaced, looking for an improvement in fuel efficiency, and a reduction, at the same time, of the pollutant emissions.
\end{abstract}

This work has been approached mainly from an experimental point of view. Firstly, different works have been performed on the engine: operation of the different combustion modes, definition of the operating strategies, and compilation of experimental data coming from the engine operation in the different regions of the engine map. And, secondly, all this data has been analyzed and studied in detail to define the strengths and weaknesses of each combustion mode applied to the different engine operating conditions.

The combination of these two works has led to obtain a large amount of data about the achievable efficiencies and the emissions values obtained in each combustion mode. And, in addition, the influence on the combustion of the burned gases recirculation in the engine $(E G R)$, has also been studied as a strategy to reduce emissions, and control the combustion at high loads in both combustion modes. Regarding the analytical part of the work, several problems have been detected. Firstly, the high combustion variability in this engine, and secondly, the coupling of two completely different combustion modes. These issues have generated the need to analyze the data obtained in a more detailed way, in order to get more information about the combustion process. To solve these two aspects, first, a different point of view has been raised when dealing with the combustion diagnosis, the cycle to cycle analysis, and secondly, a combustion analysis methodology has been proposed in order to allow the combustion analysis from a more detailed point of view. In this way the combustion development is studied, and thus, the differentiation between the different combustion events that take place in the engine can be studied.

All this work has been useful to define the strategies to operate the whole engine map by combining the lean SI and CAI combustion modes. This solution, compared to the current Euro VI engines, has presented higher efficiency values complying with the established emissions limits, showing in this way, the high potential of these combustion modes applied to $S I$ engines, as well as a real possibility of its implementation in future vehicles. 

"Genius is one percent inspiration, ninety-nine percent perspiration"

Thomas A. Edison

A los creadores de este lienzo 



\section{Agradecimientos}

This whole document has been conceived in English. However it has been created in Spain, and therefore most of the people to whom these acknowledgements are addressed have another language in their mind. This is the reason why this section, from here, has been written in Spanish, our native language.

Existen diversas formas de enfocar unos agradecimientos, dependiendo del alcance y la profundidad que se les quiera dar. Sin embargo, tras reflexionarlo un poco, el querer agradecer a todas las personas que hayan aportado su granito de arena directa o indirectamente sería una tarea muy extensa y, en consecuencia, también restaría profundidad a las personas que realmente han puesto mucho esfuerzo y dedicación en esto. Por tanto, sin olvidar en mis adentros a un colectivo mucho más amplio, he decidido orientar las siguientes líneas fundamentalmente a unas pocas figuras muy influyentes para mí en este camino.

En primer lugar Javi, mi director de tesis. Un gran referente a seguir, y quizás la persona más inteligente que conozco. Desde años atrás al inicio de la tesis, cuando aún paseaba por las clases de la universidad, aquella asignatura de Ampliación de Motores de Combustión quedó guardada en el apartado de asignaturas especiales. La temática, desde un inicio, ya me parecía interesante. Sin embargo, el aporte personal que le diste marcó la diferencia. Fue una asignatura tan bien explicada, y preparada con tanto mimo, que podríamos decir que tuvo gran peso en el resto de las decisiones tomadas hasta el momento, como, por ejemplo, la realización de mi primer PFC (de la diplomatura de ingeniería técnica industrial) y más adelante el regreso al departamento, pese a que en aquellos momentos ya me había distanciado un poco de aquel mundo de los motores y la mecánica. Debes saber, por tanto, que tú has tenido un gran peso en la toma de todas esas decisiones. Más concretamente, volviendo a la tesis, es innegable que una gran parte del trabajo también es tuyo, por tu guía, esfuerzo y dedicación en este proyecto, que no ha sido poco. Personalmente también he visto unas grandes cualidades en ti de las que espero que se me haya contagiado algo: paciente, dispuesto a compartir tu tiempo siempre que sea necesario, humilde, riguroso y capaz. $\mathrm{Y}$ un apunte que he visto siempre muy loable, es que, pase lo que pase, nunca has tenido una mala respuesta para nadie bajo ninguna circunstancia.

En segundo lugar, mis padres. Si se reflexiona bien todo lo que envuelve este vínculo, al fin y al cabo es una vida entregada al crecimiento de otra. Se podría uno incluso preguntar, ¿de quién es la tesis? Quizá de ellos desde un principio, ya que desde que nacemos somos como un lienzo en blanco que debe ser rellenado y guiado ya desde un momento tan temprano en que uno mismo no sabe hacia dónde avanzar. Por tanto, no solo la tesis sino cada uno de los pasos que he ido dando hasta el momento, de una forma o de otra, sólo han sido posibles gracias a sus decisiones y su sacrificio constante sin esperar nada a cambio.

Por último, mi abuelo Rafael también merece una mención especial en todo esto, ya que él ha sido la persona que ha puesto en mis manos, desde pequeño, las herramientas como un juguete, y más adelante, me ha transferido una valiosísima sabiduría en todo lo que las rodea. Siempre ha tenido una pasión especial por la mecánica y un gran conocimiento, aunque nunca se ha dedicado a ello 
profesionalmente. Una persona tan capaz como él ha sido para mí un gran maestro y una gran influencia.

Resulta difícil afirmar que la tesis es un logro individual con tales personas, y muchas otras que no he mencionado, detrás. 


\section{Table of Contents}

1 Introduction 1

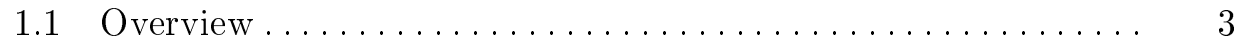

1.2 Context ........................ 11

1.3 Previous related works $\ldots \ldots \ldots \ldots \ldots \ldots \ldots \ldots \ldots \ldots \ldots \ldots$

1.4 Thesis document structure ................... 13

Bibliography $\ldots \ldots \ldots \ldots \ldots \ldots \ldots \ldots \ldots \ldots \ldots \ldots \ldots \ldots$

2 Combustion in gasoline engines $\quad 17$

2.1 Introduction $\ldots \ldots \ldots \ldots \ldots \ldots \ldots \ldots \ldots \ldots \ldots \ldots \ldots \ldots$

2.2 The conventional SI engine and its combustion process . . . . . 20

2.2.1 Premixed turbulent combustion review .......... 20

2.2.1.1 Spark and flame initiation .......... 20

2.2.1.2 Initial flame kernel development . . . . . . 21

2.2.1.3 Turbulent flame propagation .......... 22

2.2.1.4 Flame termination ............... 24

2.2.1.5 Abnormal combustion, uncontrolled autoigni-

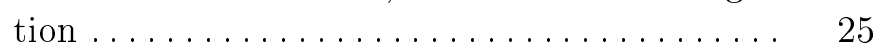

2.2.2 Exhaust emissions in SI engines ........... 27

2.2.2.1 Unburned Hydrocarbons . . . . . . . . . . 28

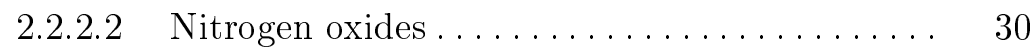

2.2.2.3 Carbon monoxide ............... 32

2.2.2.4 Particulate matter ............... 33 
2.2.2.5 Carbon dioxide $\ldots \ldots \ldots \ldots \ldots \ldots \ldots \ldots \ldots \ldots$

2.3 Strategies to improve the SI gasoline engines ........... 35

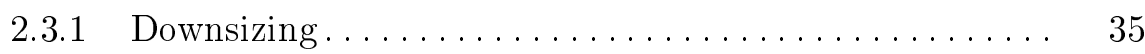

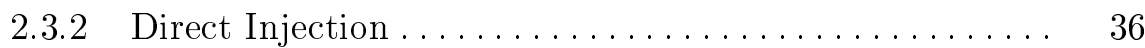

2.3.3 Variable valve Actuation systems.............. 38

2.3.4 Boosting ........................... 40

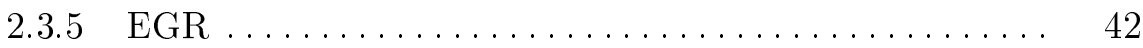

2.3.6 SI Lean Combustion........................ 44

2.3.7 Low Temperature Combustion applied to SI gasoline engines .......................... 47

2.3.7.1 The Low Temperature Combustion concept

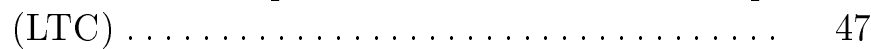

2.3.7.2 The Gasoline CAI engines............. 54

2.4 The combustion analysis $\ldots \ldots \ldots \ldots \ldots \ldots \ldots \ldots \ldots \ldots \ldots \ldots \ldots \ldots$

2.4.1 The combustion diagnostics $\ldots \ldots \ldots \ldots \ldots \ldots \ldots \ldots$

2.4.2 The SI cyclic variability and the influence on the combustion diagnostics $\ldots \ldots \ldots \ldots \ldots \ldots \ldots \ldots \ldots \ldots$

2.4.3 The combustion analysis on SI and CAI combustion

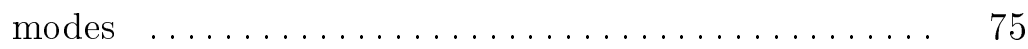

$2.5 \quad$ Summary..................................... 77

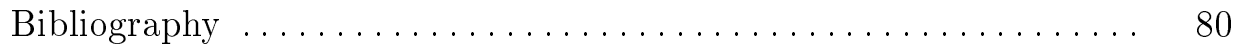

3 Thesis proposal $\quad 97$

3.1 Introduction . . . . . . . . . . . . . . . . . . . . . . . . . 99

3.2 Synthesis of the literature review $\ldots \ldots \ldots \ldots \ldots \ldots \ldots \ldots$

3.3 Thesis objectives and general methodology ............. 102

4 Experimental tools and methodology $\quad 105$

4.1 Introduction ..................................... 107

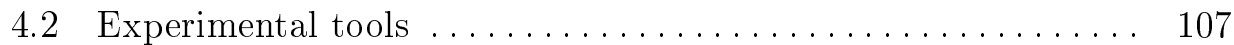

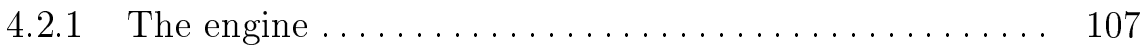

4.2.2 Test cell characteristics and equipment.......... 114 
4.3 Theoretical tools $\ldots \ldots \ldots \ldots \ldots \ldots \ldots \ldots \ldots \ldots \ldots \ldots \ldots \ldots \ldots$

4.3.1 ULCGE processing software, based on CALMEC ..... 126

4.3.2 Chemkin .............................. 127

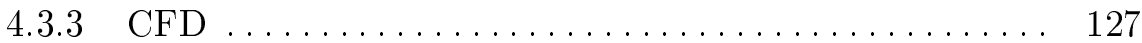

4.4 Methodological aspects ........................... 128

4.4.1 VVT position determination ................ 128

4.4 .2 Knock estimation (MAPO) . . . . . . . . . . . . . . 129

4.4.3 Estimation of the charge composition inside the cylinder 130

4.4.4 Combustion data.......................... 134

4.4.5 BSFC estimation..................... 135

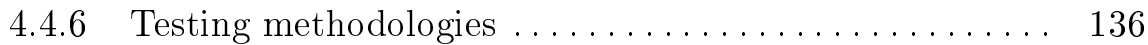

4.A Estimation of the humidity loss through the EGR system .... 140

4.B Estimation of the different mass flows inside the engine ...... 142

Bibliography ................................. 143

5 Engine peculiarities: description and analysis $\quad 147$

$5.1 \quad$ Introduction . . . . . . . . . . . . . . . . . . . . . . . . . . . . . . . . . . . 149

5.2 Different combustion modes......................... 150

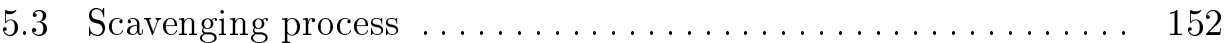

5.4 Effect of the injection and ignition systems $\ldots \ldots \ldots \ldots \ldots \ldots$

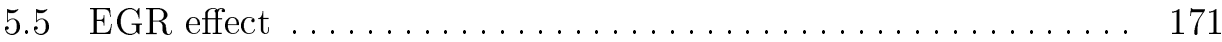

5.6 Study of the cycle to cycle variation $\ldots \ldots \ldots \ldots \ldots \ldots \ldots . \ldots \ldots$

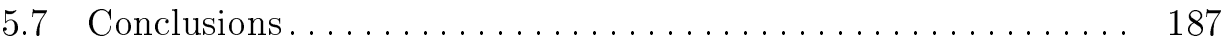

Bibliography .................................... 190

5.A Effect of IGR on the ignition delay . . . . . . . . . . . . 193

5.B Effect of the exhaust valves opening time modification over the IGR temperature . . . . . . . . . . . . . . . . . . . . . . . . . . 194

5.C DOI effect on the fuel homogenization............... 195 
6 The different operable combustion modes in the engine used 197

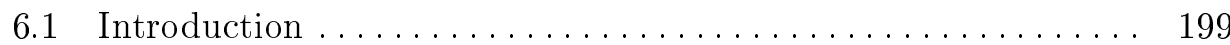

6.2 Experimental study of the diff. combustion regions in the engine 199

6.2.1 Engine operation under SI lean mixtures . . . . . . . . . 199

6.2.1.1 Equivalence ratio modification influence ..... 200

6.2.1.2 The load variation effect on the SI operation . 203

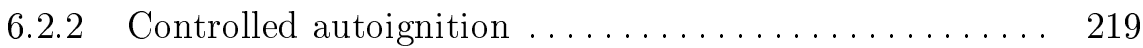

6.2.2.1 SI - CAI comparison ............... 220

6.2.2.2 Key parameters.................... 223

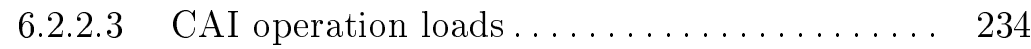

6.2.3 Hybrid modes, CAISI . . . . . . . . . . . . . . . . . . 240

6.3 Analytical approach to the different combustion modes ....... 245

6.3.1 Fundamentals of the analysis . . . . . . . . . . . 246

6.3 .2 Analysis . . . . . . . . . . . . . . . . . 250

6.3.3 Results . . . . . . . . . . . . . . . . . . . . . . . . . . 262

6.4 Conclusions ................................ 272

6.A Effect of the power stroke increase on the BSFC due to the VVT

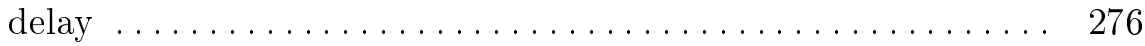

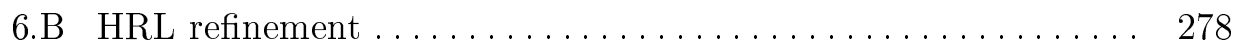

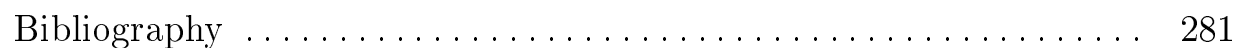

7 Conclusions and future works $\quad 285$

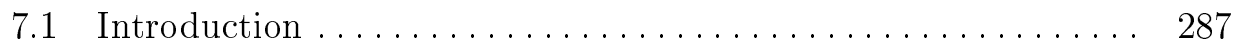

7.2 Achievements obtained in the $\mathrm{PhD}$ thesis ............ 287

7.3 The engine potential, a brief analysis . . . . . . . . . . . . . . 292

7.4 Future works .............................. 295

7.A Estimation of the theoretical results of the performance of the twin cylinder engine in standard cycles ............. 298

$\begin{array}{ll}\text { Bibliography } & 305\end{array}$ 


\section{Index of Figures}

1.1 Schematics extracted from the patent application presented by Nikolaus Otto in the United States ................. 3

1.2 Indicator diagram of an Otto engine $\ldots \ldots \ldots \ldots \ldots \ldots \ldots$

1.3 Indicator diagram of a Diesel engine $\ldots \ldots \ldots \ldots \ldots \ldots \ldots$

1.4 Implementation of the different emissions regulations in Europe, US, Japan and China $\ldots \ldots \ldots \ldots \ldots \ldots \ldots \ldots \ldots \ldots \ldots \ldots \ldots \ldots \ldots \ldots$

1.5 Values for the emissions in SI and CI engines for light passenger cars from Euro 1 to Euro $4 \ldots \ldots \ldots \ldots \ldots \ldots \ldots \ldots$

1.6 Values for the emissions in SI and CI engines for light passenger cars from Euro 5 to Euro $6 \ldots \ldots \ldots \ldots \ldots \ldots \ldots \ldots$

1.7 Evolution of the SI emissions regulations in Europe ........ 9

1.8 Evolution of the CI emissions regulations in Europe........ 9

1.9 Evolution of the $\mathrm{CO}_{2}$ emissions regulations in Europe ...... 10

2.1 Diagram of a $4 \mathrm{~S}$ cycle (above) and a $2 \mathrm{~S}$ cycle (below) representing the different phases of the cycle. ........... 19

2.2 Origin of the combustion cyclic variability $\ldots \ldots \ldots \ldots \ldots \ldots 22$

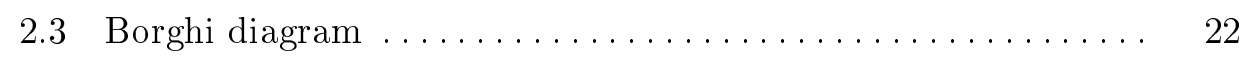

2.4 Left - Thickened flame, the spatial integral scale of the turbulence is on the same order than the thickness of the flame front. Right - Distorted flame, the scale of the turbulence is larger than the flame front thickness $\ldots \ldots \ldots \ldots \ldots \ldots \ldots$

2.5 Evolution of the pressure signal with the autoignition and apparent effect of the autoignition on the Heat Release Law (HRL) and its derivative (HRR) $\ldots \ldots \ldots \ldots \ldots \ldots \ldots \ldots$ 
2.6 Ignition delay map $(\tau)$ for an Isooctane/Air mixture in stoichiometric conditions $\ldots \ldots \ldots \ldots \ldots \ldots \ldots \ldots \ldots \ldots \ldots \ldots \ldots \ldots$

2.7 Exhaust emissions as a function of the Fuel/Air ratio ...... 29

2.8 Representation of the operating conditions for SI engines on a Fr-T diagram .............................. 31

2.9 Effect of fuel formulation on $\mathrm{CO}_{2}$ emissions $\ldots \ldots \ldots \ldots \ldots . \ldots \ldots$

2.10 Boundaries for a downsized engine map $\ldots \ldots \ldots \ldots \ldots \ldots . \ldots$

2.11 Wall-guided combustion method. Fuel spray and piston configuration......................... 37

2.12 a) Boosted engine scheme, b) Comparison between an ideal constant pressure combustion cycle naturally aspirated and

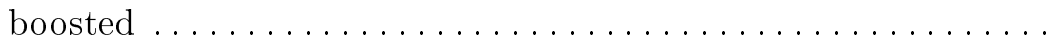

2.13 EGR rate and equivalence ratio influence on the engine net indicated thermal efficiency at medium loads for a SI engine . .

2.14 EGR influence on the ignition timing, and influence on the engine BMEP .

2.15 Operation region for lean combustion defined as a function of the engine load and the Fuel/Air ratio $\ldots \ldots \ldots \ldots \ldots \ldots$

2.16 Three way catalyst conversion efficiency for different equivalence

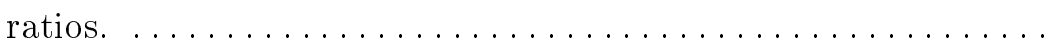

2.17 Representation of the SI, GDI, LTC and HCCI combustion

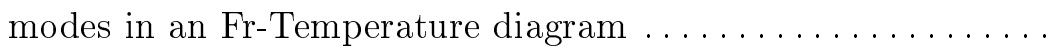

2.18 Diagram of the different achievable combustion modes in SI and CI engines $\ldots \ldots \ldots \ldots \ldots \ldots \ldots \ldots \ldots \ldots \ldots \ldots \ldots \ldots \ldots \ldots \ldots \ldots \ldots \ldots$.

2.19 Comparison between a conventional injector spray (left) and the spray developed in the PCI strategy. It can be seen that the penetration decreases and the angle of the jet increases with the angle between the two holes $\ldots \ldots \ldots \ldots \ldots \ldots \ldots \ldots$

2.20 Simulated delay times, at constant volume, for 3 different fuels. The shaded area corresponds to the representative conditions of

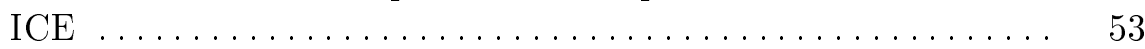

2.21 RCCI strategy, a) Facility layout, b) Main results of the RCCI operation as a function of the IMEP .............. 54

2.22 PV diagram for combustion cycles operated in SI and CAI

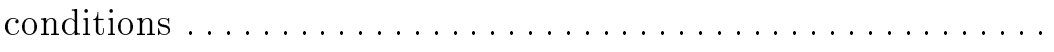


2.23 Boundary regions for CAI operation with unleaded gasoline...

2.24 Engine map proposed by Duret for a CAI-SI operation in a two

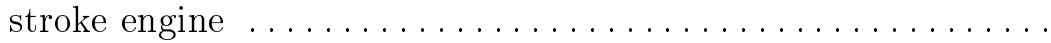

2.25 Graphical description of a NVO strategy. The exhaust and intake camshaft timings are separated from each other, creating an intermediate period where the cylinder is closed during part of the exhaust and intake strokes $\ldots \ldots \ldots \ldots \ldots \ldots \ldots$

2.26 Comparison of the SI-CAI modes in $2 \mathrm{~S}$ and $4 \mathrm{~S}$ engines with different approaches to get the CAI combustion ...........

2.27 Comparison of combustion and emission characteristics among

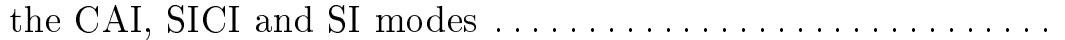

2.28 Left - Detail of the external noise registered on a pressure signal measurement. Right - Different pressure cycles measured during combustion and averaged pressure signal $\ldots \ldots \ldots \ldots \ldots \ldots$

2.29 Left - Rate of heat release. Right - burned mass fraction curves where the change from SI to CAI combustion is marked by the

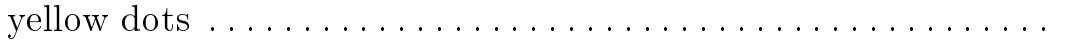

4.1 Uniflow scavenging architecture. Source: Wikipedia ......... 108

4.2 Different scavenging configurations for $2 \mathrm{~S}$ engines .......... 109

4.3 Detailed view of the basic parts of a Rotrex system . . . . . . . 110

4.4 Distribution diagram for the intake and exhaust .......... 111

4.5 Distribution scheme where the two extreme positions of the VVT

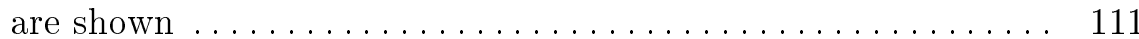

4.6 Left - Air-assisted injector assembly. Right - Operation scheme 112

4.7 Nozzle exit pressure of the premixture injector depending on the in-cylinder pressure ....................... 113

4.8 Test cell sketch with the engine and all the auxiliary systems . . 115

4.9 Diagram of the EGR system installed in the test bench...... 118

4.10 Scheme of the HORIBA FQ2100 inner fuel circuit . . . . . . . . 119

4.11 Scheme of the pressurized injection air measurement facility . . 120

4.12 Scheme of the cooling system installed ................ 121

4.13 Scheme of the lubricating system installed ............. 122 
4.14 Registered signal of the strain gauge installed in the exhaust

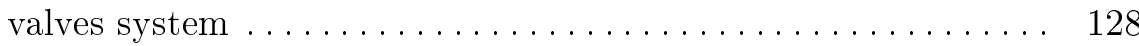

4.15 Valve lift profile, definition of the interesting angles and the valve

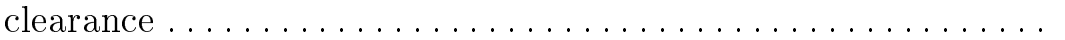

4.16 Schematics of the different gas flows and compositions along the

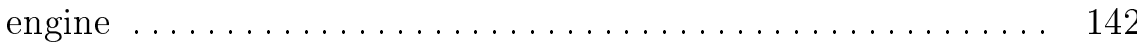

5.1 Evolution of the IGR ratio and the initial temperature of the in-cylinder charge with the engine load, and definition of the different combustion regions of the engine

5.2 Representative points of the engine map and the different

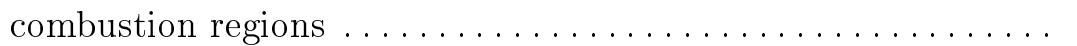

5.3 Complete scavenging process simulated by a 3D CFD model, the blue color represents the fresh gases and the green color the burnt gases ........................... 15

5.4 Effect of intake pressure on the apparent $\mathrm{F} / \mathrm{A}$ eq. ratio ...... 154

5.5 IGR rate evolution with the intake pressure (left) and with the

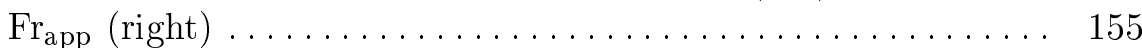

5.6 Trapping ratio as a function of the intake pressure $\ldots \ldots \ldots .155$

5.7 Relationship between the apparent $\mathrm{F} / \mathrm{A}$ eq. ratio and the incylinder F / A eq. ratio for Point $2000 @ 17 \ldots \ldots \ldots \ldots \ldots \ldots .156$

5.8 Evolution of the in-cylinder richness and the IGR ratio with the $\mathrm{Fr}_{\text {app }}$ modification for Point 2000@5 ................ 156

5.9 Evolution of the trapping ratio with the intake pressure for Point

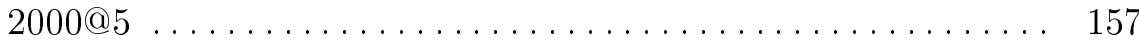

5.10 Effect of the $\mathrm{Fr}_{\mathrm{app}}$ on the HRR at Point 4000@5........... 158

5.11 VVT variation with constant $\operatorname{Fr}_{\text {app }} \ldots \ldots \ldots \ldots \ldots \ldots \ldots \ldots$

5.12 Left - Effect of SOI at Point 2000@17. Right - Effect of DOI at Point $2000 @ 17 \ldots \ldots \ldots \ldots \ldots \ldots \ldots \ldots \ldots \ldots \ldots \ldots \ldots \ldots \ldots$

5.13 Effect of DOI on different engine outputs at Point 4000@5 . . . 163

5.14 Left - Effect of SOI on different engine outputs. Right - Effect of SOI on the HRR (data from Point 4000@5)............. 164

5.15 Left - Effect of DOI on different engine outputs. Right - Effect of DOI on the HRR (data from Point 2000@5) ........... 165 
5.16 Effect of DOI on different engine outputs (left) and on the HRR (right) at Point $2500 @ 3 \ldots \ldots \ldots \ldots \ldots \ldots \ldots \ldots \ldots \ldots \ldots$

5.17 Effect of SOI on different engine outputs at Point 2500@3 . . . 166

5.18 Evaluation of the IAR parameter for different tests . ....... 167

5.19 Different spark ignition timings for operating Point 2000@17 . . 168

5.20 MAPO vs CA50 for all individual cycles (main graph) or averaged (detailed graph) for a spark timing swept........ 169

5.21 Spark ignition swept for Point $4000 @ 9 \ldots \ldots \ldots \ldots \ldots \ldots \ldots .170$

5.22 Effect of the spark timing on different engine outputs at Point

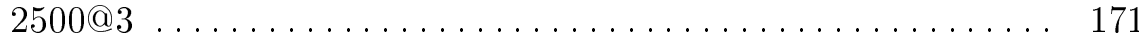

5.23 Point 2000@17, high equivalence ratio case $(\mathrm{Fr}=0.75)$. Left Evolution of different parameters as a function of the EGR rate. Right - For the same tests, correlation between BSFC and CA50, and detail of the knocking region when no EGR is used ......

5.24 Left - MAPO vs. CA50 for all individual cycles (main graph) or averaged (detailed graph) for a spark timing swept. Right - MAPO vs. CA50 for all individual cycles (main graph) or averaged (detailed graph), for two different cases: with (green) and without EGR (red) $\ldots \ldots \ldots \ldots \ldots \ldots \ldots \ldots \ldots \ldots \ldots$

5.25 Low equivalence ratio case $(\mathrm{Fr}=0.55)$. Left - Evolution of different parameters as a function of the EGR rate. Right - For the same tests, correlation between BSFC and CA50. In this case, the results previously shown in Figure 5.23 for the $\mathrm{Fr}=0.75$ case are also shown ......................... 175

5.26 $\mathrm{NO}_{\mathrm{x}}$-BSFC trade-off. The color scale gives information about the EGR rate . . . . . . . . . . . . . . . . . . . . 175

5.27 Point 4000@5, low equivalence ratio case $(\mathrm{Fr}=0.65)$. Left Evolution of different parameters as a function of the EGR rate. Right - For the same tests, correlation between BSFC and CA50. In this case, the results for a higher $\mathrm{Fr}(\mathrm{Fr}=0.75)$ case are also shown ................................... 176

5.28 Instantaneous pressure measurements in a standard diesel (50 cycles) and gasoline $(250$ cycles) engines ............. 178

5.29 Differences in the averaged cycle HRR estimation .......... 179 
5.30 Graphs for two different tests, with high and low dispersion. The IMEP is presented against the CA50 and the maximum HRR in

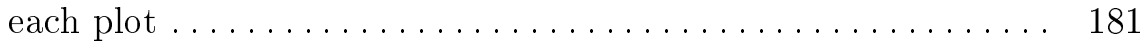

5.31 Combustion duration (CA90-CA10) against the maximum Heat Release Rate (MaxHRR)for the same cases as those in

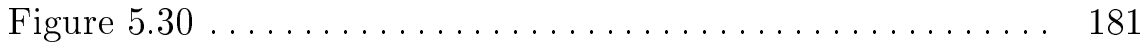

5.32 Combustion position (CA50) against the MAPO intensity (knock)for the same cases as those in Figures 5.30 and $5.31 \ldots$

5.33 MAPO intensity presented for each cycle of two test measure-

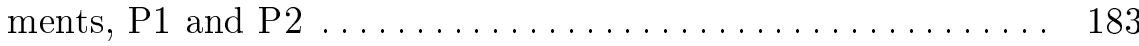

5.34 Pressure measurement for cycles 37 to $41 \ldots \ldots \ldots \ldots \ldots \ldots . . \ldots 3$

5.35 Heat release rates for cycles 37 to $41 \ldots \ldots \ldots \ldots \ldots \ldots \ldots . . \ldots 4$

5.36 Representation of the $\operatorname{Fr}_{\text {cyl }}$ and the air inside the cylinder(In-cyl ${ }_{\text {air }}$ ) for cycles 37 to 42 . The red line represents the mean value during

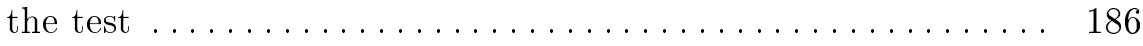

5.37 Pressure measurement for cycles 41 to $44 \ldots \ldots \ldots \ldots \ldots \ldots . \ldots 187$

5.38 Effect of the IGR rate on the ignition delay . . . . . . . . . 194

5.39 Evolution of the exhaust temperature with the EVO variation. 195

5.40 Experimental results of the DOI influence on the combustion efficiency .............................. 196

6.1 Brake specific fuel consumption for different $\mathrm{Fr}_{\text {cyl }}$ values . . . . 200

6.2 Representation of different combustion parameters for Point $2000 @ 17$ as a function of the in-cylinder $\mathrm{F} / \mathrm{A}$ eq. ratio and relationship between the in-cylinder and the apparent $\mathrm{F} / \mathrm{A}$ eq.

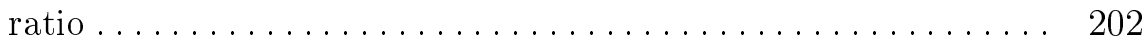

6.3 Representation of the main pollutant emissions as a function of the in-cylinder $\mathrm{F} / \mathrm{A}$ eq. ratio values ................ 203

6.4 BSFC values obtained for different CA50 positions with two different VVT configurations (dark blue $161^{\circ}$ and light blue $166^{\circ}$ ) 204

6.5 Ignition advance variation for Point 2000@17............. 205

6.6 Left - Evolution of BSFC with CA75. Right - Correlation for the same tests between BSFC and IGR ratio ........... 206

6.7 Influence of the IGR ratio on the combustion duration . . . . . 207 
6.8 Influence of the IGR ratio on the combustion duration ...... 208

6.9 Representation of 50 measured pressure cycles for two different tests, test 2000@17a (left), with lower IGR, and test 2000@17b (right), with higher IGR ................... 208

6.10 Combustion phasing, knock values, combustion stability and brake specific fuel consumption for the tests 2000@17a and $2000 @ 17 b$ shown in Figure 6.9 ......................

6.11 Influence of the Rich flow values on the IGR ratios......... 210

6.12 Extended engine operating map with high load operation Points 210

6.13 Evolution of the trapping ratio with the load increase for different

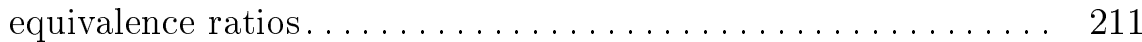

6.14 Evolution of the in-cylinder richness with the load increase for different equivalence ratios......................

6.15 Evolution of the IGR ratio with the load increase for different

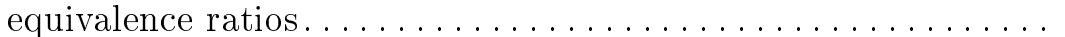

6.16 HRR (left) and HRL (right) for the different tested loads .....

6.17 Representation of the IMEP and BMEP for different loads and

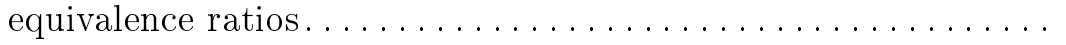

6.18 Effect of the exhaust pressure increase at Point 2000@17. Left - measured exhaust pressures for an apparent $\mathrm{F} / \mathrm{A}$ eq. ratio variation. Right - IGR ratios for the tests shown on the left ...

6.19 MAPO (left) and CA50 (right) values for different exhaust pressures during an apparent $\mathrm{F} / \mathrm{A}$ eq. ratio variation at Point

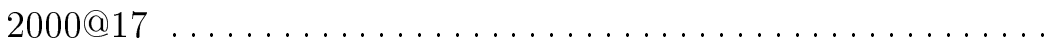

6.20 Trapping and IGR ratios for an apparent $\mathrm{F} / \mathrm{A}$ eq. ratio variation at Point 2000@5..................................

6.21 HRR laws for an apparent $\mathrm{F} / \mathrm{A}$ eq. ratio variation at Point

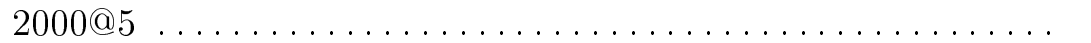

6.22 Pressure signals and HRR laws for the test $\mathrm{Fr}_{\mathrm{app}}=0.6$ at Point

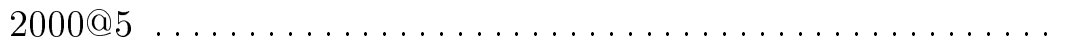

6.23 Results of the different torque, combustion phasing, combustion stability and combustion efficiency for the two idle points tested 218

6.24 Pressure signal and HRR laws for Points 1000@2 and 500@4 .. 219 
6.25 Pressure traces and HRR laws for two tests at Point 2000@5 with a $\mathrm{Fr}_{\mathrm{app}}$ of 0.5 (SI combustion) and 0.9 (CAI combustion), respectively ............................. 221

6.26 Results of the comparison between SI $\left(\mathrm{Fr}_{\mathrm{app}}=0.5\right)$ and CAI

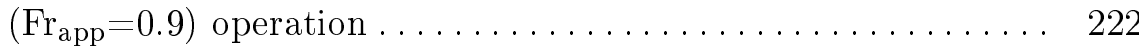

6.27 Left - Effect of the $\mathrm{Fr}_{\mathrm{app}}$ on the HRR at Point 4000@5. Right Evolution of the IGR ratio with the $\mathrm{Fr}_{\text {app }}$ variation ........ 223

6.28 Temperature of the in-cylinder charge at $30^{\circ}$ BTDC $\ldots \ldots \ldots 224$

6.29 Brake specific fuel consumption for the tests presented in

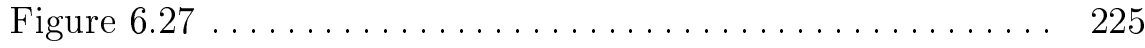

6.30 Left - Effect of VVT on the HRR when the engine is operated under CAI conditions. Right - Exhaust temperature and IGR

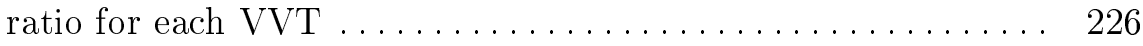

6.31 Representation of the operating Point 2000@4 on the engine map 226

6.32 Combustion performance during a SOI variation ......... 227

6.33 Evolution of the pollutant emissions during a SOI variation ... 228

6.34 Combustion performance during a DOI variation .......... 229

6.35 Evolution of the pollutant emissions during a DOI variation... 230

6.36 Effect of the EGR introduction on the in-cylinder richness and

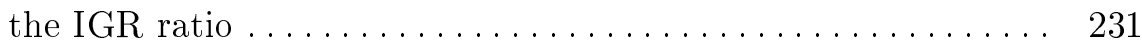

6.37 Representation of the operating Point 4000@7 on the engine map 231

6.38 Evolution of the knock with the EGR rate variation for Point

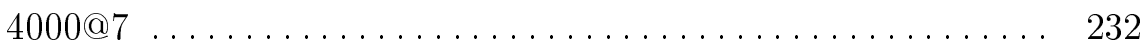

6.39 Left - Evolution of the compression temperatures with the EGR ratio. Right - HRR's for the different 4000@7 tests in an EGR

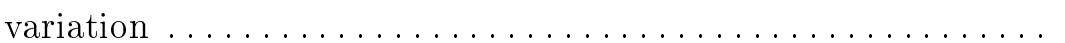

6.40 Effect of the EGR increase on the combustion efficiency and the

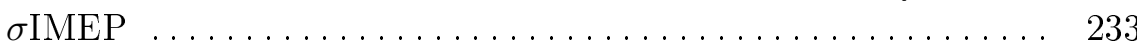

6.41 Emissions values for an EGR variation at Point $4000 @ 7$. .... 233

6.42 Load variation on CAI combustion conditions for two different engine speeds, $2000 \mathrm{rpm}$ (blue) and $4000 \mathrm{rpm}$ (red). Main engine

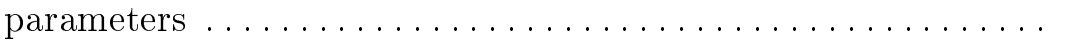

6.43 Load variation on CAI combustion conditions for two different engine speeds, $2000 \mathrm{rpm}$ (blue) and $4000 \mathrm{rpm}(\mathrm{red})$. Pollutant

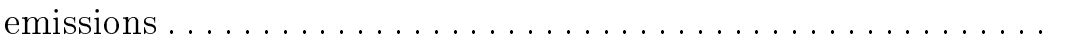


6.44 Representation of the CAI operable region (yellow area) on the

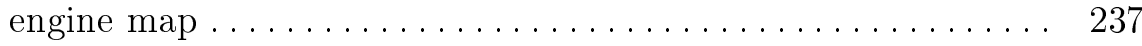

6.45 Load variation on CAI combustion conditions with (red) and without EGR (blue). Main engine parameters .......... 239

6.46 Load variation on CAI combustion conditions with (red) and without EGR (blue). Pollutant emissions .............. 240

6.47 Representation of the CAI operable region without EGR (yellow area) and with EGR (green area) on the engine map ....... 241

6.48 Apparent F/A eq. ratio variation at Point 2000@5 .......... 242

6.49 Representation of the measured pressures during CAISI operation and their respective calculated HRR's ............. 243

6.50 Apparent F/A eq. ratio variation at Point 2000@5. Main engine

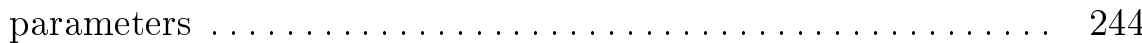

6.51 Apparent F/A eq. ratio variation at Point 2000@5. Pollutant emissions . . . . . . . . . . . . . . . . . . . . . . . . . . .

6.52 Original vs. processed HRL $\ldots \ldots \ldots \ldots \ldots \ldots \ldots \ldots \ldots$

6.53 Left - Bad estimation of the HRL end. Right - Correction of this

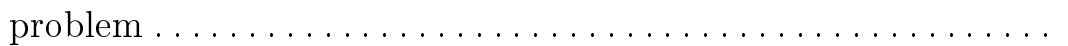

6.54 Example of the calculated temperatures for Point 2000@17. The blue color represents the spatially averaged temperature, the green color the unburned temperature and the red color the burned temperature $\ldots \ldots \ldots \ldots \ldots \ldots \ldots \ldots \ldots \ldots \ldots \ldots$

6.55 Functions for each parameter of the combustion speed equation 253

6.56 Comparison among the HRR and the FSRA obtained for a $\mathrm{Fr}_{\text {app }}$ variation at Point 2000@17 operated with different

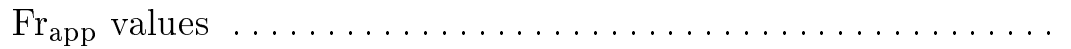

6.57 Correction of the engine speed. Left - FSRA values without any correction. Right - The same values corrected with $\mathrm{f}=1 \ldots \ldots$.

6.58 Calculation of the $A^{*}$ for a Point $2000 @ 17$ following the steps

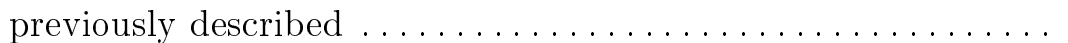

6.59 Representation of the $A^{*}$ calculation for the three correlations of the laminar combustion speed, from left to right: isooctane correlation, gasoline correlation and proposed correlation ..... 
6.60 Comparison for different $\mathrm{Fr}_{\text {app }}$ ranges of the gasoline correlation and the correlation proposed in this work. Above - the proposed correlation. Below - the gasoline correlation............ 259

6.61 Representative $A^{*}$ value (standard curve) for the SI combustion evolution in this engine..................... 260

6.62 Final output data for the combustion analysis. Left Comparison between the SI pattern and the selected test to analyze. Right - Difference parameter, representative of the similarity of the analyzed test compared to the SI pattern . . . 262

6.63 Results of different SI tests processed .............. 263

6.64 Representation of the $A^{*}$ values for all the individual cycles in a test at Point $2000 @ 17 \ldots \ldots \ldots \ldots \ldots \ldots \ldots \ldots \ldots . \ldots . \ldots . \ldots 264$

6.65 Representation of $A^{*}$ of cycles 60 (left) and 150 (right) ..... 264

6.66 Cylinder pressure for cycles \#60 and \#150 ........... 265

6.67 Representation of $A^{*}$ and the cylinder pressure of cycle\#18 . . 266

6.68 Analysis of the cycles before $\# 150 \ldots \ldots \ldots \ldots \ldots \ldots \ldots \ldots .267$

6.69 Analysis of the cycles before $\# 18 \ldots \ldots \ldots \ldots \ldots \ldots \ldots \ldots .268$

6.70 Combustion analysis of Point 2000@4 operated in CAI conditions 269

6.71 Combustion analysis of Points 4000@7 (above) and 2500@3 (below) operated in CAI conditions ................. 269

6.72 Evolution of the Difference parameter with the load increase .. 270

6.73 Results of the combustion analysis for a $\mathrm{Fr}_{\mathrm{app}}$ swept at Point

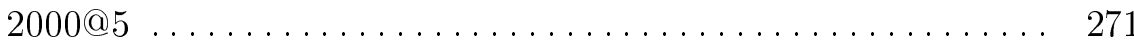

6.74 Difference between the SI pattern and the different processed tests of the $\mathrm{Fr}_{\mathrm{app}}$ swept at Point $2000 @ 5$. . . . . . . . . . . 272

6.75 Left - Evolution of BSFC with CA75. Right - Correlation for the same tests between BSFC and IGR ratio ........... 277

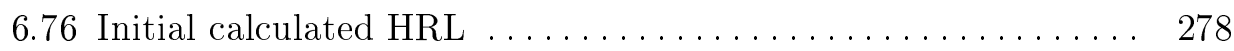

6.77 Operations on the initial calculated HRL . . . . . . . . . . . 279

6.78 HRL with the initial inclination removed ............. 279

6.79 Inclination of the HRL to find the SOC angle .......... 280

6.80 Final HRL with the lower part corrected $\ldots \ldots \ldots \ldots \ldots \ldots .281$

6.81 Delayed estimation of the EOC ................. 282 
6.82 Properly estimation of the EOC $\ldots \ldots \ldots \ldots \ldots \ldots \ldots \ldots \ldots 282$

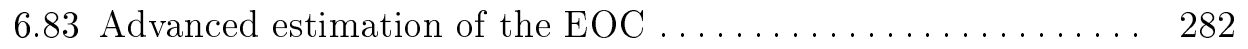

7.1 Final distribution of the different combustion modes in the

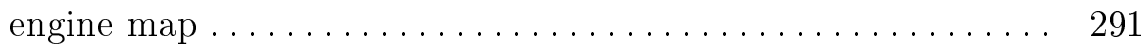

7.2 Illustrative result of the combustion analysis assuming that a CAI pattern is available ....................... 297

7.3 Detail of the velocity profile for the NEDC and the WLTC standard cycles.......................... 298

7.4 Representation of the cycle points set to define the NEDC driving cycle on the engine operating map ................ 299

7.5 Representation of the set of cartography points to define the engine operating map ........................ 301

7.6 Graphical scheme of the influence estimation of the different cartography points on a cycle point ................. 302 


\section{Index of Tables}

1.1 Summary of the main differences between SI and CI engines .. 5

4.1 Main specifications of the dynamometer used on the engine ... 116

4.2 Main specifications of the intake air compressor . . . . . . . 116

4.3 Gasoline specifications . . . . . . . . . . . . . . . . . . ... 119

4.4 Detail of the pressure sensor type and the operating range of the main instantaneous pressure sensors . . . . . . . . . . . 123

4.5 Detail of the type and operating ratio of the sensors installed in the test cell ................................ 124

4.6 Detail of the testing procedures $\ldots \ldots \ldots \ldots \ldots \ldots \ldots \ldots \ldots \ldots$

5.1 Data extracted from the CTCM . . . . . . . . . . . . . 185

5.2 Data of the instantaneous mass flows extracted from the CTCM 186

5.3 CFD simulation results for the different injection configurations at Point $2000 @ 17$............................. 196

6.1 Definition of k1 and k2 for isooctane and gasoline ........ 252

6.2 Different values for cycles $\# 60, \# 150$ and $\# 18 \ldots \ldots \ldots \ldots .265$

6.3 Estimated instantaneous combustion parameters for the cycles

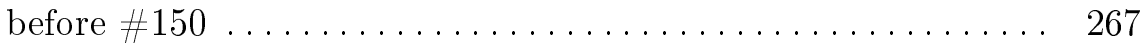

6.4 Estimated instantaneous combustion parameters for the cycles

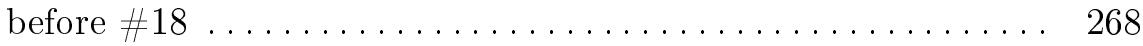

6.5 Results obtained from the SICICLO simulation.......... 276

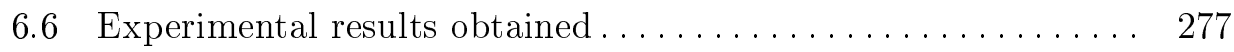


7.1 Best values obtained for the selected Points without and with EGR . . . . . . . . . . . . . . . . . . . . . 293

7.2 Results in the standard cycles obtained without EGR addition 294

7.3 Results in the standard cycles obtained with EGR addition ... 294

7.4 Fuel consumptions for different compact cars sold in Europe .. 295 



\title{
Nomenclature
}

\author{
Latin \\ A \\ Area \\ C \\ Carbon \\ $\mathrm{CH}_{4} \quad$ Methane \\ $\mathrm{CO} \quad$ Carbon monoxide emissions \\ $\mathrm{CO}_{2} \quad$ Carbon dioxide emissions \\ $c_{p}$ \\ Specific heat capacity at constant pressure \\ $c_{v}$ \\ Specific heat capacity at constant volume \\ $D a$ \\ $D$ \\ Damkohler number \\ $\mathrm{Fr}$ \\ Mass diffusivity \\ $\mathrm{FstO}_{2}$ \\ $H$ \\ Fuel/Air equivalence ratio \\ $H C$ \\ Oxygen required in a stoichiometric combustion \\ Hydrogen \\ $i$ \\ Unburnt hydrocarbon emissions \\ Ka \\ Thermodynamic cycles per engine revolution \\ $L_{\text {int }}$ \\ Karlovitz number \\ int Integral length \\ $l_{t} \quad$ Taylor length scale \\ $m \quad$ Mass \\ $\dot{m} \quad$ Mass flow \\ $n \quad$ Polytropic exponent \\ $N \quad$ Engine speed \\ $N_{2} \quad$ Nitrogen molecule \\ $N O_{x} \quad$ Nitrogen oxides \\ O Oxygen
}




\begin{tabular}{|c|c|}
\hline $\mathrm{O}_{2}$ & Oxygen molecule \\
\hline$O H$ & Hydroxyl radical \\
\hline$p$ & Pressure \\
\hline$P$ & Power \\
\hline$P M$ & Particulate Matter emissions \\
\hline$R$ & Universal gas constant \\
\hline $\operatorname{Re}_{T}$ & Turbulent Reynolds \\
\hline$S_{L}$ & Laminar burning speed \\
\hline$S_{b}$ & Effective burning speed \\
\hline$s t k$ & Stroke \\
\hline$t$ & Time \\
\hline$T$ & Temperature \\
\hline$U$ & Internal energy \\
\hline$U_{t}$ & Speed defined by the local velocity of the turbulent fluctuation \\
\hline$V$ & Volume \\
\hline$X$ & Molar fraction / volumetric \\
\hline$Y$ & Mass fraction \\
\hline \multicolumn{2}{|c|}{ Greek } \\
\hline$\alpha$ & Angle \\
\hline$\gamma$ & Isentropic exponent \\
\hline$\Delta$ & Increment \\
\hline$\eta$ & Efficiency \\
\hline$\lambda$ & Air/Fuel ratio \\
\hline$\lambda_{K}$ & Kolmogorov scale \\
\hline$\rho$ & Density \\
\hline$\sigma$ & Standard deviation \\
\hline$\tau$ & Ignition delay \\
\hline$\tau_{x}$ & Rate of the stated " $\mathrm{x}$ " subscript \\
\hline
\end{tabular}

Subscripts and superscripts

$\begin{array}{ll}\text { air } & \text { Relative to fresh intake air conditions } \\ \text { app } & \text { Apparent } \\ \text { atm } & \text { Relative to atmospheric conditions } \\ \text { avg } & \text { Referred to averaged conditions } \\ b & \text { Relative to the conditions of the burnt mixture } \\ b g & \text { Relative to the burnt gases at stoichiometric conditions }\end{array}$




$\begin{array}{ll}\text { comb } & \text { Referred to the combustion process } \\ \text { crit } & \text { Referred to critical conditions } \\ c y l & \text { Relative to the conditions inside of the cylinder } \\ d e l & \text { Referred to the delivered mass of incoming intake air (fresh }+ \text { EGR) } \\ d i l & \text { Referred to diluted conditions } \\ e & \text { Effective, relative to the brake parameters } \\ \text { exh } & \text { Relative to the exhaust manifold conditions } \\ f & \text { Relative to the fuel } \\ f f & \text { Relative to the flame front } \\ f r i c & \text { Relative to the engine friction loses } \\ \text { geo } & \text { Referred to the geometric evolution of a flame front } \\ \text { ind } & \text { Referred to indicated conditions } \\ \text { inj } & \text { Relative to the injection process } \\ \text { int } & \text { Relative to the intake manifold conditions } \\ \text { IVC } & \text { Relative to the conditions at the intake valve closing } \\ m a x & \text { Maximum } \\ r e t & \text { Referred to the retained mass of incoming intake } \\ \text { short } & \text { Referred to the short-circuited gas that goes from the intake to the } \\ \text { exhaust without being trapped in the cylinder } \\ t\end{array}$

Acronyms

$\mathrm{ACM}$

ASTM

BDC

BMEP

BTDC

BSCO

$\mathrm{BSFC}$

$\mathrm{BSHC}$

BSNOX

BSsOot
Averaged Cycle Methodology

American Society of Testing Materials

Bottom Dead Center

Brake Mean Effective Pressure

Before Top Dead Center

Brake Specific Carbon monoxide

Brake Specific Fuel Consumption

Brake Specific Hydrocarbons

Brake Specific Nitrogen Oxides

Brake Specific soot emissions

Crank Angle 


\begin{tabular}{|c|c|}
\hline CAXX & $\begin{array}{l}\text { Referred to the crankangle where XX\% of the fuel injected mass has been } \\
\text { burnt }\end{array}$ \\
\hline $\mathrm{CAD}$ & Computer-Aided Design \\
\hline CAI & Controlled Auto-Ignition \\
\hline CAISI & Combined name from CAI and SI \\
\hline CFD & Computational Fluid Dynamics \\
\hline CI & Compression Ignition \\
\hline $\mathrm{COV}$ & Covariance \\
\hline $\mathrm{CR}$ & Compression ratio \\
\hline CTCM & Cycle To Cycle Methodology \\
\hline DOC & Diesel Oxidation Catalyst \\
\hline DOI & Duration Of Injection \\
\hline DI & Direct Injection \\
\hline DPF & Diesel Particulate Filter \\
\hline $\mathrm{ECU}$ & Electronic Control Unit \\
\hline EGR & Exhaust Gas Recirculation \\
\hline $\mathrm{EOC}$ & End Of Combustion \\
\hline EOI & End Of Injection \\
\hline EPA & Environmental Protection Agency \\
\hline EVC & Exhaust Valve Closing \\
\hline $\mathrm{EVO}$ & Exhaust Valve Opening \\
\hline FSN & Filter Smoke Number \\
\hline FSR & Flame Speed Ratio \\
\hline $\mathrm{F} / \mathrm{A}$ & Fuel/Air \\
\hline GDI & Gasoline Direct Injection \\
\hline GTDI & Gasoline Turbocharged Direct Injection \\
\hline HCCI & Homogeneous Charge Compression Ignition \\
\hline $\mathrm{HD}$ & High Dispersion \\
\hline $\mathrm{HRF}$ & Highly Reactive Fuel \\
\hline HRL & Heat Release Law \\
\hline HRR & Heat Release Rate \\
\hline IAR & Injected Air Ratio \\
\hline $\mathrm{IC}$ & Internal Combustion \\
\hline $\mathrm{ICE}$ & Internal Combustion Engine \\
\hline ID & Ignition Delay \\
\hline
\end{tabular}




\begin{tabular}{|c|c|}
\hline IGR & Internal Gas Recirculation \\
\hline IMEP & Indicated Mean Effective Pressure \\
\hline ISCO & Indicated Specific Carbon monoxide \\
\hline ISFC & Indicated Specific Fuel Consumption \\
\hline ISHC & Indicated Specific Hydrocarbons \\
\hline ISO & International Organization for Standardization \\
\hline $\mathrm{ISNO}_{\mathrm{x}}$ & Indicated Specific Nitrogen Oxides \\
\hline $\mathrm{LD}$ & Low Dispersion \\
\hline LHV & Lower Heating Value \\
\hline $\mathrm{LRF}$ & Low Reactivity Fuel \\
\hline LTC & Low temperature combustion \\
\hline MAPO & Maximum Amplitude of Pressure Oscillations \\
\hline MBT & Maximum Brake Torque \\
\hline MEP & Mean Effective Pressure \\
\hline MFB & Mass Fraction Burned \\
\hline $\mathrm{MON}$ & Motor Octane Number \\
\hline NEDC & New European Driving Cycle \\
\hline NA & Naturally-Aspirated \\
\hline NVO & Negative Valve Overlap \\
\hline $\mathrm{ON}$ & Octane Number \\
\hline PCCI & Premixed Charge Compression Ignition \\
\hline PCI & Premixed Compression Ignition \\
\hline PFI & Port Fuel Injection \\
\hline $\mathrm{PhD}$ & Doctor of Philosophy \\
\hline PPCI & Partially Premixed Compression Ignition \\
\hline $\mathrm{RCCI}$ & Reactivity Controlled Compression Ignition \\
\hline $\mathrm{RCM}$ & Rapid Compression Machine \\
\hline RICE & Reciprocating Internal Combustion Engine \\
\hline $\mathrm{RON}$ & Research Octane Number \\
\hline $\mathrm{SACI}$ & Spark Assisted Compression Ignition \\
\hline $\mathrm{SCE}$ & Single Cylinder Engine \\
\hline $\mathrm{SCR}$ & Selective Catalytic Reduction aftertreatment system \\
\hline SI & Spark Ignition \\
\hline SICI & Spark Induced Compression Ignition \\
\hline
\end{tabular}




$\begin{array}{ll}\text { SOI } & \text { Start Of Injection } \\ \text { SOC } & \text { Start Of Combustion } \\ \text { TCe } & \text { Turbo-Charged petrol engine } \\ \text { TCE } & \text { Twin Cylinder Engine } \\ \text { TDCI } & \text { Top Dead Center } \\ \text { TFSI } & \text { Turbo Diesel Compression ignition } \\ \text { TR } & \text { Turbo-charged Fuel Stratified Injection } \\ \text { TWC } & \text { Thapping Ratio } \\ \text { ULCGE } & \text { Ultra Low Cost Gasoline Engine } \\ \text { VCR } & \text { Variable Compression Ratio } \\ \text { VTEC } & \text { Variable Valve Timing and lift Electronic Control } \\ \text { VVA } & \text { Variable Valve Actuation systems } \\ \text { VVT } & \text { Variable Valve Timing } \\ \text { WLTP } & \text { Worldwide Harmonized Light Vehicles Test Procedure } \\ 2 S & \text { Two Stroke } \\ 4 \text { S } & \text { Four Stroke }\end{array}$




\section{Chapter 1}

\section{Introduction}

Contents

1.1 Overview .................... 3

1.2 Context ..................... 11

1.3 Previous related works ............... 12

1.4 Thesis document structure............. 13

Bibliography ...................... 14 



\subsection{Overview}

The Spark Ignition engine (SI), or more commonly known, the gasoline engine, is well-known in today's society. It is about a reciprocating Internal Combustion Engine (RICE), with more than a century of history. If a date had to be chosen that would mark the birth of modern engines (as we know them nowadays), that would be the year 1877, when the German engineer, Nikolaus Otto, patented a gas engine operated under a combustion cycle that would be known in the future by his name, the Otto cycle (Patent No. 194,047 Aug. 14, 1877). In Figure 1.1, some drawings of the first idea of the engine extracted from the patent application filed in the United States can be seen.

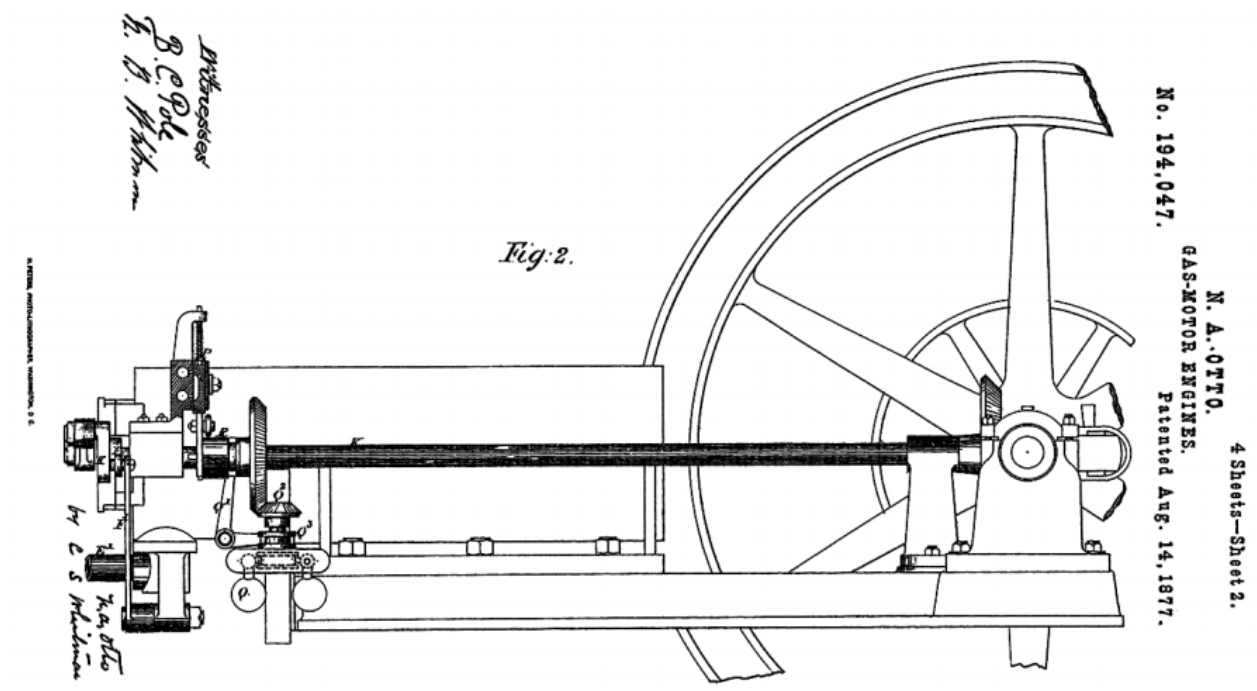

Figure 1.1. Schematics extracted from the patent application presented by Nikolaus Otto in the United States.

The Otto engine is not the starting point nor the end of this wide field (the RICE), in which it is considered as a cornerstone. From this moment, the development pathways of RICE have always kept the "core" set by this prototype, with very few variations. One of the main characteristics of these engines is how the energy from the combustion is extracted, by means of a combustion process occurring in the working fluid itself (internal combustion). As some other engines and machines at that time, the engine proposed by Otto was based on volumetric or positive-displacement machines, which means that 
the working fluid is contained within an enclosure delimited by movable walls that, when moving, its volume is modified. The operation of these machines can be understood in an intuitive way since, to a certain extent, it is easy to imagine what happens when a gas expands or is compressed inside a cylinder through the movement of a piston. These evolutions can be seen clearly in the indicator diagram (see Figure 1.2), where the evolution of the pressure as a function of the volume is represented for the Otto cycle.

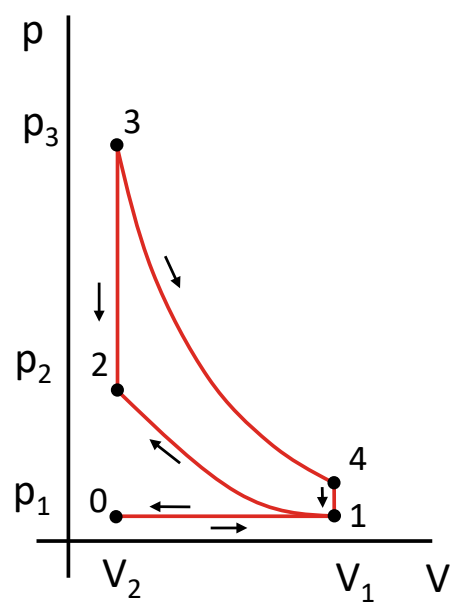

Figure 1.2. Indicator diagram of an Otto engine.

A few years later, in 1892, the engineer Rudolf Christian Karl Diesel presented another work, patented first in Germany (Theory and Construction of a Rational Heat Motor, 1893) and later in the USA (Patent No. 608.845a Aug. 9, 1898), which would lead to the engine cycle also known by his name, the Diesel cycle. The main idea of Diesel was to get as close as possible to a Carnot cycle's performance [1]. Diesel wanted to keep the temperature constant during the expansion phase. To achieve the desired expansion, he thought of injecting the fuel at the same time as it burned, with an injection law focused on maintaining the temperature constant by compensating the heating of the combustion with the cooling of the expansion. Therefore, the fluid inside the engine during the compression stroke was only air. If the indicator diagram is presented (see Figure 1.3), the main difference on the combustion is observed between points 2 and 3: in the Otto cycle the heat release is considered at constant volume, whereas in the Diesel cycle it is considered at constant pressure. 


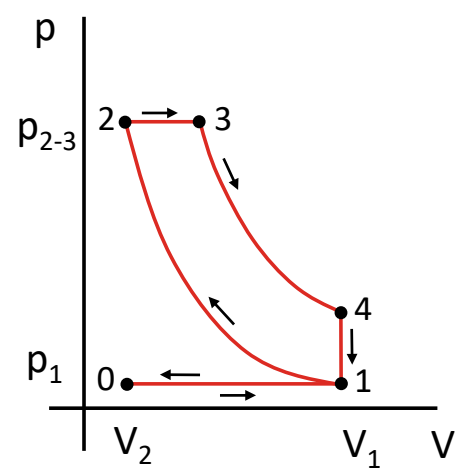

Figure 1.3. Indicator diagram of a Diesel engine.

Nowadays, these two engine cycles, Otto and Diesel, have laid the basis of what are the two main engine categories in the automotive industry, the spark ignition engine (SI) and the compression ignition engine (CI). Both cycles have differences and similarities, as well as advantages and disadvantages derived from the type of fuel they require and the differences in the combustion process developed. To summarize the main differences, Table 1.1 is included as a brief summary.

\begin{tabular}{|c|c|c|}
\hline Feature & SI & $\mathrm{CI}$ \\
\hline Ignition & $\begin{array}{l}\text { By external energy intro- } \\
\text { duction }\end{array}$ & By autoignition of the fuel \\
\hline Fuel & Autoignition resistant & Easy to autoignite \\
\hline $\begin{array}{l}\text { Mixture } \\
\text { formation }\end{array}$ & $\begin{array}{l}\text { During the intake and com- } \\
\text { pression }\end{array}$ & $\begin{array}{l}\text { End of compression and } \\
\text { beginning of expansion }\end{array}$ \\
\hline Intake gases & Air plus fuel & Only air \\
\hline $\begin{array}{l}\text { Load } \\
\text { regulation }\end{array}$ & Quantitative & Qualitative \\
\hline $\begin{array}{l}\text { Compression } \\
\text { ratios }\end{array}$ & 8 to 11 & 12 to 23 \\
\hline
\end{tabular}

Table 1.1. Summary of the main differences between SI and CI engines. 
From the appearance of these engines, the transportation sector changed very fast. The implementation of these new power plants in light and heavy vehicles became dominant in this sector thanks to their high specific power and the high energy density of the used fuels, giving high power output and high autonomy to the vehicles equipped with these engines.

The initial development works of these engines were focused on improving their reliability and performance, since these machines were in an early stage of its long way in the industry. Lots of works were performed to improve the materials, the components and the strategies to make them more powerful, more durable and to increase their application range [2-11].

In these initial years, the concern about the harmful combustion products expelled by the exhaust was very low. However, in view of the raise of different health and environmental problems, this concern increased and forced a change on the direction of the development works around these engines. ${ }^{1}$ This direction change was motivated due to the raise of different reports and articles giving information about the problems of these pollutant emissions showing, on the one hand, the relationship between the emissions and some health problems, as the ones collected in the publication of the National Academy of Sciences, Engineering and Medicine [12] and, on the other hand, the consequences of the accumulation in the atmosphere of these species coming from the combustion process, notified by different universities and governmental agencies, like the EPA [13-15]. Another important factor that encouraged the improvement of the engines fuel efficiency came from the increase of the crude price, as well as the forecasted decreasing of the oil stocks. This necessity goes in the same way as reducing the $\mathrm{CO}_{2}$ emissions, trying to stop the climate change. But, unfortunately, this way is not necessarily compatible with decreasing the rest of the pollutant emissions.

To overcome all these problems, the governments started to introduce some regulations to control the emissions of the engines destined for the transportation sector, differentiating the main pollutant emissions and limiting them during the engine operation. These regulations were approached by the different countries on an individual way. Nevertheless, the pioneer in these regulations was the California state in 1960. In the year 1955, the South Coast Air Quality Management District was founded with the aim to control the excessive air pollution in this region, and in 1960 they introduced the first regulation related to the air quality and the limitation of certain

\footnotetext{
${ }^{1}$ It has to be taken into account that, before this direction change, the technology level was high enough to ensure the high quality of these machines; these kind of works are not the most abundant anymore, but have never disappeared completely.
} 
emissions considered harmful for the local environment. This standard evolved with the time, and was used by other countries as a model to create their own regulations. Finally, in the table presented in Figure 1.4, the different regulations in Europe, US, Japan and China are presented. It can be seen how the 90s were a key date for these policies: the US already had, since a few years before, a defined initial regulation, and on this decade Europe and Japan included also their own regulation. This way has been followed progressively by other countries, such as China, which delayed the implementation of the first regulations until 2007-2010.

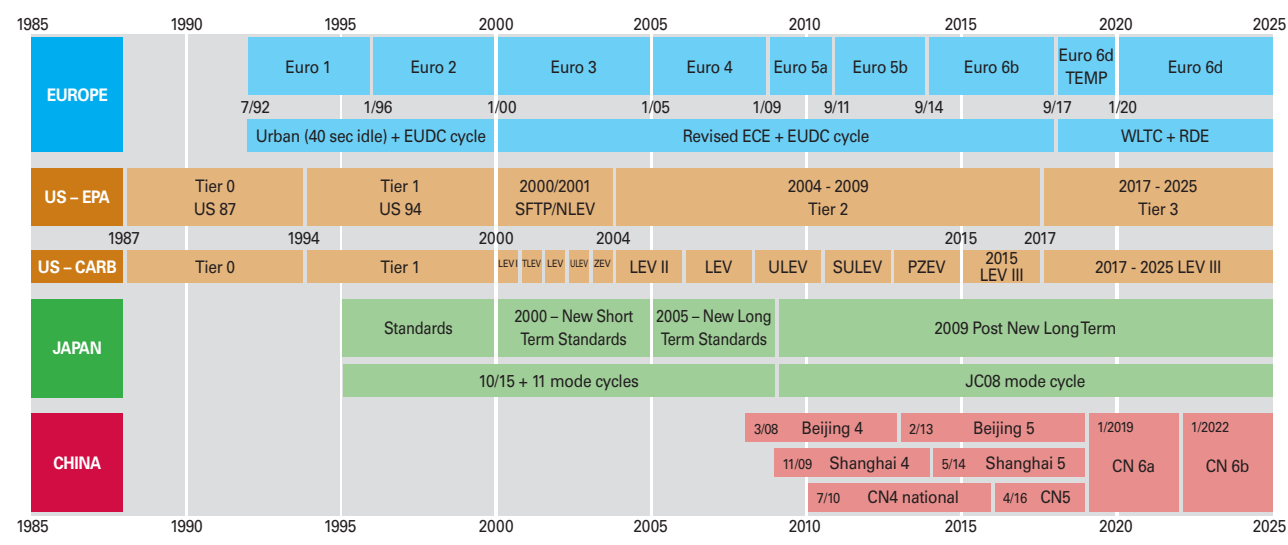

Figure 1.4. Implementation of the different emissions regulations in Europe, US, Japan and China. Source: Delphi Technologies [16].

All these regulations, with different considerations regarding when the emissions are measured and evaluated, follow approximately the same patterns. Among these four regions defined, the European standards have been chosen to be described in more detail, since the current $\mathrm{PhD}$ thesis has been carried out in Europe.

Figures 1.5 and 1.6 show the detailed definitions for all the different standards defined since 1993. In these ones, the regulated pollutants are defined in the following groups: $\mathrm{HC}$ (unburned hydrocarbons), $\mathrm{NO}_{\mathrm{x}}$ (all the nitrogen oxides), $\mathrm{HC}+\mathrm{NO}_{\mathrm{x}}$ (the resulting value of the addition of these two emissions), CO (carbon monoxide) and PM (particulate matter). Along the evolution of these standards, the emissions amounts have been reduced progressively (see Figures 1.7 and 1.8), and in some cases some new pollutants have been introduced (such as PM for SI engines, even though their amount is 
so small that it's almost impossible to appreciate them in Figure 1.7 compared to the scale of the rest of the pollutants).

\section{EUROPEAN UNION}

EURO 1-4 passenger cars Class $M(\leq 2.500 \mathrm{~kg} \mathrm{GVW}, \leq 6$ seats)

\begin{tabular}{|c|c|c|c|c|c|c|c|c|c|}
\hline \multirow{2}{*}{\multicolumn{2}{|c|}{ Directive }} & \multirow{2}{*}{\multicolumn{2}{|c|}{$\begin{array}{c}\text { Euro } 1 \text { (EC 93) } \\
\text { 91/441/EEC or 93/59/EEC }\end{array}$}} & \multirow{2}{*}{\multicolumn{2}{|c|}{$\begin{array}{c}\text { Euro } 2 \text { (EC } 96 \text { ) } \\
\text { 94/12/EC or 96/69/EC }\end{array}$}} & \multicolumn{2}{|c|}{ Euro 3 (EC 2000) } & \multicolumn{2}{|c|}{ Euro 4 (EC 2005) } \\
\hline & & & & & & \multicolumn{4}{|c|}{ 70/220/EC, as amended by 98/69/EC and 2003/76/EC } \\
\hline \multicolumn{2}{|c|}{ Application date } & \multicolumn{2}{|c|}{ TA 7/1992, FR 1/1993 } & \multicolumn{2}{|c|}{ TA 1/1996, FR 1/1997 } & \multicolumn{2}{|c|}{ TA $1 / 2000$, FR 1/2001 } & \multicolumn{2}{|c|}{ TA $1 / 2005$, FR $1 / 2006$} \\
\hline \multicolumn{2}{|c|}{ Test type } & \multicolumn{4}{|c|}{ Urban $(40$ sec idle $)+$ EUDC } & \multicolumn{4}{|c|}{ Revised Urban + EUDC } \\
\hline \multicolumn{2}{|c|}{ Combustion type } & $\begin{array}{l}\text { Positive ignition } \\
\text { (PI) }\end{array}$ & $\begin{array}{l}\text { Compression } \\
\text { ignition (Cl) }\end{array}$ & $\begin{array}{l}\text { Positive ignition } \\
\text { (PI) }\end{array}$ & $\begin{array}{l}\text { Compression } \\
\text { ignition }(\mathrm{C})^{22}\end{array}$ & $\begin{array}{l}\text { Positive ignition } \\
\text { (PI) }\end{array}$ & $\begin{array}{l}\text { Compression } \\
\text { ignition (Cl) }\end{array}$ & $\begin{array}{c}\text { Positive ignition } \\
\text { (PI) }\end{array}$ & $\begin{array}{l}\text { Compression } \\
\text { ignition (CI) }\end{array}$ \\
\hline $\mathrm{HC}$ & $\mathrm{g} / \mathrm{km}$ & - & - & - & - & 0.2 & - & 0.1 & - \\
\hline NOx & $\mathrm{g} / \mathrm{km}$ & - & - & - & - & 0.15 & 0.5 & 0.08 & 0.25 \\
\hline $\mathrm{HC}+\mathrm{NOx}$ & $\mathrm{g} / \mathrm{km}$ & $0.97(1.13)^{11}$ & $0.97(1.13)^{11}$ & 0.5 & 0.7 & - & 0.56 & - & 0.3 \\
\hline $\mathrm{CO}$ & $\mathrm{g} / \mathrm{km}$ & $2.72(3.16)^{11}$ & $2.72(3.16)^{11}$ & 2.2 & 1.0 & 2.3 & 0.64 & 1.0 & 0.5 \\
\hline PM & $\mathrm{mg} / \mathrm{km}$ & - & $140(180)^{11}$ & - & 80 & - & 50 & - & 25 \\
\hline \multicolumn{2}{|c|}{ Deterioration factors } & $\mathrm{CO}, \mathrm{HC}, \mathrm{NOx}: 1.4$ & $\begin{array}{c}\text { CO: } 1.1 \\
\text { HC+NOx, NOx: } 1.0 \\
\text { PM: } 1.2 \\
\end{array}$ & $\mathrm{CO}, \mathrm{HC}, \mathrm{NOx}: 1.5$ & $\begin{array}{c}\text { CO: } 1.1 \\
\text { HC+NOx, NOx: } 1.0 \\
\text { PM: } 1.3 \\
\end{array}$ & $\mathrm{CO}, \mathrm{HC}, \mathrm{NOx}: 1.2$ & $\begin{array}{c}\text { CO: } 1.1 \\
\text { HC+NOx, NOx: } 1.0 \\
\text { PM: } 1.2\end{array}$ & $\mathrm{CO}, \mathrm{HC}, \mathrm{NOx}: 1.2$ & $\begin{array}{c}\text { CO: } 1.1 \\
\text { HC+NOx, NOx: } 1.0 \\
\text { PM: } 1.2 \\
\end{array}$ \\
\hline Durability & $\mathrm{km}$ & 80,000 & 80,000 & 80,000 & 80,000 & 80,000 or 5 years & 80,000 or 5 years & 100,000 or 5 years & 100,000 or 5 years \\
\hline EOBD & & & & & & EOBD & EOBD & EOBD & EOBD \\
\hline
\end{tabular}

1) COP values in brackets.

3) Required recording of in-use durability.
4) Up to $12 / 2002$ Diesel cars with $G V W>2 T$ and $>6$ seats or off-road vehicles were considered as

2) Limits for IDI Diesel. For DI Diesel up to 10/1999: HC+NOX: 0.9 g/km, CO 1g/km, PM 100 mg/km. N1 vehicles.

Figure 1.5. Values for the emissions in SI and CI engines for light passenger cars from Euro 1 to Euro 4. Source: Delphi Technologies [16].

\section{EUROPEAN UNION}

EURO 5-6

\begin{tabular}{|c|c|c|c|c|c|c|c|c|c|c|}
\hline \multirow[b]{2}{*}{ Emissions } & \multirow[b]{2}{*}{ Unit } & \multicolumn{3}{|c|}{ PC M", LCV N1 CL 1} & \multicolumn{3}{|c|}{ LCV N1 CL 2} & \multicolumn{3}{|c|}{ LCV N1 CL 3, N2 } \\
\hline & & Euro 5a & Euro $5 \mathrm{~b} / \mathbf{b +}$ & $\begin{array}{l}\text { Euro } 6 \mathrm{~b}, \mathbf{6 c}, \\
\text { 6d-Temp, 6d }\end{array}$ & Euro 5a & Euro $5 \mathrm{~b} / \mathbf{b +}$ & $\begin{array}{l}\text { Euro 6b, 6c, } \\
\text { 6d-Temp, 6d }\end{array}$ & Euro 5a & Euro 5b/b+ & $\begin{array}{l}\text { Euro 6b, 6c, } \\
\text { 6d-Temp, 6d }\end{array}$ \\
\hline \multicolumn{11}{|c|}{ EURO 5-6 Positive ignition emissions limits (IEC) 715/2007 as amended (EC) 692/2008) } \\
\hline THC & \multirow{5}{*}{$\mathrm{mg} / \mathrm{km}$} & 100 & 100 & 100 & 130 & 130 & 130 & 160 & 160 & 160 \\
\hline NMHC & & 68 & 68 & 68 & 90 & 90 & 90 & 108 & 108 & 108 \\
\hline NOx & & 60 & 60 & 60 & 75 & 75 & 75 & 82 & 82 & 82 \\
\hline $\mathrm{CO}$ & & 1000 & 1000 & 1000 & 1810 & 1810 & 1810 & 2270 & 2270 & 2270 \\
\hline $\mathrm{PM}^{233}$ & & 5.0 & 4.5 & 4.5 & 5.0 & 4.5 & 4.5 & 5.0 & 4.5 & 4.5 \\
\hline $\mathrm{PN}^{21}$ & $\mathrm{Nb} / \mathrm{km}$ & - & - & $6 \times 10^{114}$ & - & - & $6 \times 10^{114}$ & - & - & $6 \times 10^{144}$ \\
\hline \multicolumn{11}{|c|}{ EURO 5-6 Compression ignition emissions limits ((EC) 715/2007 as amended (EC) 692/2008) } \\
\hline NOx & \multirow{4}{*}{$\mathrm{mg} / \mathrm{km}$} & 180 & 180 & 80 & 235 & 235 & 105 & 280 & 280 & 125 \\
\hline $\mathrm{HC}+\mathrm{NOx}$ & & 230 & 230 & 170 & 295 & 295 & 195 & 350 & 350 & 215 \\
\hline $\mathrm{CO}$ & & 500 & 500 & 500 & 630 & 630 & 630 & 740 & 740 & 740 \\
\hline PM" & & 5.0 & 4.5 & 4.5 & 5.0 & 5.0 & 4.5 & 5.0 & 5.0 & 4.5 \\
\hline PN" & $\mathrm{Nb} / \mathrm{km}$ & - & $6 \times 10^{11}$ & $6 \times 10^{11}$ & - & $6 \times 10^{11}$ & $6 \times 10^{11}$ & - & $6 \times 10^{11}$ & $6 \times 10^{11}$ \\
\hline
\end{tabular}

Figure 1.6. Values for the emissions in SI and CI engines for light passenger cars from Euro 5 to Euro 6. Source: Delphi Technologies [16].

The introduction of $\mathrm{CO}_{2}$ regulations in order to control also the fuel efficiency of the engines has been more recent. In 2009 the EU regulated the average specific emissions of $\mathrm{CO}_{2}$ for each manufacturer (EC no. 443/2009). 


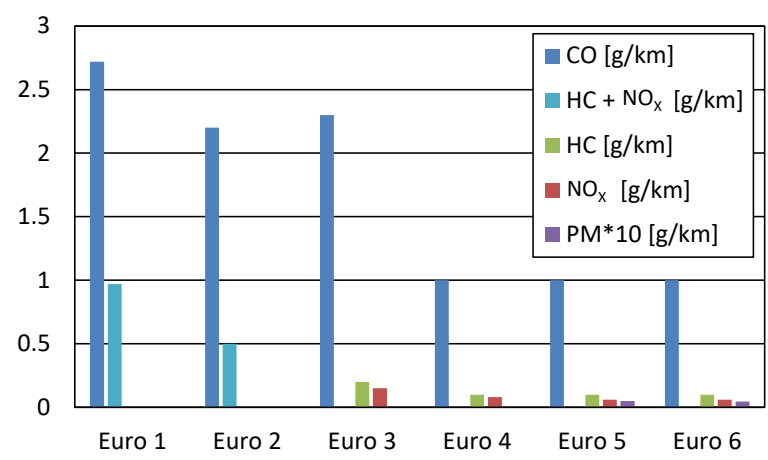

Figure 1.7. Evolution of the SI emissions regulations in Europe.

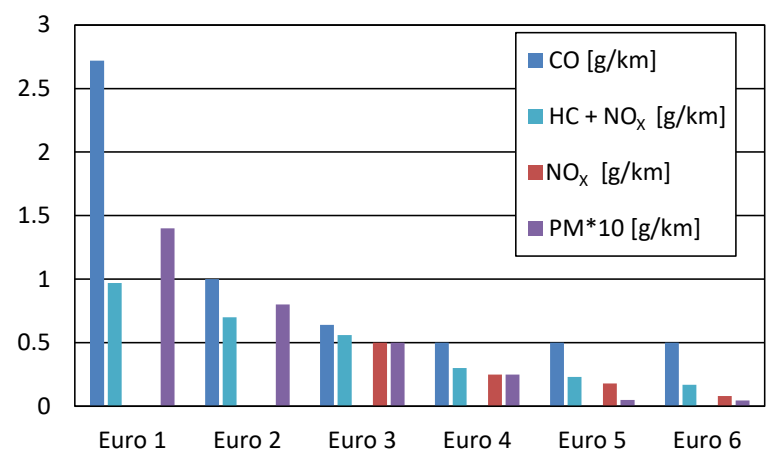

Figure 1.8. Evolution of the CI emissions regulations in Europe.

This regulation was effective from the year 2012, encouraging the increase in fuel efficiency for all the motored vehicles (Figure 1.9), and also trying to stop the raise of $\mathrm{CO}_{2}$ emissions to the atmosphere (which is one of the main factors affecting the climate change).

All the regulations described above have guided the recent development of the engines on a way focused on their fulfilment. In CI engines, these regulations favored the introduction of the direct injection, the generalization of the turbocharging and, probably as a key element, the use of some specific aftertreatment systems: DOC (Diesel Oxidation Catalyst), DPF (Diesel Particulate Filter), SCR (Selective Catalytic Reduction), etc. And in SI engines, the adoption of stoichiometric mixtures combined with the TWC (Three-Way Catalyst) presented the best solution to overcome the regulations 


\begin{tabular}{l|c|c|c|c|}
\multirow{2}{*}{ Vehicle type } & \multirow{2}{*}{ Years } & $\mathbf{a}$ & Target & M0 \\
\cline { 3 - 5 } & & $\mathbf{g} / \mathbf{k m} / \mathbf{k g}$ & $\mathbf{g} / \mathbf{k m}$ & $\mathbf{k g}$ \\
\hline \multirow{3}{*}{ Passenger Cars } & $2012-2015$ & 0.0457 & 130 & 1372 \\
\cline { 2 - 5 } & 2016 & 0.0457 & 130 & 1392.4 \\
\cline { 2 - 5 } & 2020 & 0.0333 & 95 & TBD \\
\hline \multirow{2}{*}{$\begin{array}{l}\text { Light } \\
\text { Commercial }\end{array}$} & $2014-2017$ & 0.093 & 175 & 1706 \\
\hline Vehicles & 2018 & 0.093 & 175 & TBD \\
\hline
\end{tabular}

Figure 1.9. Evolution of the $\mathrm{CO}_{2}$ emissions regulations in Europe.

in terms of pollutants emissions. As it can be seen, the strategies adopted for each type of engine were different. Diesel engines found more problems to overcome the emissions regulations due to the higher values of certain emissions and the difficulties to reduce them. This fact forced their continuous development to fulfill the successive regulations. All this, combined with the initial higher efficiency of the Diesel cycle, has led to a higher improvement of these engines compared to SI engines, which remained almost stagnant in their development, since it was not necessary until recently to continue developing them in order to accomplish the fixed regulations.

However, the combination of some recent events is leaving the diesel engine in an adverse situation. On the one hand, the well-known Dieselgate case has moved to the forefront around the world the emissions of diesel engines and the bad practices of some car manufacturers. This piece of news, combined with the big difference noticed between the certified and the real emissions obtained during the standard driving cycle, have deteriorated greatly the social image of the diesel engine. And, on the other hand, the new emissions regulations (either those from the recent past of those coming in the near future) are increasing the complexity and the prices of the vehicles powered by a diesel engine, as well as the uncertainty about the implementation of traffic regulations, especially for diesel vehicles, do not help to improve the complicated situation of these engines.

Therefore, it has seen that they are more efficient engines, but more pollutant, and the concern about the health problems inside the highly polluted cities is more important than the efficiency. This fact has promoted the interest on the gasoline engine as a cleaner alternative to the diesel engine, and thus their development has been "activated" again strongly, since these engines, nowadays, are cleaner but still need to improve their lower efficiency to fulfil the $\mathrm{CO}_{2}$ new regulations. With this new effort to improve their efficiency, 
gasoline engines will be a really serious and attractive alternative to diesel engines.

The initial solutions already implemented for these engines, have been the introduction of the direct injection system, turbocharging and downsizing. With these improvements, the efficiency achieved nowadays in these engines has increased to a new level after lots of years remaining in the same efficiency ranges. Nevertheless, the next steps to continue improving the efficiency of these engines move the combustion conditions out of the stoichiometric mixture. This change gives a new room to improve efficiency, but moves gasoline engines out of that "comfortable position" where all the emissions coming from the combustion process were easily removed by the three-way catalyst. These changes are the stratified charge and the lean combustion, which represent a new challenge on the development of the gasoline engine towards a more advanced and efficient engine.

In the current scene, it must not be forgotten the emerging electrical solutions and the hybridization of the vehicles aiming at getting better efficiencies and reducing the local emissions (these are nowadays the ones taken into account). These solutions can be understood as a new competitor of the combustion engines (full electric vehicles) or as a complementary way to help these engines to work in a more efficient way (hybridization). Currently the second statement is gaining more importance, since the benefits of both solutions can be exploited. In both cases, the combustion engines (at least for the short and medium term) do not collide directly with these solutions, and the work to improve the engines continues being mandatory to ensure the fulfillment of the standards, as well as very important to preserve the competitive advantages of these devices. With that, the maximum benefit for the final users of these vehicles could be ensured.

\subsection{Context}

This work performed in the current $\mathrm{PhD}$ thesis has been framed inside a bigger project leaded by the car manufacturer Renault (project ULCGE [17], Ultra Low Cost Gasoline Engine). In this project, the main goal was to develop a new gasoline engine concept dedicated to the Indian market, with the intention of creating an engine more efficient and clean than its competitors, but with the premise of making it simpler and, therefore, cheaper.

In the Indian market, the standard regulation in force during the development of this work was the Bharat IV, the implementation of which 
started on April 1, 2010, and which finally was implemented for the nationwide on April1, 2017. This regulation is based on the Euro 4, in application from 2005 to 2009 in Europe. Therefore, the emissions requirements of this engine initially were to fulfil Euro 4, and for this purpose, the goal was to design an ultra-low $\mathrm{NO}_{\mathrm{x}}$ gasoline engine, only including an oxidation catalyst in the exhaust line.

With this basis, the engine used to perform the works of this thesis has been the same under development for this ULCGE project, since both works were performed in parallel. At the beginning of the project, the engine was in a very early stage. The initial part of the work was to choose and adjust the best engine design and configuration, and after those works (more technical and less interesting for the purpose of the present thesis) the next step was to operate the engine and study the combustion and the potential of this engine concept. This part has been the core of the thesis work, which has been devoted to try to implement and study the CAI (Controlled AutoIgnition) combustion and the lean operation concepts in an engine close to a real industrialization and commercialization. This last feature makes a difference compared to other works, since the engine has been built with less complex systems (feasible components for production engines) and the study has been performed for the whole operation range, trying to study the potential of a complete operating solution based on these modes.

\subsection{Previous related works}

The CMT-Motores Térmicos institute (CMT) has a great deal of experience working with several engine manufacturers and leading own projects related to the investigation of the combustion process and the engine development. Inside the group, there have been some similar works related to this project, and in the following lines some of them are going to be shortly mentioned.

Regarding the field of the SI engines improvement and the introduction of gasoline fuel in CI engines to approach the research of new ways to improve the gasoline engines efficiency, there are two recent works that should be remarked here. These are the works of Dr. Manuel Rivas [18] and Dr. Daniela de Lima [19]. The first work dealt with the implementation and the study of the EGR effect on gasoline engines, and the attempt to use this strategy to replace the over-fueling strategies as a way to reduce knock at high loads. In this way, it was demonstrated that this new strategy resulted better to control knock and, at the same time, improved the engine fuel efficiency. And the second work was developed in order to explore the potential of a new combustion concept 
using gasoline in a CI engine to study PPCI combustion and to evaluate its potential. Both works present some similarities on the way to undertake the work performed in the present thesis, and can be used in some aspects as a previous reference of the experience in this institute with this kind of works.

On an indirect way, inside this institute there have been some works related to the study of Low Temperature Combustion Modes (LTC) but, up to now, all these works have been performed with diesel applications (diesel engines, as already mentioned, have had a more continuous development compared to gasoline engines). These works have been performed by Dr. Eduardo Belarte [20], Dr. Vicente Boronat [21] and Dr. Rogerio Jorge [22]. Therefore, the combustion study of the gasoline and the LTC modes represents, in some aspects, a new challenge for this institute and the personal involved in the current project.

\subsection{Thesis document structure}

In this brief subsection, the structure of the whole document is going to be described, in order to guide the reader and give him a whole idea about its content.

- Chapter 1:

This chapter has been a brief introduction of the thesis topic and the context around the work to be performed, since this is a very important aspect affecting the fundamentals of this work and the goals to achieve.

- Chapter 2:

In this chapter, a deeper review of the topics closely related with this thesis are summarized. Therefore, this chapter is a literature review to position the reader and offer a state of the art analysis around the topics to deal along the thesis.

- Chapter 3:

Taking as a reference the previous chapter, a synthesis and evaluation of Chapter 2 will be exposed, in order to use this synthesis to establish the thesis objectives to follow during this work.

- Chapter 4:

In this chapter the experimental tools and the methodologies used and followed during the thesis work will be described and detailed. 
- Chapter 5:

Chapter 5 will be focused on the description of the main peculiarities of the engine, as well as the key points that make it different compared to a more common engine for this type of works. In this way, a more technical point of view of the engine performance will be given.

- Chapter 6:

This chapter presents the analysis of the results obtained during the study of the different combustion modes operated in this engine, and a proposal for a different analysis methodology approach to study in a deeper way the combustion cycles.

- Chapter 7:

Finally, this chapter will present a summary of the main conclusions obtained during the whole work, as well as a brief study of the potential of this engine based on the theoretical results obtained in different standard cycles.

\section{Bibliography}

[1] Carnot S. Réflexions sur la puissance motrice du feu et sur les machines propres à développer cette puissance. Bachelier, 1824.

[2] Goering C.E. and Fry B. "Engine durability screening test of a diesel oil/soy oil/alcohol microemulsion fuel". Journal of the American Oil Chemists Society, Vol. $61 \mathrm{n}^{o} 10$, pp. 1627-1632, 1984.

[3] Barron M.B. and Powers W.F. "The role of electronic controls for future automotive mechatronic systems". IEEE/ASME Transactions on Mechatronics, Vol. $1 \mathrm{n}^{\circ} 1$, pp. $80^{-}$ 88, 1996.

[4] Kohany T. and Sher E. "Using the 2nd law of thermodynamics to optimize variable valve timing for maximizing torque in a throttled SI engine". SAE Technical Paper $n$. 1999-01-0328, 1999.

[5] Kleinschmidt P. and Schmidt F. "How many sensors does a car need?". Sensors and Actuators: A. Physical, Vol. $31 \mathrm{n}^{o}$ 1-3, pp. 35-45, 1992.

[6] Kamo R., Bryzik W. and Glance P. "Adiabatic engine trends-worldwide". SAE Technical Paper n. 870018, 1987.

[7] Bybee K. "Reliable electronics for high-temperature downhole applications". JPT, Journal of Petroleum Technology, Vol. $52 \mathrm{n}^{\circ}$ 7, pp. 56-57, 2000.

[8] Brandi F.K., Wünsche P. and Gschweltl E. "Design strategies for low noise engine concepts". SAE Technical Paper n. 911070, 1991.

[9] Wandell J.L. "Shot peening of engine components". American Society of Mechanical Engineers, Internal Combustion Engine Division (Publication) ICE, Vol. 29, pp. 101$108,1997$. 
[10] Ohgami E., Ohsawa N. and Saito T. "Nissan's new V8 and L4 aluminum cylinder block - Design and production". SAE Technical Paper n. 910431, 1991.

[11] Bird G.L. "Ford 2.5 liter direct injection naturally aspirated diesel engine". Proceedings of the Institution of Mechanical Engineers. Part D, Transport engineering, Vol. 199 $\mathrm{n}^{\circ} 2$, pp. 113-122, 1985.

[12] Santodonato J., Basu D. and Howard P. "Health effects associated with diesel exhaust emissions, literature review and evaluation". National Academy of Sciencies, Engineering and Medicine, $\mathrm{n}^{\circ}$ EPA/600/1-78/063, 1978-11.

[13] Hill J., Polasky S., Nelson E., Tilman D., Huo H., Ludwig L., Neumann J., Zheng H. and Bonta D. "Climate change and health costs of air emissions from biofuels and gasoline". Proceedings of the National Academy of Sciences of the United States of America, Vol. $106 \mathrm{n}^{\circ}$ 6, pp. 2077-2082, 2009.

[14] EPA U.S. The benefits and costs of the clean air act from 1990-2010. 1999.

[15] Bernstein L., Bosch P., Canziani O., Chen Z., Christ R. and Riahi K. Synthesis Report. Intergovernmental Panel on Climate Change 200\%. 2007.

[16] Technologies Delphi. "Worldwide emissions standards, Passenger cars and light duty vehicles". Delphi informative booklet, 2018/2019.

[17] López J.J., Novella R., Valero-Marco J., Coma G. and Justet F. "Evaluation of the Potential Benefits of an Automotive, Gasoline, 2-Stroke Engine". SAE Technical Paper n. 2015-01-1261, 2015-April.

[18] Rivas M. "Assessment of fuel consumption reduction strategies on a gasoline turbocharged direct injection engine with a cooled EGR system". PhD thesis. Universitat Politècnica de València, Departamento de Máquinas y Motores Térmicos, 2016.

[19] de Lima D. "Analysis of combustion concepts in a poppet valve two-stroke downsized compression ignition engine designed for passenger car applications". PhD thesis. Universitat Politècnica de València, Departamento de Máquinas y Motores Térmicos, 2016.

[20] Belarte E. "Estudio del proceso de combustión premezclada controlada por la reactividad del combustible en un motor de encendido por compresión". PhD thesis. Universitat Politècnica de València, Departamento de Máquinas y Motores Térmicos, 2015 .

[21] Boronat V. "Dual-fuel dual-mode combustion strategy to achieve high thermal efficiency, low NOx and smoke emissions in compression ignition engines". PhD thesis. Universitat Politècnica de València, Departamento de Máquinas y Motores Térmicos, 2018.

[22] Amorim R. "Combustión por difusión de baja temperatura en motores Diesel de pequeña cilindrarada". PhD thesis. Universitat Politècnica de València, Departamento de Máquinas y Motores Térmicos, 2010. 



\section{Chapter 2}

\section{Combustion in gasoline engines}

\section{Contents}

2.1 Introduction . . . . . . . . . . . . 19

2.2 The conventional SI engine and its combustion process ...................... 20

2.2.1 Premixed turbulent combustion review ........ 20

2.2.1.1 Spark and flame initiation ......... 20

2.2.1.2 Initial flame kernel development ...... 21

2.2.1.3 Turbulent flame propagation ......... 22

2.2.1.4 Flame termination ............... 24

2.2.1.5 Abnormal combustion, uncontrolled autoignition $\ldots \ldots \ldots \ldots \ldots \ldots \ldots \ldots \ldots \ldots \ldots \ldots \ldots \ldots$

2.2.2 Exhaust emissions in SI engines ........... 27

2.2.2.1 Unburned Hydrocarbons ............ 28

2.2.2.2 Nitrogen oxides ............. 30

2.2.2.3 Carbon monoxide ............. 32

2.2.2.4 Particulate matter .............. 33

2.2.2.5 Carbon dioxide ............. 34

2.3 Strategies to improve the SI gasoline engines... 35

2.3.1 Downsizing...................... 35

2.3 .2 Direct Injection $\ldots \ldots \ldots \ldots \ldots \ldots \ldots \ldots \ldots \ldots \ldots$

2.3.3 Variable valve Actuation systems $\ldots \ldots \ldots \ldots \ldots . \ldots$

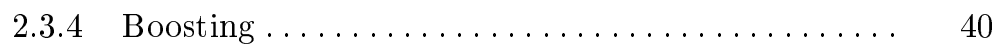

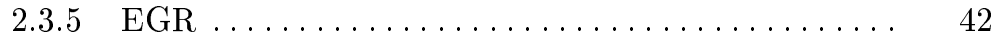


2.3.6 SI Lean Combustion...................... 44

2.3.7 Low Temperature Combustion applied to SI gasoline engines $\ldots \ldots \ldots \ldots \ldots \ldots \ldots \ldots \ldots \ldots .47$

2.3.7.1 The Low Temperature Combustion concept

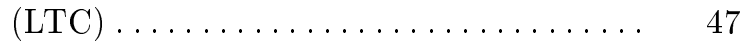

2.3.7.2 The Gasoline CAI engines ........... 54

2.4 The combustion analysis.............

2.4.1 The combustion diagnostics $\ldots \ldots \ldots \ldots \ldots \ldots \ldots . \quad 70$

2.4.2 The SI cyclic variability and the influence on the

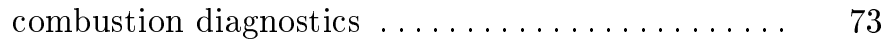

2.4.3 The combustion analysis on SI and CAI combustion

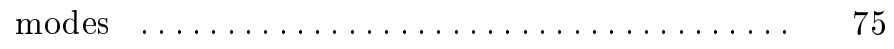

$2.5 \quad$ Summary................

Bibliography $\ldots \ldots \ldots \ldots \ldots \ldots \ldots \ldots \ldots \ldots \ldots \ldots, \quad 80$ 


\section{$2.1 \quad$ Introduction}

Gasoline engines are employed as power plants by means of burning a volatile liquid fuel mixed with air to obtain mechanical energy. They are classified as internal combustion engines, and the ignition of the fuel/air mixture is initiated externally by a spark plug. This fact gives them their commonly known name: SI engines (Spark Ignition engines). The exposed literature review on the next pages will be focused on gasoline engines intended for the automotive industry. This is the most common application for this type of engines, since they power the major part of automobiles and motorcycles, as well as some light trucks.

These engines are based on the Otto cycle, and they can be operated in two or four strokes $(2 \mathrm{~S}-4 \mathrm{~S})$, combining the compression, power, exhaust and intake processes described by Otto. Some operating diagrams, representative of these cycles, are shown in Figure 2.1.

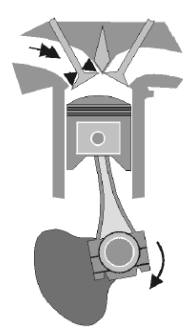

Intake

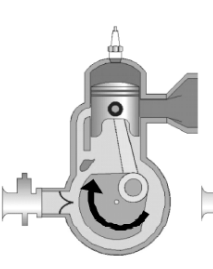

Power

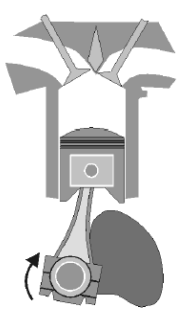

Compression

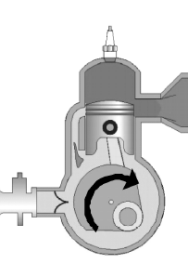

Exhaust

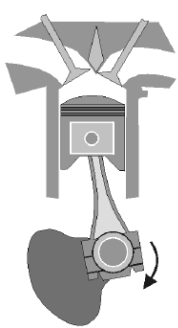

Power

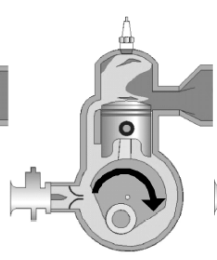

Scavenging

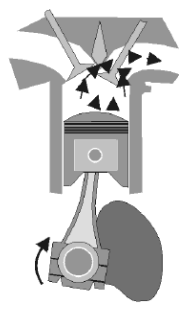

Exhaust

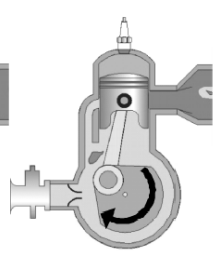

Compression

Figure 2.1. Diagram of a $4 S$ cycle (above) and a $2 S$ cycle (below) representing the different phases of the cycle. Source: Adapted from [1].

This chapter is divided in three main themes. Firstly, the classical SI combustion process is described, and its main peculiarities as well as the pollutant formation processes are discussed. Secondly, the main attempts to improve these engines are exposed, going from the most common and applied nowadays to some of the most recent and interesting for this $\mathrm{PhD}$ thesis. And, 
finally, a brief overview of the most common combustion diagnostics methods used in the context of SI engines will be shown.

\subsection{The conventional SI engine and its combustion process}

\subsubsection{Premixed turbulent combustion review}

For gasoline engines, the normal combustion development can be described in four stages [2]: spark and flame initiation, initial flame kernel development, turbulent flame propagation and flame termination.

The first two stages, the spark and flame initiation and the initial flame kernel development, represent approximately $5 \%$ of the overall combustion process. During this stage the cylinder pressure rise is very small (compared to the corresponding motoring case) and there is no useful work, since ignition has just occurred and the combustion process is initiating. The largest part of the work is performed during the turbulent flame propagation stage, where most of the energy is released (around $80 \%$ to $90 \%$ ). During this stage, the incylinder pressure is raised (compared to the motoring case), producing the work along the power stroke. Finally, the remaining $5 \%$ of the combustion process is the flame termination, where the combustion finishes and the pressure starts to decrease [3].

\subsubsection{Spark and flame initiation}

Maly et al. [4] carried out a detailed review of the spark ignition process for this type of engines. The spark plug is activated by a high increase of the electrical potential $(\approx 10 \mathrm{kV})$ across the electrode gap, producing an electric arc with a very high current value, but a very short duration. This energy is transmitted very efficiently to the plasma generated [5] and, during the breakdown phase, the electric arc remains activated in the order of $100 \mu \mathrm{s}$ [6], and the voltage is decreased down to around 50 to $100 \mathrm{~V}$.

During the final phase of the spark activation, the glow phase, the electrical discharge represents most of the energy released by the spark [7], and this one is transmitted with a voltage of around $500 \mathrm{~V}$ and a low current value $(\approx 0.1$ A). During this last phase, the self-sustained propagation is established and the initial flame kernel development stage is initiated. 


\subsubsection{Initial flame kernel development}

The flame kernel consists on a small volume of combustion products inside the unburned fuel/air mixture where the combustion reactions start. This kernel presents a spherical shape under steady conditions, as it can be observed by optical procedures, and it needs to reach a critical size to ensure a stable flame propagation, as reported in [8]. Its initial flame is developed always in laminar conditions and the size of this first stage is typically compared to the gap between the spark electrodes. Therefore, the gap size of the spark plug is very important to the initial flame development.

The capacity of the kernel generated during the ignition process to progress and generate a flame front will depend on the turbulence existing around the spark plug, as well as the local thermal and chemical conditions at that moment (local temperature and richness). In the case of kernels without strong deformations due to the local turbulences and heat losses, the initial combustion propagates continuously until all the reactants are consumed. But as the turbulence levels increase, the flame front deformation increases and it can be even quenched if the deformation is too strong. In order to understand the flow effect on the flame propagation, well-controlled laminar vortex models have been used in different works $[9,10]$. The vortex strength is used to characterize the turbulence speeds, and this is a very important factor affecting flame kernel quenching. As a general trend, when the spatial scales of these vortices are increased, lower speeds are required to provoke quenching. Normally, flame kernel quenching happens when a strong flow exists, which creates diverse local reaction fronts spreading towards each other. This effect can occur locally, and the overall process can continue to consume the rest of the reactant charge, but if the deformation is large enough, the entire kernel can be extinguished. The main factors that affect the initial formation of this kernel and its development are: the ignition system, the temperatures in the cylinder, the degree of turbulence, the design of the combustion chamber and the degree of fuel homogenization. In this type of engines, the development of this initial phase has a randomness degree caused mainly by the turbulence conditions in the spark plug region. This effect is very difficult to control and gives to these engines a certain cyclical variability in the development of the combustion (Figure 2.2) that will affect the output power, the torque stability, and the pollutant emissions of the engine [11]. 

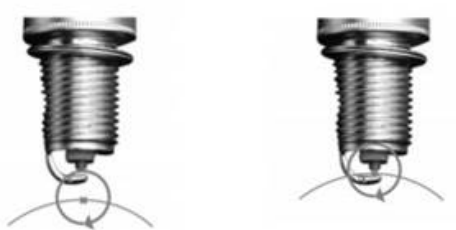

Figure 2.2. Origin of the combustion cyclic variability. Source: [1].

\subsubsection{Turbulent flame propagation}

The turbulent premixed combustion can be classified into different regimes $[12,13]$. As can be seen in the Borghi diagram (Figure 2.3), depending on the numbers of Damkohler, Karlovitz and Reynolds, different types of turbulent premixed combustion are differentiated. Within this diagram, the greatest area of interest for SI engines is the area of thickened wrinkled flames and corrugated flamelets (Pockets formation). And the differentiation between these two zones is defined when $\lambda_{K}=\delta$, moment in which the small size fluctuations get into the flame front expanding it. Other authors place this limit rather in the moment in which $K a=1$, moment in which the characteristic reaction time and the smaller characteristic times of the Kolmogorov scale are equal [14].

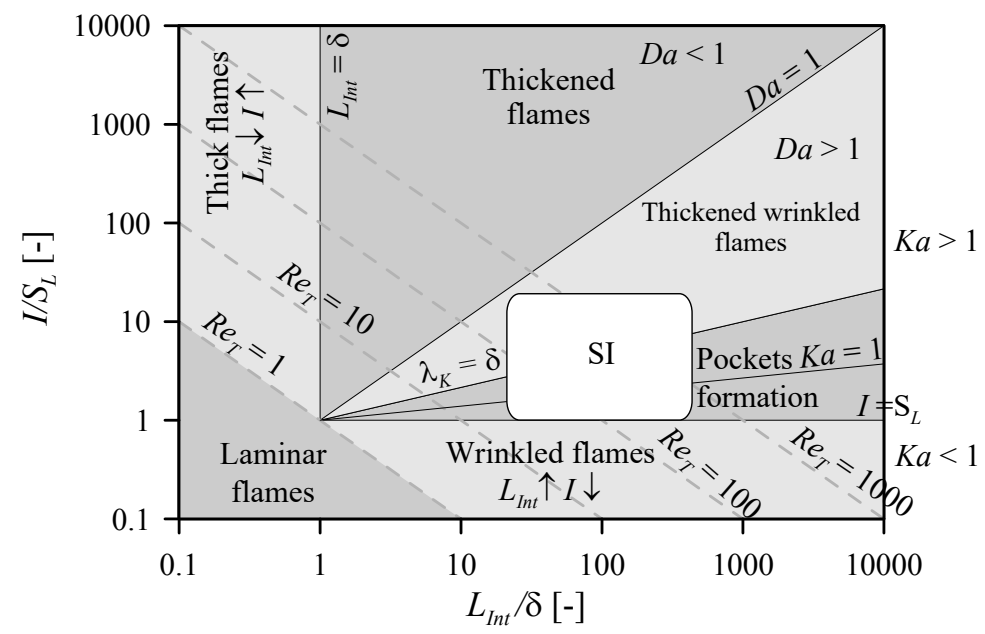

Figure 2.3. Borghi diagram. Source: Adapted from [1]. 
The corrugated flamelets region is found increasing the turbulence level with respect to the wrinkled flames area. The effect of this increase in the turbulence level is the formation of pockets (small bags of burned products in the fresh mixture and/or vice versa). In this regime, the increase in the rate of combustion is explained, fundamentally, by the increase in the surface of the flame front caused by the deformations. And if the turbulence level continues to be further increased, it would lead to a situation where $\lambda_{k}$ becomes smaller than $\delta$. At that time, the small size fluctuations get into the flame front, widening it (Figure 2.4). This change constitutes a transition point between the wrinkled flames and the thickened flames.
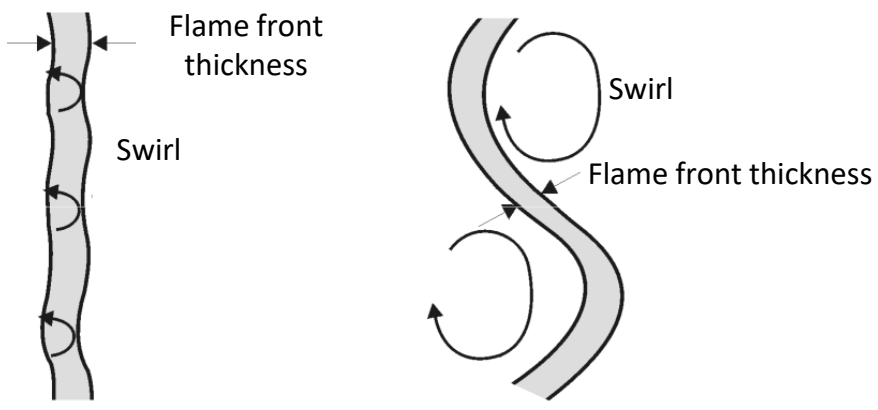

Figure 2.4. Left - Thickened flame, the spatial integral scale of the turbulence is on the same order than the thickness of the flame front. Right - Distorted flame, the scale of the turbulence is larger than the flame front thickness. Source: Adapted from [1].

This process can be reproduced by a simple entrainment combustion model suggested by Keck et al. [15]. The flame front with an $A_{f f}$ area advances through unburned gases with a $\rho_{u b}$ density at a $U_{t}$ speed defined by the local velocity of the turbulent fluctuation. This entrained gas is consumed in a time scale $l_{t} / S_{L}$, where $l_{t}$ is the turbulent length scale and $S_{L}$ is the laminar flame speed.

$$
\frac{d_{m_{u b}}}{d t}=\rho_{u b} \cdot A_{f f} \cdot U_{t}-\frac{m_{u b}}{\frac{l_{t}}{S_{L}}}
$$

In the Eq. $2.1 m_{u b}$ represents the mass of unburned gas entrained but still not burned. Therefore, the burning rate is the sum of the effect of the laminar combustion at the nominal front and that of the entrained fresh mixture. 


$$
\frac{d m_{b}}{d t}=\rho_{u b} \cdot A_{f f} \cdot S_{L}+\frac{m_{u b}}{\frac{l_{t}}{S_{L}}}
$$

From Eqs. 2.1 and 2.2, the burn rate in quasi-steady (i.e. if $d_{m_{u b}} / d_{t}=0$ ) conditions results in:

$$
\frac{d m_{b}}{d t}=\rho_{u b} \cdot A_{f f} \cdot\left(S_{L}+U_{t}\right)
$$

The quasi-steady combustion speed will therefore be the sum of $S_{L}+U_{t}$. Consequently, the turbulent speed increases respect to the laminar flame speed as far as the initially smooth and uniform flame front transforms into a wrinkled one, with an increased surface. But if the laminar speed is too low, the burning time $l_{t} / S_{L}$ can become comparable or even greater than the characteristic diffusion time $l_{t}^{2} / D$ ( $\mathrm{D}=$ mass diffusivity). At this moment, the model of wrinkled laminar flame is no longer valid, and the combustion will start to develop as thickened flames.

The relationship between the movement of the charge inside the cylinder and the local turbulences generated that increase the area of the flame front is not simple [16]. The small eddies are those useful to provoke the flame front wrinkling, thus effectively affecting the combustion velocity. These eddies, however, are not generated during the intake process, but during the final stage of the compression stroke, when the turbulence patterns (swirl or tumble) are broken. The details on how this turbulence breakup takes place has a direct impact in combustion velocity.

\subsubsection{Flame termination}

Once most of the mixture has been burned (90-95\%), the last fractions to burn are found in the corners of the combustion chamber, as well as in regions close to the cylinder walls and the piston. The proximity to the colder metal of the walls makes the heat flows from the combustion chamber to the engine walls very high, thus reducing the combustion rates. Finally, the fractions of the mixture closest to the walls remain unburned, due to the low temperature levels. Although this combustion phase contributes with a very little work to the piston, it is an important phase because at this moment the unburned mixture remaining in the cylinder has taken a relatively long period of time being compressed and heated by the combustion process, so this part of the 
mixture can be autoignited, causing a problem known as knock. Therefore, a control over the end of the combustion results in a smooth operation of the engine since if knock appears, the presence of pressure oscillations can be harmful to the engine [3].

\subsubsection{Abnormal combustion, uncontrolled autoignition}

The autoignition of the fuel/air mixture, more commonly known as knock, occurs when part of the unburned mixture autoignites before being reached by the flame front [17]. Usually, this event happens in the final fraction of the mixture (usually called end-gas), as the flame front takes longer to arrive.

When this phenomenon (autoignition) occurs at different points in the combustion chamber, there is a strong increase of the pressure and temperature of the unburned mixture, and both things (autoignition + increase in $\mathrm{p}$ and $\mathrm{T}$ ) strongly increase the rate of burned mass, deriving in a loop process that could be catastrophic for the engine [18-20].

The autoignition of the end-gas in a SI has the following consequences:

- It causes a very fast increase in temperature and pressure in the autoignition region, leading to a violent pressure wave that propagates (at the speed of sound) through the combustion chamber [21].

- A very characteristic noise is generated by this pressure wave. This noise comes together with a high pressure gradient that mechanically damages the engine. In Figure 2.5, to the right, a cylinder pressure signal is represented, in which the autoignition phenomenon occurs. A significant oscillation in the pressure signal (high frequency) can be observed, the intensity of which is proportional to the amount of mixture that has autoignited. Additionally, a sudden increase in the final part of the HRL can be observed, which is associated to a large peak in the HRR.

- This pressure wave breaks the thermal boundary layer that exists close to the walls of the combustion chamber. If this boundary layer is broken, the high temperature of the gas reaches the surface of the wall, causing a melting of the metallic material.

Now the thermochemical basis of this process will be summarized. When a mixture with a certain richness is under a given pressure and temperature condition, some chemical activity begins to take place by a series of chain reactions that, after a certain time, lead to the combustion of the reactants 

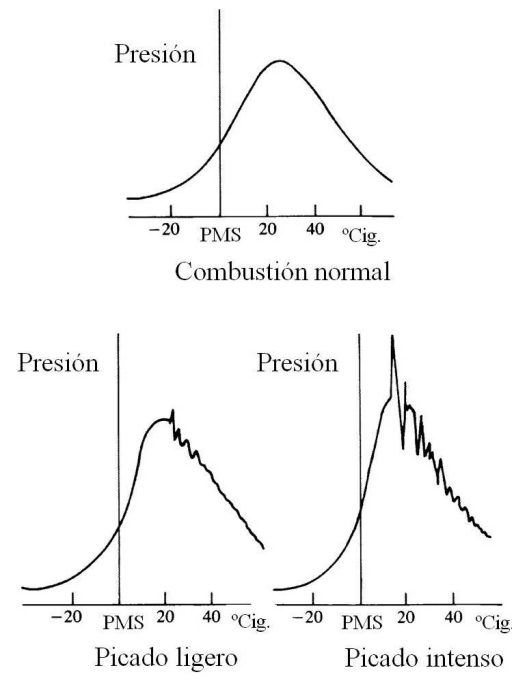

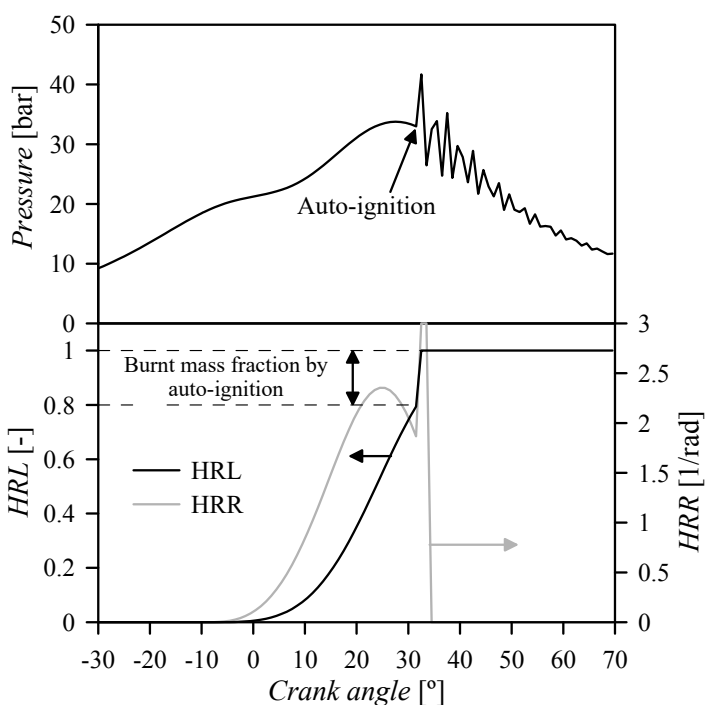

Figure 2.5. Evolution of the pressure signal with the autoignition and apparent effect of the autoignition on the Heat Release Law (HRL) and its derivative (HRR). Source: Adapted from [1].

$[22,23]$. This time necessary for the autoignition is called ignition delay $(\tau)$, and its magnitude depends mainly on the fuel characteristics, the temperature, pressure, oxygen mass fraction and equivalence ratio of the mixture. In particular, a higher temperature and/or pressure and/or oxygen mass fraction, as well as an equivalence ratio close to stoichiometric, lead to a reduction in the ignition delay [24]. Figure 2.6 shows a map of the ignition delays (in seconds) for a stoichiometric mixture of isooctane and air, where the dependence of this parameter on pressure and temperature is clear.

Finally, it is interesting to present a correlation that allows determining the ignition delay for an fuel/air mixture with a conventional gasoline. Although the predictive capacity of this type of correlation is always uncertain [25], among the various existing correlations, the most usual comes from the work of Douaud and Eyzat [26], which allows the prediction for a mixture of air with a gasoline with a given octane number, depending on the pressure and temperature conditions (the authors do not specify the richness of the mixture, since the effect of this parameter is not very important in traditional gasoline engines, because it can be considered as a stoichiometric mixture): 


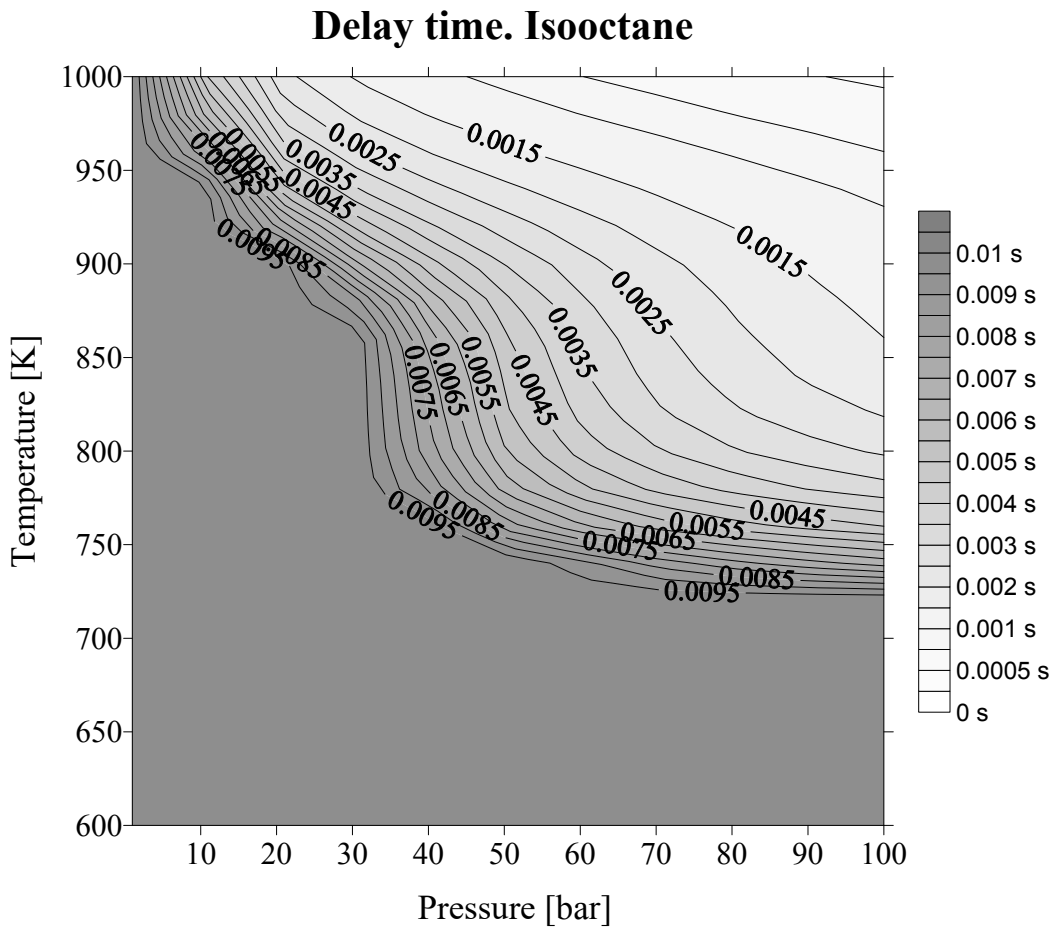

Figure 2.6. Ignition delay map $(\tau)$ for an Isooctane/Air mixture in stoichiometric conditions. Source: Adapted from [1].

$$
\tau=18.06 \cdot\left(\frac{O N}{100}\right)^{3.402} \cdot p^{-1.7} \cdot \exp \left(\frac{3800}{T}\right)
$$

where $\tau$ is the ignition delay in ms, $p$ is the absolute pressure in bar, $T$ is the temperature in Kelvin and $O N$ is the octane number. Although in their work the authors perform a thorough study to determine the most appropriate $O N$ to obtain a good prediction, reasonable estimations can be obtained using the RON.

\subsubsection{Exhaust emissions in SI engines}

The fuel known as gasoline results from the combination of a large variety of hydrocarbons formed mainly by chains of hydrogen and carbon atoms. If a perfect combustion with enough oxygen levels is considered, the resulting 
composition of the exhaust gases will be $\mathrm{H}_{2} \mathrm{O}$ and $\mathrm{CO}_{2}$ (and $\mathrm{O}_{2}$-if the mixture is lean- and $\mathrm{N}_{2}$ coming from the air), resulting from the oxidation of the hydrogen and the carbon of the fuel molecules. However, since the combustion process is not perfect, intermediate products are produced as a result of incomplete combustion, or due to the high temperatures and pressures during the process. In this section the main groups of pollutant emissions defined for internal combustion engines will be reviewed: unburned hydrocarbons (HC), nitrogen oxides $\left(\mathrm{NO}_{\mathrm{x}}\right)$, carbon monoxide $(\mathrm{CO})$, particulate matter $(\mathrm{PM})$ and carbon dioxide $\left(\mathrm{CO}_{2}\right)$.

\subsubsection{Unburned Hydrocarbons}

Unburned hydrocarbons are issued, mainly, as a result of an incomplete combustion of the fuel and, therefore, their composition is extremely heterogeneous. This will depend on the composition of the fuel, the geometry of the combustion chamber and the engine operating conditions.

When hydrocarbon emissions are in contact with the atmosphere, they react with nitrogen oxides in the presence of sunlight to form ozone, which is an important component of the photochemical smog that significantly affects pollution in urban areas. This smog is toxic and can cause problems in the health of people such as eye irritation, damage to the lungs or some respiratory problems.

The main causes of $\mathrm{HC}$ emissions are the following:

- Fuel/air mixtures out of the stoichiometric conditions. When the mixture is out of stoichiometric conditions, two things can happen. On the one hand, it can be rich $(\lambda<1)$, and therefore there won't be enough oxygen to oxidize all the hydrocarbons in the mixture. This situation happens at the engine start-up, during high load demands or when there is a problem in the engine. On the other hand, the mixture may be lean, which implies (beyond a certain equivalence ratio) that the mixture may be outside the flammability limits, and therefore it wouldn't ignite (Figure 2.7).

- Incomplete combustion. Even when operating in a correct F/A equivalence ratio, the combustion is not carried out in an ideal way, and there can be several factors that make the combustion incomplete. When the flame front reaches the walls of the combustion chamber, there is always a portion of the unburned mixture near the walls that is not burnt. Another source of hydrocarbons is due to the cooling of the unburned 
mixture during the expansion stroke, which reduces the reactivity of the mixture, leaving some unburned areas in the cylinder at the end of combustion. And finally, the addition of high rates of residual gases in the engine affects the mixture homogenization, decreasing the oxygen levels and lowering the combustion efficiency, thus leaving unburned portions of the mixture.

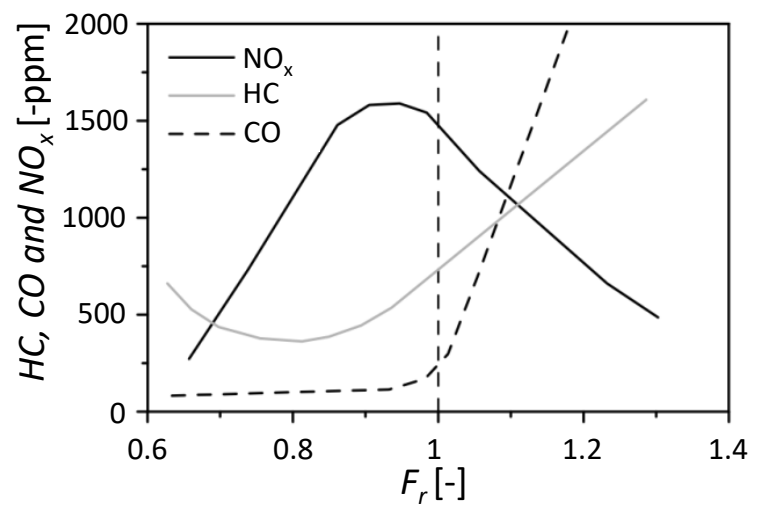

Figure 2.7. Exhaust emissions as a function of the Fuel/Air ratio. Source: Adapted from [1].

- Crevice volumes. In the combustion chamber there are small spaces, like the gap existing between the cylinder and the piston, among others. During the compression stroke, part of the fresh fuel/air mixture is introduced into these spaces (as much as $3 \%$ of the fuel in the chamber can be forced into these crevice volumes). After this stroke, during the expansion of the gases and the pressure drop in the power stroke, a portion of these gases leave towards the combustion chamber. Consequently, they can be partly burned, but there is always a portion that remains inside and cannot be burned because the conditions were not reactive enough for the flame front to continue without extinguishing. The design of the pistons and rings, as well as the tolerances between them, have a great influence on this part of the hydrocarbons emissions.

- Valve overlap. During this period, the intake and exhaust are communicated, and therefore there might be some short-circuiting (i.e. some unburned mixture directly moves from the intake to the exhaust), strongly increasing the hydrocarbon emissions. This effect is much more dramatic in two-stroke engines rather than in four-stroke ones, since 
there are no specific strokes for intake and exhaust, and the charge is renewed during a scavenging process, where both intake and exhaust are necessarily opened at the same time. Anyway, this problem can exist in both types of engine. The implementation of Variable Valve Actuation (VVA) systems allowing the adjustment of the valves position at each moment can greatly improve this problem, and the introduction of direct injection systems in gasoline engines almost eliminates this problem, since the fuel can be injected once the cylinder is closed.

- Deposits on combustion chamber walls. The formation of deposits in the combustion chamber creates porous structures that absorb part of the unburned hydrocarbons from the mixture with the increase of the pressure during the compression stroke. Subsequently, these hydrocarbons are released again when the pressure drops in the combustion chamber, and are later released directly to the exhaust. This problem is accentuated in the frame of boosted or high compression ratio engines, since these ones work at higher pressures. A correct design of the combustion chamber in combination with fuels that include additives to minimize the formation of these deposits can greatly reduce this problem.

- Oil on the combustion chamber walls. The engine needs to be continuously lubricated to protect the engine components from the heat generated by friction when they have relative motion between them. For this reason, in the cylinder walls there is always a thin layer of oil to lubricate the movement of the piston in the cylinder. On the one hand, this oil will generate a similar effect to that described previously for the deposits in the combustion chamber, absorbing and releasing fuel molecules depending on the existing pressure. And, on the other hand, with the aging of the engine the tolerances between the piston rings and the cylinder walls are increasing. This makes the oil layer thickness higher, and part of that oil can end up being part of the combustion. This oil is a hydrocarbon heavier than gasoline, and consequently its combustion is slower, leaving generally unburned hydrocarbons after its combustion.

\subsubsection{Nitrogen oxides}

Nitrogen Oxides $\left(\mathrm{NO}_{\mathrm{x}}\right)$ generated during combustion are formed from the nitrogen molecules present in the air, when these are exposed to an oxidizing atmosphere with temperatures above $2200 \mathrm{~K}$. For the combustion conditions in standard gasoline engines, the temperatures reach the necessary values to 
initiate the formation of this pollutant, and with the introduction of stratified GDI engines this problem has increased. Figure 2.8 shows the operation zones of both type of engines in a graph where the richness and the temperature of the combustion are represented in each axis. Inside the diagram also the characteristic zones of $\mathrm{NO}_{\mathrm{x}}$ and Soot formation are represented.

As it can be seen, the characteristic $\mathrm{NO}_{\mathrm{x}}$ region is found at high combustion temperatures and Fuel/Air ratios where the oxygen is present in relative abundance [27]. This is because high activation energies are necessary to initiate the dissociation process of both the nitrogen and oxygen molecules. Apart from this, it is required some oxygen excess, enough time during which the molecules are at high temperatures and a mixture as heterogeneous as possible, since the fuel molecules have greater affinity for the available oxygen, and these heterogeneities in the mixture make it easier the formation of this pollutant [28].

The main factors that affect the formation of $\mathrm{NO}_{\mathrm{x}}$ will be enumerated and described in the following lines:

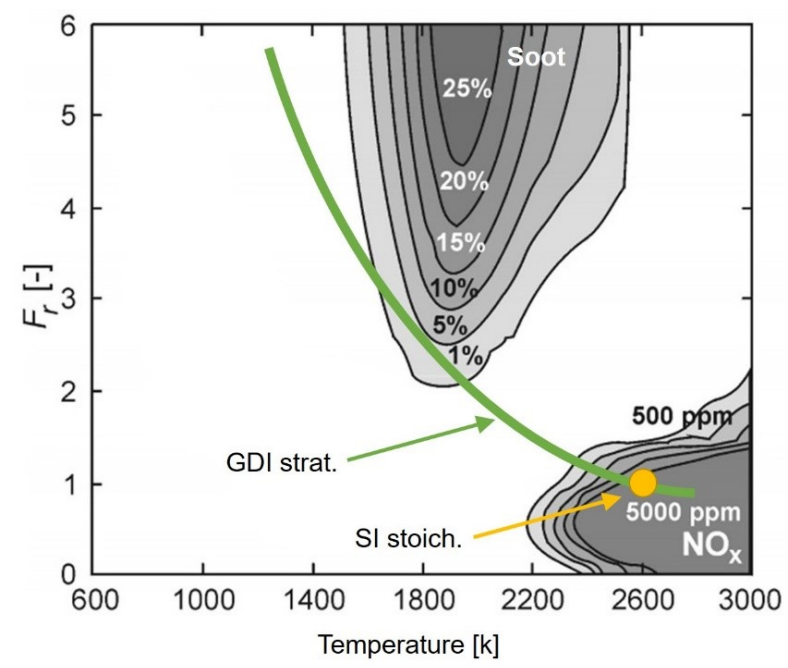

Figure 2.8. Representation of the operating conditions for SI engines on a Fr-T diagram. Source: Adapted from [1].

- The Fuel/Air ratio. It is a key point in the $\mathrm{NO}_{\mathrm{x}}$ emissions formation process since oxygen is the second element necessary for the formation of these molecules. When the engine is operating with rich mixtures, the amount of oxygen available is very limited, and so the process 
of the nitrogen oxidation interferes with the formation of $\mathrm{OH}$ and $\mathrm{H}$ radicals [29]. Therefore the emission of this pollutant will be very limited. However, when the mixture is lean, $\mathrm{NO}_{\mathrm{x}}$ formation is enhanced, since there is oxygen in excess to oxidize all the fuel. This happens in the new generation engines operated with lean mixtures that try to improve their efficiency working with oxygen excess. Therefore, the increase in the compression ratios of this type of engines together with the presence of oxygen in excess aggravates the process of $\mathrm{NO}_{\mathrm{x}}$ formation [30].

- Combustion temperature. As it has been said before, this is the other dominant factor on the formation of this type of emissions. The combustion rates developed in the engine have a high influence on the amounts of emitted $\mathrm{NO}_{\mathrm{x}}$. The increase in combustion rates is associated with higher temperatures, and therefore $\mathrm{NO}_{\mathrm{x}}$ emissions will also increase, being directly proportional to the temperature peaks recorded during combustion [31]. On the other hand, combustions with slower combustion rates will see their $\mathrm{NO}_{\mathrm{x}}$ emissions reduced [32].

$\mathrm{NO}_{\mathrm{x}}$ emissions represent a big problem for the environment. The main biochemical and physiological effects of $\mathrm{NO}_{\mathrm{x}}$ are the following:

- $\mathrm{NO}_{\mathrm{x}}$ is one of the main responsible for acid rain and potentially producer of smog.

- As a result of the acid rain, affected lands become acidified, damaging trees and plants, and making them impossible to absorb the necessary nutrients [33].

- Nitrogen dioxide, with an intense odor and a reddish brown color, can irritate the lungs and reduce their resistance to infectious diseases if the level exceeds $600 \mathrm{mg} / \mathrm{m}^{3}$ [34].

- Nitrogen monoxide participates in the ozone reduction in the stratosphere, thus facilitating the passage of solar ultraviolet radiation to the earth's surface.

\subsubsection{Carbon monoxide}

The CO formation mechanism is a fundamental intermediate step during the oxidation of a hydrocarbon and is mainly controlled by the Fuel/Air equivalence ratio. 
$\mathrm{CO}$ is one of the most important pollutant species in combustion processes in which the heterogeneity of the mixture can derive in local rich mixtures. This can happen in combustion systems that work with stoichiometric or rich mixtures, such as gasoline engines, or in systems that use lean mixtures but the mixing conditions are quite heterogeneous, such as diesel engines. These emissions are more important in the context of gasoline engines, and the formation of $\mathrm{CO}$ in these engines is mainly due to the lack of oxygen in some local regions during the combustion and, to a lesser extent due to the $\mathrm{CO}_{2}$ molecules dissociation, taking place at high temperatures, approximately beyond $2000 \mathrm{~K}$, which are typical local temperatures that are reached in a combustion process. Another mechanism that usually causes the formation of $\mathrm{CO}$ is the flame quenching close to the cylinder walls due to the low temperatures in that region, but this process has less importance in this type of engines. The amount of $\mathrm{CO}$ generated during the combustion depends on the balance between the formation processes (rapid reactions) and oxidation (slow reactions), both of which are very active at high temperatures. Therefore, in processes where the residence times are of the order of seconds, the reactions of oxidation of the $\mathrm{CO}$ would reach the equilibrium and the amount of $\mathrm{CO}$ in the exhaust gases would be practically zero. However, in systems with short residence times, such as gasoline engines, the temperatures drop very fast, resulting in the freezing of the reaction and emitting a considerable amount of $\mathrm{CO}$ into the atmosphere.

This gas is colorless, odorless and poisonous. And it is especially known for its ability to get combined with the hemoglobin present in the blood, disabling the function of the red blood cells. In an extreme case it may cause the death to a person who would be exposed to it for a sufficiently long period of time.

\subsubsection{Particulate matter}

Soot emissions had been a problem rather related to diesel engines so far. These emissions have been very important in diesel engines and represent a serious problem for health. With the arrival of GDI engines, this type of emissions is not only a problem associated with diesel engines, since these new engines also generate particulate matter (PM). This has been shown in works such as Aakko and Nylund [35], Mohr et al. [36], and Braisher et al. [37]. PM emissions in gasoline engines are not exactly the same as in diesel engines. They are lower in quantity and with a smaller size [38]. This means that the knowledge about this type of emissions in diesel is not $100 \%$ applicable to gasoline engines, and therefore there is not such a deep understanding about the soot formation in gasoline engines. 
Smoke emissions come from the areas where combustion has been developed with extremely rich mixtures ( $\mathrm{F} / \mathrm{A}$ equivalence ratio higher than 2 ). In this situation there is not enough oxygen to convert all the carbon atoms of the fuel into $\mathrm{CO}_{2}$, not even into $\mathrm{CO}$, and therefore the carbon atoms generate carbonaceous particles. These particles oscillate between diameters from 10 $\mathrm{nm}$ to $80 \mathrm{~nm}$ and their composition is based on solid carbon, traces of $\mathrm{HC}$ and other components absorbed on their surface [39].

In direct injection engines, the injection jet is often guided through a preformed piston, towards the vicinity of the spark plug to facilitate the ignition of these mixtures. This implies two things: first the mixture heterogeneity is increased, thus increasing the presence of regions with local rich mixtures; and second, the fuel can be deposited on the piston surface or even in the cylinder walls, and later on will burn as a diffusion flame, since it has not been properly homogenized. Both effects favor the appearance of PM emissions.

Stevens et al. [40] studied the soot formation based on the modification of the fuel injection strategy and the fuel films deposited on the walls of a GDI engine. They observed a direct relationship between the amount of fuel deposited on the walls and the increase in soot emissions.

\subsubsection{Carbon dioxide}

Among the gases recognized as the main contributors to the greenhouse effect, only $\mathrm{CO}_{2}$ emissions generated by combustion engines are significant as direct emissions, although the molecular potential of global warming for other gases such as methane or nitrous oxide is 23 and 296 times greater than that of $\mathrm{CO}_{2}$, respectively. This is because the emitted amounts of these other gases are much lower than those of $\mathrm{CO}_{2}$. The only factor that can affect $\mathrm{CO}_{2}$ emissions of an engine, in addition to its operating conditions, is the fuel composition. And if the type of fuel used in an engine is not modified, $\mathrm{CO}_{2}$ emissions are directly proportional to its fuel consumption (efficiency). The dependence of $\mathrm{CO}_{2}$ emissions with the fuel (assuming its molecule as $\mathrm{HmCnOp}$ ), is reflected through two parameters that describe its composition: the hydrogen/carbon ratio $(\mathrm{m} / \mathrm{n})$ and the oxygen/carbon ratio $(\mathrm{p} / \mathrm{n})$, the latter especially significant in the case of biofuels, as shown in Figure 2.9. Fuels with low carbon content, and therefore with lower potential for $\mathrm{CO}_{2}$ generation, such as methanol, carbon monoxide, natural gas (basically methane) and hydrogen, are rare in the automotive industry, at least nowadays, but could be a good solution to reduce this type of emissions. 


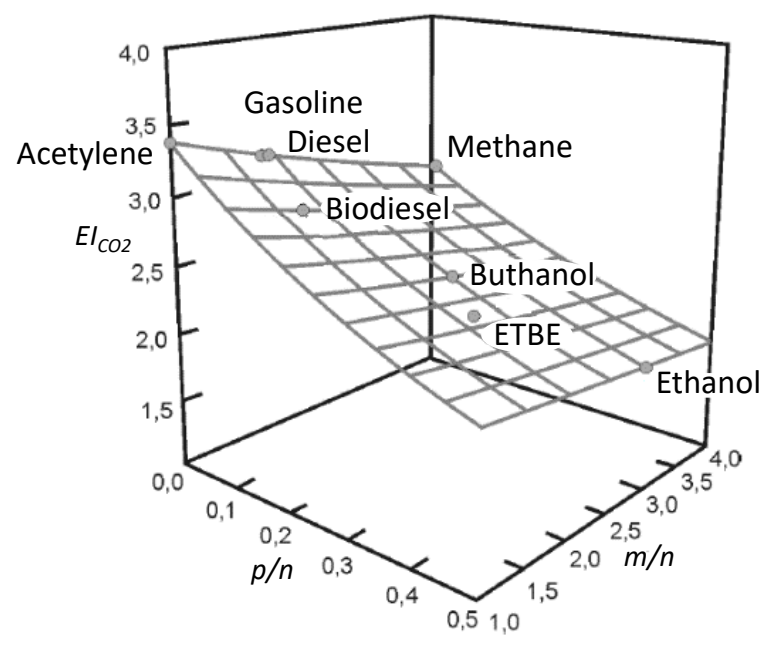

Figure 2.9. Effect of fuel formulation on $\mathrm{CO}_{2}$ emissions. Source: Adapted from [1].

\subsection{Strategies to improve the SI gasoline engines}

\subsubsection{Downsizing}

This strategy is based on the reduction of the volume displaced by the engine and the increase of its BMEP in order to offer a similar performance compared to a larger engine.

This trend is being adopted by the vast majority of manufacturers, reducing the number of cylinders of the engine and adding a boosting system to compensate the loss of engine capacity. Some examples are Ford with its 1.0 liter Ecoboost engine that replaced the naturally-aspirated (NA) 1.6 engine, Volkswagen with its 1.4 TFSI engine that came to replace the 1.6 and $2.0 \mathrm{NA}$ engines or Renault with its 1.2 and 1.3 TCe engines that replace its 1.5 and 1.6 liter NA engines.

The consumption improvements obtained through this strategy depend on the size reduction degree, and can reach up to $35 \%$ for a NEDC standard cycle as announced in the work of Turner et al. [41], where a reduction of a NA 5.0 to a turbocharged 2.0 liter engine was studied. In other cases with a smaller reduction of the displaced volume of the engine, the improvement may be less significant [42]. 
Downsizing strategies present a challenge in the development of engines to reduce $\mathrm{CO}_{2}$ emissions. The fact of reducing the capacity of the engine makes it working at higher loads, which increases the risk of autoignition of the mixture and it increases the thermal and mechanical loads of the engine parts. In Figure 2.10 an engine map is shown, where the downsizing strategy is approached. As the downsizing degree is higher, the available area in the engine map to operate the engine is reduced. Another problem with the size reduction of the engine is the lesser space available in the cylinder head to accommodate all the necessary components, spark plug, injectors, valves... which also presents a challenge in terms of engine design.

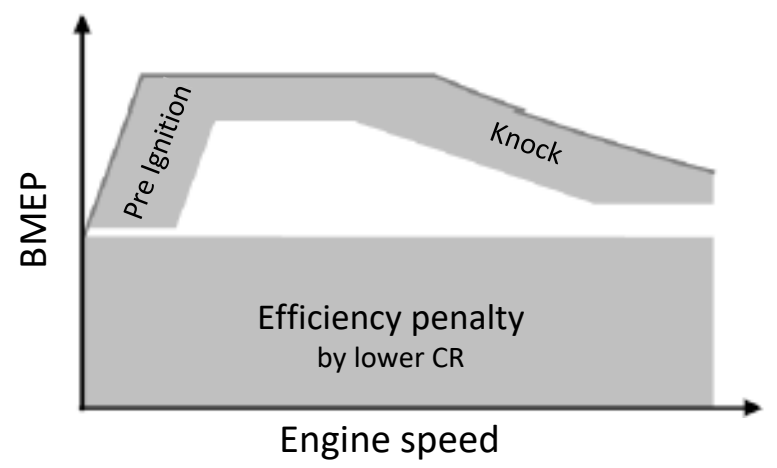

Figure 2.10. Boundaries for a downsized engine map. Source: Adapted from [43].

Part of the proposed solutions to address this strategy is the improvement of the boosting systems, which have to be much more flexible to ensure a smooth operation of the engine and an efficient operation in the entire engine operating map. The developed solutions to get this goal have been, for example, variable geometry compressors [44] or turbines [45], and electrically driven compressors [46].

Finally, regarding the problems of high temperatures and the knock raising trend, these can be reduced by the use of EGR, specific injection strategies, or variable valve actuation systems (VVA).

\subsubsection{Direct Injection}

Direct injection systems for SI engines took longer to be developed than for diesel. However, they started to appear in passenger vehicles since 1996, when 
Mitsubishi launched the first gasoline engine equipped with a direct injection system for a passenger car.

A benefit derived of the fuel injection directly into the combustion chamber is the heat absorption produced by the fuel evaporation in the combustion chamber, and not in the intake walls and in the cylinder head port. Thanks to this temperature reduction of the in-cylinder gases, the engines equipped with this system can have higher compression ratios without the problems of knocking that would have an engine with an injection system at the intake port. For example, Toyota and Mazda have reported compression ratio increments in their NA engines thanks to this strategy [47]. In the case of boosted engines, the benefit is the same despite having lower compression ratios due to the high intake and exhaust working pressures [48].

Another benefit of direct injection systems is a greater flexibility on the injection laws configurations and additionally the possibility to operate the engine with stratified mixtures [49]. This strategy allows the operation of the engine with lean mixtures, since through the moment of injection and the guiding of the spray through the combustion chamber, the quality of the mixture in the region close to the spark plug can be modulated to ensure the ignition of a lean mixture at low loads [50]. Figure 2.11 shows a small sketch of the injection spray guided to the spark plug.

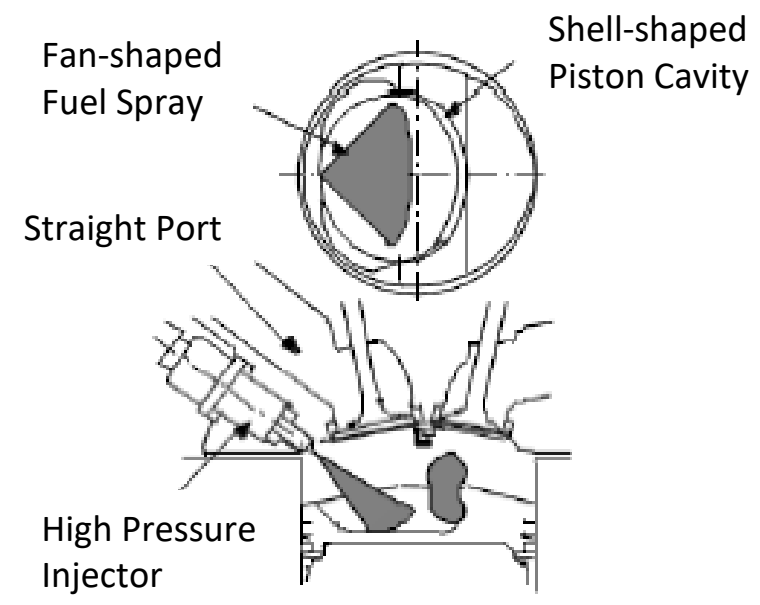

Figure 2.11. Wall-guided combustion method. Fuel spray and piston configuration. Source: [50]. 
Regarding the pollutant emissions associated to this technology, unfortunately direct injection presents more problems than the previous injection strategies at the intake port [49]. The mixture heterogeneity is higher in DI engines, therefore the efficiency of combustion is lowered and the temperature in the combustion chamber will be more heterogeneous. This will increase the emissions related to rich mixture combustions, such as particles, unburned hydrocarbons and CO. Additionally, direct injection tends to cause greater wall wetting problems inside the combustion chamber, which is also directly related to the soot emissions [51, 52].

The development of these technologies is increasing the particles emissions in this type of engines. Therefore detailed studies are needed on the different soot formation mechanisms in gasoline engines to be able to create optimum strategies to minimize the production of these emissions. In parallel, studies that evaluate the impact of these particles on the environment and on human health [53] are needed as well, since it is predictable that emission regulations will be progressively hardened in this aspect for gasoline engines, limiting the amount and number of particles emissions.

Regarding the design of strategies to reduce these particles emissions, there are studies trying to reduce the emissions of this type of engines, as for example Whitaker et al. [51], who studied injection strategies based on the fragmentation of the fuel injection in order to homogenize it better without causing the effect of wall wetting. With the results obtained, the GDI engine studied was able to fulfil with Euro IV without the need of a particulate filter. Another work related to the reduction of particle emissions was developed by Price et al. [52] to try to optimize the cold start of this type of engines, moment in which this type of emissions is increased.

The introduction of direct injection in gasoline engines has been shown to be a very important strategy to improve $\mathrm{CO}_{2}$ emissions. However the emissions of particles generated by this change must be studied and reduced to avoid a negative impact on human health and the environment.

\subsubsection{Variable valve Actuation systems}

Before the emergence of these technologies, the valve actuation on the engines was prefixed during the engine design and the actuation of the valves was the same for all the different operating points of the engine. This situation was not optimum for all the operating range of the engine, so it was necessary to define the best compromise to ensure a correct efficiency of the engine and decide which part of the operating range was going to be the 
optimized. With the emergence of these technologies, the possibility to adjust the valves actuation for different operating ranges opened the door to improve considerably the performance and the efficiency of the engines.

This concept brings different ways to actuate and modify the valve configurations. On one hand there are the fully adjustable valve systems $[54,55]$, where the moment of the opening and closing events, the lift of the valve and the way to reach this lift can be customized. And on the other hand, more simplified actuators, able to adjust to a lesser extent different parameters of the valve, can be found. For example the Honda VTEC system, which was able to vary the lift profile between two different shapes depending on the desired engine behavior. Or the commonly known Variable Valve Timing (VVT) system [54, 55] included in some engines nowadays. This technology allows the adjustment of the opening and closing moments of the intake and exhaust valves, improving the optimization of the scavenging process and the duration of the compression and exhaust strokes depending on the operating conditions of the engine.

The adjustment of this system is a function of the engine load and speed, since they strongly affect the amount of air that has been consumed during its operation. In general terms, the operating criteria would be the following:

- High load and low engine speed: in this case the VVT is positioned increasing the overlap of the valves, since it is important to allow the scavenging of the exhaust gases trying to reduce the hot residual gases from the cylinder as much as possible, thus decreasing the risk of knock and allowing the correct phasing of the combustion.

- High load and high engine speed: theoretically, the strategy should be the same as for the low speeds, and even increasing the valve overlap because the time available for the scavenging process is lower. However, in boosted engines, the turbo is designed to operate optimally at medium engine speeds (since it will operate there most of the time). Therefore when the exhaust gases mass flow is increased the turbo causes an increment in the exhaust pressure, producing a backflow effect of the exhaust gases inside the cylinder. This is why the overlap is reduced to avoid this harmful effect.

- Part load: for this operating region, the VVT is adjusted to maximize the output torque in order to optimize fuel consumption and the engine response. 
- Low load: the guideline is still similar to that exposed for part loads. However, in this case SI engines have many losses due to the throttling effect. Therefore the control strategies of the VVT are aimed at reducing these losses by approaching the operation of the engine to the Atkinson or Miller cycles [56, 57].

\subsubsection{Boosting}

The increase in boosting pressure has been a general trend in internal combustion engines.

The BMEP went from 12 bar around 1960 to 20 bar at the beginning of the 80s, and there is a tendency to surpass the 25 bar BMEP. Currently, Ford's 2010 generation of EcoBoost GTDI engines (Ford Gasoline Turbocharged Direct Injection) reaches 23.5 bar BMEP.

It is important to point out that the increase in the boosting level in recent years (and in the future) has not been and will not be conditioned by the increase in power, but by the consumption and emissions reduction thanks to the downsizing of the engines. In parallel, the engine had a technical and technological evolution that has resulted in a significant elevation of the acceptable thermal and mechanical stresses. The combustion peak pressures in IC engines have been growing, reaching currently around 124 bar in passenger cars (in the case of the mentioned already Ford EcoBoost engines). The same has happened with the maximum exhaust temperatures, which are currently at around $950{ }^{\circ} \mathrm{C}$ for SI engines.

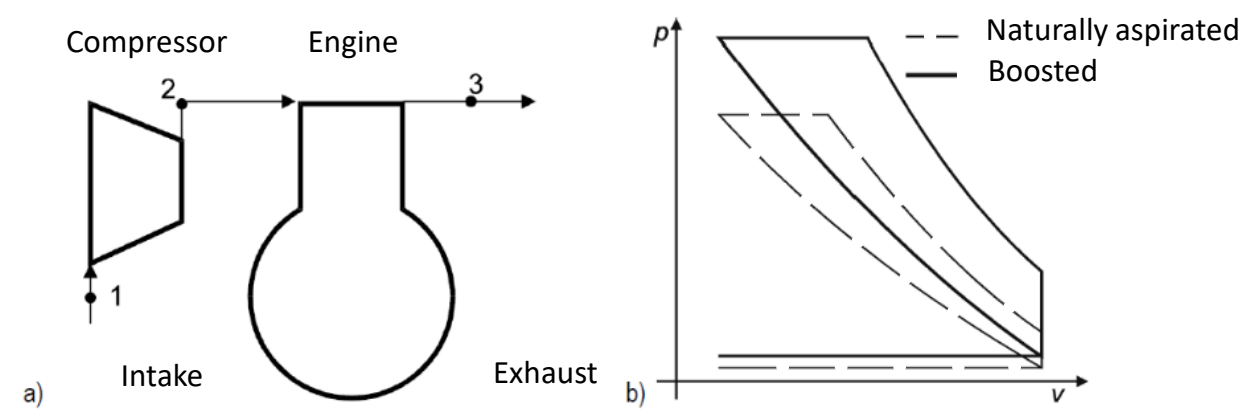

Figure 2.12. a) Boosted engine scheme, b) Comparison between an ideal constant pressure combustion cycle naturally aspirated and boosted. Source: Adapted from [1]. 
The boosting of internal combustion engines consists of increasing the density of the intake air by means of an increase in pressure. The pressure increase in the intake manifold is achieved by a compressor, as shown in the diagram presented in Figure 2.12 a). The density increase at the engine inlet allows to increase the air mass flow, for a certain displacement and volumetric efficiency, as shown by Eq. 2.5.

$$
\dot{m}_{\text {air }}=\eta_{v} \cdot V_{t} \cdot \rho_{\text {air }} \cdot N \cdot i
$$

where $\dot{m}_{a i r}$ is the air mass flow, $\rho_{a i r}$ is the air density, $V_{t}$ is the displaced volume, $\eta_{v}$ is the volumetric efficiency, $N$ is the engine speed (in rps) and $i$ indicates the number of thermodynamic cycles per engine revolution.

With the increase of the air flow, the fuel flow is increased in the same proportion, if the $\mathrm{F} / \mathrm{A}$ ratio is kept constant. Formulating the additional hypothesis that the performance is not affected, which is true in a first approximation, we can conclude, as expressed by Equation 2.6, that the power of the engine will grow linearly with the air flow. The $\mathrm{p}-\mathrm{V}$ graph of Figure 2.12 b) exemplifies the effect of boosting on power, through the indicated diagram of an ideal cycle at constant pressure.

$$
P_{e}=L H V \cdot \eta_{e} \cdot \dot{m}_{f}=L H V \cdot \eta_{e} \cdot F / A \cdot \dot{m}_{a i r}
$$

where $P_{e}$ is the effective power, $L H V$ is the low heating value, $\dot{m}_{f}$ is the fuel mass flow and $\eta_{e}$ is the effective efficiency.

The main advantage of the intake boosting consists on the increase of power for a certain displacement and, therefore, on the increase of the specific power and the brake mean effective pressure, as shown in Equation 2.7.

$$
M E P=\frac{P_{e}}{V_{t} \cdot N \cdot i}=L H V \cdot \rho_{a i r} \cdot \eta_{v} \cdot F / A \cdot \eta_{e}
$$

The increase of the density in the combustion chamber due to the boosting affects in an important way the combustion process and, therefore, the emissions and the indicated performance of the engine. This increase in pressure and temperature in SI engines increases the risk of knock, which is usually compensated with lower ignition advances and the use of reduced compression ratios. In the case of SI direct injection, the high density favors the mixing process when the engine works with stratified charge. It should be reminded that the reduction of the relative heat losses due to boosting (Equation 2.8) means an improvement in the indicated performance. 


$$
\frac{\dot{m}_{\text {coolant }}}{\dot{m}_{f}} \propto \frac{1}{\left(c_{m} \rho\right)^{0.25}} \cdot\left(T_{\text {charge }}-T_{\text {coolant }}\right)
$$

where $\left(c_{m} \rho\right)$ is the mass flow per unit area of piston.

Moreover, the friction losses remain practically constant while there is an increase in the IMEP, which means an increase in the mechanical efficiency. The mechanical losses remain constant especially if the boosting compressor is driven by a turbine moved by the exhaust gases of the engine (turbocharger). If it is moved by the engine crankshaft (mechanical boosting), there is a deterioration of the mechanical efficiency due to the increase in the necessary power of the auxiliaries.

\subsubsection{EGR}

This strategy has been widely used as a method of reducing pollutants (mainly $\mathrm{NO}_{\mathrm{x}}$ ) in diesel engines. It is based on the introduction of a variable amount of recirculated exhaust gases through the intake that will be mixed with the fresh air before getting inside the cylinder. When this strategy started to be applied in gasoline engines, it was observed that the effect was wider than in diesel engines; apart from reducing $\mathrm{NO}_{\mathrm{x}}$, it also influenced the development of combustion.

The EGR application in gasoline engines started from the 90s. Apart from reducing $\mathrm{NO}_{\mathrm{x}}$ emissions, it was applied in NA engines to improve fuel consumption at low and medium loads. At high loads this system should not be used, since in this type of engines the aspiration capacity is limited and it defines the maximum output power. The fact of replacing the intake fresh air with exhaust gases reduce the maximum power of the engine, therefore it was not an interesting actuation [58].

Additionally, Hacohen et al. [58] observed the effect of the introduction of small EGR ratios. With this strategy the net indicated thermal efficiency of the engine could be improved at medium loads. These improvements were due to a decrease in the pumping losses combined with a slight increase in the temperatures of the mixture during the compression phase that helped to improve the combustion stability. Figure 2.13 shows one of their results, where the net indicated thermal efficiency of the engine is observed for different mixture richnesses and EGR rates. It can be seen that for an EGR rate of $10 \%$ the efficiency is improved. However with a further increase of the EGR rate, the dilution effect of the mixture is stronger and the thermal efficiency is worsened due to the combustion efficiency drop. 


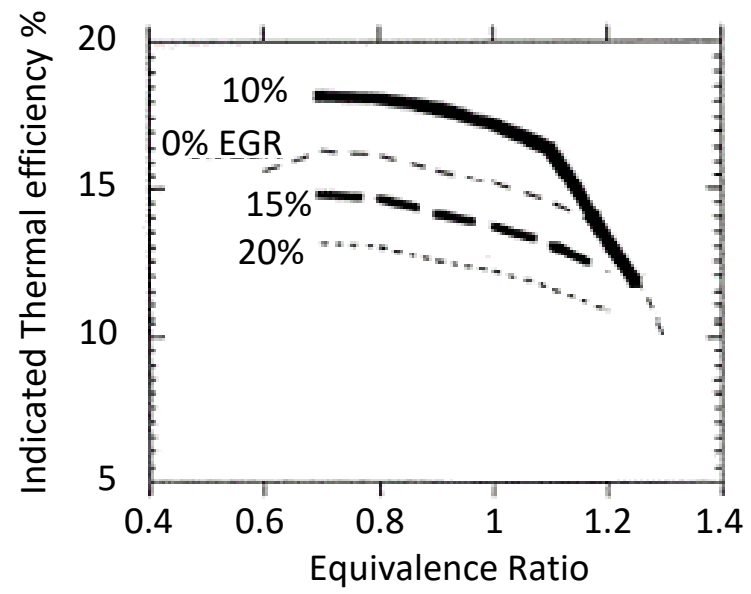

Figure 2.13. EGR rate and equivalence ratio influence on the engine net indicated thermal efficiency at medium loads for a SI engine [58].

After the EGR application in NA engines, few years later the application of EGR in boosted SI engines was studied. In these engines, due to the use of a booster, the restriction on the EGR application at high loads is reduced thanks to the boosting: the necessary air could be supplied together with the EGR without the loss of volumetric efficiency. The EGR introduced in these engines was previously cooled to try to decrease the reactivity that the temperature of these gases provided to the mixture. In the studies of Grandin et al. [59] it is shown how the addition of cooled EGR reduced considerably the knock at high loads. This strategy was therefore better than the enrichment of the mixtures, since it had a greater effect on the knock and, additionally, an improvement in fuel efficiency, as the extra fuel introduced to decrease the temperatures in not necessary anymore.

Figure 2.14 shows some tests carried out by Grandin et al. [59] at high loads, where different EGR rates were added in order to advance the ignition timing as much as possible. Thanks to the knock reduction with the EGR rate increase, the combustion could be advanced and therefore a greater BMEP could be achieved for the same operating conditions. This was due to the dilution effect of the mixture that lowered the combustion temperatures and therefore affected the (auto)ignition delay of the fuel.

When the engine is turbocharged, the exhaust temperatures must be controlled to avoid damage in the energy recovery systems installed in the 


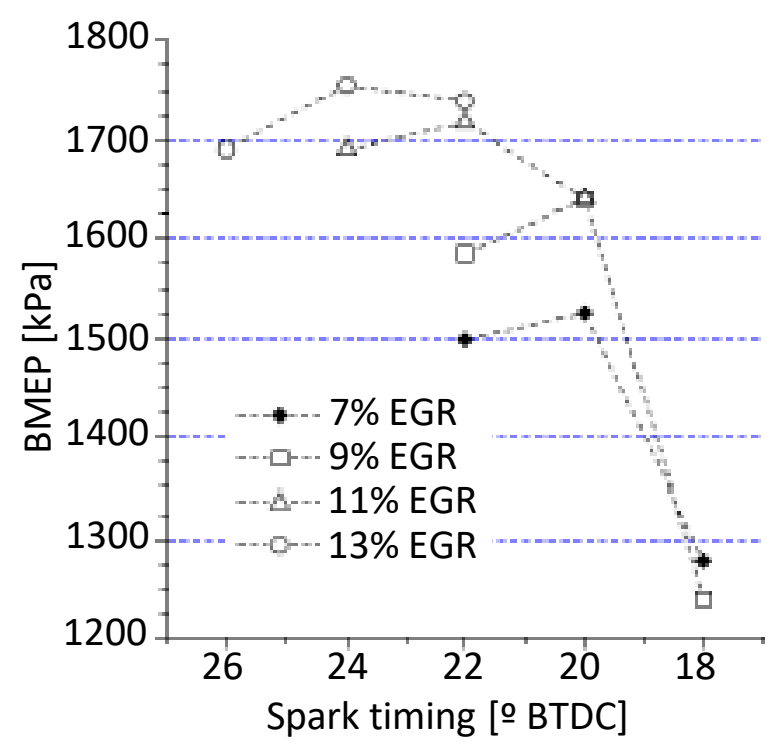

Figure 2.14. EGR influence on the ignition timing, and influence on the engine BMEP [59].

exhaust. This implies that the exhaust temperatures should not exceed a temperature of around $900^{\circ} \mathrm{C}$. This, applied to gasoline engines, was a barrier when operating at maximum loads, making necessary to increase the richness of the mixture to reduce the exhaust temperatures. Grandin et al. and other authors [60-62] showed how the EGR addition to the engine had an influence on the exhaust temperatures, since on the one hand the combustion was carried out at lower temperatures, and on the other hand the advance of the combustion also allowed to have lower temperatures in the exhaust.

\subsubsection{SI Lean Combustion}

SI Lean combustion is a combustion mode working outside the stoichiometric conditions (which is, by far, the most usual strategy in gasoline engines). More specifically, it is based on the engine operation with an air excess during the combustion, which implies lean mixtures. In Figure 2.15, the lean combustion operating region can be seen (in an approximate way) in a BMEP/equivalence ratio chart. From the figure, it can be seen, on the one hand, that when the mixture gets close to stoichiometric and the engine load increases, the risk of knock. And, on the other hand, that an excessive dilution 
of the mixture causes ignition problems. This type of combustion, compared to a stoichiometric combustion, has always offered a great improvement in the efficiency of the engine. The pumping losses are reduced (mainly at low loads, which are a great problem for SI engines), the combustion efficiency increases thanks to a greater amount of available oxygen to oxidize the fuel, and the engine has less heat losses since it is working at lower temperatures [61-63]. Regarding the emissions of this strategy, in comparison to stoichiometric mixtures, $\mathrm{HC}$ and $\mathrm{CO}$ are reduced. However, $\mathrm{NO}_{\mathrm{x}}$ emissions are more difficult to reduce, and the use of specific after-treatment systems is necessary [60].

This combustion approach has been developed during the last decades, and in the 80s it had its first appearance in the market [64]. However, the evolution of the pollutant emissions regulations made necessary that this type of engines had to use an oxidation catalyst together with a $\mathrm{NO}_{\mathrm{x}}$ reduction system. Therefore this technology almost disappeared in favor of engines operated with stoichiometric mixtures equipped with TWC. In recent years, with the appearance of direct injection and charge stratification, the interest in this type of combustion and associated improvements is reemerging despite the need of using two different systems to reduce pollutants [65, 66].

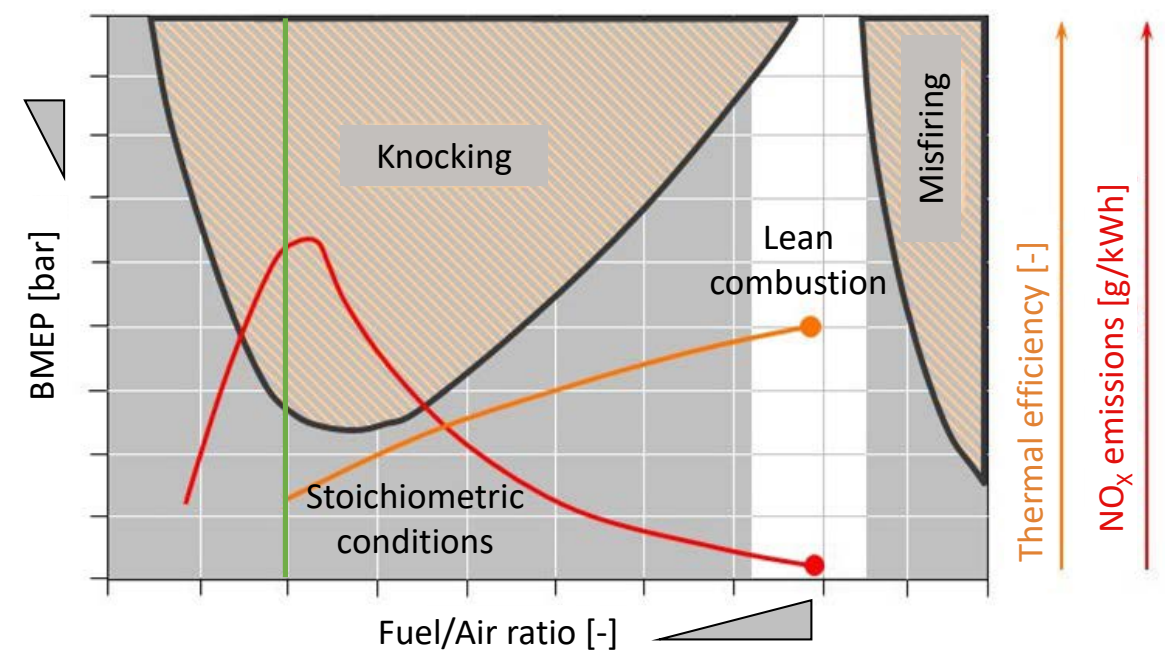

Figure 2.15. Operation region for lean combustion defined as a function of the engine load and the Fuel/Air ratio. Source: Adapted from [67].

The main problem of the lean mixtures combustion, unlike the operation in stoichiometric mixtures, is the need for a complex pollutant reduction system. This is because the three-way catalyst, widely used in gasoline engines, loses 
its $\mathrm{NO}_{\mathrm{x}}$ conversion efficiency when the presence of oxygen molecules increases in the exhaust gases (Figure 2.16). Consequently, it is necessary to look for other alternative systems combining an oxidation catalyst for the $\mathrm{HC} / \mathrm{CO}$ and a $\mathrm{NO}_{\mathrm{x}}$ trap or an SCR system for the reduction of $\mathrm{NO}_{\mathrm{x}}$ emissions.

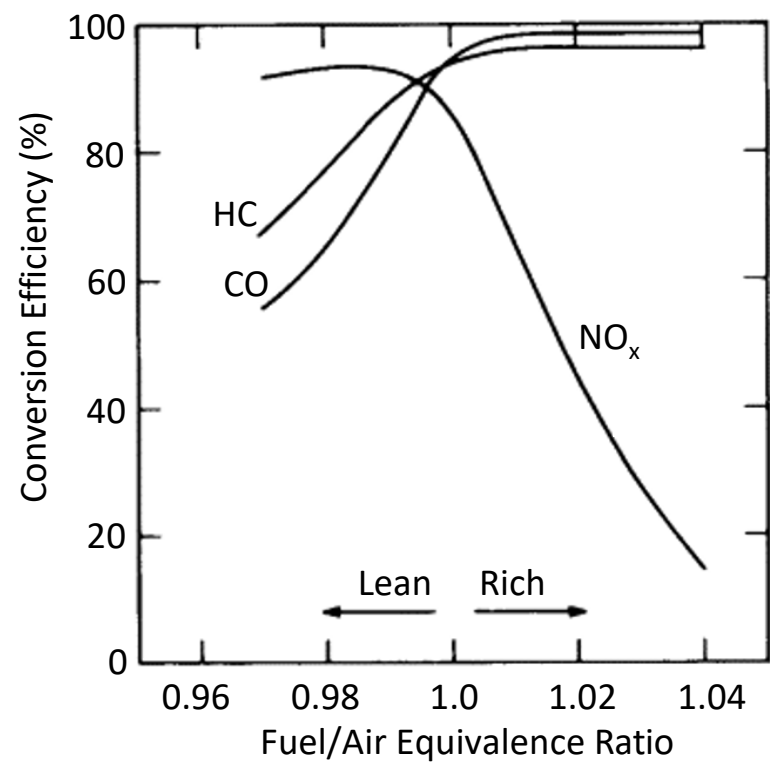

Figure 2.16. Three way catalyst conversion efficiency for different equivalence ratios. Source: Advances in energy systems and technology, volume 3 [68].

The years when the standard cycles were softer than today, the low restrictions on $\mathrm{NO}_{\mathrm{x}}$ emissions, together with the reduction of $\mathrm{HC}$ and $\mathrm{CO}$ emissions from this combustion mode, encouraged studies that tried to overcome these restrictions without the use of catalysts, such as the work of John J. [69], where the advantages of this strategy were analyzed and it was stated that its future will depend on the evolution of antipollution regulations.

With the time and the evolution of the emissions regulations, there was a trade-off in the interest of this combustion mode. On the one hand, there was the benefit obtained in the efficiency achieved; and, on the other hand, there was the problem of reducing the emissions. Therefore, several studies appeared, trying to study the benefits obtained, taking into account the disadvantages presented by these engines. Authors, such as Gomez and Reinke [70], made several reviews trying to summarize the advantages obtained and the most common approaches to the operation of lean combustion modes. Hiroyuki et al. 
[71] worked, for example, with a high-compression ratio engine operated on lean mixtures, and in their study they showed improvements in fuel consumption between $10 \%$ and $6 \%$ depending on the standard cycle that would have to be overcome, along with their corresponding pollutant gas restrictions.

Another common problem of combustion with lean mixtures is the flame quenching due to the low reactivity of the mixture. For this reason studies like that of $\mathrm{Yu}$ et al. [63] were carried out trying to expand the combustion limits in lean mixtures to mitigate the problem of flame quenching. In this case they worked with factors such as the mixture stratification and the ignition system energy supplied.

This strategy started to be compared to another one being under study that consisted on the introduction of EGR in the intake gases. Both strategies were efficient to reduce the problem of engine knocking at high loads and control the high exhaust temperatures. In the study developed by Grandin and Angstrom [60], it is shown that lean strategy reduced also the emissions of $\mathrm{HC}$ and CO. However it was impossible to use a three-way catalyst, penalizing $\mathrm{NO}_{\mathrm{x}}$ emissions compared to the use of EGR as diluent of the mixture. Therefore, the extra cost of adding a specific system of $\mathrm{NO}_{\mathrm{x}}$ reduction compared to the improvement obtained in $\mathrm{HC}$ and $\mathrm{CO}$ emissions, according to their criteria, did not compensate for the industrial implementation of this type of strategy.

It is expected that in future regulations, the particle emissions will be more restricted. Therefore, it is expected that the implementation of a particle filter, as already used in diesel engines, will also be necessary for direct injection gasoline engines operated with lean mixtures. This means another extra component, along with the $\mathrm{NO}_{\mathrm{x}}$ reduction system, increasing the cost and complexity. So, the potential benefit will have to be evaluated in front of the extra cost and complexity.

\subsubsection{Low Temperature Combustion applied to SI gasoline engines}

\subsubsection{The Low Temperature Combustion concept (LTC)}

In this section, the description of the LTC concept will be addressed, that is, the low temperature combustion mode and the various combustion strategies developed to get it in modern engines. These strategies are based on the early injection of the fuel to ensure its correct homogenization, thus avoiding the combustion zones with rich mixtures to finally obtain a generalized autoignition 
combustion of the mixture as homogeneous as possible [72, 73]. This concept is totally new for diesel combustions, since the fuel is premixed with the air previously, whereas in gasoline engines the mixture pre-homogenization is not new. However the autoignition of the fuel breaks with the typical provoked ignition of these last type of engines. These strategies try to achieve a combustion without $\mathrm{NO}_{\mathrm{x}}$ formation. Akihama et al. [74] suggest that with a flame temperature below $2100 \mathrm{~K}$, the $\mathrm{NO}_{\mathrm{x}}$ formation in significant quantities would no longer be observed (see Figure 2.17).

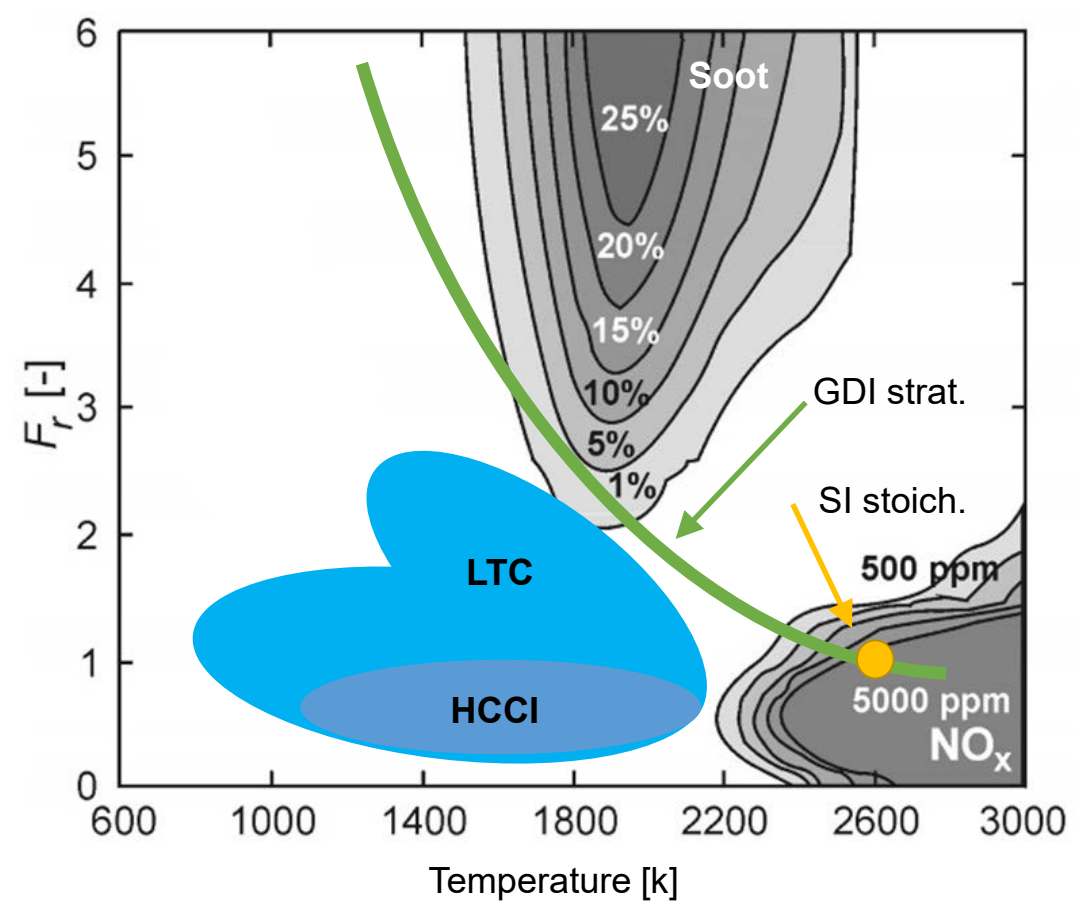

Figure 2.17. Representation of the SI, GDI, LTC and HCCI combustion modes in an Fr-Temperature diagram. Source: Adapted from [1].

Due to the increasingly stringent regulations, LTC combustion strategies are more important year after year, and therefore are increasingly studied. These combustions can be developed for both diesel and gasoline engines, since they are based on the mixture reactivity to initiate the combustion process [75]. In the diagram presented in Figure 2.18, the different achievable combustion modes in SI and CI engines are presented according to the chosen fuel. In this diagram, the LTC combustion modes are highlighted. The HCCI combustion mode (Homogeneous Charge Compression Ignition) is the ideal representation 
of this type of combustion, where a perfectly premixed mixture is autoignited in a homogeneous way by increasing the enthalpy of the in-cylinder charge. This combustion mode is applicable to both types of fuel. Depending on the reactivity of the fuel, a lower or a higher enthalpy increase will be required to provoke the autoignition and, therefore, a different strategy to control the combustion will be necessary.

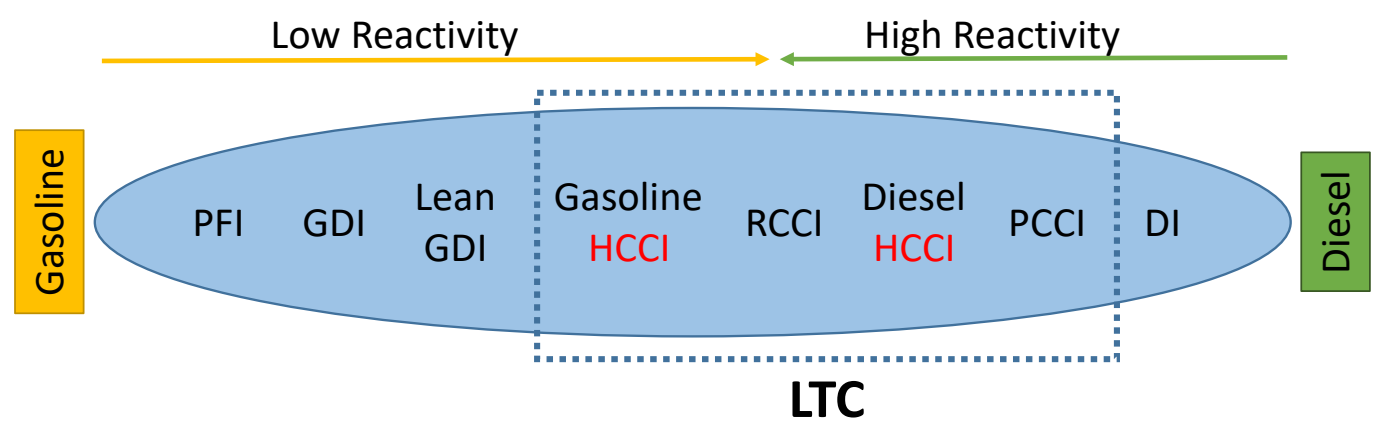

Figure 2.18. Diagram of the different achievable combustion modes in SI and CI engines.

In addition to the benefits obtained from reducing $\mathrm{NO}_{\mathrm{x}}$ and Soot emissions, the LTC combustion modes allow the increase of the engine compression ratio, reduce the engine pumping losses, reduce the combustion duration [76], allow fuels combination, and present the benefits of SI and CI engines [77]. However, the combustion control of these engines is very complex and the combustion operation is often reduced to very small load ranges with current engines [78]. Apart from this, there is also an increase in combustion noise [79], and in $\mathrm{CO}$ [80] and HC [81] emissions.

\section{HCCI, the ideal LTC combustion mode}

During the last decades, as stated in the book written by Hua Zao [82], this combustion mode has received different names from the authors who have worked around this type of combustion mode:

1. ATAC (Active Thermo-Atmospheric Combustion) [83]

2. TS (Toyota-Soken) [84]

3. ARC (Active Radical Combustion) [85] 
4. CIHC (Compression-Ignited Homogeneous Charge) [86]

5. HCCI (Homogeneous Charge Compression Ignition) [87]

6. CAI (Controlled AutoIgnition) [88-91]

7. UNIBUS (UNIform BUlky combustion System) [92]

8. PREDIC (PREmixed lean DIesel Combustion) [93]

9. MK (Modulated Kinetics) [94]

10. PCCI (Premixed Charge Compression Ignition) [95]

11. OKP (Optimised Kinetic Process) [96]

If all these announced combustion modes are examined, it can be seen that all of them have two fundamental common aspects: the first is the premixing of fuel/air before combustion, and the second is the use of autoignition as the ignition procedure.

Finally, with the progress of the related works in this field, the name adopted for this type of combustion has been HCCI. This combustion mode is characterized by a completely homogenous premixed combustion, and it has become very interesting because of its great potential for reducing pollutant emissions, mainly $\mathrm{NO}_{\mathrm{x}}$ and soot, and for achieving high thermal efficiency. In this type of combustion, fuel is usually injected in the intake manifold or directly inside the cylinder, but early enough for the fuel/air mixture to be homogeneous at the start of combustion. The mixing process starts early in the cylinder, and the combustion of the fuel/air mixture starts when it reaches the autoignition conditions. Unlike in a standard SI engine combustion, the homogeneous and lean mixture ignites spontaneously in several places at the same time thanks to the enhanced reactivity. The combustion is not generated through a spark or a flame front but in a generalized way [76, 97], the local temperatures are lower than in a conventional combustion, and $\mathrm{NO}_{\mathrm{x}}$ formation does not occur during combustion. On the other hand, soot emissions are inhibited by the fact that the lean and homogeneous mixture does not promote the formation of soot precursors.

This strategy, associated with high EGR rates, offers the advantage of low soot and $\mathrm{NO}_{\mathrm{x}}$ emissions. However, HCCI still has some disadvantages compared to conventional combustion, and consequently this combustion mode is still being researched for its better development. 
1. $\mathrm{HC}$ and $\mathrm{CO}$ emissions are higher than in conventional combustion. The necessary conditions for HCCI, as lean mixtures and high EGR rates, decrease the combustion temperatures, resulting in an increase of the unburned regions [76, 97-102].

2. The difficulty of controlling the autoignition instant also causes problems for its practical application. Various investigations are being carried out with the aim of better understanding the process and its dependence on various factors such as the mixture homogeneity, compression ratio, intake air and engine temperatures, concentration of oxygen in the air, intake pressure, engine speed, turbulence level, etc. [76, 97-106].

3. Mixture preparation to avoid the impact of the fuel with the piston or cylinder walls. The impact with the walls can lead to high $\mathrm{HC}$ emissions and dilution of the engine oil, damaging both the emissions and the integrity of the engine. In addition, problems related to the homogeneity of the mixture can lead to undesired effects such as knock or problems with the autoignition [107-112].

4. Besides all this, there is an additional problem, which is the difficulty in controlling the rate of heat release, since it is a purely premixed and self-ignited combustion. This has undesired consequences, such as a high combustion noise [76, 97].

\section{PCCI and RCCI, alternative approaches to LTC combustion modes}

From the basis to operate in LTC, there are very similar modes but with different approaches, with the intention of moving this HCCI operating principle to a more realistic operation mode, or making combustion easier to control in the available engines.

PCI ("Premixed Compression Ignition") or PCCI ("Premixed Charge Compression Ignition") is a combustion strategy with similarities to HCCI applied in CI engines, but with direct fuel injection occurring during the compression stroke as a method to reduce wall wetting and the loss of combustion efficiency. Iwabuche et al. presented it in 1999 with the name of PCI [78]. In this study, the engine developed was equipped with a piston shaped with a large, open bowl, and a new type of injector nozzle, in which each orifice was replaced by two smaller orifices that converged into a single diesel spray, which, according to the study, managed to reduce this penetration and, at the same time, to increase its dispersion. A comparison of the spray between a conventional nozzle (left) and the double-hole nozzle (right) with 
several contact angles can be seen in Figure 2.19. There was a considerable reduction in $\mathrm{NO}_{\mathrm{x}}$ emissions compared to conventional combustion without any soot emissions rising. However, $\mathrm{HC}$ emissions were increased, as well as specific fuel consumption. Further studies continued with the objective of getting better results regarding combustion performance or pollutant emissions. The addition of water vapor in the intake [113], cooled EGR [114], multiple injection strategies [115], or the introduction of gasoline as a fuel [116] have been used with the objective of reducing $\mathrm{NO}_{\mathrm{x}}$, soot and $\mathrm{HC}$ emissions, and to increase the operating range of the PCI strategy in CI engines.

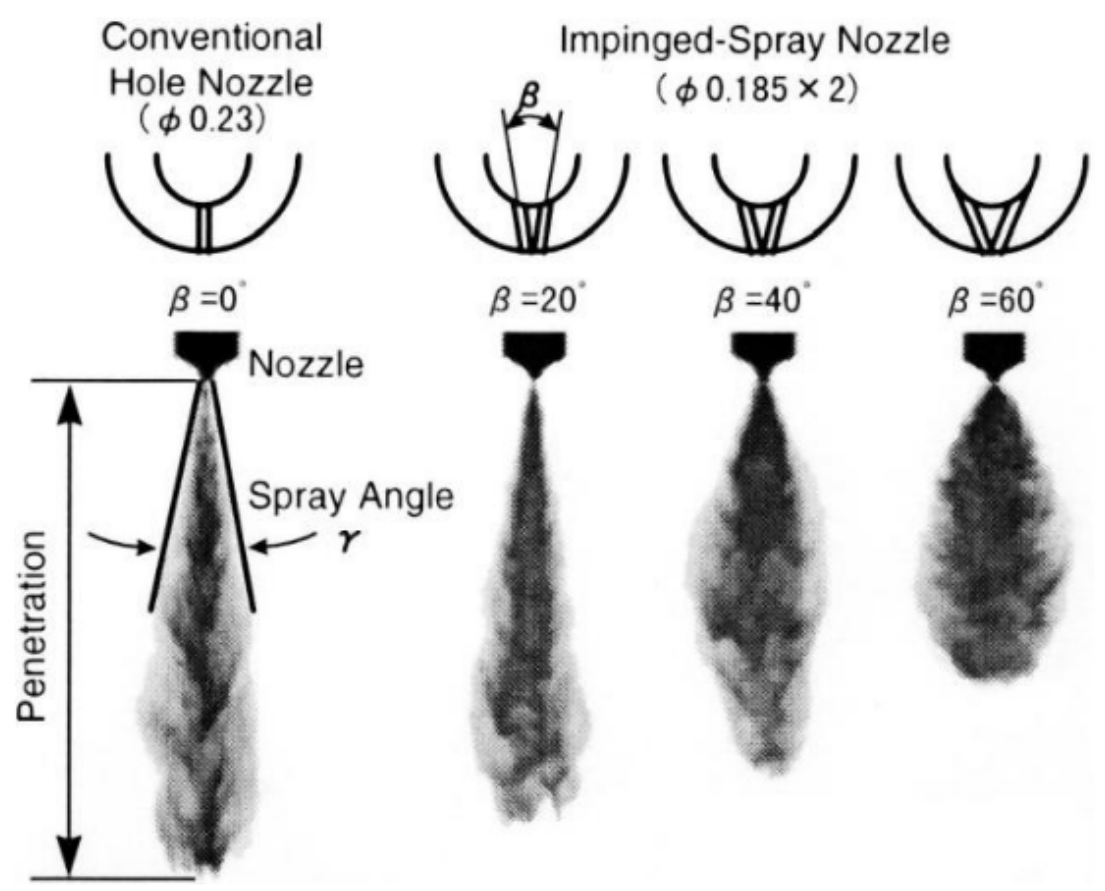

Figure 2.19. Comparison between a conventional injector spray (left) and the jet developed in the PCI strategy. It can be seen that the penetration decreases and the angle of the jet increases with the angle between the two holes [78].

According to the conclusions derived from the investigation of the PCCI combustion, its implementation through different fuel mixtures, depending on the operating conditions, shows great potential for the improvement of combustion control. In the work of Ra et al. [117] it is shown that each fuel has a single ignition delay/temperature curve for a defined $\mathrm{YO}_{2}$, as can be seen in Figure 2.20. Unlike in laboratory tests, on the road, the in-cylinder 
charge temperature depends on multiple factors (environmental conditions, engine speed, load degree...), so that each fuel has a limited operating range where the thermal efficiency of combustion is maximized. Therefore, since the combustion phasing must be perfectly controlled to maximize the efficiency, it would be desirable to have the capacity to operate with different fuel mixtures, depending on the operating conditions.

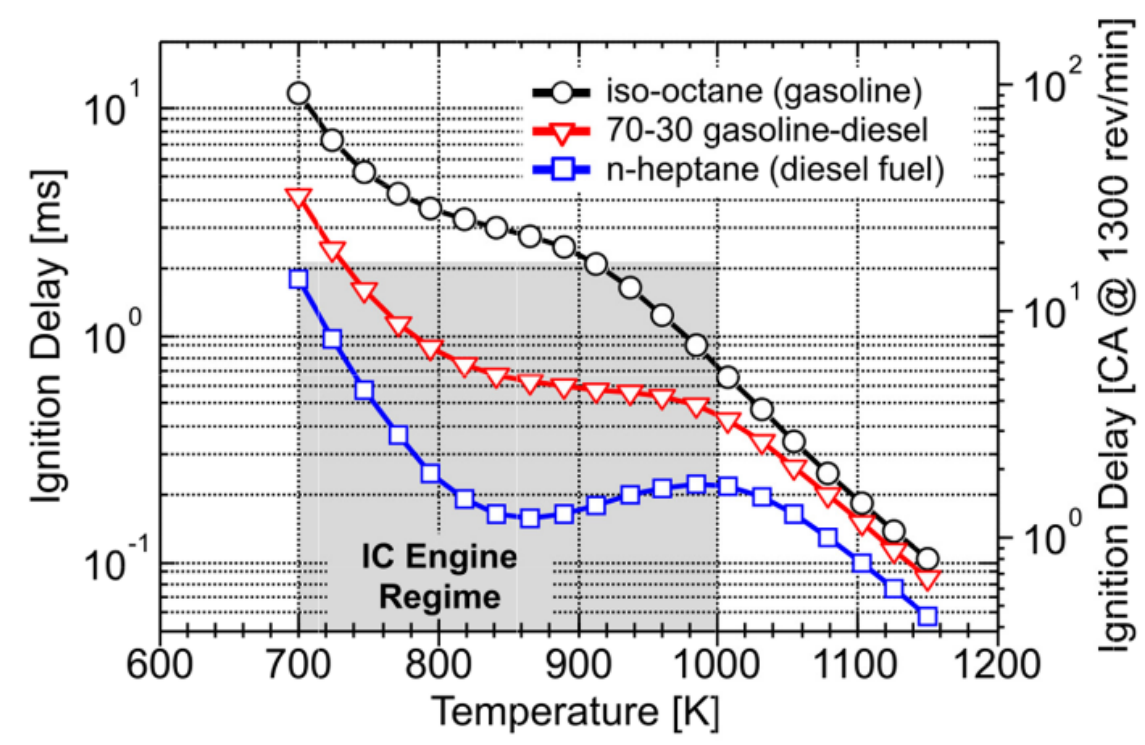

Figure 2.20. Simulated delay times, at constant volume, for 3 different fuels. The shaded area corresponds to the representative conditions of ICE [73].

Following this trend, Inagaki et al. [118] investigated the combustion process working with a homogeneous premixture of iso-octane and direct injection of diesel (as shown in the scheme of Figure 2.21 (a)), with the aim of reducing the EGR needed for premixed combustions. The main result, apart from the low levels of $\mathrm{NO}_{\mathrm{x}}$ and soot emissions, confirms that different fuel blending ratios are required for different operating conditions: according to Figure 2.21 (b), a fuel with high cetane number at load is desirable, whereas with low cetane number at high load.

Taking into account this approach, Kokjohn et al. [119] named as RCCI (Reactivity Controlled Compression Ignition) combustion the strategy where a low reactivity fuel (LRF, with a low cetane index) is injected in the intake manifold, creating a homogeneous mixture together with the air and recirculated exhaust gases, which is compressed inside the cylinder; then, a 

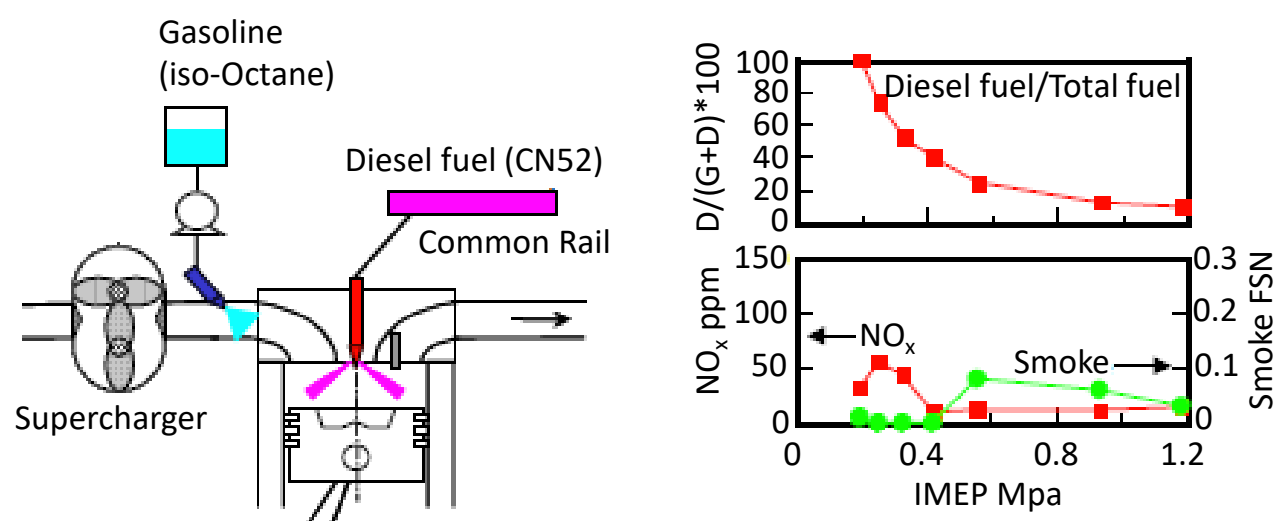

Figure 2.21. RCCI strategy, a) Facility layout, b) Main results of the RCCI operation as a function of the IMEP [118].

highly reactive fuel ( $\mathrm{HRF}$, with a high cetane number) is injected directly into the cylinder, in one or several events, and the conditions in the chamber promote its autoignition. This leads to the sub-sequent ignition of the homogeneous mixture with the LRF.

This behavior is demonstrated in the research of Splitter et al. [120] by means of optical techniques. In addition, it concludes that the decomposition of the fuel progresses smoothly from the most reactive species to those that are less reactive, as long as there is a suitable reactivity gradient.

In this way it is possible to create fuel blends, controlling the distribution of the reactivity in order to optimize the combustion phasing and the rate of heat release, according to the operating conditions [121].

\subsubsection{The Gasoline CAI engines}

Among the combustion modes described in the previous section, there was one called HCCI gasoline, which is therefore the operating HCCI strategy with a gasoline-type fuel. This LTC mode, as already seen, can be operated with both fuels (gasoline and diesel). For this reason, to try to disambiguate this situation, some authors adopt the name CAI (Controlled AutoIgnition) to refer to an HCCI combustion obtained with gasoline in a SI engine [82, 89, 122, 123]. Therefore, this differentiation leaves the name of HCCI to be used in the context of CI engines, with high cetane number fuels, and marks a differentiation between these two modes. This is based on the fact that HCCI 
engines, as the name suggests, will initiate the combustion of the mixture through the increase of its energy due to compression, whereas CAI engines will require the use of strategies (other than compression) to increase the reactivity of the mixture (such as increasing the rate of hot residual gases in the engine) in order to promote the mixture autoignition.

In this case, in order to achieve a CAI combustion, the starting point is a SI engine, in which the fuel and air are premixed in the intake or inside the cylinder before the compression stroke (or in its initial stage), so that at the end of compression, the fuel and air mixture is completely homogenized. Close to the end of the compression stroke, the mixture will reach a high enough temperature, thus initiating the autoignition process in a similar way as would happen in a CI engine. However, in this engine due to the autoignition resistance of the fuel and the lower compression ratio, the mixture must be preheated to reach, at the end of the compression stroke, an adequate enthalpy level for the mixture to ignite and the subsequent combustion development [124]. This effect is mainly achieved in two ways: the first is by heating the intake air before introducing it into the cylinder, and the second, by retaining part of the hot residuals from the combustion of the previous cycle. The application of this type of combustion to SI engines offers an increase in fuel efficiency and a great decrease in $\mathrm{NO}_{\mathrm{x}}$ emissions compared to SI standard operation.

As it has been said, CAI combustion is achieved by controlling the mixture conditions, i.e. pressure, temperature and composition of the charge. Unlike SI and $\mathrm{CI}$ engines, there is no direct control over the mixture ignition timing, and therefore the initial conditions of each combustion cycle will be more important than in the previously mentioned engines. In this type of combustion, chemical kinetics plays a fundamental role in the development of combustion. Many studies have been developed with the intention of giving light to the chemical mechanisms developed during the instants in which the fuel initiates the autoignition process. For example, Zhao et al. [125] studied the process by simulating a 4-stroke engine fueled with isooctane. They used a model with detailed chemical kinetics of the fuel to study the different parameters affecting CAI combustion. Kelly-Zion et al. [126] developed a work by modeling an engine where the effect on the autoignition delay was studied when the initial conditions of the mixture or the type of fuel used were varied.

Other very important works for the understanding of these mechanisms have also been developed in parallel by the use of rapid compression machines (RCM), in which it has been possible to study in detail the chemical part of the autoignition process, isolating very well the rest of effects such as temperature, 
composition or pressure, since in an engine it is often impossible to isolate the effect of each parameter separately. Tanaka, S. et al. [127] used an RCM to study the effects of fuel structure on the self-ignition process. Desantes, J.M., Lopez, J.J. and López-Pintor, D. appear in numerous works related to the self-ignition of fuel/air mixtures in rapid compression machines, having contributed with a great knowledge about this field of research [17, 128-132].

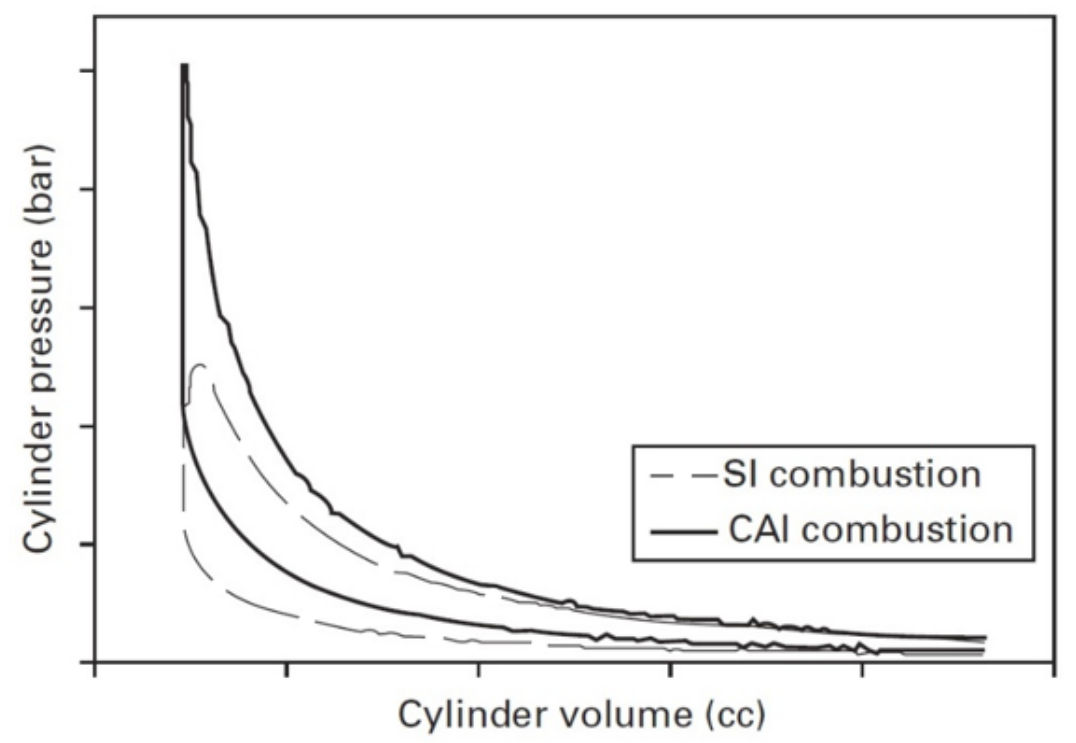

Figure 2.22. PV diagram for combustion cycles operated in SI and CAI conditions. Source: Adapted from [82].

In an ideal CAI combustion case, the ignition of the mixture occurs simultaneously in the entire volume occupied by the fuel/air mixture, without a defined flame front [133]. Therefore, this process develops with higher heat release rates. Consequently, the resulting combustion speed would be much faster than the one achieved by a flame front-based combustion. So, it could be considered that the heat release would take place at constant volume (see Figure 2.22). This process is much more repetitive and stable compared to a SI standard combustion [134].

This combustion mode will always be bounded in an area smaller than the complete engine operation map. Beyond that area, problems of (1) misfire, (2) partial burn or (3) knock will appear. In Oakley's work [135] some engine maps are presented where the CAI operation region is defined for a given SI engine, based on the lambda used and the EGR rate. In this engine, the air 


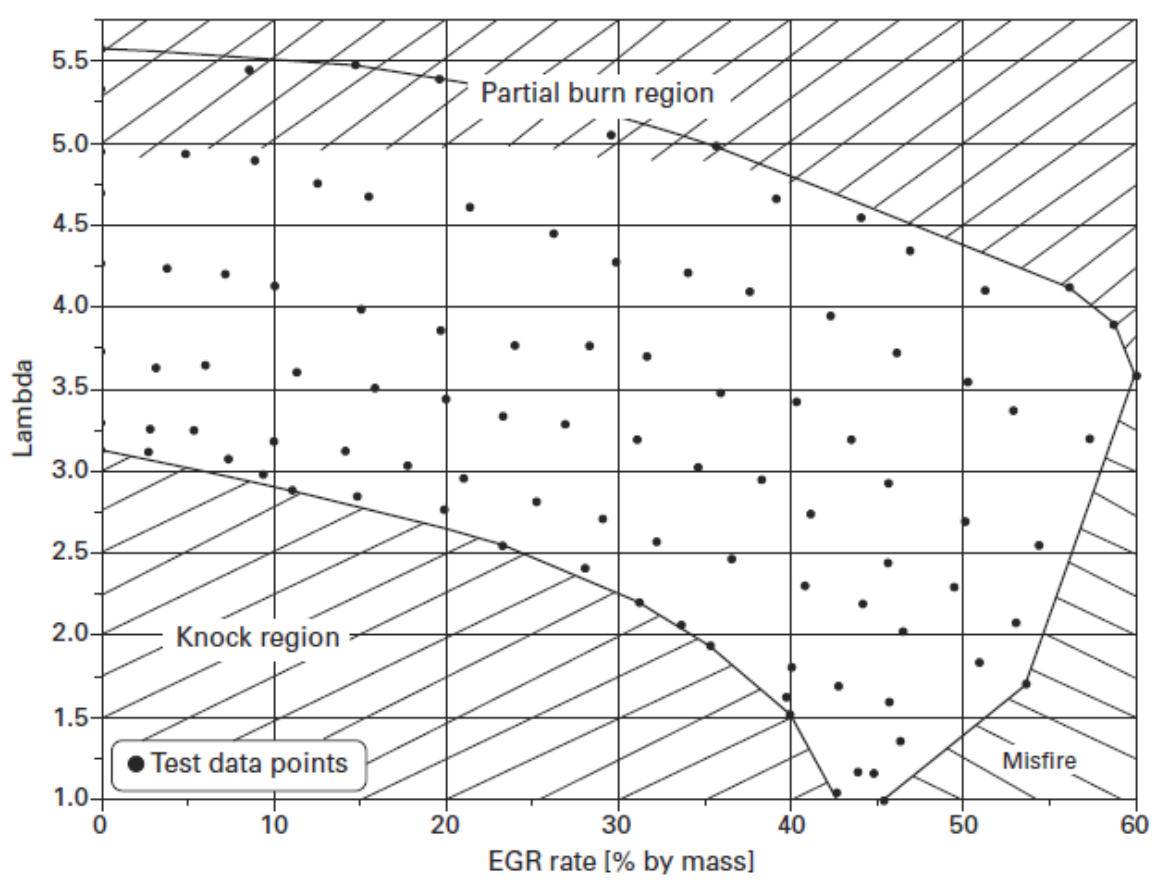

Figure 2.23. Boundary regions for CAI operation with unleaded gasoline [135].

was introduced at a temperature of $320{ }^{\circ} \mathrm{C}$ and the intake pressure was kept constant at 2.7 bar, so that with the variation of the amount of fuel injected, both the IMEP and the lambda were modified. The first boundary defines the region of misfires, where the EGR rate is very high and the excessive amount of $\mathrm{CO}_{2}$ and $\mathrm{H}_{2} \mathrm{O}$ hinders the mixture autoignition. This EGR rate can be higher with higher lambdas, since the amount of oxygen present in the EGR increases significantly. With the decrease in the amount of fuel, the lambda increases until it reaches the second boundary, the partial burn region, where combustion begins to be incomplete. The combustion stability is lost, and CO and $\mathrm{HC}$ emissions are increased. Finally, the knock region occurs when the mixture is richer and the EGR rates are low because the reactivity increases excessively and the combustion goes out of control.

In Duret's work [136], an engine operation map is presented as a result of the work on a two-stroke engine, where the CAI region and the SI region are specified (Figure 2.24). As it can be seen, the autoignition region of the engine map presented by Duret was wide enough wide to move the vehicle from about 
$15 \mathrm{~km} / \mathrm{h}$ in first gear until $95 \mathrm{~km} / \mathrm{h}$ in fourth gear, providing by this way an engine able to take advantage of the benefits of the CAI combustion.

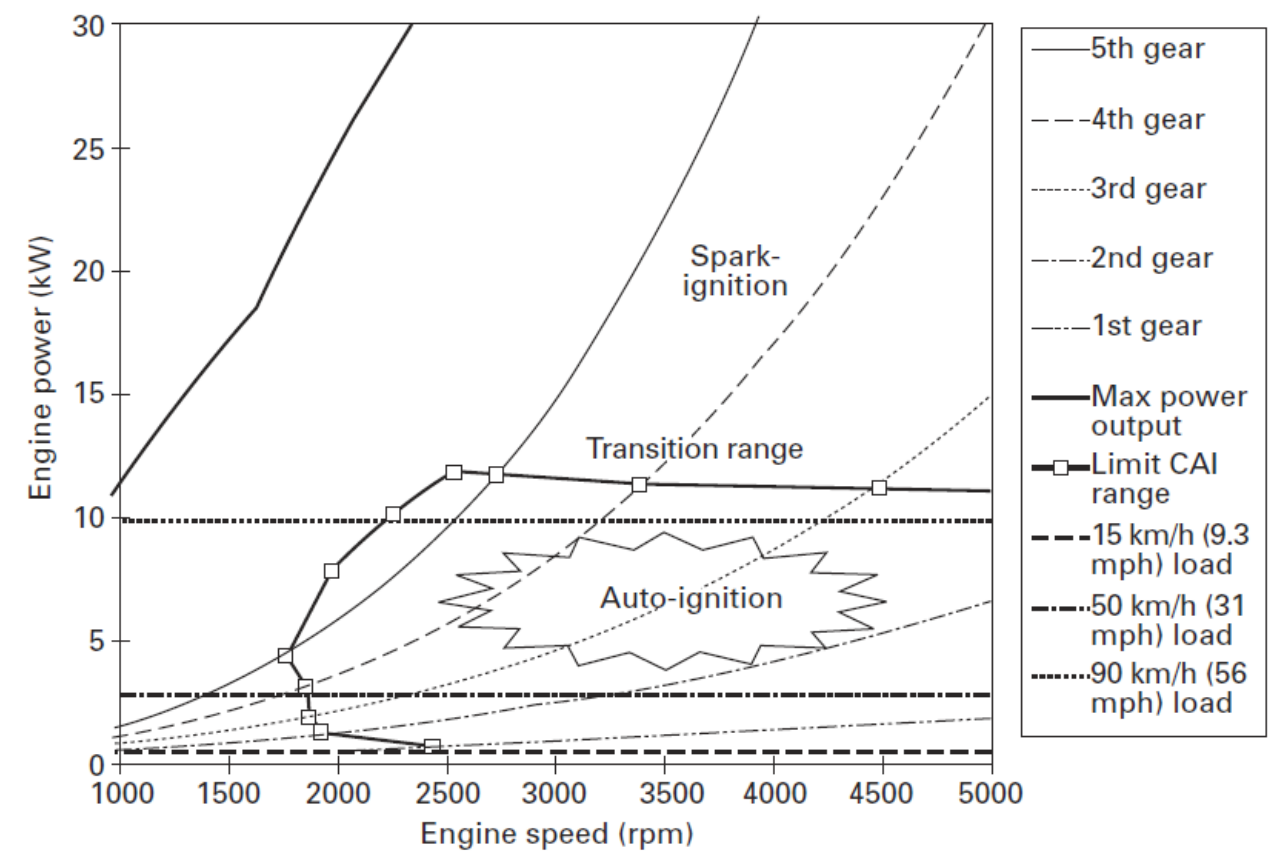

Figure 2.24. Engine map proposed by Duret for a CAI-SI operation in a two stroke engine [136]. Source of the figure: [82].

\section{Approaches to CAI operation in gasoline engines}

As already seen, this combustion mode has high potential to reduce fuel consumption and minimize emissions. Therefore a great effort has been done in the last decade in order to try to transfer this combustion mode to the current engines running on the roads.

First of all, the most obvious strategy to get CAI is the intake heating. This work was carried out by Najit and Foster in 1983 [86]. In this work the temperature of the intake air was increased to achieve a CAI combustion, later controlled by the dilution degree of the mixture. This heating can be achieved in different ways: through the heat rejected by the engine to the coolant or exhaust gases [137], or through an external heat source installed in the intake.

Another methodology to achieve CAI combustion is the increase of the engine compression ratio in order to reach the autoignition temperatures by 
compressing the mixture [138-140]. The problem of this solution is the limited operation range if there is not a VCR (Variable Compression Ratio) system installed.

The fuel characteristics modification through the blending of different fuels, or the variation of its original composition has also proven to be, on the one hand, a tool with a great potential for the CAI application to the current engines, and to achieve larger operating ranges [141-144]. However, this strategy is limited by the complexity and cost of implementing a dual fuel system. On the other hand, Lacey et al. [145] warn that CAI conditions are very sensitive to fuel composition, and therefore the variability of its composition generated in the refinery, transport and storage can affect the final operation of the engine, its efficiency and emissions.

Finally, the most successful method to achieve CAI combustion in gasoline engines is by retaining the hot residual gases from the previous combustion cycle inside the engine [88, 91, 146-148]. These gases are at high temperatures and, therefore, when they are mixed with the fresh charge introduced by the intake, the temperature of the resulting in-cylinder charge can be modulated according to the retained residual rate. This strategy makes CAI operation possible in engines with a standard compression ratio without the need of an external preheating system. This last strategy can be performed by different ways depending on the engine configuration (residual gases retaining), and will be described in more detail in the following paragraphs.

One way is advancing the closure of the exhaust valve in order to prevent the expelling of the complete amount of exhaust gases. When the exhaust valve is closed before TDC, the pressure in the cylinder increases during the rest of the exhaust stroke. Accordingly, the intake opening must be delayed until the cylinder pressure is lower than the intake pressure (see Figure 2.25). This strategy is known as Negative Valve Overlap (NVO), and one of its major drawbacks is the loss of engine permeability. However, this strategy creates a period of recompression of the retained gases that can be used to inject part of the fuel and thus further increase the reactivity of the mixture, since when this fuel is precompressed and exposed to high temperatures and pressures, it begins its decomposition in chains of shorter hydrocarbons with greater reactivity $[140,149]$.

This strategy is widely used by different authors in their work to study CAI combustion. Yang [150], for example, studied CAI combustion in an optical engine with the NVO strategy to trap the residuals in the cylinder. Hunicz [151] studied the effect of NVO on the combustion phasing control and the effect of fuel injections during the recompression period in the NVO. The second 


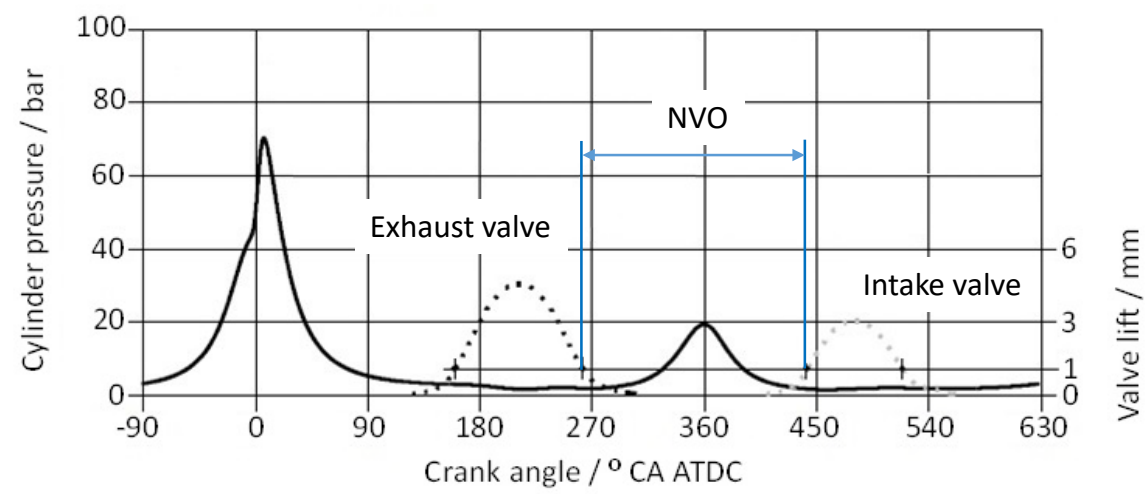

Figure 2.25. Graphical description of a NVO strategy. The exhaust and intake camshaft timings are separated from each other, creating an intermediate period where the cylinder is closed during part of the exhaust and intake strokes. Source: Adapted from [149].

way is based on the exhaust gases recirculation. In this case, they leave the cylinder to be reintroduced again. This process can be carried out by means of the so-called internal EGR, thanks to the positive overlap of the valves. However, in this strategy an additional energy input is usually required due to the temperature loss of the exhaust gases, either by preheating the intake air or by an increase in the compression ratio [139, 146, 152]. The other alternative in which less exhaust gas energy can be recovered is called exhaust rebreathing, and consists on letting the exhaust gases out and then reabsorbing them by opening again the exhaust valve or leaving it open during part of the intake stroke [153].

There are other strategies that have been presented by different authors to keep residual gases in the cylinder, and thus achieve CAI combustion. These ones are very similar, on the basis, to the ones already mentioned above, but with slight differences when acting to retain the gases.

Cinar et al. [154] reduced the lift of the exhaust valves by adjusting it to retain the necessary amount for the autoignition of the mixture, which finally is a strategy similar to that of using the NVO for the same purpose. In the work of Caton et al. [155], the valve timings were adjusted to control the effective compression ratio, the amount of residual gases inside the cylinder and the exhaust temperature. And finally, Li et al. [156] studied the intake backflow so as to achieve autoignition conditions. 
If these ways are compared, the exhaust recirculation is characterized by the lower temperature of the residuals since these lose part of the heat during the period in which they are recirculated. This characteristic can be beneficial to operate at high loads, since the reactivity of the mixture is decreased. On the contrary, the retention of the exhaust gases inside the cylinder eliminates these heat losses and, therefore, the initial temperature is higher. This method can be advantageous for the operation of the engine at low loads to favor the autoignition of the mixture and a faster combustion [157].

\section{Injection strategies}

Once the strategies used to modulate the reactivity of the mixture and to achieve autoignition have been presented, the way in which the fuel is injected also has a great importance in the development of the combustion, because the homogenization of the fuel will be different depending on the selected strategy.

Fuel injection strategies in these types of engines cover different aspects. Firstly, the injection point: either the intake port or to inject the fuel directly into the cylinder can be chosen. Secondly, the way in which the fuel will be injected can be adjusted. In the case of intake port injections, the flexibility is not very big. However in the case of the direct injection of gasoline, both the injection timing and the number of injections to be made can be adjusted.

The intake port injection is, a priori, a solution with less complexity and price. This one guarantees a good homogenization of the fuel. However, this operation mode is very rigid and does not allow for great adjustments when setting injection timings. Authors such as Milpied, J. [158] and Choi et al. [159] present works with this injection mode, and talk about their problems and benefits.

The direct injection in the cylinder is the most commonly used strategy nowadays. This one allows greater flexibility when modifying the injection settings to control combustion. Cao et al. [160] conducted a study using CFD simulation where the effect of injection timing on a gasoline GDI engine was analyzed. They observed how the SOI affects the in-cylinder fuel/air mixing and mixture temperature. Therefore it was shown as a very influential parameter in CAI combustion optimization and engine performance. In another of his works [161], Cao also states that direct fuel injection can result in lower fuel consumption and higher loads than with a PFI strategy. The SOI variation also affects the combustion phasing through the effect of charge cooling. But, on the other hand, direct injection of fuel so early in the cylinder favors piston wetting, considerably increasing $\mathrm{HC}$ emissions [153].

Another strategy used to take control over ignition and combustion development in CAI is the distribution of the fuel in two pulses. In this way, it 
is possible to modulate the homogenization of the mixture and, thereby, create a charge stratification that will allow the autoignition of the mixture, as well as a decrease in the heat release rate. If the engine operated in CAI uses the NVO strategy to retain the hot residual gases in the cylinder, the first injection can be made during the recompression of the residual gases, thus creating a fuel reforming effect in the injected fuel that will make easier later the autoignition of the mixture, thus giving a better stability and a more advanced SOC [151]. In some engines, the combination of both systems (the PFI and the DI) has also been studied, resulting in greater flexibility to create stratified charges despite presenting similar results to what would be obtained with a strategy of split injections [162].

\section{Emissions and efficiencies}

SI engines rely on a plasma discharge originated by the spark plug to start the combustion process in a mixture under stoichiometric conditions. This combustion will advance through the combustion chamber as a defined flame front that will separate the areas of fresh unburned mixture and burnt products. During this process the temperatures in the flame front can reach up to $2500 \mathrm{~K}$, which causes the formation of $\mathrm{NO}_{\mathrm{x}}$ that will be directly related to the temperatures reached during the combustion process. Regarding smoke emissions, the SI engine is a virtually smoke free. However the need to operate with stoichiometric mixtures makes it necessary to install an intake throttle to regulate the air mass flow entering the engine. This results in high pumping losses, and therefore a worsened efficiency at low and medium loads.

Unlike SI combustion, in CAI combustion a premixed and highly diluted mixture is autoignited at different points in the combustion chamber at the same time, so that it progresses through the combustion chamber more quickly. An important difference is that the combustion temperature is lower due to the presence of an excess of air or diluents in the mixture, which lead to combustion temperatures usually below $2200 \mathrm{~K}$, resulting in the elimination of $\mathrm{NO}_{\mathrm{x}}$ emissions. In addition, lean mixtures are also virtually free of smoke emissions during combustion.

The possibility of working with lean mixtures makes the adjustment of the intake throttle less restrictive, even to work without it. This reduces the pumping losses, making the SI engine in this aspect similar to a CI engine. Therefore, it could be said that, by means of the CAI mode, the engine can reach the efficiencies of a CI with very low emissions.

However, this combustion mode, since it is operated with lean mixtures and low temperatures, can increase the unburned hydrocarbons emissions. On the one hand, the emissions due to crevices are similar to the ones of SI engines 
when operating in conditions close to stoichiometric. But with the dilution of the mixture, the unburned hydrocarbons emissions increase due to the partial combustions [163]. Regarding CO emissions, these are not eliminated under CAI operation. However, it is true that the use of residual gases to initiate combustion helps to reduce the emissions of this pollutant $[89,146]$.

The work developed by Zhang and Zhao [164] focuses on the comparison of SI and CAI combustion modes in $2 \mathrm{~S}$ and $4 \mathrm{~S}$ engines. They show the comparative results of the efficiencies obtained and the emissions values in each type of engine, when being operated in different combustion modes. From the results presented in the paper, the following figure (Figure 2.26) has been extracted, where their main results are shown. It can be seen how these results go in the same line than the statements explained in this section.
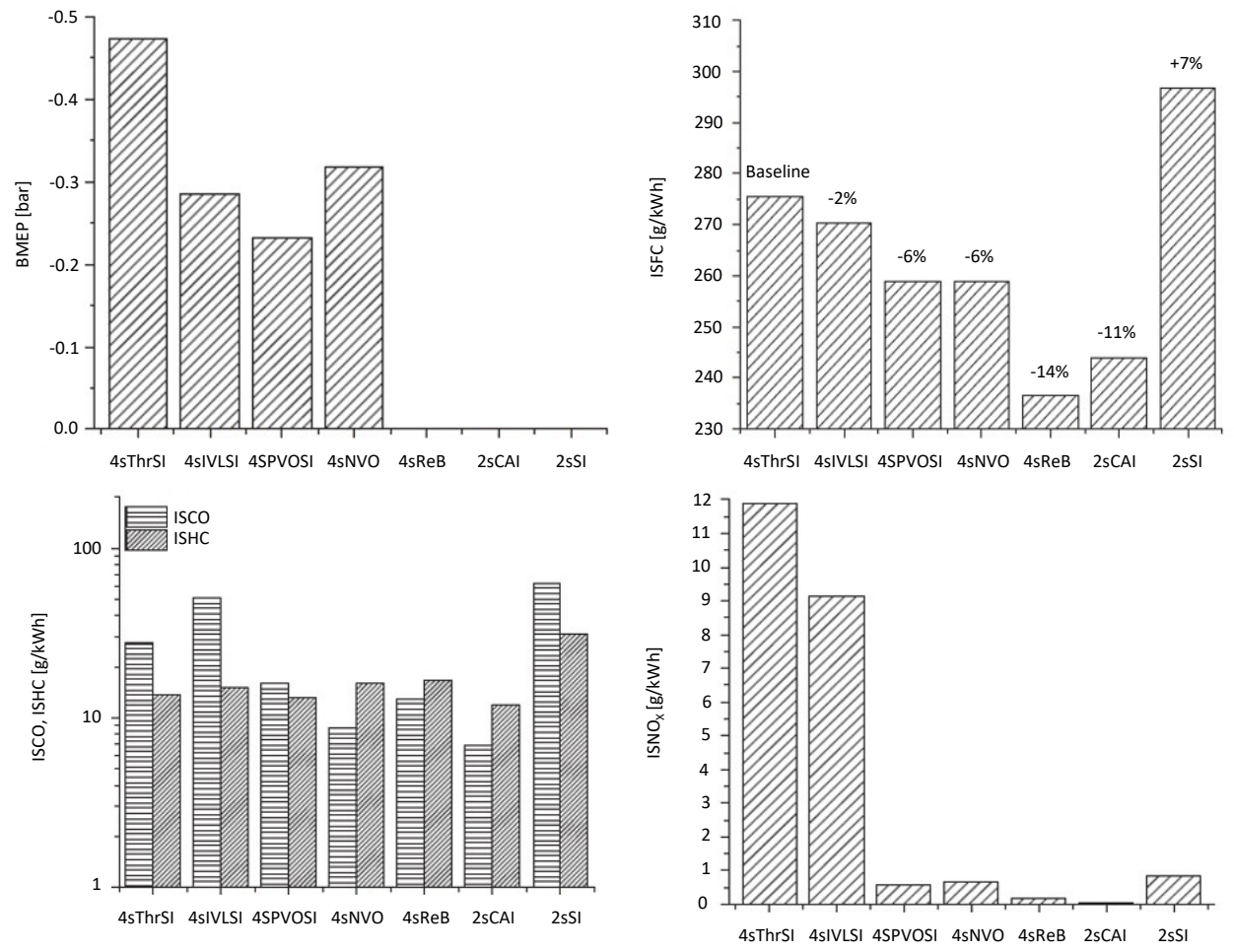

Figure 2.26. Comparison of the SI-CAI modes in $2 S$ and $4 S$ engines with different approaches to get the CAI combustion. Source: [164]. 
In order to better understand the figure, a brief description of the $\mathrm{X}$ axes labels of each graph is presented:

- Mode 1: 4-stroke throttle-controlled SI mode.

- Mode 2: 4-stroke intake valve throttled SI mode.

- Mode 3: 4-stroke positive valve overlap SI mode.

- Mode 4: 4-stroke negative valve overlap CAI mode.

- Mode 5: 4-stroke exhaust rebreathing CAI mode.

- Mode 6: 2-stroke CAI mode.

- Mode 7: 2-stroke SI mode.

It must be said that all the tests were operated with an equivalent output power and the operation was made in all cases under stoichiometric conditions.

Zhi Wang et al. [165] also conducted a study comparing the combustion modes SI, SICI (Spark Induced Compression Ignition) and CAI on the same engine, obtaining results also in line with those presented above (Figure 2.27).
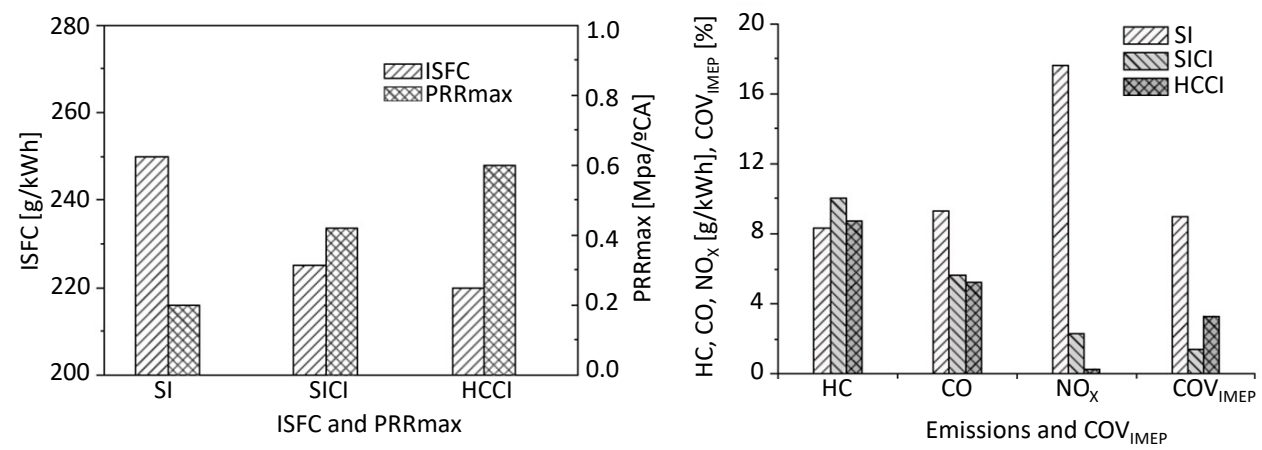

Figure 2.27. Comparison of combustion and emission characteristics among the CAI, SICI and SI modes. Source: [165].

This type of works have been extensive in recent years, and the main part of them have provided similar conclusions together with a better understanding of the efficiencies obtained and the emissions associated to this type of combustion [123, 134, 164, 166-169]. 


\section{Hybrid combustion mode, between CAI and SI}

CAI engines, always need a spark plug to run and work when they are cold, and to complete the operation range of the engine through the SI mode at very low loads and high loads, since in the first case the mixture does not reach enough temperature to autoignite and, in the second case, the autoignition operation leads to high levels of knocking and uncontrolled combustion due to the excessive reactivity of the mixture.

The influence of the spark plug on CAI combustion has been studied in different works, and it can be found that, according to some authors, this can affect very little the combustion when the engine is operating in CAI [152]or, on the contrary, for some other authors, it can have a greater influence on the combustion, affecting its positioning and development [170-172], even helping at certain points to operate the engine in CAI conditions, as for instance at low loads, where the reactivity needs an extra energy supply, thus extending the range of operation in CAI conditions. This is why a hybrid combustion mode called Spark-Assisted Compression Ignition (SACI) can be found in the literature [173]. This mode has received other names such as SI-CAI, CAISI... all of them related to the ignition assistance by spark plug in CAI combustion.

In this type of operation, the reactivity conditions are modulated in such a way that the initial contribution of the energy generated by the spark plug and a small combustion kernel can later start a generalized combustion by autoignition [174]. This combustion mode allows the positioning of the combustion, since it can be adjusted by the spark timing. In this way, the benefits of both combustion modes (SI and CAI) can be partly provided: on the one hand, greater control over the combustion positioning and, on the other hand, the benefits of CAI combustion compared to SI [175-177].

\section{Expanding the CAI operation limits}

One of the main problems with the CAI combustion mode is that it cannot be used in the complete operation range of an engine. Therefore, the combustion modes have to be alternated according to the load degree demanded. This means that part of the interest in this combustion mode is lost, since it adds a great engine operation complexity and the benefit is very limited due to the small region where the engine is operable in CAI combustion.

This problem has generated a great working field for the researchers that, little by little and with successive works, have been increasing the application range of this type of combustion in the engine. The approaches have been very different. Most of them have focused on controlling the mixture reactivity 
more precisely with the available settings, whereas others have tried to add new parameters to have additional degrees of freedom when adjusting the operation of the engine.

- Injection strategies:

The injection strategies have already been discussed in this section, since they play an important role in the homogenization of the mixture and the adjustment of the reactivity of the final charge. Therefore, the continuous work on these strategies can lead to higher operation loads under CAI conditions. In the work presented by Li et al. [178], the application of different timings for simple and split injections is studied. At the end of the study they state that, with the advance of the injection and the use of split injections, the maximum load under CAI conditions can be increased.

- Residuals rate adjustment:

The valve timing configuration has shown to be essential to achieve the necessary reactivity to make the engine work in CAI combustion. By modifying these parameters the initial reactivity of the mixture is strongly affected, and so it is not surprising that an improvement over the performance in these parameters can lead to an expansion of the combustion region by auto ignition [179]. It is worth to mention in this section the work of Yang et al. [180] where the effect of residual gases trapped in the engine is studied. In their study they state that not only the effect of the temperature of these gases must be taken into account, but also the effect of the mixture dilution has a great importance when expanding the CAI operation range.

- Fuel modification:

Another interesting strategy to work in CAI combustion mode and to increase the operating range is based on the modification of the fuel composition. This is a strategy that moves away from what would be understood by CAI combustion in purely gasoline engines. However the need of different mixture reactivities at each operating point suggest not only to modify the conditions of the gases, but also the fuel itself. The work of Zhang et al. [181] and Uyumaz [182] show that, in the first case, the addition of ethanol to the fuel favors the increase of the maximum load in CAI, since this one has a greater cooling effect in the mixture and presents slower combustion rates. And, in the second case, that the mixture of different fuels also results in an increase of the equivalent octane number of the resulting fuel, allowing to extend the limit of CAI operation towards higher loads. 
- Water addition:

The combustion at high loads presents the problem of an excessive reactivity of the mixture, losing the control over the knock and the combustion performance. Therefore, a field of study has focused on the introduction of reactivity suppressors like water, through the addition of this element by mixing it with the fuel [183-185] or by injecting it directly into the combustion chamber $[186,187]$.

The addition of water to the combustion chamber implies a drop in the initial charge temperature and a lower heat release rate thanks to the heat absorption required to evaporate this element and to the higher $c_{p}$ of the $\mathrm{H}_{2} \mathrm{O}$ molecules that absorb a greater amount of energy to increase its temperature. All these phenomena have a great effect on the combustion temperature. This strategy offers promising results to be able to considerably increase the maximum achievable load in CAI mode [149].

\section{- EGR:}

In the same direction as the water addition, the EGR introduction also seeks a decrease in the mixture reactivity, thus favoring the increase of the maximum allowable load. For this purpose the EGR gases must be cooled, and once introduced into the cylinder, they reduce the charge reactivity thanks to the lowering of the oxygen concentration and the higher $c_{p}$ thanks to the water vapor contained in these gases. Therefore, some works have also been developed using the EGR as a tool to expand the range of operation in CAI mode [188, 189].

- Spark adjustment:

Finally, the use of the spark plug in the CAI combustion mode has shown to be a useful element, since it can be used to initiate a combustion that normally would not have started by autoignition. By this way, the engine can be operated with a sufficiently low reactivity, so that the mixture is unable to autoignite without a small extra energy supply. This energy will be provided by the spark plug and by the small combustion kernel formed, thus initiating the process in two phases: the first phase starts with an SI ignition, and the second phase, thanks to this increment of additional energy, it will cause the general autoignition of the rest of the mixture [190].

\section{The two stroke CAI engines}

The use of two-stroke engines has always been very complex. One of their main problems has been a very unstable operation at low and medium loads. 
During the 70s different works emerged trying to improve this aspect. Among these, Onishi et al. [83] and Noguchi et al. [84] presented an improvement of the combustion at part loads in this type of engines that improved their efficiency, stability and emissions of these engines. This improvement set the foundations of combustion by autoignition in gasoline engines. From this moment, several works focused on studying the advantages and disadvantages of these engines were developed. These works tried to establish the ways in which it can be taken advantage of this new combustion mode and how to apply it to the engines that in the future could power the vehicles used for transportation. Many of these have been described in the previous lines of this section, since the combustion basis is the same for $2 \mathrm{~S}$ and $4 \mathrm{~S}$ engines.

As seen today, the use of $2 \mathrm{~S}$ engines is increasingly anecdotal against the massive use of $4 \mathrm{~S}$ engines. However, two-stroke engines can offer virtually twice as much power per displaced volume as a $4 \mathrm{~S}$, since they perform a complete cycle in each crankshaft revolution. This means that these engines can be more compact and more efficient due to lower heat losses and lower friction losses during the cycle [191]. Nevertheless, these engines are more complex and unstable during operation, and this theoretical benefit has always been very difficult to be attained in reality. Despite this, there have always been different works in progress trying to continue improving this type of engines, or studying the implementation of new solutions or approaches in their operation that could offer a competitive advantage over $4 \mathrm{~S}$ engines.

CAI combustion can push the development of this type of engines improving their combustion stability and improving low and medium loads operation performance, since these are the operating areas where this type of engines have their main problems. Therefore, there is a large working field in which several studies have been made even though, due to its lesser presence in the automotive world, the amount of these works is much less than those done for $4 \mathrm{~S}$ engines.

Along the following lines, a series of works carried out in years close to the development of this $\mathrm{PhD}$. thesis will be shown, trying to see the aspects in which the authors have focused on.

Wijesinghe and Hong [192] worked on a two-stroke engine $\left(160 \mathrm{~cm}^{3}\right.$, pistonported, single-cylinder). In this engine, valves were installed at the intake and exhaust to control the scavenging process and to trap residual gases inside the engine. With this arrangement they made tests analyzing the operation of the engine at low and high loads. These authors published in other works [193, 194] an analysis of the effect of maintaining the spark assistance on the engine while operating in CAI combustion to improve the combustion stability and 
eliminate misfires problems. They state that, by advancing the spark timing, the autoignition onset can be influenced, thus giving an extra adjustment degree of the combustion phasing. However, they observed that the combustion duration was independent of the ignition timing. This duration depends on the composition and conditions of the mixture in the cylinder.

Hung et al. [195] developed a study based on the modeling of a two-stroke free piston linear engine, in which they analyzed the effect of different operating parameters such as the intake temperature, $\mathrm{F} / \mathrm{A}$ equivalence ratio, engine load, intake pressure or the spark plug effect on combustion.

Duret has also contributed to the development of different works related to the development of two-stroke engines. One of them has been the development of a two-stroke engine capable of operating in CAI combustion called ELEVATE [196, 197].

Andwari appears related to different works on the development of twostroke engines (piston ported single-cylinder) operated in CAI conditions. These works are focused on the analysis of the effect of the hot residual gases on the combustion and the addition of EGR to the intake charge [191, 198-201].

The authors Zhao and Zhang have made a great contribution in this research field with numerous investigations and works related to the CAI engines and also with architectures of two-stroke engines. Zhao, has edited a book about CAI engines [82] where he tries to collect much of the knowledge developed up to that moment, and summarizing in a chapter dedicated to the two-stroke engines the work done on these engines and their peculiarities.

Some works of these authors are detailed in the following lines:

In 2000, Zhao and other authors worked on the 4-SPACE project with the aim to develop an innovative controlled autoignition combustion process for lean burn automotive gasoline 4-stroke engines application [88].

In 2001 and 2002, Zhao continued researching about the CAI combustion with a Ford 1.7L Zetec-SE 16V engine [89, 152].

In 2004, Zhao studied in an optical engine the CAI heat release by means of 2-D PLIF imaging of formaldehyde [202].

In 2006, Zhang presented a study about the combustion and emission characteristics of ethanol on a port fuel injection HCCI engine [203].

In 2012, they published a paper about the measurement of the short-circuit of intake gases to the exhaust in two-stroke engines and the effects for the CAI operation [204]. 
In 2013 both authors published a study using DME directly injected to control the mixture reactivity and the combustion timing [205]. In another work [206], they studied the implementation of a sensor in the engine to measure the $\mathrm{CO}_{2}$ concentration inside the cylinder and thus quantify the amount of hot residual gases during the operation of the engine. Finally, they also studied the influence of intake backflow on HCCI autoignition timing [207].

In 2014 and 2015, Zhang et al. [164, 208] worked with a single-cylinder engine able to work work as a $2 \mathrm{~S}$ or a $4 \mathrm{~S}$ thanks to a camless system, to study the possible benefit of operating the engine in CAI through a two-stroke cycle.

In 2015 they published some results using gasoline with ethanol [181]. In this study the influence of the introduction of different fuel compositions was analyzed.

These investigations, together with others shown during the development of this chapter and many others not mentioned here, have contributed to improve the understanding of the CAI operation and its application in twostroke engines.

\subsection{The combustion analysis}

\subsubsection{The combustion diagnostics}

The combustion diagnostics is a key tool to obtain precious data from the combustion occurred during any engine test. This data gives information about the essential process in IC engines, since the combustion is the way how the energy is introduced in the engine, which will be recovered at the power stroke. Therefore, the way in which this is developed plays an important role on the engine performance. The most extended way to analyze the combustion is based on the estimation of the heat release law (HRL) from the pressure data measured directly from the combustion chamber. In the literature two, main ways to estimate this parameter can be found [39, 209], named as the "burning rate analysis" and the "heat release analysis".

- The burning rate estimation comes from SI engines, in which the combustion development is clearly differentiated in two regions: the burned and the unburned gases. By this way, the evolution of the burned region determines the burning rate from the combustion initiation $(0 \%)$ to the end of combustion (100\%). The estimation of this parameter is based on simplified models to approximate the thermodynamic 
evolution of the cylinder charge, but nevertheless this is less accurate than the application of the first law of thermodynamics (heat release analysis). Moreover, the main advantage of this methodology is the faster estimation of the MFB (mass fraction burned).

One of the most extended models is the one of Rassweiler and Withrow [210]. By analogy with a constant volume combustion, the authors link the pressure increment with the evolution of the burned fraction, obtaining a simplified equation to estimate the MFB:

$$
M F B(\alpha)=\frac{p^{\frac{1}{n}}(\alpha) \cdot V(\alpha)-p_{0}^{\frac{1}{n}} \cdot V_{0}}{p_{f}^{\frac{1}{n}} \cdot V_{f}-p_{0}^{\frac{1}{n}} \cdot V_{0}}
$$

where $\alpha$ is the angular position of the crankshaft, $p$ and $V$ are the pressure and the instantaneous volume inside the cyclinder and the subscripts 0 and $f$ are refered to the intial and the final conditions.

- The heat release analysis is based on the application of an energy balance to the combustion chamber, based on the first law of thermodynamics. By this way, for the estimation of the HRL, all the variables of this balance are considered: internal energy, expansion work, heat flows to the walls and enthalpy of the combustion chamber incoming and out-coming mass flows. Usually the most important parameters on this estimation are the internal energy and the expansion work, the rest of the variables can be simplified or neglected. According to Heywood [39] , its usual to differ between two ways to estimate the HRL.

- The first one takes in account a model to estimate the heat loses to the cylinder walls, by this way the chemical energy released from the fuel can be estimated. This estimated HRL is known on the literature as the gross heat release [39, 209, 211-214]. ${ }^{1}$

- The second way does not consider any heat loss for the estimation of the HRL, by this way the obtained HRL is known as the net heat release [39, 215-217].

A simplified example of the HRL estimation is suggested by Brunt et al. [209] based on the polytropic evolution hypothesis presented by Rassweiler and Withrow. Applying the first law of thermodynamics the gross heat release rate can be obtained.

\footnotetext{
${ }^{1}$ This is the chosen methodology for the HRL estimations all along this thesis work.
} 


$$
\Delta H R L=m \cdot \Delta U=m \cdot c_{v} \cdot \Delta T=\frac{V_{2}}{\gamma-1}\left[p_{2}-p_{1}\left(\frac{V_{1}}{V_{2}}\right)^{n}\right]
$$

where $p_{1}, p_{2}, V_{1}$ and $V_{2}$ are the pressure and the volume inside the cylinder refered to the starting (1) and the final conditions (2) during the considered period of time to calculate the HRL variation, $\gamma$ is the isentropic exponent and $n$ represents the polytropic exponent.

Regarding these diagnostic models, it is possible to sort them depending also on the considered zones inside the combustion chamber. There are single zone models [211-213, 216, 218-220] and models with two or more zones [215, $217,220,221]$. The second are more accurate, but that accuracy implies an increment of the numerical complexity, and for the estimation of the HRL the single zone models are widely considered as accurate enough [209].

As said at the beginning, all these estimations depend mainly on the cylinder pressure registered signal. This experimental data measurement presents some difficulties and uncertainties that modify the obtained data compared to the original values. Two of the main problems are: first, the signal disturbance by external influences, as the noise introduction inside the measured signal. And second, the slight combustion variabilities that can be found in the individual measured cycles that are not representative of the whole combustion performance. These two problems are solved processing the pressure signal from the raw data. First, the final pressure signal is the result of the measurement and averaging of a set of measured cycles. By this way the small differences and dispersion between the individual cycles are reduced (see Figure 2.28, right), thus obtaining a representative pressure cycle. And secondly, the signal is filtered to remove the high frequency noise introduced in the signal coming from external sources (see Figure 2.28, left). By averaging the pressure cycles, besides getting a more representative pressure data, this operation implies also a signal filtering. Some authors, as Callahan et al. [222], for instance, do not include any additional filtering beyond the averaging of 100 measured pressure cycles.

These methodologies are widely employed for the combustion diagnostics in SI and CI engines, thus obtaining a representative HRL to analyze the combustion process on the engine. However, there are two concerns during the present work. The first one is which the quality of this methodology is when working with a SI engine with a high cycle to cycle variability, since the averaged pressure analysis is a very good methodology for engines with small variability during the combustion process (as CI engines), while with the 

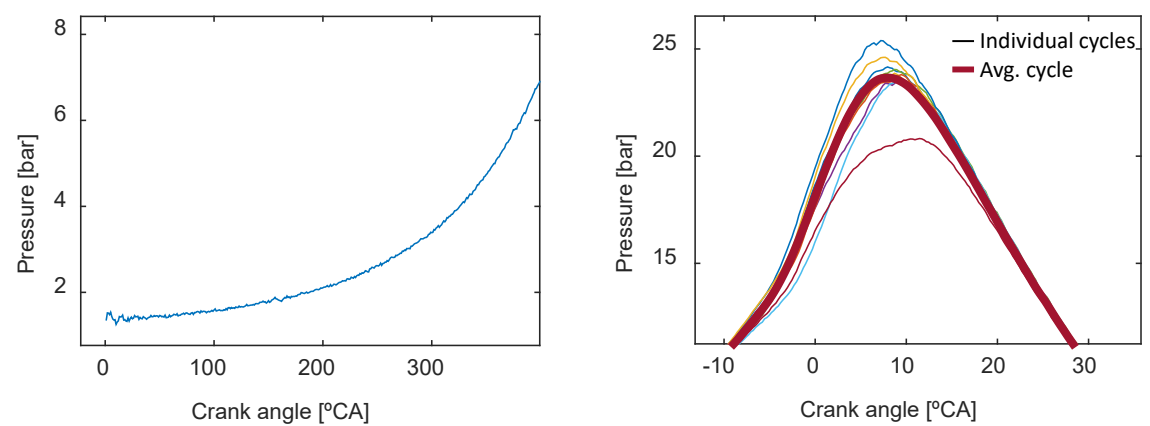

Figure 2.28. Left - Detail of the external noise registered on a pressure signal measurement. Right - Different pressure cycles measured during combustion and averaged pressure signal.

increase of the scattering, the averaged pressure cycle is less representative of the whole process. And the second concern is about the availability of a deeper combustion analysis from the HRL information, especially with the emergence of all these combustion modes and their potential coexistence during the engine operation. From these two points, the next subsections have been created in order to review the approaches to these two questions related to the combustion diagnostics.

\subsubsection{The SI cyclic variability and the influence on the combustion diagnostics}

The cyclic variability is a common phenomenon during the combustion process, observed from the very beginning of the Spark Ignition (SI) engines development [223]. This variability mainly causes fluctuations in the rate of heat release, giving a variable power output, increased emissions and a worsened fuel consumption [224]. It is therefore not surprising that the instabilities were identified as a fundamental combustion problem in spark ignition engines [11, 225]. The main factors affecting the cycle to cycle variability of the SI combustion have been classified, for example, at Heywood [39], and these are the following: mixtures not close to the stoichiometric values (lean mixtures operation), aerodynamics in the cylinder during combustion, homogenization of the fuel, residual and recirculated exhaust gases supplied to the cylinder, composition of the local mixture near the spark plug, etc. 
The unpredictable and stochastic character of this variability produce several problems for the development of optimized engine control systems and limits the maximum efficiency and power achievable [226]. Around the literature it can be found information about several works dealing with this phenomenology and trying to improve the engine efficiency by reducing the variability [227]. Nevertheless, despite of the work made trying to solve the different aspects of combustion instabilities, a controlled stable combustion process in an SI engine has not yet been solved [228-230].

So, it is necessary to deal with the combustion variability when these engines are being used. Normally, for these type of studies, the most common way to approach a combustion study is by the analysis of a representative averaged pressure cycle calculated from the ' $n$ ' measured cycles, which is assumed as representative of the whole test [231]. This methodology is perfect for diesel engines because the variability of the combustion is nearly cero, so the averaged cycle is very similar to each instantaneous measured cycle. It has not much sense to think about analyzing the instantaneous cycles in that case. However with SI engines the averaged cycle could not be representative enough of the whole combustion inside the cylinder due to the big discrepancies among the different instantaneous cycles.

Some works have been done dealing with these problems in SI engines. For example, E. Galloni [232] talks about the adjustment of the spark ignition timing individualized for each cycle and the associated problems of the adjustment of this parameter just with the mean values. Baratta studied for several years the cyclic variability in SI engines. In 2005 [233] developed a new diagnostic technique based on a quasi-dimensional multizone model and named it the "cycle resolved model". With this tool he studied, in this case, the influence of the cyclic variability on the different aspects of the combustion diagnostics. Afterwards, in 2006 this model was also used to estimate the start of combustion (SOC) for each cycle [234], and finally, in 2012 [235] he presented a methodology based on the cycle-resolved heat release analysis to estimate the end of combustion for each cycle.

Other interesting point of view related to the cyclic variability comes from the raising interest to get an online diagnostic of the combustion for each singular cycle. D'Ambrosio [236] analyzed, for SI engines, the available pressure based techniques to obtain the HRL in order to check the viability to implement them in onboard diagnostics tools. These kind of works try to optimize the estimation of the HRL and search for an accurate calculation in the minimum time and with the minimum calculation sources as possible, in order to allow 
the online diagnostic of the combustion. This aim reveal the need to perform the combustion diagnostics cycle by cycle.

Aside from these works, it becomes a difficult task to find a considerable number of references dealing with the different ways to proceed to the combustion diagnostic in cases with high cyclic variability.

\subsubsection{The combustion analysis on SI and CAI combustion modes}

The basic combustion information available coming from the combustion diagnostic of the experimental data is the Heat Release Law, calculated from the in-cylinder pressure evolution, the operating conditions and the trapped mass inside the cylinder [211]. From this law, different parameters, such as the Heat Release Rate (HRR), and other related parameters, as the combustion phasing, are obtained. This HRL depends on multiple factors affecting the combustion development: the fuel used, the mass trapped inside the cylinder, the temperatures and pressures, the Fuel/Air equivalence ratio, the turbulence effect, the mixture dilution, the combustion chamber design or the mixture homogenization. All these variables affect the performance of the combustion and their characterization can help to obtain a more complete combustion analysis. For example, D'Ambrosio [237] worked on the development of an improved combustion diagnostic tool integrating a multizone heat-release model with a CAD procedure for the burned-gas front geometry simulation with the aim of studying the combustion velocities inside the engine.

Along this chapter different combustion modes have been referred, some of them more common (SI -stoichiometric- and CI), and others more difficult to find in common engines (SI -lean- and LTC combustion modes). The lean SI and the CAI combustion are the focus of this thesis and, therefore, it could be interesting to see how the authors deal with the combustion diagnostic and analysis of these two combustion modes, since they present very different ways to burn the fuel (by flame front developed and by autoignition, respectively).

This kind of works to analyze the SI and CAI combustion have been addressed from different approaches. Some of them are more experimental, based on empirical data, whereas others through the simulation of the different combustion processes.

The part of SI combustion has been investigated from long. This combustion characterization is based on the turbulent flame propagation, which is a function of the estimated laminar combustion speed and the modification of this speed caused by the turbulence inside the combustion 
chamber. Metghalchi and Keck developed an empirical correlation for the estimation of this laminar combustion speed as a function of temperature, pressure and Fuel/Air eq. ratio, for different fuels [238]. Later, Rhodes and Keck developed an improved correlation based on the same equation for gasoline-type fuels [239]. With these type of experimental correlations and the different ways to estimate the turbulence inside the cylinder, the SI combustion has been characterized from more simple and analytical ways, to more complex and detailed multidimensional simulations.

From the advent of HCCI and CAI concepts, the works related to the development of chemical kinetic models have had great development, since the combustion mechanisms are governed by chemical kinetics instead of physical phenomena. These works try to characterize and predict the necessary conditions to reach autoignition based on detailed chemistry mechanisms, starting from zero dimensional single-zone models, as the one developed by Curran et al. [240] to predict the isooctane autoignition, to multi-dimensional CFD models with multi-zone detailed chemistry, as the one developed by Aceves et al. [241-243].

The ways to characterize each combustion mode are very different, since they are governed by different mechanisms. For this reason, it is quite difficult to find some works trying to deal with both modes by an analytical way, studying both combustion modes and their differentiation. These methodologies, however, result very interesting when CAI and SI combustion can coexist in the same engine, since at some given operating points, it could be difficult to know the exact combustion process nature. The particular case of the SACI combustion puts in evidence the need to develop analytic tools to evaluate in detail the combustion process under those conditions. Olesky et al. [244] defined a method to detect the transition between SI to CAI combustion. This is based on the change in the curvature of the heat release law just after the initial gradual heat release period (i.e. flame propagation), assuming that this change is due to the change in combustion performance, as it can be seen in Figure 2.29.

Other authors, as Persson et al. [245], worked also to identify the moment of the combustion mode change from SI to CAI by the pressure signal analysis, and Reuss et al. [246] worked on the definition of the cycle to cycle variation origins of the SACI combustion. In this work they also worked on the combustion modes differentiation, basing their analysis on the pressure signals and the HRR laws.

Finally, it has to be noted that nowadays this type of works related to the combustion analysis are being replaced by the detailed chemistry models and 

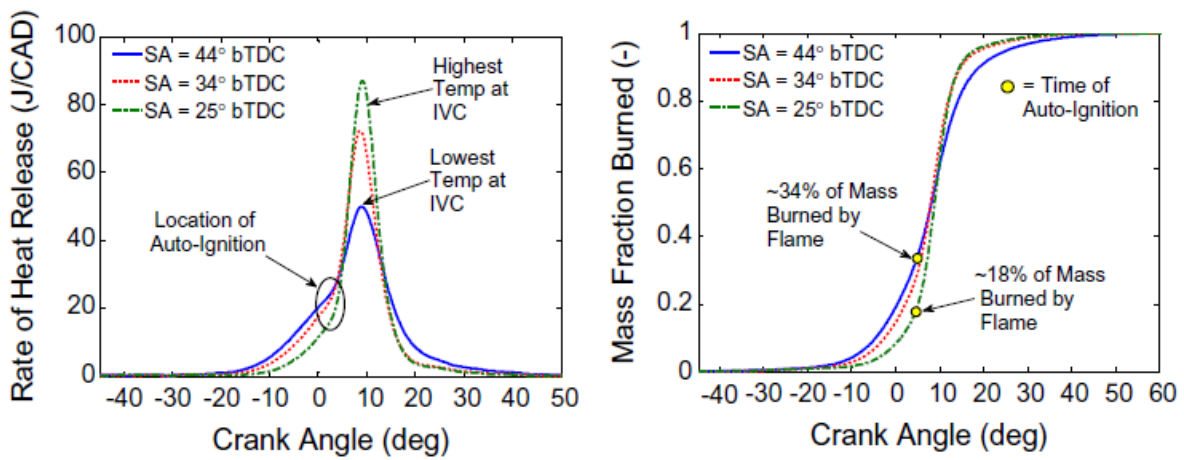

Figure 2.29. Left - rate of heat release. Right - Mass fraction burned curves where the change from SI to CAI combustion is marked by the yellow dots. Source: Olesky et al. [244].

the CFD simulations, thanks to the accuracy in the results obtained. With these tools, the real fuel (i.e. a blend of many different hydrocarbons) is substituted by a surrogate fuel (build from a few hydrocarbons, the chemistry of which is known), which allows the accurate combustion characterization. These methodologies are more predictive than analytical, but they are also used to look in detail the combustion performance and to compare the results with the experimental data as a way to analyze the combustion process. Around the literature it is very easy to find works about these simulations to characterize the CFD results, comparing them with experimental data [247-249]. Nevertheless, the necessary time and computing power make these tools sometimes restrictive and limited for a few number of calculations.

\subsection{Summary}

Throughout this chapter, a review of combustion in SI gasoline engines has been made, analyzing from the basis of the traditional SI combustion concepts to the most recent advances, which try to improve these engines in order to make them more efficient and clean.

As described in the chapter, SI combustion is a turbulent, pre-mixed combustion that requires an external ignition for combustion initiation, and it is governed by the development and propagation of a flame front that burns progressively the fuel/air mixture, separating it in two differentiated zones: burned and unburned regions. This type of combustion has usually been 
operated under stoichiometric conditions until today, and the most common pollutant emissions produced by it are $\mathrm{HC}, \mathrm{CO}, \mathrm{NO}_{\mathrm{x}}$ and $\mathrm{CO}_{2}$, all of them derived from the high temperatures reached and the combustion irregularities during its development. The $\mathrm{CO}_{2}$ emissions, despite not being a pollutant, are a regulated emission and give an indication of the engine efficiency.

Once the bases of combustion in gasoline engines have been set, the next step has been to search for the strategies followed to improve these engines, with the intention of making them more efficient and less pollutant for the environment where they operate.

The first group of reviewed strategies are focused on improving the available systems to operate the engine in a more efficient way. These strategies are better known nowadays, since they can be considered of wide application in the latest engines generation. These strategies are:

- Downsizing: this action consists on the reduction of the displaced volume of the engine and the increase of the BMEP in order to have a smaller engine with the same performance of a larger engine but with a better efficiency.

- Direct injection: the direct injection in gasoline engines has come to replace the port fuel injection. In this way the engines gain in efficiency, since the compression ratio can be increased and they can operate with stratified charges.

- Variable valve actuation: the introduction of these mechanisms allows adjusting the valve actuation for each operating point, thus allowing the engine scavenging optimization, as well as obtaining some improvements in engine efficiency.

- Boosting: this strategy has allowed to increase the volumetric efficiency of the engines. It has been a very important step for the application of the downsizing strategies.

The second group of strategies to improve gasoline engines is focused on the development of combustion, and this is a more active research field nowadays, since it still needs many solutions to apply these concepts in a massive way on the engines intended for the automotive industry.

- EGR: this strategy has been always associated to diesel engines. However, based on certain studies, it can be an effective tool in gasoline engines to reduce nitrogen oxides, to control combustion speeds and to prevent knock appearance. 
- Lean combustion: this strategy is based on operating the engine with lean mixtures, since in this way the engine can reach higher efficiency levels, mainly due to different changes:

- The throttle can be suppressed, decreasing in this way the pumping losses affecting SI engines.

- The compression ratios can be higher, thanks to the higher mixture dilution that decreases the knocking risk.

- The thermal loses are decreased since the combustion is performed at lower temperatures.

- The combustion efficiency can be improved due to a higher amount of available oxygen, because the fuel/air mixture always has some heterogeneities. So, in stoichiometric conditions, the probability of local rich mixtures was high.

However, this combustion mode has the problem that it cannot be used with a three-way catalytic converter. This fact makes it to lose part of its interest by having to employ more complex aftertreatment systems.

- Low Temperature Combustion modes: these combustion modes try to place the engine operation out of the $\mathrm{NO}_{\mathrm{x}}$ and Soot formation regions. The present work is focused on CAI combustion, since this is the LTC mode for SI engines. This combustion mode is presented as a solution to get high efficiencies in the engine and a low level of pollutant emissions, and it is based on the autoignition of a homogeneous fuel/air mixture, avoiding the use of a spark and the progression of a single flame front along the combustion chamber. The combustion is developed spontaneously in several points of the combustion chamber, resulting in a faster combustion, with lower flame temperatures. However, the control of these combustions is not easy, and so the implementation of this technology still requires a lot of development work.

Finally, a brief review of the combustion diagnostics methodology has been performed. The most widely and reliable methodology chosen for experimental works is the application of an energy balance on the combustion chamber based on the first law of thermodynamics. This analysis uses an averaged pressure cycle, considered as representative of the operating conditions of the engine in a given moment, to finally obtain the HRL. However, this diagnostic methodology has shown to give poor information if the engine operation presents cycle to cycle variations. Furthermore, when different combustion 
modes are studied, the HRL continues being a valid diagnostic to analyze the combustion development, but for a finer analysis this parameter can be further break down in order to evaluate the differences of each combustion mode.

As will be seen later, all these strategies have influenced the work of this $\mathrm{PhD}$. thesis, either in the development of the engine concept to be used, or in the research work performed on the analysis of the different operating combustion modes.

\section{Bibliography}

[1] Pairy F. and Desantes J.M. Motores de combustión interna alternativos. Editorial Reverté and Editorial UPV, 2011.

[2] Lancaster David R., Krieger Roger B., Sorenson Spencer C. and Hull William L. "Effects of turbulence on spark-ignition engine combustion". SAE Technical Paper n. $760160,1976$.

[3] W. Pulkrabek Willard. Engineering Fundamentals of the Internal Combustion Engine. Upper Saddle River, New Jersey 07548, 1997.

[4] R. Maly. Spark Ignition: Its Physics and Effect on the Internal Combustion Engine in Fuel Economy in Road Vehicles Powered by Spark-Ignition Engines. Hilliard, J. C. and Springer, G. S. Plenum Press, New York, 1984.

[5] R. Maly. Initiation and Propagation of Flame Fronts in Lean CH4-Air Mixtures by the Three Modes of Ignition Spark in Fuel Economy in Road Vehicles Powered by Spark-Ignition Engines. Hilliard, J. C. and Springer, G. S. Plenum Press, New York, 1984.

[6] Sher E. and Keck J. C. "Spark ignition of combustible gas mixtures". Combustion and Flame, Vol. $66 \mathrm{n}^{\circ}$ 1, pp. 17-25, 1986.

[7] Kalghatgi G. T. "Spark ignition, early flame development and cyclic variation in I.C. engines". SAE Technical Paper n. 870163, 1987.

[8] Ko Y., Arpaci V. S. and Anderson R. W. "Spark ignition of propane-air mixtures near the minimum ignition energy: Part II. A model development". Combustion and Flame, Vol. 83 n $^{o} 1-2$, pp. 88-105, 1991.

[9] Eichenberger D. A. and Roberts W. L. "Effect of unsteady stretch on spark-ignited flame kernel survival". Combustion and Flame, Vol. 118 n 3, pp. 469-478, 1999.

[10] Xiong Y., Roberts W. L., Drake M. C. and Fansler T. D. "Investigation of pre-mixed flame-kernel/vortex interactions via high-speed imaging". Combustion and Flame, Vol. $126 \mathrm{n}^{\circ}$ 4, pp. 1827-1844, 2001.

[11] Patterson D. J. "Cylinder pressure variations, a fundamental combustion problem". SAE Technical Paper n. 290016, 1966.

[12] Peters N. "Laminar flamelet concepts in turbulent combustion". Symposium (International) on Combustion, Vol. $21 \mathrm{n}^{\circ}$ 1, pp. 1231-1250, 1988.

[13] Peters N. and Williams F. A. "Premixed combustion in a vortex". Symposium (International) on Combustion, Vol. $22 \mathrm{n}^{\circ}$ 1, pp. 495-503, 1989. 
[14] Williams F. A. "An approach to turbulent flame theory". Journal of Fluid Mechanics, Vol. $40 \mathrm{n}^{\circ}$ 2, pp. 401-421, 1970.

[15] Beretta G. P., Rashidi M. and Keck J. C. "Turbulent flame propagation and combustion in spark ignition engines". Combustion and Flame, Vol. $52 \mathrm{n}^{\circ}$ C, pp. 217-245, 1983.

[16] Hill P. G. and Zhang D. "The effects of swirl and tumble on combustion in sparkignition engines". Progress in Energy and Combustion Science, Vol. $20 \mathrm{n}^{\circ}$ 5, pp. 373429, 1994.

[17] Desantes J. M., Bermúdez V., López J. J. and López-Pintor D. "Correlations for the ignition characteristics of six different fuels and their application to predict ignition delays under transient thermodynamic conditions". Energy Conversion and Management, Vol. 152, pp. 124-135, 2017.

[18] Nates, R.J. Yates A.D.B. "Knock damage mechanisms in spark-ignition engines". $S A E$ Technical Paper n. 942064, 1994.

[19] Fitton, J. Nates R. "Knock erosion in spark-ignition engines". SAE Technical Paper n. 962102, 1996.

[20] Konig, G. Maly R.R. Bradley D. Lau A.K.C. Sheppard C.G.W. "Role of exothermic centres on knock initiation and knock damage". SAE Technical Paper n. 902136, 1990.

[21] Konig, G. Sheppard C.G.W. "End gas auto-ignition and knock in a spark ignition engine". SAE Technical Paper n. 902135, 1990.

[22] Hirst, S.L. Kirsch L.J. "The application of a hydrocarbon auto-ignition model in simulating knock and other engine combustion phenomena, in: Combustion modeling in reciprocating engines". New York: Plenum, 1980.

[23] Westbrook, C.K. Pitz W.J. Leppard W.R. "The autoi-gnition chemistry of paraffinic fuels and pro-knock and anti-knock additives: a detailed chemical kinetic study". SAE Technical Paper n. 912314, 1991.

[24] Warnatz J., Maas U. and Dibble R.W. Combustion: Physical and chemical fundamentals, modeling and simulation, experiments, pollutant formation. 2006.

[25] Radu, B. Martin G. Chiriac R. Apostolescu N. "On the knock characteristics of LPG in a spark ignition engine". SAE Technical Paper n. 2005-01-3773, 2005.

[26] Douaud A. M. and Eyzat P. "Four-octane-number method for predicting the anti-knock behavior of fuels and engines". SAE Technical Paper n. 780080, 1978.

[27] Goto S. and Fukuda T. "Study on NOx, formation and reduction of lean-burn spark ignition gas engine". JSAE Review, Vol. 19 n $^{\circ}$ 4, pp. 351-354, 1998.

[28] Hermann F., Zeuch T. and Klingmann J. "The effect of diluents on the formation rate of nitrogen oxide in a premixed laminar flame". In Proceedings of the ASME Turbo Expo 2004, volume 1, pp. 559-566, 2004.

[29] D. Szczepanski. "Factors influencing NOx emissions at Tarong and Stanwell power stations". PhD-Thesis. The University of Queensland, 1998.

[30] Ouellette P., Douville B., Hill P. G. and Ursu B. "NOx reduction in a directly injected natural gas engine". American Society of Mechanical Engineers, Internal Combustion Engine Division (Publication) ICE, Vol. 31-33 n 3 , pp. 59-71, 1998.

[31] Michaels H. C. and Fulper B. K. "Nitrous oxide emission factors for mobile sources USEPA". In AWMA emissions inventory conference, New Orleans, USA, 1998., 1998. 
[32] Soltic P. and Hausberger S. "On-Road Emission Measurements and emission modeling results for a tractor-semi trailer in Trans-Alpine operation". 13th International Scienfftic Symposium Transport and Air Pollution Boulder, September 13-15, 2004.

[33] Odell P. R. "Why carbon fuels will dominate the 21st century's global energy economy". Geopolitics of Energy, Vol. $26 \mathrm{n}^{\circ}$ 3-4, pp. 2-8, 2004.

[34] Ladommatos N., Abdelhalim S. and Zhao H. "Control of oxides of nitrogen from diesel engines using diluents while minimising the impact on particulate pollutants". Applied Thermal Engineering, Vol. $18 \mathrm{n}^{\circ}$ 11, pp. 963-980, 1998.

[35] Aakko P. and Nylund N. . "Particle emissions at moderate and cold temperatures using different fuels". SAE Technical Paper n. 2003-01-3285, 2003.

[36] Mohr M., Forss A. . and Lehmann U. "Particle emissions from diesel passenger cars equipped with a particle trap in comparison to other technologies". Environmental Science and Technology, Vol. $40 \mathrm{n}^{\circ}$ 7, pp. 2375-2383, 2006.

[37] Braisher M., Stone R. and Price P. "Particle number emissions from a range of European vehicles". SAE Technical Paper n. 2010-01-0786, 2010.

[38] Mathis U., Mohr M. and Forss A. . "Comprehensive particle characterization of modern gasoline and diesel passenger cars at low ambient temperatures". Atmospheric Environment, Vol. $39 \mathrm{n}^{\circ}$ 1, pp. 107-117, 2005.

[39] Heywood JB. Internal combustion engine fundamentals. McGraw-Hill, 1988.

[40] Stevens E. and Steeper R. "Piston wetting in an optical DISI engine: Fuel films, pool fires, and soot generation". SAE Technical Paper n. 2001-01-1203, 2001.

[41] Turner J.W.G., Popplewell A., Patel R., Johnson T.R., Darnton N.J., Richardson S., Bredda S.W., Tudor R.J., Bithell C.I., Jackson R., Remmert S.M., Cracknell R.F., Fernandes J.X., Lewis A.G.J., Akehurst S., Brace C.J., Copeland C., Martinez-Botas R., Romagnoli A. and Burluka A.A. "Ultra Boost for Economy: Extending the Limits of Extreme Engine Downsizing". SAE Technical Paper n. 2014-01-1185, 2014.

[42] Coltman D., Turner J. W. G., Curtis R., Blake D., Holland B., Pearson R. J., Arden A. and Nuglisch H. "Project Sabre: A close-spaced direct injection 3-cylinder engine with synergistic technologies to achieve low CO2 output". SAE Technical Paper n. 2008-01-0138, 2009.

[43] Glahn C., Kluin M., Konigstein A. and Cloos L.K. "Cooled External EGR - System Optimization of the Cooling and Charging System on a 3-Cylinder Gasoline DI T/C Engine". 24th Aachen Colloquium Automobile and Engine Technology, pp. 189-204, 2015.

[44] Herbst F., Stöber-Schmidt C. ., Eilts P., Sextro T., Kammeyer J., Natkaniec C., Seume J., Porzig D. and Schwarze H. "The potential of variable compressor geometry for highly boosted gasoline engines". SAE Technical Paper n. 2011-01-0376, 2011.

[45] Andersen J., Karlsson E. and Gawell A. "Variable turbine geometry on SI engines". SAE Technical Paper n. 2006-01-0020, 2006.

[46] George S., Morris G., Dixon J., Pearce D. and Heslop G. "Optimal boost control for an electrical supercharging application". SAE Technical Paper n. 2004-01-0523, 2004.

[47] Akihisa D. and Daisaku S. "Research on Improving Thermal Effiiency through Variable Super-High Expansion Ratio Cycle". SAE Technical Paper n. 2003-32-0039, 2010.

[48] Watanabe I., Kawai T., Yonezawa K. and Ogawa.T. "The New Toyota 2.0-Liter Inline 4-Cylinder ESTEC D-4ST Engine - Turbocharged Direct Injection Gasoline Engine". 23rd Aachen Colloquium Automobile and Engine Technology, 2014. 
[49] Knop V. and Essayem E. "Comparison of PFI and DI operation in a downsized gasoline engine". SAE Technical Paper n. 2013-01-1103, 2013.

[50] Mori S. and Shimizu R. "Analysis of EGR cyclic variations in a direct injection gasoline engine by using raman scattering method". SAE Technical Paper n. 2002-01-1646, 2002.

[51] Whitaker P., Kapus P., Ogris M. and Hollerer P. "Measures to Reduce Particulate Emissions from Gasoline DI engines". SAE Technical Paper n. 2011-01-1219, 2011.

[52] Price P., Stone R., Oudenijeweme D. and Chen X. "Cold start particulate emissions from a second generation di gasoline engine". SAE Technical Paper n. 2007-01-1931, 2007.

[53] Karjalainen P., Pirjola L., Heikkila J., Lahde T., Tzamkiozis T., Ntziachristos L., Keskinen J. and Ronkko T. "Exhaust particles of modern gasoline vehicles: A laboratory and an on-road study". Atmospheric Environment, Vol. 97, pp. 262-270, 2014.

[54] Allen J. and Law D. "Production electro-hydraulic variable valve-train for a new generation of I.C. Engines". SAE Technical Paper n. 2002-01-1109, 2002.

[55] Gould L.A., Richeson W.E. and Erickson F.L. "Performance evaluation of a camless engine using valve actuators with programmable timing". SAE Technical Paper $n$. $910450,1991$.

[56] Franca O. "Impact of the Miller Cycle in the Efficiency of an FVVT (Fully Variable Valve Train) Engine During Part Load Operation". SAE Technical Paper n. 2009-36$0081,2009$.

[57] Miklanek L., Vitek O., Gotfryd O. and Klir V. "Study of unconventional cycles (Atkinson and Miller) with mixture heating as a means for the fuel economy improvement of a throttled SI engine at part load". SAE Technical Paper n. 201201-1678, 2012.

[58] Hacohen J., Ashcroft S. J. and Belmont M. R. "Lean burn versus EGR S.I. engine". SAE Technical Paper n. 951902, 1995.

[59] Grandin B., Angström H., Stalhammar P. and Olofsson E. "Knock suppression in a turbocharged SI engine by using cooled EGR". SAE Technical Paper n. 982476, 1998.

[60] Grandin B. and Angström H. "Replacing Fuel Enrichment in a Turbo Charged SI Engine: Lean Burn or Cooled EGR". SAE Technical Paper n. 1999-01-3505, 1999.

[61] Saito H., Shirasuna T. and Nomura T. "Extension of Lean Burn Range by Intake Valve Offset". SAE Technical Paper n. 2013-32-9032, 2013.

[62] Lumsden G., Eddleston D. and Sykes R. "Comparing lean burn and EGR". SAE Technical Paper n. 970505, 1997.

[63] Yu C., Kim T., Yi Y., Lee J., Noh S. and Choi K. "Development of kmc 2.4l Lean burn engine". SAE Technical Paper n. 950685, 1995.

[64] Zhao F.-Q., Lai M.-C. and Harrington D.L. "A review of mixture preparation and combustion control strategies for spark-ignited direct-injection gasoline engines". SAE Technical Paper n. 970627, 1997.

[65] Park C., Kim S., Kim H. and Moriyoshi Y. "Stratified lean combustion characteristics of a spray-guided combustion system in a gasoline direct injection engine". Energy, Vol. $41 \mathrm{n}^{\circ}$ 1, pp. 401-407, 2012. 
[66] Oh H. and Bae C. "Effects of the injection timing on spray and combustion characteristics in a spray-guided DISI engine under lean-stratified operation". Fuel, Vol. 107, pp. 225-235, 2013.

[67] Wärtsilä Finland Corporation. "Wartsila 50DF Engine Technology". Brochure Wärtsilä Co., 2015.

[68] Auer P. "Advances in Energy Systems and Technology, Vol.3". Academic Press, Vol. 3, 1982.

[69] John J. E. A. "Lean burn engine concepts-emissions and economy". SAE Technical Paper n. 750930, 1975.

[70] Gomez A. J. and Reinke P. E. "Lean burn: A review of incentives, methods, and tradeoffs". SAE Technical Paper n. 880291, 1988.

[71] Hiroyuki Oda, Yasuyuki Morita, Toshimitsu Fujishima and Masashi Marubara. "Investigation of High-Compression Lean Burn Engine". SAE Technical Paper $n$. $871215,1987$.

[72] Zheng J. and Caton J.A. "Second law analysis of a low temperature combustion diesel engine: Effect of injection timing and exhaust gas recirculation". Energy, Vol. $38 \mathrm{n}^{\circ} 1$, pp. $78-84,2012$.

[73] Siebers D.L. "Scaling liquid-phase fuel penetration in diesel sprays based on mixinglimited vaporization". SAE Technical Paper n. 1999-01-0528, 1999.

[74] Akihama K., Takatori Y., Inagaki K., Sasaki S. and Dean A.M. "Mechanism of the smokeless rich diesel combustion by reducing temperature". SAE Technical Paper n. 2001-01-0655, 2001.

[75] Ramesh N. and Mallikarjuna J.M. "Evaluation of in-cylinder mixture homogeneity in a diesel HCCI engine - a CFD analysis". Engineering Science and Technology, an International Journal, Vol. $19 \mathrm{n}^{\circ}$ 2, pp. 917-925, 2016.

[76] Epping K., Aceves S., Bechtold R. and Dec J. "The potential of HCCI combustion for high efficiency and low emissions". SAE Technical Paper n. 2002-01-1923, 2002.

[77] Hadia F., Wadhah S., Ammar H. and Ahmed O. "Investigation of combined effects of compression ratio and steam injection on performance, combustion and emissions characteristics of HCCI engine". Case Studies in Thermal Engineering, Vol. 10, pp. 262-271, 2017.

[78] Iwabuchi Y., Kawai K., Shoji T. and Takeda Y. "Trial of new concept diesel combustion system - Premixed compression - ignited combustion -". SAE Technical Paper n. 199901-0185, 1999.

[79] Hou J., Qiao X., Wang Z., Liu W. and Huang Z. "Characterization of knocking combustion in HCCI DME engine using wavelet packet transform". Applied Energy, Vol. $87 \mathrm{n}^{\circ}$ 4, pp. 1239-1246, 2010.

[80] BP. Pundir. "Engine emissions: pollutant formation and advances in control technology". Narosa Publishing House, New Delhi, 2007.

[81] Sluder C.S. and Wagner R.M. "An estimate of diesel high-efficiency clean combustion impacts on FTP-75 aftertreatment requirements". SAE Technical Paper n. 2006-013311, 2006.

[82] Zhao H. HCCI and CAI Engines for the Automotive Industry. Woodhead Publishing Limited, 2007. 
[83] Onishi S., Jo S.H., Shoda K., Jo P.D. and Kato S. "Active Thermo-Atmosphere Combustion (ATAC) - A new combustion process for internal combustion engines". SAE Technical Paper n. 790501, 1979.

[84] Noguchi M., Tanaka Y., Tanaka T. and Takeuchi Y. "A study on gasoline engine combustion by observation of intermediate reactive products during combustion". SAE Technical Paper n. 790840, 1979.

[85] Yamaguchi J. "Honda readies activated radical combustion two-stroke engine for production motorcycle". Automotive Engineer, pp. 90-92, SAE publications, January 1997, 1997.

[86] Najt P.M. and Foster D.E. "Compression-ignited homogeneous charge combustion". SAE Technical Paper n. 830264, 1983.

[87] Thring R.H. "Homogeneous-Charge Compression-Ignition (HCCI) engines". SAE Technical Paper n. 892068, 1989.

[88] Lavy J., Dabadie J.-C., Angelberger C., Duret P., Willand J., Juretzka A., Schäflein J., Ma T., Lendresse Y., Satre A., Schulz C., Krämer H., Zhao H. and Damiano L. "Innovative ultra-low NOx controlled auto-ignition combustion process for gasoline engines: The 4-SPACE project". SAE Technical Paper n. 2000-01-1837, 2000.

[89] Zhao H., Li J., Ma T. and Ladommatos N. "Performance and analysis of a 4-stroke multi-cylinder gasoline engine with CAI combustion". SAE Technical Paper n. 200201-0420, 2002.

[90] Chen T., Xie H., Li L., Zhang L., Wang X. and Zhao H. "Methods to achieve $\mathrm{HCCI} / \mathrm{CAI}$ combustion at idle operation in a 4VVAS gasoline engine". Applied Energy, Vol. 116, pp. 41-51, 2014.

[91] Law D., Kemp D., Allen J., Kirkpatrick G. and Copland T. "Controlled combustion in an IC-engine with a fully variable valve train". SAE Technical Paper n. 2001-01-0251, 2001.

[92] Yanagihara H., Satou Y. and Mizuta J. "A simultaneous reduction of NOx and soot in diesel engines under a new combustion system (Uniform Bulky Combustion System - UNIBUS)". 17th Int. Vienna Motor Symposium, 1996.

[93] Nishijima Y., Asaumi Y. and Aoyagi Y. "Premixed lean Diesel Combustion (PREDIC) using impingement spray system". SAE Technical Paper n. 2001-01-1892, 2001.

[94] Kimura S., Aoki O., Ogawa H., Muranaka S. and Enomoto Y. "New combustion concept for ultra-clean and high-efficiency small di diesel engines". SAE Technical Paper n. 1999-01-3681, 1999.

[95] Aoyama T., Hattori Y., Mizuta J. and Sato Y. "An experimental study on premixedcharge compression ignition gasoline engine". SAE Technical Paper n. 960081, 1996.

[96] Yang J., Culp T. and Kenny T. "Development of a Gasoline Engine System using HCCI Technology - the Concept and the Test Results". SAE Technical Paper n. 200201-2832, 2002.

[97] Stanglmaier R.H. and Roberts C.E. "Homogeneous charge compression ignition (HCCI): Benefits, compromises, and future engine applications". SAE Technical Paper n. 1999-01-3682, 1999.

[98] Chen Z. and Mitsuru K. "How to put the HCCI engine to practical use: Control the ignition timing by compression ratio and increase the power output by supercharge". SAE Technical Paper n. 2003-01-1832, 2003. 
[99] Peng Z., Zhao H. and Ladommatos N. "Effects of air/fuel ratios and EGR rates on HCCI combustion of N-heptane, a diesel type fuel". SAE Technical Paper n. 2003-01$0747,2003$.

[100] Ryan III T.W. and Callahan T.J. "Homogeneous charge compression ignition of diesel fuel". SAE Technical Paper n. 961160, 1996.

[101] Christensen M. and Johansson B. "Supercharged homogeneous charge compression ignition (HCCI) with exhaust gas recirculation and pilot fuel". SAE Technical Paper n. 2000-01-1835, 2000.

[102] Bhave A., Kraft M., Mauss F., Oakley A. and Zhao H. "Evaluating the EGR-AFR operating range of a HCCI engine". SAE Technical Paper n. 2005-01-0161, 2005.

[103] Christensen M. and Johansson B. "Influence of mixture quality on homogeneous charge compression ignition". SAE Technical Paper n. 982454, 1998.

[104] Ryu J., Kim H. and Lee K. "A study on the spray structure and evaporation characteristic of common rail type high pressure injector in homogeneous charge compression ignition engine". Fuel, Vol. 84 n $^{\circ}$ 18, pp. 2341-2350, 2005.

[105] Richter M., Engström J., Franke A., Aldén M., Hultqvist A. and Johansson B. "The influence of charge inhomogeneity on the HCCI combustion process". SAE Technical Paper n. 2000-01-2868, 2000.

[106] Hu T., Liu S., Zhou L. and Zhu C. "Combustion and emission characteristics of a homogeneous charge compression ignition engine". Proceedings of the Institution of Mechanical Engineers, Part D: Journal of Automobile Engineering, Vol. $219 \mathrm{n}^{\circ}$ 9, pp. 1133-1139, 2005.

[107] Yu H., Guo Y., Li D., Liang X., Shu G.-Q., Wang Y., Wang X. and Dong L. "Numerical Investigation of the Effect of Spray Cone Angle on Mixture Formation and $\mathrm{CO} / \mathrm{Soot}$ Emissions in an Early Injection HCCI Diesel Engine". SAE Technical Paper n. 201501-1070, 2015.

[108] Yu H., Liang X., Wang Y. and Zhang H. "Effect of the nozzle diameter variation on the mixture formation and combustion characteristics in an HCCI-DI engine using an early injection strategy: CFD modeling". ASPACC 2015 - 10th Asia-Pacific Conference on Combustion, 2015.

[109] Gowthaman S. and Sathiyagnanam A.P. "Experimental investigation on performance and emission characteristics of homogeneous charge compression ignition (HCCI) engine fuelled by biodiesel". International Journal of Applied Engineering Research, Vol. $10 \mathrm{n}^{\circ}$ 11, pp. 10134-10139, 2015.

[110] Jiao Q. and Reitz R.D. "Modeling soot emissions from wall films in a direct-injection spark-ignition engine". International Journal of Engine Research, Vol. 16 n $^{\circ}$ 8, pp. 9941013, 2015.

[111] Zhang Y., Jia M., Liu H., Xie M., Wang T. and Zhou L. "Development of a new spray/wall interaction model for diesel spray under PCCI-engine relevant conditions". Atomization and Sprays, Vol. $24 \mathrm{n}^{\circ}$ 1, pp. 41-80, 2014.

[112] Anbari Attar M., Herfatmanesh M.R., Zhao H. and Cairns A. "Experimental investigation of direct injection charge cooling in optical GDI engine using tracerbased PLIF technique". Experimental Thermal and Fluid Science, Vol. 59, pp. 96-108, 2014 . 
[113] Kaneko N., Ando H., Ogawa H. and Miyamoto N. "Expansion of the operating range with in-cylinder water injection in a premixed charge compression ignition engine". SAE Technical Paper n. 2002-01-1743, 2002.

[114] Simescu S., Ryan III T.W., Neely G.D., Matheaus A.C. and Surampudi B. "Partial pre-mixed combustion with cooled and uncooled EGR in a heavy-duty diesel engine". SAE Technical Paper n. 2002-01-0963, 2002.

[115] Okude K., Mori K., Shiino S. and Moriya T. "Premixed compression ignition (PCI) combustion for simultaneous reduction of nox and soot in diesel engine". SAE Technical Paper n. 2004-01-1907, 2004.

[116] López J.J., García-Oliver J.M., García A. and Domenech V. "Gasoline effects on spray characteristics, mixing and auto-ignition processes in a CI engine under Partially Premixed Combustion conditions". Applied Thermal Engineering, Vol. $70 \mathrm{n}^{\circ} 1$, pp. 996-1006, 2014.

[117] Ra Y. and Reitz R.D. "A combustion model for IC engine combustion simulations with multi-component fuels". Combustion and Flame, Vol. 158 n $^{\circ}$ 1, pp. 69-90, 2011.

[118] Inagaki K., Fuyuto T., Nishikawa K., Nakakita K. and Sakata I. "Dual-fuel PCI combustion controlled by in-cylinder stratification of ignitability". SAE Technical Paper n. 2006-01-0028, 2006.

[119] Kokjohn S.L., Hanson R.M., Splitter D.A. and Reitz R.D. "Experiments and modeling of dual-fuel HCCI and PCCI combustion using in-cylinder fuel blending". SAE Technical Paper n. 2009-01-2647, 2010.

[120] Splitter D., Kokjohn S., Rein K., Hanson R., Sanders S. and Reitz R. "An optical investigation of ignition processes in fuel reactivity controlled PCCI combustion". SAE Technical Paper n. 2010-01-0345, 2010.

[121] Hanson R.M., Kokjohn S.L., Splitter D.A. and Reitz R.D. "An experimental investigation of fuel reactivity controlled pcci combustion in a heavy-duty engine". SAE Technical Paper n. 2010-01-0864, 2010.

[122] Qin J., He B., Xie H. and Zhao H. "Auto-ignition and heat release correlations for controlled auto-ignition combustion in gasoline engines". Transactions of Tianjin University, Vol. $13 \mathrm{n}^{\circ}$ 5, pp. 328-333, 2007.

[123] Albayrak çeper B., Yildiz M., Akansu S.O. and Kahraman N. "Performance and emission characteristics of an IC engine under SI, SI-CAI and CAI combustion modes". Energy, Vol. 136, pp. 72-79, 2017.

[124] Knop V. "Analysis of mixture structure and of its influence on combustion in a CAI engine". International Journal of Engine Research, Vol. 19 n 4, pp. 393-410, 2018.

[125] Zhao H., Peng Z. and Ladommatos N. "Understanding of controlled autoignition combustion in a four-stroke gasoline engine". Proceedings of the Institution of Mechanical Engineers, Part D: Journal of Automobile Engineering, Vol. $215 \mathrm{n}^{\circ} 12$, pp. 1297-1310, 2001.

[126] Kelly-Zion P.L. and Dec J.E. "A computational study of the effect of fuel type on ignition time in homogeneous charge compression ignition engines". Proceedings of the Combustion Institute, Vol. $28 \mathrm{n}^{\circ}$ 1, pp. 1187-1194, 2000.

[127] Tanaka S., Ayala F., Keck J.C. and Heywood J.B. "Two-stage ignition in HCCI combustion and HCCI control by fuels and additives". Combustion and Flame, Vol. 132 $\mathrm{n}^{\circ} 1-2$, pp. 219-239, 2003. 
[128] Desantes J.M., López J.J., García-Oliver J.M. and López-Pintor D. "Experimental validation and analysis of seven different chemical kinetic mechanisms for n-dodecane using a Rapid Compression-Expansion Machine". Combustion and Flame, Vol. 182, pp. 76-89, 2017.

[129] Desantes J.M., García-Oliver J.M., Vera-Tudela W., López-Pintor D., Schneider B. and Boulouchos K. "Study of the auto-ignition phenomenon of PRFs under HCCI conditions in a RCEM by means of spectroscopy". Applied Energy, Vol. 179, pp. 389$400,2016$.

[130] Desantes J.M., Bermúdez V., López J.J. and López-Pintor D. "A new method to predict high and low-temperature ignition delays under transient thermodynamic conditions and its experimental validation using a Rapid Compression-Expansion Machine". Energy Conversion and Management, Vol. 123, pp. 512-522, 2016.

[131] Desantes J.M., López J.J., Molina S. and López-Pintor D. "Validity of the Livengood and Wu correlation and theoretical development of an alternative procedure to predict ignition delays under variable thermodynamic conditions". Energy Conversion and Management, Vol. 105, pp. 836-847, 2015.

[132] Desantes J.M., López J.J., Molina S. and López-Pintor D. "Theoretical development of a new procedure to predict ignition delays under transient thermodynamic conditions and validation using a Rapid Compression-Expansion Machine". Energy Conversion and Management, Vol. 108, pp. 132-143, 2016.

[133] Peng Z., Zhao H. and Ladommatos N. "Visualization of the homogeneous charge compression ignition/controlled autoignition combustion process using twodimensional planar laser-induced fluorescence imaging of formaldehyde". Proceedings of the Institution of Mechanical Engineers, Part D: Journal of Automobile Engineering, Vol. $217 \mathrm{n}^{o}$ 12, pp. 1125-1134, 2003.

[134] Christensen M., Johansson B. and Einewall P. "Homogeneous Charge Compression Ignition (HCCI) using isooctane, ethanol and natural gas - A comparison with spark ignition operation". SAE Technical Paper n. 972874, 1997.

[135] Oakley A., Zhao H., Ladommatos N. and Ma T. "Experimental studies on controlled auto-ignition (CAI) combustion of gasoline in a 4-stroke engine". SAE Technical Paper n. 2001-01-1030, 2001.

[136] Duret P. and Venturi S. "Automotive calibration of the IAPAC fluid dynamically controlled two-stroke combustion process". SAE Technical Paper n. 960363, 1996.

[137] Xie H., Li L., Chen T. and Zhao H. "Investigation on gasoline homogeneous charge compression ignition (HCCI) combustion implemented by residual gas trapping combined with intake preheating through waste heat recovery". Energy Conversion and Management, Vol. 86, pp. 8-19, 2014.

[138] Christensen M., Hultqvist A. and Johansson B. "Demonstrating the multi fuel capability of a homogeneous charge compression ignition engine with variable compression ratio". SAE Technical Paper n. 1999-01-3679, 1999.

[139] Yang C., Zhao H. and Megaritis T. "Investigation of CAI combustion with positive valve overlap and enlargement of CAI operating range". SAE Technical Paper n. 200901-1104, 2009.

[140] Haraldsson G., Tunestal P., Johansson B. and Hyvönen J. "HCCI combustion phasing in a multi cylinder engine using variable compression ratio". SAE Technical Paper n. 2002-01-2858, 2002. 
[141] Olsson J.-O., Tunestal P. and Johansson B. "Closed-loop control of an HCCI engine". SAE Technical Paper n. 2001-01-1031, 2001.

[142] Kaimai T., Tsunemoto H. and Ishitani H. "Effects of a hybrid fuel system with diesel and premixed DME/methane charge on exhaust emissions in a small di diesel engine". SAE Technical Paper n. 1999-01-1509, 1999.

[143] Lü X., Han D. and Huang Z. "Fuel design and management for the control of advanced compression-ignition combustion modes". Progress in Energy and Combustion Science, Vol. $37 \mathrm{n}^{\circ}$ 6, pp. 741-783, 2011.

[144] Lü X.-C., Chen W. and Huang Z. "A fundamental study on the control of the HCCI combustion and emissions by fuel design concept combined with controllable EGR. Part 2. Effect of operating conditions and EGR on HCCI combustion". Fuel, Vol. 84 $\mathrm{n}^{\circ}$ 9, pp. 1084-1092, 2005.

[145] Lacey J.S., Filipi Z.S., Sathasivam S.R., Cannella W.J. and Fuentes-Afflick P.A. "HCCI operability limits: The impact of refinery stream gasoline property variation". Journal of Engineering for Gas Turbines and Power, Vol. $135 \mathrm{n}^{\circ}$ 8, 2013.

[146] Koopmans L. and Denbratt I. "A four stroke camless engine, operated in homogeneous charge compression ignition mode with commercial gasoline". SAE Technical Paper $n$. 2001-01-3610, 2001.

[147] Kaahaaina N.B., Simon A.J., Caton P.A. and Edwards C.F. "Use of dynamic valving to achieve residual-affected combustion". SAE Technical Paper n. 2001-01-0549, 2001.

[148] Fuerhapter A., Piock W.F. and Fraidl G.K. "CSI - Controlled auto ignition - The best solution for the fuel consumption - Versus emission trade-off?". SAE Technical Paper n. 2003-01-0754, 2003.

[149] Valero-Marco J., Lehrheuer B., López J.J. and Pischinger S. "Potential of water direct injection in a CAI/HCCI gasoline engine to extend the operating range towards higher loads". Fuel, Vol. 231, pp. 317-327, 2018.

[150] Yang C. and Zhao H. "In-cylinder studies of CAI/HCCI combustion with negative valve overlap in a direct injection gasoline optical engine". Combustion Science and Technology, Vol. $183 \mathrm{n}^{\circ}$ 5, pp. 467-486, 2011.

[151] Hunicz J. "An experimental study of combustion phasing control in CAI gasoline engine with in-cylinder fuel reforming". SAE Technical Paper n. 2011-24-0052, 2011.

[152] Li J., Zhao H., Ladommatos N. and Ma T. "Research and development of Controlled Auto-Ignition (CAI) combustion in a 4-stroke multi-cylinder gasoline engine". SAE Technical Paper n. 2001-01-3608, 2001.

[153] Zhang Y., Zhao H., Ojapah M. and Cairns A. "Effects of injection timing on CAI operation in a 2/4-stroke switchable GDI engine". SAE Technical Paper n. 2011-01$17793,2012$.

[154] Çinar C., Uyumaz A., Polat S., Yilmaz E., Can Ö. and Solmaz H. "Combustion and performance characteristics of an HCCI engine utilizing trapped residual gas via reduced valve lift". Applied Thermal Engineering, Vol. 100, pp. 586-594, 2016.

[155] Caton P.A., Song H.H., Kaahaaina N.B. and Edwards C.F. "Residual-effected homogeneous charge compression ignition with delayed intake-valve closing at elevated compression ratio". International Journal of Engine Research, Vol. 6 n$^{\circ}$ 4, pp. 399-419, 2005 . 
[156] Li N., Xie H., Chen T., Li L. and Zhao H. "The effects of intake backflow on incylinder situation and auto ignition in a gasoline controlled auto ignition engine". Applied Energy, Vol. 101, pp. 756-764, 2013.

[157] Li H., Cheng P., Tan M.-Z., Gu Y.-H., Wang H., Peng Y.-P. and Guo Y.-N. "CAI combustion comparison between NVO strategy and EGRB strategy". Jilin Daxue Xuebao (Gongxueban)/Journal of Jilin University (Engineering and Technology Edition), Vol. $41 \mathrm{n}^{\circ}$ SUPPL. 1, pp. 47-52, 2011.

[158] Milpied J. and Jeuland N. "Which fuel properties for improved CAI combustion? Study of fuel impacts on the operating range of a CAI PFI engine". SAE Technical Paper n. 2009-01-1100, 2009.

[159] Choi S., Lim J., Ki M., Min K. and Choi H. "Analysis of cyclic variation and the effect of fuel stratification on combustion stabilityin a Port Fuel injection (PFI) CAI engine". SAE Technical Paper n. 2009-01-0670, 2009.

[160] Cao L., Zhao H., Jiang X. and Kalian N. "Numerical investigation into effect of fuel injection timing on CAI/HCCI combustion in a four-stroke GDI engine". International Journal of Computational Methods in Engineering Science and Mechanics, Vol. $7 \mathrm{n}^{\circ} 1$, pp. 41-57, 2006.

[161] Cao L., Zhao H., Jiang X. and Kalian N. "Mixture formation and controlled autoignition combustion in four-stroke gasoline engines with port and direct fuel injections". International Journal of Engine Research, Vol. $6 \mathrm{n}^{\circ}$ 4, pp. 311-330, 2005.

[162] Wang X., Zhao H., Xie H. and He B.-Q. "Numerical Study of the Effect of Piston Shapes and Fuel Injection Strategies on In-Cylinder Conditions in a PFI/GDI Gasoline Engine". SAE Technical Paper n. 2014-01-2670, 2014.

[163] Kaiser E.W., Yang J., Culp T., xu N. and Maricq M.M. "Homogeneous charge compression ignition engine-out emission-does flame propagation occur in homogeneous charge compression ignition?". International Journal of Engine Research, Vol. $3 \mathrm{n}^{o}$ 4, pp. 185-195, 2002.

[164] Zhang Y. and Zhao H. "Investigation of combustion, performance and emission characteristics of 2-stroke and 4-stroke spark ignition and CAI/HCCI operations in a DI gasoline". Applied Energy, Vol. 130, pp. 244-255, 2014.

[165] Wang Z., He X., Wang J.-X., Shuai S., Xu F. and Yang D. "Combustion visualization and experimental study on spark induced compression ignition (SICI) in gasoline HCCI engines". Energy Conversion and Management, Vol. $51 \mathrm{n}^{\circ}$ 5, pp. 908-917, 2010.

[166] Çinar C., Uyumaz A., Solmaz H., Sahin F., Polat S. and Yilmaz E. "Effects of intake air temperature on combustion, performance and emission characteristics of a HCCI engine fueled with the blends of $20 \%$ n-heptane and $80 \%$ isooctane fuels". Fuel Processing Technology, Vol. $130 \mathrm{n}^{\circ}$ C, pp. 275-281, 2015.

[167] Li W., Liu Z., Wang Z. and Xu Y. "Experimental investigation of the thermal and diluent effects of EGR components on combustion and NOx emissions of a turbocharged natural gas SI engine". Energy Conversion and Management, Vol. 88, pp. 1041-1050, 2014.

[168] Qin J., Xie H., Zhang Y. and Zhao H. "Study on CAI combustion heat release model in 4-stroke gasoline engine". Neiranji Xuebao/Transactions of CSICE (Chinese Society for Internal Combustion Engines), Vol. $24 \mathrm{n}^{\circ}$ 3, pp. 242-249, 2006.

[169] Martins M. and Zhao H. "Experimental studies of a 4-stroke multi-cylinder gasoline engine with controlled auto-ignition (CAI) combustion". SAE Technical Paper n. 200\%01-2609, 2007. 
[170] Leach B., Zhao H., Li Y. and Ma T. "Control of CAI combustion through injection timing in a gdi engine with an air-assisted injector". SAE Technical Paper n. 2005-01$0134,2005$.

[171] Li Y., Zhao H., Brouzos N., Ma T. and Leach B. "Effect of injection timing on mixture and CAI combustion in a GDI engine with an air-assisted injector". SAE Technical Paper n. 2006-01-0206, 2006.

[172] Standing R., Kalian N., Ma T., Zhao H., Wirth M. and Schamel A. "Effects of injection timing and valve timings on CAI operation in a multi-cylinder di gasoline engine". $S A E$ Technical Paper n. 2005-01-0132, 2005.

[173] Manofsky L., Vavra J., Assanis D. and Babajimopoulos A. "Bridging the gap between HCCI and SI: Spark-assisted compression ignition". SAE 2011 World Congress and Exhibition, 2011.

[174] Wang Z., Wang J.-X., Shuai S.-J., Tian G.-H., An X. and Ma Q.-J. "Study of the effect of spark ignition on gasoline HCCI combustion". Proceedings of the Institution of Mechanical Engineers, Part D: Journal of Automobile Engineering, Vol. $220 \mathrm{n}^{\circ} 6$, pp. 817-825, 2006.

[175] Zhang Y., Xie H. and Zhao H. "Investigation of SI-HCCI Hybrid combustion and control strategies for combustion mode switching in a four-stroke gasoline engine". Combustion Science and Technology, Vol. $181 \mathrm{n}^{\circ}$ 5, pp. 782-799, 2009.

[176] Lavoie G.A., Martz J., Wooldridge M. and Assanis D. "A multi-mode combustion diagram for spark assisted compression ignition". Combustion and Flame, Vol. 157 $\mathrm{n}^{\circ}$ 6, pp. 1106-1110, 2010.

[177] Xie H., Yang L., Gao R., He B.-Q. and Zhao H. "Influence of spark discharge on CAI combustion process". Neiranji Xuebao/Transactions of CSICE (Chinese Society for Internal Combustion Engines), Vol. 23 n $^{o}$ 5, pp. 410-416, 2005.

[178] Li Y., Zhao H., Brouzos N. and Leach B. "Managing controlled auto-ignition combustion by injection on a direct-injection gasoline engine". Proceedings of the Institution of Mechanical Engineers, Part D: Journal of Automobile Engineering, Vol. $221 \mathrm{n}^{\circ}$ 9, pp. 1125-1137, 2007.

[179] Qin J., Xie H., Zhang Y., Chen T., He B.-Q. and Zhao H. "Experimental study on CAI gasoline engine equipped with 4-variable valve actuating system". Neiranji Xuebao/Transactions of CSICE (Chinese Society for Internal Combustion Engines), Vol. $25 \mathrm{n}^{\circ}$ 4, pp. 316-321, 2007.

[180] Yang J. "Expanding the operating range of homogeneous charge compression ignitionspark ignition dual-mode engines in the homogeneous charge compression ignition mode". International Journal of Engine Research, Vol. $6 \mathrm{n}^{\circ}$ 4, pp. 279-288, 2005.

[181] Zhang Y., Dalla Nora M. and Zhao H. "Comparison of Performance, Efficiency and Emissions between Gasoline and E85 in a Two-Stroke Poppet Valve Engine with Lean Boost CAI Operation". SAE Technical Paper n. 2015-01-0827, 2015.

[182] Uyumaz A. "An experimental investigation into combustion and performance characteristics of an HCCI gasoline engine fueled with n-heptane, isopropanol and n-butanol fuel blends at different inlet air temperatures". Energy Conversion and Management, Vol. 98, pp. 199-207, 2015.

[183] Dempsey A.B., Das Adhikary B., Viswanathan S. and Reitz R.D. "Reactivity controlled compression ignition using premixed hydrated ethanol and direct injection diesel". Journal of Engineering for Gas Turbines and Power, Vol. 134 n $^{\circ}$ 8, 2012. 
[184] Megaritis A., Yap D. and Wyszynski M.L. "Effect of water blending on bioethanol HCCI combustion with forced induction and residual gas trapping". Energy, Vol. 32 $\mathrm{n}^{o} 12$, pp. 2396-2400, 2007.

[185] Steinhilber T. and Sattelmayer T. "The effect of water addition on HCCIdiesel combustion". SAE Technical Paper n. 2006-01-3321, 2006.

[186] Iwashiro Y., Tsurushima T., Nishijima Y., Asaumi Y. and Aoyagi Y. "Fuel consumption improvement and operation range expansion in HCCI by direct water injection". SAE Technical Paper n. 2002-01-0105, 2002.

[187] Christensen M. and Johansson B. "Homogeneous charge compression ignition with water injection". SAE Technical Paper n. 1999-01-0182, 1999.

[188] Lee K., Cho S., Kim N. and Min K. "A study on combustion control and operating range expansion of gasoline HCCI". Energy, Vol. 91, pp. 1038-1048, 2015.

[189] Jang J., Lee Y., Cho C., Woo Y. and Bae C. "Improvement of DME HCCI engine combustion by direct injection and EGR". Fuel, Vol. 113, pp. 617-624, 2013.

[190] Yoshizawa K., Teraji A., Miyakubo H., Yamaguchi K. and Urushihara T. "Study of high load operation limit expansion for gasoline compression ignition engines". Journal of Engineering for Gas Turbines and Power, Vol. 128 n $^{\circ}$ 2, pp. 377-387, 2006.

[191] Andwari A.M. and Aziz A.A. "Homogenous Charge Compression Ignition (HCCI) technique: A review for application in two-stroke gasoline engines". Applied Mechanics and Materials, Vol. 165, pp. 53-57, 2012.

[192] Wijesinghe J. and Hong G. "Study of the autoignition combustion operating region of a small two-stroke engine". Proceedings of the Institution of Mechanical Engineers, Part D: Journal of Automobile Engineering, Vol. 223 n $^{\circ}$ 5, pp. 651-659, 2009.

[193] Wijesinghe J. and Hong G. "Effect of spark assistance on improving cyclic stability of auto-ignition at light load in a small two-stroke engine". SAE Technical Paper $n$. 2009-32-0021, 2009.

[194] Wijesinghe J.S. and Hong G. "Effect of spark assistance on autoignition combustion in a small two-stroke engine". Proceedings of the Institution of Mechanical Engineers, Part D: Journal of Automobile Engineering, Vol. 225 n $^{\circ}$ 1, pp. 115-126, 2011.

[195] Hung N.B., Lim O. and Iida N. "The effects of key parameters on the transition from SI combustion to HCCI combustion in a two-stroke free piston linear engine". Applied Energy, Vol. 137, pp. 385-401, 2015.

[196] Blundell D., Turner J., Duret P., Lavy J., Oscarsson J., Emanuelsson G., Bengtsson J., Hammarstrom T., Perotti M., Kenny R. and Cunningham G. "Design and evaluation of the elevate two-stroke automotive engine". SAE Technical Paper n. 2003-01-0403, 2003.

[197] Duret P., Dabadie J.-C., Lavy J., Allen J., Blundell D., Oscarsson J., Emanuelsson G., Perotti M., Kenny R. and Cunningham G. "The air assisted direct injection ELEVATE automotive engine combustion system". SAE Technical Paper n. 2000-01-1899, 2000.

[198] Andwari A.M., Aziz A.A., Said M.F.M., Latiff Z.A. and Ghanaati A. "Influence of hot burned gas utilization on the exhaust emission characteristics of a controlled autoignition two-stroke cycle engine". International Journal of Automotive and Mechanical Engineering, Vol. $11 \mathrm{n}^{\circ}$ 1, pp. 2396-2404, 2015.

[199] Andwari A.M., Abdul Aziz A., Muhamad Said M.F. and Abdul Latiff Z. "An experimental study on the influence of EGR rate and fuel octane number on the 
combustion characteristics of a CAI two-stroke cycle engine". Applied Thermal Engineering, Vol. $71 \mathrm{n}^{\circ}$ 1, pp. 248-258, 2014.

[200] Andwari A.M., Aziz A.A., Said M.F.M. and Latiff Z.A. "A converted two-stroke cycle engine for compression ignition combustion". Applied Mechanics and Materials, Vol. 663, pp. 331-335, 2014.

[201] Andwari A.M., Aziz A.A., Muhamad Said M.F. and Abdul Latiff Z. "Controlled autoignition combustion in a two-stroke cycle engine using hot burned gases". Applied Mechanics and Materials, Vol. 388, pp. 201-205, 2013.

[202] Zhao H., Peng Z. and Ma T. "Investigation of the HCCI/CAI combustion process by 2-D PLIF imaging of formaldehyde". SAE Technical Paper n. 2004-01-1901, 2004.

[203] Zhang Y., He B.-Q., Xie H. and Zhao H. "The combustion and emission characteristics of ethanol on a port fuel injection HCCI engine". SAE Technical Paper n. 2006-01$0631,2006$.

[204] Zhang Y. and Zhao H. "Measurement of short-circuiting and its effect on the controlled autoignition or homogeneous charge compression ignition combustion in a two-stroke poppet valve engine". Proceedings of the Institution of Mechanical Engineers, Part D: Journal of Automobile Engineering, Vol. 226 n $^{\circ}$ 8, pp. 1110-1118, 2012.

[205] Zhang H.F., Seo K. and Zhao H. "Combustion and emission analysis of the direct DME injection enabled and controlled auto-ignition gasoline combustion engine operation". Fuel, Vol. 107, pp. 800-814, 2013.

[206] Zhang Y., Zhao H., Peckham M. and Campbell B. "Direct in-cylinder CO2 measurements of residual gas in a GDI engine for model validation and HCCI combustion development". SAE Technical Paper n. 2013-01-1654, Vol. 2, 2013.

[207] Zhao H., Zhang L., Xie H., Xie L., Wang X. and Chen T. "Influence of intake backflow on HCCI auto-ignition timing". Ranshao Kexue Yu Jishu/Journal of Combustion Science and Technology, Vol. $19 \mathrm{n}^{\circ}$ 3, pp. 206-212, 2013.

[208] Zhang Y., Dallanora M. and Zhao H. "Investigation of Valve Timings on Lean Boost CAI Operation in a Two-stroke Poppet Valve di Engine". SAE Technical Paper $n$. 2015-01-1794, 2015.

[209] Brunt M.F.J., Rai H. and Emtage A.L. "The calculation of heat release energy from engine cylinder pressure data". SAE Technical Paper n. 981052, 1998.

[210] Rassweiler G.M. and Withrow L. "Motion pictures of engine flames correlated with pressure cards". SAE Technical Paper n. 380139, 1938.

[211] Gatowski J.A., Balles E.N., Chun K.M., Nelson F.E., Ekchian J.A. and Heywood J.B. "Heat release analysis of engine pressure data". SAE Technical Paper n. 841359, 1984.

[212] Eriksson L. "Requirements for and a systematic method for identifying heat-release model parameters". SAE Technical Paper n. 980626, 1998.

[213] Cheung H.M. and Heywood J.B. "Evaluation of a one-zone burn-rate analysis procedure using production SI engine pressure data". SAE Technical Paper n. 932749, 1993.

[214] Payri F., Armas O., Desantes R. and Leiva A. "Modelo termodinámico para el diagnóstico experimental del proceso de combustión en motores Diesel de inyección directa (ID)". III Congreso Iberoamericano de Ingeniería Mecánica, La Habana, 1997.

[215] Egnell R. "Combustion diagnostics by means of multizone heat release analysis and NO calculation". SAE Technical Paper n. 981424, 1998. 
[216] Ghojel J. and Honnery D. "Heat release model for the combustion of diesel oil emulsions in di diesel engines". Applied Thermal Engineering, Vol. $25 \mathrm{n}^{\circ} 14-15$, pp. 2072-2085, 2005 .

[217] Kamimoto T., Minagawa T. and Kobori S. "A two-zone model analysis of heat release rate in diesel engines". SAE Technical Paper n. 972959, 1997.

[218] Brunt M.F.J. and Platts K.C. "Calculation of heat release in direct injection diesel engines". SAE Technical Paper n. 1999-01-0187, 1999.

[219] Mehl M., Chen J.Y., Pitz W.J., Sarathy S.M. and Westbrook C.K. "An approach for formulating surrogates for gasoline with application toward a reduced surrogate mechanism for CFD engine modeling". Energy and Fuels, Vol. $25 \mathrm{n}^{o} 11$, pp. 52155223, 2011.

[220] Krieger R.B. and Borman G.L. "The computation of apparent heat release for internal combustion engines". ASME Paper 66-WA/DGP-4, 1966.

[221] Guezennec Y.G. and Hamama W. "Two-zone heat release analysis of combustion data and calibration of heat transfer correlation in an I. C. engine". SAE Technical Paper n. 1999-01-0218, 1999.

[222] Callahan T.J., Yost D.M. and Ryan III T.W. "Acquisition and interpretation of diesel engine heat release data". SAE Technical Paper n. 852068, 1985.

[223] Clerk Dugald. The gas engine. Longmans Green, 1887.

[224] Curto-Risso P. L., Medina A., Calvo Hernández A., Guzmán-Vargas L. and AnguloBrown F. "On cycle-to-cycle heat release variations in a simulated spark ignition heat engine". Applied Energy, Vol. 88 n $^{\circ}$ 5, pp. 1557-1567, 2011.

[225] Litak G., Kaminski T., Czarnigowski J., Sen A. K. and Wendeker M. "Combustion process in a spark ignition engine: Analysis of cyclic peak pressure and peak pressure angle oscillations". Meccanica, Vol. $44 \mathrm{n}^{\circ}$ 1, pp. 1-11, 2009.

[226] De Bellis V., Bozza F., Siano D. and Valentino G. "A modeling study of cyclic dispersion impact on fuel economy for a small size turbocharged SI engine". SAE Technical Paper n. 2016-01-2230, 2016.

[227] Ozdor N., Dulger M. and Sher E. "Cyclic variability in spark ignition engines a literature survey". SAE Technical Paper n. 940987, 1994.

[228] Sawamoto K., Kawamura Y., Kita T. and Matsushita K. "Individual cylinder knock control by detecting cylinder pressure". SAE Technical Paper n. 871911, 1987.

[229] Matekunas F.A. "Engine combustion control with ignition timing by pressure ratio management, 18 Nov. 1986". US Pat A4622939, 1986.

[230] Reyes M., Tinaut F. V., Giménez B. and Pérez A. "Characterization of cycle-to-cycle variations in a natural gas spark ignition engine". Fuel, Vol. 140, pp. 752-761, 2015.

[231] Armas O. "Diagnóstico experimental del proceso de combustión en motores Diesel de inyección directa". PhD thesis. Universitat Politècnica de València, Departamento de Máquinas y Motores Térmicos, 1998.

[232] Galloni E. "Analyses about parameters that affect cyclic variation in a spark ignition engine". Applied Thermal Engineering, Vol. 29 n ${ }^{\circ}$ 5-6, pp. 1131-1137, 2009.

[233] Baratta M., D'Ambrosio S., Spessa E. and Vassallo A. "Analysis of cyclic variability in a bi-fuel engine by means of a 'cycle-resolved' diagnostic technique". 2005 Fall Technical Conference of the ASME Internal Combustion Engine Division, pp. 175-191, 2005. 
[234] Baratta M., Spessa E., D'Ambrosio S. and Vassallo A. "Cycle-resolved detection of combustion start in SI engines by means of different in-cylinder pressure data reduction techniques". Proceedings of the Spring Technical Conference of the ASME Internal Combustion Engine Division, pp. 303-316, 2006.

[235] Baratta M. and Misul D. "Development and assessment of a new methodology for end of combustion detection and its application to cycle resolved heat release analysis in IC engines". Applied Energy, Vol. 98, pp. 174-189, 2012.

[236] D'Ambrosio S., Ferrari A. and Galleani L. "In-cylinder pressure-based direct techniques and time frequency analysis for combustion diagnostics in IC engines". Energy Conversion and Management, Vol. 99, pp. 299-312, 2015.

[237] D'Ambrosio S., Misul D., Spessa E. and Vassallo A. "Evaluation of combustion velocities in bi-fuel engines by means of an enhanced diagnostic tool based on a quasidimensional multizone model". SAE Technical Paper n. 2005-01-0245, 2005.

[238] Metghalchi M. and Keck J.C. "Burning velocities of mixtures of air with methanol, isooctane, and indolene at high pressure and temperature". Combustion and Flame, Vol. $48 \mathrm{n}^{\circ}$ C, pp. 191-210, 1982.

[239] Rhodes D.B. and Keck J.C. "Laminar burning speed measurements of indolene-airdiluent mixtures at high pressures and temperatures". SAE Technical Paper n. 85004\%, 1985.

[240] Curran H.J., Gaffuri P., Pitz W.J. and Westbrook C.K. "A comprehensive modeling study of iso-octane oxidation". Combustion and Flame, Vol. $129 \mathrm{n}^{\circ} 3$, pp. 253-280, 2002.

[241] Aceves S.M., Flowers D.L., Westbrook C.K., Smith J.R., Pitz W., Dibble R., Christensen M. and Johansson B. "A multi-zone model for prediction of HCCI combustion and emissions". SAE Technical Paper n. 2000-01-0327, 2000.

[242] Aceves S.M., Flowers D.L., Martinez-Frias J., Smith J.R., Westbrook C.K., Pitz W.J., Dibble R., Wright J.F., Akinyemi W.C. and Hessel R.P. "A sequential fluid-mechanic chemical-kinetic model of propane HCCI combustion". SAE Technical Paper n. 200101-1027, 2001.

[243] Aceves S.M., Martinez-Frias J., Flowers D.L., Smith J.R., Dibble R.W., Wright J.F. and Hessel R.P. "A decoupled model of detailed fluid mechanics followed by detailed chemical kinetics for prediction of iso-octane HCCI combustion". SAE Technical Paper n. 2001-01-3612, 2001.

[244] Olesky L.M., Martz J.B., Lavoie G.A., Vavra J., Assanis D.N. and Babajimopoulos A. "The effects of spark timing, unburned gas temperature, and negative valve overlap on the rates of stoichiometric spark assisted compression ignition combustion". Applied Energy, Vol. 105, pp. 407-417, 2013.

[245] Persson H., Hultqvist A., Johansson B. and Remón A. "Investigation of the early flame development in spark assisted HCCI combustion using high speed chemiluminescence imaging". SAE Technical Paper n. 2007-01-0212, 2007.

[246] Reuss D.L., Kuo T.-W., Silvas G., Natarajan V. and Sick V. "Experimental metrics for identifying origins of combustion variability during spark-assisted compression ignition". International Journal of Engine Research, Vol. 9 n ${ }^{\circ}$ 5, pp. 409-434, 2008.

[247] Coskun G., Delil Y. and Demir U. "Analysis of an HCCI engine combustion using toluene reference fuel for different equivalence ratios - Comparison of experimental results with CFD and SRM simulations". Fuel, pp. 217-227, 2019. 
[248] Demir U., Yilmaz N., Coskun G. and Soyhan H.S. "Evaluation of zero dimensional codes in simulating IC engines using primary reference fuel". Applied Thermal Engineering, Vol. 76, pp. 18-24, 2015.

[249] Turkcan A., Ozsezen A.N., Canakci M., Coskun G., Soyhan H.S. and Demir U. "An experimental and modeling study to investigate effects of two-stage direct injection variations on HCCI combustion". Combustion Science and Technology, Vol. $187 \mathrm{n}^{o} 4$, pp. $642-658,2015$. 


\section{Chapter 3}

\section{Thesis proposal}

\section{Contents}

3.1 Introduction $\ldots \ldots \ldots \ldots \ldots \ldots \ldots \ldots \ldots \ldots \ldots, \quad 99$

3.2 Synthesis of the literature review $\ldots \ldots \ldots \ldots \ldots .99$

3.3 Thesis objectives and general methodology .... 102 



\subsection{Introduction}

In this brief chapter, an analysis of the state of the art in SI engines will be performed based on the previous chapter. In this way, the current working fields to continue with the development of these engines will be detailed, and based on this analysis, the objectives and the lines to follow in this $\mathrm{PhD}$ thesis will be established, to carry out a work that contributes to the improvement of this type of engines.

\subsection{Synthesis of the literature review}

The literature review made in Chapter 2 has been focused on the analysis of SI engines, reviewing the keys of their combustion process and analyzing the recent improvements that have been implemented during their development with the aim of achieving more efficient and clean power units.

This review, therefore, shows an image of the state of the art in this field. As it has been seen, there are different development areas where the research works have been very intense, and are still bringing results to improve SI engines. These areas are mainly: downsizing, the direct injection introduction, boosting, and variable valve actuation systems implementation. All these improvements have allowed the emergence of a new SI engines generation totally different from the SI engine concept known some years ago. These development fields, despite being better known nowadays, still have some improvement margin. The BMEP and the efficiency of this type of engines is being increased continuously, and this requires better combustion control methodologies to reduce the knocking (one of the major problems in these engines), and other problems, such as the reduction of the pollutant emissions generated by this type of engines, since they are rising with their progressive evolution.

Currently, another development way is the implementation of new combustion modes, with the aim to get a great improvement of these engines. This field is attracting many efforts, since there are different approaches under development to achieve a much more efficient and clean combustion, something that has proven being necessary in view of the problems arisen with the advances of the new SI engines design.

One of the approaches with a predictably more immediate application, is the change in the operation of SI engines from stoichiometric (as traditionally operated) to lean conditions. However, this change presents different challenges 
that are difficult to be solved nowadays, such as the development of optimal strategies to minimize the pollutant emissions generated, as well as the simplification and cheapening of the aftertreatment systems. On the other hand, it is necessary to face the task of igniting, in a reliable and repetitive way, a lean mixture that will often be close to the flammability limits, and this is not trivial in most cases. Most of the current strategies are based on the stratification of the charge, thus increasing the heterogeneity of the mixture to make the ignition process easier. But this strategy increases the pollutant emissions and limits the efficiency that theoretically could be achieved thanks to the lean mixtures operation.

Another approach at an earlier development stage is the CAI combustion mode, which offers a big theoretical potential, but results in a great complexity for the engine management. The benefits obtained if stable CAI combustion is achieved are high: the efficiencies of a Diesel cycle can be obtained but with pollutant emissions levels below those produced by this type of combustion, and even below the levels of an Otto cycle. However, the operation of this combustion mode is based on achieving a controlled autoignition of a homogenized mixture of gasoline and air without using any mechanism with a direct action on the combustion initiation. The biggest challenges to face with this combustion mode, and to transfer these theoretical benefits to the daily use, are:

- The development of an optimum way to manage the reactivity of the mixture, allowing the controlled autoignition at the optimum moment and a development of combustion that does not affect the integrity of the engine.

As it has been seen, different approaches are being investigated to achieve the control of this reactivity, but it is still difficult to determine which will be the best applicable strategy that will work in different engines and variable operating conditions.

- The design of methodologies that will allow to extend this operation mode to the whole engine map.

Another big problem for CAI combustion nowadays, is the operating limitation in terms of IMEP. There are works and methodologies to try to extend this mode to greater operation ranges. However, nowadays it is practically impossible to operate the entire working range of an engine in CAI conditions. 
- The design of the appropriate control methodologies to allow the use of the engine along different load levels and speeds with a smooth operation and uninterrupted combustion during transient operation.

This combustion mode, as already said, does not have a direct mechanism to act on the start of combustion. Consequently, it is necessary to work continuously on the mixture reactivity. This makes necessary the design of advanced combustion control strategies totally different to the ones already seen, in order to make possible in the future the operation of these engines out of a test bench in stationary conditions.

- The simplification of the number of elements to add, as well as the necessary changes to achieve the operation in this combustion mode.

The complexity of the systems necessary to operate in this combustion mode is very high, depending on the approach to get CAI combustion. Some necessary systems will never be available outside of a test cell in a laboratory. Therefore, it is necessary to simplify all the required systems, or at least make it possible for them to operate correctly in a vehicle.

- The necessary reliability of the engine performance when it is subjected to the variability of the working conditions and the differences in fuel composition supplied to the engine.

During the engine development, there are some standardized operating conditions that establish the temperature, humidity, pressure and fuel composition during the tests. Normally, a series of corrections are established in the values obtained from the engine to standardize the data obtained at any operating condition. However, it has been observed that in these combustion modes, the variation of these conditions can deeply affect the performance of the engine. So, before considering this technology as mature, it should be evaluated if this combustion mode can operate correctly during all the working conditions that can be found throughout the different driving situations.

All these challenges have a great relationship with the choice of the optimal engine architecture to operate this type of combustion and the design of each individual component to adapt it perfectly to the new operating conditions at which it will be working. Up to now, it can be said that the definitive CAI engine does not yet exist. Prototypes have been shown, but these may be very far from what would be understood in the future as a CAI engine.

These new developments also entail some doubts about the suitability of using the standard combustion diagnostics and subsequent analysis for 
them. The use of SI engines combined with the implementation of lean combustion and CAI combustion modes, raises the importance to proceed to the combustion diagnostic cycle by cycle, in order to take into account the intrinsic variability of these engines and their higher combustion control complexity. And regarding the combustion analysis methodologies, these ones also present some lacks if a deeper information to distinguish different combustion modes has to be established from the HRL information.

\subsection{Thesis objectives and general methodology}

\section{Thesis objectives}

Based on the current state of the art, the main objective of the thesis will be to study the SI lean combustion and CAI combustion in an engine that presents a combination of the different advances achieved in SI engines up to now.

If this main objective is separated in a series of more specific objectives, these can be taken as a guide for the development of the current thesis works, and the following list can be proposed:

- To evaluate the potential of two-stroke engine architectures with the latest technologies incorporated.

The engine under study will be an engine that works under a two-stroke cycle. This decision was taken with the intention of trying to take advantage of the higher theoretical power output per volume that this type of engines is capable to achieve, as well as the higher mechanical simplicity compared to four-stroke engines. That fact would allow to decrease the cost of the future CAI engines. This decision is also in line with the downsizing trend of the engines development, since in a two-stroke engine, the BMEP achieved is twice the equivalent one in a 4 -stroke engine, thus being able to reduce the displaced volume of the engine.

- To analyze the potential of CAI and SI lean combustion modes.

These combustion modes will be tested with the intention of enlarging the existing knowledge in relation to the required operation strategies, the efficiencies, the pollutant emissions and the limitations of each operating mode. 
- To study the potential of the EGR applied to the different combustion modes.

A low pressure EGR system will be implemented in the engine with the intention of controlling the pollutant emissions and to study its effect on both lean and CAI combustion. In this last combustion mode, there is a special interest to see the effect of this strategy (EGR) on the combustion development, since this effect has not yet been studied extensively, and it can be considered as a useful tool to extend the CAI operation range at high loads.

- To study the convenience of changing the combustion diagnostics methodology from the averaged pressure cycle to the individualized cycle analysis.

If there are cycle to cycle variations during the engine operation, some authors state that it becomes necessary to proceed with more detailed solutions for the combustion diagnostic.

- To develop a deeper combustion analysis methodology to study the HRL in depth in both SI and CAI modes.

After seeing that, in the reviewed current bibliography, there is not much information about any quantitative analysis to differentiate the CAI and SI combustion modes, the development of a combustion analysis methodology is proposed here in order to study these combustion processes. The aim of this study is to look for the differences between these two combustion modes, and try to quantify in some way the differences between a combustion carried out by a standard flame front progression and a combustion developed by autoignition.

- Try to offer a complete engine solution with the available technologies described along the literature review.

Although there is not yet an obvious and widely accepted way to develop a CAI engine suitable to be industrialized, in this $\mathrm{PhD}$ thesis, thanks to the study of the different combustion modes, a final engine design capable of operating either in lean or CAI combustion mode along its whole working range will be proposed. With the data obtained during the development of the work carried out, some theoretical results of the engine performance in standard cycles will be calculated, thus demonstrating if it could be considered as an effective solution for the mobility of future vehicles. 


\section{General methodology}

To achieve all those objectives, the starting point will be a prototype single cylinder engine equipped with all the technologies described in Section 2.3. Once the engine is installed in the corresponding test cell, equipped with all the necessary sensors and actuators for its control, and some equipment for data acquisition is available, this one will be ready to be operated.

The first part of this thesis work will be the design and execution of the experiments. Since there is not any previous engine map or preconfiguration of this engine, the first part of the work will be to explore the possibilities of each engine setting, so as to define the operation possibilities. Once the effect of the different settings is known and the engine map is defined, the experiments to optimize the engine performance in lean conditions and CAI combustion will be carried out, with the aim of searching for the best results as possible, as well as identifying the different operation regions of each mode.

All this work will be developed together with different software tools required to process the information obtained and to show the results of the different tests. Along the work carried out in the frame of the present $\mathrm{PhD}$ thesis, there are different processing phases: the first one will be faster and carried out in parallel to the experimental work, in order to guide the experimental tests depending on the results obtained. And the other one will be oriented to analyze in detail the obtained data, as well as to understand the information obtained from this engine. 


\section{Chapter 4}

\section{Experimental tools and methodology}

\begin{tabular}{|c|c|c|c|}
\hline \multicolumn{4}{|l|}{ Contents } \\
\hline 4.1 & \multicolumn{2}{|c|}{ Introduction ........ } & 107 \\
\hline 4.2 & \multicolumn{2}{|c|}{ Experimental tools... } & 107 \\
\hline & 4.2 .1 & The engine $\ldots \ldots \ldots \ldots \ldots \ldots \ldots \ldots \ldots$ & 107 \\
\hline & 4.2 .2 & Test cell characteristics and equipment $\ldots \ldots \ldots \ldots$ & 114 \\
\hline \multirow{4}{*}{4.3} & \multicolumn{2}{|r|}{ Theoretical tools $\ldots \ldots \ldots \ldots \ldots \ldots \ldots \ldots$} & 126 \\
\hline & 4.3 .1 & ULCGE processing software, based on CALMEC . & 126 \\
\hline & 4.3 .2 & Chemkin ............................. & 127 \\
\hline & 4.3 .3 & CFD $\ldots \ldots \ldots \ldots \ldots \ldots \ldots \ldots \ldots \ldots \ldots \ldots \ldots \ldots$ & 127 \\
\hline \multirow{7}{*}{4.4} & \multicolumn{2}{|c|}{ Methodological aspects .................. } & 128 \\
\hline & 4.4 .1 & VVT position determination................. & 128 \\
\hline & 4.4 .2 & Knock estimation (MAPO) $\ldots \ldots \ldots \ldots \ldots \ldots \ldots$ & 129 \\
\hline & 4.4 .3 & $\begin{array}{l}\text { Estimation of the charge composition inside the } \\
\text { cylinder } \ldots \ldots \ldots \ldots \ldots \ldots \ldots \ldots \ldots \ldots \ldots\end{array}$ & 130 \\
\hline & 4.4 .4 & Combustion data $\ldots \ldots \ldots \ldots \ldots \ldots \ldots \ldots$ & 134 \\
\hline & 4.4 .5 & BSFC estimation $\ldots \ldots \ldots \ldots \ldots \ldots \ldots \ldots$ & 135 \\
\hline & 4.4 .6 & Testing methodologies $\ldots \ldots \ldots \ldots \ldots \ldots \ldots \ldots$ & 136 \\
\hline 4.A & \multicolumn{2}{|r|}{$\begin{array}{l}\text { Estimation of the humidity loss through the EGR } \\
\text { system } \ldots \ldots \ldots \ldots \ldots \ldots \ldots \ldots \ldots \ldots \ldots\end{array}$} & 140 \\
\hline 4.B & \multicolumn{2}{|r|}{$\begin{array}{l}\text { Estimation of the different mass flows inside the } \\
\text { engine } \ldots \ldots \ldots \ldots \ldots \ldots \ldots \ldots \ldots \ldots \ldots \ldots \ldots\end{array}$} & 142 \\
\hline & \multicolumn{2}{|c|}{ ibliography $\ldots \ldots \ldots \ldots \ldots \ldots \ldots \ldots \ldots \ldots \ldots$} & 143 \\
\hline
\end{tabular}





\subsection{Introduction}

In any research work, the use of certain experimental and theoretical tools as well as some theoretical fundamentals and working methodologies is necessary to get a contrasted work and solid results. Particularly, to carry out all the work necessary to develop the current $\mathrm{PhD}$ thesis, several facilities and tools are required, so as to fulfill the already defined objectives, due to the particular working field in which it is developed. For this reason, in this section all the employed tools, as well as all the necessary basis to warrant a correct working methodology and to provide enough quality to the presented results will be defined and detailed here.

This chapter has been structured in three separate sections: the first one is focused on the experimental tools, the engine and all the necessary equipment to work with it; the second one deals with the theoretical tools used along the development of this thesis; and, finally, the third one describes the methodologies employed during the thesis work.

\subsection{Experimental tools}

\subsubsection{The engine}

In this thesis, the engine selected to work with has been a prototype twostroke (2S) engine. This engine comes from the ULCGE project, and it is a single cylinder engine specially built for the research and development stage of the project, which is representative of the final engine. Along this section, the specifications of the final engine, as well as of the single cylinder engine, are going to be detailed.

The final engine is a twin-cylinder engine, with a displaced volume of around $600 \mathrm{~cm}^{3}$. From this datum, it can be deduced that the engine will be a medium-small size engine, intended for light passenger cars. It has to be noted that $2 \mathrm{~S}$ engines can achieve a higher specific power, since the power strokes number is twice compared to $4 \mathrm{~S}$ engines, with a lower cost thanks to their mechanical simplicity. The main reasons behind the selection of the engine configuration finally retained will be discussed in this subsection.

In a two stroke engine, usually the engine architecture is not the same as the one commonly extended in $4 \mathrm{~S}$ engines, where the intake and the exhaust gases are introduced and removed thanks to the valves placed on the cylinder head. In this case, the chosen configuration has been a uniflow scavenged one 
(Fig. 4.1). This means that the intake gases are introduced inside the cylinder by the ports placed at the cylinder bottom, and the exhaust gases are removed by the valves located on the cylinder head. This configuration allows higher engine permeability, because the exchange area for the intake and the exhaust gases can be further increased, which is extremely important in a two stroke cycle, since the time available for the scavenging process is much smaller and the piston does not force the exhaust gases exit, nor the intake gases entrance.

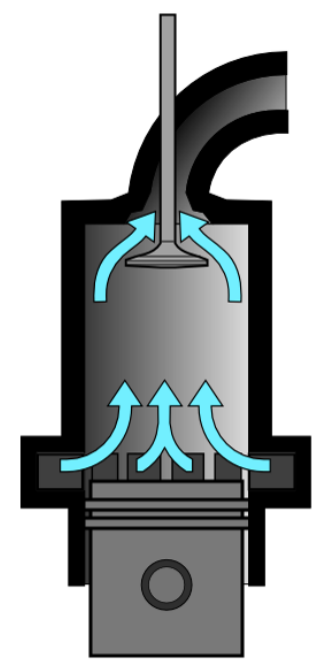

Figure 4.1. Uniflow scavenging architecture. Source: Wikipedia.

Among the different scavenging configurations available for $2 \mathrm{~S}$ engines (Fig. 4.2), the uniflow configuration presents a greater scavenging quality than the other configurations [1]. This is a widely employed configuration in applications other than automotive, with extremely good results [2-7]. One of the main applications for this architecture is large marine $2 \mathrm{~S}$ diesel engines. These engines are operated at very low engine speeds (around $100 \mathrm{rpm}$ ) and their peak efficiencies are very high, up to $55 \%[8,9]$. The engine developed in the frame of this $\mathrm{PhD}$ thesis tries to get closer to this concept in order to take advantage of the high efficiency values achieved in these other applications.

Since the intake of the fresh air is not induced and the exhaust gases are not removed by the piston motion like in $4 \mathrm{~S}$ engines, some scavenging pump is needed to perform the scavenging process in $2 \mathrm{~S}$ engines. This means that all $2 \mathrm{~S}$ engines have to be boosted in some way, so as to guarantee a positive pressure difference between the intake and the exhaust, allowing the renewal of the in-cylinder gases every cycle. To allow the maximum flexibility with a 


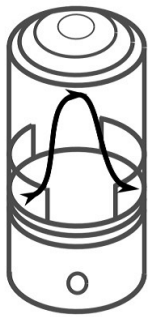

(a)

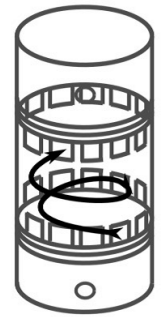

(b.1)

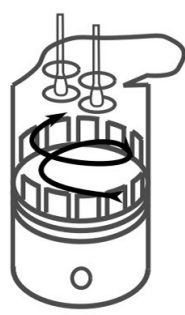

(b.2)

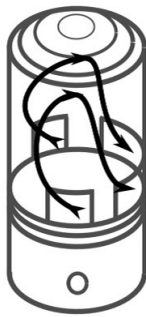

(c.1)

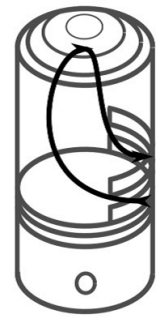

(c.2)

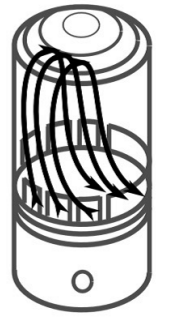

(c.3)

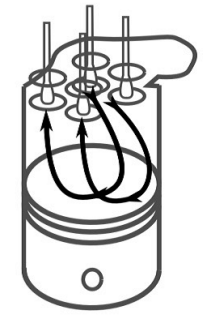

(c.4)

Figure 4.2. Different scavenging configurations for $2 S$ engines: (a) cross scavenging (b.1) Uniflow with opposed pistons (b.2) Uniflow with head valves (c.1) Schnuerle porting (c.2) MAN reverse scavenging (c.3) Curtis porting (c.4) Poppet valves scavenging. Source [10].

reasonable cost, a ROTREX (Fig. 4.3) has been chosen, which is a mechanical blower driven by the crankshaft.
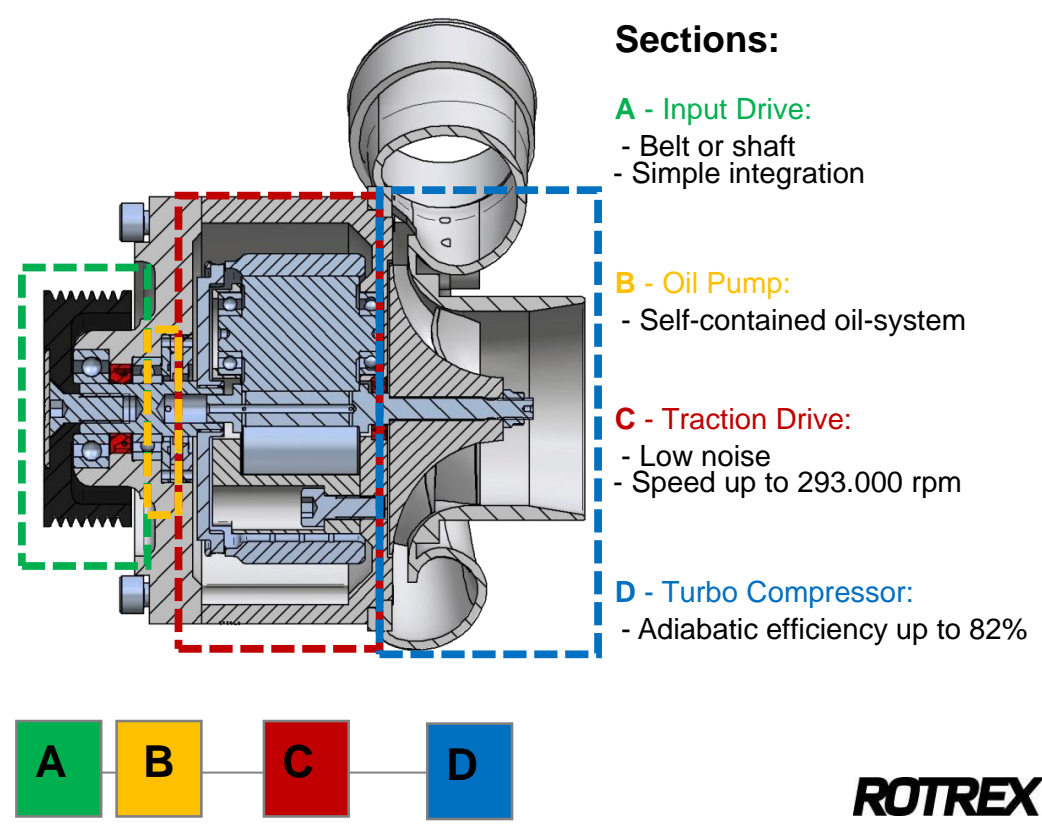

ROTREX"

Figure 4.3. Detailed view of the basic parts of a Rotrex system. Source:Rotrex Technical Handbook [11]. 
Regarding the driving of the exhaust valves, a Variable Valve Actuator (VVA) has been installed to give higher flexibility during the engine calibration and to get better overall fuel efficiency in the engine. Among the different VVA systems, a Variable Valve Timing (VVT) system has been installed in the camshaft, actuating on the exhaust valves and enabling the symmetrical modification of its angular position (Fig. 4.4). This system allows the scavenging process optimization at different engine speeds, as well as the modification of the effective compression and expansion strokes. It is important to remind that, with this system, the valves opening and closing will be modified at the same time, and the lift duration will remain the same.

Starting from a centered VVT position, this one can be advanced or delayed (taking as a reference the angular position, lower values mean advanced VVT's, whereas higher values mean delayed VVT's). If the VVT is advanced, the power stroke is decreased and the compression stroke is increased, whereas the opposite effect will be achieved if the VVT is delayed.

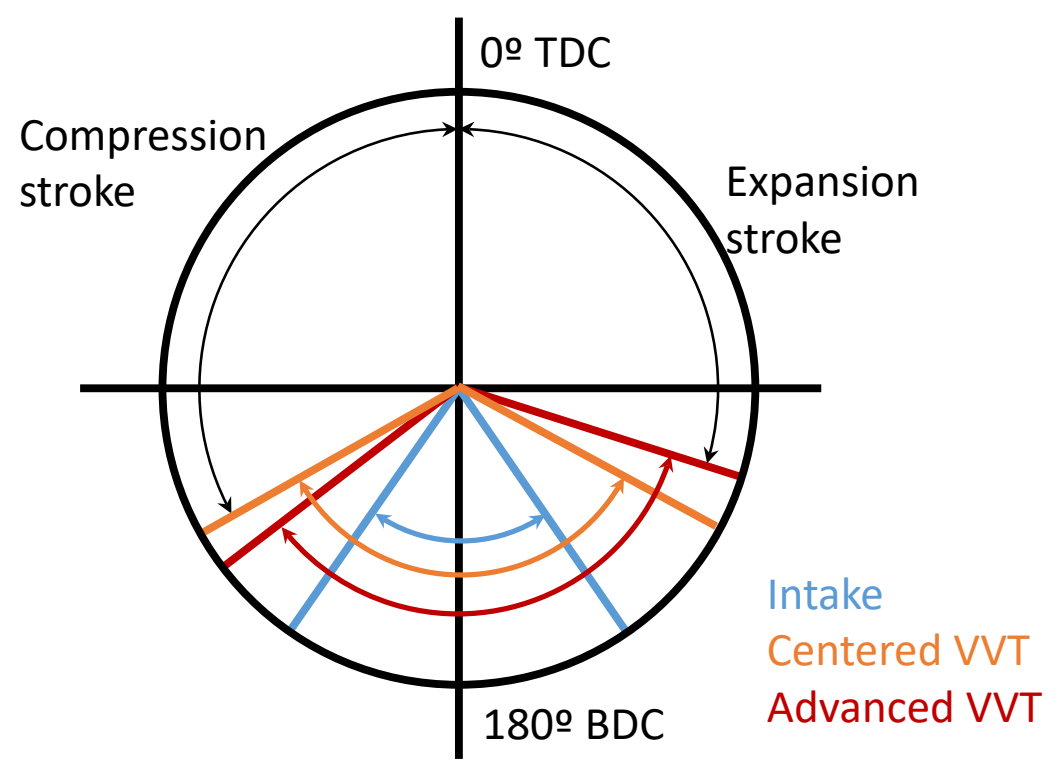

Figure 4.4. Distribution diagram for the intake and exhaust.

In Figure 4.5 and further on, the camshaft angular position will be depicted by the midpoint position of the exhaust valve opening and closing (EVO and $\mathrm{EVC}$ ) defined as $\mathrm{VVT}=(\mathrm{EVC}+\mathrm{EVO}) / 2$ (a centered position corresponds to a value of $180^{\circ} \mathrm{CA}$ ). For this engine, the VVT moving range is $30^{\circ} \mathrm{CA}$, and the 
optimum range in order to improve the overall engine performance has been defined between $150^{\circ}$ and $180^{\circ} \mathrm{CA}$.

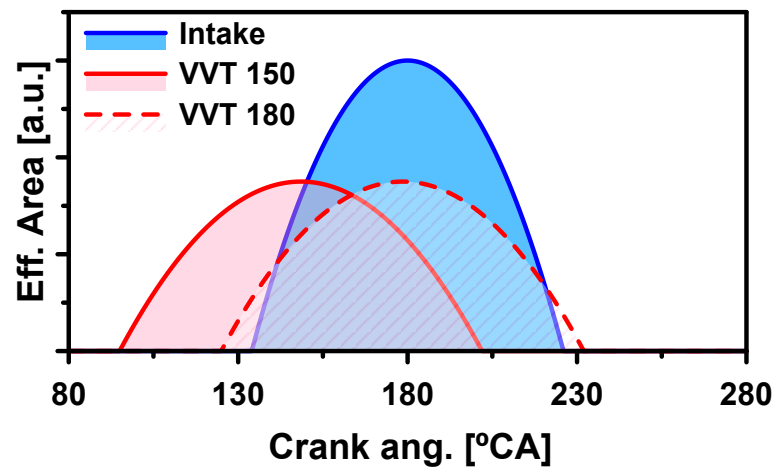

Figure 4.5. Distribution scheme where the two extreme positions of the VVT are shown.

As in any $2 \mathrm{~S}$ engine, air short-circuiting is unavoidable, and consequently it is strongly recommended to inject the fuel directly inside the combustion chamber, once the ports and valves are already closed. Thus, a fuel direct injection system is required, but in this application attention should be paid to the cost of the system. The search of the best compromise between those two objectives has led to the choice of an air-assisted fuel injection system [12]. This system consists of two injectors: the first one introduces the gasoline inside a pressurized chamber, filled with air and located just above the second injector, which is installed in the cylinder head and introduces that premixture inside the cylinder (Fig. 4.6, left). Such a system allows a good enough atomization without the need of high (and "expensive") fuel pressures (10 bar, in this case).

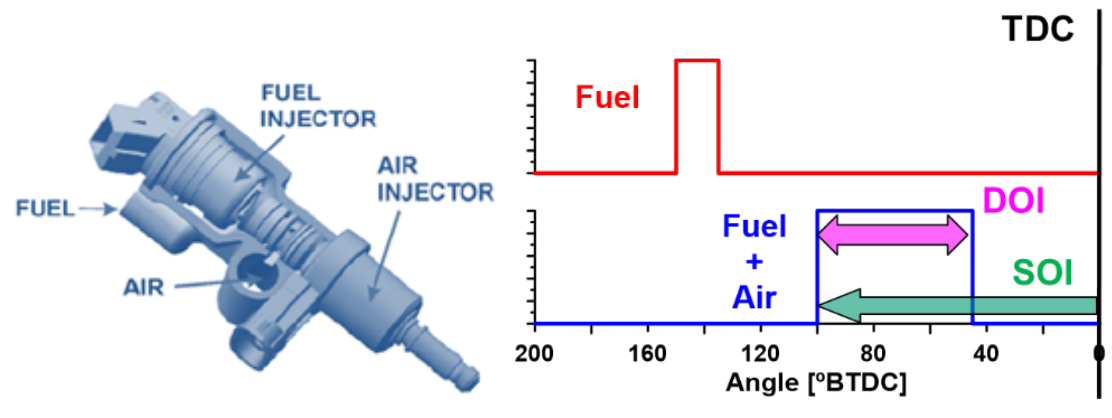

Figure 4.6. Left-Air-assisted injector assembly. Right-Operation scheme. 
The operating scheme shown in Fig. 4.6 to the right, shows the preinjection of the fuel inside the air injector and, after a prefixed delay, the injection of this premixture (air + fuel) inside the cylinder. The main parameters to set during the engine operation are the following: the amount of fuel introduced, the starting angle of the premixture injection (SOI, Start Of Injection, defined as an injection advance in degrees BTDC), and the duration of this injection (DOI, Duration Of Injection, defined also in degrees). With this last parameter, the amount of air injected together with the fuel can be modified. The SOI and DOI of the fuel injection are calculated automatically with the required fuel amount (knowing the injection rate characteristics), and the prefixed separation time between the EOI (End Of Injection) of the fuel injection and the SOI of the premixture injection.

However, this system does not come without weaknesses. The first is the limited minimum EOI (taken as degrees BTDC). This limit is achieved when the in-cylinder pressure is equal to the premixture injection pressure (7.5 bar in this case). For lower EOI values, the in-cylinder pressure surpasses the premixture injection pressure, and some backflow inside the injector starts to occur. Another problem of this fuel injection system is the obstruction of the injector nozzle due to the freezing of the air humidity on the nozzle during the injection when the engine is cold, because of the significant temperature drop in the injection air caused by its expansion in the nozzles. To avoid this problem along this work, the humidity in the air has been removed previously.

Going back to the first problem stated above, it would be interesting to determine the maximum in-cylinder pressure below which the nozzle will work at choking conditions, since in this operating regime the injection rate would be constant (maximum) and stable. This maximum pressure is, in fact, the critical pressure. To estimate this value $\left(p_{\text {crit }}\right)$, an isentropic evolution of an air flow through an injector nozzle can be assumed, taking the injection pressure as the stagnation pressure $\left(p_{0}\right)$, Eq 4.1.

$$
p_{\text {crit }}=\frac{p_{0}}{\left(\frac{\gamma+1}{2}\right)^{\frac{\gamma}{\gamma-1}}}
$$

When the in-cylinder pressure is below $p_{\text {crit }}$, the injection rate is maximum and constant. Once $p_{c y l} \geqslant p_{c r i t}$, the injection rate will progressively decrease, until reaching the limit condition when $p_{c y l}=p_{0}$, where the injection rate is stopped. Beyond this point, if the injector remains opened, the in-cylinder gas will be pushed inside the injector, and the flow will be reversed. Figure 4.7 
shows the injection pressure of the fuel/air mixture together with the evolution of the nozzle exit pressure and the in-cylinder pressure. This last one was measured in an operating point at $2000 \mathrm{rpm}$, and $5 \mathrm{mg} / \mathrm{stk}$ of injected fuel, during the compression stroke.

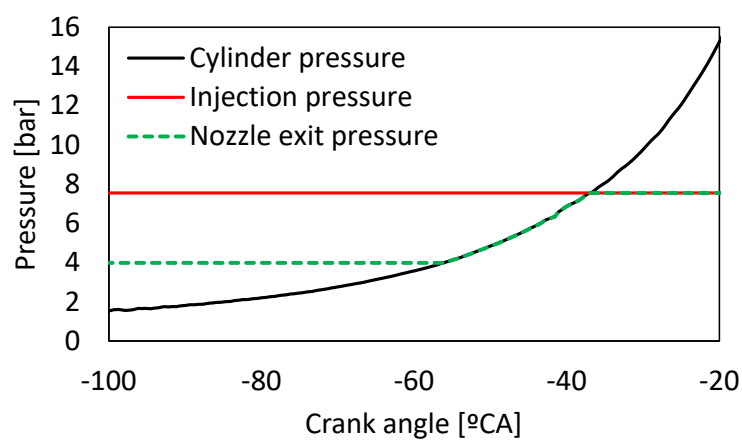

Figure 4.7. Nozzle exit pressure of the premixture injector depending on the incylinder pressure.

\section{The prototype single cylinder engine}

Once the engine and the different systems installed have been described, it becomes necessary to describe the particular characteristics of the single cylinder engine used during the thesis work, as representative of this final or complete engine. This other engine has the same cylinder architecture and dimensions as the cylinders of the final engine, with a displacement volume of around $300 \mathrm{cc}$, and an elevated compression ratio (so as to promote CAI combustion) compared to standard $2 \mathrm{~S}$ engines. The specific power and torque are around $70 \mathrm{~kW} / 1$ and $70 \mathrm{Nm} / 1$, respectively. With this data the reader can get the idea about the engine, since it's not possible to give further details about the engine specifications for confidentiality reasons derived from the ULCGE project.

The rest of the systems and components are the equivalent versions for the single cylinder engine (the VVT and the injection system) or external supplies provided by the systems installed in the test bench (like the boosting function of the Rotrex or the oil and coolant conditioning). Those supplies have to be included later in the calculations to adapt the single cylinder engine results to the complete engine final results.

The air management of this engine requires a special mention, since this is a two stroke engine. The air supply is provided by an external compressor, 
since the single cylinder engine has not any boosting system installed, and the exhaust manifold installed on the single cylinder engine has been designed in order to reduce as much as possible the acoustic effects of the exhaust gases (which is a really important parameter in $2 \mathrm{~S}$ engines). The main problem to face between the two engine versions is the acoustic effect on the intake and the exhaust. This is a very important parameter in these engines, since it affects the scavenging process. The intake of the final engine, given that it is a twin-cylinder engine, is a double ring around the intake ports connected on the middle part where both cylinders are closer to each other (both cylinders are aligned; an in-line architecture has been considered), whereas in the single cylinder engine there is a single ring around the intake ports. This difference might be considered as being negligible, but the air movement in both intake ducts are not going to be the same. For the exhaust system a similar problem is expected, since the interaction of both cylinders and the exhaust design will influence the final acoustics of this system.

\subsubsection{Test cell characteristics and equipment}

Besides having the engine, which is the main experimental tool for this work, it becomes necessary to have a properly equipped place to run this experimental tool, to control its operation and to measure all the relevant parameters. This place is the test cell, and depending on the tests and the needs of the project, it has different requirements in terms of equipment. In Figure 4.8, a detailed sketch of all the equipment installed is presented, and in the following lines of this section, all these elements will be described.

\section{Engine dynamometer}

The dynamometer available for this engine is an electric dynamometer provided by AVL. This device can be configured as a motor or as a generator (brake), which is necessary to run the SCE, since these engines are not available to start by themselves, and by this means the combustion tests are directly started from motored conditions. The brake torque is measured at the output shaft of the engine with a strain-gauge torque meter, and the engine speed and crankshaft angular position are measured continuously by means of an optical encoder placed on the crankshaft. The main specifications of the dynamometer are presented in Table 4.1.

\section{Air supply and exhaust system}

For this engine, the air supply has to be adapted in two aspects. The first aspect is the control of the intake conditions in order to remove any effect of these conditions on the combustion data. With that purpose, the air has 


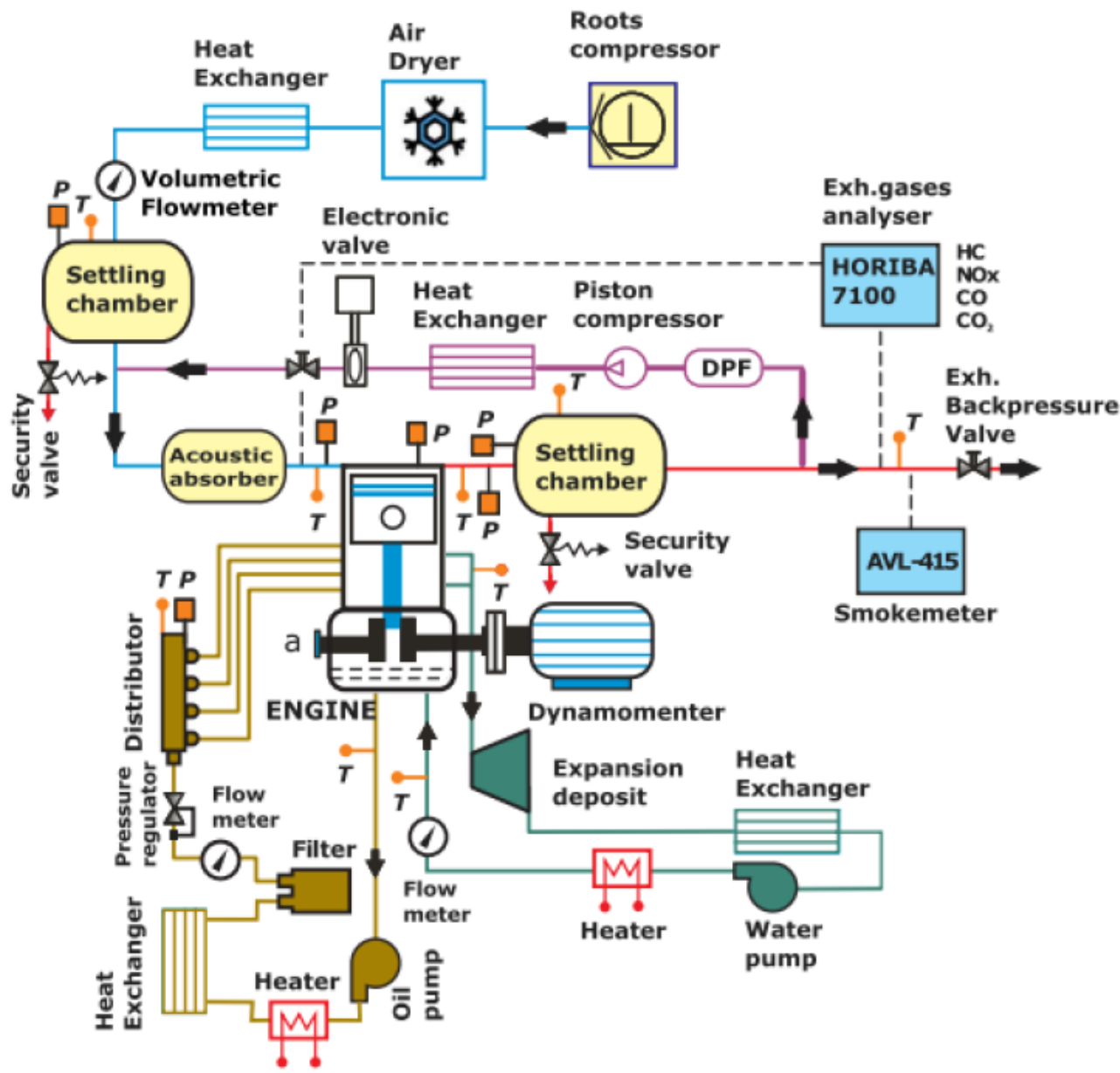

Figure 4.8. Test cell sketch with the engine and all the auxiliary systems.

to be previously dried to keep a relative humidity below $25 \%$ and a constant temperature of $20^{\circ} \mathrm{C}$. The second aspect is the control of the intake pressure (or intake mass flow) for each test depending on the defined operating conditions. The air compressor chosen for this purpose is an oil free screw air compressor, the characteristics of which are described in Table 4.2. This device has the air dryer included inside by means of a refrigerator, and for the final conditioning of the intake air, an extra heat exchanger and different acoustic absorbers are placed to get an air flow as stable as possible. 


\begin{tabular}{ll}
\hline \multicolumn{2}{c}{ Engine dynamometer specifications } \\
\hline \hline Type & 4 pole AC electric dynamometer \\
Supplier and model & AMK Type DW3 \\
Nominal power & $38 \mathrm{~kW}$ \\
Nominal torque & $120 \mathrm{Nm}$ \\
Nominal speed & $3000 \mathrm{rpm}$ \\
Maximum speed & $9000 \mathrm{rpm}$ \\
Test cell control platform & AVL EMCOM + PUMA \\
\hline
\end{tabular}

Table 4.1. Main specifications of the dynamometer used on the engine.

\begin{tabular}{ll}
\hline \multicolumn{2}{c}{ Air path sub-systems specifications } \\
\hline \hline Compressor type & Oil-free screw air compressor \\
Supplier and model & Atlas Copco ZA1-98 \\
Maximum pressure & $4 \mathrm{bar}$ (abs) \\
Flow rate at maximum speed & $450 \mathrm{~m}^{3} / \mathrm{h}$ \\
Air dryer type & Refrigerant compressed air dryer \\
Supplier and model & Atlas Copco FD $380 \mathrm{~W}$ \\
Air temperature on the inlet & $35^{\circ} \mathrm{C}$ \\
Dew point temperature & $3{ }^{\circ} \mathrm{C}$ \\
Intake settling chamber volume & $250 \mathrm{l}$ \\
Exhaust settling chamber volume & 501 \\
\hline
\end{tabular}

Table 4.2. Main specifications of the intake air compressor.

The exhaust system has the main purpose of conducting the exhaust gases from the engine output out of the test cell. This exhaust line has to be designed with a defined backpressure and acoustic characteristics, in order to emulate the conditions of the final designed exhaust line. This definition is very important in this case, since it has a big influence on the scavenging process of this particular engine. Since the definitive exhaust line for the twin-cylinder engine was not yet defined, the one installed in the test bench was chosen in 
such a way to inhibit, as much as possible, any acoustical effect. Thanks to this choice, the results obtained wouldn't be pessimistic, nor optimistic. At the end of the exhaust line, a back-pressure valve was installed for controlling purposes, allowing the choice of realistic exhaust gas pressure values.

\section{EGR system}

The EGR system was designed specifically for this test cell. Since the $2 \mathrm{~S}$ nature of the engine forces the intake pressure to be always above the exhaust pressure, the selected EGR system was, necessarily, a low pressure system. In this circuit, the exhaust gases are taken downstream of the valve for exhaust back-pressure control, to avoid any impact on this control, and conducted to a piston compressor, which pumps them to the early part of the intake line, to ensure a proper homogenization with the fresh air. Before entering the EGR system, the exhaust gases are filtered with a particulate filter, where any solid particle is removed, and before arriving to the compressor the gases are filtered again to remove any accidental solid particle or any water droplet in order to protect this machine. The exhaust gases also circulate inside a heat exchanger for temperature control. The purpose of this control is twofold: on the one hand, to avoid an excessively high temperature (when these come directly from the exhaust), which would be dangerous for the compressor integrity; and, on the other hand, to avoid an excessively low temperature (when these are recirculated inside the compressed loop -as it will be seen in the following lines-), which would lead to water condensation. The way to define the correct temperature to minimize the water condensation and the calculations to estimate this water condensation are briefly presented in Appendix 4.A. In Figure 4.9 a diagram of the EGR circuit is presented, with all the construction details. The system has been built in such a way that the EGR flow is regulated through two electronic control valves, and not by the actuation over the compressor operation. The first valve controls the gases recirculation on the compressed loop whereas the second controls the mass flow sent to the intake manifold. In this way the system regulation is more accurate in a wide range of EGR mass flows (especially when small amounts are required). Additionally, this way to control the EGR system has shown to be less intrusive with the exhaust and intake pressures, obtaining results with high accuracy.

\section{Fuel and pressurized air supply for the injection system}

The fuel supply and conditioning is managed by a Horiba FQ2100 (see detailed diagram of the device in Figure 4.10). This device undertakes the temperature and pressure regulation of the fuel, as well as the measurement of the fuel mass flow consumed by the fuel injector. For this work, the pressure 


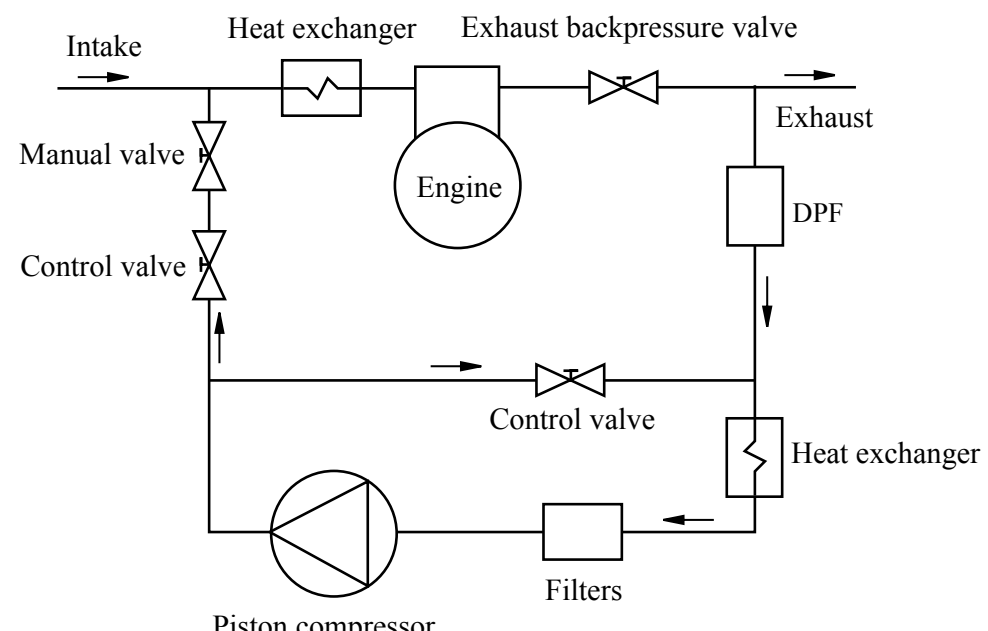

Figure 4.9. Diagram of the EGR system installed in the test bench.

is fixed at 10 bar and the temperature at $20{ }^{\circ} \mathrm{C}$, and they are constant along the whole study.

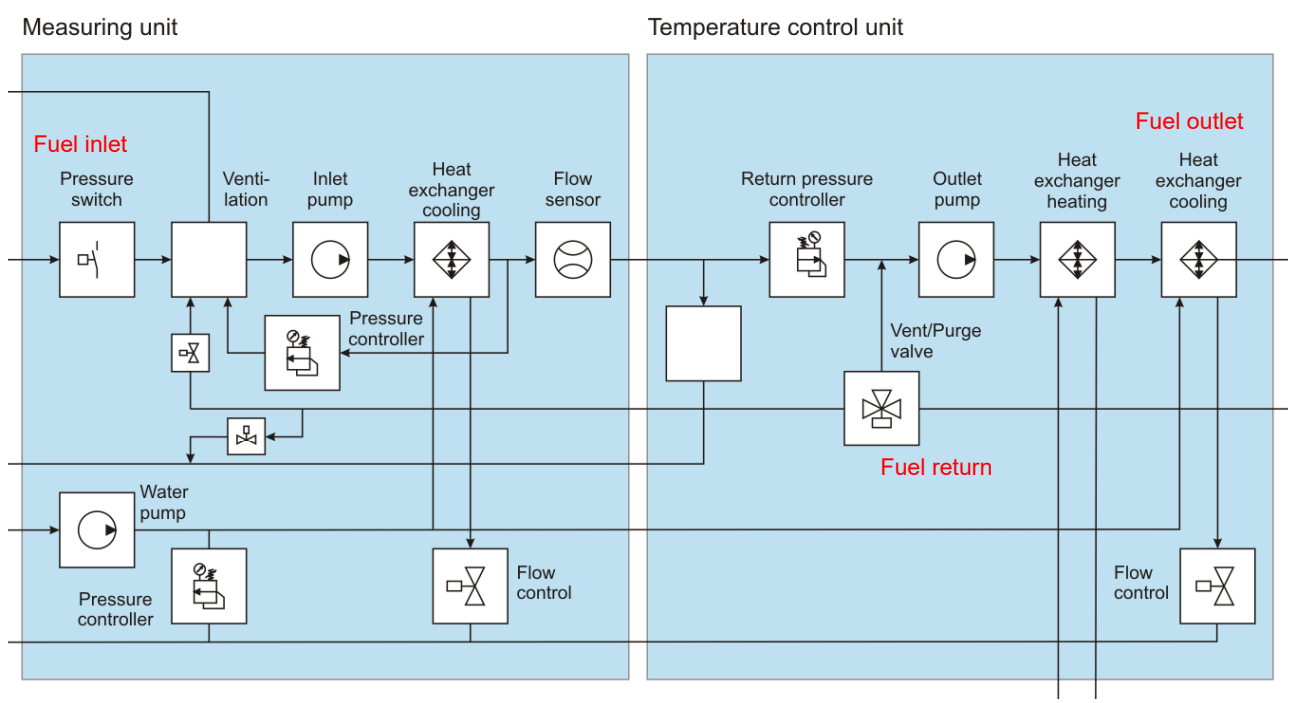

Figure 4.10. Scheme of the HORIBA FQ2100 inner fuel circuit. 
The gasoline employed during all this work is a $95 \mathrm{RON}$ calibrated fuel provided by TOTAL. The choice for this fuel, with a very precisely controlled composition, was to guarantee the engine behavior repeatability. The main characteristics of this fuel are provided in Table 4.3.

\begin{tabular}{llll}
\hline Concept & Units & Results & Method \\
\hline \hline Density@15 $\mathrm{C}$ & $\mathrm{kg} / \mathrm{m}^{3}$ & 758.1 & ASTM D 86 \\
RON & Index & 94.6 & ISO 5164 \\
MON & Index & 84.8 & ISO 5163 \\
Heating power & $\mathrm{kJ} / \mathrm{kg}$ & 42790 & GC - calculated \\
$\% \mathrm{C}$ & $\%$ mass & 87.2 & GC - calculated \\
$\% \mathrm{H}$ & $\%$ mass & 12.8 & GC - calculated \\
$\% \mathrm{O}$ & $\%$ mass & $<0.1$ & GC - calculated \\
Sulphur & $\mathrm{mg} / \mathrm{kg}$ & 16.1 & EN ISO 20846 \\
\hline
\end{tabular}

Table 4.3. Gasoline specifications.

Regarding the pressurized air required for the injection system, it is supplied at a constant pressure and temperature of 7.5 bar and $20{ }^{\circ} \mathrm{C}$, respectively, and with a relative humidity lower than $20 \%$. Since this air mass flow becomes pulsated during the injection process, it is difficult to measure it directly with enough accuracy. For this reason, the system presented in Figure 4.11 has been designed, to ensure the accuracy of the injected air mass flow measurement. With this design, there is a constant air mass flow through the main line (from the inlet to the regulation valve). In this line there is a derivation to the injector, and two air mass flowmeters are placed before and after this derivation (with the corresponding settling volumes, to isolate the flowmeters from the pressure waves, thus ensuring a more reliable measurement). In this way the injected air mass flow is obtained through the difference of the values obtained in these two flowmeters.

\section{Cooling and lubricating systems}

The cooling and lubrication of the engine are fundamental, on the one hand, to ensure the correct operation and the protection of all the mechanical elements. On the other hand, the selection of a convenient value of the oil and coolant temperature, which can be controlled thanks to these systems, is vital to guarantee that the data obtained from the engine is representative of 


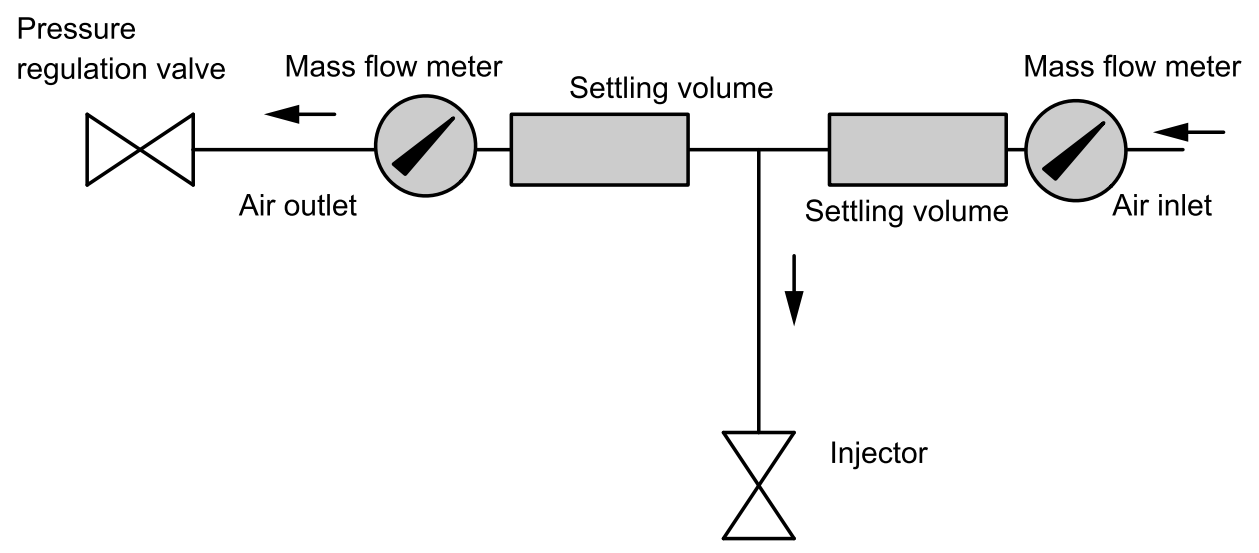

Figure 4.11. Scheme of the pressurized injection air measurement facility.

real driving conditions, since they have a significant impact on the heat flows inside the engine.

The cooling system installed on the test cell for the single cylinder engine is presented in Figure 4.12. The working fluid inside the circuit is ethylene glycol. Its temperature is regulated at $80{ }^{\circ} \mathrm{C}$ at the engine inlet, with a mass flow rate of $55 \mathrm{l} / \mathrm{min}$.

As the engine has not its own lubricating system, it has been necessary to design an auxiliary circuit to provide the necessary lubrication to the engine, also controlling the conditions of this fluid. The oil introduced inside the engine is a $\mathrm{SAE} 5 \mathrm{~W} 30$, at a constant temperature of $85^{\circ} \mathrm{C}$ at the engine inlet, and a pressure of 4.5 bar. The designed circuit to control and measure the oil conditions is presented in Figure 4.13. The circuit is made up of a threebody oil pump, an external tank and different filters, heat exchangers and sensors. Regarding the oil pump, one body is set to increase the pressure of the oil circuit taking the oil from the tank, and the other two are connected to the engine oil outlets, in order to suck the oil from the crankcase and the cylinder head, sending it back to the tank. The circuit has three oil inputs towards the engine. These ones are connected to the cylinder head, to lubricate the camshafts, to the crankshaft, and to a small oil injector installed at the bottom of the cylinder, to cool down and to ensure the correct lubrication of the cylinder and the piston during the engine operation (this last connection has its own flowmeter, since this is a critical part of the engine: too much oil 


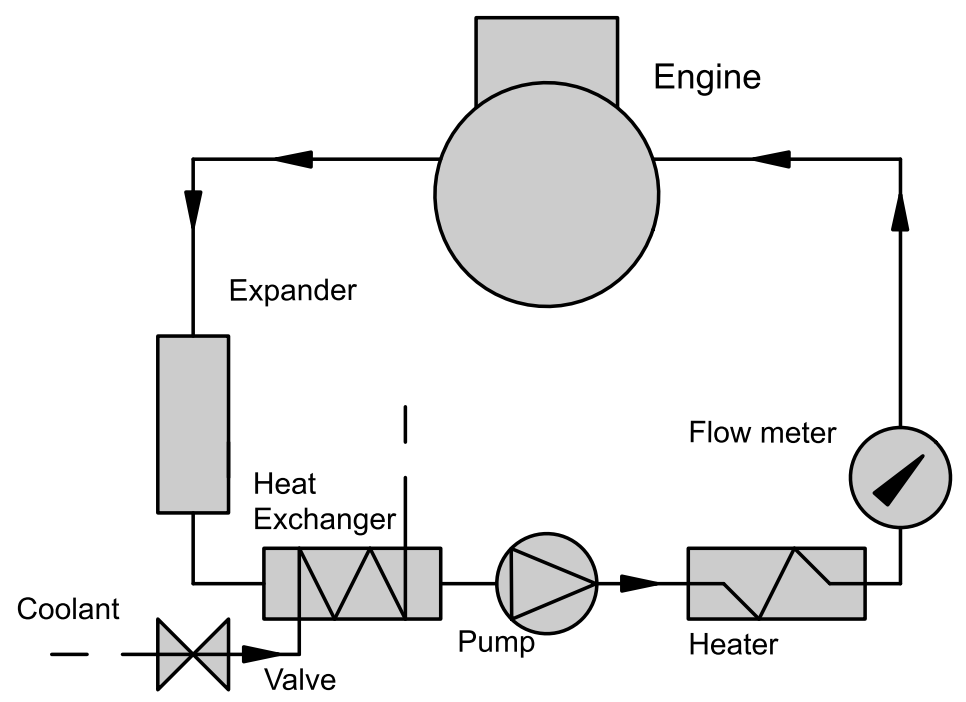

Figure 4.12. Scheme of the cooling system installed.

causes oil penetration into the combustion chamber, whereas not enough oil can derive in a fast engine seizure).

This oil from this circuit is also used to control, by periodic analysis, the engine wear by monitoring the evolution of the metal particles content in the oil.

\section{Engine management and data acquisition}

First, the sensors in the engine and test bench are going to be described. Almost all these sensors are included in Figure 4.8, labeled with a $\mathrm{T}$ and a $\mathrm{P}$ for the Temperature and Pressure sensors, respectively, and with a specific indication for the flowmeters.

The pressure sensors are installed throughout the engine and the test bench to control and register the necessary pressure data. They have been subdivided in three groups:

- Installed on the engine:

- Two piezoelectric Kistler 6061B installed in the cylinder head to measure and register the in-cylinder pressure. These sensors come with a cooling system using external liquid. 


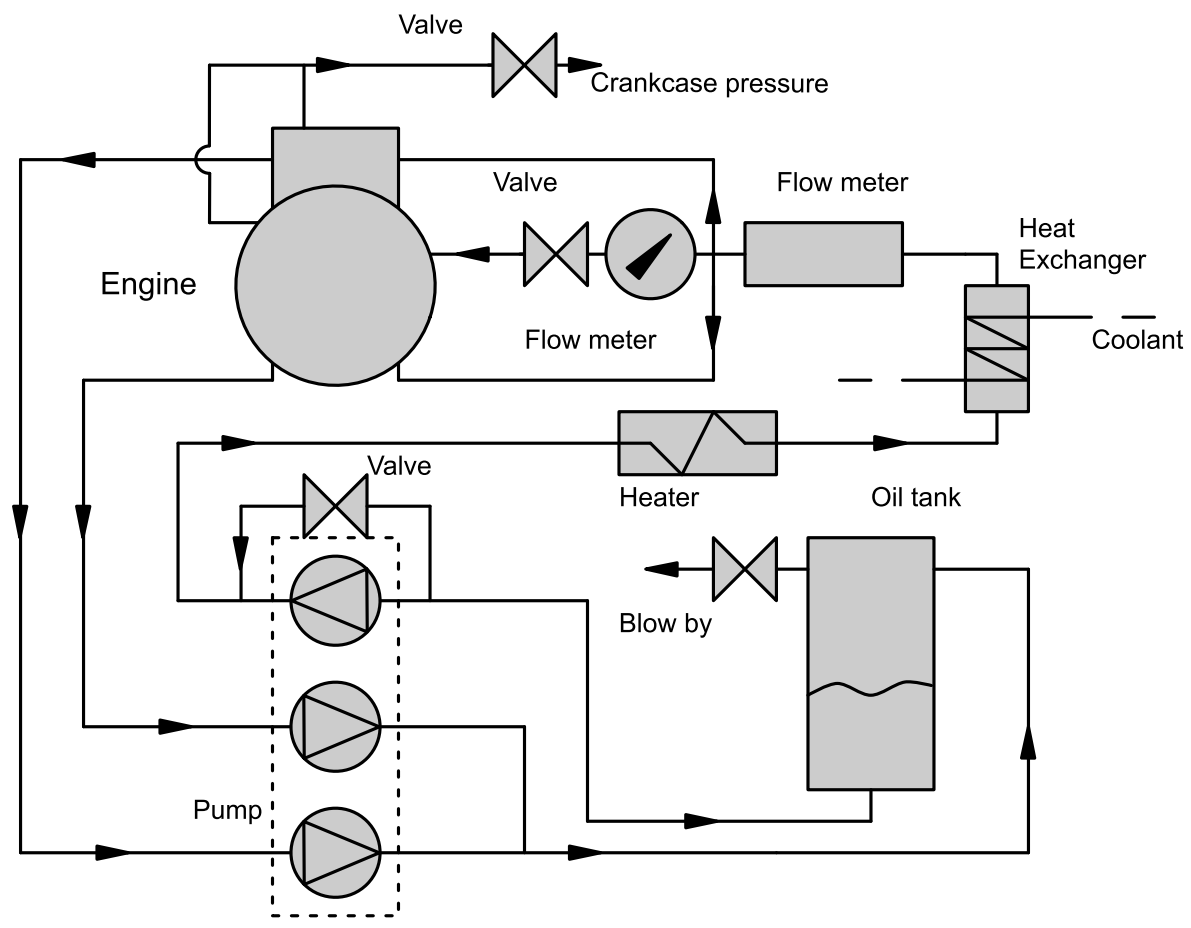

Figure 4.13. Scheme of the lubricating system installed.

- One piezoresistive Kistler 4007BA20FS installed at the bottom of the liner to register the cylinder pressure around BDC. The information of this sensor is used for pegging the signal of the two previous piezoelectric sensors.

- Intake and exhaust manifolds:

- Both are equipped with a piezoresistive Kistler 4603 B10, and in the case of the exhaust duct, the sensor is cooled with external liquid.

The first two detailed groups are high frequency sensors destined to measure the instantaneous evolution of the pressure during the tests. In Table 4.4, the measurement ranges for each sensor are also detailed.

- Other pressure sensors: Besides the previous main sensors, necessary to collect the engine data, there are other sensors installed to control the correct operation of the test bench. 


\begin{tabular}{lll}
\hline Signal & Sensor/equipment & Specification \\
\hline \hline Cylinder pressure [bar] & Piezoelectric sensor & 0 to 250 \\
Intake pressure [bar] & Piezoresistive sensor & 0 to 10 \\
Exhaust pressure [bar] & Piezoresistive sensor & 0 to 10 \\
BDC pressure [bar] & Piezoresistive sensor & 0 to 20 \\
\hline
\end{tabular}

Table 4.4. Detail of the pressure sensor type and the operating range of the main instantaneous pressure sensors.

- Pressure sensors in different points of the air supply from the compressor to the intake manifold.

- Oil circuit.

- Coolant circuit.

- High pressure injected air.

- Fuel circuit.

There are also several temperature sensors installed in different points of the engine and the test cell. These are thermocouples (K-type), and it has to be taken into account that the measurement provided by these sensors has a very long response time. Therefore the measurement of these devices has to be taken into account only as an averaged measurement. They are installed in the following points:

- Engine inlet and outlet points of the oil circuit.

- Inlet and outlet points of the coolant circuit.

- Inlet of the exhaust duct and extraction point of the gases for the exhaust gas analyzer (HORIBA).

- Intake manifold and intake ring duct.

Finally there are some mass flowmeters installed at the following places:

- Intake manifold.

- Oil circuit derivation to the cylinder bottom (oil injector). 
- Coolant circuit.

- Fuel system.

- Pressurized air for the injection system (two flowmeters).

All these sensors, as well as some others described in different lines of this chapter, are detailed in Table 4.5, where the type of sensor and the operating range are defined.

\begin{tabular}{lll}
\hline Variable & Sensor/equipment & Specification \\
\hline \hline Engine speed $[\mathrm{rpm}]$ & Optical angular encoder & 1 to 6000 \\
Engine torque $[\mathrm{N} \cdot \mathrm{m}]$ & Strain-gauges torque meter & -200 to 200 \\
Intake pressure $[\mathrm{bar}]$ & Piezoresistive transducer & 0 to 10 \\
Exhaust pressure $[\mathrm{bar}]$ & Piezoresistive transducer & 0 to 10 \\
Intake temperature $\left[{ }^{\circ} \mathrm{C}\right]$ & Thermocouple K-type & 0 to 1000 \\
Exhaust temperature $\left[{ }^{\circ} \mathrm{C}\right]$ & Thermocouple K-type & 0 to 1000 \\
Fluid temperature $\left[{ }^{\circ} \mathrm{C}\right]$ & Pt100 thermoresistance & 0 to 100 \\
Air flow $\left[\mathrm{m}^{3} / \mathrm{h}\right]$ & Rotary flowmeter & 0.05 to 160 \\
Blow-by flow $\left[\mathrm{m}^{3} / \mathrm{h}\right]$ & Blow-by Flowmeter AVL 442 & 0. to 4.5 \\
Equivalence $\mathrm{F} / \mathrm{A}$ ratio $[-]$ & UEGO NGK sensor & 0.01 to 2 \\
\hline
\end{tabular}

Table 4.5. Detail of the type and operating ratio of the sensors installed in the test cell.

Once the sensors installed on the engine and the test cell have been described, the systems to control the engine, the test cell and to collect all the data obtained from the tests are going to be described:

- Control of the test cell: together with the test bench (dynamometer set), a management system developed by AVL, called PUMA, is provided. This system is used to control the dynamometer and the auxiliary systems of the test bench, (mainly lubricating and cooling systems), and the temperature in the test cell. Furthermore, this system is used to collect the data of all the monitoring sensors and define a control panel of the engine and the test cell operation. 
- Control of the injection system: for this system an ETAS flexible ECU controlled with INCA software has been installed to control manually the injection parameters of each operating point. With this software, SOI, DOI and the amount of fuel are specified to the ECU.

- Control of the VVT system: the VVT has its own control system provided by Renault acting on a control valve to regulate the camshaft position.

- Data acquisition of the "fast signals": as fast signals, it is meant the instantaneous pressure measurements, which is a very important data for the different tests performed on the engine. To register and save this data, a multichannel oscilloscope provided by YOKOGAWA has been selected and connected to the data processing computer.

- Data acquisition of the averaged signals: for this other variables registered, the PUMA system is employed, all the control data and the averaged measurements are connected to this system and stored during each test to be sent subsequently to the data processing computer.

\section{Exhaust gas analysis}

The exhaust pollutant emissions are an important part of the engine test results nowadays. To obtain these results, the exhaust gases have to be analyzed by complex systems and procedures, since those results are not a direct measurement as the temperature or the pressure. The selected devices to analyze the exhaust gases of the engine are (1) the HORIBA MEXA-7100DEGR to measure the gaseous emissions $\left(\mathrm{HC}, \mathrm{NO}_{\mathrm{x}}, \mathrm{CO}, \mathrm{CO}_{2}\right.$ and $\left.\mathrm{O}_{2}\right)$ and (2) the smokemeter AVL 415 for the solid emissions (soot).

The first device is a set of four exhaust gas analyzers: a flame ionization detector, to measure the unburned hydrocarbons; a chemiluminescence detector, to measure the $\mathrm{NO}_{\mathrm{x}}$ emissions; a non-dispersive infrared detector, to measure $\mathrm{CO}$ and $\mathrm{CO}_{2}$ concentrations; and a magneto-pneumatic detector, for the oxygen concentration. And the second device is specifically dedicated to analyze the concentration of carbonaceous particles on the exhaust gases. This device uses a single use filter to retain the soot particles of a defined sampling volume coming from the exhaust manifold. These particles cause a darkening of the paper filter, which is measured by a photoelectric reflectometer and translated to a scale from 0 to 10, defining in this way the units of Filter Smoke Number (FSN): 0 is considered a clean gas and 10 is considered the maximum concentration in FSN units. This value can be translated into 
$\mathrm{mg} / \mathrm{m}^{3}$ (concentration value per volume of gas analyzed) thanks to an empirical correlation defined by Christian et al. [13]:

$$
\text { soot }=\frac{1}{0.405} \cdot 4.95 \cdot F S N \cdot e^{0.38 \cdot F S N}\left[\mathrm{mg} / \mathrm{m}^{3}\right]
$$

\subsection{Theoretical tools}

\subsubsection{ULCGE processing software, based on CALMEC}

The ULCGE processing software tool has been developed in Matlab, as a processing software for the data measured from the engine during the different tests carried out. The development of this specific tool was motivated by the singularity of the engine used. The common procedure at CMT-Motores Térmicos is the following: first, the raw data is preprocessed in Matlab; second, the combustion analysis, based in the in-cylinder pressure, is carried out by the in-house code CALMEC [14-18]; and, finally, with all the data available from the first and second steps, the definitive files are obtained. However, the engine under study is a $2 \mathrm{~S}$ engine, possessing a significantly high number of particularities that make the processing procedure longer and more difficult (e.g. the compression work required by the blower needs to be computed, to estimate the BSFC of the twin-cylinder engine, which means that the current operating point needs to be plotted in the compressor map, to find its efficiency, etc., as will be detailed later). For this reason a single processing tool has been designed, where the combustion diagnostics was included, with the aim of reducing the effort but yet keeping the accuracy of the results.

This tool, therefore, has been used to process all the obtained data from the tests performed in the engine. By this means, all the measured data, the combustion estimations, the heat release laws, power, fuel consumptions, efficiencies and emissions are estimated and represented in standardized datasheets and databases, allowing their easy management and data query during the next steps of the analysis work.

\subsubsection{Chemkin}

For the theoretical study of the different effects that affect the autoignition of the fuel, some numerical methods have been used to calculate the chemical kinetics processes involved in this phenomenon. For these calculations, 
chemical kinetics mechanisms are used, which are sets of species and chemical reactions that, together with their thermodynamic properties, describe the behavior of these species for any reaction that occurs within some given ranges of physical and chemical properties. The chemical kinetics mechanisms used for the combustion simulations are classified according to the simulated fuel and their complexity level. Due to the usually large number of reactions and chemical species that these mechanisms take into account, detailed mechanisms and reduced mechanisms can be found, being the first more accurate but with a longer computational time, and the second group less accurate but demanding less computational time. An example of a detailed chemical kinetics mechanism is the Gasoline Surrogate model developed by the Lawrence Livermore National Laboratory, which consists of 1404 chemical species and 6003 reactions, and as a reduced model, the two reduced models of the mechanism previously stated, which consist of 679 and 323 species, respectively [19, 20].

In this case, these tools have been used as a support information to check some results and statements. In fact, in this whole document, the only information obtained using this software is the one presented in Appendix 5.A. The selected software to solve the differential equations of chemical kinetics in this work has been CHEMKIN (Reaction Design, ANSYS). This includes different models allowing to solve chemical kinetics mechanisms for the study of ignition delays, combustion rates, equilibrium compositions, flame temperatures and pollutant emissions, simulating the existing conditions inside a combustion chamber.

\subsubsection{CFD}

In this work, a CFD (Computational Fluid Dynamics) software has also been used to support the understanding of some engine details. For this purpose, a model provided by Renault of the single cylinder engine was available, running in CONVERGE [21]. As a brief description of this software, it generates a structured and orthogonal mesh, automatically adapted to the needs of the geometry introduced during the calculations, based on some control parameters previously defined by the user, and later performs the physical 3D simulation of the fluid dynamics and the thermal evolution inside the combustion chamber. In the frame of this $\mathrm{PhD}$ thesis, this CFD tool has been used mainly to understand the behavior of the air-assisted fuel injection system, and more specifically the effect of the DOI parameter on the engine brake efficiency. 


\subsection{Methodological aspects}

In this last section of Chapter 4, the methodological aspects of this work are going to be detailed. By methodological aspects, two different concepts are meant: first, the procedures for the estimation of different engine parameters and variables; and, secondly, the necessary procedures to operate correctly all the experimental facilities and to properly define the different test sets.

\subsubsection{VVT position determination}

To determine the VVT position, two strain gauges (one per valve) are installed on the rocker arms. These gauges register the force on these elements, thus indicating the camshaft actuation on the valves. In Figure 4.14, an example of the signal registered is shown, where the iddle signal and the camshaft actuation can be easily diferentiated. This signal is processed, and the two extreme edges (rising and falling) are identified. These edges correspond to the EVO and EVC, respectively, and once these angles are defined, the midpoint position calculation is strightforward.

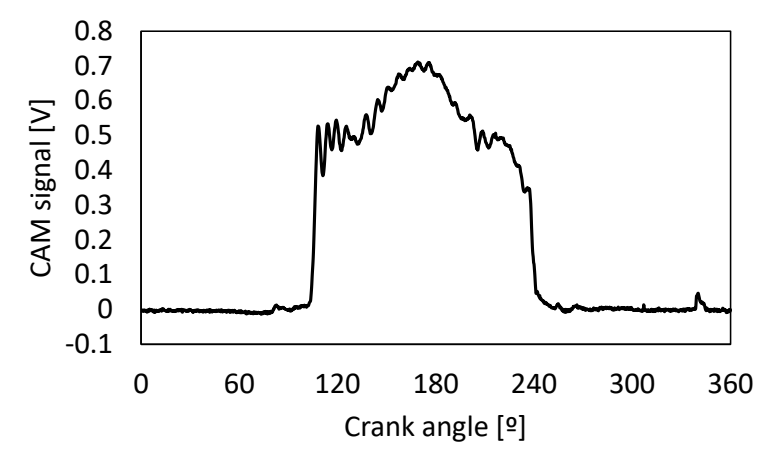

Figure 4.14. Registered signal of the strain gauge installed in the exhaust valves system.

This measurement, besides providing the VVT position, is also used to control the valve clearance. This extra verification is made with the experimental estimated EVO and EVC and the measured valve lift profile ${ }^{1}$. Once the values of EVO and EVC are experimentally determined, these are

\footnotetext{
${ }^{1}$ This valve lift profile is measured before installing the camshaft, during the cam profile (and, thus, the camshaft) characterization.
} 
placed on the valve lift profile to estimate the valve clearance, as shown in Figure 4.15 , if the obtained value is out of an acceptable range ${ }^{2}$, the valves system should be inspected and readjusted.

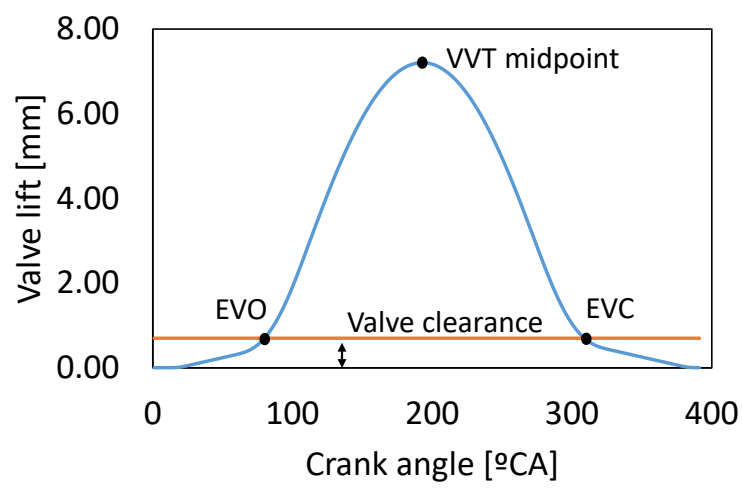

Figure 4.15. Valve lift profile, definition of the interesting angles and the valve clearance.

\subsubsection{Knock estimation (MAPO)}

The MAPO (Maximum Amplitude of Pressure Oscillations) is the parameter selected to detect and monitor the appearance of knock during the engine operation, which is based on the analysis of the high frequency amplitudes of the in-cylinder pressure signal $[22,23]$. To obtain the MAPO, the raw pressure signal is band-pass filtered (between 5 and $20 \mathrm{kHz}$ ), and the maximum amplitude of the resulting signal is taken.

When the MAPO value surpasses a given limit, the knock is considered too high and the engine operation should be interrupted unless some settings are modified to reduce this parameter. The MAPO limit is considered to depend linearly with the engine speed [24]. In this case, the defined limits have been $1.8 \mathrm{bar}$ at $2000 \mathrm{rpm}$ and $3.8 \mathrm{bar}$ at $4000 \mathrm{rpm}$.

\footnotetext{
${ }^{2}$ The acceptable range for this clearance is located on the ramps (opening and closing ramps), i.e. the areas with very low slope at the beginning and the end of the valve lift profile.
} 


\subsubsection{Estimation of the charge composition inside the cylinder}

The charge composition in this engine results from the combination of the gases (air, or air + EGR) coming from the intake and those remaining inside the cylinder after the scavenging process. Apart from that, since this is a $2 \mathrm{~S}$ engine, the effect of the trapping ratio has to be taken into account, because not all the introduced gases will remain inside the cylinder during the closed cycle.

\section{Trapping ratio}

The trapping ratio (TR), also known as trapping efficiency, is the result of the ratio between the intake mass trapped inside the cylinder and the total intake mass. Under the assumption that the engine is operating without EGR, this parameter is the indicative of the rate of fresh air enclosed inside the cylinder during the scavenging process. For the determination of this parameter, an experimental measurement of the fresh air quantity in the intake and exhaust manifolds is performed. This measurement is made by the introduction of a known amount of methane in the intake manifold, and measuring the methane increase in the exhaust manifold derived from this external source. This technique is known as the gas-tracer technique [25], which is quite usual in the context of $2 \mathrm{~S}$ engines.

The procedure to measure the trapping ratio of the engine for a determined operating point (with or without EGR), in steady conditions, is divided in the following steps:

- Initial measurement of the methane concentration in the intake and exhaust without any methane injection. In this step, the methane concentration in the fresh air (hopefully 0) and the "natural emissions" derived from the combustion process are measured, to be removed later from the measurements with externally added methane.

- Second measurement. In this step, methane is introduced in the intake manifold and regulated until reaching a constant concentration during the operation.

The amount of methane to be introduced in the intake manifold to ensure the correct measurement of the trapping ratio without affecting excessively the combustion, has been considered to be between 1000 and $1500 \mathrm{ppm}$. Once the operation is stabilized, the operating point is measured and processed together with the additional information collected during the previous measurement. 
During the processing, the trapping ratio is calculated as shown in Equation 4.20, where $X_{C H 4}^{e x h}$ and $X_{C H 4}^{i n t}$ represent the methane concentration in the engine exhaust and intake, respectively, during the test with methane injection and $X_{0, C H 4}^{e x h}$ and $X_{0, C H 4}^{i n t}$ are the methane concentrations measured in the engine exhaust and intake, respectively, during the test without methane injection. The rest of the variables are: $\dot{m}_{\text {air }}$ (intake fresh air mass flow), $\dot{m}_{f}$ (Fuel mass flow), $\dot{m}_{\text {air inj }}$ (air mass flow introduced by the injection system), $\dot{m}_{E G R}$ (EGR mass flow), $\dot{m}_{\text {del }}$ (delivered mass flow, i.e. $\dot{m}_{\text {air }}+\dot{m}_{E G R}$ ), and $\eta_{\text {comb }}$ (the combustion efficiency). This last term is included to take into account the part of the methane introduced inside the engine that has not burnt. Finally the amount of intake gas retained will be defined as $\dot{m}_{r e t}$ and the shortcircuited mass as $\dot{m}_{\text {short }}$ (Eqs. 4.20, 4.4 and 4.5).

$T R=\frac{\left(X_{C H 4}^{e x h}-X_{C H 4}^{0, e x h}\right) \cdot\left(\dot{m}_{d e l}+\dot{m}_{f}+\dot{m}_{a i r ~ i n j}\right)-(1-\eta) \cdot X_{C H 4}^{i n t} \cdot \dot{m}_{d e l}}{\left(X_{C H 4}^{i n t}-X_{0, C H 4}^{i n t}\right) \cdot \dot{m}_{d e l}}$

$$
\dot{m}_{r e t}=\dot{m}_{d e l} \cdot T R=\left(\dot{m}_{a i r}+\dot{m}_{E G R}\right) \cdot T R
$$

$$
\dot{m}_{\text {short }}=\dot{m}_{d e l} \cdot(1-T R)=\left(\dot{m}_{\text {air }}+\dot{m}_{E G R}\right) \cdot(1-T R)
$$

Consequently, by this method, the TR can be accurately measured in different operating conditions, except in operating points where the exhaust temperature is above the methane oxidation temperatures (around $537{ }^{\circ} \mathrm{C}$ ). Above these exhaust temperatures, the trapping ratio measurements start to lose their reliability, since the methane is also burnt in the exhaust manifold. Consequently, this methodology is difficult to be applied at high loads.

\section{IGR}

The IGR (Internal Gas Recirculation) is the amount (in terms of proportion) of residual hot gases remaining inside the cylinder once the gas exchange process is over. Unlike other parameters, this one cannot be measured directly and has to be estimated from other measurements and making different hypotheses to set the data required for its determination. 
To estimate this parameter, first, it is necessary to know the fresh charge amount trapped in the cylinder (the trapping ratio determined as indicated in the previous paragraph). Once this is known, the trapped residual gases are estimated with the equation of state and an in-cylinder enthalpy balance at the beginning of the compression process (also described in [25]), with the following assumptions: the trapped air is assumed to have the temperature measured in the intake manifold (i.e. around the intake ports), and its quantity is known thanks to the trapping ratio determined previously; the residual gases temperature is calculated from the temperature measured in the exhaust manifold, taking into account the possible amount of short-circuited fresh charge; the in-cylinder pressure is assumed to be the one measured in the cylinder at the corresponding crank angle. To have this last information, as already mentioned above in Section 4.2, a piezo-resistive pressure sensor was installed near BDC, to be able to measure this pressure. Finally, with the two equations mentioned above, the mass and temperature of the residuals is determined with Equations 4.6 and 4.7.

$$
\begin{gathered}
T_{I G R}=\frac{c_{p_{e x h}} \cdot\left(\dot{m}_{\text {del }}+\dot{m}_{f}\right) \cdot T_{\text {exh }}-c p_{\text {short }} \cdot \dot{m}_{\text {short }} \cdot T_{\text {short }}}{c p_{\text {exh }} \cdot\left(\dot{m}_{\text {del }}+\dot{m}_{f}+\dot{m}_{\text {short }}\right)} \\
m_{I G R}=\frac{c_{p_{\text {int }}} \cdot P_{I V C} \cdot V_{I V C}}{c_{p_{\text {exh }}} \cdot R_{I V C} \cdot T_{I G R}}-\frac{c_{p_{\text {int }}} \cdot m_{\text {air ret }} \cdot T_{\text {air ret }}}{c_{p_{\text {exh }}} \cdot T_{I G R}}- \\
\frac{m_{E G R ~ r e t} \cdot T_{E G R ~ r e t}}{T_{I G R}}
\end{gathered}
$$

\section{Fuel/Air equivalence ratio calculation and definitions}

The Fuel/Air ratio is the ratio between the mass of air and that of fuel available during the combustion process. This parameter can be represented in different ways depending on the hypotheses or simplifications applied. The first and more commonly used representation is the estimation of this parameter from the intake air mass flow rate and the fuel mass flow rate, which is known as the apparent $\mathrm{F} / \mathrm{A}$ ratio (Eq. 4.8).

$$
\text { apparent } F / A \text { ratio }=\dot{m}_{f} / \dot{m}_{\text {air }}
$$

From this definition the apparent $\mathrm{F} / \mathrm{A}$ equivalence ratio can be determined making use of the stoichiometric $\mathrm{F} / \mathrm{A}$ ratio (value that represents the exact 
amount of fresh air to oxidize the $100 \%$ of the fuel). So, if the apparent $\mathrm{F} / \mathrm{A}$ ratio is divided by the stoichiometric $\mathrm{F} / \mathrm{A}$ ratio, the apparent $\mathrm{F} / \mathrm{A}$ equivalence ratio is obtained (noted also as Fr), and this is a commonly used parameter to refer to the fuel/air ratio during the engine operation. To continue with the discussion, it will be assumed that no EGR is performed in the engine. Under this assumption, in $4 \mathrm{~S}$ engines, usually the apparent $\mathrm{F} / \mathrm{A}$ equivalence ratio matches quite well with the "real" $\mathrm{F} / \mathrm{A}$ equivalence Ratio, since the amount of air measured in the intake is virtually equal to the air enclosed inside the cylinder. But in a $2 \mathrm{~S}$ engine, the apparent $\mathrm{F} / \mathrm{A}$ eq. ratio calculated from the intake mass flow and the fuel mass flow can differ compared to the final $\mathrm{F} / \mathrm{A}$ eq. ratio of the in-cylinder charge during the engine operation. So in this point, two possible obtained values have to be differentiated, the apparent $\mathrm{F} / \mathrm{A}$ equivalence ratio and the in-cylinder (or "real") F/A equivalence ratio, defined in Equation 4.9. In the first case, the total amount of intake air is taken into account, whereas in the other case, the intake air fraction enclosed inside the cylinder is taken into account to obtain the Fr. Therefore, in this last value, the TR is taken into account.

$$
\begin{aligned}
F r_{\text {app }} & =\frac{F / \text { A eq. ratio }}{\text { stoichiometric } F / A \text { eq. ratio }} \\
F r_{c y l} & =\frac{F / A \text { eq } \cdot \text { ratio } \cdot \frac{1}{T R}}{\text { stoichiometric } F / A \text { eq. ratio }}
\end{aligned}
$$

As already indicated, all these parameters have been obtained considering operation without EGR introduction. If EGR is introduced, the main difference is that the intake gas (air + EGR) would have a variable oxygen concentration. Therefore, the $\mathrm{F} / \mathrm{A}$ equivalence ratio has to be defined in the same way but taking into account the $\mathrm{F} / \mathrm{O}$ (fuel to oxygen ratio), so as to obtain a parameter that is not affected by the EGR introduction.

\section{EGR}

The measurement of the EGR rate is performed based on the $\mathrm{CO}_{2}$ content in the intake and in the exhaust gases. With this twofold measurement performed by the Horiba MEXA-7100D-EGR, the EGR content in the intake charge can be determined using Equation 4.10.

$$
\tau_{E G R}=\frac{C O_{2} \text { int }-C O_{2} \text { atm }}{C O_{2} \text { exh }-C_{2} \text { atm }}
$$


where $\mathrm{CO}_{2}$ atm is the $\mathrm{CO}_{2}$ content in the ambient. Once this rate has been found, the EGR mass flow rate $\left(\dot{m}_{E G R}\right)$ is obtained from the air mass flow rate $\left(\dot{m}_{\text {air }}\right)$ :

$$
\dot{m}_{E G R}=\dot{m}_{a i r} \cdot \frac{\tau_{E G R}}{1-\tau_{E G R}}
$$

Together with this subsection, the Appendix 4.B has been included, and inside this extra documentation, the scheme of the different gas flows inside the engine is defined.

\subsubsection{Combustion data}

\section{Heat Release Law and Heat Release Rate}

The Heat Release Law (HRL) and its derivative, the Heat Release Rate (HRR), are calculated by the ULCGE software using the classical combustion analysis approach. This one makes use of the instantaneous in-cylinder pressure, and applies the first law of thermodynamics and a heat losses model based on the Woschni equation.

\section{Combustion phasing}

The combustion phasing is detailed for the 10, 25, 50, 75 and $90 \%$ of the total heat released. Each position is calculated by means of the HRL estimated values, being for example the CA10 the angular position where the HRL has reached $10 \%$ of its maximum value.

\section{Combustion efficiency}

This parameter is estimated based on the concentration of $\mathrm{HC}, \mathrm{CO}$ and soot measured in the exhaust gases during the engine operation. Thanks to a mass balance, and assuming that the LHV (Lower Heating Value) of the CO is around 4 times lower compared to that of the fuel, and that the LHV of the soot is 1.25 times lower, the ratio between the introduced fuel and the fuel completely burnt can be obtained.

$$
\eta_{c o m b}=1-\frac{m_{H C}+\frac{m_{C O}}{4}+\frac{m_{\text {soot }}}{1.25}}{m_{f}}
$$

Usually, the Soot term is neglected because it represents a very small mass fraction of the exhaust gases. 


\section{Combustion stability}

The combustion stability is estimated by means of the standard deviation of all the IMEP values registered during the test. This value is called $\sigma \mathrm{IMEP}$. In order to normalize this parameter, an $\sigma \mathrm{IMEPlim}$, which defines the maximum $\sigma$ IMEP to be considered acceptable, will be defined and used. This $\sigma \mathrm{IMEPlim}$ is taken assuming a limit value for the $\mathrm{COV}_{I M E P}(\sigma \mathrm{IMEP} / \mathrm{IMEP})$ of $6 \%$, which is equivalent to $3 \%$ in a $4 \mathrm{~S}$ engine. As a result, the parameter $\sigma \mathrm{IMEP} / \sigma \mathrm{IMEPlim}$ that will be obtained will be indicative of the relative stability of the combustion, being 1 its upper limit.

\subsubsection{BSFC estimation}

The single-cylinder prototype engine used in this research is far from the real engine in many aspects. First, it has not installed its own mechanical blower, driven by the crankshaft. Instead, the intake air is blown by an external compressor available in the test cell. And, second, the SCE presents also different values for the mechanical losses compared to the twin-cylinder engine, for several reasons: in the SCE there are two counter-rotating balance shafts installed for inertia compensation, and these will not be used in the real engine; an oil injector is used in the SCE, whereas it will not be used in the TCE (twin cylinder engine); the crankshaft holders in the SCE are bigger compared to the ones intended to be used in the TCE, etc. Because of these many differences, it is important to adapt the calculations to estimate the brake parameters for the real engine, in such a way that these parameters are more fair and useful for comparison. For this reason, the BMEP (Brake Mean Effective Pressure) and the BSFC (Brake Specific Fuel Consumption) are estimated from the IMEP (Indicated Mean Effective Pressure), taking into account the following mechanical losses ${ }^{3}$ :

- The friction losses and the driving power of the water pump, using a suitable correlation as a function of the engine speed. This correlation (shown in Eq. 4.13) was provided by Renault, based on their expertise.

$$
P_{\text {fric }}=\frac{a \cdot N^{3}+b \cdot N^{2}+c \cdot N^{1}-d}{1000}[k W]
$$

\footnotetext{
${ }^{3}$ For confidentiality reasons, only the type of correlations and the parameters considered for the estimation of the different losses will be presented here.
} 
- The work performed by the mechanical blower supplying the intake air $\left(P_{\text {rotrex }}\right)$, using an experimental correlation after testing the real blower.

The correlation mentioned above depends on the engine speed and the mass flow rate. No further details are provided here for confidentiality reasons.

- The work performed by the high pressure compressor supplying the air for the fuel injection system.

This correlation has the same aspect as the friction losses. It was obtained from an experimental characterization of the compressor intended to be used in the TCE, and shown in Eq. 4.14.

$$
P_{i n j}=\frac{a \cdot N^{3}+b \cdot N^{2}+c \cdot N^{3}-d}{1000}[k W]
$$

After considering all these losses, the Brake Power $\left(P_{\text {brake }}\right)$, the BMEP and, thus, the BSFC of the twin-cylinder engine can be properly estimated making use of the expressions shown in Eqs. 4.15, 4.16 and 4.17:

$$
\begin{gathered}
P_{\text {brake }_{T C E}}=2 \cdot P_{\text {ind }_{S C E}}-P_{\text {rotrex }}-P_{\text {fric }}-P_{\text {inj }}[k W] \\
B M E P=\frac{P_{\text {brake }} \text { TCE }}{\left(N * 2 * V_{t}\right)}[\text { bar }] \\
B S F C=\frac{2 \cdot \dot{m}_{f}}{P_{\text {brake }} T C E}[g / k W h]
\end{gathered}
$$

where both $V_{t}$ and $m_{f}$ refer to the SCE, and $\mathrm{N}$ is the engine speed in rps.

\subsubsection{Testing methodologies}

Along this subsection the procedures used during the experimental tests are going to be discussed. Along the discussion, the reasons to perform the tests in one or another way will be explained, as well as the necessary routines and verifications to ensure the correct management of the experimental equipment and the quality control of the recorded data. 


\section{Tests procedures}

The engine and the facilities available in the test cell are subject to hard operating conditions derived from the necessary tests. For this reason, the wear and possible failures of the facilities have to be strictly controlled, to ensure the correct operation of all the devices, as well as the data quality obtained from them along the time. For this purpose, the use of the experimental facilities should follow a strict procedure. This one can be divided in three main parts: start-up, measurement and shut-down procedures (see Table 4.6).

\begin{tabular}{lll}
\hline Start-up procedure & Measurement procedure & Shut-down procedure \\
\hline \hline Engine warm-up & Engine test session & Engine cool down \\
Offset determination & & Shut down of the lu- \\
and sensors checkup & bricating and cooling \\
& systems \\
Validation tests & Shut down of the test \\
& cell \\
\hline
\end{tabular}

Table 4.6. Detail of the testing procedures.

- The start-up procedure is considered the most important one, since all the facility is checked and prepared to be used. So, in this phase, the test cell is initiated, checked and calibrated.

The initial tasks are a sequential initiation of the different systems, as well as the warm-up of the oil and coolant until reaching the desired temperature. Once this work is done, all the sensors are checked and a measurement with the engine stopped at atmospheric conditions is launched. This measurement has two purposes: the first one is to check that all the sensors are working properly; and the other one is to use it later during the tests of that day to remove any "offset" in the signal of the sensors, and to put all of them in the same reference level (specially the pressure sensors and the flowmeters). With this procedure, the measuring system is daily calibrated and the small deviations are removed. After that, the injection air circuit is pressurized, and a measurement with the two flowmeters used to determine the injected air mass is performed. Since the engine is still stopped, both flowmeters should indicate the same value. The eventual discrepancies found will be used to correct the 
registered values during the subsequent tests, to obtain a more accurate value for the injected air during them. Finally, the engine operation is also checked measuring three standardized operating points: the first is a motored test, the second is a low load operating point and, finally, for the third measurement the engine load is increased to high load conditions. Since these points are always the same, they are used to check the repeatability of the engine operation. In this way, any problem in the engine or in the measuring devices can be detected before starting the engine test campaign, where it would be more difficult to detect any small problem in the engine or in the measuring devices.

- During the testing campaign, the measurement of the set of tests planned for the day is carried out under controlled conditions and defined methodologies.

First, it has to be noted that the in-cylinder pressure in all these tests is a critical measurement, since the results obtained are strongly dependent of the proper measurement of that variable. For this reason, the measurement of this variable is performed twice by two different pressure sensors, and the deviation between these two sensors during each test is checked, as an imperative condition to consider the test as being valid.

All the tests performed follow the same measuring methodology. First the operating conditions are adjusted and controlled, until reaching a stationary operation of the engine at the desired operating conditions. Once these conditions are reached the point is measured. There are two measurement types: averaged and instantaneous data. For the averaged data, each sensor registers its corresponding magnitude during 60 seconds, at a sampling rate of $10 \mathrm{~Hz}$, and later this data is averaged, whereas for the instantaneous data (instantaneous pressure signals, mainly), a set of 250 cycles are measured and stored, to process them later.

Finally, during the tests, there are some control parameters to protect the engine integrity during its operation. These control parameters are the knock monitoring (defined in Section 4.4.2), some key temperatures (e.g. in the coolant and in the test cell), and the oil and coolant mass flow rates. If any of these parameters is out of the defined range, the engine is immediately stopped. And additionally, the cylinder pressure sensors drift, the exhaust pressure, the combustion stability and the correct measurements of the exhaust gas analyzer are extra control parameters used to reject the saved data if they are not inside the defined ranges. 
- The shut-down procedure is the most simple of the three parts of the testing procedure, but it's also important to follow a minimum procedure to keep the facility in the better conditions and avoid any damage derived from a wrong procedure. After the operation of the engine, this one has to be left in operation under motoring conditions and with a minimum intake pressure, until the exhaust manifold temperature is below 200 ${ }^{\circ} \mathrm{C}$. The oil and water systems have to follow a sequential switch off procedure: first, the heaters have to be disconnected and the pumps must remain working for a few minutes (this is because if all the system is totally disconnected immediately, the residual heat of the heaters would damage the portion of the oil and coolant that remains inside these devices). After this, all the systems are disconnected in a predefined order. And, finally, as preventive procedure, all the intake discharge valves have to be opened before leaving the facility, and all the power supplies have to be disconnected.

\section{Tests definition}

The tests sets for each campaign are defined depending on the work to perform at that time. Since the engine is in an early development stage, these sets can be very different depending on the scheduled work (testing of new configurations, CAI tests, SI lean combustion tests, engine performance optimization...). Usually the general methodology has been to define sets of tests where two parameters are swept. By this way the data obtained isolates the influence of the parameters tested, and those results can be used to study the influence of those parameters on the engine performance, and also to search for the optimum combination of both for a given engine output.

The parameters to be swept are often related to each other. For example, one set of tests can be a combined variation of the VVT position and the Fr, obtaining detailed maps of different engine parameters (e.g. exhaust temperature, BSFC, etc.) for a given operating point. Or a SOI - DOI variation, where the influence of the injection settings can also be studied for an operating region of the engine. Apart from these more "standardized" sets, load variations, combustion phasing variations and any other required tests have also been performed. But, in any case, always the general methodology has been to define a parameter to be swept, and to study its individual impact on the engine performance.

All along this work, the definition of the operating points has been done, on the one hand, by a given engine speed and, on the other hand, by a fixed fuel amount, being the latter approximately representative of the load degree on 
the engine map. The operation at constant load is a common practice in real engines, but this is not the case in the current research: the engine is a SCE, merely representative of a real engine; therefore, the real load degree is not a direct measurement, and it should be estimated online (which is not evident) if the engine is intended to be operated in this way (at constant load). By this alternative (operation at constant fuel amount), the testing procedures are much simplified, and the engine management is much faster. Based on that, the definition of the operating points will be as "rpm@mf", where "rpm" is the engine speed in rpm and mf the injected fuel mass per cycle. This nomenclature to identify the operating points will be used along the whole document.

\section{A Estimation of the humidity loss through the EGR system}

The loss of water contained in the exhaust gases during the EGR recirculation is estimated in order to know the final humidity of the intake gases when EGR is introduced. To this end, the following steps have been followed:

- The humidity of the exhaust gases $\left(X_{H 2 O_{e x h}}\right.$, molar fraction) is estimated taking into account the fuel composition and the apparent $\mathrm{F} / \mathrm{A}$ eq. ratio.

- In order to estimate the water condensation, the EGR path from the exhaust to the engine is divided in two parts. In this way two possible condensation events are taken into account:

- The first part covers the part of the gas recirculation from the exhaust extraction to the intake duct introduction (see Fig. 4.9, page 118). In this part, the exhaust gas is filtered, compressed, and its temperature is controlled by a heat exchanger installed.

Along the first part, the temperature of the gas is considered to be the same as the one of the heat exchanger $\left(T_{H E}\right)$, and the pressure $\left(p_{E G R}\right)$ is considered to be 200 mbar higher than the intake pressure. With this data the water saturation pressure of a gas in those conditions and the water partial pressure of the exhaust gas are calculated. Finally, the water condensation is estimated taking into account that the Water Saturation Pressure must be equal or higher than the Water partial pressure. If not, the difference between both 
is the amount of condensed water. And the new molar fraction of water on this first part of the circuit is recalculated.

$$
\text { W.Sat.press. }=10^{5.074-\frac{1675.4}{T_{H E}+273.15-46.13}} \text { [bar] }
$$

$$
\text { W.Part.press. }=P_{E G R} \cdot X_{H 2 O_{e x h}}[\text { bar }]
$$

- The second part takes into account the EGR gas introduction in the intake duct and the corresponding mixture with the fresh air.

For this second part, the EGR gas is combined with the fresh air coming from the upstream intake. The water content at this point on the EGR gas is the one estimated during the previous step. Therefore, the total water content on the intake mixture is calculated as a combination of the humidity coming from the fresh air and the humidity coming from the EGR.

From this point the procedure is the same as before: the water saturation pressure of that gas (at the intake temperature) is calculated, and with the estimated water partial pressure of the intake gases, the water condensation of this second part is determined. At this point, the humidity of the intake gases $\left(Y_{H 2 O_{i n t}}\right.$, mass fraction) and the water condensation fraction can be calculated.

$$
\text { Water loss }=\frac{\tau_{E G R} \cdot Y_{H 2 O_{e x h}}+\left(1-\tau_{E G R}\right) \cdot Y_{H 2 O_{a i r}}-Y_{H 2 O_{i n t}}}{\tau_{E G R} \cdot Y_{H 2 O_{e x h}}+\left(1-\tau_{E G R}\right) \cdot Y_{H 2 O_{a i r}}} .
$$

where $\tau_{E G R}$ is the EGR rate, and $Y_{H 2 O_{e x h}}$ is the water mass fraction in the exhaust gases, $Y_{H_{2} O_{a i r}}$ is the water mass fraction on the fresh intake air.

This estimation has two purposes: the first one, previously stated, is to consider the correct humidity of the intake gases when EGR is introduced in the engine; and the second one, to optimize the heat exchanger temperature to avoid water condensations along the first part of the EGR circuit. 


\section{B Estimation of the different mass flows inside the engine}

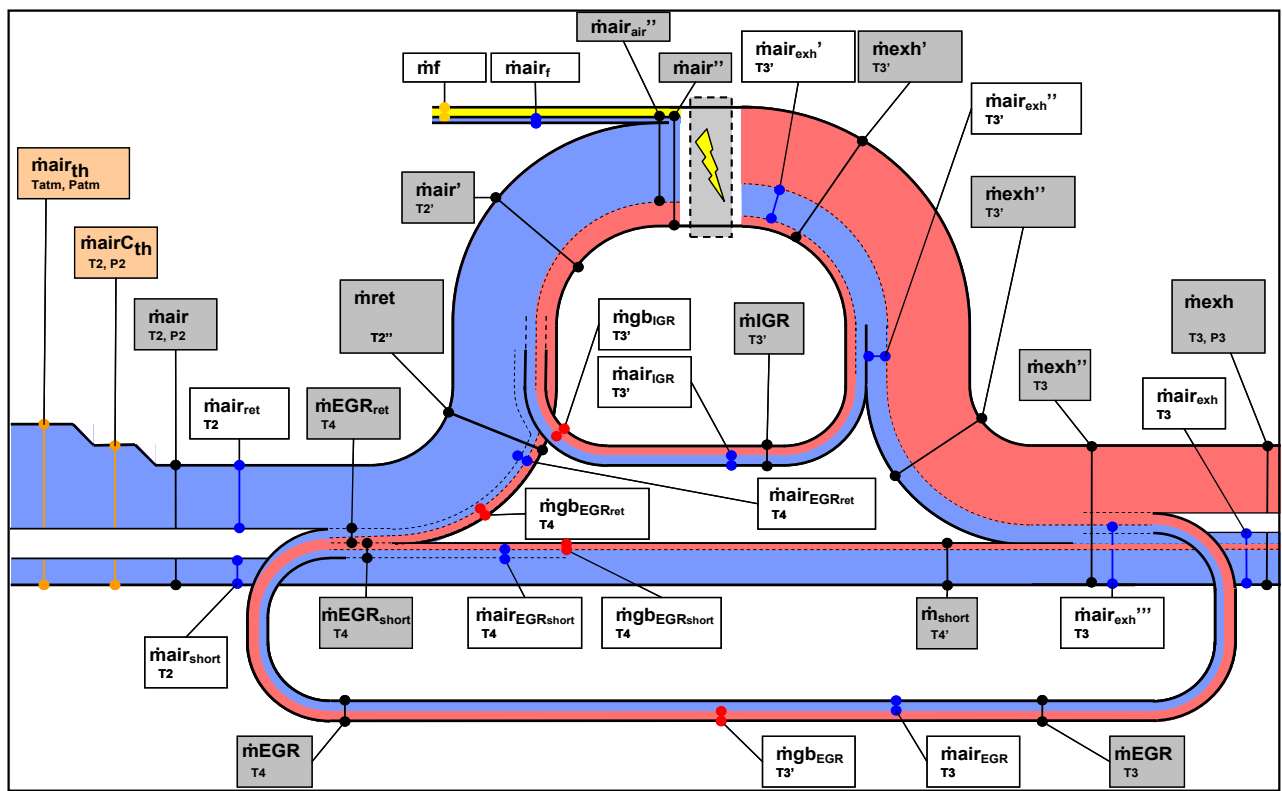

Figure 4.16. Schematics of the different gas flows and compositions along the engine.

In this appendix a detail of the considered schematics to calculate the composition of the intake, in-cylinder and exhaust gases is given in Figure 4.16. As can be seen in the figure, the different mass flows are represented in two colors: in blue color fresh air, and in red color stoichiometric exhaust gases.

Finally, along the following lines, each label is going to be described, in order to understand the assumed composition of the charge moving inside the engine:

\section{Intake mass flows:}

$\dot{m a i r}$, $\dot{m a i r} C_{t h}$, mair: these flows are the fresh air mass flow rate introduced in the intake. The three variables consider different conditions: Atmospheric, intake duct and just before getting inside the cylinder.

$\dot{m}^{2} i_{r e t} / \dot{m}_{\text {air }}$ short: the first one is the amount of air trapped in the cylinder and the second one is the amount of air lost through the exhaust valves (shortcircuited mass). 
$\dot{m} E G R / \dot{m} E G R_{\text {ret }} / \dot{m} E G R_{\text {short }}$ : this is the EGR mass flow, and the following variables are the EGR retained inside the cylinder and the EGR lost through the exhaust valves (shortcircuited).

This $\dot{m} E G R$ is composed of fresh air ( $\dot{m a i r}_{E G R}, \dot{m}^{2} \operatorname{ir}_{E G R_{r e t}}$ and $\left.\dot{m a i r}{ }_{E G R_{\text {short }}}\right)$ and stoichiometric exhaust gases $\left(\dot{m} g b_{E G R}, \dot{m} g b_{E G R_{\text {ret }}}\right.$ and

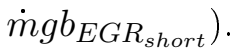

\section{In-cylinder mass flows:}

$\dot{m} a i r^{\prime}$ / $\dot{m} a i r^{\prime \prime}:$ the first one is the total charge trapped inside the cylinder before the injection event, whereas the second takes into account also the air mass flow coming from the injection (air assisted system).

$\dot{m} f / \dot{m a i r}_{f}$ : these variables represent the mass flows of fuel and air introduced in the cylinder by the injection system.

$\dot{m a i r}{ }_{a i r}^{\prime \prime}$ : this is the fresh air mass flow inside the cylinder (coming both from the intake and the injection system).

$\dot{m} I G R / \dot{m} g b_{I G R} / \dot{m} a i_{I G R}$ : this variable represents the IGR mass in the cylinder and, like the EGR, it is composed by stoichiometric exhaust gases and fresh air.

\section{Exhaust mass flows:}

$\dot{m}_{\text {short }}$ : this variable represents the mass flow lost from the intake to the exhaust.

$\dot{m} e x h / \dot{m} a i r_{e x h}$ : this first value of the $\dot{m} e x h$ represents the final mass flow through the exhaust (without EGR and IGR), and $\dot{m a i} r_{\text {exh }}$ the fraction of fresh air contained in these gases.

$\dot{m} e x h^{\prime} / \dot{m} a i r_{e x h}^{\prime}$ : this second value represents the total amount of mass inside the cylinder after combustion $\left(\dot{m} a i^{\prime \prime}+\dot{m} f\right)$.

$\dot{m} e x h^{\prime \prime} / \dot{m a i r} r_{e x h}^{\prime \prime}$ : this third value represents the exhaust mass flow coming from the combustion without the $\dot{m} I G R$.

$\dot{m} e x h^{\prime \prime \prime}$ : this last value represents the exhaust mass flow taking into account the shortcircuited gases and the EGR.

\section{Bibliography}

[1] Sturm S., Schmidt S. and Kirchberger R. "Overview of Different Gas Exchange Concepts for Two-Stroke Engines". SAE Technical Paper n. 2018-32-0041, 2018. 
[2] Kyrtatos N.P. and Koumbarelis I. "A three-zone scavenging model for two-stroke uniflow engines". Journal of Engineering for Gas Turbines and Power, Vol. $110 \mathrm{n}^{\circ}$ 3, pp. 531$537,1988$.

[3] Andersen F.H. and Mayer S. "Parametric study of the scavenging process in marine twostroke diesel engines". ASME 2015 Internal Combustion Engine Division Fall Technical Conference, ICEF 2015, Vol. 1, 2015.

[4] Turner J.W.G., Head R.A., Wijetunge R., Chang J., Engineer N., Blundell D.W. and Burke P. "Analysis of different uniflow scavenging options for a medium-duty 2-stroke engine for a U.S. light-truck application". ASME 2018 Internal Combustion Engine Division Fall Technical Conference, ICEF 2018, Vol. 2, 2018.

[5] Wang X., Ma J. and Zhao H. "Analysis of scavenge port designs and exhaust valve profiles on the in-cylinder flow and scavenging performance in a two-stroke boosted uniflow scavenged direct injection gasoline engine". International Journal of Engine Research, Vol. $19 \mathrm{n}^{\circ}$ 5, pp. 509-527, 2018.

[6] Wang X. and Zhao H. "A High-Efficiency Two-Stroke Engine Concept: The Boosted Uniflow Scavenged Direct-Injection Gasoline (BUSDIG) Engine with Air Hybrid Operation". Engineering, Vol. 5 n $^{\circ}$ 3, pp. 535-547, 2019.

[7] Ding Y., Li J., Xiang L. and Zhang Y. "Two-zone simulation modeling of gas exchange process of super-long-stroke low-speed diesel engine". Journal of Harbin Engineering University, Vol. $40 \mathrm{n}^{\circ}$ 1, pp. 210-216, 2019.

[8] Konrad R. Dieselmotor-Management im Überblick. 2nd edition. Springer, 2014.

[9] Heywood JB. Internal combustion engine fundamentals. McGraw-Hill, 1988.

[10] Pairy F. and Desantes J.M. Motores de combustión interna alternativos. Editorial Reverté and Editorial UPV, 2011.

[11] Superchargers Rotrex. "Rotrex Technical Handbook". Official technical handbook for Rotrex C-type superchargers, 2014.

[12] Cathcart G. and Zavier C. "Fundamental characteristics of an air-assisted direct injection combustion system as applied to 4-stroke automotive gasoline engines". SAE Technical Paper n. 2000-01-0256, 2000.

[13] Christian R., Knopf F., Jasmek A. and Schindler W. "A new method for the filter smoke number measurement with improved sensitivity". MTZ Motortechnische Zeitschift, Vol. 54, pp. 16-22, 1993.

[14] Lapuerta M. "Un modelo de combustión fenomenológico para un motor Diesel de inyección directa rápido". PhD thesis. Universitat Politècnica de València, Departamento de Máquinas y Motores Térmicos, 1988.

[15] Armas O. "Diagnóstico experimental del proceso de combustión en motores Diesel de inyección directa". PhD thesis. Universitat Politècnica de València, Departamento de Máquinas y Motores Térmicos, 1998.

[16] Lapuerta M., Armas O. and Hernandez J.J. "Diagnosis of DI Diesel combustion from in-cylinder pressure signal by estimation of mean thermodynamic properties of the gas". Applied Thermal Engineering, Vol.19 no5, pp.513-529, 1999.

[17] Lapuerta M., Armas O. and Bermúdez V. "Sensitivity of diesel engine thermodynamic cycle calculation to measurement errors and estimated parameters". Applied Thermal Engineering, Vol. $20 \mathrm{n}^{\circ}$ 9, pp. 843-861, 2000. 
[18] Martín J. "Diagnóstico de la combustión en motores Diesel de inyección directa". PhD thesis. Universitat Politècnica de València, Departamento de Máquinas y Motores Térmicos, 1998.

[19] Mehl M., Pitz W.J., Westbrook C.K. and Curran H.J. "Kinetic modeling of gasoline surrogate components and mixtures under engine conditions". Proceedings of the Combustion Institute, Vol. $33 \mathrm{n}^{\circ}$ 1, pp. 193-200, 2011.

[20] Mehl M., Chen J.Y., Pitz W.J., Sarathy S.M. and Westbrook C.K. "An approach for formulating surrogates for gasoline with application toward a reduced surrogate mechanism for CFD engine modeling". Energy and Fuels, Vol. $25 \mathrm{n}^{\circ} 11$, pp. 5215-5223, 2011.

[21] Senecal P.K., Richards K.J., Pomraning E., Yang T., Dai M.Z., McDavid R.M., Patterson M.A., Hou S. and Shethaji T. "A new parallel cut-cell cartesian CFD code for rapid grid generation applied to in-cylinder diesel engine simulations". SAE Technical Paper n. 200\%-01-0159, 2007.

[22] Zhen X., Wang Y., Xu S., Zhu Y., Tao C., Xu T. and Song M. "The engine knock analysis - An overview". Applied Energy, Vol. 92, pp. 628-636, 2012.

[23] Wang Z., Liu H. and Reitz R.D. "Knocking combustion in spark-ignition engines". Progress in Energy and Combustion Science, Vol. 61, pp. 78-112, 2017.

[24] Haenel P., Seyfried P., Kleeberg H. and Tomazic D. "Systematic approach to analyze and characterize pre-ignition events in turbocharged direct-injected gasoline engines". SAE Technical Paper n. 2011-01-0343, 2011.

[25] Benajes J., Novella R., De Lima D., Tribotté P., Quechon N., Obernesser P. and Dugue V. "Analysis of the combustion process, pollutant emissions and efficiency of an innovative 2-stroke HSDI engine designed for automotive applications". Applied Thermal Engineering, Vol. 58 n $^{\circ}$ 1-2, pp. 181-193, 2013. 



\section{Chapter 5}

\section{Engine peculiarities: description and analysis}

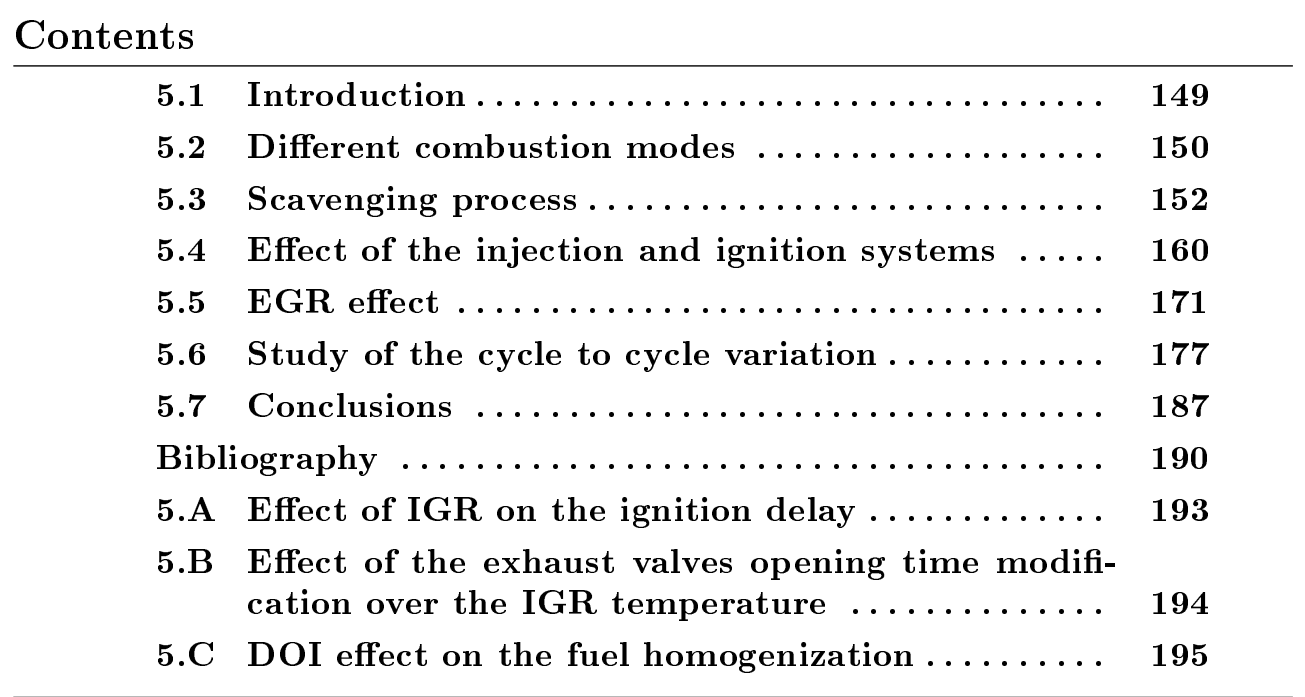





\subsection{Introduction}

The engine used in the present work is not a common engine used in other studies for research purposes or used by the industry for automotive applications. This is a unique prototype, developed in order to evaluate its potential as a different approach for a more efficient mobility. From its arrival to CMT it needed a complete set up, a definition of its optimal configuration and the design of the operating maps, since it was at an early stage of its development.

Compared to a standard $4 \mathrm{~S}$ solution, there are big differences and aspects to be understood on this engine:

- The scavenging process does not follow a classical model where each cycle is perfectly renewed independently. In these engines the scavenging process is incomplete and depends a lot on the load degree and on the scavenging configuration chosen [1].

- The injection system, instead of being a common gasoline injector (direct or ported), is a combination between a gasoline injector and an air injector. Due to that, the system injects an air/gasoline mixture, adding more degrees of freedom to configure the best injection strategy.

- The engine, although not being very common for gasoline engines, will also have an EGR system, in order to reduce the $\mathrm{NO}_{\mathrm{x}}$ emissions and to study its influence on combustion.

- And finally, this type of engine has a higher cycle to cycle variability than a $4 \mathrm{~S}$ engine, because of its peculiar scavenging process and the lean operation.

Moreover, there is also an interest to operate the engine in different combustion modes to study their application and potential. On the one hand, the operation in SI will be carried out with lean mixtures and, on the other hand, the operation in CAI will require specific strategies to achieve this type of combustion.

All these differences, peculiarities and needs make this chapter necessary to define and understand how to handle all the variables properly. The different aspects indicated above will be addressed in the following subsections. 


\subsection{Different combustion modes}

Because of its characteristics, this engine can switch between two different combustion modes: SI and CAI. The operation in one or the other mode mainly depends on the mixture reactivity, which will allow or not the autoginition of the mixture. The IGR ratio and the initial temperature of the in-cylinder charge are the main parameters having an influence on the mixture reactivity, allowing its adjustment. In fact, both parameters are strongly affected by the engine load, as illustrated qualitatively in Figure 5.1. As far as the engine load is reduced, the amount of air required by the engine is lower, and the scavenging process is less efficient, thus explaining why the IGR ratio increases, as it will be discussed later. Regarding the initial temperature of the in-cylinder charge, it is the result of an enthalpy balance between the fresh charge (at the intake temperature) and the IGR gases (at the exhaust temperature, as a first approach). The increase in IGR ratio as far as the engine load is reduced explains why the initial temperature of the charge increases initially. But at very low loads, this trend is reversed, which is justified by the decrease in exhaust temperature (i.e. the temperature of the IGR gases) due to the decreasing amount of burnt fuel mass.

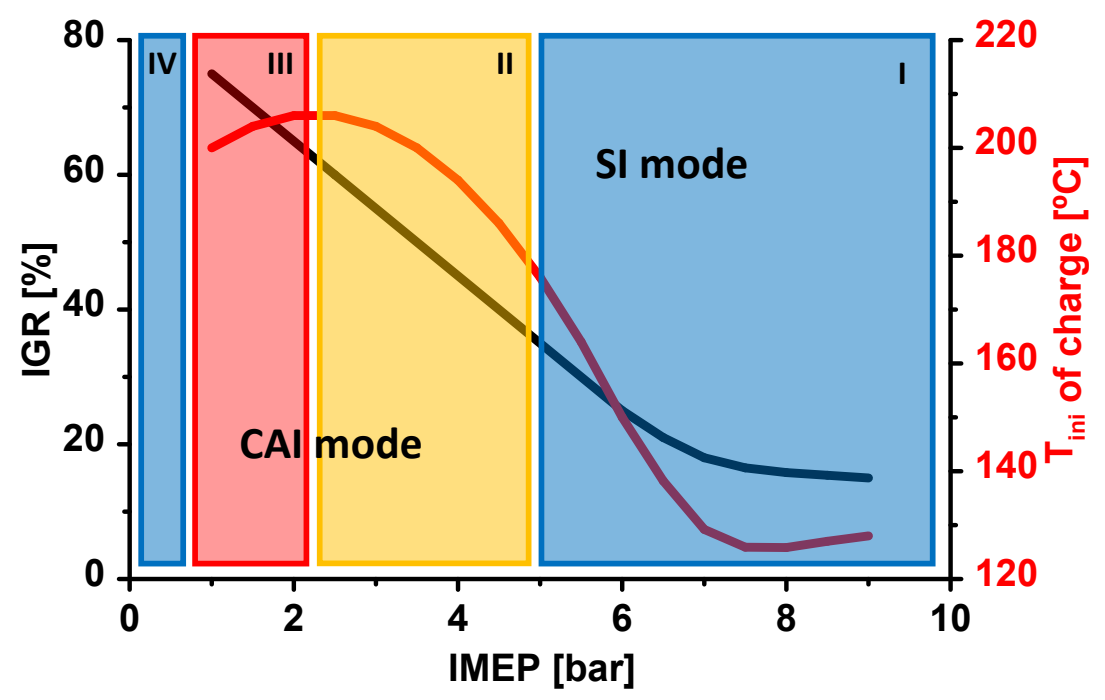

Figure 5.1. Evolution of the IGR ratio and the initial temperature of the in-cylinder charge with the engine load, and definition of the different combustion regions of the engine. 
- Region I: at high loads, where the IGR and the initial temperature of the charge are moderate, the combustion process is controlled by the spark, as in any conventional SI engine. In this scenario, the autoignition of the mixture is dangerous for the mechanical integrity of the engine (knock), and consequently it needs to be avoided.

- Region III: at low loads, the fuel burns in purely controlled autoignition (CAI) mode because of the enhanced reactivity of the in-cylinder charge caused by its high temperature (this is demonstrated in Appendix 5.A). This CAI operation mode introduces some advantages that will be further discussed later: increased engine stability, misfiring avoidance (which commonly takes place in engines operating with high percentages of residual gases), low $\mathrm{NO}_{\mathrm{x}}$, etc.

- Region II: between the two previous regions, at medium loads, a transition between SI and CAI takes place, and a hybrid combustion situation can appear.

- Region IV: there is also a small region at the lower loads, where the initial temperature of the charge is not enough to support a CAI combustion process. Despite the high amount of residual gases, these ones do not have the necessary temperature due to the small amount of fuel burned in the previous cycle.

In order to have an overall knowledge of the operation of the engine, and trying to optimize the amount of work, some operating points are set in an operation map as representative of the overall engine performance. These have been defined taking into account the different combustion regions that will be representative of the operation of the engine on the different areas defined in Figure 5.1. This set of selected operating points are shown in Figure 5.2, and are described here:

- Point 2000@17, at maximum torque, has been taken as representative for region I because of its importance in the engine map as being the maximum torque point.

- Points 2000@5 and 4000@5 have been taken as representative for region II. These are medium load points capable to be operated in SI and in CAI combustion modes.

- Point 2500@3 for region III at low load conditions. This point will be operated as CAI and also has a big relevance in standard cycles calculation. 


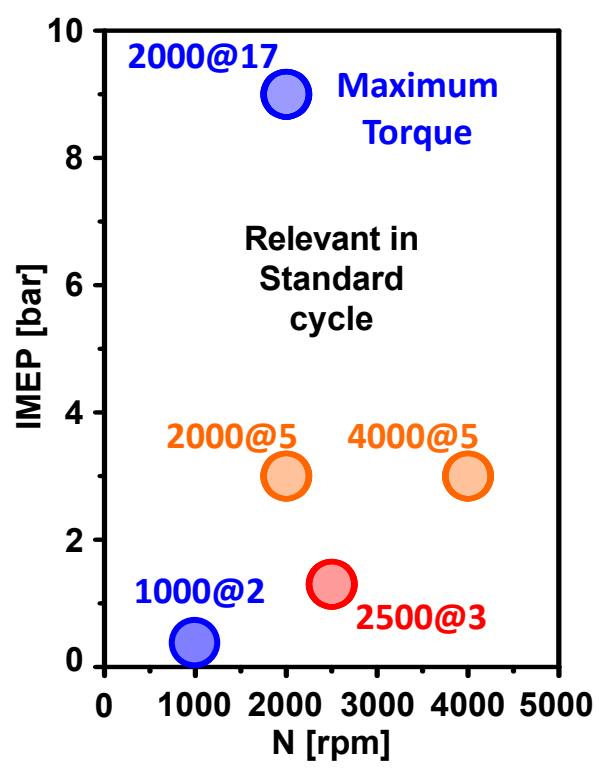

Figure 5.2. Representative points of the engine map and the different combustion regions.

- Point 1000@2 is the point selected for region IV, where the engine has to be operated as SI. More specifically this is the idle operation of the engine.

Therefore, to evaluate the potential of this solution, all these points have to be optimized, trying to find the best compromise between efficiency and emissions.

\subsection{Scavenging process}

As explained in Section 4.2, the engine scavenging architecture is a uniflow configuration, with intake ports and exhaust valves. To modify this scavenging process, the two fundamental actuations in this engine are the intake pressure modification and the variation of the VVT position. Therefore, in this section the effect of both modifications will be studied. In order to know how the process has been developed, there are four main parameters that give helpful information about it: the trapping ratio, the IGR rate, the apparent $\mathrm{F} / \mathrm{A}$ equivalence ratio (also referred as $\mathrm{Fr}_{\mathrm{app}}$ ), and the in-cylinder $\mathrm{F} / \mathrm{A}$ equivalence ratio or $\mathrm{Fr}_{\text {cyl }}$. 
Firstly, to illustrate in an understandable way the scavenging process, some CFD results of this process are going to be shown.

In the images of Figure 5.3, a complete scavenging process of the in-cylinder hot gases is represented. For this layout, the color scale is representative of the gases temperature, differentiating between the hot gases coming from the combustion in green color, and the cooler gases from the intake in blue color.

The scavenging begins with the exhaust valves opening, located in the cylinder head. The hot gases of the combustion start to leave the cylinder by the pressure difference between the cylinder and the exhaust. Then, the intake ports begin to open and the fresh gases start to enter in the cylinder from its bottom part. These gases will take the space of the burned gases and will move them towards the exhaust, thus renewing the charge of the cylinder until the intake and exhaust ducts will be closed.

As it can be seen in the figure, the scavenging process is not perfect: the intake gases do not completely remove, from the bottom of the cylinder to the valves, all the burned gases. This is a normal behavior due to the aerodynamic interactions generated by the different elements of the combustion chamber and the velocity gradients existing between the main flow (i.e. the "direct" way to the exhaust) and the flow close to the walls. These effects have mainly two consequences: on the one hand, the short circuit of the fresh gases from the intake to the exhaust during the scavenging of the charge, and, on the other hand, the presence in the cylinder of a portion of hot residual gases that have not been swept away by the fresh gases.

\section{Apparent $\mathbf{F} / \mathrm{A}$ equivalence ratio effect}

Once the overall process has been described, in order to better understand and quantify the different events observed during the scavenging, some tests will be shown so as to see the effect of the apparent $\mathrm{F} / \mathrm{A}$ equivalence ratio variation (further on referred also as $\mathrm{Fr}_{\mathrm{app}}$ ). First, the effect of this parameter at operating Point 2000@17 will be shown, and after that the results for $2000 @ 5$ will be presented. This way, the scavenging process will be analyzed for different load degrees.

In a first approach, the intake pressure modification is the key parameter to modify the amount of fresh gases introduced in the cylinder. Therefore, for a fixed fuel mass, it acts directly on the richness of the mixture (see Figure 5.4).

Additionally, by means of the introduction of a greater amount of fresh gases inside the cylinder, the sweep of the hot residual gases remaining inside the cylinder improves. Therefore, as it can be seen in Figure 5.5 to the left, the intake pressure also affects the IGR rate. As a result, the intake pressure 


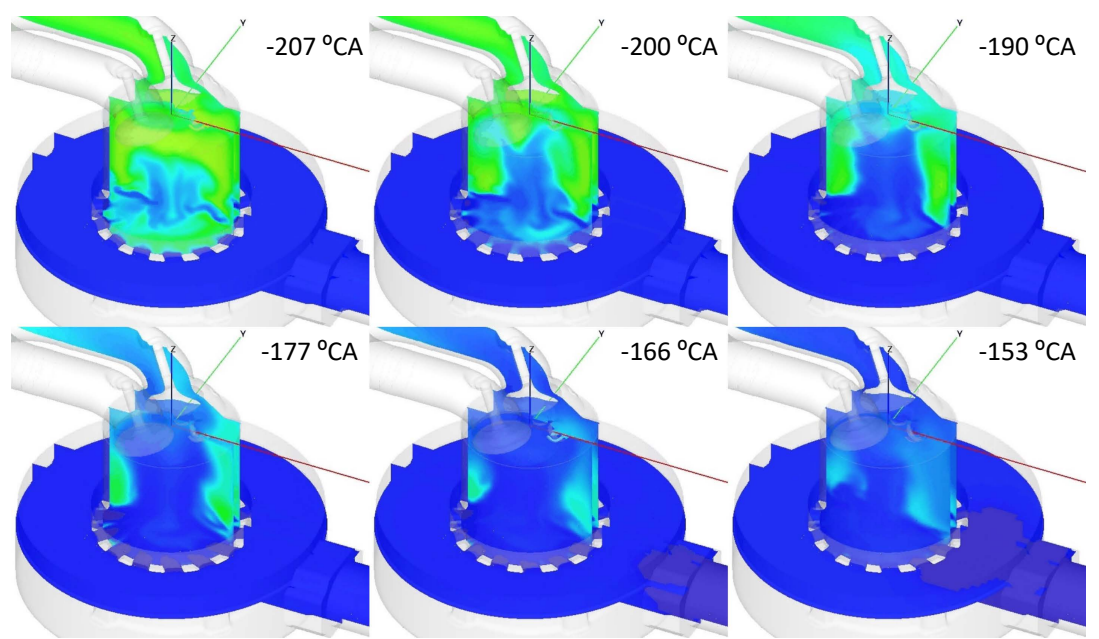

Figure 5.3. Complete scavenging process simulated by a $3 D$ CFD model, the blue color represents the fresh gases and the green color the burnt gases.

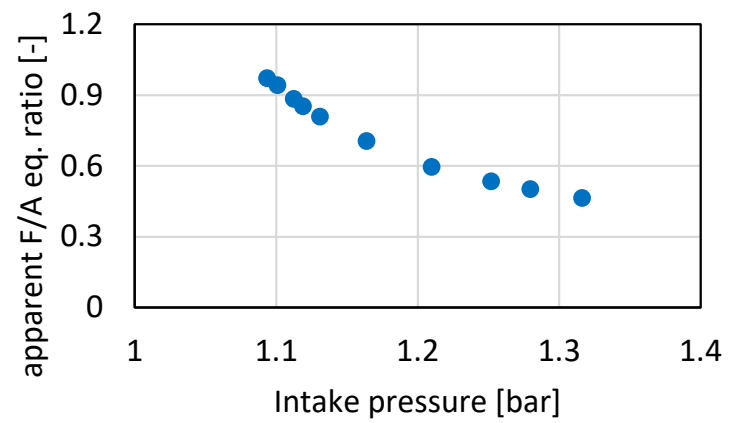

Figure 5.4. Effect of intake pressure on the apparent $F / A$ eq. ratio.

modification will lead to the variation of both the $\mathrm{F} / \mathrm{A}$ ratio and the IGR rate, and they will vary always at the same time (see Figure 5.5, to the right).

The CFD images presented before have shown that not all the fresh gases are trapped inside the cylinder. Unfortunately, a portion of the fresh gases is short-circuited, i.e. it goes away through the exhaust valves, and is not trapped in the cylinder. This lost fraction of fresh gases increases with the intake pressure, since the exhaust pressure is not modified respect to the one of the intake, and therefore the pressure differential between intake and exhaust 

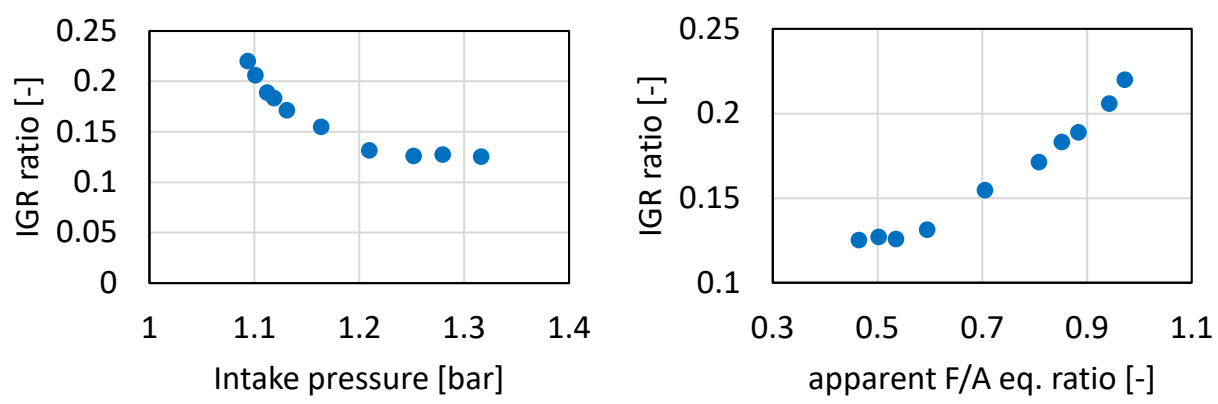

Figure 5.5. IGR rate evolution with the intake pressure (left) and with the $F_{\text {app }}$ (right).

is increased, thus increasing the velocity gradients existing between the main flow and the flow close to the walls. This leads to a reduction in the trapping ratio or trapping efficiency (see Figure 5.6).

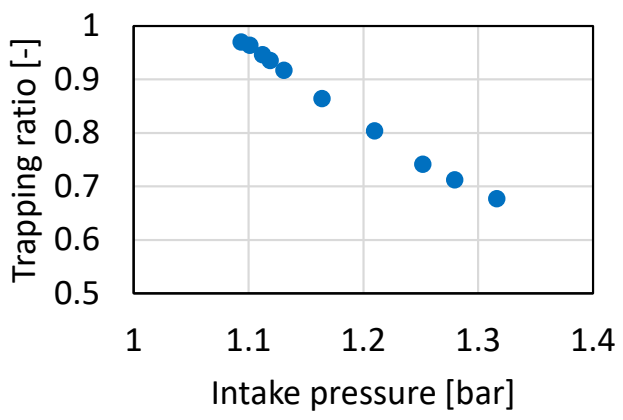

Figure 5.6. Trapping ratio as a function of the intake pressure.

The combination of all these effects on the scavenging process makes that, finally, the richness existing inside the cylinder, once the intake and exhaust ducts are closed, will be different to the apparent $\mathrm{F} / \mathrm{A}$ equivalence ratio, obtained from the fuel and intake air mass flows (see Figure 5.7). This is because of two main reasons: on the one hand, because the short-circuited air has been lost and is not among the in-cylinder charge; and, on the other hand, because the hot residual gases remaining in the cylinder from the combustion 
of the previous cycle affect the richness, since they may include some extra oxygen depending on the equivalence ratio operated.

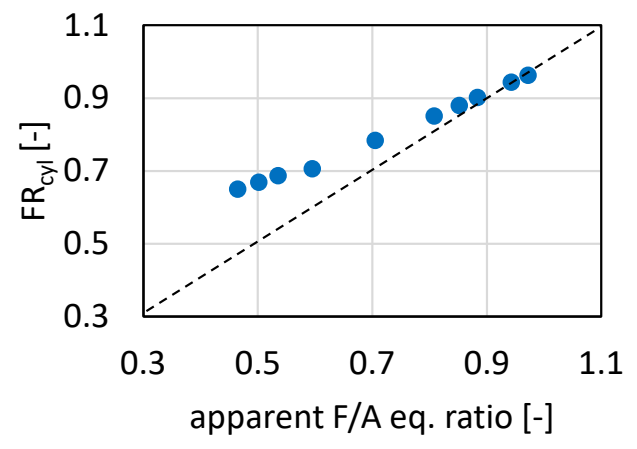

Figure 5.7. Relationship between the apparent $F / A$ eq. ratio and the in-cylinder F/A eq. ratio for Point 2000@17.

If the same study is performed now for a medium load point (2000@5), the results observed are quite similar, even though there are some important changes: since the necessary air mass flows are much lower, the intake pressures are also lower. The effect on the apparent $\mathrm{F} / \mathrm{A}$ equivalence ratio is the expected one. However, compared to the previous case (Point 2000@17), the in-cylinder richness is lower, because the IGR rate is much higher, and the mixture has higher dilution rate.
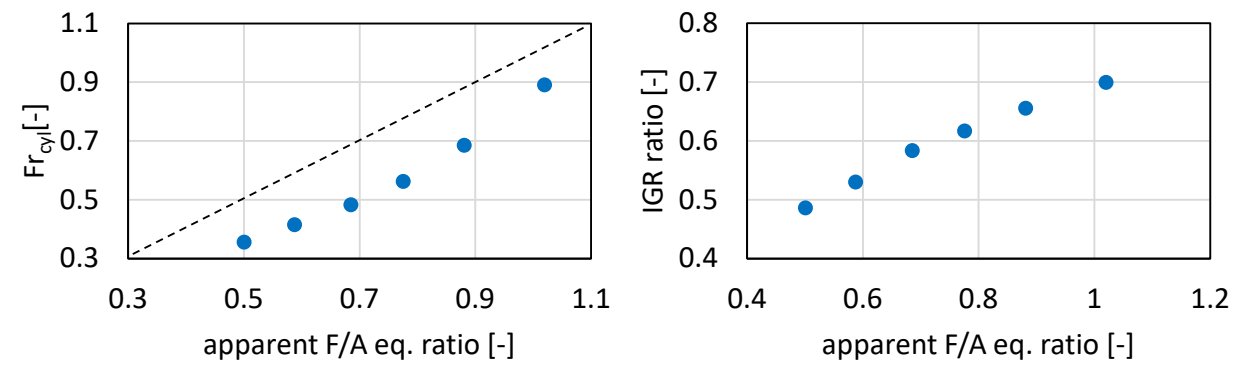

Figure 5.8. Evolution of the in-cylinder richness and the IGR ratio with the Fr $_{\text {app }}$ modification for Point 2000@5. 
The IGR rates for these points are much higher, moving between $50 \%$ and $70 \%$ of the total trapped mass, depending on the chosen Fr. Regarding the trapping ratio, the trend is the same as before: it is improved with the intake pressure decrease, as can be seen in Figure 5.9. However, the variation is very marginal. It can be stated that, at this load degree, almost all of the mass supplied by the intake is enclosed in the cylinder.

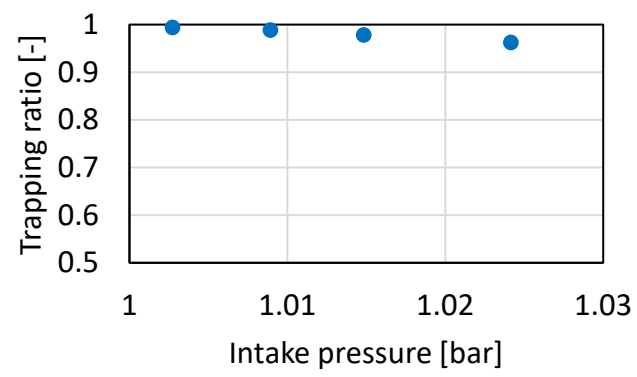

Figure 5.9. Evolution of the trapping ratio with the intake pressure for Point $2000 @ 5$.

In the region under study right now (Region II, at medium load), the in-cylinder charge composition changes very significantly during a variation of apparent $\mathrm{F} / \mathrm{A}$ equivalence ratio, because the IGR rate is significantly modified. Without going into more details about the combustion parameters (since they will be addressed in the following chapter), it will be shown how a transition between a spark ignition to a CAI combustion mode can be achieved by the modification of the charge composition induced by a variation of the apparent $\mathrm{F} / \mathrm{A}$ equivalence ratio. The point selected to analyze this transition is Point $4000 @ 5$, and the results are shown in Figure 5.10. The graph illustrates the average HRR's for different values of the apparent $\mathrm{F} / \mathrm{A}$ equivalence ratio.

\section{VVT effect}

The second main tool to act on the engine scavenging process is the variation of the VVT position. However, the effect of this parameter is lower than the effect of the Fr, and it could be said that this effect is, somehow, complementary. The VVT affects the instant in which the exhaust valves open and close. Therefore it will have an influence on the charge composition the temperature of this charge, as well as on the effective compression and power strokes.

The VVT variation shows two different behaviors, depending on if it is located before or after the VVT position $=169^{\circ} \mathrm{CA}$. This is the position where 


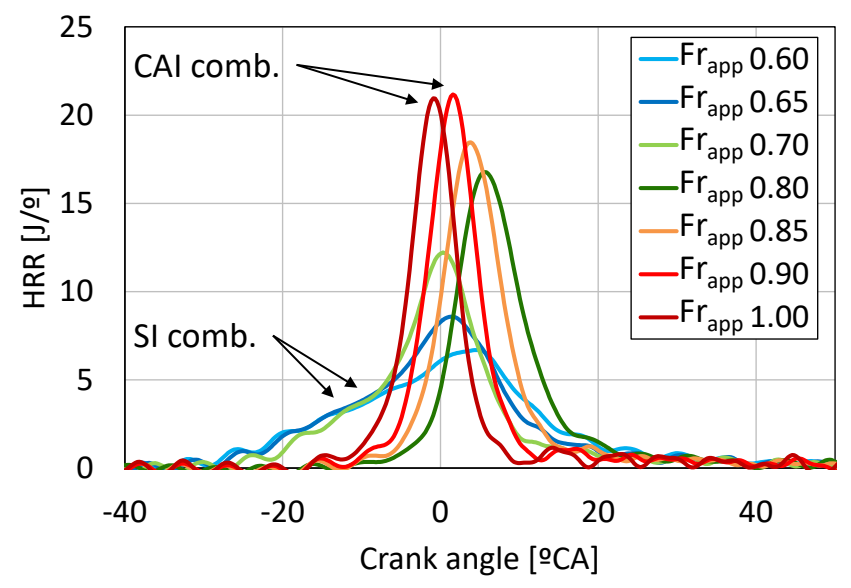

Figure 5.10. Effect of the $F_{a p p}$ on the HRR at Point $4000 @ 5$.

the intake and exhaust closure take place simultaneously. From this angle, if the VVT is delayed, the intake is closed before the exhaust (therefore, during this period, the cylinder loses part of its charge, depending on the pressure difference between cylinder and exhaust) and the exhaust opens closer to the intake opening, which hinders the initial entry of fresh air into the cylinder. On the contrary, if the VVT is advanced, the exhaust closes before the intake and also opens sooner. Therefore, it makes easier the exit of the exhaust gases before the intake opening (loosing part of the power stroke, however) and the permeability of the engine is lowered by closing the exhaust sooner (the intake air retention is favored).

To analyze these effects on the engine scavenging process, some tests have been performed on Point 2000@17, where the position of the VVT has been modified keeping a constant apparent $\mathrm{F} / \mathrm{A}$ equivalence ratio. The results are shown in Figure 5.11.

- First of all, the exhaust gases temperature (also the IGR temperature) decreases with the delay of the VVT position. This is due to the fact that the expansion stroke is longer and the exhaust gases have been more expanded. A brief and more detailed explanation of this phenomenon can be found in Appendix 5.B.

- The trapping ratio remains almost constant for the VVT positions before $169^{\circ} \mathrm{CA}$. However, for delayed VVT's, a fall in the trapping ratio values takes place, since the trapped charge is going out the cylinder through 

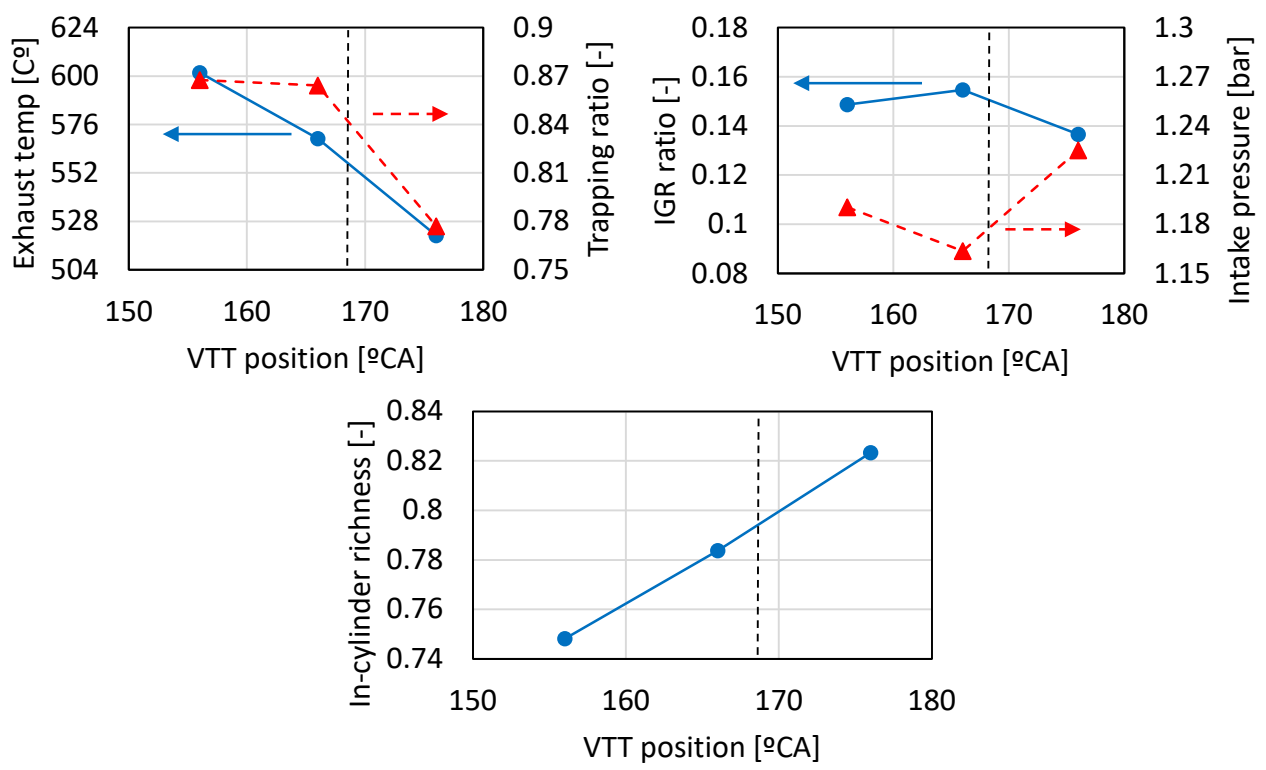

Figure 5.11. VVT variation with constant $F r_{a p p}$.

the exhaust during the time when the exhaust is open and the intake is closed.

- The necessary intake pressure is minimum at values close to $169^{\circ} \mathrm{CA}$ if the apparent $\mathrm{F} / \mathrm{A}$ equivalence ratio is kept constant. If the VVT is delayed from this value, the intake pressure must be increased to compensate the initial high pressure inside the cylinder due to a delayed exhaust opening. And, in the other direction, with the advance of the VVT, although the initial cylinder pressure will be lower, the closure of the exhaust occurs earlier as well. Consequently, there is less time available from the intake opening to the exhaust closing, and the intake pressure has to be increased to introduce the same amount of air.

- The IGR rates have few variations if the Fr remains constant. However with VVT's advanced respect to $169^{\circ} \mathrm{CA}$, the emptying of the exhaust gases before the intake opening is greater, and since there is less time available from the intake opening to the exhaust closing, the intake pressure has to be higher to keep the Fr. Both effects will cause the IGR rates to be slightly lower in the advanced VVT's. In the other direction, with the delay of the VVT from the $169^{\circ} \mathrm{CA}$ position, the 
IGR rates are reduced because the intake pressure has to be increased again to keep the Fr, which improves the residuals scavenging.

- The in-cylinder richness values are finally the combined result of the changes in the trapping ratio and the evolution of the IGR rate in the engine for the different VVT's.

\subsection{Effect of the injection and ignition systems}

\section{Injection system}

In this engine, the fuel injection system is air assisted, a system which is not very common in ordinary engines. Even if some authors have carried out some studies about the performance of such a system [2-5], the knowledge about its operation is not at the same level as other more commonly used injection systems. The reasons for the choice of this system are based on the improvement of fuel atomization, and therefore a better dispersion of the mixture, with lower injection pressures. Thanks to this, a high-pressure gasoline pump and more expensive injectors are unnecessary. This decision is translated into a competitive improvement in terms of production costs and simplicity of the elements.

For the above reasons, it seems necessary to study the behavior of an injection composed of a mixture of high pressure air and fuel that is introduced through an injector directly inside the cylinder. This analysis will be focused on two main parameters: the SOI (Start Of Injection) and the DOI (Duration Of Injection). The SOI (defined as degrees BTDC) determines the instant when the mixture starts to be introduced in the cylinder, whereas the DOI (defined as crank angle degrees), defines the duration of the injection, as well as the amount of air introduced together with the fuel (the fuel injection is fixed, controlled by another injector; only the amount of air assisting the injection process is modified by the DOI).

To carry out this analysis, some data has been taken from each operating point defined on Figure 5.2. With this data, a general behavior of these two parameters and the key points for their optimization will be searched.

\section{High loads, Point 2000@17}

In this particular operating point, where the engine speed is moderate, the mixing process relies mostly on the injection process. Both SOI and DOI significantly affect the mixture homogeneity (it is enhanced by an early 
injection, i.e. SOI $\uparrow$, and a long injection ${ }^{1}$, i.e. DOI $\left.\uparrow\right)$. As a general trend, higher mixture homogeneity (attained either by a high SOI or DOI) produces:

- Increased combustion efficiency, since there are less lean regions, unable to burn correctly.

- Better combustion stability (lower $\sigma \mathrm{IMEP}$, i.e. the standard deviation of the IMEP), since the characteristics of the mixture near the spark plug are more repeatable.

In order to verify and illustrate those statements, Figure 5.12 shows a SOI variation with a constant DOI, and a DOI variation with a constant SOI, respectively.

In agreement with the above comments, in the figures it can be seen that $\sigma$ IMEP and combustion efficiency improve with the increase of both DOI and SOI. And, as a result, BSFC is also improved.
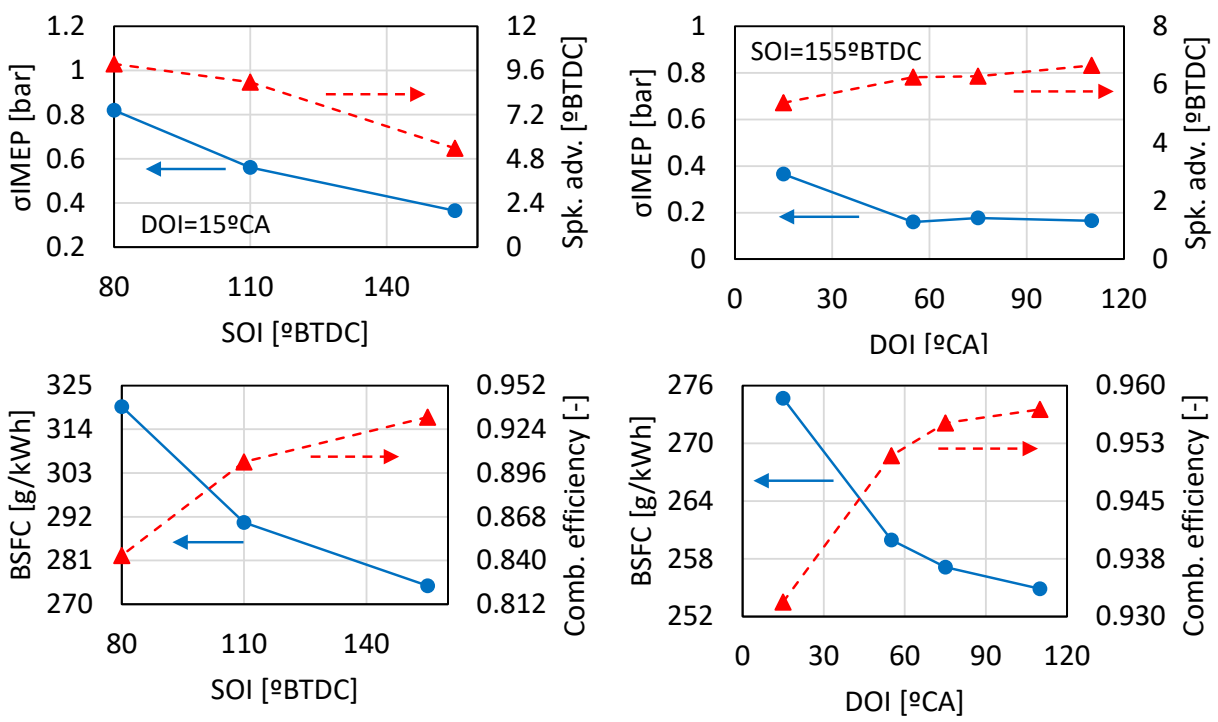

Figure 5.12. Left - Effect of SOI at Point 2000@17. Right - Effect of DOI at Point 2000@17.

\footnotetext{
${ }^{1}$ The effect of the DOI variation affects the fuel atomization, and is analyzed in the Appendix 5.C in order to get a better understanding of this phenomenon.
} 
The only difference between the trends observed for these two parameters is the effect on the spark timing. It is worth to underline that the spark timing is advanced up to the knock limit in any case, in order to work in equivalent conditions. This difference in trend can be easily explained as follows. On the one hand, for a constant SOI, the higher the DOI, the higher the allowed spark timing, since there are less fuel-rich regions with higher risk of knock. On the other hand, for a constant DOI, the higher the SOI (i.e. the residence time of the fuel in the cylinder $\uparrow$ ), the higher the risk of knock, and consequently the lower the allowable spark timing.

Generally speaking, at this operating condition (high load, moderate engine speed), the engine behavior is optimized with high SOI's and DOI's. But as far as the engine load decreases, the optimum value for these two parameters will change, as shown in the next paragraph.

\section{Medium loads, Points 2000@5 and 4000@5}

The tests at conditions $4000 @ 5$ show that the effect on BSFC, engine stability and combustion efficiency is exactly the same as already shown at high load (Figure 5.13): a higher mixture homogeneity (i.e. DOI $\uparrow$ ) improves the engine stability, combustion efficiency and BSFC (as a result of the two previous aspects).

The corresponding $\mathrm{NO}_{\mathrm{x}}$ emissions are mainly explained by the location of the combustion process (earlier combustion $\Rightarrow \mathrm{NO}_{\mathrm{x}} \uparrow$ ) and the mixture homogeneity (less homogeneous mixture $\Rightarrow$ richer regions $\Rightarrow$ local $\mathrm{T} \uparrow \Rightarrow$ $\left.\mathrm{NO}_{\mathrm{x}} \uparrow\right)$.

Regarding the effect of SOI, the results are shown in Figure 5.14. Now the trends differ from those explained in the previous scenario (high load). Based on all the results available (among which those of Figures 5.14 have been selected), the following general trends can be extracted:

- Small SOI's are not good, since BSFC increases, stability decreases, $B S N O_{x}$ increase, and combustion efficiency decreases.

- As the SOI increases, at the beginning the mixture homogenization is improved (SOI $110^{\circ} \mathrm{CA}$ ). This improvement can be seen in three results shown in Figure 5.14: first, the combustion velocity slightly increases, as can be seen in Figure 5.14 right; second, the specific fuel consumption decreases; and, third, the $\mathrm{NO}_{\mathrm{x}}$ emissions decrease, thanks to a better mixture homogenization that implies less local rich mixtures and lower combustion temperatures. However, since these points have a high level of residual gases, when the combustion efficiency is observed, it can be 

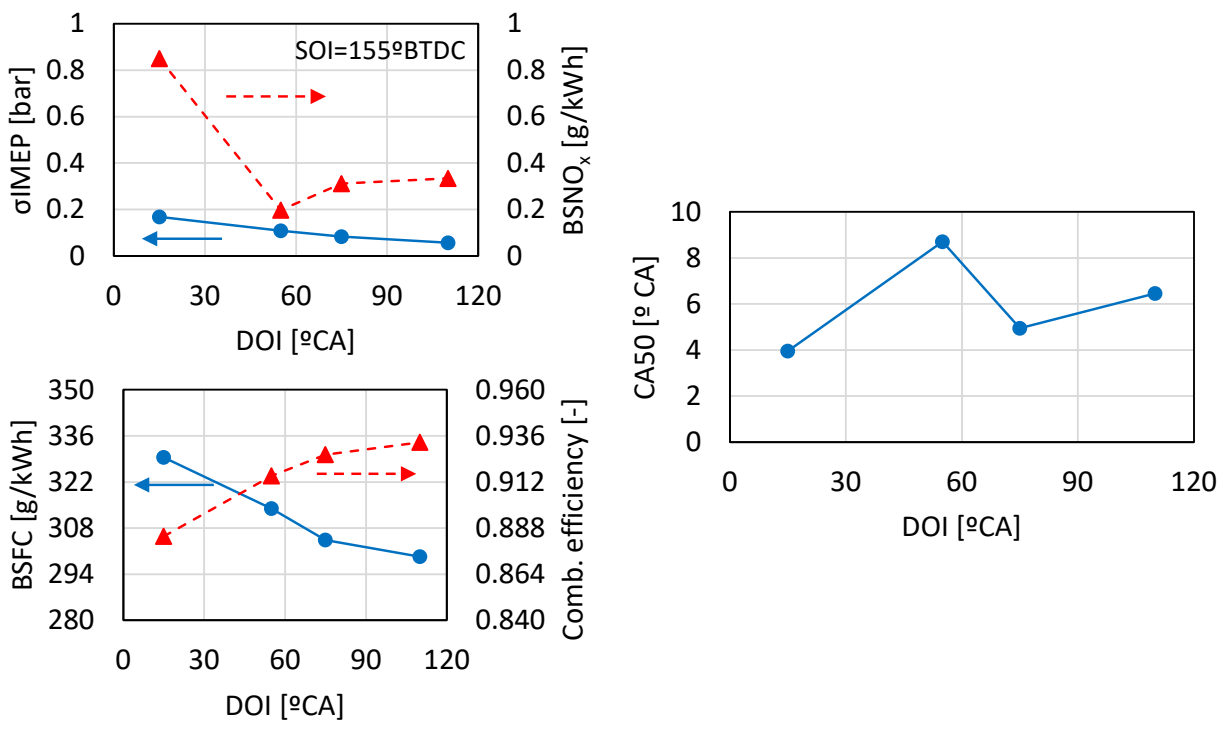

Figure 5.13. Effect of DOI on different engine outputs at Point 4000@5.

seen that it decreases. This is an indication that there are unburned portions of the mixture. If the SOI continues to increase $\left(155^{\circ} \mathrm{CA}\right)$, an excessive dispersion of the mixture can be reached. This fact, combined with an environment with many residuals, is detrimental. This effect can be seen in four results presented in the figures: 1.- The combustion efficiency decreases, since the mixture is not completely burnt; 2.- The $\mathrm{NO}_{\mathrm{x}}$ continue decreasing, because the combustion temperature continues decreasing; 3.- The graph of the HRR shows a loss in combustion velocity despite the combustion event is advanced; and 4.- The BSFC starts to get worse due to the above listed effects. Thus, in contrast to the results obtained in the previous scenario, the maximum allowable SOI is now not necessarily the best choice.

The effect of the DOI is presented also for Point 2000@5 in Figure 5.15. Besides the change in engine speed (from 4000 to $2000 \mathrm{rpm}$ ), the optimum $\mathrm{Fr}_{\text {app }}$ is now 0.75 instead of 0.65 . Because of these two differences, the effect of the DOI is significantly different than before. At these other conditions, where the mixture characteristics relies more markedly on the injection characteristics (because at lower engine speed the level of turbulence is lower) and the 

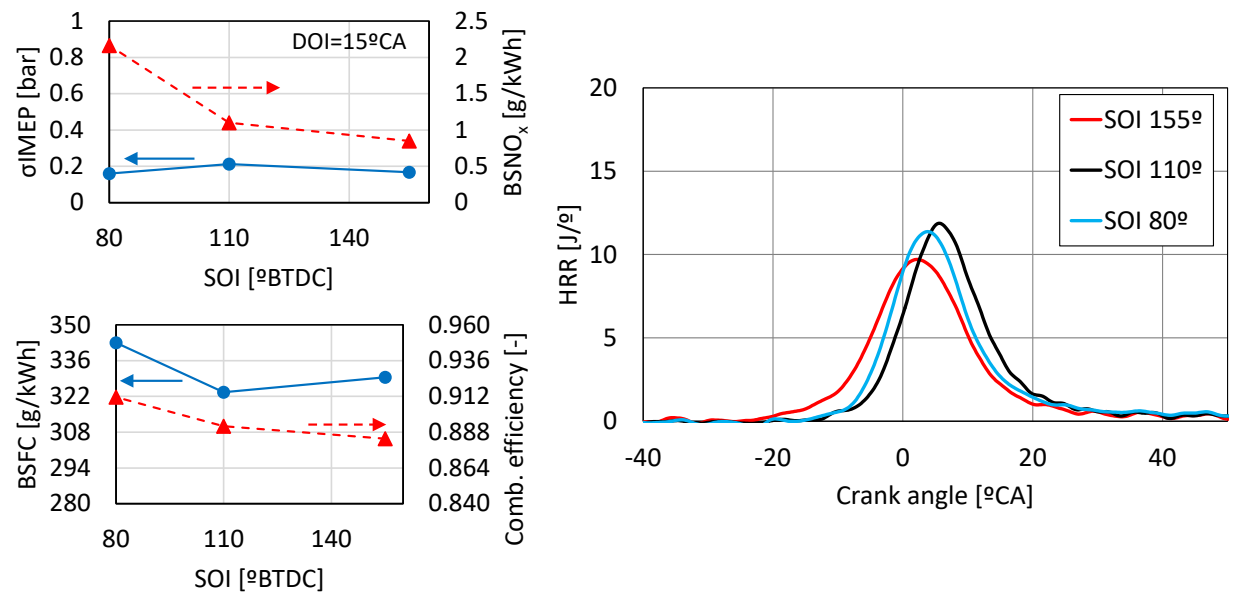

Figure 5.14. Left - Effect of SOI on different engine outputs. Right - Effect of SOI on the HRR (data from Point 4000@5).

combustion tends to be more CAI (because of the higher richness), the following trends can be observed:

- Shorter injections (DOI smaller) lead to earlier and faster combustions (i.e. more CAI, with narrower HRR): because of the higher mixture heterogeneity, there are more rich regions in the mixture that autoignite earlier. This is good for BSFC, the combustion efficiency and the engine stability.

- The main drawback of the above behavior is that $\mathrm{NO}_{\mathrm{x}}$ emissions increase significantly.

In this operating point, the HRR is seen to be narrower for shorter injections. This is mainly due to the higher local richness, which tends to make the combustion process more CAI. This produces higher combustion velocity, as well as higher repeatability. As a consequence, the HRR of the mean cycle is narrower. Longer injections, as it can be seen in the $\sigma$ IMEP evolution, produce an excessive mixture dilution, and the combustion starts to be less efficient and to lose stability. 

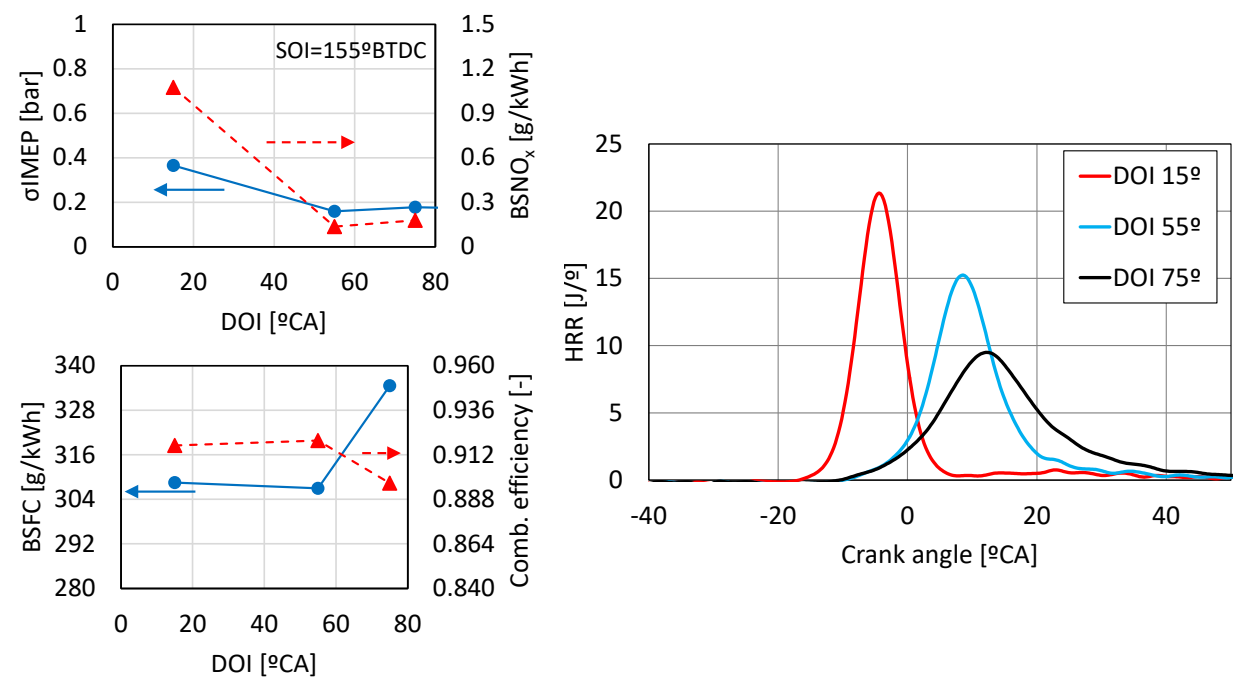

Figure 5.15. Left - Effect of DOI on different engine outputs. Right - Effect of DOI on the HRR (data from Point 2000@5).

\section{Low loads, Point 2500@3}

For lower loads, the main observations of the injection parameters variation are the following:

- Based on Figure 5.16, the DOI needs to be small. This produces improved stability, BSFC, combustion efficiency and $\mathrm{NO}_{\mathrm{x}}$. The HRR for small DOI's is much narrower (more CAI; see Figure 5.16): this might be the result of a less homogeneous mixture, with more rich regions with enhanced reactivity, which seems to be very important at these conditions with extremely high IGR ratios.

- The effect of SOI is shown in Figure 5.17. High SOI's improve the engine behavior in terms of BSFC, combustion efficiency and $\mathrm{NO}_{\mathrm{x}}$, and this parameter does not have any significant effect on stability.

Generally speaking, at these operating conditions, it is interesting to perform a not too long injection to avoid fuel dispersion near TDC (i.e. when the temperature is higher, and so is reactivity), and to place this injection quite far from TDC. 


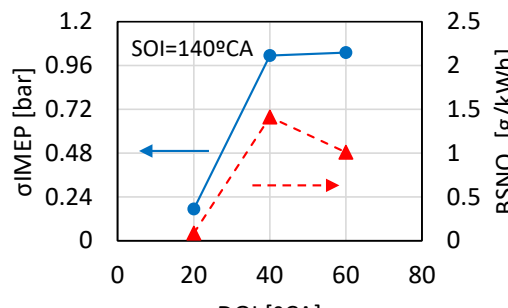

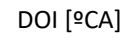
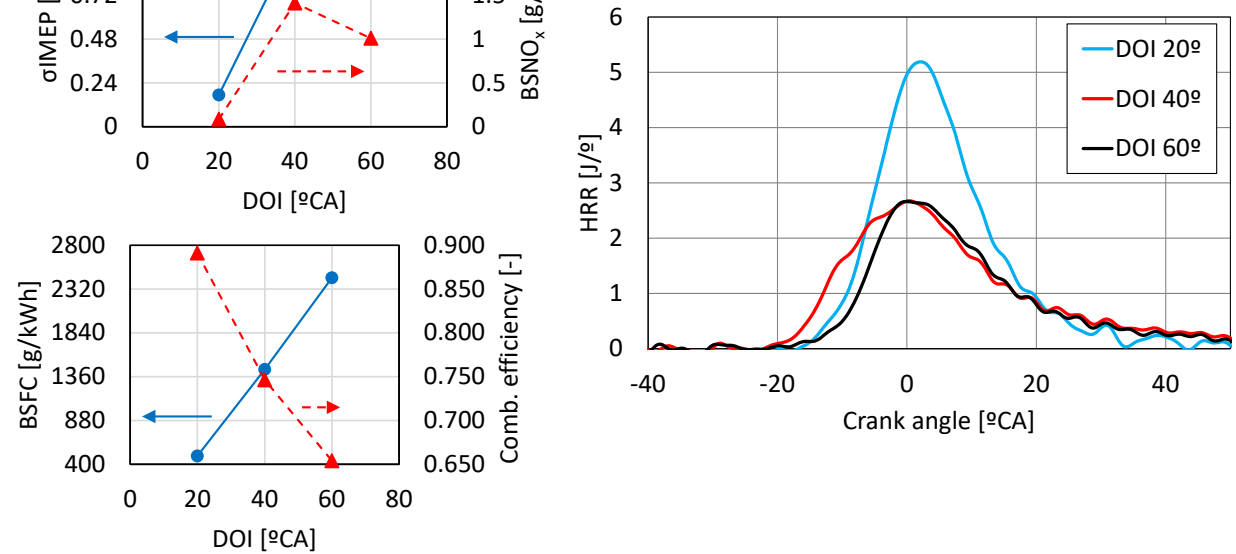

Figure 5.16. Effect of DOI on different engine outputs (left) and on the HRR (right) at Point 2500@3.
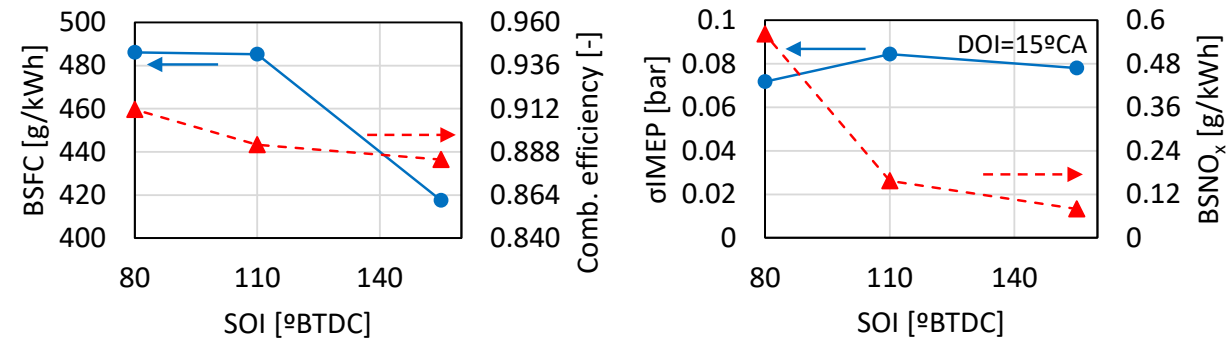

Figure 5.17. Effect of SOI on different engine outputs at Point 2500@3.

Finally, with the aim of trying to better understand why the effect of DOI depends markedly on the operating point, all the results presented in this section showing the effect of this parameter at each operating point will be put together in a single graph, and will be plotted as a function of a parameter more meaningful than the DOI. The parameter designed for this purpose is the ratio between the mass of air injected and the total air available in the combustion chamber for the combustion process (injected air + trapped intake 
air), which will be referred as the injected air ratio, IAR (defined as indicated in Eq. 5.1) ${ }^{2}$. The corresponding results are shown in Figure 5.18.

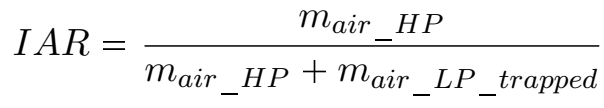
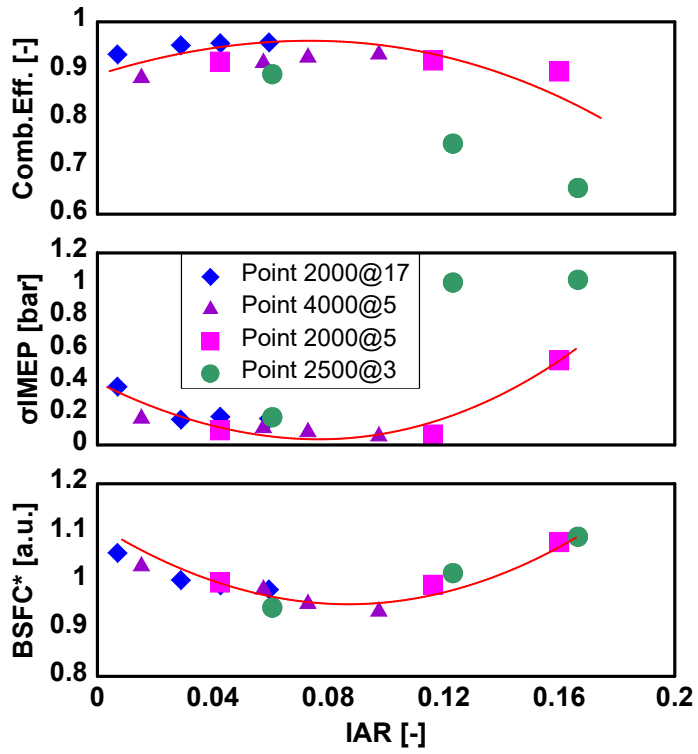

Figure 5.18. Evaluation of the IAR parameter for different tests.

On the top of the figure, the combustion efficiency is presented. Even if this parameter is not fully comparable among the different operating points, since at low loads it is considerably lower than at high load, the results show that an optimum value for the IAR exist, at around 0.1. The same observation can be done for the engine stability (middle figure) and the corrected BSFC (bottom figure). This last parameter was obtained by a linear transformation of the BSFC at each operating point, to homogenize the values. This result shows that an IAR too high (i.e. too much fuel dispersion) or too low (i.e. not enough fuel dispersion) are not a good option.

\footnotetext{
${ }^{2}$ Another parameter was also checked, namely injected air $/ \mathrm{mf}$, which is similar to the IAR but not taking into account the $\mathrm{F} / \mathrm{A}$ ratio. However, the correlation of the parameters shown in Fig. 5.18 is significantly better for the IAR, and that is the reason why it was the parameter finally considered.
} 


\section{Ignition System}

The ignition system used in this engine is a conventional spark plug and, therefore, a system widely known. For this reason, the analysis presented here will be shorter, since it will not present any great mystery for the engine community.

The aim of this paragraph is to make a brief summary of the different cases that can be found in this engine. Therefore, three different situations will arise: one with the engine working at high loads, another with the engine operating at medium loads with lean mixtures, and finally, one where the engine will be working at low load.

Region I. First, when the engine is operating at high load (e.g. Point 2000@17), the ignition advance is used to optimize the combustion position. In Figure 5.19, the results of an ignition timing variation are shown. For these tests, all the settings of the engine have remained constant except the advance of the ignition. In this case, the ignition advance is a useful tool to position the combustion, parameter that is interesting to be as advanced as possible at high loads, as can be seen in the improvement of the BSFC. However, this advance of the combustion causes a rapid growth of the knock in the engine, thus preventing the combustion to be placed in its optimum position, to achieve the maximum efficiency. Therefore, for high loads, where the engine operates as a SI, the ignition timing will be as advanced as possible, taking into account the limiting factor of the knock appearance.
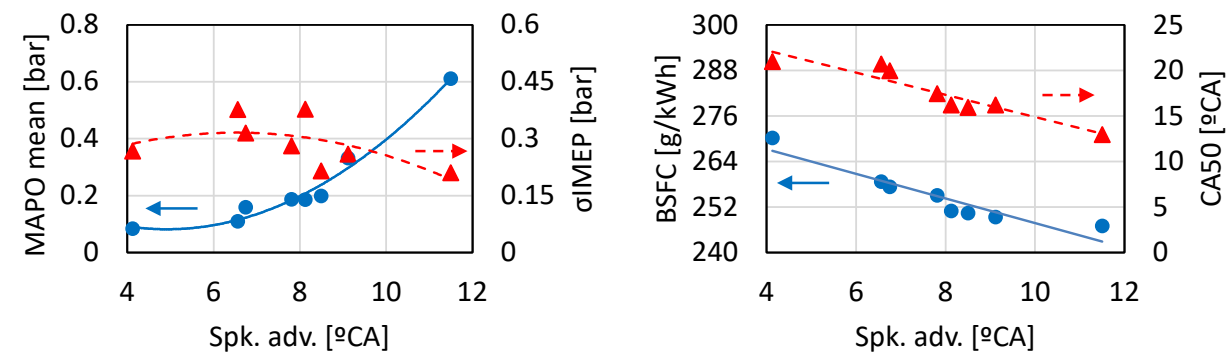

Figure 5.19. Different spark ignition timings for operating Point 2000@17.

As for the stability of the combustion, it can be observed that the variations are not significant, and they don't follow any defined trend. Consequently, in these cases the combustion stability is not a parameter to worry about. 
In order to illustrate the effect of the increase of the knocking tendency with the ignition advance, some data has been taken from a test where the ignition advance of the same operating Point 2000@5 was modified. The result is shown in Figure 5.20, where the MAPO and the combustion center of gravity (CA50) position for all measured cycles during the three tests have been represented. As a complementary information, inside the plot there is a sub-plot with the averaged combustion position and the averaged MAPO for the three cases. In the figure legend, the value of the ignition advance for each test is given.

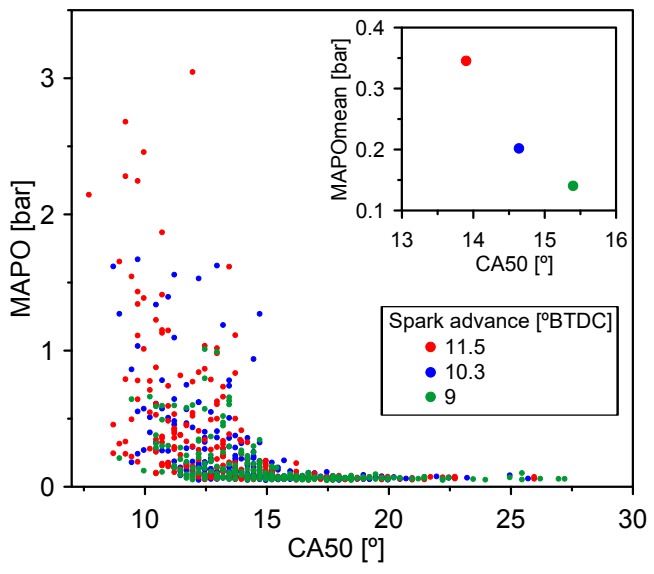

Figure 5.20. MAPO vs CA50 for all individual cycles (main graph) or averaged (detailed graph) for a spark timing swept.

In this graph, the fast increase of the knocking tendency can be seen, which does not follow a linear trend, but an exponential one, as already observed in the results of Figure 5.19.

Region II. The next case to be shown, corresponds to the region two of the engine operation map. This is a region of medium loads, and the engine can be operated either in SI or in CAI combustion, depending on the mixture reactivity (mainly Fr). The point selected to present the results of this region is a point that does not correspond to any of the ones defined initially on the engine map. It is taken at $4000 \mathrm{rpm}$ with a mass of fuel of $9 \mathrm{mg} / \mathrm{stk}$, which would be representative of a $\sim 5$ bar IMEP.

This point has the peculiarity of being a point with a lean mixture $\left(\mathrm{Fr}_{\mathrm{app}}=0.6\right)$ and an EGR rate of $10 \%$. Because of this, it is difficult to reach knocking combustion through the ignition advance, since the engine load is low enough (the effective compression ratio is low, and the mixture is quite 
diluted thanks to a high IGR rate and an additional 10\% EGR in the intake). Therefore there is no such limiting factor, in contrast with what happened in the previous case.

Once the optimum point for the ignition advance is reached, if the ignition is further advanced, the engine efficiency is worsened. In Figure 5.21, the results of an ignition variation are shown. It can be seen that the optimum advance for the operation of the engine was around $27^{\circ}$ BTDC. From this point, if the spark is further advanced, combustion is worsened. The combustion stability decreases and the combustion phasing seems to not further advance. The reasons behind this behavior are:

- Such a high ignition advance makes the ignition to happen with lower density of the mixture, because of the further distance between the piston and the cylinder head.

- The mixture is diluted in this case, which would hinder the ignition process.

- The engine has a direct injection system, and the mixture takes some time to homogenize. For this reason, a too early ignition finds more mixture heterogeneities, and the cycle to cycle variability increases.
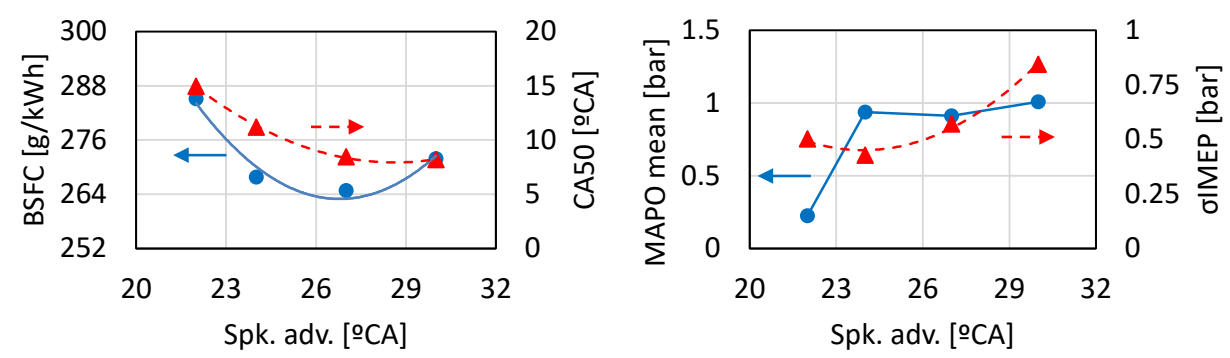

Figure 5.21. Spark ignition swept for Point 4000@9.

Region III. The last case to be shown refers to Region III of the engine map, where the engine is operated at low loads. For the operation points where the engine is operating under CAI combustion, the ignition advance loses its function, since the ignition mechanism of the mixture has changed and it is necessary to act on other variables to control the combustion onset. As can 
be seen in Figure 5.22, once the engine is operating under CAI conditions, the choice of one or another spark advance has no effect in any engine output: the combustion efficiency is not affected, and the same can be said for the rest... So, the spark could be disabled without any apparent problem. However, if reliability prevails, the ignition can remain activated. In that case, it will be set to a specific value so that in the event that the autoignition process fails, the spark will avoid fluctuations on the load, or even the engine shutdown.
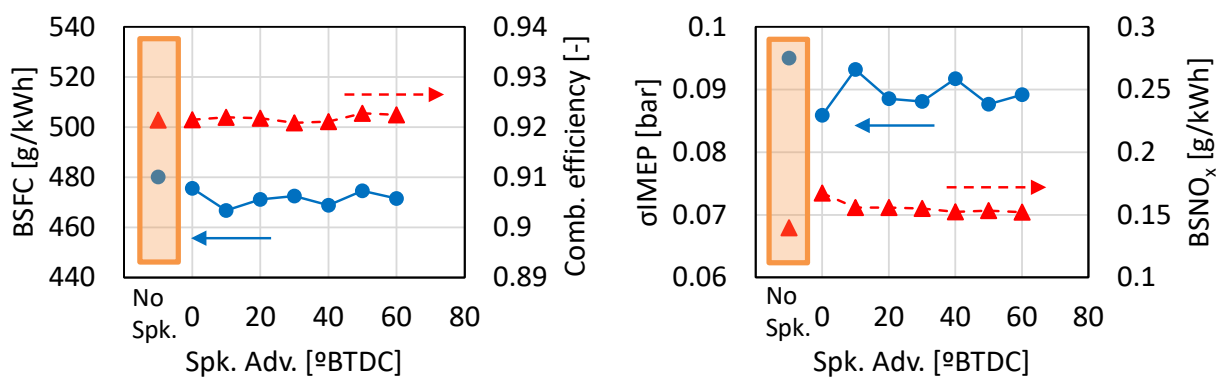

Figure 5.22. Effect of the spark timing on different engine outputs at Point 2500@3.

\subsection{EGR effect}

The addition of an EGR system in this engine allows introducing another control parameter for the engine operation and the charge reactivity management, research topic in which other authors have been working with similar approaches [6-8]. Besides, as an additional benefit, EGR could also lead to further reduce $\mathrm{NO}_{\mathrm{x}}$ emissions, which would be necessary in some stringent markets. In the following paragraphs, the effect of introducing EGR on the combustion process of this engine and its control will be analyzed.

This strategy is based on the use of exhaust gases, which are re-introduced in the intake, and mixed together with the fresh air. This strategy is very popular in diesel engines to reduce $\mathrm{NO}_{\mathrm{x}}$ emissions. In the frame of SI, gasoline engines, it has been shown in some works that it can bring some extra benefits than just the $\mathrm{NO}_{\mathrm{x}}$ emissions reduction, as it will be illustrated later. The EGR was introduced in gasoline engines for the first time in the 90's. It was focused on the improvement of fuel consumption at low loads and the reduction of exhaust emissions. This was not tested at high loads for naturally-aspirated 
engines, because the introduction of an inert mass in the cylinder reduced the maximum output power since the volumetric efficiency of the engine was worsened, as observed by Hacohen et al. [9]. However, this effect can be mitigated if the engine is boosted. Anyway, a fundamental difference between the previously cited works and the current study is that now the EGR will be introduced in a cylinder charge where there is already a significant amount of hot residual gases (by internal recirculation), so the expected effect may differ from previous studies.

The EGR introduction in this engine has shown to affect in different ways the engine performance depending on the load degree. Therefore, the results will be presented divided in the different engine load regions, as already done in the previous subsection.

\section{High load}
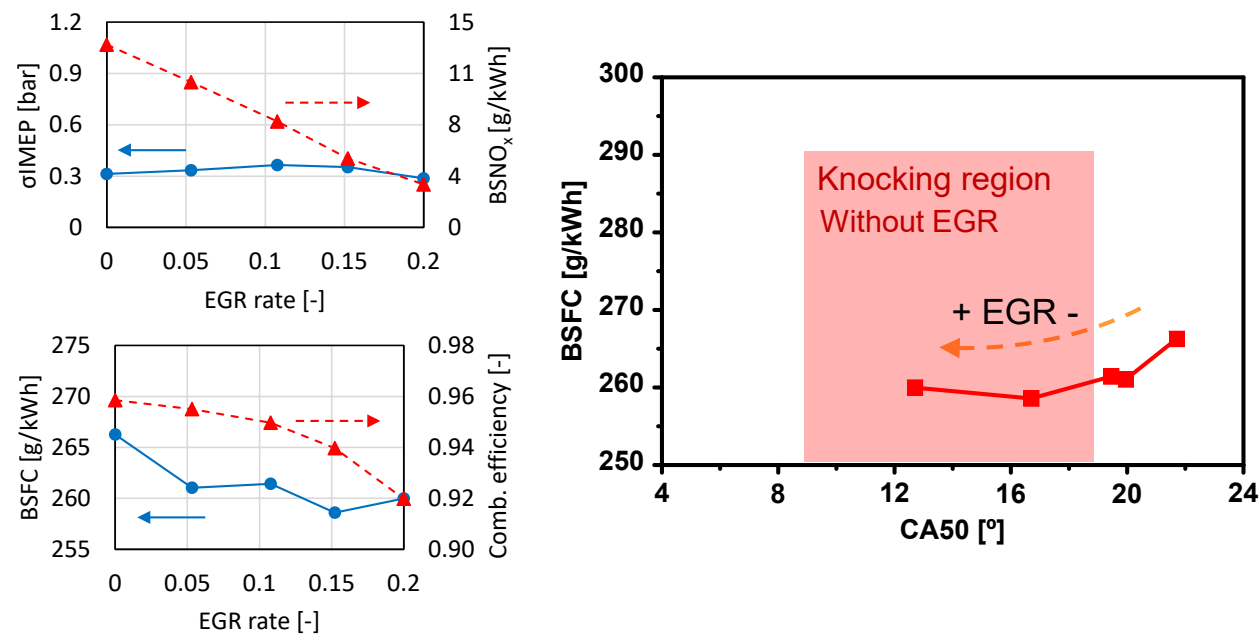

Figure 5.23. Point 2000@17, high equivalence ratio case $(\mathrm{Fr}=0.75)$. Left - Evolution of different parameters as a function of the EGR rate. Right - For the same tests, correlation between $B S F C$ and CA50, and detail of the knocking region when no EGR is used.

At high load operation, an increase in the equivalence ratio leads to a limitation in the CA50 advance due to the appearance of knock: the increase of the temperatures leads to an increase in mixture reactivity, making it easier to autoginite. This effect prevents the correct positioning of the combustion event in the cycle, thus limiting the achievable efficiency at these loads. The 
EGR introduction leads to two main effects: first, an increase of the $c_{p}$ of the intake gases, and so the temperature of the mixture during the compression stroke will be lower; and, second, there is a reduction of the $\mathrm{O}_{2}$ concentration in the mixture, and therefore the dilution degree is higher. Both effects decrease the mixture reactivity, making it easier to avoid the autoignition of the mixture. In this context, thanks to the EGR introduction the knock is mitigated [10] and, thus, the combustion can be further advanced (see Figure 5.23, to the right). This leads to an improvement in BSFC despite the loss in combustion efficiency associated to the lower $\mathrm{O}_{2}$ content in the intake gases caused by the EGR introduction (see Figure 5.23, to the left): fuel consumption is improved in $2.3 \%$ even assuming a loss of $4 \%$ in combustion efficiency, and $\mathrm{NO}_{\mathrm{x}}$ emissions are reduced in $75.6 \%$. These results show the strong potential of EGR to reduce $\mathrm{NO}_{\mathrm{x}}$, which is a more than usual result [11]. But, at the same time, EGR also serves to improve BSFC, because of its knock mitigation capability. This capability will be further shown in the following paragraphs.

Figure 5.24 shows a cycle-to-cycle analysis from a test with the same configuration as before $\left(\mathrm{Fr}_{\mathrm{app}}=0.75\right)$, where the spark advance and the EGR rate are modified, respectively, in order to advance the combustion position (i.e., the CA50). These two figures include two graphs in both cases: the main graph shows the instantaneous MAPO (to quantify knock) for each measured cycle (250 cycles per test) vs. the corresponding CA50, whereas the sub-graph shows the same information but averaged (MAPO mean vs. CA50 mean). The first case (Fig. 5.24, to the left) shows an attempt to advance the combustion position without EGR, only advancing the spark timing. As it can be seen, in this case the MAPO increases with the combustion advance (CA50), as expected.

However, in Fig. 5.24, to the right, for the same operating point in similar conditions, the intake charge has been modified by introducing $15 \%$ of EGR. As a consequence, now the mixture will be more diluted and the temperatures at the end of compression will be lower. The result is that combustion position can be significantly advanced (by an advanced spark timing) without any significant change in knock (in fact, the mean value of the MAPO is even slightly lower than in the starting point). This result illustrates the strong potential of EGR to mitigate knock, thus allowing significant improvements in terms of fuel economy [12] and $\mathrm{NO}_{\mathrm{x}}$ emissions.

Still at high load, but with lower equivalence ratios (Figure 5.25), where knock is not a problem for the correct combustion positioning, the introduction of EGR does not bring the clear benefit seen before, since the combustion onset is placed even too early in the cycle. Thus, in this other case, the $\mathrm{NO}_{\mathrm{x}}$ reduction 

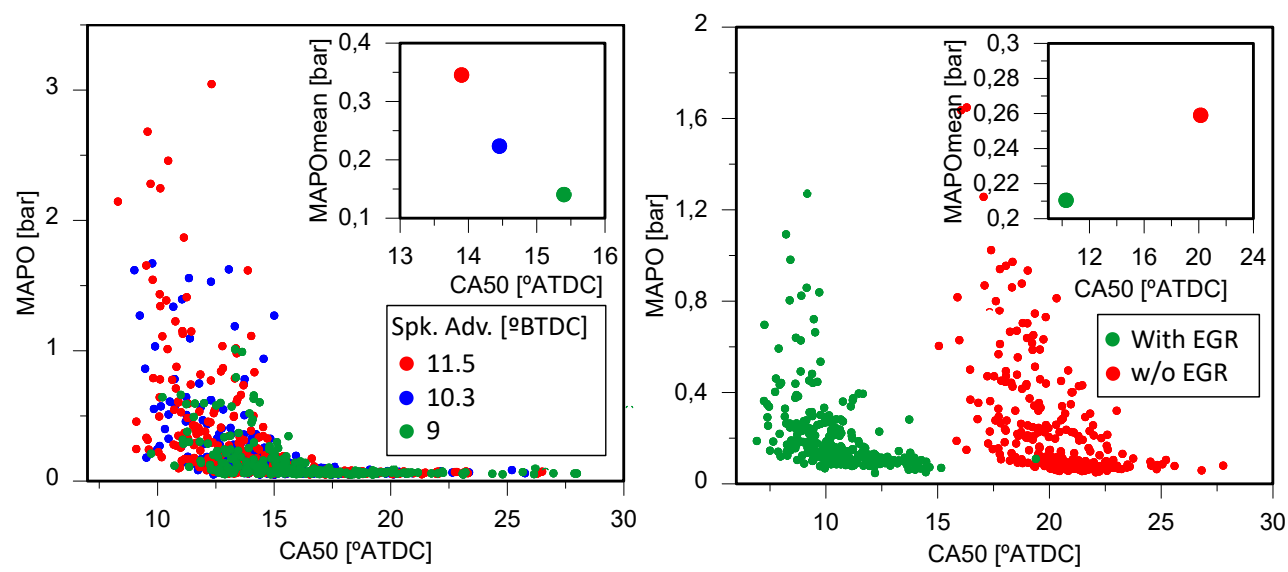

Figure 5.24. Left - MAPO vs. CA50 for all individual cycles (main graph) or averaged (detailed graph) for a spark timing swept. Right - MAPO vs. CA50 for all individual cycles (main graph) or averaged (detailed graph), for two different cases: with (green) and without EGR (red).

is attained at the expense of an increase in BSFC. This BSFC deterioration can be explained as follows: the dilution effect of the mixture and the reactivity loss, both caused by EGR, lead to a decrease in combustion stability that needs to be compensated by an advanced spark timing (CA50 is placed too early) to hold a stable combustion process. This, coupled to the deterioration in combustion efficiency, leads to a significant increase in BSFC.

Given the widely-known $\mathrm{NO}_{\mathrm{x}}$ reduction effect of EGR and all the previous explained effects, it is found that, at high loads, the EGR strategy improves considerably the $\mathrm{NO}_{\mathrm{x}}$-BSFC trade-off of this engine (shown in Fig. 5.26). In view of this figure, it can be stated that $\mathrm{NO}_{\mathrm{x}}$ emissions can be reduced by a factor of 4 without any increase in BSFC, or even slightly improving it.

\section{Medium and low load}

As far as the engine load is reduced, the limitation in CA50 position caused by knock disappears. Besides, in contrast with the previous scenario, because the combustion mode switches to CAI mode, the spark timing loses its controlling capability over the combustion process. Thus, now the CA50 can be correctly positioned by some means (e.g. Fr and/or VVT position, not the spark timing) other than EGR. Consequently, the role of EGR in this other scenario will be less important. 

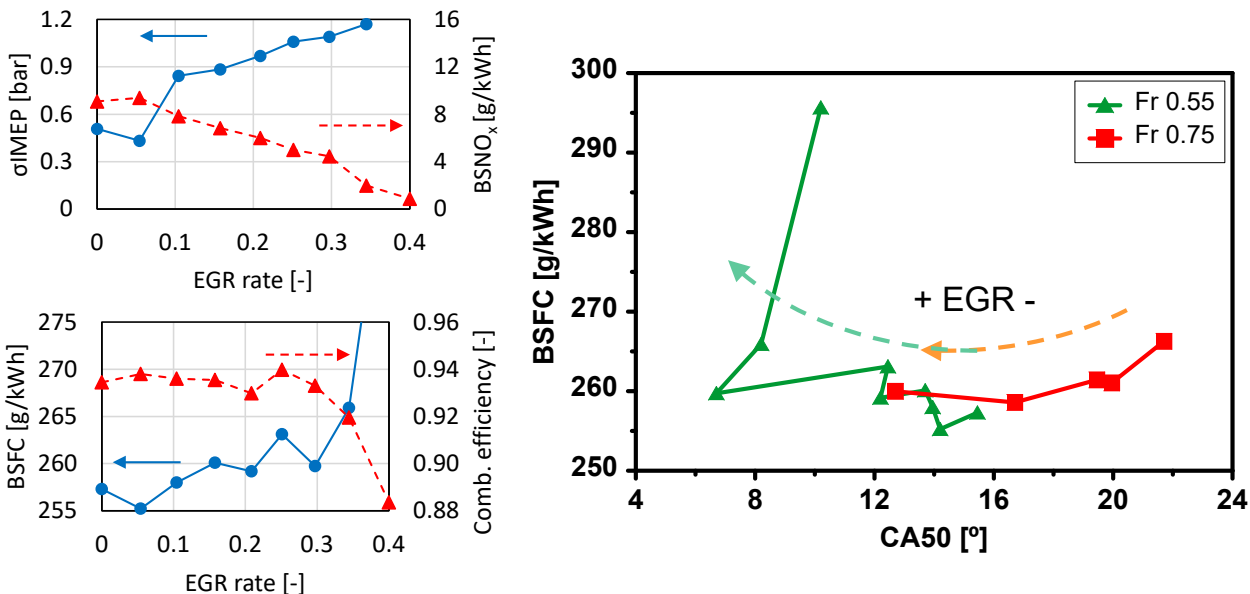

Figure 5.25. Low equivalence ratio case $(F r=0.55)$. Left - Evolution of different parameters as a function of the EGR rate. Right - For the same tests, correlation between BSFC and CA50. In this case, the results previously shown in Figure 5.23 for the $\mathrm{Fr}=0.75$ case are also shown.

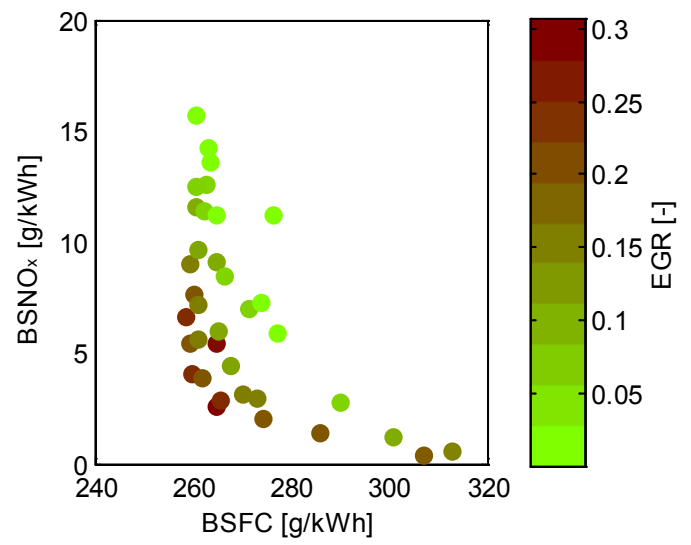

Figure 5.26. $N O_{x}$-BSFC trade-off. The color scale gives information about the EGR rate.

As in the previous subsection, the effect of the EGR will be analyzed at two different Fr values. In Fig. 5.27, to the left, the evolution of different engine parameters as a function of the EGR rate is presented, for Point $4000 @ 5$ at 
low $\operatorname{Fr}(0.65)$. The trends are similar to the ones already seen in the previous subsection, for higher loads.
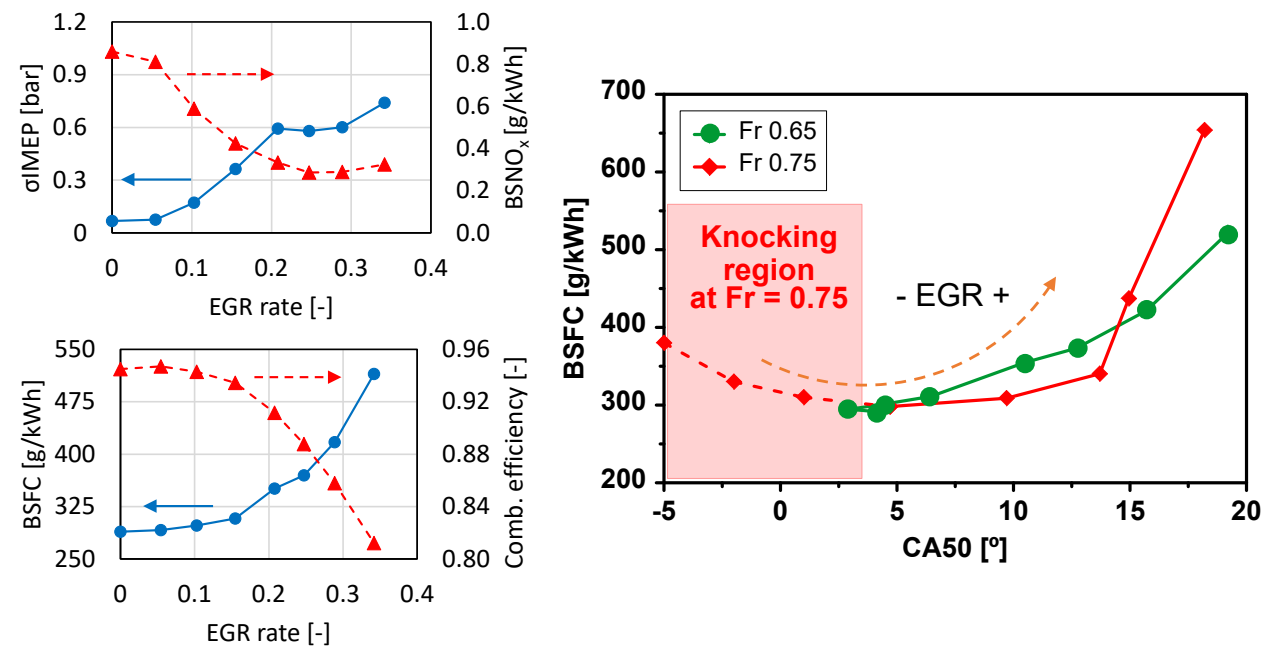

Figure 5.27. Point 4000@5, low equivalence ratio case $(F r=0.65)$. Left - Evolution of different parameters as a function of the EGR rate. Right - For the same tests, correlation between BSFC and CA50. In this case, the results for a higher Fr $(\mathrm{Fr}=0.75)$ case are also shown.

The following comments can be done:

- EGR significantly reduces $\mathrm{NO}_{\mathrm{x}}$ emissions. However, the starting levels of $\mathrm{NO}_{\mathrm{x}}$ are already low, and the use of EGR is less justified than at higher loads. Remember that at CAI operating mode, the IGR rate is significantly high, and $\mathrm{NO}_{\mathrm{x}}$ emissions are naturally low.

- BSFC worsens with EGR. On the one hand, as observed in Fig. 5.27, to the right, this is because the combustion process is delayed (CA50 moves away from TDC). The reason for this is the lower reactivity of the in-cylinder mixture, and cannot be compensated with the spark timing, since it does not control the combustion onset anymore. On the other hand, this is also the result of the loss in combustion efficiency caused by EGR that can be observed in the figure as well.

- The lower mixture reactivity also explains the decrease in combustion efficiency, as well as the increase in $\sigma \mathrm{IMEP}$ (the engine is more unstable). 
For higher Fr's (e.g. 0.75 in Fig. 5.27), because of the higher mixture reactivity, the combustion onset takes place too early, and the engine operates in the non-interesting region shaded in the figure to the right. The operation in this region needs to be avoided because, depending on the operating point, either the combustion onset is placed too early or some knock can appear. In this other case, EGR can help to place the combustion onset on the right place, as shown in Fig. 5.27 to the right, thus allowing to meet, together, lower $\mathrm{NO}_{\mathrm{x}}$ and BSFC. Therefore, at the operating points where the combustion process was already well placed in the cycle, EGR only serves to reduce $\mathrm{NO}_{\mathrm{x}}$ emissions. But taking into account the initially low $\mathrm{NO}_{\mathrm{x}}$ emissions because of the CAI combustion, it might be not necessary to add EGR in most cases.

As a conclusion, the use of EGR, besides reducing $\mathrm{NO}_{\mathrm{x}}$ emissions, allows the exploration of operating points that were previously impossible to achieve due to the excessively high knock level or the too early combustion onset. At the operating points where the excessive mixture reactivity represents a problem for the point optimization, the introduction of EGR decreases this reactivity and allows the correct combustion positioning, thus improving the fuel efficiency with a lower level of $\mathrm{NO}_{\mathrm{x}}$ emissions. With this new degree of freedom in the engine, a wider range is now available at each operating point to look for lower $\mathrm{NO}_{\mathrm{x}}$ together with the same or even lower BSFC. Besides, even the engine peak power can be increased.

\subsection{Study of the cycle to cycle variation}

As it has been said in Chapter 2, the analysis of the combustion through the averaged pressure cycle from the ' $n$ ' measured cycles has usually been the most common and widely methodology employed. For diesel combustion cases, where the cyclic deviation is almost zero, this method is perfectly valid. But when this methodology is extrapolated to the analysis of SI engines, the assumption that the averaged cycle will be representative of the rest of the cycles could not be correct. These kind of engines have significant cyclic variability, and in these cases the analysis through a representative averaged cycle may not have enough quality to understand well enough the combustion process or to make decisions about combustion optimization.

In order to illustrate this different behavior, the plots included in Figure 5.28 show two different tests where a diesel test and a gasoline test have been represented. In each plot all the measured instantaneous cycles of the test have been plotted, 50 for the diesel test and 250 for the gasoline one. 

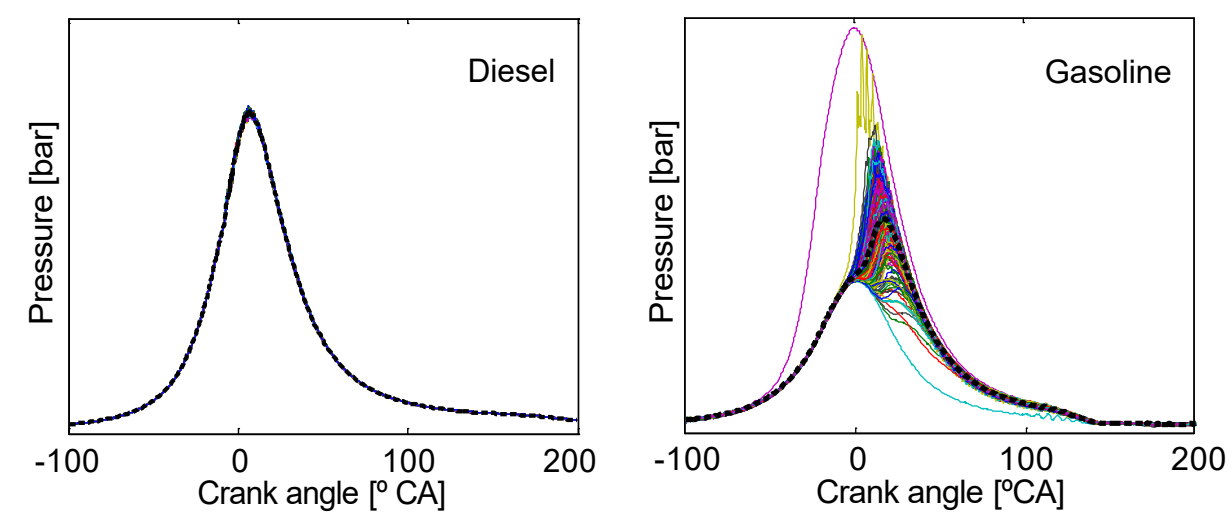

Figure 5.28. Instantaneous pressure measurements in a standard diesel (50 cycles) and gasoline (250 cycles) engines.

The instantaneous pressure cycles have been presented with colored continuous lines, and the averaged pressure cycle is plotted with a black, dashed, thicker line. For the diesel test it can be seen that the instantaneous and the averaged cycle are almost equal. Nevertheless the gasoline test has a high variability, so the averaged cycle is not similar to all the measured cycles. All those possible big discrepancies due to the cyclic variability among the different instantaneous cycles may lead to an unreal estimated HRL and HRR. To illustrate this, in Figure 5.29, there are two plots showing two hypothetical HRR's: on the right the most critical possible case, where both HRR's have a different phasing, and on the left a more favorable case, where the HRR's are placed in the same position and there is only a small shift on the vertical coordinate. If the averaged cycle is calculated, the right case estimation is not representative of the overall combustion. Furthermore, the resulting HRR has not any sense in that particular case. However, on the left case, the methodology is totally valid, since the two cycles have the same phasing and the difference between both cycles is very small.

In the cases where there is a considerable cycle to cycle dispersion, it starts to be necessary to take a deeper look and analyze all the instantaneous cycles individually, in order to get a wider information about what has happened during the measurement. This different approach for the combustion analysis is not only helpful for traditional SI gasoline engines. It becomes even more necessary with new engine concepts and with the different combustion modes. For example: lean operation, controlled auto-ignition (CAI), Homogeneous 

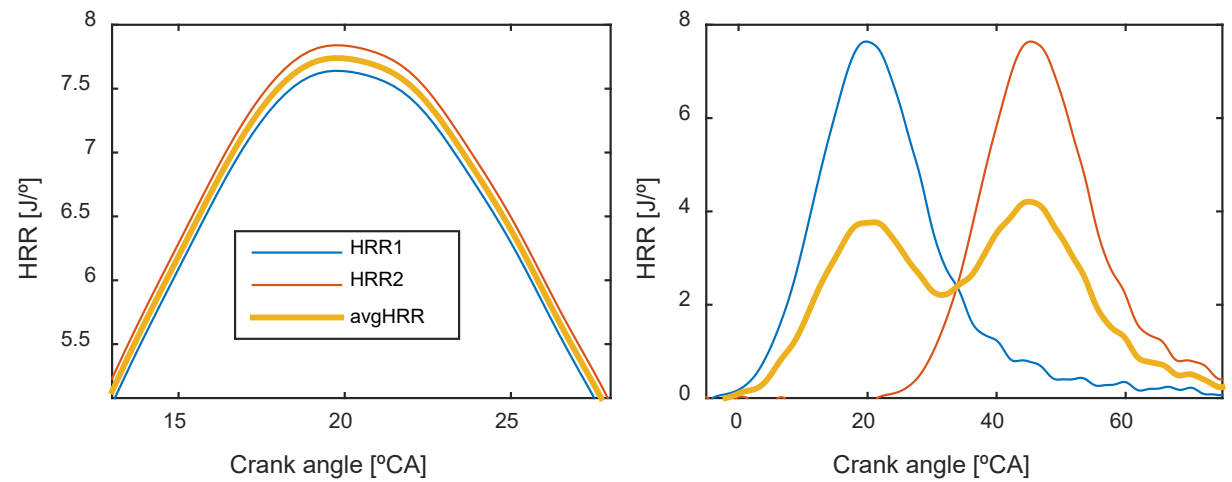

Figure 5.29. Differences in the averaged cycle HRR estimation.

Charge Compression Ignition (HCCI), Reactivity Controlled Compression Ignition (RCCI), Partially Premixed Compression Ignition (PPCI), etc. For all these engines, although not being SI or gasoline (at least, some of them), they need a deeper analysis and control of the combustion and the cylinder conditions in each moment to get a stable and efficient combustion.

The above necessity also applies to the two specific cases discussed in this work. First, lean operation, which is desired in spark ignition engines to reduce nitrogen oxides and hydrocarbon emissions as well as to improve fuel efficiency. One of the major constraints to get lean operation has been the high number of misfires and partial burns, which can be studied and controlled with a more detailed cycle to cycle analysis. And, second, CAI operation, where the previous cycle has a strong influence on the next cycle. Therefore to operate the engine, the analysis should be more detailed and cycle by cycle to get more information and define the correct strategies.

Once reached this point, there seems to be two different approaches to analyze engine data. The first one is the one using the average cycle (ACM, Averaged Cycle Methodology). This one is the most widespread, and it is suitable when there is no significant cycle-to-cycle variability. From this averaged pressure measurement, parameters such as the Heat Release Law (HRL) and the Heat Release Rate (HRR), the combustion position characteristic angles, indicated mean pressures, etc, are calculated. With these values and some other measured data, as e.g. mass flows and temperatures (which are averaged data), there is enough information to explore what has happened inside the engine in a representative way. The second approach is, in 
the cases where there is significant cyclic variability, to analyze cycle by cycle the pressure measurements to get the parameters relative to the combustion of each cycle separately. This way will be called the Cycle To Cycle Methodology (CTCM) from now on. However for this way to proceed, some care must be taken with the data coming from sensors with low response speed (as mass flow meters or temperature sensors), because the registered values are, in fact, averaged data during the whole test, and the cycle to cycle variation has been lost. So, when some parameters are calculated requiring information from such sensors, those parameters will not be representative of the individual cycles.

The results obtained from each type of analysis have significant differences when those are analyzed. In Figures 5.30 and 5.31, data from two tests is shown under the same load and very similar settings. However, one of them (the blue one) has a much greater cyclic dispersion (High Dispersion, HD) than the other one (red; Low Dispersion, LD). Inside each graph three types of data are represented: first, each of the instantaneous cycles, which are the solid color points without perimeter. Second, as solid color dots with a black outline, the results obtained from averaging the results of the cycle to cycle analysis. And, third, as points with a textured color, the results obtained from the analysis through the averaged cycle.

In Figure 5.30, the IMEP of each cycle against the position of the combustion and the maximum HRR from each cycle are represented. The most obvious difference is that with the case of analysis by the averaged cycle there is a single point on which all the information is synthetized, whereas with the other analysis a cloud of points is obtained, with much more information for the analysis. This cloud can acquire different trends: linear, curved, random trends... And these should be analyzed to better understand the relationship between the parameters plotted and the phenomenology that has led to this dispersion. On the other hand, when averaging the results, also some differences between the two processing methods can be appreciated, which are more important when the dispersion (cycle-to-cycle variability) is higher. The most significant case is on Figure 5.31, where the combustion duration is represented against the maximum heat release rate. It can be seen that the analysis of the combustion by means of the averaged cycle is not $100 \%$ representative of the set of individual cycles: there is an error of $\sim 18 \%$ in the average combustion duration for the point with higher cyclic dispersion, and of $\sim 10 \%$ in the case where the combustion has been more stable. This is not the case if the cycles are analyzed individually and then averaged. In this other case, the result is much more embedded inside the cloud of points obtained from the test. To emphasize these differences, two black lines are plotted passing through the two calculated points: the discontinuous for the 
calculation by the average cycle and the continuous for the calculation of the instantaneous cycles. It can be seen how the trend for the averaged cycle is not on the dots cloud.
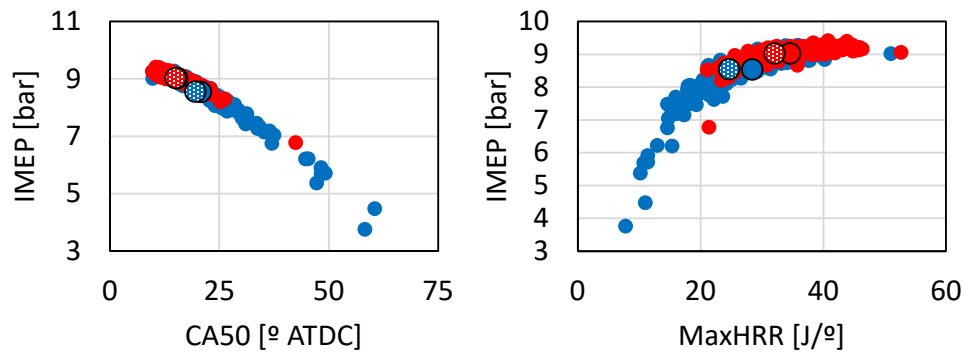

- HD - CTCM

- LD - CTCM

O HD - Avg CTCM

O High Disp. - ACM

O LD - Avg CTCM

Low Disp. - ACM

Figure 5.30. Graphs for two different tests, with high and low dispersion. The IMEP is presented against the CA50 and the maximum HRR in each plot.

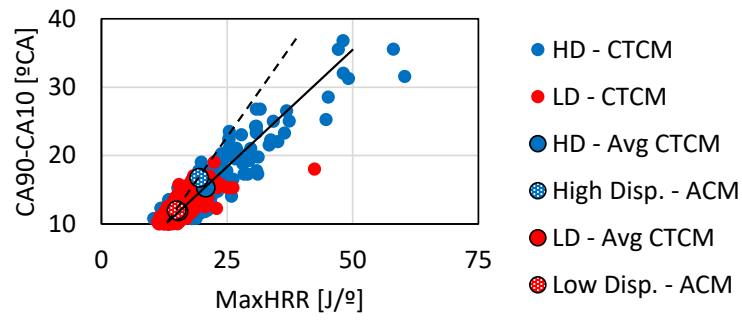

Figure 5.31. Combustion duration (CA90-CA10) against the maximum Heat Release Rate (MaxHRR)for the same cases as those in Figure 5.30.

Now considering the knock analysis for these two tests, the corresponding results are shown in Figure 5.32. In this figure, the values of the combustion position (CA50) are plotted against the Maximum Amplitude of Pressure Oscillations (MAPO) [13] obtained by the two exposed methods (the only parameter that is affected by the calculation methodology is CA50; the MAPO only makes sense to be calculated from the individual cycles, and never from an averaged cycle). The way to present the graph is the same as the on already shown in Figures 5.30 and 5.31. If the minimum CA50 compatible with an acceptable MAPO limit is intended to be determined, this cannot be done properly with the analysis of the combustion by the averaged cycle, nor with the average of the parameters of all cycles. This relationship between the limit 
MAPO and the limit CA50 can only be correctly established by using the cycle-to-cycle information. If the combustion position is represented against the MAPO, the most appropriate area for the combustion phasing can be determined: in this case, it would be about 14 degrees after Top Dead Center (ATDC). Through this kind of representations, better information would be available about which parameters should be corrected or controlled through the adjustment of the combustion settings.

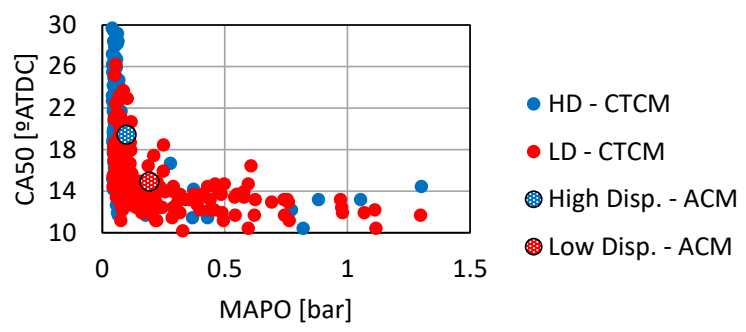

Figure 5.32. Combustion position (CA50) against the MAPO intensity (knock)for the same cases as those in Figures 5.30 and 5.31.

If the evaluation of the points is made by means of the maximum MAPO registered (this is how it is commonly done among the engine community), some mistakes can be made when only this value is taken into account instead of taking the totality of the cycles. Figure 5.33, for example, shows the MAPO cycle by cycle for two different operating points measured with similar load. The MAPO limit for these operating points was 4 bar. The two points appearing in this plot have exceeded that limit and, therefore, both are considered as invalid operating points. In case of having to choose one of the two as valid, taking the maximum MAPO as the only information for the choice, the selected point would be P1, because the maximum MAPO has been about 6 bar, whereas the other case has reached the value of 8 bar. However, if all the cycles of the test are examined, it is clear that at Point P2 this maximum value reached has been erratic, and is not representative of the whole cycles population. On the contrary, at Point P1 there are many cycles that have exceeded the limit of 4 bar. Therefore, with this more detailed analysis it is concluded that Point P2 is much more valid than Point P1.

Once the data from the cycle to cycle analysis is available, it is easier to analyze the anomalous cycles, and to understand what happened with them. An example of a strange combustion occurred during the operation of an operating point running under CAI conditions was shown in Figure 5.2. In 


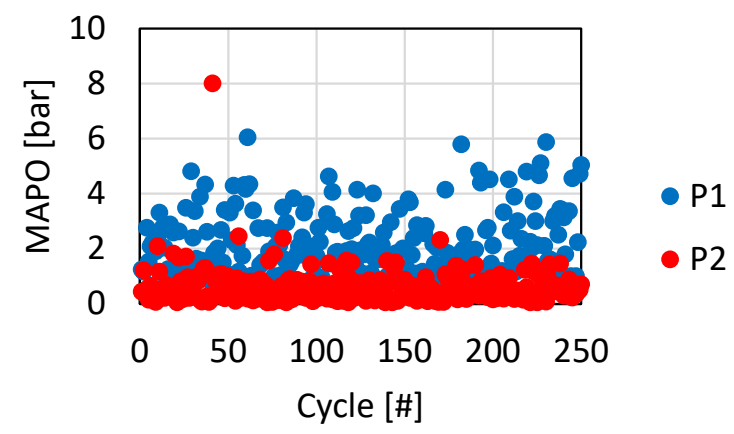

Figure 5.33. MAPO intensity presented for each cycle of two test measurements, $P 1$ and $P 2$.

this case, the engine was burning the mixture without any action on the spark plug. The figure shows a peculiar pressure cycle, clearly differentiated and much larger than the others. So the questions which arise are: why has this happened? Has it been spontaneous or influenced by previous cycles?

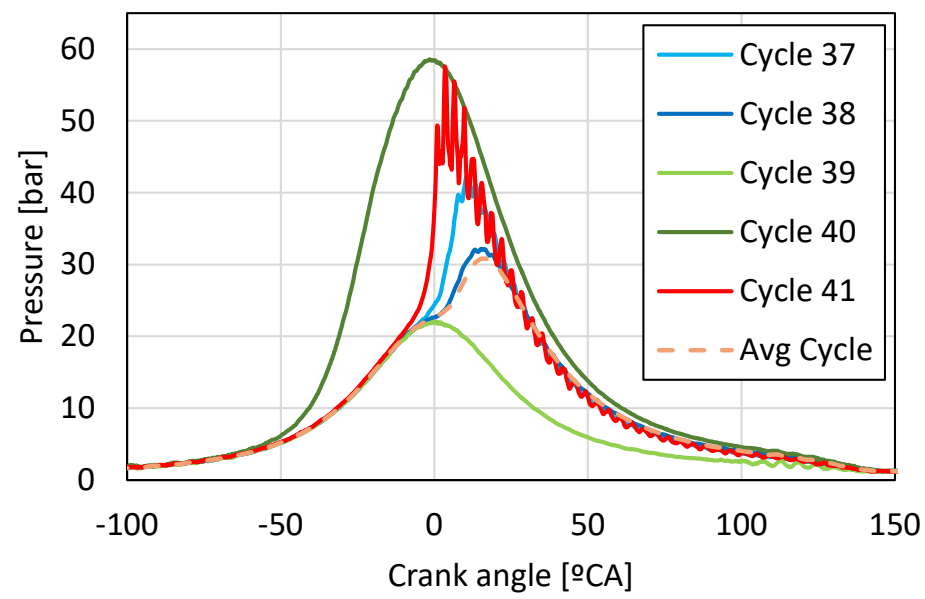

Figure 5.34. Pressure measurement for cycles 37 to 41.

The singular cycle of the test measurement is cycle number 40 . This cycle has had an abnormal combustion. It has been ignited too early and, therefore, the combustion heat has been released well before TDC (see Figure 5.35), 
reaching an excessively high pressure in comparison to the representative cycles of this test. Taking a look to the previous cycles, cycles number 37 and 38 have been normal cycles for this test. However, in the following cycle (\#39, just before the cycle under study) there has been a misfire. The cycle to cycle analysis already gives a clue about what might have happened: after cycle \#39, there were residual gases with a large amount of unburned hydrocarbons inside the cylinder, which had been previously compressed and, therefore, they would be significantly hot and decomposed (some chemical activity might be initiated). These gases will auto-ignite sooner than configured, causing the combustion of the mixture too soon. However, despite having such an early heat release and despite having reached much greater pressure, there has been no knock in this cycle. Nevertheless the next cycle (\#41) has presented problems of knock (see Table 5.1).

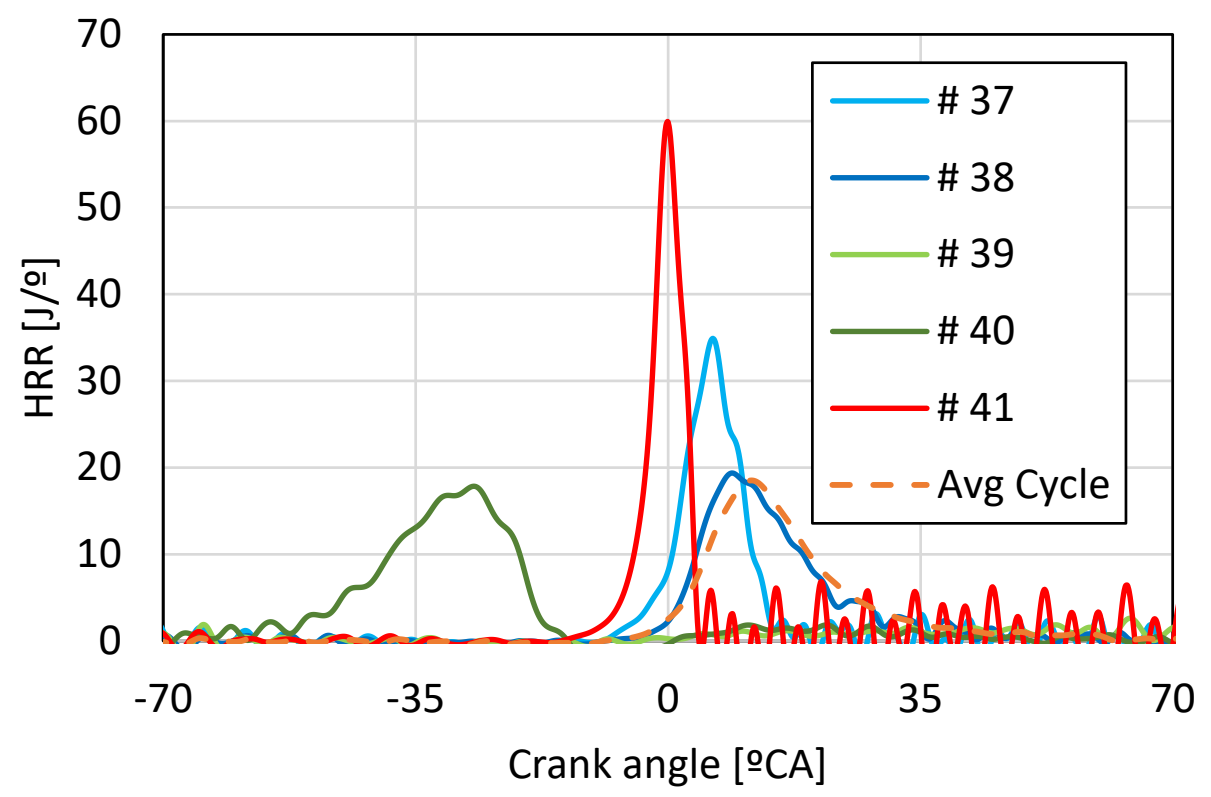

Figure 5.35. Heat release rates for cycles 37 to 41.

Aside from the results previously presented from the processing of the pressure signal by means of CALMEC, where combustion data is obtained, it would also be interesting to know some other parameters, such as mass flows, which are only available as an averaged value due to the lack of measuring speed 


\begin{tabular}{|l|l|l|l|l|l|l|}
\hline Cycle & $\# 37$ & $\# 38$ & $\# 39$ & $\# 40$ & $\# 41$ & Avg Cycle \\
\hline \hline MAPO [bar] & 1.31 & 0.27 & 0.08 & 0.15 & 8.01 & 0.62 \\
\hline IMEP [bar] & 4.42 & 4.44 & 0.68 & 3.67 & 4.42 & 4.44 \\
\hline CA50 $\left[{ }^{\circ}\right.$ ATDC] & 6.45 & 12.95 & 58.20 & -29.8 & -0.05 & 15.03 \\
\hline CA90-CA10 $\left[{ }^{\circ} \mathrm{CAD}\right]$ & 11.75 & 28 & 68.75 & 28.75 & 6.5 & 23.39 \\
\hline Pmax [bar] & 42.27 & 32.18 & 22.06 & 58.56 & 57.45 & 32.16 \\
\hline HRLmax [J] & 332 & 351 & 97 & 405 & 330 & 352 \\
\hline
\end{tabular}

Table 5.1. Data extracted from the CTCM.

of the sensors that provide that data. To estimate the intake and exhaust mass flows, as well as the instantaneous cylinder composition, the pressure data can be used together with some other parameters of the engine. For this calculation the instantaneous pressure signal from the intake, exhaust and cylinder are needed. Also the intake and exhaust discharge coefficients, the instantaneous volume in the cylinder, intake and exhaust temperatures, the composition of intake gases and fuel, and, finally, the averaged data of the measured flows, to verify that the calculated data is equivalent to the real measurement.

As already indicated, all the results shown come from a two stroke engine. It is well-known that the scavenging process in a $2 \mathrm{~S}$ engine is much more complex than the gas exchange process in a $4 \mathrm{~S}$ engine, because it is strongly influenced by the combustion process. So, it is not possible to say that the instantaneous flows are repetitive and coincident with the measured (average) flow. By means of this calculation more details about the test are available, helping to explain the variations in the combustion process. For example, analyzing the cycles presented above (Table 5.2 and Figure 5.36), it is possible to see how the air mass flow across the engine has also changed, and this one has influenced the in-cylinder richness and, therefore, the reactivity of the mixture. The presented values called as $\mathrm{In}_{-} \mathrm{cyl} \mathrm{l}_{\mathrm{air}}$ and $\mathrm{In}-\mathrm{cyl} \mathrm{bg}_{\mathrm{bg}}$ are representative of the equivalent mass flows of fresh air and burnt gases (respectively) in each individual cycle.

Thanks to this more detailed way to process the data, it can be observed that the instantaneous richness is not coincident with the average richness measured during the entire time interval (red line in Figure 5.36). From cycles $\# 37$ and \#38, points considered within the range of combustion similar to the average cycle, the analysis of the richness evolution can be started. It is 


\begin{tabular}{|l|l|l|l|}
\hline Cycle & Fr $_{\text {cyl }}[-]$ & In-cyl $_{\text {air }}[\mathrm{kg} / \mathrm{h}]$ & $\mathrm{In}_{-\mathrm{cyl}}{ }_{\mathrm{bg}}[\mathrm{kg} / \mathrm{h}]$ \\
\hline \hline$\# 37$ & 0.86 & 40.6 & 27.2 \\
\hline$\# 38$ & 0.87 & 39.9 & 20.7 \\
\hline$\# 39$ & 1.05 & 33.1 & 18.5 \\
\hline$\# 40$ & 1.15 & 30.3 & 26.1 \\
\hline$\# 41$ & 1.07 & 32.5 & 24.3 \\
\hline$\# 42$ & 0.96 & 36.3 & 21.0 \\
\hline$\# 43$ & 0.92 & 37.8 & 21.2 \\
\hline$\# 44$ & 0.91 & 38.2 & 17.8 \\
\hline
\end{tabular}

Table 5.2. Data of the instantaneous mass flows extracted from the CTCM.
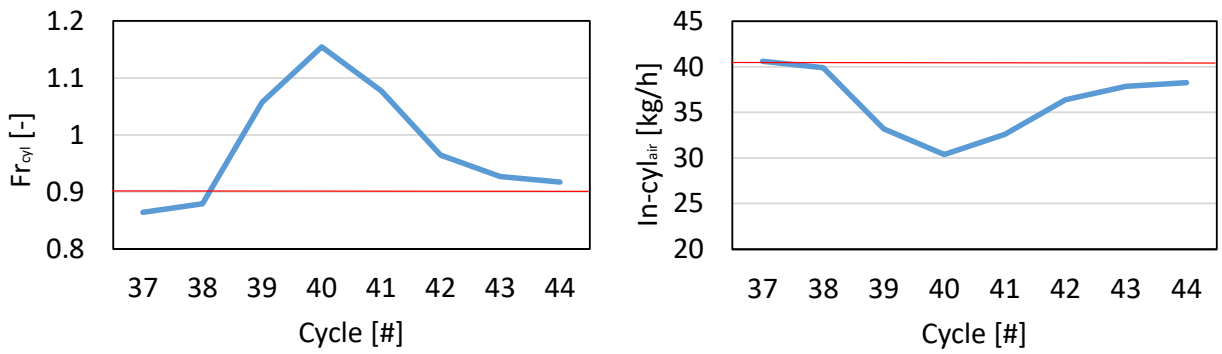

Figure 5.36. Representation of the $F r_{c y l}$ and the air inside the cylinder(In-cyl $l_{\text {air }}$ ) for cycles 37 to 42. The red line represents the mean value during the test.

observed how in cycle \#39 there is a smaller amount of air inside the cylinder, and this, combined with a misfire of the mixture in that cycle, has lead to the particular behavior of cycle \#40, which has burned with a high richness (and with the residual unburned hydrocarbons from the previous unburned cycle, which have not been taken into account for the richness calculation). Finally, in later cycles, it is observed how the engine starts to burn progressively in a way closer to what has been the average of the test cycles, and both the in-cylinder richness and the combustion position return to their normal values. 


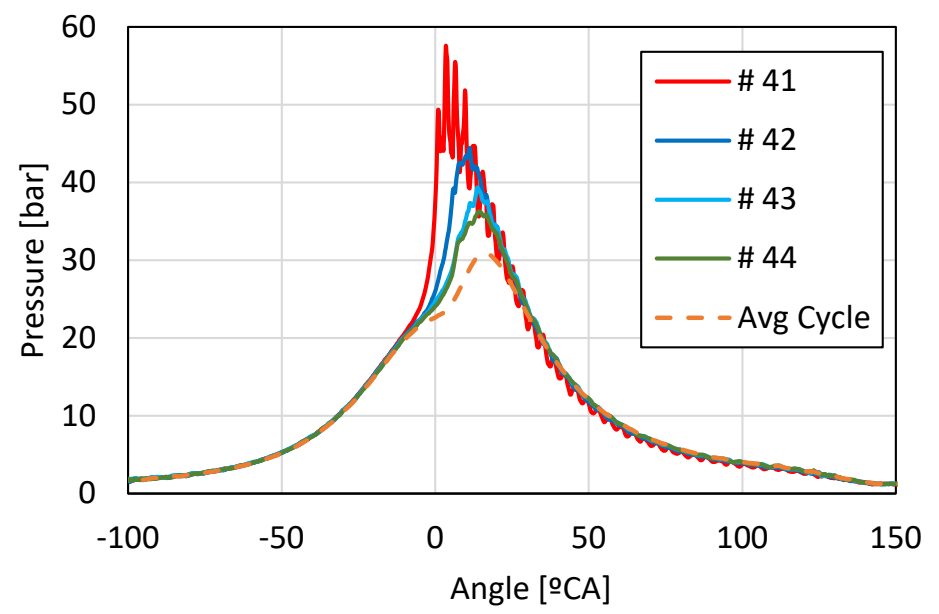

Figure 5.37. Pressure measurement for cycles 41 to 44.

\subsection{Conclusions}

Through the chapter, different aspects have been addressed. In this final section of the chapter, the most important ideas are going to be summarized.

- Different combustion modes:

The engine can be operated in two different combustion modes: SI and CAI.

The possibility to move between CAI and SI depends, mainly, on the engine load, since the conditions of the in-cylinder charge are modified with this parameter.

Four operating regions in the engine map were identified: region I will be an area where the engine can only be operated in SI; region II, where it can alternate between SI and CAI; region III, where the engine will operate in auto-ignition conditions; and Region IV, where it will operate again under SI conditions.

- Scavenging process:

As this is a two-stroke engine, the scavenging process of this engine does not remove all the residual gases of the previous cycle, nor retains all the fresh intake gases. The charge that will remain inside the cylinder 
will be a mixture between the portion of fresh trapped gases and the hot residual gases that have remained from the previous cycle.

The main "levers" to control the scavenging process are the intake pressure and the VVT position. Firstly, by means of the intake pressure, the richness and the scavenging process can be regulated. And, to a lesser extent, by means of the VVT modification, a complementary adjustment of the in-cylinder charge characteristics (the IGR rate and its corresponding temperature) can be achieved.

With the reduction of the load degree, the IGR rate increase unavoidably. These residuals in the cylinder can be used to adjust the composition of the charge and its initial temperature, which can be used to operate the engine in CAI combustion mode.

- Effect of the injection and ignition systems:

The injection system introduces a mixture of fuel and air into the engine. This system offers better spray homogenization with lower fuel injection pressures. The parameters to be adjusted are the SOI (Start Of Injection) and the DOI (Duration Of Injection). It is important to remark that the DOI parameter directly affects the air amount injected together with the fuel.

The strategies to optimize these parameters are focused on defining a SOI as advanced as possible for high loads, which guarantees a good mixture homogeneity, and to reduce this SOI value as far as the engine load is reduced, since the mixture dispersion starts to be excessive. Regarding the DOI, a new parameter, named IAR (Injected Air Ratio), has been defined. With this parameter, an optimum relationship between the injected air and the total in-cylinder air mass can be determined.

Regarding the ignition system, the three scenarios that can be found during the operation of the engine have been addressed. The first one is the most common case, where the ignition timing is used to adjust the combustion position, and the increase of the knock level is the limiting factor to advance the combustion. The second case occurs with very lean mixtures, which allows an over-advanced ignition without any limitation arisen by knock. This over-advance would cause a loss in both efficiency and combustion stability, so it has to be controlled. And the third case, with CAI combustion, the effect of the spark is lost and the ignition of the mixture starts to be governed by other mechanisms. 
- EGR effect:

The EGR strategy has been chosen as a new variable for the configuration of the composition of the charge and its reactivity. Additionally, it also has some benefits in terms of $\mathrm{NO}_{\mathrm{x}}$ reduction.

Depending on the engine load, the EGR has shown different results. At high loads, it has shown a strong capacity of reducing $\mathrm{NO}_{\mathrm{x}}$ and, additionally, it has helped to improve the performance of the engine thanks to the decrease in the knocking tendency, thus allowing a better combustion positioning.

With lower loads, if the combustion was already well positioned, this improvement margin can no longer be exploited, and so its benefit is limited to the $\mathrm{NO}_{\mathrm{x}}$ reduction.

- The cyclic variability:

Two methods to analyze the combustion process have been presented and discussed: the one based on the average cycle, and the one based on the cycle-to-cycle analysis. After seeing the differences between both methods, it is possible to see that each of them has its interest depending on the information to be analyzed. The cycle-to-cycle analysis method provides a large amount of detailed information about what has happened at each instant during the test measurement. In this way, some specific phenomena during the combustion process can be studied, and anomalous cycles can be isolated and studied separately.

The problems associated to the averaged cycle analysis when there is cyclic dispersion have also been exposed. The main problems are the deviation of the data obtained because of the deformation of the averaged pressure cycle. In these cases, the average of the results from each cycle separately usually presents more accurate values than the one obtained from the averaged cycle.

On the other hand, for combustion processes without cyclic deviation (e.g. in diesel engines), the high amount of information obtained through the CTCM is not useful, since it results in a large amount of redundant information. The required processing effort is much greater, and therefore a longer calculation time and a greater amount of resources are required. Apart from that, a greater effort to deal with this large amount of data and interpret the results of the analysis is also needed.

Finally, it should be noted that this type of methodologies are going to be necessary in new engine concepts where, for example, the engine will be operated in HCCI or CAI conditions, since a greater degree of detail 
is needed for the analysis of the combustion. And, in a next step, this will be useful to perform the control of the combustion in closed loop, allowing to operate directly on the anomalous combustions and on the instabilities with predictive and corrective strategies. This leads to higher levels of efficiency, better control of the knock, and makes it possible the use of combustion modes practically unachievable through an open loop combustion control.

\section{Bibliography}

[1] Sturm S., Schmidt S. and Kirchberger R. "Overview of Different Gas Exchange Concepts for Two-Stroke Engines". SAE Technical Paper n. 2018-32-0041, 2018.

[2] Li Y., Zhao H., Brouzos N., Ma T. and Leach B. "Effect of injection timing on mixture and CAI combustion in a GDI engine with an air-assisted injector". SAE Technical Paper n. 2006-01-0206, 2006.

[3] Cathcart G. and Tubb J. "Application of air assisted direct fuel injection to pressure charged gasoline engines". SAE Technical Paper n. 2002-01-0705, 2002.

[4] Bai H., Li Z., Li J., Lai W. and Hu C. "Experiment on spray characteristics with air-assisted injector of direct-injection gasoline engine". Neiranji Xuebao/Transactions of CSICE (Chinese Society for Internal Combustion Engines), Vol. $31 \mathrm{n}^{\circ}$ 1, pp. 38-44, 2013.

[5] Bai H., Hu C., Hou S., Liu N. and Li Z. "Comparison of spray characteristics of airassisted direct injector using kerosene and gasoline". Ranshao Kexue Yu Jishu/Journal of Combustion Science and Technology, Vol. $21 \mathrm{n}^{\circ}$ 5, 2015.

[6] Glahn C., Kluin M., Hermann I. and Koenigstein A. "Cooled external egr as a key technology for high-efficient gasoline combustion systems". FISITA 2016 World Automotive Congress - Proceedings, 2016.

[7] Syaiful, Nuryasin M. and Bae M.-W. "Effect of hot EGR on performance and exhaust gas emissions of EFI gasoline engine fueled by gasoline and wet methanol fuel blends". ARPN Journal of Engineering and Applied Sciences, Vol. $11 \mathrm{n}^{\circ}$ 6, pp. 4065-4069, 2016.

[8] Mardi M.K., Abdolalipouradl M. and Khalilarya Sh. "The effect of exhaust gas recirculation on performance and emissions of a SI engine fuelled with ethanol-gasoline blends". International Journal of Engineering, Transactions A: Basics, Vol. $28 \mathrm{n}^{\circ} 1$, pp. 133-138, 2015.

[9] Hacohen J., Ashcroft S. J. and Belmont M. R. "Lean burn versus EGR S.I. engine". SAE Technical Paper n. 951902, 1995.

[10] Grandin B., Angström H., Stalhammar P. and Olofsson E. "Knock suppression in a turbocharged SI engine by using cooled EGR". SAE Technical Paper n. 982476, 1998.

[11] Alger T., Chauvet T. and Dimitrova Z. "Synergies between high EGR operation and GDI systems". SAE Technical Paper n. 2008-01-0134, 2009.

[12] Luján J.M., Climent H., Novella R. and Rivas-Perea M.E. "Influence of a low pressure EGR loop on a gasoline turbocharged direct injection engine". Applied Thermal Engineering, Vol. 89, pp. 432-443, 2015. 
[13] Zhen X., Wang Y., Xu S., Zhu Y., Tao C., Xu T. and Song M. "The engine knock analysis - An overview". Applied Energy, Vol. 92, pp. 628-636, 2012.

[14] Curran H.J., Gaffuri P., Pitz W.J. and Westbrook C.K. "A comprehensive modeling study of iso-octane oxidation". Combustion and Flame, Vol. $129 \mathrm{n}^{\circ} 3$, pp. 253-280, 2002. 



\section{A Effect of IGR on the ignition delay}

In this appendix the ignition delay of a mixture of air + IGR is assessed as a measure of its knocking tendency. The motivation is to find out which effect is stronger: the effect of the oxygen content reduction when the IGR rate increases, which would reduce the mixture reactivity; or the effect of the increase in mixture temperature when the IGR increases, which would increase the mixture reactivity.

For the study, the following hypotheses and assumptions were taken:

- The air in the intake manifold is at $323 \mathrm{~K}$. This is assumed to be the initial temperature of the air trapped in the cylinder.

- The exhaust gases in the exhaust manifold are at $827 \mathrm{~K}^{3}$. This one is also assumed to be the initial temperature of the residual gases (IGR) trapped in the cylinder, thus neglecting the shortcircuiting.

- With the two previous assumptions, the initial temperature of the mixture is calculated, as a function of the IGR rate, taking into account the $c_{p}$, initial temperature and mass fraction of both air and IGR.

- The mixture at known initial conditions is assumed to be compressed up to TDC (consequently both the temperature and pressure are significantly increased), and then introduced in a PSR (Perfectly Stirred Reactor, i.e. a perfectly homogeneous reactor), where the autoignition process is going to be studied with Chemkin. It is worthy to note that the compression up to TDC is necessary to ensure the mixture autoignition.

- The ignition delay is considered to happen when $50 \%$ of the total temperature increase in the reactor takes place.

- The fuel considered was isooctane (the chemical mechanism considered was that from Curran et al. [14]), and the equivalence fuel/air ratio was 1 (for $\mathrm{Fr}=0.6$, it was checked that the conclusions are exactly the same).

The results of the simulations are presented in Fig. 5.38. It can be seen that, in the main range of IGR rates, the higher the IGR rate, the lower the ignition

\footnotetext{
${ }^{3}$ This assumption might seem not realistic, since as far as the IGR rate is increased, the exhaust temperature will probably be lower, because the amount of fresh mixture (and, consequently, the amount of fuel burned) is lower. However, the initial in-cylinder temperature also increases with the IGR rate, and this might compensate the lower heat released during combustion. Consequently, the assumption that the temperature in the exhaust is constant independently of the IGR rate makes sense.
} 


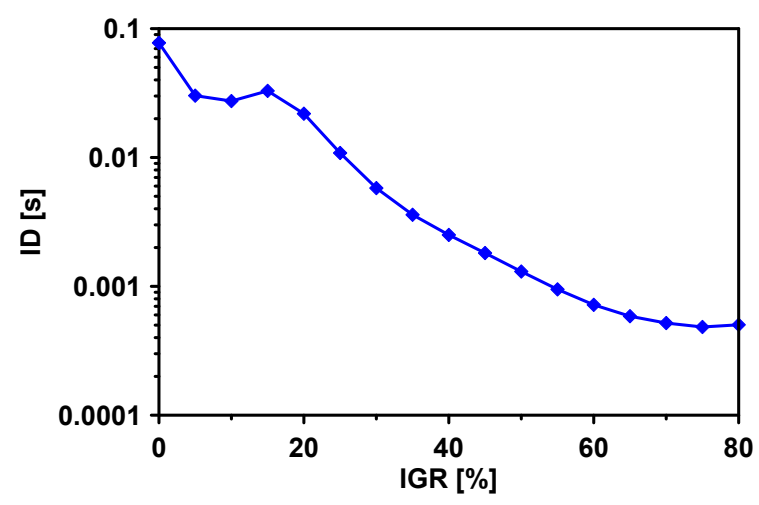

Figure 5.38. Effect of the IGR rate on the ignition delay.

delay, meaning that the thermal effect is stronger than the dilution effect. This trend is broken at very high IGR rates (above $75 \%$; for an $\mathrm{Fr}_{\mathrm{app}}=0.6$, this shift in the trend takes place at an IGR rate of 90\%), and at low IGR rates (below $15 \%)$. However, it should be taken into account that the minimum IGR rate achievable in the engine is between 10 and $15 \%$, whereas the maximum IGR rate is between 80 and $90 \%$. Consequently, it can be concluded that, in the possible range of IGR allowed in the engine, the higher the IGR, the higher the mixture reactivity.

\section{B Effect of the exhaust valves opening time modification over the IGR temperature}

At a given operating point, with the EVO advance, the exhaust gases show to have a higher temperature. This effect is due to the modification of the effective expansion rate.

To begin with, the case when the EVO is delayed is going to be analyzed. In this situation, the in-cylinder gases are further expanded inside the cylinder, and the irreversible expansion taking place when the valve is opened is reduced. As a result, the overall expansion takes place mainly in the cylinder, and consequently this expansion is more similar to an isentropic expansion. On the contrary, when the EVO is advanced, the in-cylinder gases are less expanded in the cylinder, and the irreversible expansion when the valve is opened increases in magnitude, and overall, the expansion is further away from an isentropic 
expansion. If these two processes are compared, the gases temperature is decreased faster trough an isentropic expansion, and this is the main reason why the exhaust gases temperature changes when the EVO is modified.

This effect can be demonstrated easily with experimental data of some points measured at the same operating conditions where the EVO has been modified. As it can be seen in Figure 5.39, the measured exhaust gases temperature increases with the advance of the exhaust opening.

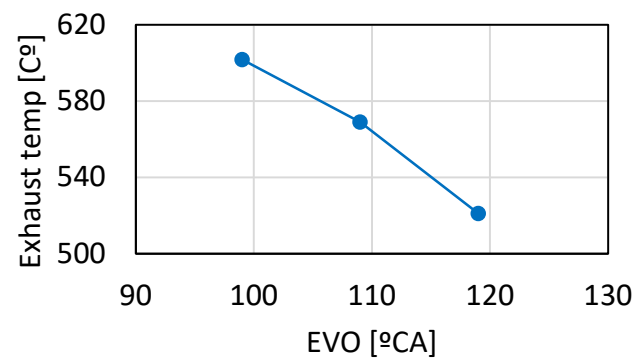

Figure 5.39. Evolution of the exhaust temperature with the EVO variation.

\section{C DOI effect on the fuel homogenization}

There is some experimental evidence that the increase of the injected air mass flow ( $\uparrow$ DOI) for the same fuel amount improves the combustion efficiency (see e.g. Fig. 5.40) ${ }^{4}$. To analyze this behavior, the two extreme experimental cases have been taken as a reference to study this effect (the highest and the lowest DOI, later referred as long and short injection, respectively).

This increase in injected air has been simulated in a CFD model in order to investigate the origin of this improvement. In a first step, only the modification in injected air has been simulated, assuming that nothing else changes in the engine operation when this parameter is modified. Under this assumption, the CFD model does not reproduce the experimental result (see Table 5.3, first two columns; the combustion efficiency is the same in both cases). After this result, it was thought that, probably, the addition of a higher amount of air to the same amount of fuel would improve the fuel atomization process. To validate this hypothesis, the droplet size was increased for the short injection

\footnotetext{
${ }^{4}$ This statement is true provided that the IAR parameter (presented in Chapter 5) is below its optimal value.
} 


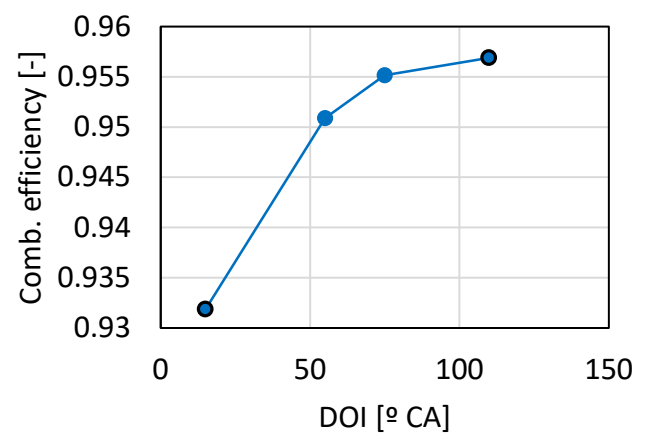

Figure 5.40. Experimental results of the DOI influence on the combustion efficiency.

case in a second step (last column in the table). Now the results show more consistency with the experimental results.

\begin{tabular}{llll}
\cline { 2 - 4 } & $\begin{array}{l}\text { Long } \\
\text { injection }\end{array}$ & $\begin{array}{l}\text { Short } \\
\text { injection }\end{array}$ & $\begin{array}{l}\text { Short } \\
\text { injection }\end{array}$ \\
\hline \hline Droplet size $[\mu \mathrm{m}]$ & 20 & 20 & 40 \\
Comb. efficiency $[-]$ & 0.9564 & $\mathbf{0 . 9 5 5 9}$ & $\mathbf{0 . 9 0 4 8}$ \\
\hline
\end{tabular}

Table 5.3. CFD simulation results for the different injection configurations at Point 2000@17.

Based on the results obtained with the CFD model, the effect of the injected air amount on the fuel atomization process seems to be the key factor to explain the observed trend in combustion efficiency. The main reason would be that the droplet size might have a direct impact on the fuel mixing process, since the fuel evaporation is proportional to the surface that is in contact with the air. In this case, the smaller the diameter of the droplets, the higher the total surface, thus improving the fuel evaporation process, and therefore the combustion efficiency. 


\section{Chapter 6}

\section{The different operable combustion modes in the engine used}

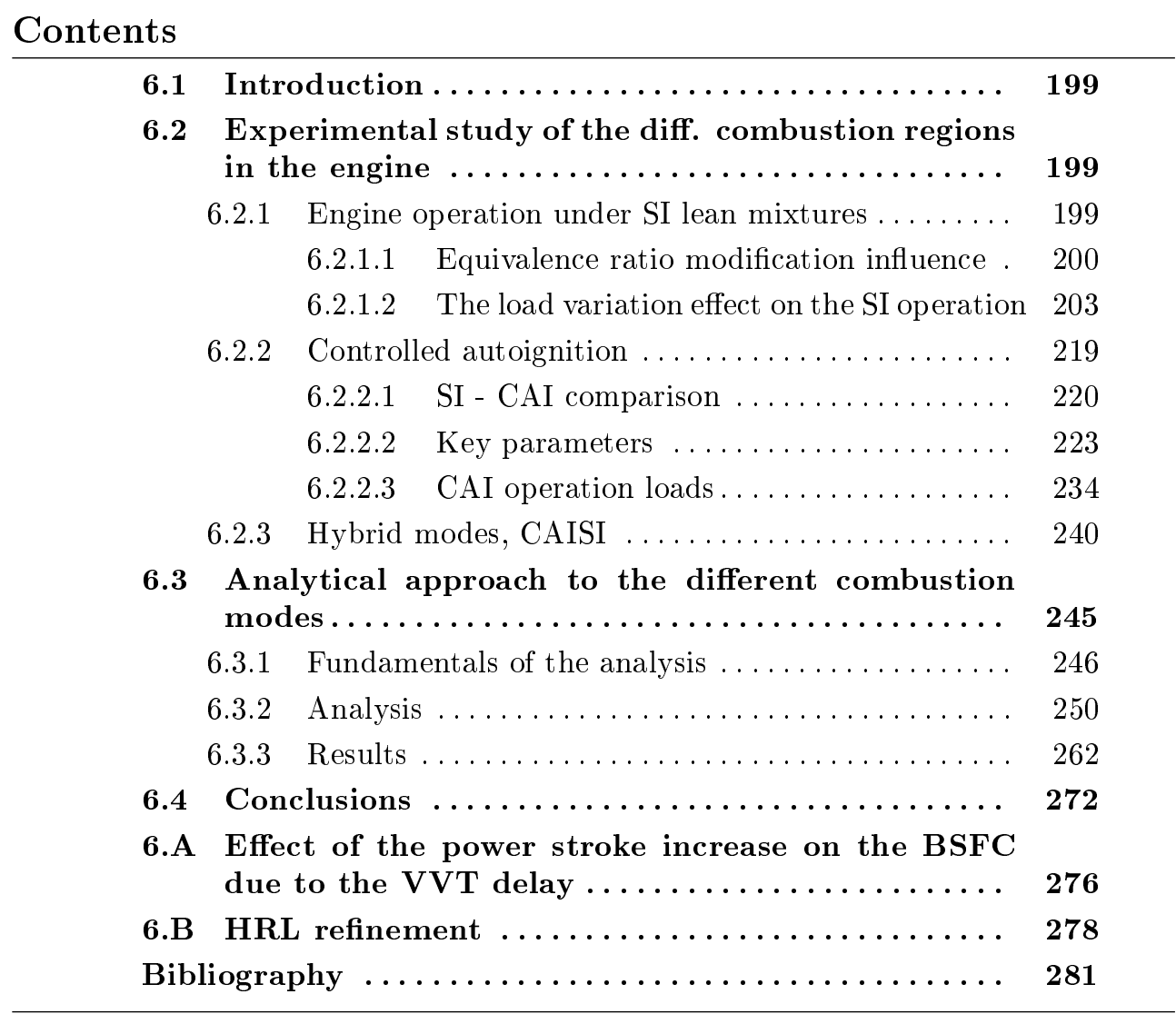





\subsection{Introduction}

The focus of this chapter has been the study of the SI lean combustion and CAI combustion modes. Both modes present a series of potential improvements in efficiency or emissions compared to the traditional SI operation in stoichiometric conditions that make them very interesting for the improvement and development of current SI gasoline engines. For this study, the first part of the chapter is focused on the experimental study of both combustion modes, analyzing the potential of each separately, as well as the key parameters to control and optimize the combustion through the different operation regions of the engine. During the second part of the chapter, the need to analyze in a more detailed (and quantitative) way the combustion development is raised. By this way, more detailed and valuable information is obtained and serves to evaluate the information coming from the engine. This information can be used to better understand these two combustion modes and their differences, and to distinguish, by an analytical way, which type of combustion has occurred in a cycle if it is analyzed.

\subsection{Experimental study of the different combustion regions in the engine}

\subsubsection{Engine operation under SI lean mixtures}

In this section, the engine operation in SI conditions will be studied (i.e., the normal combustion process in gasoline engines). However, unlike the SI operation in stoichiometric conditions, the lean mixture operation will be studied in order to try to identify the advantages of this operation mode. The engine map described in Section 5.2 shows two regions defined as "SI operated" (I and IV), being region I of greater importance, operated at high loads and taking a large part of the map of this engine. In fact, the whole engine map could be operated in SI conditions, since this combustion mode is the standard mode of this engine.

Therefore, to start this section, the potential of working with lean mixtures instead of stoichiometric mixtures will be analyzed, and later the combustion performance through the different load levels of the engine will be studied. 


\subsubsection{Equivalence ratio modification influence}

Usually SI engines have been operated always in stoichiometric conditions, to make them compatible with the use of a simple and cheap aftertreatment system, the TWC [1]. However, lean operation leads to different advantages that make its application very interesting to get an improvement in terms of fuel efficiency in SI engines.

To show the effects of the application of this combustion mode on the engine, some results at Point 2000@17 will be shown, where the F/A equivalence ratio has been varied. In order to show the effect of this parameter on the combustion process, the VVT position and the fuel injection (mass and settings) have remained constant for all the presented tests. However the spark timing has always been varied, adjusting it to try to optimize torque (MBT, Maximum Brake Torque), even if, in most of the cases, the knock limit was reached earlier. Since this engine works in a two stroke cycle, the apparent $\mathrm{F} / \mathrm{A}$ equivalence ratio may not be representative of the in-cylinder equivalence ratio due to the possible presence of some short-circuiting of the intake charge. For this reason, the in-cylinder conditions are going to be used in order to represent the real conditions inside the combustion chamber.

The first interesting result is the improvement of the engine efficiency by increasing the air excess. For that, Figure 6.1 shows the evolution of the brake specific fuel consumption when the mixture is moved out of stoichiometric conditions (in these tests $\mathrm{Fr}_{\text {cyl }}$ has been reduced, starting from the value 1 -stoichiometric-). This parameter is significantly reduced, going from a value of 286 to $240 \mathrm{~g} / \mathrm{kWh}$, which represents an improvement of $16 \%$ in fuel consumption.

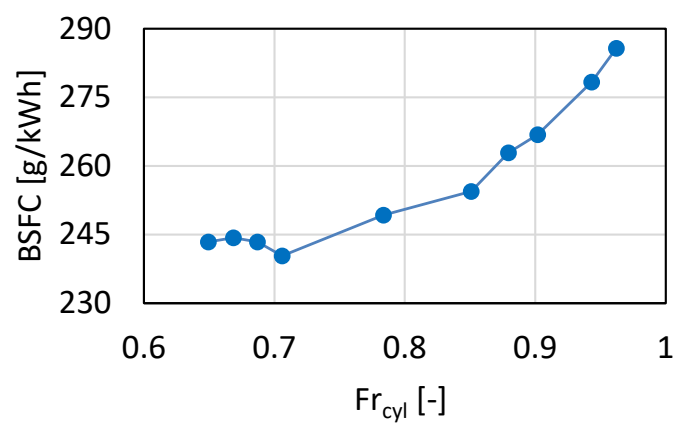

Figure 6.1. Brake specific fuel consumption for different $F r_{\text {cyl }}$ values. 
This efficiency improvement is mainly due to four reasons:

- First, the combustion position (CA50) has been advanced as the $\operatorname{Fr}_{\text {cyl }}$ has been reduced (Figure 6.2, CA50). This advance has shown to be beneficial, since the combustion advance in stoichiometric conditions was limited by knock. It has to be noted that for $\mathrm{Fr}_{\text {cyl }}$ values close to stoichiometric conditions the spark timing has not been advanced. This effect might be due to the improvement of the mixture homogenization and the extra oxygen available for combustion, leading to an increase in the mixture reactivity compared to the stoichiometric conditions. If $\mathrm{Fr}_{\text {cyl }}$ is further decreased, both the dilution effect and the decrease in combustion temperatures reduce the risk of knock. For this reason, the combustion can be advanced and placed better in the cycle, thus improving the engine efficiency.

- Second, the combustion efficiency is improved, especially in the first part of the variation starting from stoichiometric conditions, because of the better homogenization of the mixture (the local rich areas are reduced) and the greater availability of oxygen to oxidize the fuel. As can be seen in the graph, there is an optimum $\mathrm{Fr}_{\text {cyl }}$ for this parameter, in the mid of the explored range: for Fr's richer than this optimum, the mixture does not burn completely due to the lack of oxygen; and for Fr's leaner than this optimum, the excessive dilution of the fuel brings the mixture close to the flammability limit and, therefore, there will be areas with low temperatures or with low fuel concentrations that won't be burnt (Figure 6.2, Comb. efficiency). When the mixture composition gets close to the flammability limits, the combustion stability deteriorates progressively, and these instabilities will cause a rapid increase in $\mathrm{HC}$ emissions and a drop in the fuel efficiency.

- Third, the decrease of the combustion temperatures caused by the $\mathrm{Fr}_{\text {cyl }}$ reduction, reduces the heat losses to the combustion chamber walls, and therefore the engine will be more adiabatic and efficient. This reduction is provoked by the higher dilution of the mixture, and more energy will be available to be recovered during the expansion stroke. This reduction in combustion temperature can be partly seen in the exhaust temperatures drop, which is the combination of the combustion temperature reduction together with the combustion advance (Figure 6.2, Exhaust temperature).

- Fourth, the theoretical cycle efficiency is improved due to the higher specific heat ratio $(\gamma)$ at lean conditions. 

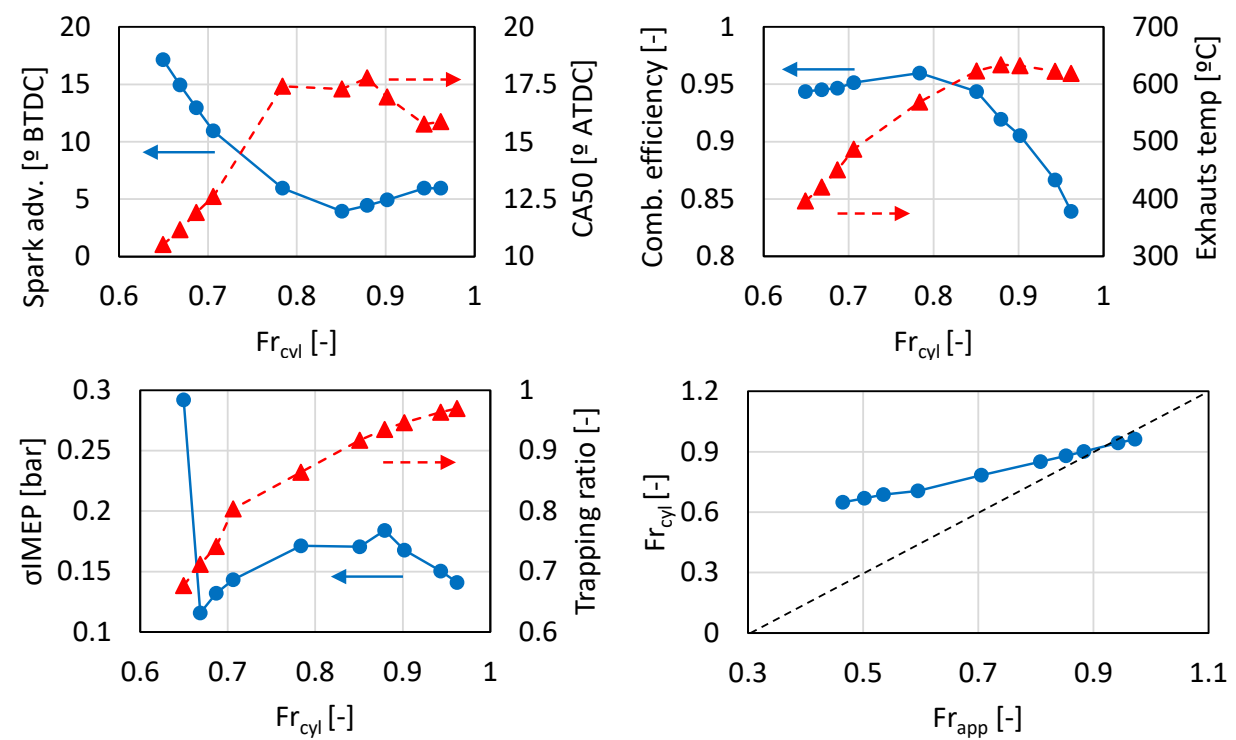

Figure 6.2. Representation of different combustion parameters for Point 2000@17 as a function of the in-cylinder $F / A$ eq. ratio and relationship between the in-cylinder and the apparent $F / A$ eq. ratio.

The trapping ratio evolution for these tests is also shown in Figure 6.2. This parameter is worsened with the increase of the delivered air mass (required to decrease $\mathrm{Fr}$ ). As observed in the plot where $\mathrm{Fr}_{\mathrm{cyl}}$ and $\mathrm{Fr}_{\mathrm{app}}$ are presented, the $\mathrm{Fr}_{\text {cyl }}$ does not decrease as fast as the $\mathrm{Fr}_{\text {app }}$ due to the short-circuiting of fresh air coming from the intake directly to the exhaust. This fact has to be taken into account when the engine operation strategies have to be defined, since in many cases the $\mathrm{Fr}_{\text {cyl }}$ will not coincide with the $\mathrm{Fr}_{\text {app }}$, and during the engine operation the $\mathrm{Fr}_{\text {cyl }}$ is not available as a direct measurement.

Finally, to complete the study of the in-cylinder F/A eq. ratio modification from stoichiometric to lean conditions, the evolution of the pollutant emissions will be analyzed (Fig. 6.3).

- $\mathrm{NO}_{\mathrm{x}}$ : in a premixed combustion, these emissions depend on oxygen availability and combustion temperature. When $\mathrm{Fr}_{\text {cyl }}$ decreases from stoichiometric, oxygen availability increases, without no significant decrease in combustion temperature, leading to an increase in $\mathrm{NO}_{\mathrm{x}}$ emissions. However, when the mixture is lean enough, combustion temperature significantly decreases, and $\mathrm{NO}_{\mathrm{x}}$ emissions start to decrease. 

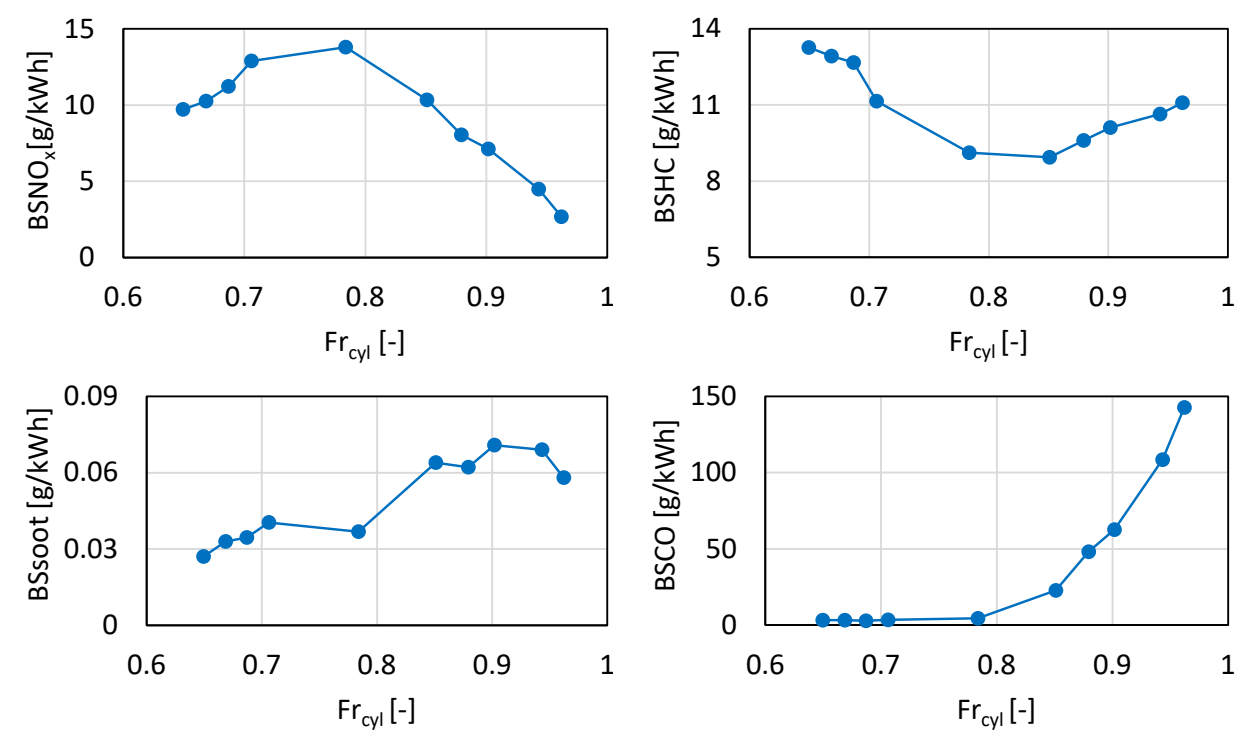

Figure 6.3. Representation of the main pollutant emissions as a function of the in-cylinder $F / A$ eq. ratio values.

- Soot: soot formation is usually insignificant in the present case, since the fuel is premixed before the combustion event. Even so, there is a decreasing trend in soot emissions when $\mathrm{Fr}_{\mathrm{cyl}}$ decreases, thanks to the greater homogenization of the mixture.

- HC emissions are closely related to the combustion efficiency, as mentioned above. These emissions have an optimum point, and out of this optimum point, $\mathrm{HC}$ emissions will increase due to an incomplete combustion of the charge.

- Finally, CO decreases very quickly thanks to the increase of the oxygen available in lean mixtures to oxidize the carbon atoms and to the decrease of the combustion temperatures that slow down the dissociation mechanism of the $\mathrm{CO}_{2}$ molecules.

\subsubsection{The load variation effect on the SI operation}

In this section the load degree effect on the SI lean combustion process will be studied, since the scavenging process is strongly influenced by the load in 
this engine. Besides, the engine load also has an influence on the conditions inside the cylinder, thus affecting the combustion performance.

\section{High loads}

When this engine is operated at high loads, as already seen, it is very important to get the highest combustion advance in order to improve fuel efficiency, since normally the combustion is always delayed with respect to its optimal position because of knock issues.

Figure 6.4 shows a graph where the combustion phasing (CA50) of each test is plotted with its brake specific fuel consumption value. These tests come from Point 2000@17 and, for all of them, the injection configuration and the apparent $\mathrm{F} / \mathrm{A}$ eq. ratio have been kept constant $\left(\mathrm{Fr}_{\mathrm{app}}=0.6\right)$. On the one hand, the main trend observed in the plot is an improvement of the fuel efficiency with the combustion advance. On the other hand, it has to be noted that two groups of points on the chart are clearly differentiated. The difference between the two groups is a variation in VVT position. However, in both groups the relationship between CA50 and fuel efficiency is the same. Calton [2] studied the influence of the combustion position on the fuel efficiency, and the results obtained showed that, depending on the operating conditions of the engine, the combustion phasing (CA50) should be placed between 5 and $10^{\circ}$ ATDC. As it can be seen on the figure, all the tests are far away from that optimum theoretical position (striped area on the plot).

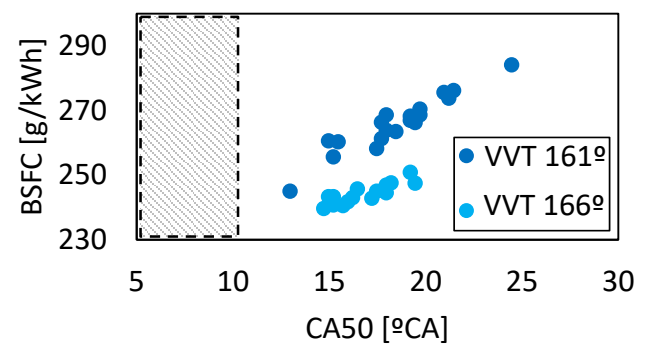

Figure 6.4. BSFC values obtained for different CA50 positions with two different VVT configurations (dark blue $161^{\circ}$ and light blue $166^{\circ}$ ).

Now, if one of those tests is repeated, and the spark advance is increased progressively (keeping the other parameters constant) trying to place the combustion on that optimum position and paying no attention to knock (which will surely raise), the results obtained are shown in Figure 6.5. As expected, the combustion advance brings an improvement in engine efficiency, because 
of the more appropriate location of the combustion process in the engine cycle. However, the knock raises very fast, limiting the engine's potential at high loads. Additionnally, a clear correlation between the CA50 and the combustion duration can be observed: the closer the CA50 to TDC, the shorter the combustion duration. This might be linked to the reduction in the volume of the combustion chamber, which reduces the distance to be covered by the flame front.
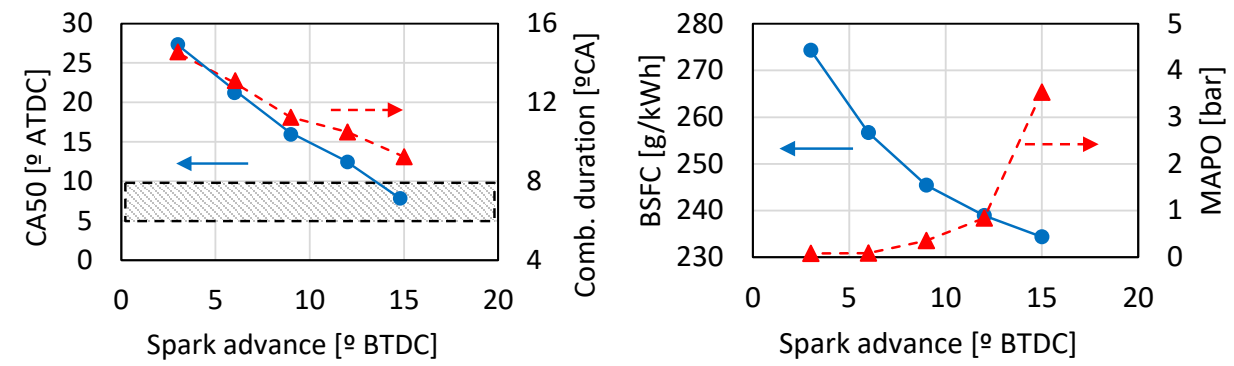

Figure 6.5. Ignition advance variation for Point 2000@17.

A very important element in this engine that helps to explain why the combustion is so delayed and why the knock increases so fast, is the rate of residual gases remaining inside the cylinder, the IGR ratio. In Figure 6.6, two graphs are presented with the same tests already presented in Figure 6.4. On the left, the brake specific fuel consumption is presented, now against the CA75 values (position where $75 \%$ of the fuel has been burnt ${ }^{1}$ ) and, on the right, the specific fuel consumption is presented against the IGR ratio ${ }^{2}$.

The results show the influence of the IGR ratio on the BSFC: as far as the IGR ratio is reduced (right plot), the engine efficiency is improved (when the engine is operated in SI mode). This result, combined with the trend observed on the left plot, where the advance of the CA75 results in an improvement of the fuel efficiency, indicates that the IGR restricts the combustion advance due to an increase of the in-cylinder charge temperature (directly related to the increase on the knock tendency). Therefore, the correct scavenge of

\footnotetext{
${ }^{1}$ This parameter is, somehow, related to the end of combustion. Why this parameter has been chosen for this graph, instead of CA50, will be discussed later in this section.

${ }^{2}$ It is worthy to note that the scattering of the points is significantly higher when BFSC is plotted against IGR compared to when plotted versus CA75. This can be easily justified taking into account that the IGR parameter is not measured directly, but calculated from some other measurements, which surely increases the uncertainty of the actual value.
} 
these residual gases when the engine is operated under SI mode becomes very important to get the maximum efficiency as possible.
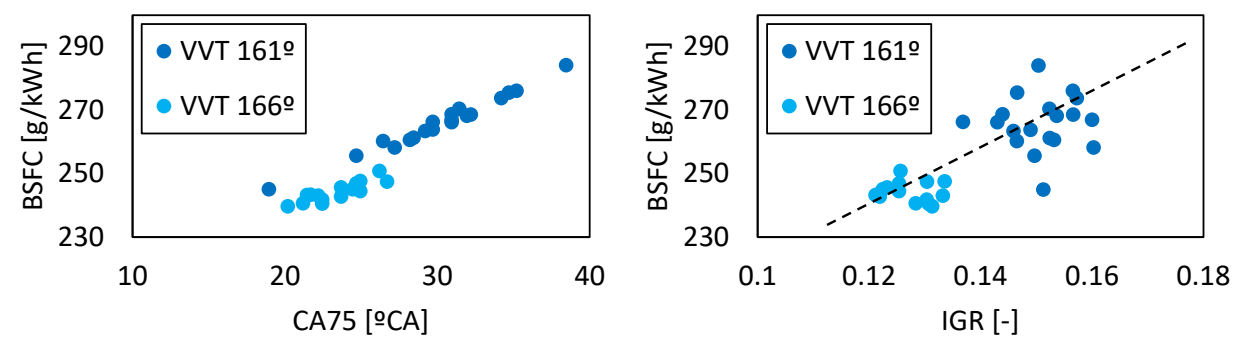

Figure 6.6. Left - Evolution of BSFC with CA75. Right - Correlation for the same tests between BSFC and IGR ratio.

On the IGR plot analyzed before, two defined groups of points were differentiated. This difference is due to a different VVT position chosen for these tests: one group was operated with a VVT $=166^{\circ} \mathrm{CA}$ and the other with a $\mathrm{VVT}=161^{\circ} \mathrm{CA}$ in order to get different IGR values for the same apparent Fr. But when the position of the VVT is modified, the expansion stroke is modified and the BSFC values can be also affected. To clarify this possible question, the effect of a VVT delay in $5^{\circ} \mathrm{CA}$ has been analyzed by means of a simulation software of combustion cycles, and the results obtained indicate that the improvement due to this effect is negligible (these results can be found in more detail in Appendix 6.A). Thus, the IGR reduction is the main responsible for the BSFC improvement, and the expansion stroke modification derived from the VVT variation has a minor influence.

The points with higher IGR ratio have also shown to have lower combustion rates (Figure 6.7). This is mainly caused by two main reasons: on the one hand, the dilution effect of the residual gases (although being hot gases) reduces the oxygen content of the mixture, thus hindering the flame propagation; on the other hand,the in-cylinder temperature, risen by the higher amount of residual gases, favors the knocking tendency, and the spark timing needs to be delayed (therefore, the combustion rates are worsened due to the delayed position).

When Figures 6.4 and 6.6 are compared, it can be seen that the parameter CA75 is more appropriate to correlate the combustion phasing with the engine efficiency, than the most usual one, the CA50. This is because with the use of the CA75 parameter both the combustion position and its duration are taken into account. This combustion duration has shown to play an important 


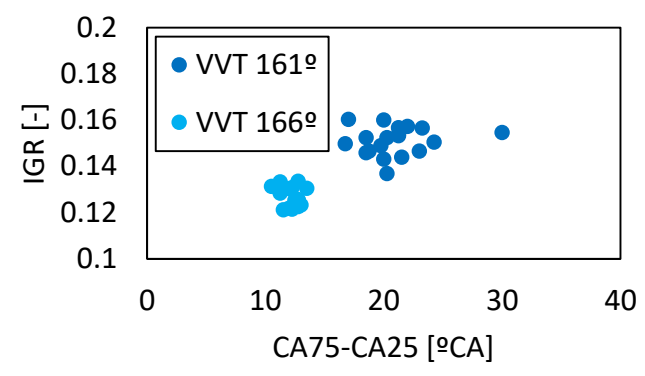

Figure 6.7. Influence of the IGR ratio on the combustion duration.

role in these tests, since the charge composition is very variable. Thus, different combustion durations can be found for the same CA50, and it becomes necessary to take into account both parameters. In traditional SI engines, operated with stoichiometric mixtures and with small amounts of residual gases $(4 \mathrm{~S})$, the combustion position and its duration are univocally related to each other for a given operating condition. Under these circumstances, both the CA50 and the CA75 correlates well with BSFC. However, this is not the case for the current engine, where the Fr is not fixed and the IGR ratio can be significant (2S): this fact breaks the relationship between combustion position and its duration. This peculiarity can be observed in Figure 6.8, where two tests from Figure 6.4 have been analyzed in more detail (with the cycle to cycle methodology). These tests are: one with the $\mathrm{VVT}=166^{\circ}$ and the other with the VVT $=161^{\circ}$, and both of them present the same averaged CA50 (18 ATDC). As shown in the figure, both tests present clearly different relations between the combustion phasing and the combustion duration, which is due to the different charge composition provoked by the IGR variation.

It might be concluded, then, that the key factor to understand the BSFC trend at a given operating condition is to know when the combustion ends (CA75).

Once shown that the IGR is detrimental for the engine operation in SI conditions, this effect is going to be analyzed in more detail, trying to isolate the IGR effect on the combustion performance. For this purpose, two tests will be shown with the same load degree and similar operating conditions, but with a different IGR ratio (selected among the whole set of cases already shown before). For these selected cases the engine settings will be different, and the key parameter to consider them equivalent and comparable has been 


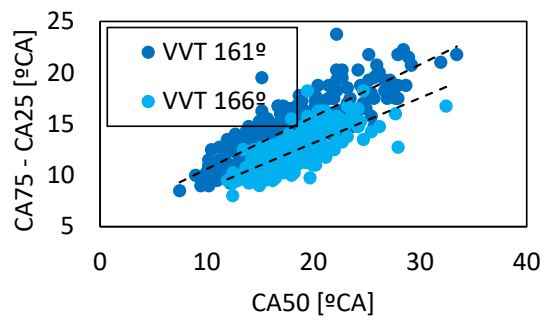

Figure 6.8. Influence of the IGR ratio on the combustion duration.

the in-cylinder richness (please note that the fuel mass was already constant for the whole set of cases).
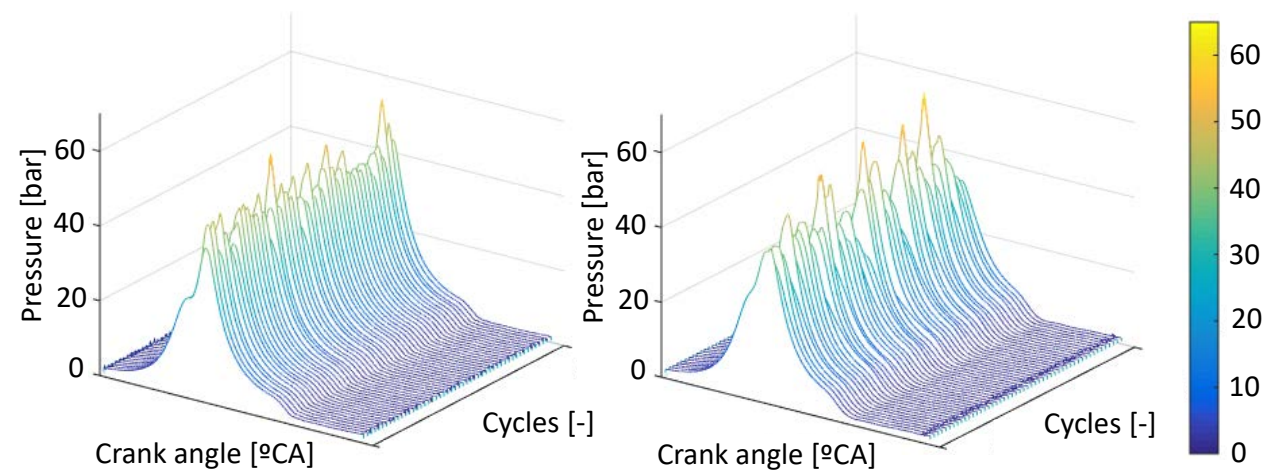

Figure 6.9. Representation of 50 measured pressure cycles for two different tests, test2000@17a (left), with lower IGR, and test2000@17b (right), with higher IGR.

Figure 6.9 shows 50 recorded pressure cycles for each test. Test 2000@17a represents a case with lower IGR ratio (13\%), whereas test 2000@17b represents a case with higher IGR ratio $(15 \%)$. The main visible difference between the two tests is the increase of the erratic knock, affecting the combustion process, with the increase in IGR ratio. In that case, the mixture reactivity is greater due to the increase in temperature caused by the higher amount of IGR and, at the same time, the mixture is more diluted with residual gases, what reduces the combustion rates. Both factors (higher temperature and slower flame propagation) increase the knocking risk during the combustion process. Therefore, the ignition advance must be reduced in order to control the high 
pressures and temperatures during combustion, and reduce by this way the knocking tendency. As far as the combustion is delayed, the BSFC and the $\sigma$ IMEP are negatively affected, as can be seen in Figure 6.10.

Concerning knock (quantified by the MAPO parameter), it is of course worsened when IGR increases. However, the value of this parameter does not show in detail what happened during all the cycles of the test because, after all, this is a maximum value along all the cycles registered during the test. In Section 5.6 the problems of quantifying knock as a single value during the whole test were further discussed.
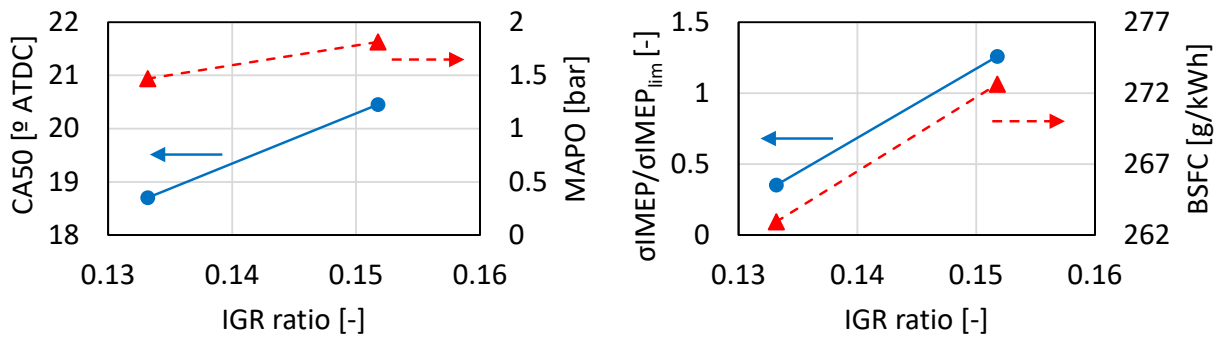

Figure 6.10. Combustion phasing, knock values, combustion stability and brake specific fuel consumption for the tests 2000@17a and 2000@17b shown in Figure 6.9.

Up to now, it has been shown (1) how the in-cylinder $\mathrm{F} / \mathrm{A}$ equivalence ratio reduction has a great influence on the improvement of the engine performance and (2) how the influence of the IGR ratio on the SI operation has shown to be detrimental for the engine performance due to the increased knocking risk. The introduction of more fresh air into the engine, apart from lowering the incylinder $\mathrm{F} / \mathrm{A}$ equivalence ratio, also improves the sweep of the residual gases (Figure 6.11). Therefore, to reach the maximum efficiencies in this engine, when working under SI mode, the mixture should be as lean as possible until the worsening of the combustion stability is achieved, since beyond this point, the fuel efficiency will be lost.

If the load degree is further increased, it is desirable to keep $\mathrm{Fr}$ as low as possible in order to reduce the mixture reactivity, thus avoiding knock. However, in $2 \mathrm{~S}$ engines the trapping ratio will always be affected by the pressure difference between intake and exhaust. The desired increase of the air trapped inside the cylinder may not be possible, because of the degradation of the trapping ratio when the intake pressure is increased, which causes higher shortcircuiting of the intake air directly to the exhaust. To evaluate the effect 


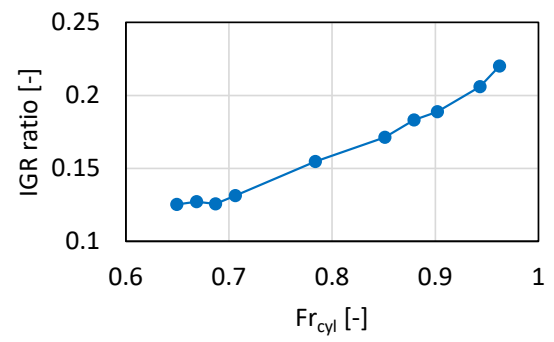

Figure 6.11. Influence of the Rich flow values on the IGR ratios.

of the load increase beyond Point 2000@17 (representative of the maximum torque conditions), three new Points will be used: Points 4000@17, 4000@21 and 4000@25, all of them represented on the engine operating map shown in Figure 6.12.

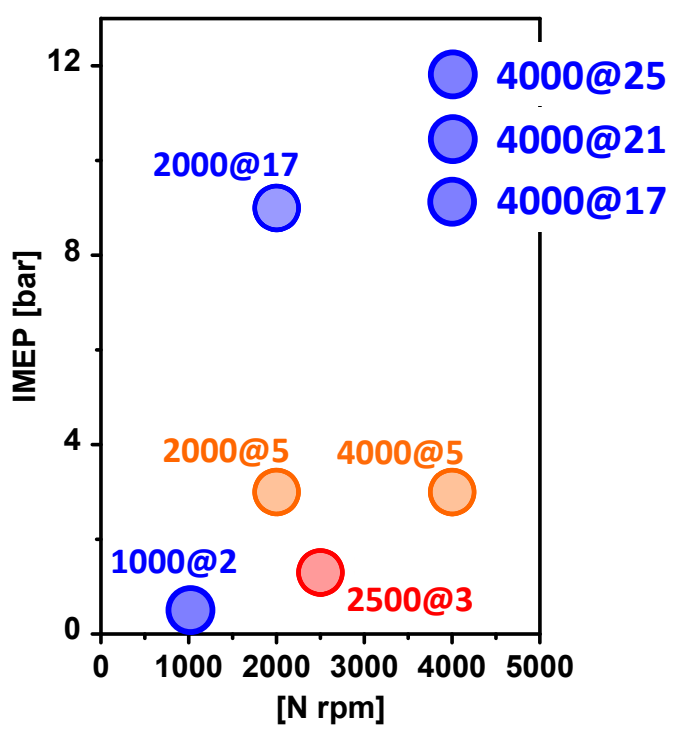

Figure 6.12. Extended engine operating map with high load operation Points.

Along the coming up discussion about the increase in engine load, all the graphs shown are going to be plotted with a horizontal axis representing the fuel mass injected, in milligrams per stroke $(\mathrm{mg} / \mathrm{stk})$, of each of the three high load operation points (see e.g. Figure 6.13). Therefore, each of these graphs represent a load variation at an engine speed of $4000 \mathrm{rpm}$. It has to be noted 
that, due to the high load level demanded on the engine, Points 4000@21 and $4000 @ 25$ have been tested with an EGR rate of $5 \%$, otherwise it was impossible to operate the engine below the allowable knocking limits.

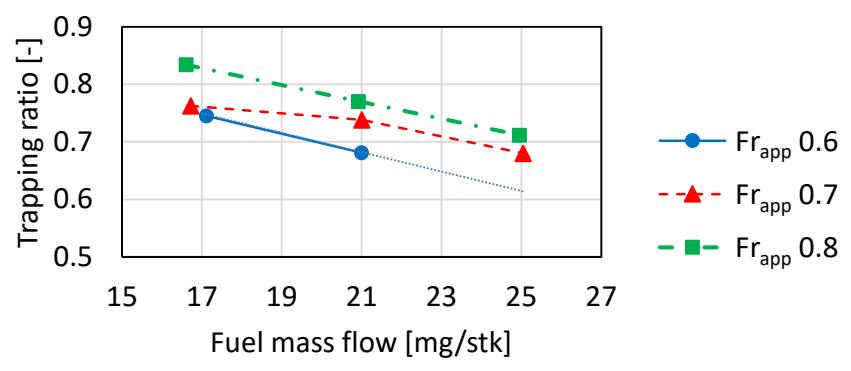

Figure 6.13. Evolution of the trapping ratio with the load increase for different equivalence ratios.

During the scavenging process, since the intake and exhaust remain opened at the same time, the increase in the intake pressure necessary to introduce more air into the engine causes a greater short-circuiting of the fresh gases to the exhaust. This effect can be seen in Figure 6.13, where the trapping ratio drops very fast when trying to increase the engine load beyond certain limits. This means that, unfortunately, the engine is not able to retain the necessary fresh gases to be operated at higher loads. Additionally, it can be seen that an operating point is missing in the graph: the Point 4000@25 with a $\mathrm{Fr}_{\text {app }}=0.6$. In this point, the predictable trapping ratio would be as low as $60 \%$, and therefore the necessary intake pressure to keep an acceptable in-cylinder richness would have been too high. All the energy invested to introduce a given amount of gases inside the engine that finally end-up directly in the exhaust, represent a big loss in engine efficiency, and the interest of this way to operate the engine completely disappears.

This problem with the limited capacity to retain the fresh gases inside the cylinder causes that the maximum amount of air retained will be limited, and therefore the increase of the in-cylinder $\mathrm{F} / \mathrm{A}$ eq. ratio with the increase of the engine load is unavoidable. Figure 6.14 shows, for the points presented above, the in-cylinder $\mathrm{F} / \mathrm{A}$ eq. ratio during the tests. This one has been much higher than the apparent $\mathrm{F} / \mathrm{A}$ eq. ratio, even reaching rich values at Point 4000@25. So, it can be stated that the engine cannot be further operated in lean mixtures beyond certain load degrees. 


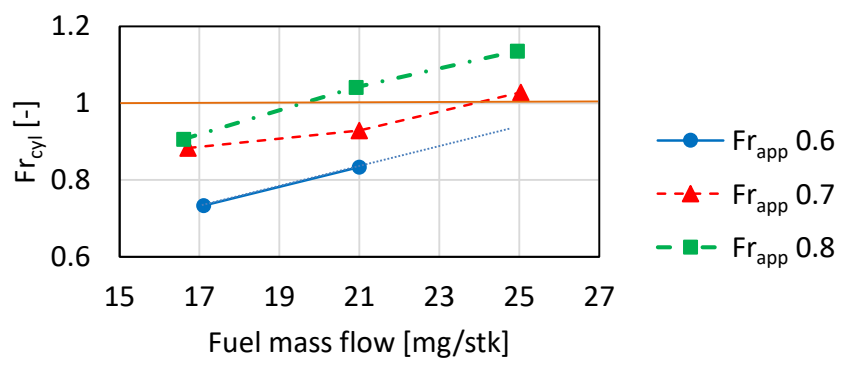

Figure 6.14. Evolution of the in-cylinder richness with the load increase for different equivalence ratios.

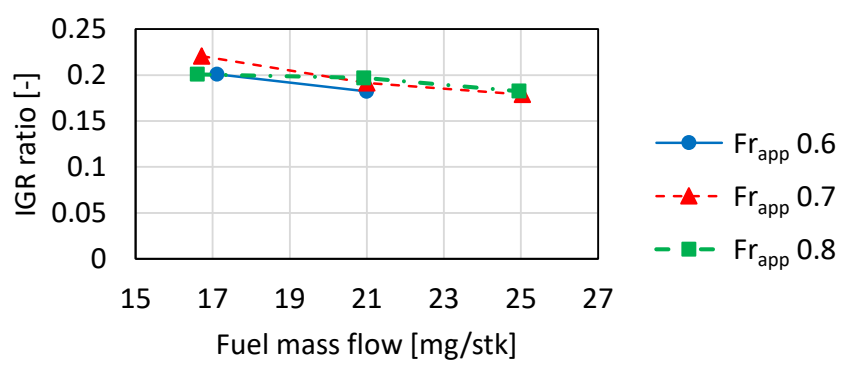

Figure 6.15. Evolution of the IGR ratio with the load increase for different equivalence ratios.

Theoretically, the IGR ratio decreases with the increase of the intake pressure, and so it would be expected that, at very high load, the residual gases would be completely swept away. However, since the scavenging process is not perfect, there is always a remaining IGR ratio (a lower limit or threshold). This effect can be observed in Figure 6.15, where the IGR ratio is seen to stabilize and does not go down anymore, even though the intake pressure continues to increase with the load.

Therefore, when the engine load is increased, in order to avoid the knock derived from the increase of $\mathrm{Fr}_{\text {cyl }}$ (caused by the drop in TR indicated above), which increases the mixture reactivity, the most straightforward solution is to delay the combustion retarding the spark timing, to have lower pressures and temperatures during the combustion process. As widely known, the IMEP is reduced when the combustion is retarded, and the increase in the output power 
obtained is lower than expected, since the energy of the fuel introduced in the cylinder cannot be used properly (see Figure 6.16).
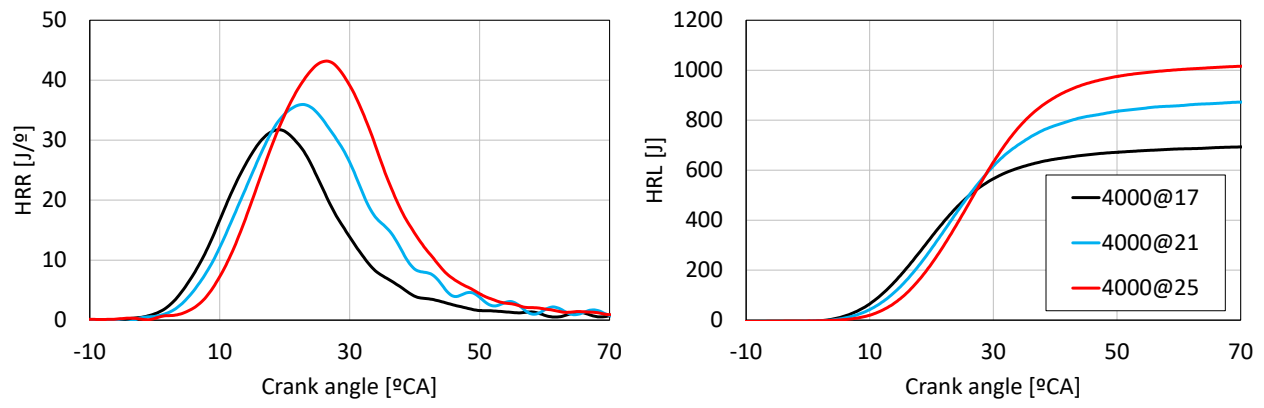

Figure 6.16. HRR (left) and HRL (right) for the different tested loads.

The small increase in the IMEP obtained, due to the drop in engine efficiency, is even more pronounced if the BMEP is analyzed, since within the IMEP, the energy required by the compressor is not taken into account. If this energy consumption is taken into account (this is done in the BMEP parameter, shown in Figure 6.17, to the right), it can be seen how for Point $4000 @ 21$, with a Fr of 0.6, the effective engine power has even dropped despite of the "hopefully" higher load degree. This is because the compressor requires more extra-energy to move the intake gases than the one obtained in the engine shaft from the increase in fuel mass.
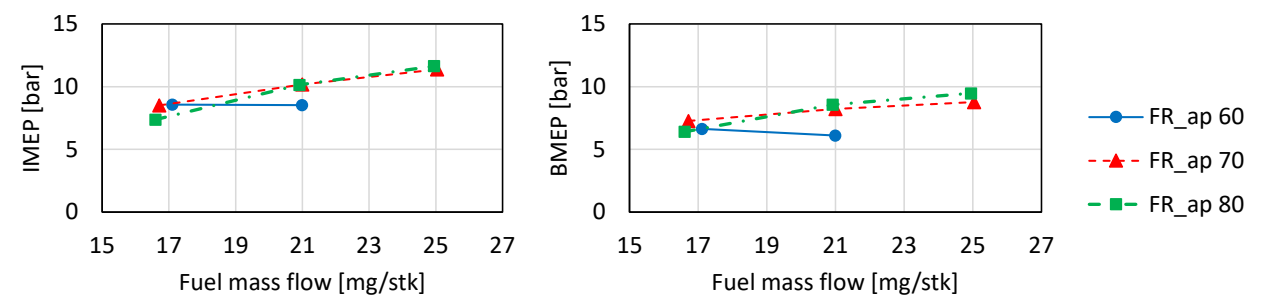

Figure 6.17. Representation of the IMEP and BMEP for different loads and equivalence ratios.

A possible solution to mitigate this problem may be to increase the exhaust pressure in order to decrease the pressure difference between the intake and 
exhaust. In this way the trapping ratio could be improved by retaining more fresh air, thanks to the increase of the in-cylinder charge density. To evaluate this hypothesis, some tests have been carried out at Point 2000@17, where the exhaust pressure has been increased, to see its effect on the engine behavior.
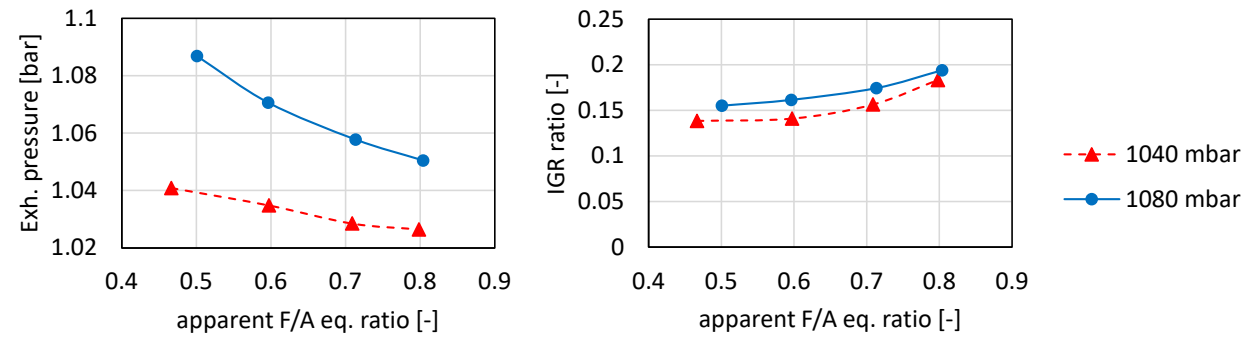

Figure 6.18. Effect of the exhaust pressure increase at Point 2000@17. Left measured exhaust pressures for an apparent $F / A$ eq. ratio variation. Right - IGR ratios for the tests shown on the left.

The results of the exhaust pressure increase study show that it is not a particularly good strategy to trap more air mass in the cylinder. The problem found is that the increase in charge density is applied equally to the fresh gases and to the IGR (see Figure 6.18). Therefore, the total trapped mass can be increased, but the mass of residual gases are also increased, since their exit through the exhaust is hindered. Finally, the combination of a greater amount of IGR together with higher pressures in the cylinder (for the residual gases, the higher the pressure, the higher the temperature), significantly increase the MAPO values for the same CA50 (see Figure 6.19).

\section{Medium loads}

In this subsection, the engine is operated in Region II of the presented engine map in Section 5.2, page 150. This zone is a medium-load region, where the engine can be operated in SI or CAI conditions. Along this section, only the SI operation in this region will be analyzed.

With the decrease of the load degree, the dilution of the mixture with residual gases is gradually increased, since the scavenging process is progressively worsened, and this causes a loss in combustion stability and engine performance. In order to illustrate this effect, some results from an apparent A/F eq. ratio variation on Point 2000@5 are shown. 

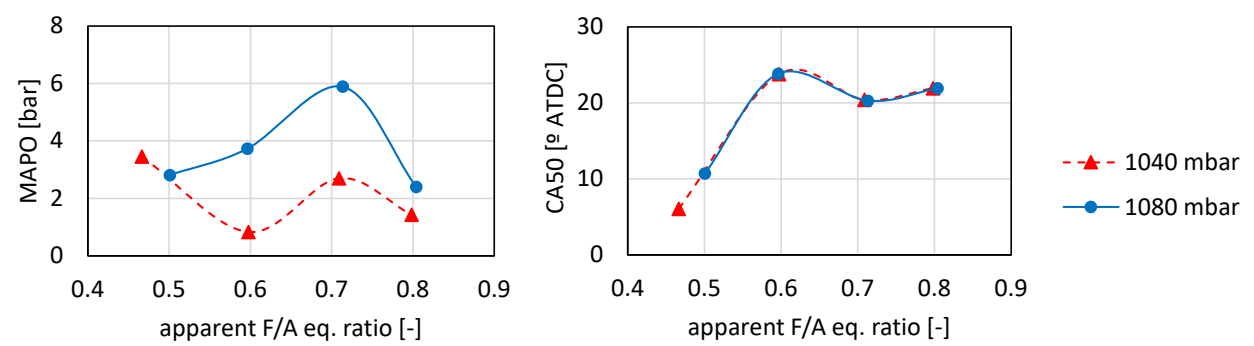

Figure 6.19. MAPO (left) and CA50 (right) values for different exhaust pressures during an apparent $F / A$ eq. ratio variation at Point 2000@17.

For this load degree, as can be seen in Figure 6.20, the trapping ratio values are very high, since a smaller amount of air is being introduced into the cylinder compared to higher loads. Due to this small amount of fresh air, the sweep of residual gases inside the cylinder is not complete and, therefore, for these tests, the IGR ratio is in the range of $50 \%$ to $70 \%$, depending on the equivalence ratio.

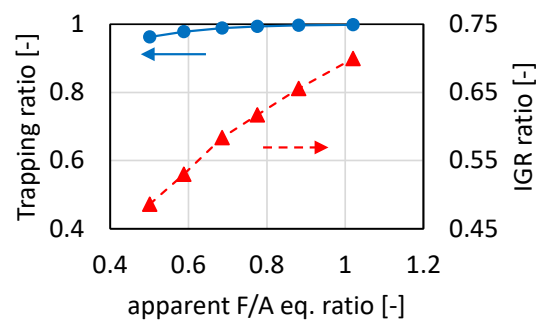

Figure 6.20. Trapping and IGR ratios for an apparent $F / A$ eq. ratio variation at Point2000@5.

In this situation, if a low operating equivalence ratio is chosen in order to sweep as many residuals as possible and decrease the charge temperature, the resulting mixture is extremely diluted both by fresh air and residual gases. Therefore, the combustion rate will be very low and the combustion stability will be worsened (this is a common problem in $2 \mathrm{~S}$ engines operated at partial loads). On the contrary, if the equivalence ratio is increased close to the stoichiometric values, the IGR ratio is very high, and therefore the high temperature of the in-cylinder charge promotes its auto-ignition, thus making 
it difficult to operate the engine as an SI. The change in combustion nature can be easily seen in a graph where the HRR's of the different equivalence ratios are represented (see Figure 6.21). These HRR's curves change with the increase in Fr from a slow and spark plug-governed combustion, to a very fast combustion, where its onset depends on the auto-ignition process. During these tests, the spark timing was fixed at $40^{\circ}$ BTDC and left constant throughout the Fr variation.

For the lower $\mathrm{Fr}_{\text {app }}$ 's (0.5 and 0.6), the start of the combustion is initiated by the spark. The HRR's start a bit later than $40^{\circ}$ BTDC and, at the same time, after that, the combustion progresses in a slower way (which is characteristic of lean SI combustion). However, with the increase of Fr, the control over the start of combustion is lost, as can be seen in the figure: the different tests ignite at positions far from the spark timing, and the combustion onset is even different among them. This indicates that the ignition procedure is now governed by a mechanism different from the spark.

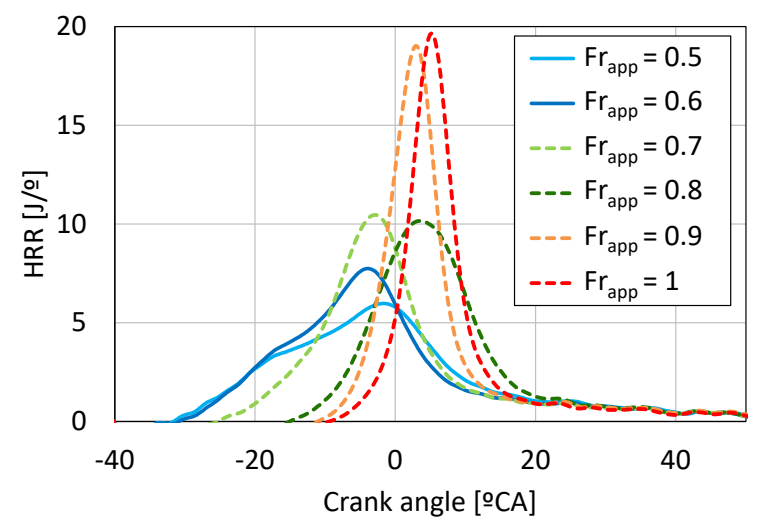

Figure 6.21. HRR laws for an apparent $F / A$ eq. ratio variation at Point $2000 @ 5$.

Along the current subsection, it has been stated that the progressive decrease of the load degree results in an increase of the charge dilution that leads to a loss on combustion stability and a lower combustion speed. To support this statement, some measured cylinder pressures at Point 4000@5 are presented in Figure 6.22. These cycles show to be very variable, and the corresponding HRR's are very slow, taking around $15^{\circ} \mathrm{CA}$ to burn between 25 and $75 \%$ of the HRL, and $46^{\circ} \mathrm{CA}$ to burn between $10 \%$ and $90 \%$ of the HRL. 

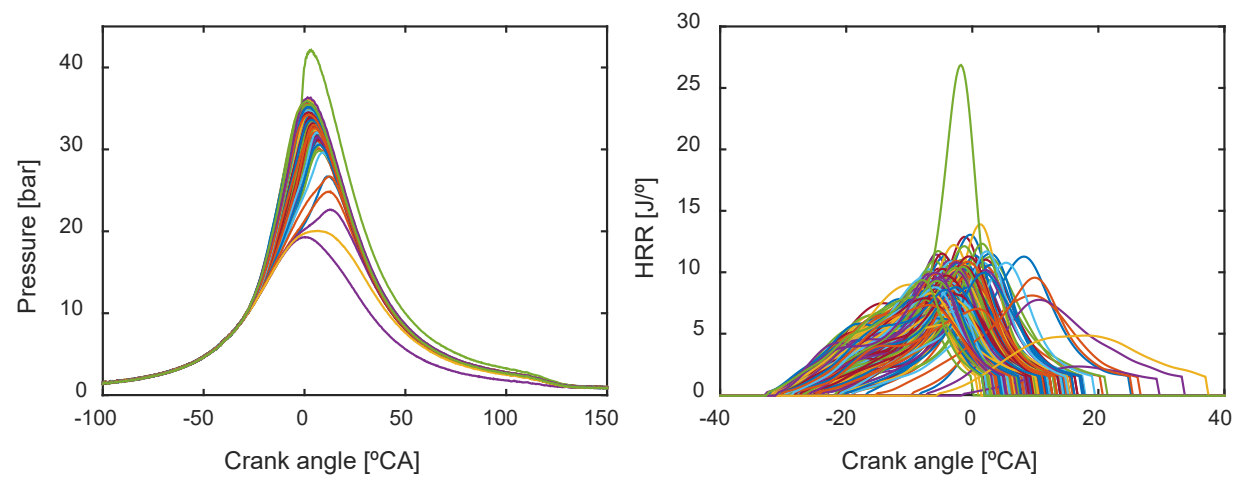

Figure 6.22. Pressure signals and HRR laws for the test $F_{a p p}=0.6$ at Point $2000 @ 5$.

\section{Low loads}

The lower loads in this engine represent Region IV of the engine map (Figure 5.1, page 150). In this situation, the engine also needs to be operated in SI mode, since the decrease in IGR temperature and the small amount of air mass introduced inside the engine make it impossible to reach enough reactivity to sustain an autoignition process. Among the points contained in this region, the point at idle conditions probably has the highest interest, not only because it is the point with the lowest engine load, but also because a considerable part of the time during real operation, the engine will be working at idle conditions. An idle point would be an operating point where the engine is turning at a low speed, around $1000 \mathrm{rpm}$, and with the amount of fuel injected just required to compensate the mechanical losses and keep the engine running at constant speed (this is the defined Point 1000@2).

Knowing that the load decrease worsens the performance of the engine, an interesting strategy taking advantage of the fact that the $2 \mathrm{~S}$ engine performs twice as many combustions as a four-stroke engine, would be to decrease the engine speed ${ }^{3}$ in order to increase the equivalent load degree per cylinder and cycle. In this way, the scavenging process could be improved and, together with this, also the engine performance.

To evaluate this hypothesis, two operating points are defined: Point 1000@2, and the alternative Point, which will be operated at $500 \mathrm{rpm}$ with the same fuel flow (500@4). The way to assess the suitability of the engine

\footnotetext{
${ }^{3}$ As the number of combustions per unit of time is higher, the engine speed could be decreased without worsening the engine performance compared to a $4 \mathrm{~S}$ engine.
} 
operation at these points, has not been based on the evaluation of the brake specific fuel consumption, since the effective power is almost zero, and the values obtained for this parameter do not have much sense (in fact, they tend to infinity). The parameter selected for the assessment has been the effective torque (parameter measured directly on the dynamometer for the SCE), since for the same fuel flow in both points, a higher value in the torque will imply a better engine efficiency, as well as a possible reduction in the fuel required to maintain the idle speed.
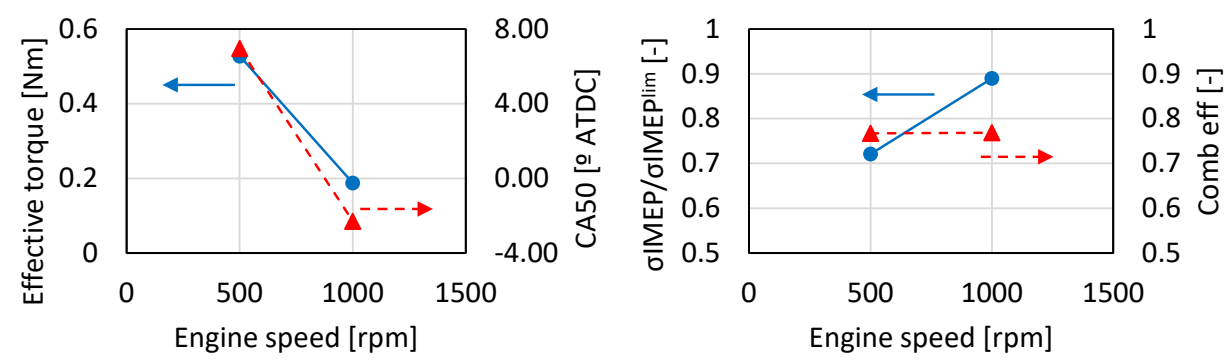

Figure 6.23. Results of the different torque, combustion phasing, combustion stability and combustion efficiency for the two idle points tested.

The results presented in Figure 6.23 show that the torque is higher for Point $500 @ 4$, and although the combustion efficiency is identical for both points, the combustion position and the combustion stability are much better.

This higher torque value is mainly caused by two factors: on the one hand, because the mechanical losses of the engine are reduced with the lower engine speed and, on the other hand, because the combustion at Point 1000@2 is over advanced (CA50 $=-2.3^{\circ}$ ATCD), whereas it is better positioned at Point 500@4 $\left(\mathrm{CA} 50=6.95^{\circ} \mathrm{ATDC}\right)$. Figure 6.24 shows some additional evidence about the combustion positioning in these tests. In the HRR graph, the over advance to achieve a stable combustion in Point $1000 @ 2$ forces all the combustion process to be developed before TDC. This means that an extra work during the compression stroke needs to be performed, and therefore the efficiency will be lower. On the contrary, at Point 500@4, this over advance to get a stable combustion is not necessary, and an improvement in engine efficiency is achieved. 

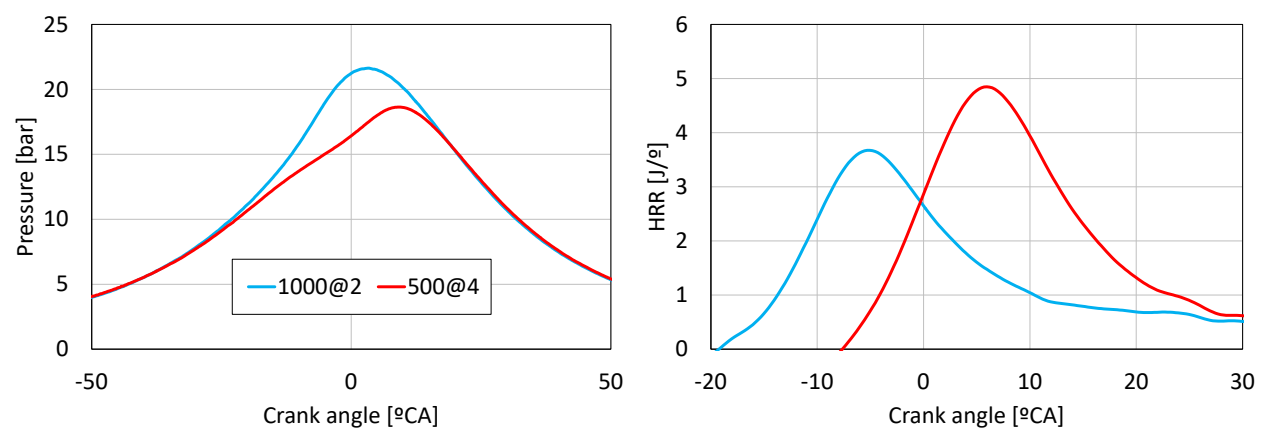

Figure 6.24. Pressure signal and HRR laws for Points 1000@2 and 500@4.

\subsubsection{Controlled autoignition}

This mode of operation, as reviewed in detail in Chapter 2, is framed within the low temperature combustion (LTC) modes. In this case, the combustion is developed by the generalized autoignition of a previously homogenized mixture. The single flame front originated by the spark plug no longer progresses through the entire combustion chamber, as is the case of the SI operation. This difference in the combustion development of this other operating mode offers some advantages in terms of efficiency and pollutant emissions. These benefits will be experimentally analyzed through the study of the necessary strategies for its implementation in the engine, as well as through the analysis of the results obtained.

The CAI operation has been limited to the low-load region in SI engines, since the increase in engine load rapidly causes an excessive increase in the pressure gradients generated by the fast combustion of the fuel, resulting in a combustion mode extremely difficult to control. Based on this information, the regions where the operation in CAI has been studied are those at low loads, which are typically, in $2 \mathrm{~S}$ engines, the worst in terms of efficiency. For this reason, this type of combustion is of great interest in the context of these engines. Subsequently, since one of the major problems of this combustion mode is the reduced operating window, the use of EGR as a tool to control the excessive reactivity when the engine is operated in CAI conditions at higher loads will be studied. This strategy will allow the extension of the maximum achievable load. 


\subsubsection{SI - CAI comparison}

The CAI operation presents important differences with respect to the operation of the engine in SI conditions. Firstly, the mixture is no longer ignited through the action of the spark plug. Instead, this one ignites when the pressure and temperature reach the autoignition conditions. And, secondly, the combustion progression does not develop in the same way: under CAI conditions the in-cylinder charge burns from multiple points distributed through the combustion chamber [3].

The best way to compare these two combustion modes will be through the analysis of the results of an operating point placed on Region II, since in this region the engine can be operated in both combustion modes. The point selected for this comparison is Point 2000@5, which has been operated under SI conditions $(\mathrm{Fr}=0.5)$ and CAI conditions $(\mathrm{Fr}=0.9)$, by means of a variation of the mixture reactivity through the Fr modification. The first significant difference can be seen in the development of pressure cycles and combustion laws (Figure 6.25). Firstly, the pressure cycles are much more repetitive when operated under CAI conditions; and, secondly, the HRR's indicate that the combustion rates have been higher and more homogeneous.

The (average) combustion duration (in both cases taken as the CA75-CA25 value) has been significantly reduced, from $18.6^{\circ}$ for the SI case to $7.27^{\circ}$ in the CAI case. Additionally, no misfires or cycles with abnormal combustion can be seen among the recorded data for the CAI case.

If the results of both tests are further examined (see Figure 6.26), it can be found that, firstly, the IGR ratio has been increased from $48 \%$ to $65 \%$. This change, added to the Fr increase, results in an enhancement of the charge reactivity, sufficient to promote the fuel autoignition without the need for a spark plug. Thanks to this change, the combustion stability has improved by $76 \%$ with respect to the SI conditions. Regarding the combustion position, it has been delayed in the CAI mode, since during the SI operation it was necessary to over advance the spark timing in order to maintain a stable combustion process, due to the extremely high charge dilution. These changes have resulted in an improvement of the specific fuel consumption of $7.8 \%, 4.2 \%$ in combustion efficiency, and $5.7 \%$ in indicated efficiency. Finally, in terms of pollutant emissions: $\mathrm{NO}_{\mathrm{x}}$ have virtually disappeared (reduction of $84 \%$ ), the smoke emissions (already low when working with homogenized mixtures) have been reduced by $44 \%$, and $\mathrm{CO}$ and $\mathrm{HC}$ emissions have been reduced by $34 \%$ and $38 \%$, respectively, thanks to the improved combustion efficiency. 

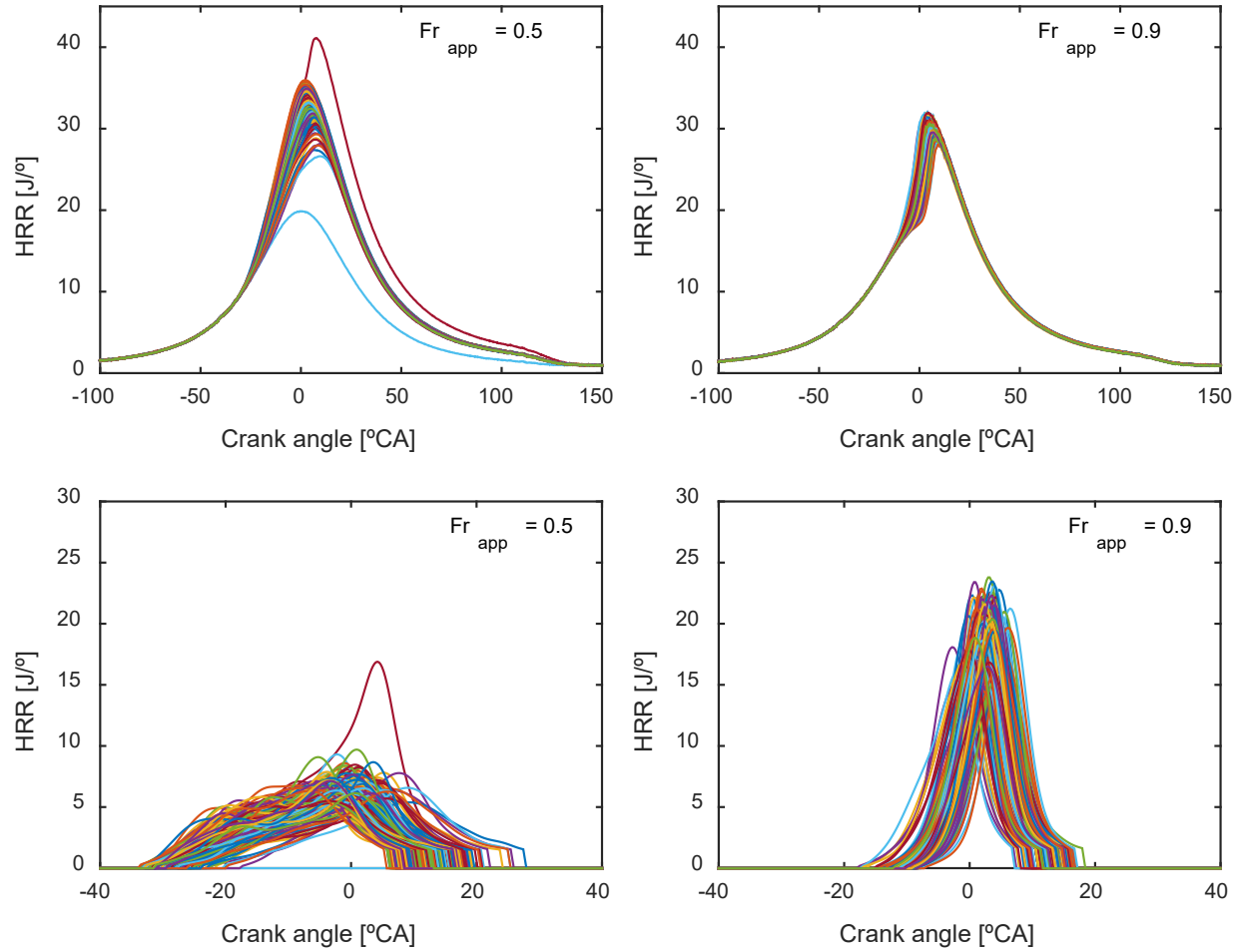

Figure 6.25. Pressure traces and HRR laws for two tests at Point 2000@5 with a $F_{\text {app }}$ of 0.5 (SI combustion) and 0.9 (CAI combustion), respectively.

As it has been shown, all these changes imply some advantages over SI combustion:

- The autoignition process has proven to be more stable, avoiding the combustion variability generated by (1) the flame kernel formation and development at the spark plug, and (2) the mixture misfires. In this particular engine, due to the operation in lean mixtures together with the significantly high residual rates, CAI operation appears to be a suitable strategy to improve the engine performance at mid and low loads.

- Higher indicated and combustion efficiency values. The improvement in combustion efficiency allows burning most of the fuel introduced into the engine. This improvement, together with the better combustion phasing, 


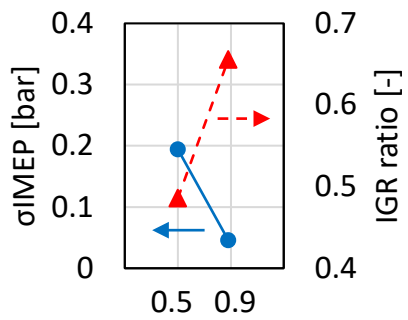

apparent F/A eq. ratio [-]

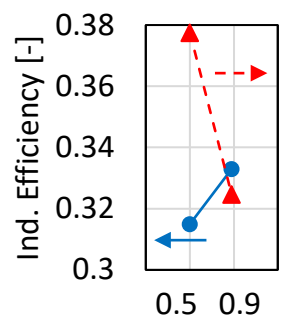

apparent F/A eq. ratio [-]

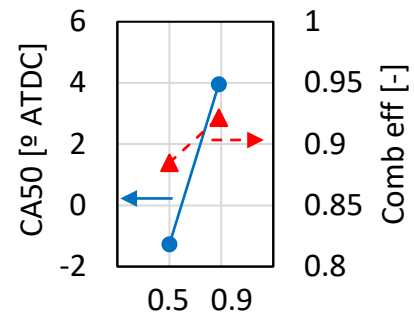

apparent F/A eq. ratio [-]
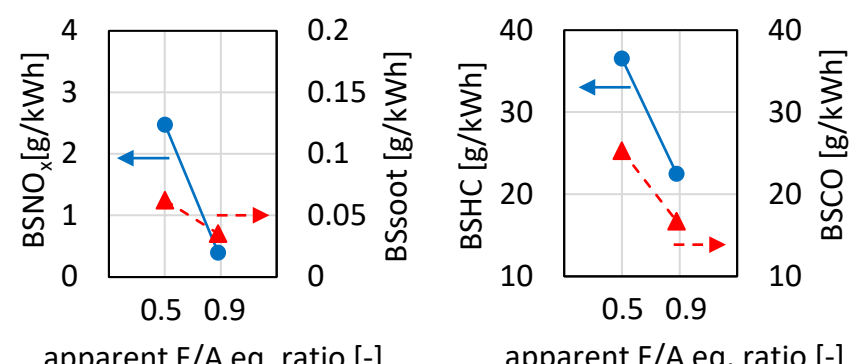

apparent F/A eq. ratio [-]

apparent F/A eq. ratio [-]

Figure 6.26. Results of the comparison between $S I\left(F r_{a p p}=0.5\right)$ and $C A I\left(F r_{a p p}=0.9\right)$ operation.

leads to an increased indicated efficiency and therefore this is reflected in greater fuel economy.

- Suppression of $\mathrm{NO}_{\mathrm{x}}$ and smoke emissions (at these operating conditions). This $\mathrm{NO}_{\mathrm{x}}$ reduction is extremely important, because it will allow the engine to keep these emissions below the legal limit without the need for any specific aftertreatment system for this pollutant.

Taking advantage of these fundamental advantages can help to improve the overall engine results by applying this combustion strategy in the lower part of the engine map, which, as discussed in the previous section, is a complicated region for $2 \mathrm{~S}$ engines.

However, these benefits are not unlimited, and they have several limitations. The first and fundamental one is that the desired reactivity cannot always be available or adjusted properly. The optimal conditions to reach autoignition are dependent on the temperature and pressure reached before TDC, and these are a function of Fr, IGR ratio and the effective compression rate of the in-cylinder charge. These parameters depend on the engine load 
and, unfortunately, they cannot always be adjusted as desired. Secondly, this combustion mode is very sensitive to small changes in the operating conditions (charge renewal, intake pressure, mixture homogenization, temperatures...). Therefore, the adjustment of all the operating parameters must be very precise to avoid variations that worsen the proper and stable combustion development. And, finally, working in a combustion mode where combustion is developed by autoignition, using a high autoignition-resistance fuel, leads to an operation that is always on the limit between a fast combustion and a knocking combustion.

\subsubsection{Key parameters}

The CAI ignition mechanism is based on the chemical kinetics for the fuel autoignition [4]. Therefore, to control the initiation of that autoignition process, the conditions of the charge must be modified, thus adapting the reactivity of the mixture to achieve a controlled autoignition process leading to a complete combustion development without any knocking problem. To achieve this goal, in Section 5.3 it has been talked about the effect of the Fr and VVT position modification on the scavenging process, and consequently on the IGR ratios, a fundamental parameter to modulate the temperature of the in-cylinder charge.
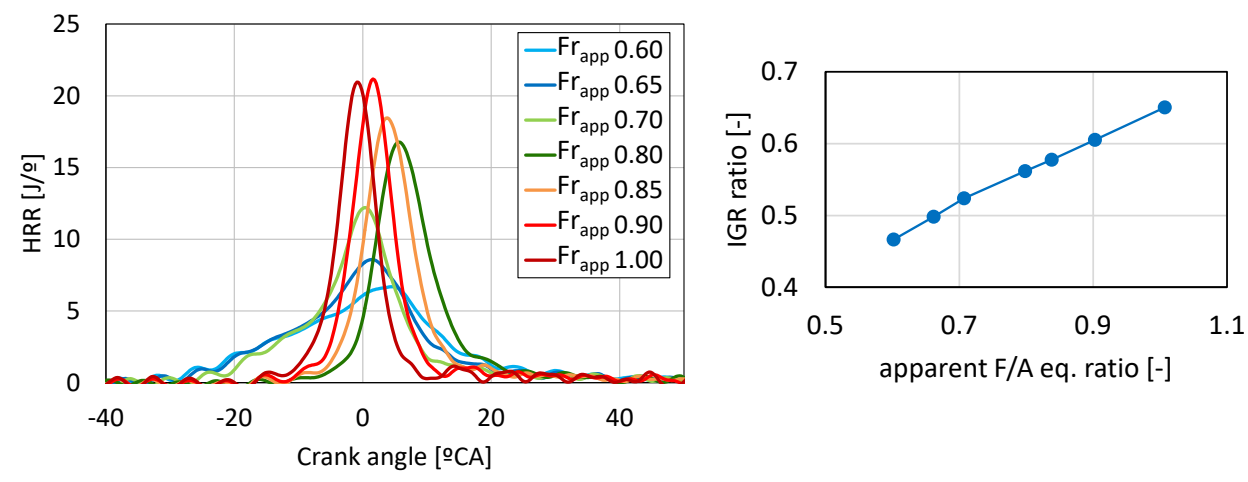

Figure 6.27. Left - Effect of the $F r_{a p p}$ on the HRR at Point 4000@5. Right Evolution of the IGR ratio with the $F_{r}$ app variation.

The IGR ratio modification changes the reactivity of the charge, modifying, first, the combustion mode and, secondly, once operating under CAI mode, the way in which combustion develops. Figure 6.27 shows this effect by means of 
a Fr variation at Point 4000@5. From the lowest to the highest Fr's, the combustion process begins to change from a slower combustion controlled by the spark, to a faster combustion where the control over the charge ignition by the spark is lost. This transition takes place between $\mathrm{Fr}=0.7$ and $\mathrm{Fr}=0.8$. Then, from $\mathrm{Fr}=0.8$ on, the SOC is not controlled by the spark anymore, but by the autoignition process which, in turn, depends on the reactivity of the incylinder charge. Once operating in this Fr range, if Fr (and, therefore, the IGR ratio, as seen in the graph to the left) continues increasing (both modifications enhance the mixture reactivity), the combustion becomes faster and its onset takes place earlier.

In Figure 6.28, the temperature of the in-cylinder charge at the angle $30^{\circ}$ BTDC is shown. This position has been chosen because (1) it is close to the end of compression, and (2) the average in-cylinder temperature at this location is still not significantly affected by combustion in all the tests. This temperature, at a fixed piston position and corresponding to that of the unburned charge, would be a useful parameter to quantify some aspects of the mixture reactivity. Despite the Fr increase (by reducing the air supply), which implies less mass enclosed in the cylinder and slightly higher heat losses, the in-cylinder temperature increases thanks to the increase of the IGR ratio, thus demonstrating the enthalpy increase potential of the residual gases. Thanks to this strategy, high temperatures can be achieved at the end of compression with a richer Fr, thus making easier the autoignition of the mixture.

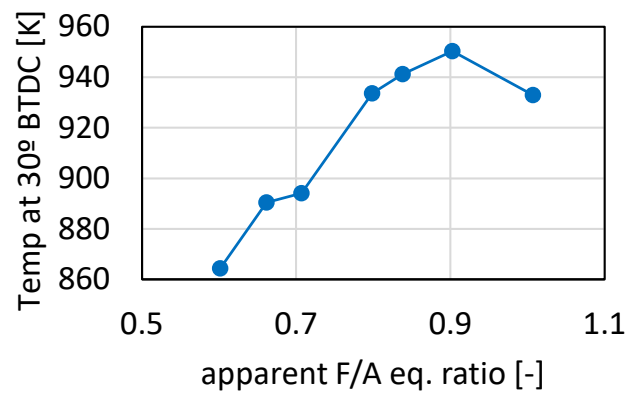

Figure 6.28. Temperature of the in-cylinder charge at $30^{\circ} B T D C$.

Once operating in CAI, the correct modulation of the IGR has a very important role in getting the engine to work efficiently. The excess of reactivity will cause an over advanced combustion that will disrupt the expected improvements. On the contrary, the lack of reactivity will cause the drop of the combustion stability. Figure 6.29 shows the results of the BSFC 
and the combustion position for the tests just discussed before. Regions B and $\mathrm{C}$ of the graph are those operated by autoignition, and the best efficiencies for the CAI tests are those with lower Fr values since combustion has a better phasing.
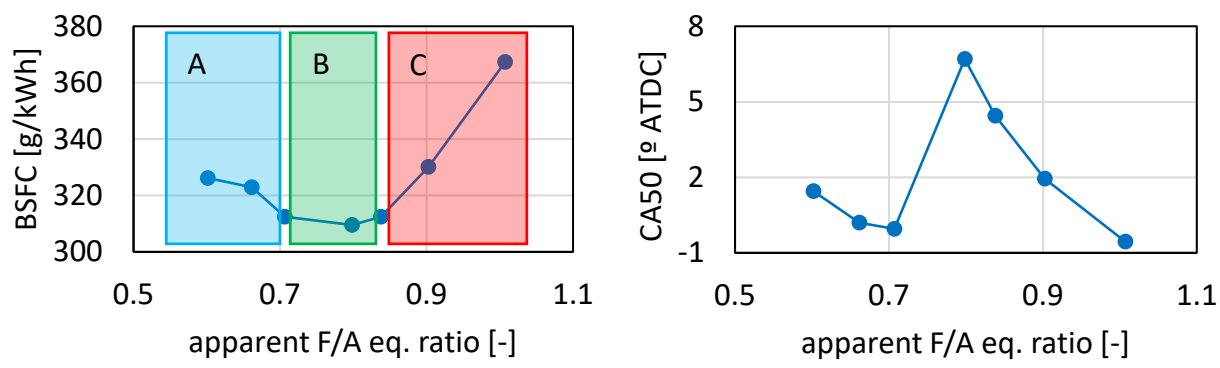

Figure 6.29. Brake specific fuel consumption for the tests presented in Figure 6.27.

\section{VVT effect}

As explained in Section 5.3, the VVT modification affects the scavenging process in a complementary way compared to the Fr. These modifications in the charge composition can be used for a finer adjustment of the mixture reactivity. For example, the $\mathrm{Fr}_{\mathrm{app}}$ can be kept constant and the mixture reactivity can be adjusted through the IGR ratio modification. Figure 6.30 shows the effect of the VVT modification on the HRR's when Frapp $_{\text {ap }}$ is kept constant. It can be seen how this variation affects the combustion position. The operating conditions still correspond to Point 4000@5 (mid load). The advance of the exhaust opening and closing have led to an increase in the IGR temperature and rate, since the exhaust gases have been less expanded (thus higher $\mathrm{T}$ ) and the early exhaust closure retains more residuals inside the cylinder (thus higher IGR ratio).

\section{Fuel injection}

Fuel injection plays a fundamental role homogenizing the fuel in the cylinder charge. A wrong injection configuration can lead to a loss in engine performance and increased emissions. The two parameters to be controlled in the system installed on this engine are the start of the injection and the injection duration of the air +fuel mixture (this duration defines the amount of air that accompanies the fuel). The results shown come from Point 2000@4, a CAI operating point with a load degree slightly lower than that of Point 2000@5, see Fig. 6.31. 

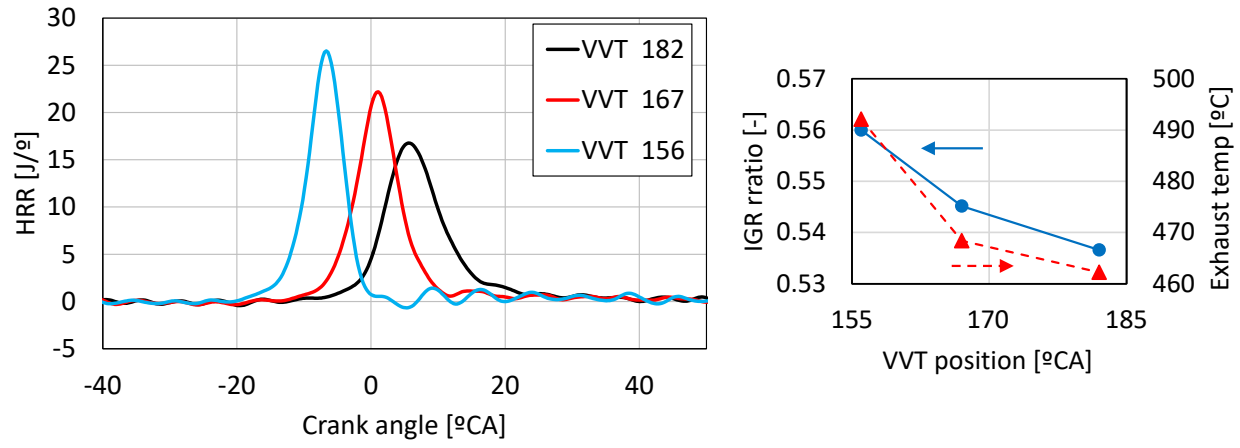

Figure 6.30. Left - Effect of VVT on the HRR when the engine is operated under CAI conditions. Right - Exhaust temperature and IGR ratio for each VVT.

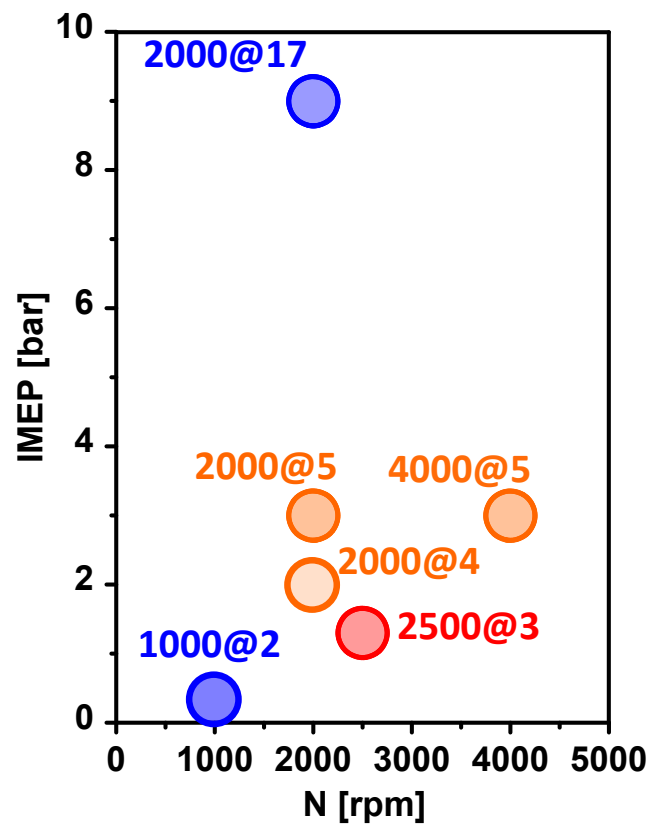

Figure 6.31. Representation of the operating Point 2000@4 on the engine map.

First of all, the effect of the SOI modification is going to be analyzed (see Figure 6.32). This parameter directly influences the mixture homogenization, thus affecting the combustion development. Soot emissions are a good "tracer" of this homogenization (see Figure 6.33), since for the smaller SOI's there is a 
fast increase in these emissions due to a stratified combustion of the charge (i.e. there are more rich regions, which is the key aspect for soot production). With the increase of the SOI, the fuel homogenization process is improved, and the charge moves from stratification to perfect homogenization. This effect can also be reflected in the combustion position and duration. The combustion position tends to be delayed with the initial increase of the SOI, until the $\mathrm{SOI}=150^{\circ}$ is reached. Beyond this value, the trend is reversed, and combustion tends to be advanced. Based on this change, two situations can be distinguished. In the first situation, the mixture is stratified and the areas with higher local richness are those that initiate the combustion process, propagating it to the rest of the charge. Now, with the increase of the SOI, these rich areas start to disappear, and combustion is delayed until the mixture is completely homogeneous. The second situation is when the mixture is correctly homogenized. In this other case, if the SOI is further advanced, the combustion position begins to be also advanced because the early injection of the fuel allows more time to increase its temperature, reaching the autoignition conditions earlier.
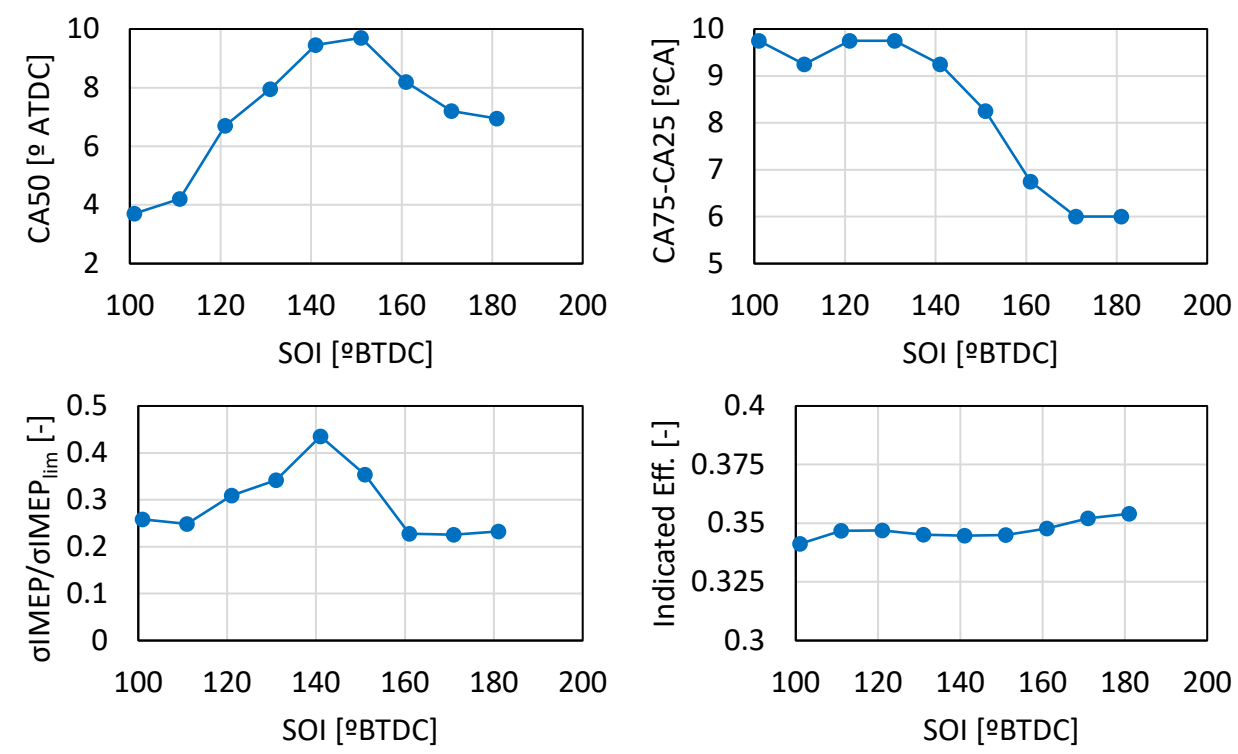

Figure 6.32. Combustion performance during a SOI variation.

The combustion duration, despite not presenting a perfect linear trend, shows a decreasing trend with the increase in SOI, since this duration is 
influenced by the quality of the mixture. The better homogenization will be reflected on a higher combustion speed, and at the highest SOI's, the rapid increase in speed due to a homogeneous mixture with a higher temperature during the combustion.
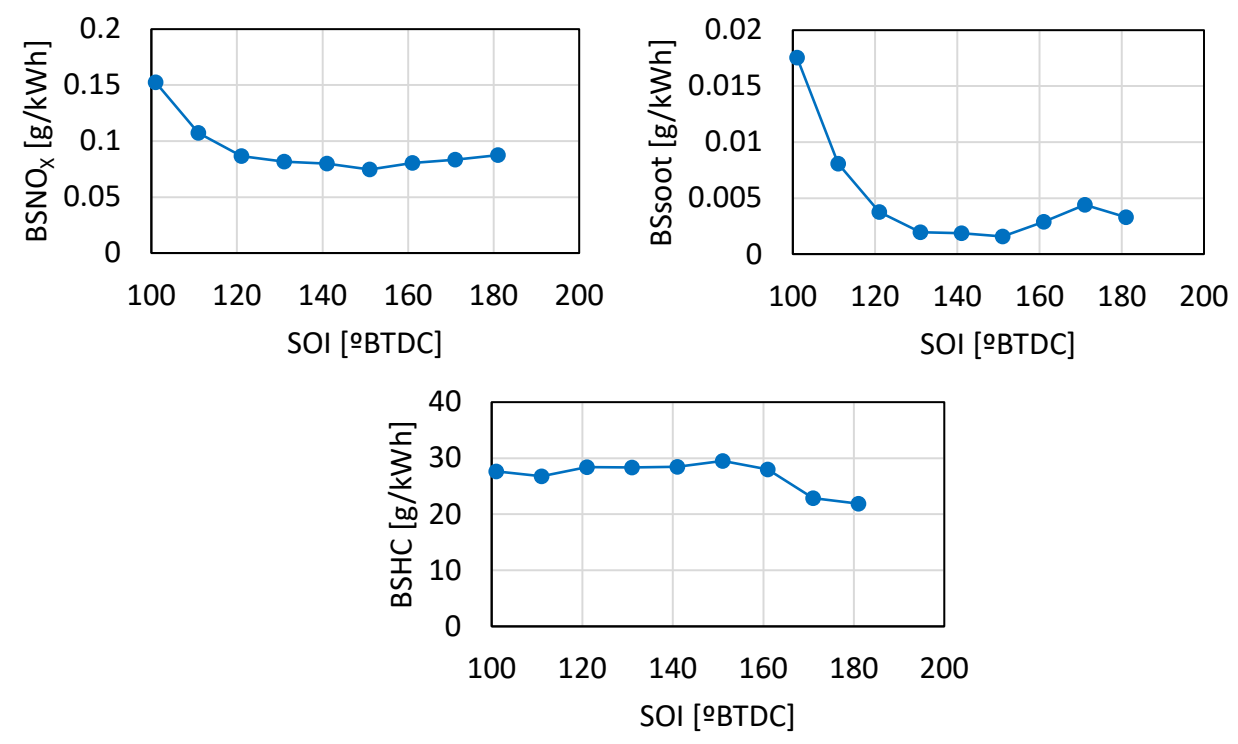

Figure 6.33. Evolution of the pollutant emissions during a SOI variation.

On the other hand, the evolution of the combustion stability is linked to the local reactivity of the mixture. The local rich mixtures improve this stability, and as these local areas are reduced, the stability is worsened. Once the mixture is already homogeneous, increasing the fuel residence time in the cylinder makes this stability to improve thanks to a greater reactivity.

Finally, the efficiency of the engine is the result of the combination of all the effects described above, and the maximum value will be at the point where the combustion position is as centered as possible, as faster as possible and with the best stability. For the particular case under analysis now, this optimum is reached with the greatest injection advance.

If the emission evolution is examined with the increase in SOI (Figure 6.33), either $\mathrm{NO}_{\mathrm{x}}$, soot and $\mathrm{HC}$ are in line with the improvement of the mixture homogenization. $\mathrm{NO}_{\mathrm{x}}$ and soot are greatly influenced by the stratification 
of the mixture, and $\mathrm{HC}$ emissions decrease when the combustion is as homogeneous as possible and when the reactivity of the mixture is maximized.

To analyze the DOI effect, there are two possibilities when deciding how to perform the tests. The first option is to keep the SOI constant, assuming that the end of the injection will change. And the second option is to keep the end of the injection constant, thus increasing the DOI leaving free the SOI. The choice of one strategy or the other will change the results obtained in the test, since the residence time of the fuel in the cylinder will be affected. In this case it was decided that the best criterion was to fix the EOI during the DOI variation, assuming that from the end of the injection event, the residence time will be the same for all tests.
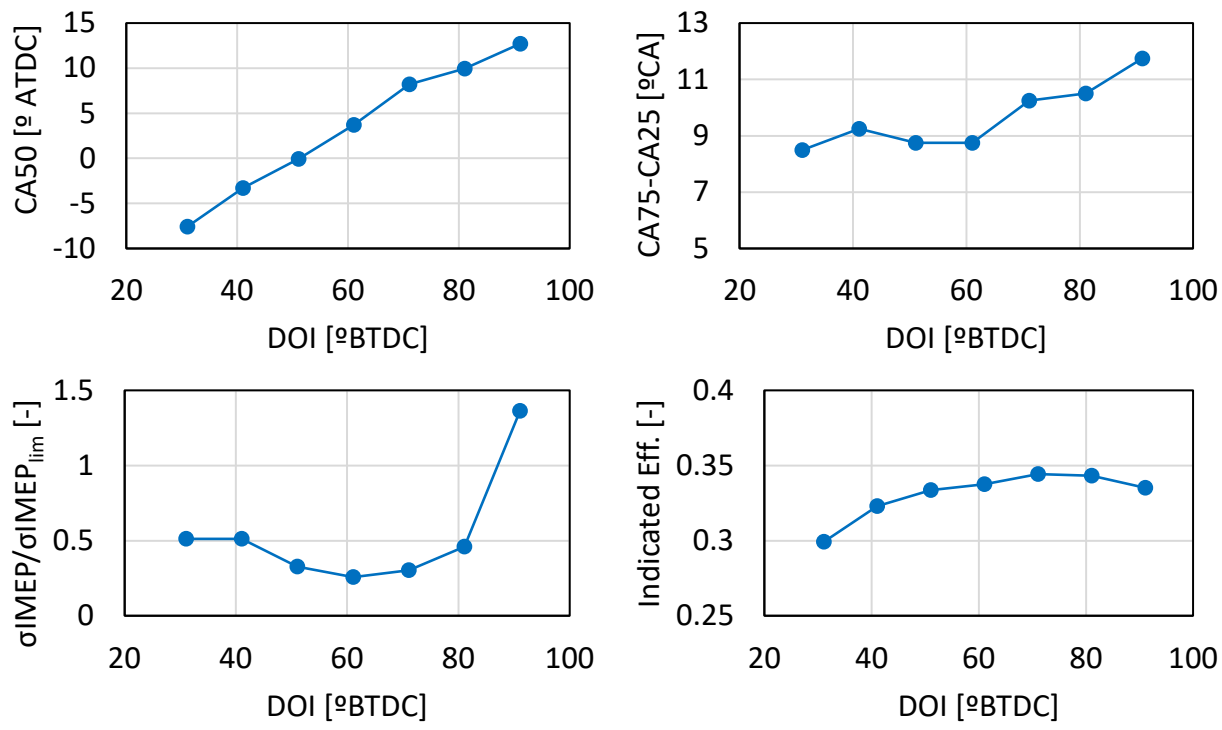

Figure 6.34. Combustion performance during a DOI variation.

The increase of this DOI implies that the fuel will be dispersed in a greater amount of fresh air during the injection (i.e. the injected air mass will increase). This effect leads to a delayed and slowed down combustion due to the cooling effect on the charge and the higher dispersion of the fuel. The engine efficiency and combustion stability values show that there is an optimal DOI for each operating point, where the dispersion of the mixture and the cooling effect due to the variable amount of air injected are optimal to achieve a stable and well 
positioned combustion (Figure 6.34). This optimal DOI value has also been mentioned in Chapter 5, where it was linked to an optimum value for the IAR parameter, which is the ratio between the injected air amount and the total amount of fresh air enclosed in the cylinder. The results right now presented about the DOI effect are totally consistent with those already presented in the previous chapter for the IAR.
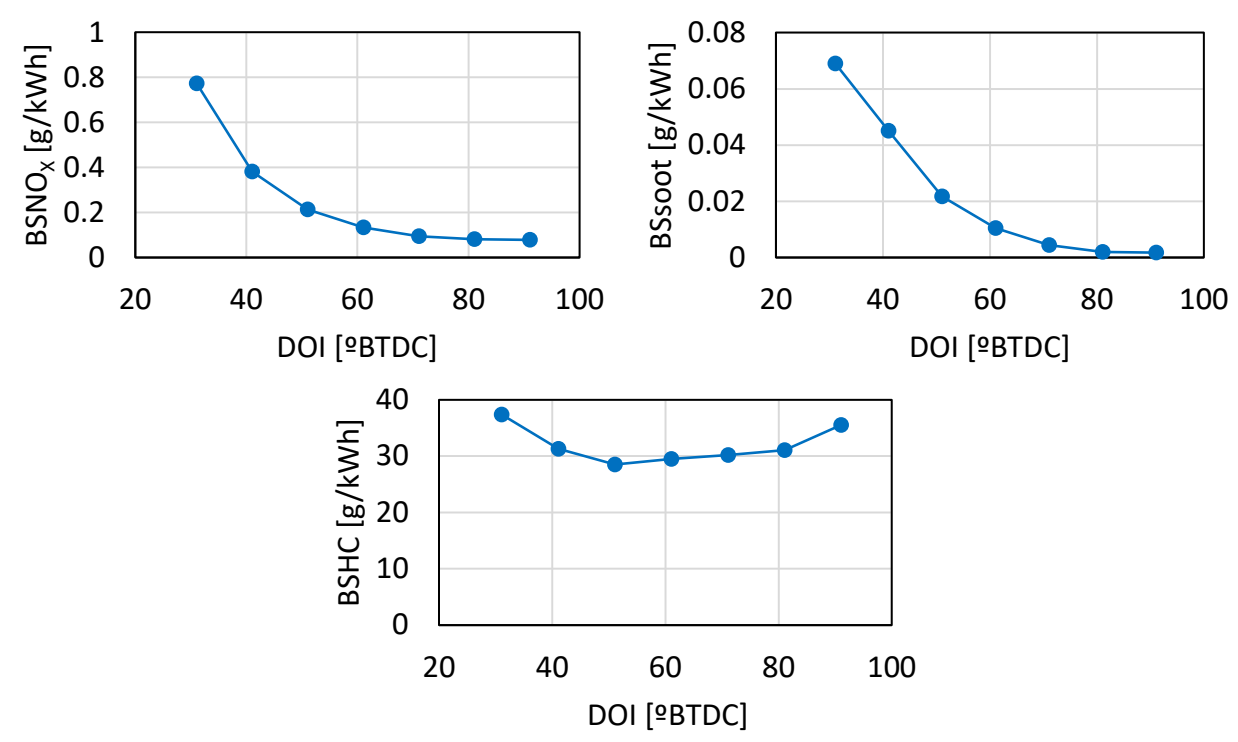

Figure 6.35. Evolution of the pollutant emissions during a DOI variation.

Regarding pollutant emissions, the dispersion/homogenization of the mixture always favors the $\mathrm{NO}_{\mathrm{x}}$ and Soot emissions reduction, whereas $\mathrm{HC}$ emissions present an optimum DOI value related to the best values of combustion efficiency and combustion stability, meaning that the charge is correctly burned and there are no misfire events during the engine operation (see Figure 6.35).

\section{EGR}

The application of this strategy replaces the intake air with low pressure (and temperature) EGR, and therefore the amount of oxygen of the intake charge is reduced. This implies that the in-cylinder richness will be increased, but the IGR ratios will be the same, since the sweep of the cylinder is maintained (see Figure 6.36). 


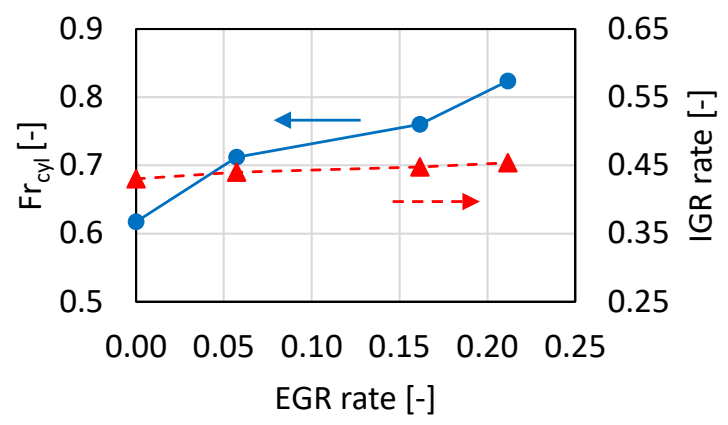

Figure 6.36. Effect of the EGR introduction on the in-cylinder richness and the IGR ratio.

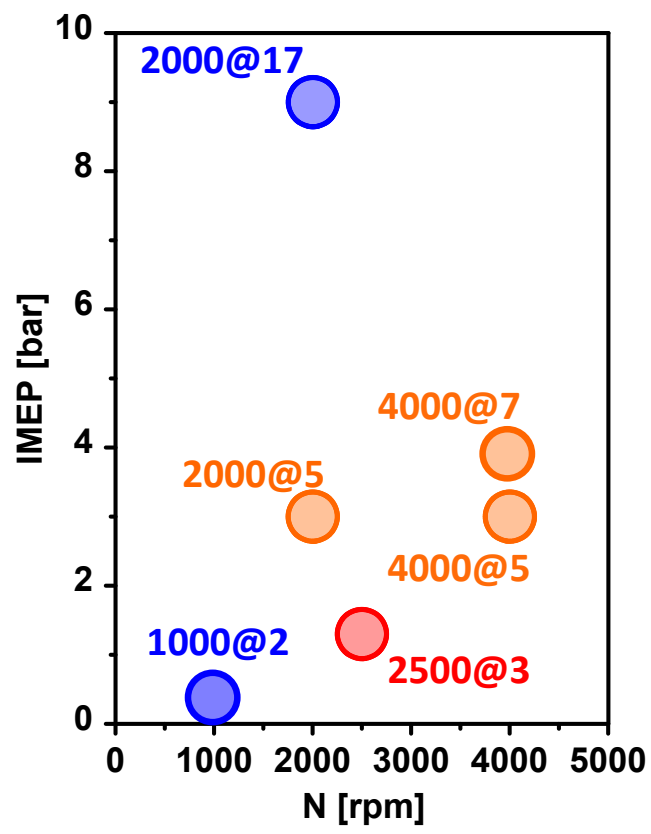

Figure 6.37. Representation of the operating Point 4000@7 on the engine map.

These cooled exhaust gases will lower the mixture reactivity, which can be useful during CAI operation to control the knock raise due to the high combustion rates of some operating points. The results that are going to be shown in this subsection to analyze the EGR effect correspond to an operation point of Region II, with an approximate IMEP of 3.8 bar (Point 4000@7 shown in Figure 6.37). This load degree starts to be excessive for the engine operation 
in CAI conditions since the knock starts to be very strong, making it difficult to operate at these conditions. Thanks to the EGR introduction, it has been possible to reduce the knock progressively with the increase of the introduced rate as can be seen in Figure 6.38.

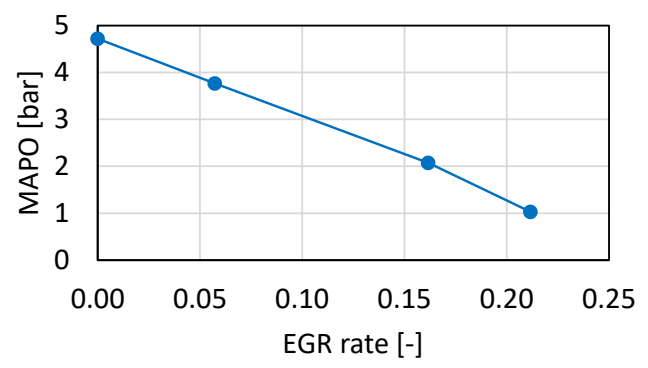

Figure 6.38. Evolution of the knock with the EGR rate variation for Point $4000 @ 7$.

The knock reduction in the case of EGR introduction does not happen due to the decrease of the temperature during the compression stroke, but due to a decrease of the combustion rates thank to the reduction in $\mathrm{YO}_{2}$. This can be seen in Figure 6.39. The compression temperatures are increased with the EGR introduction (due to the higher temperature of the IGR gases, which is closely related to the exhaust temperature, also shown in the figure, which also increase with the EGR rate). However, the HRR's show how combustion has been delayed and the heat release rates are reduced with the increase in EGR rate, because of the lower reactivity associated to the lower oxygen content.
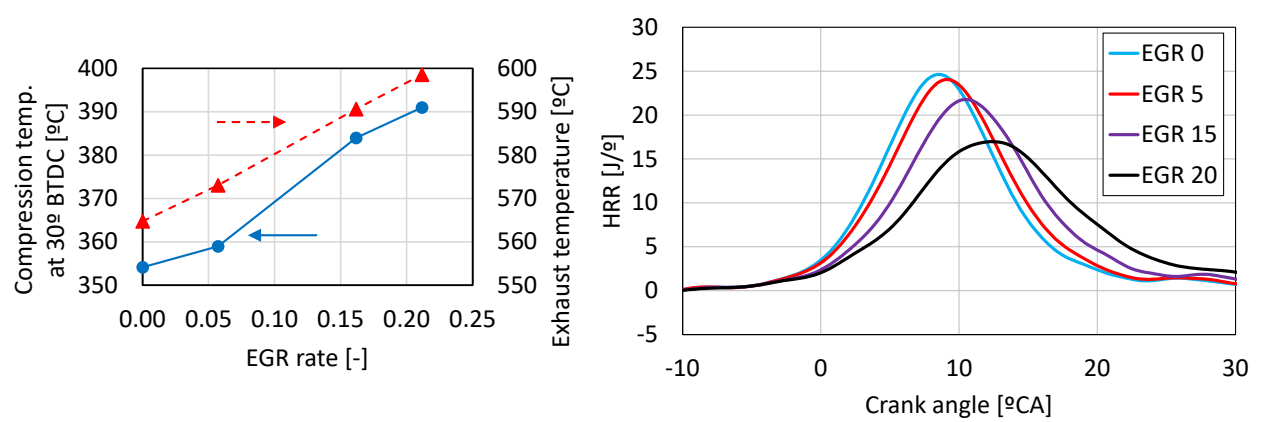

Figure 6.39. Left - Evolution of the compression temperatures with the EGR ratio. Right - HRR's for the different 4000@7 tests in an EGR variation. 
However, the use of this strategy has some disadvantages: the increase of the amount of exhaust gases progressively deteriorates the combustion efficiency and tends to increase the $\sigma \mathrm{IMEP}$ (see Figure 6.40). Therefore it is not interesting to apply very high EGR rates to control the heat release rates during the engine operation.
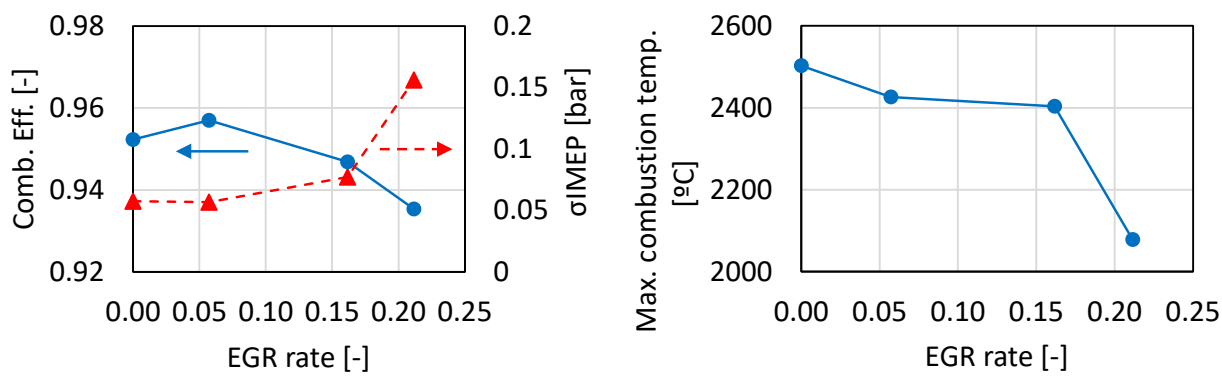

Figure 6.40. Effect of the EGR increase on the combustion efficiency and the $\sigma I M E P$.

Regarding the effect of this strategy on pollutant emissions, as can be seen in Figure 6.41, $\mathrm{NO}_{\mathrm{x}}$ and soot emissions tend to decrease, both mainly due to lower combustion temperatures (see Figure 6.40). HC emissions, on the other hand, remain more constant and follow the trend of combustion efficiency. Finally, CO emissions tend to increase due to the lower amount of available oxygen and the reduction of the combustion temperatures that increase the time needed for these molecules to get converted in its stable form of $\mathrm{CO}_{2}$.
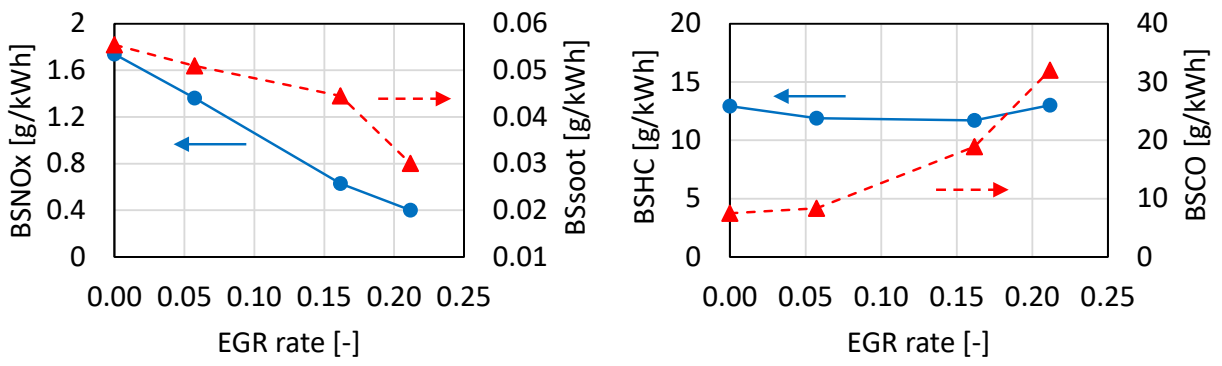

Figure 6.41. Emissions values for an EGR variation at Point 4000@7. 


\subsubsection{CAI operation loads}

After presenting the benefits of the CAI operation and describing the key factors to control this combustion on this engine, the following question arises: which is the region of the engine map where it is possible to work in CAI? To determine this region, some tests have been carried out in which the mass of fuel has been progressively increased at 2000 and $4000 \mathrm{rpm}$. The figures that will be presented below show the results obtained at both engine speeds: in blue the points at $2000 \mathrm{rpm}$ and in red the points at $4000 \mathrm{rpm}$.

First, Figure 6.42 shows the most significant parameters that have been considered to analyze the different loads operated on the engine. This figure is composed of different graphs that are going to be analyzed one by one:

- The IMEP range through CAI conditions has been in an approximate range between 1 and 3.5 bar maximum in both regimes. Despite showing a higher IMEP for $4000 \mathrm{rpm}$, the knock intensity for that particular test is too high to be considered as a valid point for the engine operation.

- The indicated efficiency of these points has been increasing with the engine load, reaching values of $36 \%$ at $2000 \mathrm{rpm}$ and $38 \%$ at $4000 \mathrm{rpm}$ at 3.5 bar IMEP.

- The combustion speed has been increasing with the progressive increase of the load until the excessive reactivity caused an increase of the knocking. Beyond these conditions, the need to lower the reactivity makes that the combustion duration does not continue decreasing. It has to be noted that, for the lower loads, the duration of the combustion is considered excessive. Therefore the combustion could be started by autoignition but, at some moment, it could have continued its development by means of a flame front.

- The required IGR ratio has been decreasing with the load increase in order to keep a controlled reactivity. For the lowest loads, a large temperature input is necessary, since the enclosed mass is low and during the compression stroke it does not reach temperatures high enough to promote the charge autoignition. With the increase of the engine load and, therefore, the mass enclosed, the necessary IGR ratio gets lower to reach the autoignition temperatures of the fuel.

- The MAPO, as expected, has been increasing with the load, making impossible the engine operation in CAI conditions beyond a certain load degree. In the $4000 \mathrm{rpm}$ tests, a point outside the operating limits has 

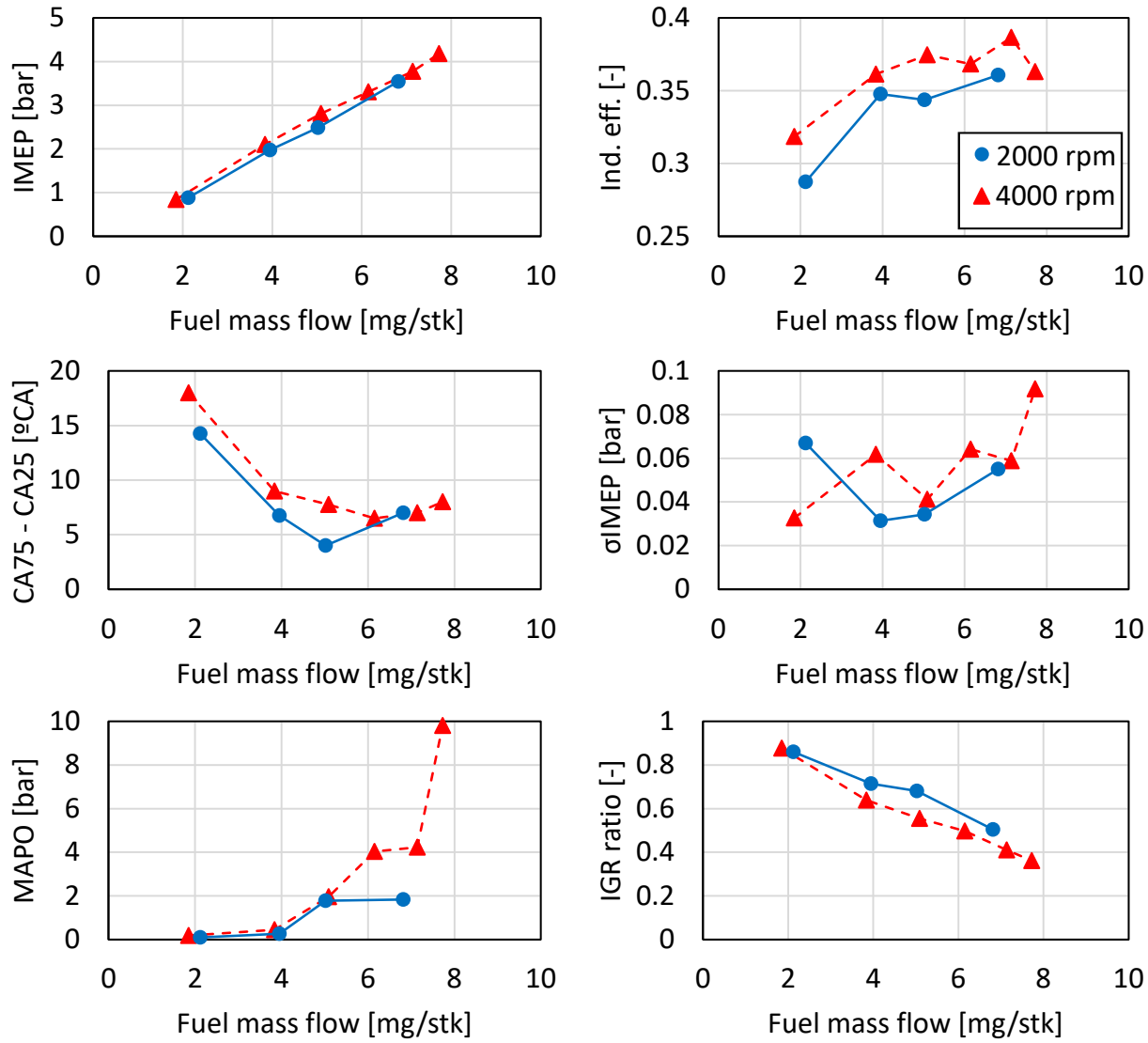

Figure 6.42. Load variation on CAI combustion conditions for two different engine speeds, $2000 \mathrm{rpm}$ (blue) and $4000 \mathrm{rpm}$ (red). Main engine parameters.

been included, where it is observed that the increase of this value is not progressive. When the control over this parameter is lost, the values obtained are very high.

- The combustion stability oscillates between acceptable values in these tests, since the operation in this mode allows little room for variation in this parameter. When the $\sigma$ IMEP begins to increase, and some misfires take place, the loss of the IGR temperature causes the combustion extinction. The observed behavior during the operation of the engine indicates that, for low loads, the loss of the IGR temperatures causes a $\sigma$ IMEP increase until combustion vanishes, and for high loads, the need 
to reduce the mixture reactivity to control the knock causes a situation where the reactivity is not enough to maintain the autoignition process, and the engine stops.

Regarding pollutant emissions (see Figure 6.43), $\mathrm{NO}_{\mathrm{x}}$ and soot emissions are not as low as theoretically expected, and they show an increasing trend with the increase in load. This effect might be due to the applied measures to control the combustion that lead to a worse charge homogenization and to a reactivity out of the optimum values during these tests. On the other hand, $\mathrm{HC}$ and $\mathrm{CO}$ emissions show extremely high values at low loads. This can be interpreted in the following way: at low load, the combustion by autoignition has not developed in a homogeneous way along the whole charge, and some regions may change to a flame front combustion mode due to the poor reactivity. In this way, the temperature becomes too low towards the end of combustion and flame quenching may appear. This interpretation also explains the significantly long duration of the combustion in these conditions already seen in the previous figure.
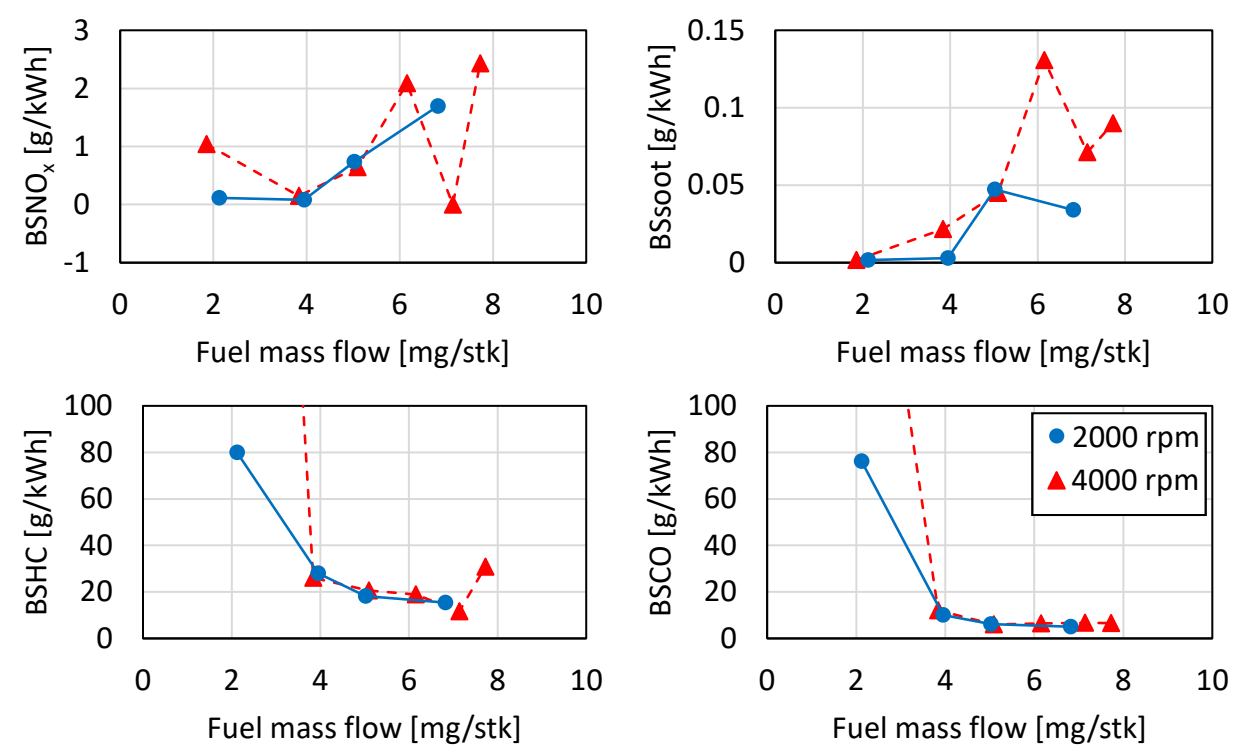

Figure 6.43. Load variation on CAI combustion conditions for two different engine speeds, $2000 \mathrm{rpm}$ (blue) and $4000 \mathrm{rpm}(\mathrm{red})$. Pollutant emissions. 
The results obtained during this load variation can be represented on the engine map in order to see the CAI region of this engine. This information is shown in Figure 6.44. It can be seen that this region covers from a very low load degree (despite not reaching the idle points) up to approximately $35 \%$ of the maximum engine load. This result indicates that quite a large part of the vehicle's usage time could be operated in CAI conditions. However, it is worth to note that the engine would be continuously changing between the SI and CAI modes: every time the vehicle would move from idle conditions, or during an engine load variation, etc.

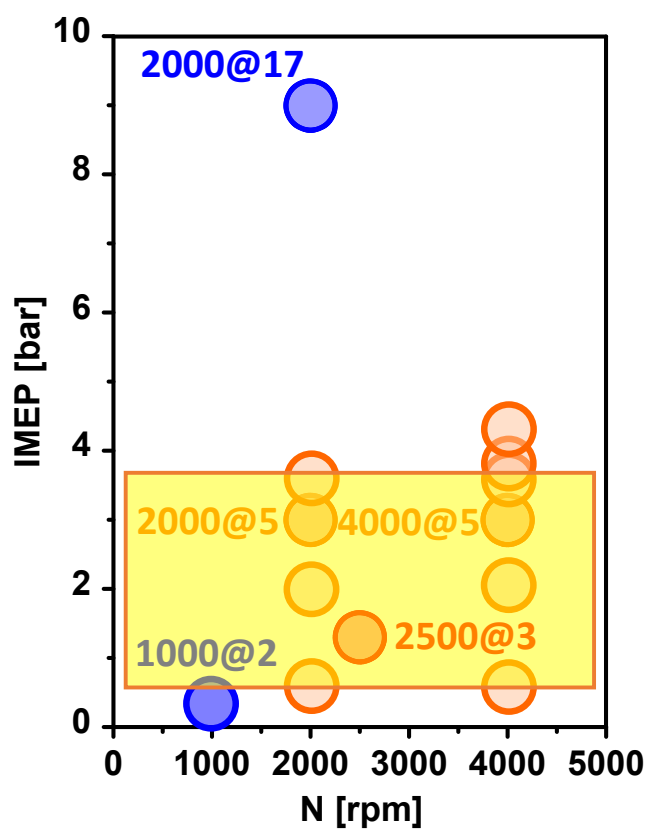

Figure 6.44. Representation of the CAI operable region (yellow area) on the engine map.

Increase of the CAI operation loads through strategies to control the mixture reactivity

The EGR addition in premixed combustion has proven to be useful to control the charge reactivity, helping to reduce knock, as already seen in the literature review [5] and, subsequently, on the results obtained in this engine (see Section 5.5). For this reason, its effect on CAI combustion has been analyzed, and this analysis has been included in the previous subsection. EGR has shown to be a very useful tool to control the high combustion rates during the engine operation that cause an increase of the knock level and hinder the 
engine operation at high loads. This strategy is therefore interesting to try to increase the maximum achievable load degree in CAI conditions.

In order to analyze the potential of this strategy and the potential enlargement of the maximum achievable load limit in CAI conditions, the previous tests have been completed including now EGR as a strategy to continue with the load increase. In this case, only the results obtained at $4000 \mathrm{rpm}$ are shown in Figure 6.45, since the trends obtained were the same for both engine speeds. The points operated without EGR are represented in blue, whereas the new points obtained when using EGR are shown in red.

- The maximum load degree has been increased up to values of around 5 bar IMEP, which represents an increase of approximately $30 \%$ compared to the engine operation without EGR.

- It has been possible to control the knock in a higher load range. The point presented with an injected mass of $8 \mathrm{mg} / \mathrm{stk}$ without EGR had an excessive MAPO of 10 bar. Thanks to the use of EGR, the MAPO has been reduced to allowable values for this engine ( 4 bar).

- The combustion duration has changed its decreasing trend with the EGR introduction since it is necessary to reduce the high heat release rates in order to continue operating the engine.

- The $\sigma$ IMEP while operating in CAI conditions is always kept below the maximum operability limits (otherwise the combustion extinguishes). However, with the increase of the EGR rates, the reactivity of the charge is decreased, thus increasing the $\sigma \mathrm{IMEP}$ and causing the stop of the engine with higher EGR rate.

- The IGR ratio has remained approximately constant at these points and has not been further reduced since in that case the mixture could not be autoignited. This is because the air mass was reduced when EGR was introduced (i.e. the EGR displaced the air), thus leading to a higher incylinder richness, which partly compensates the loss of mixture reactivity.

- Regarding the indicated efficiency, it can be seen how the use of the EGR has deteriorated slightly this value since the combustion slows down and is delayed. Therefore the heat release is not optimal in order to maximize fuel efficiency.

The pollutant emissions during these tests (see Fig. 6.46) show that $\mathrm{NO}_{\mathrm{x}}$ and soot are still present in combustion. However, in view of the trends, 

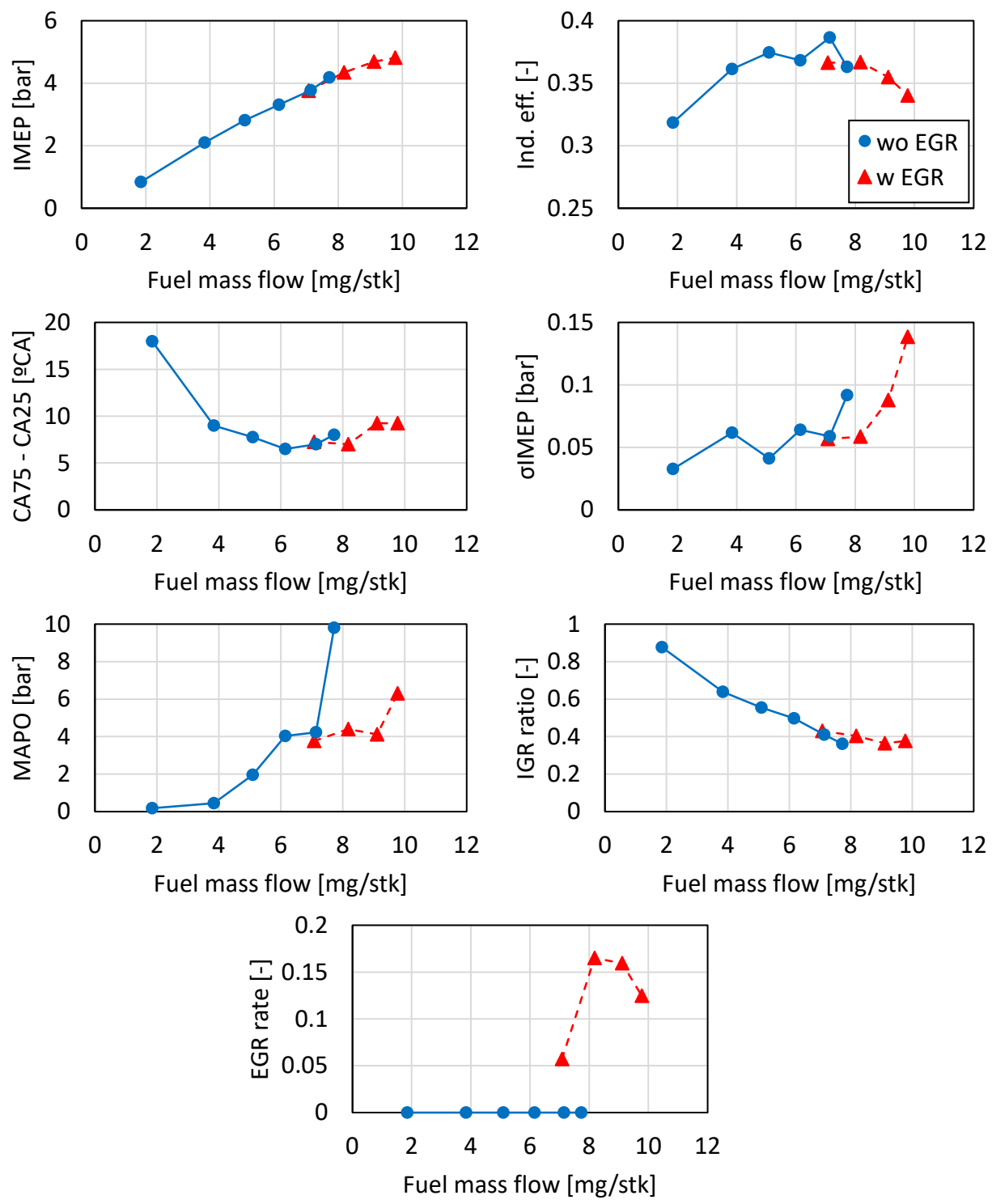

Figure 6.45. Load variation on CAI combustion conditions with (red) and without EGR (blue). Main engine parameters.

they have stopped increasing and have been controlled thanks to EGR, which causes a decrease in combustion temperatures. As for $\mathrm{HC}$ and $\mathrm{CO}$ emissions, 

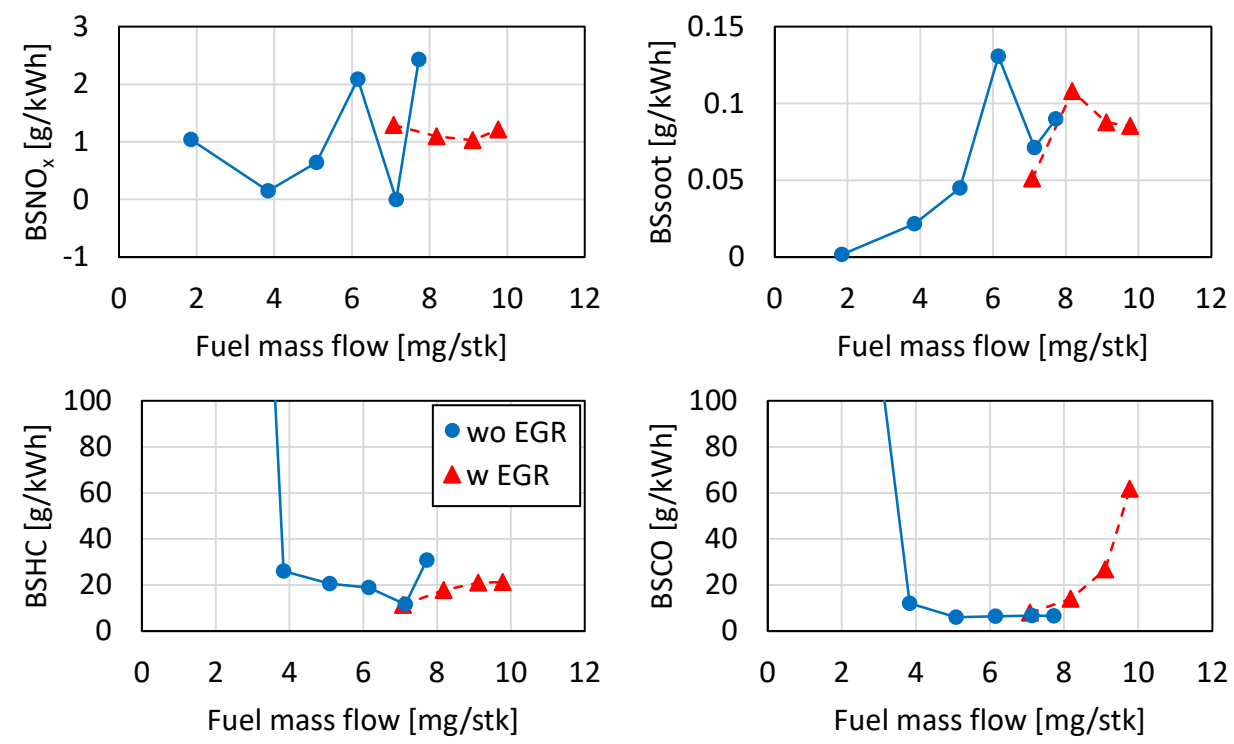

Figure 6.46. Load variation on CAI combustion conditions with (red) and without EGR (blue). Pollutant emissions.

they show an upward trend with the use of EGR, since the quality of the mixture is worsened and the in-cylinder richness is increased.

Finally, the engine map obtained with the EGR inclusion to extend the maximum loads is shown in Figure 6.47. The upper limit has been increased from 3.5 to 5 bar IMEP (remember that this value in a two-stroke engine is twice if compared to a four-stroke). The result of this strategy has led to a larger CAI region on the engine map. In view of this improvement, EGR is demonstrated to be a valid strategy to try to extend the operational limits in CAI conditions, giving a solution to the typical problem of this combustion mode: its restriction to low loads.

\subsubsection{Hybrid modes, CAISI}

In a CAI engine, normally both the SI and CAI combustion modes can be operated, since the main difference when working in these combustion modes is essentially the reactivity of the in-cylinder charge during the compression 


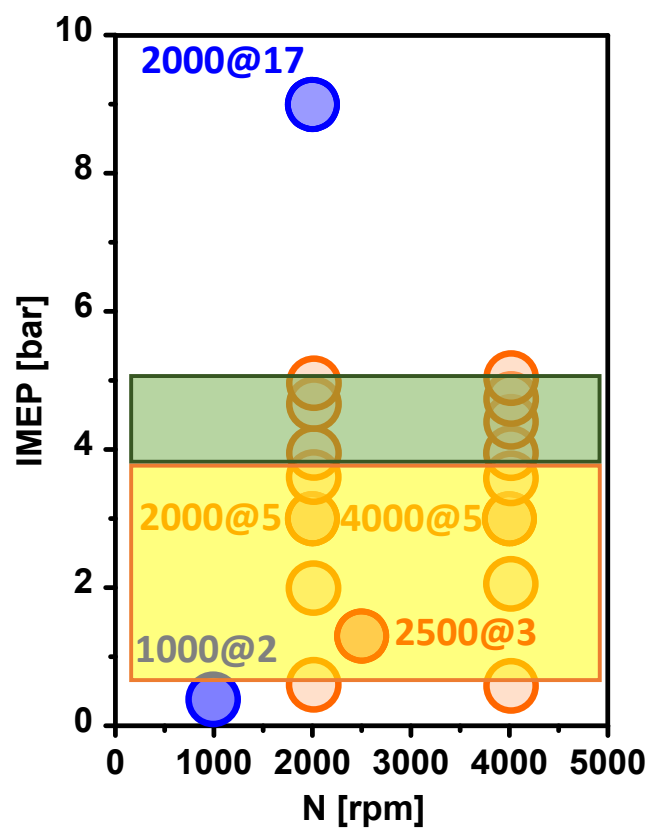

Figure 6.47. Representation of the CAI operable region without EGR (yellow area) and with EGR (green area) on the engine map.

stroke. Therefore, by adjusting this reactivity, the combustion mode can be varied between SI and CAI, or vice versa, during its operation [6].

The transition point from SI to CAI mode occurs when the reactivity of the charge is sufficiently high to sustain a stable autoignition process in the engine without any assistance from the spark plug. However, just before this limit, the in-cylinder charge is not able to autoignite with the existing conditions in the cylinder, but only a small external energy supply is sufficient to trigger the autoignition process of the charge [7]. In these engines, this extra-energy supply can be provided by (1) the spark plug and (2) the subsequent development of a combustion kernel that will cause an increase in pressure and temperature in the combustion chamber during the combustion development [8]. Under these conditions, there is a hybrid combustion mode, placed between the SI and CAI modes, in which a small part of the mixture is ignited by the spark plug and, later on, the combustion quickly starts to develop by autoignition, which is promoted thanks to this extra energy. This operation mode can be found referred with different names. However, the most common one seems to be CAISI/SACI (Controlled Auto-Ignition Spark Ignited/Spark Assisted Compression Ignition) $[6,7]$ and, unlike the CAI combustion mode, the main 
advantage of operating in this other mode is the greater control on the charge ignition thanks to the action of the spark plug.

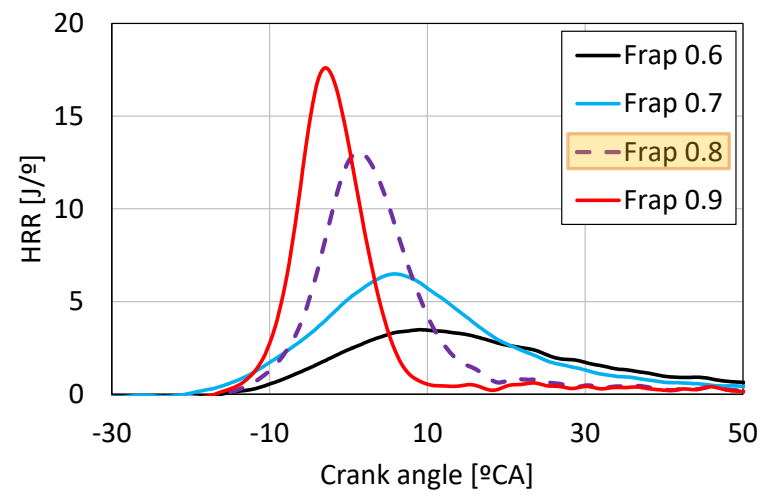

Figure 6.48. Apparent F/A eq. ratio variation at Point 2000@5.

Point 2000@5 is a good example of this peculiar combustion mode, since the optimum settings for this point are reached when operating in hybrid mode. In order to show the differences between these combustion modes, the optimum operating configuration of this point has been chosen, and from this one, the apparent $\mathrm{F} / \mathrm{A}$ equivalence ratio has been modified to change from hybrid combustion to CAI and SI conditions. The results are shown in Figure 6.48. The highlighted $\mathrm{Fr}_{\mathrm{app}}=0.8$ case corresponds to the hybrid operating point. From this point, with the lowering of the Fr, the combustion has changed to a flame front controlled combustion, whereas with the increase of the Fr, the combustion has been fully developed by autoignition. For the SI tests, the heat release rates have decreased due to the change in the combustion mode, since the flame front has to progress in a highly diluted charge. On the contrary, in the CAI mode, the charge is autoignited too early due to an excessive mixture reactivity, and the heat release rates are much faster. As can be seen, in the hybrid mode case, the combustion onset is smoother compared to the CAI mode cases, and the final heat release rates during combustion are high, but do not reach the values of these other cases where CAI combustion takes place from the beginning.

Figure 6.49 is a figure that goes in line with Figure 6.25 (page 221), already presented in Section 6.2.2.1. In this last figure, the pressure cycles measured and the calculated HRR laws were shown for a SI and a CAI point. In the current figure, however, the same information but for a CAISI point is presented. This point is more similar to a CAI test, since the combustion 

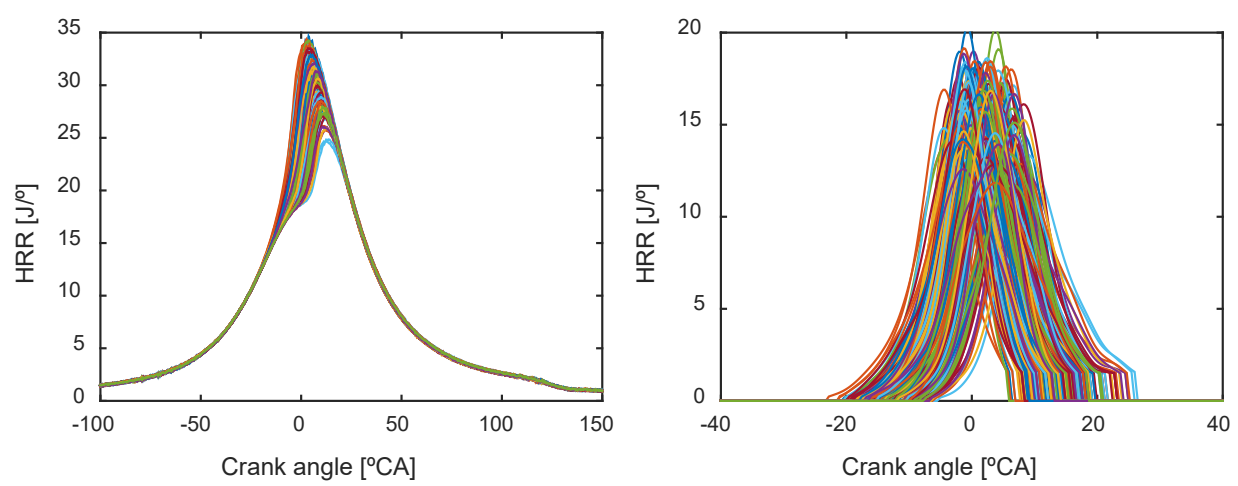

Figure 6.49. Representation of the measured pressures during CAISI operation and their respective calculated HRR's.

stability is high and similar to the CAI conditions. However, the fact of starting the combustion with the spark plug provides the characteristic variability in the ignition process of this mechanism, since this process is always subject to a certain degree of randomness due to the effect of the turbulence in the region located between the electrodes. This effect can be easily seen on the HRR graph as there is a high dispersion on the different cycle's positions if this test is compared with the CAI example.

The results obtained from these tests (Figure 6.50) confirm that the best values for brake specific fuel consumption and indicated efficiencies are for the point operated in this combustion mode. This is due to several reasons: positioning, temperatures, stability and combustion efficiency.

- This combustion mode allows operating in CAI-like conditions with slightly leaner Fr values and lower IGR ratios, which is translated into lower combustion temperatures and, therefore, less heat losses.

- As it can be seen in the graph showing the combustion position, the SI tests are too delayed and, on the contrary, the change to a CAI combustion mode causes an excessive combustion advance due to the high reactivity of the mixture.

- The combustion stability at this point is very similar to that of a CAI point. After all, the combustion ends as a CAI. In this case, it should be noted that, starting from the CAISI point, the Fr modification in order 

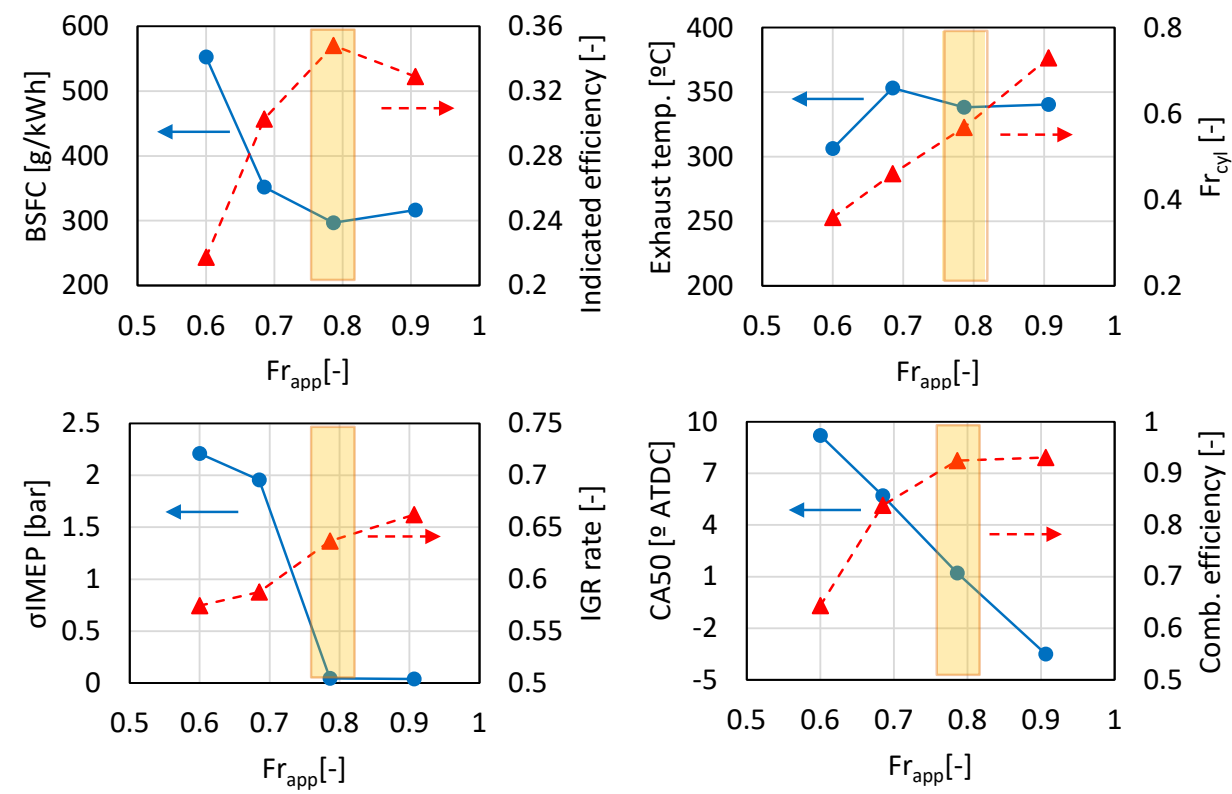

Figure 6.50. Apparent F/A eq. ratio variation at Point 2000@5. Main engine parameters.

to obtain either SI or CAI points, with the same engine configuration, is not the optimum strategy. The SI points, for instance, have resulted very unstable, most probably because the optimal VVT for this point is not the best option for SI operation.

- The combustion efficiency has been greatly improved, since in this range of load degrees the IGR ratios are very high and the in-cylinder richness values very low. Therefore the SI combustion efficiency at these points has very low values since there will be many regions of the mixture below the flammability limits.

In terms of pollutant emissions (see Figure 6.51) the $\mathrm{Fr}_{\mathrm{app}}=0.8$ has shown as being the optimum compromise. $\mathrm{NO}_{\mathrm{x}}$ and soot are minimal because the combustion process takes place with higher dilution and lower charge temperature compared to stoichiometric conditions, and the $\mathrm{HC}$ and $\mathrm{CO}$ emissions are also low due to the high combustion efficiency achieved, because the charge has burned mainly by autoignition. Once the characteristics of this 

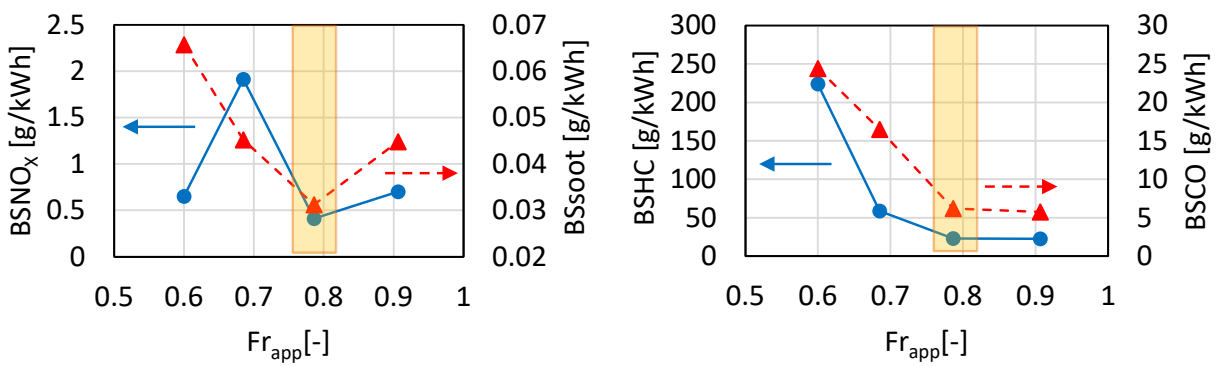

Figure 6.51. Apparent $F / A$ eq. ratio variation at Point 2000@5. Pollutant emissions.

mode have been seen, it can be stated that this particular way of burning the fuel represents an engine operating way in between the two combustion modes: on the one hand, the combustion is initiated by the spark plug, which gives a greater control of the combustion position and gives the possibility to operate with charges with a lower reactivity; and, on the other hand, the bulk of the combustion develops by autoignition, obtaining the advantages of the two operation modes. However, this type of combustion is difficult to be achieved in this engine at different loads, since such a precise adjustment of the mixture reactivity, so close to the autoignition threshold, is often problematic. And, additionally, sometimes these conditions where CAISI can be operated result being so narrow that it is impossible to operate in this combustion mode. The region of this engine where this mode is most easily attainable is Region II, where the engine can be operated in CAI and SI modes. Particularly this mode is interesting when the combustion position of the CAI operating points is outside what would be considered an optimal position, since by this way the combustion position can be moved without losing the benefits of CAI operation. Finally, it should be underlined that the fact of working with the spark activated makes it possible to avoid sometimes erratic misfires.

\subsection{Analytical approach to the different combustion modes}

The SI combustion is going to be deeper analyzed decomposing the experimental HRR's and searching for the basic evolution of the flame front in different combustion conditions. The goal of this analysis is to be able 
to characterize the "ideal" SI combustion for this engine, getting a valuable information to be used later for the analysis of the different combustion cycles, so as to have a deeper understanding of the different agents affecting the combustion development. Once the SI combustion details would have been studied, the CAI combustion could be also analyzed with the same approach, in order to search for the differences on the combustion evolution and, if possible, define a methodology to differentiate both combustion modes during the experimental data processing.

\subsubsection{Fundamentals of the analysis}

Before starting with the combustion analysis proposed in this work, the necessary data has to be refined, adapted, or even calculated in some cases, from the available measured data.

\section{Processing of the different individual cycles of each test}

This analysis takes each measured cycle separately. So the necessary initial data has to be individualized. The start of the processing methodology requires the pressure data, the calculated HRL and the mass flows of all the different gases (and fuel) inside the engine. For this purpose, the methodology described in Section 5.6, defined to analyze the tests cycle by cycle, is used to calculate the necessary individualized data from each test.

\section{HRL refinement}

The heat release laws present inaccuracies in some cases. These ones come from different origins, as disturbances on the pressure signals or deviations due to the difficulties to estimate accurately the trapped mass and the initial conditions of the cylinder charge at the beginning of the cycle. To solve these problems, the pressure signal is filtered and the effect of those disturbances is easily removed. However, the deviations in the estimated trapped mass are more complicated to be solved, and this problem worsens with the decrease in engine load, since the relative errors increase. This problem can be observed in Figure 6.52, where the HRL curve presents a significant slope, both during the compression stroke, and at the end of the expansion stroke. These slopes cannot be real, and lead to wrong calculations when the HRL is processed. To solve this problem, these slopes are removed, and the HRL is correctly placed on the vertical axis ${ }^{4}$. The details about how this correction process is performed are given in Appendix 6.B.

\footnotetext{
${ }^{4}$ The small step observed at the end of the refined law in considered a residual variation caused by the definition of the new EOC.
} 

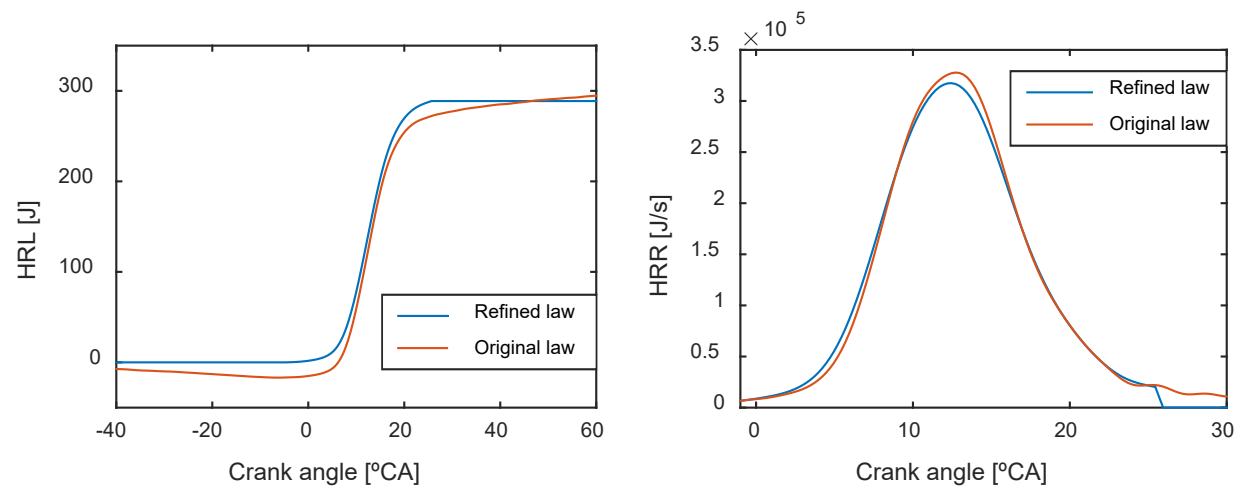

Figure 6.52. Original vs, processed HRL.

The correction of the final part of the HRL presents some difficulties, since the determination of the exact inclination to remove from the HRL end and the exact point when the combustion is finished is not easy to find. To check if the estimation has been correct, the representation of the HRR vs the HRL can be examined (see Figure 6.53).
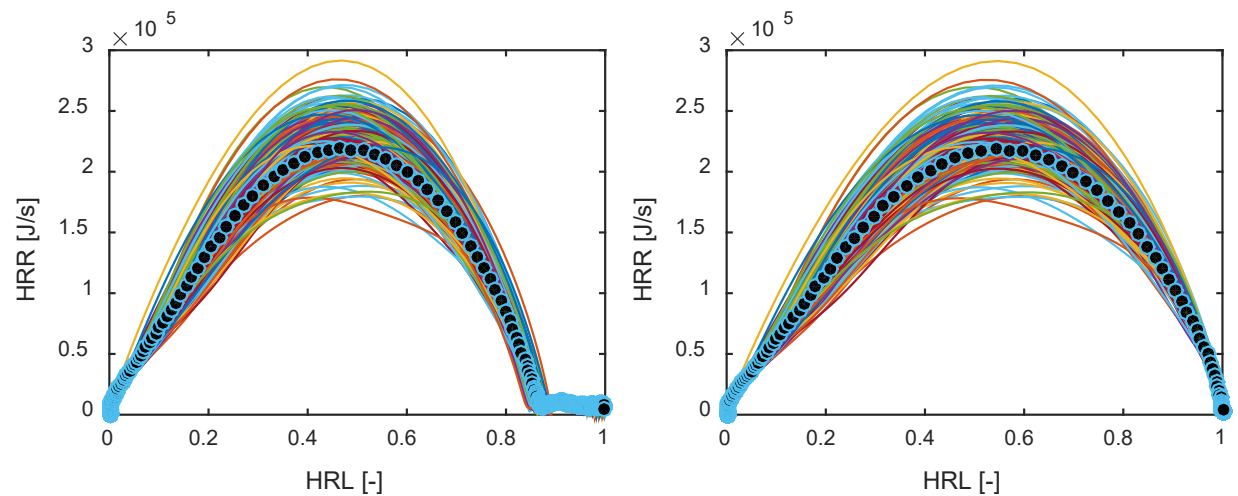

Figure 6.53. Left - Bad estimation of the HRL end. Right - Correction of this problem.

In this plot the combustion laws of each cycle are represented, and in blue dots the average of all those cycles. The start and the end of the HRR should cross the HRL axis on the values 0 and 1, as shown in Figure 6.53 on the 
right. If this representation shows a case like the one shown on the left of this figure, this means that the end of the HRL is poorly estimated (the end of the combustion is earlier than estimated) and the residual inclination of the final part has to be removed in order to remove this error.

\section{Instantaneous temperatures}

During the analysis of the combustion it is necessary to know the instantaneous conditions of the two regions in the combustion chamber (burned and unburned regions). This calculation is performed through the pressure signals and the estimated instantaneous composition of the in-cylinder charge.

First, the mean in-cylinder temperature $\left(T_{\text {avg }}\right)$ is calculated by means of the equation of state for ideal gases (Eq. 6.1). In this equation, $p_{c y l}$ is the cylinder pressure, $\mathrm{V}$ is the instantaneous volume of the combustion chamber, $\mathrm{R}$ is the constant for the particular gas trapped in the cylinder (estimated from the in-cylinder composition), and $m$ is the trapped mass evolution during the cycle (it changes slightly due to blow-by losses). This estimated temperature will be used later to estimate the temperatures of the burned and unburned regions during the combustion process.

$$
T_{\text {avg }}=\frac{p_{c y l} \cdot V}{R \cdot m}[K]
$$

The temperature in the unburned region $\left(T_{u b}\right)$ is considered to be equal to the average in-cylinder temperature during the period before the SOC, and after this point, it is estimated as an adiabatic compression process of the unburned gases caused by the expansion of the burned mass generated during the combustion process, as illustrated in Eqs. 6.2 and 6.3, where gamma is calculated at the instantaneous temperature and composition of the unburned gas.

$$
\begin{gathered}
\text { If } I V C<\alpha<S O C, T_{u b}(\alpha)=T_{a v g}(\alpha)[K] \\
\text { If } \alpha>S O C, T_{u b}(i)=T_{u b}(i-1) \cdot \frac{p_{c y l}(i)}{p_{c y l}(i-1)} \frac{\gamma_{c y l}-1}{\gamma_{c y l}} \quad[K]
\end{gathered}
$$


Once this temperature is estimated, the density of the unburned mixture $\left(\rho_{u b}\right)$ can be deduced, as shown in Eq. 6.4:

$$
\rho_{u b}=\frac{p_{c y l}}{R \cdot T_{u b}}\left[\mathrm{~kg} / \mathrm{m}^{3}\right]
$$

Finally the burned region temperature $\left(T_{b}\right)$ is estimated, from the start of combustion, as an enthalpy balance between the unburned region temperature and the mean temperature during the combustion process, as shown in Eq. 6.5. The different $c_{p}$ values are estimated from the composition and instantaneous temperatures for the in-cylinder charge $\left(c_{p_{c y l}}\right)$ and the burnt gases $\left(c_{p_{e x h}}\right)$, and the HRL represents the fraction of mass burned at each instant.

$T_{b}=\frac{\left(\left(c_{p_{c y l}} \cdot(1-H R L)+c_{p_{e x h}} \cdot H R L\right) \cdot T_{a v g}\right)-\left((1-H R L) \cdot T_{u b} \cdot c_{p_{c y l}}\right)}{c_{p_{e x h}} \cdot H R L}[K]$

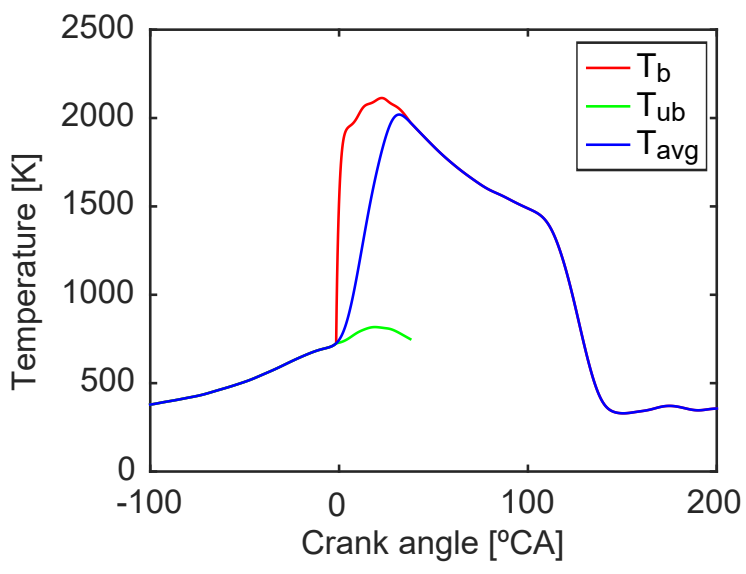

Figure 6.54. Example of the calculated temperatures for Point 2000@17. The blue color represents the spatially averaged temperature, the green color the unburned temperature and the red color the burned temperature.

Finally, with all these calculations the different temperatures and densities of the two different regions during the combustion can be estimated. An example of some of the results obtained is shown in Figure 6.54. 


\subsubsection{Analysis}

Now, the HRR is going to be decomposed, in order to subtract the different effects affecting this heat release and, thus, go deeper in the analysis of the different parameters of the combustion development. In this way the results of different tests performed in the engine could be compared despite having different settings.

This process can be separated in different steps, described below.

$$
\mathbf{1}^{\text {st }} \text { step: } H R R m f[g / s]=H R R[J / s] / L H V[k J / k g]
$$

In the first step the effect of the fuel is removed from the HRR, as shown in Eq. 6.6, where the HRR is divided by the Low Heating Value (LHV) of the fuel. The result is a mass flow rate, indicative of the fuel burned at each instant (HRRmf).

$$
\begin{aligned}
& \mathbf{2}^{\text {nd }} \text { step: } H \operatorname{RRmsq}[\mathrm{g} / \mathrm{s}]= \\
& \quad H R R m f[\mathrm{~g} / \mathrm{s}] \cdot\left(1+\left(1 / \mathrm{FstO}_{2}[-] \cdot Y O_{2 c y l}[-] \cdot \mathrm{Fr}_{c y l}[-]\right)\right)
\end{aligned}
$$

With this mass flow rate of burned fuel, the mass flow rate of unburned mass (i.e. the mass flow rate going through the flame front) can be determined (HRRmsq). It is important to distinguish the HRRmf from the HRRmsq, since this last parameter takes into account the amount of gases mixed with the fuel, modifying the first parameter as a function of the in-cylinder $\mathrm{F} / \mathrm{A}$ eq. ratio, the dilution of the charge $\left(\mathrm{YO}_{2 \mathrm{cyl}}\right)$, and the oxygen required in a stoichiometric combustion $\left(\mathrm{FstO}_{2}\right)$.

$$
\mathbf{3}^{\text {rd }} \text { step: } A S\left[\mathrm{~m}^{3} / \mathrm{s}\right]=(H R R m s q / 1000)[\mathrm{kg} / \mathrm{s}] / \rho_{u b}\left[\mathrm{~kg} / \mathrm{m}^{3}\right]
$$

If this last mass flow rate is divided by the density of the unburned mixture $\left(\rho_{u b}\right)$, the AS parameter is obtained. This parameter is representative of the flame front surface during the combustion (A) and the speed of this combustion (S). Once this value is obtained, two hypotheses can be considered in the context of turbulent premixed flames to continue with the analysis: 
The first one considers the area $(\mathrm{A})$ as an effective area $\left(A_{e f f}\right)$ of the flame front and the combustion speed (S) as the laminar combustion speed for those conditions $\left(S_{L}\right)$. With this assumption, the effective area is the result of a "theoretical" area developed in quiescent conditions $\left(A_{\text {geo }}\right)$, i.e. a smooth surface, which is later wrinkled by the in-cylinder charge turbulence (the surface increase factor is taken as $k$ ), increasing its area to make it equivalent to the flame front effective surface. Finally, this area is multiplied by the laminar combustion speed, since each area differential is assumed to progress under laminar conditions, see Eq. 6.9.

$$
A_{e f f} \cdot S_{L}=A_{g e o} \cdot k \cdot S_{L}
$$

The second consideration takes the area (A) as the theoretical area developed in quiescent conditions $\left(A_{\text {geo }}\right)$ and the speed $(\mathrm{S})$ as an equivalent speed $\left(S_{b}\right)$, adding the turbulent effect to the laminar combustion speed. In this way the result is basically the same, even if now the turbulence effect is associated to the modification of the combustion speed, as shown in Eq. 6.10.

$$
A_{g e o} \cdot S_{b}=A_{g e o} \cdot k \cdot S_{L}
$$

Finally, it is observed that both considerations lead to the same equation. In this equation, a term $(k)$ appears, associated to the turbulence, which increases the rate of heat release. This term is often called FSR (Flame Speed Ratio), and is related to the internal movements of the charge, which are affected by the geometry, the scavenging process and the engine speed, among others, wrinkling the surface of the flame front (or affecting the combustion speed). If the first proposed Equation 6.9 is taken into account, when the AS parameter is divided by $S_{L}$, the resulting parameter will be $A_{\text {eff }}$.

$$
4^{\text {th }} \text { step: } F S R A[\text { a.u. }]=A S\left[\mathrm{~m}^{3} / s\right] /\left(S_{L} / 100\right)[a . u .]
$$

Dividing AS by the $S_{L}$ calculated for the instantaneous in-cylinder conditions, the parameter FSRA is obtained, which is representative of the effective area at each instant of the combustion process.

For this step (\#4), it is necessary to define how to determine the laminar combustion speed as a function of the different conditions that may be present in the cylinder during the engine operation. If the literature is 
reviewed, Metghalchi and Keck [9] worked on the definition of the laminar combustion speeds for methanol, isooctane and indolene at different pressures and temperatures (Eq. 6.12). These combustion speeds are based on the correction of a known value of $S_{L}$ for some given conditions taken as a reference. Later, Rhodes and Keck [10] defined an improved correlation for the standard gasoline, basing their work on the equation already proposed by Metghalchi.

$$
S_{L}=S_{L_{r e f}} \cdot\left(T_{u b} / T_{r e f}\right)^{k 1} \cdot\left(p / p_{r e f}\right)^{k 2}[\mathrm{~cm} / \mathrm{s}]
$$

where $\mathrm{k} 1$ and $\mathrm{k} 2$ are defined for each fuel, and depend on the $\mathrm{F} / \mathrm{A}$ equivalence ratio, as shown in Table 6.1.

\begin{tabular}{lll}
\hline Fuel & $\mathrm{k} 1$ & $\mathrm{k} 2$ \\
\hline \hline Isooctane & $2.18-0.8 \cdot(F r-1)$ & $-0.16+0.22(F r-1)$ \\
Gasoline & $2.4-0.27 \cdot F r^{3.51}$ & $-0.357+0.14 \cdot F r^{2.77}$ \\
\hline
\end{tabular}

Table 6.1. Definition of $k 1$ and $k 2$ for isooctane and gasoline $[9,10]$.

This equation was expanded in order to take into account the addition of residual gases to the charge [9]. For this purpose, an extra term related to the mixture dilution was added, as illustrated in Eq. 6.13.

$$
S_{L}=S_{L_{r e f}} \cdot\left(T_{u b} / T_{r e f}\right)^{k 1} \cdot\left(p / p_{r e f}\right)^{k 2} \cdot\left(1-2.1 \cdot Y_{d i l}\right)[\mathrm{cm} / \mathrm{s}]
$$

This equation is reliable as long as the combustion conditions are within the defined range of use. To obtain the above equation, a relatively narrow range of $\mathrm{F} / \mathrm{A}$ equivalence ratios was used. Consequently, the Fr valid range for the equation is very close to the stoichiometric conditions, and the values obtained when the calculation is out of this range are not reliable. The operating range of this engine, as already seen before, always present a significantly high dilution degree of the mixture, either with air (lean mixtures) or with residual gases (IGR or EGR). Therefore, knowing the limitations of the formulations proposed by Metghalchi and Keck, in the present work an alternative formulation for the laminar combustion speed estimation is going to be obtained and proposed, specifically adapted to this engine. The proposal is the following: 


$$
S_{L}=S_{L_{r e f}} \cdot\left(\frac{T_{u b}}{T_{r e f}}\right)^{a} \cdot\left(\frac{p}{p_{r e f}}\right)^{b} \cdot\left(\frac{Y_{d i l}}{0.231}\right)^{c} \cdot e^{-\frac{1}{2} \cdot\left(\frac{F r-m}{d}\right)^{2}}[\mathrm{~cm} / \mathrm{s}]
$$

As it can be observed, the proposed equation is based on the one already proposed by Metghalchi. It depends on a predefined combustion speed value at some given conditions taken as a reference. From this point, the combustion speed will be modified according to the current temperature, pressure, oxygen concentration and apparent $\mathrm{F} / \mathrm{A}$ equivalence ratio. However, in Eq. 6.14, the effect of each parameter is isolated from the others, i.e. each term in the equation depends on only one parameter (the exponents $a$ and $b$, for instance, now are constants, and do not depend on Fr, as proposed by Metghalchi). Besides, the function considered for each parameter is defined based on its already known theoretical influence over the combustion speed (see Figure 6.55). The selection/definition of each function is justified in the following paragraph.
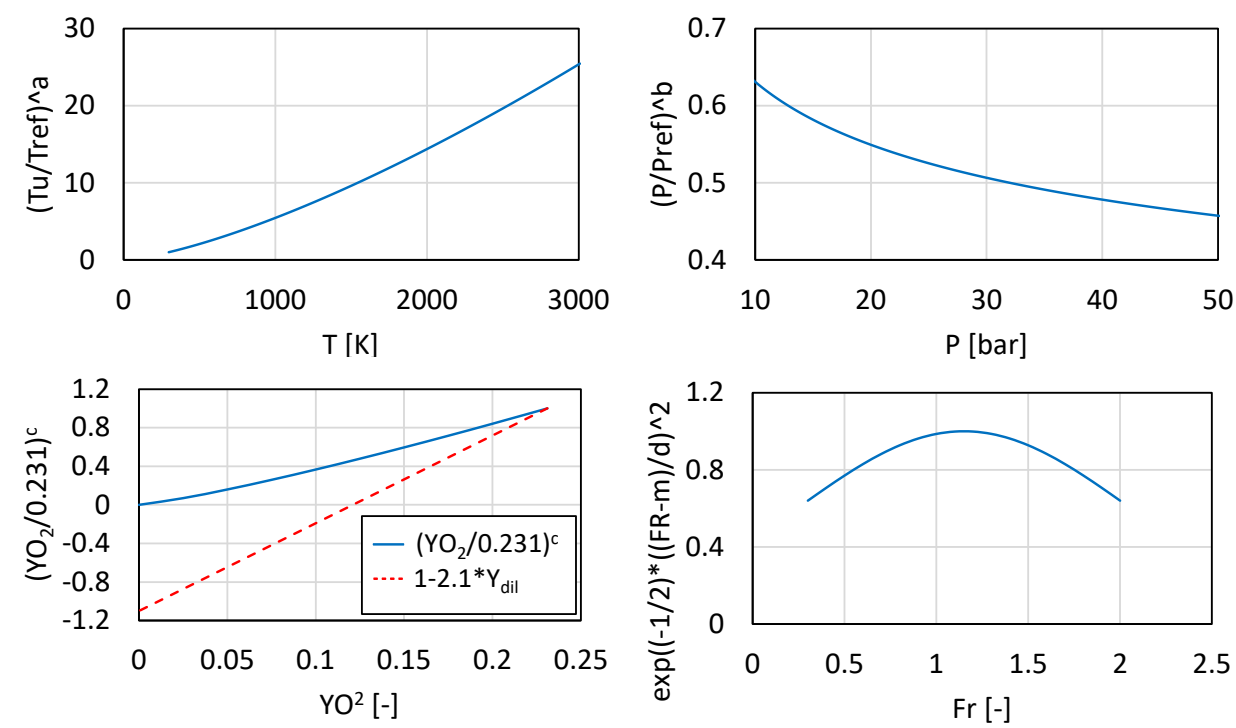

Figure 6.55. Functions for each parameter of the combustion speed equation.

The functions for temperature and pressure are essentially the same as those proposed by Metghalchi, only modifying the exponent: now they 
are constant, whereas Metghalchi proposed a function of Fr. The major modifications in the proposed equation concern the effect of $\mathrm{Fr}$ and $\mathrm{Y}_{\mathrm{dil}}$, with the intention to make more flexible, reliable and "physical" their effect. The influence of the mixture dilution with residual gases has been defined as a power law of the oxygen mass fraction $\left(\mathrm{YO}_{2}\right)$, relative to the atmospheric oxygen content. In this case, the choice of the exponent determines the final influence of $\mathrm{YO}_{2}$ on the combustion speed. It is worth noting that the function proposed here to take into account the effect of $\mathrm{YO}_{2}$ is more suitable than that originally introduced by Metghalchi (Eq. 6.13), as illustrated in the bottomleft plot in Figure 6.55, where this last function provides negative values for oxygen mass fractions below 0.12. Finally, the Fr influence has been defined as a Gaussian function. This bell-shape function has been considered because of its consistency with experimental observations (e.g. Heywood [11]). The position of the maximum, as well as the width of the "bell" can be adjusted with the constants $m$ and $d$. All the constants that need to be determined in Eq. 6.14 will be fitted based on experimental data taken from the engine used for this research. Details about the fitting methodology will be given in the following paragraphs.

Regarding the reference values appearing in the equation, the following choices have been done: for the $S_{L_{r e f}}$, a unitary value will be considered, and for $p_{\text {ref }}$ and $T_{\text {ref }} 298 \mathrm{~K}$ and 1 bar, respectively. This means that the correlation of the laminar combustion speed will not provide any physical value in absolute terms. Nevertheless, since the interest of this equation at this stage of the analysis is to evaluate the relative deviation between the different processed tests, the choice of an arbitrary value for $S_{L_{r e f}}$ does not introduce any particular effect, because it is a constant value for all the considered cases. Therefore, if all the data used for the comparison is processed with the same methodology, there won't be any particular error during this comparison.

The methodology to determine the different parameters of the equation proposed for the $S_{L}$ calculation (i.e. the constants $a, b, c, d$, and $m$ ) is based on the analysis and optimization of a given group of tests, carefully selected, that are considered to have been totally burnt by a flame front (with this engine this is a very important and critical point, since total or partial CAI combustion can be found in some operating regions). The chosen points are mainly high load operating points, because in those conditions it's impossible to operate the engine by autoignition, and if this phenomenon occurs, it will be easily detected, since knock will appear. Besides, in this first phase of the analysis, the different tests have been chosen with the same engine speed and a similar load degree, to ensure that the FSR value should be equivalent for all of them. Once an appropriate group of tests at different conditions of Fr and 
$\mathrm{YO}_{2}$ has been selected, the equation is tested for multiple combinations of the parameters. In each iteration, a combination is chosen and applied to calculate the different laminar combustion speeds, and with that, the FSRA values are calculated for each cycle of the selected tests (as indicated in Eq. 6.11). After that, the dispersion among them is calculated as the standard deviation of all the cycles respect to the mean FSRA cycle.

$$
\sigma=\sqrt{\frac{1}{n} \sum_{i=1}^{n}\left(x_{i}-\mu\right)^{2}}, \mu=\frac{1}{n} \sum_{i=1}^{n} x_{i}
$$

The optimum parameters will be those presenting the minimum dispersion on all the calculated FSRA, since this would mean that the effect of the different combustion conditions affecting the combustion speed have been satisfactorily removed from the FSRA parameter.

Finally, after the optimization work, the parameters and the final laminar combustion speed equation for this engine are presented:

$$
\begin{aligned}
a & =1.4 ; b=-0.2 ; c=1.2 ; d=0.9 ; m=1.15 \\
S_{L} & =S_{L_{r e f}} \cdot\left(\frac{T_{u b}}{T_{r e f}}\right)^{1.4} \cdot\left(\frac{p}{p_{\text {ref }}}\right)^{-0.2} \cdot\left(\frac{Y_{\text {dil }}}{0.231}\right)^{1.2} \cdot e^{-\frac{1}{2} \cdot\left(\frac{F r-1.15}{0.9}\right)^{2}} \quad[\text { a.u.] }
\end{aligned}
$$

Once the equation for the laminar combustion speed is defined, the FSRA parameter can be obtained. With this parameter, the effect of the different laminar combustion speed reached depending on the charge conditions are removed. This FSRA thus represents the evolution of the effective flame front area during the combustion process $\left(A_{g e o} \cdot k\right.$-see Eq.6.9-). Therefore, if the $A_{\text {geo }}$ evolution is assumed equivalent ${ }^{5}$ for all the operating conditions and the $\mathrm{k}$ (turbulence parameter) is mainly dependent on the engine speed, the FSRA should aggregate, in a similar trend, the different tests if the engine speed is kept constant. In order to show this effect, in Figure 6.56, a $\mathrm{Fr}_{\text {app }}$ variation at Point 2000@17 is presented, and the standard deviation between the average cycles for each test is reduced from the HRR to the FSRA in a factor of 2.35.

As seen in Figure 6.56, all the steps of the analysis and the graphs derived from these calculations will be represented in a graph format where the $\mathrm{X}$

\footnotetext{
${ }^{5}$ The geometrical area evolution is the same if the compared combustions present the same combustion phasing. If not, this evolution would be slightly different. For the present work, this difference has been neglected.
} 
axis is the non-dimensional HRL. In this way, cycles with different combustion durations can be represented in the same graph, and all of them will have the same start and end. Besides, this way of representing the information allows to use the $\mathrm{Y}$ axis dimension to compare how the different cycles have been developed.
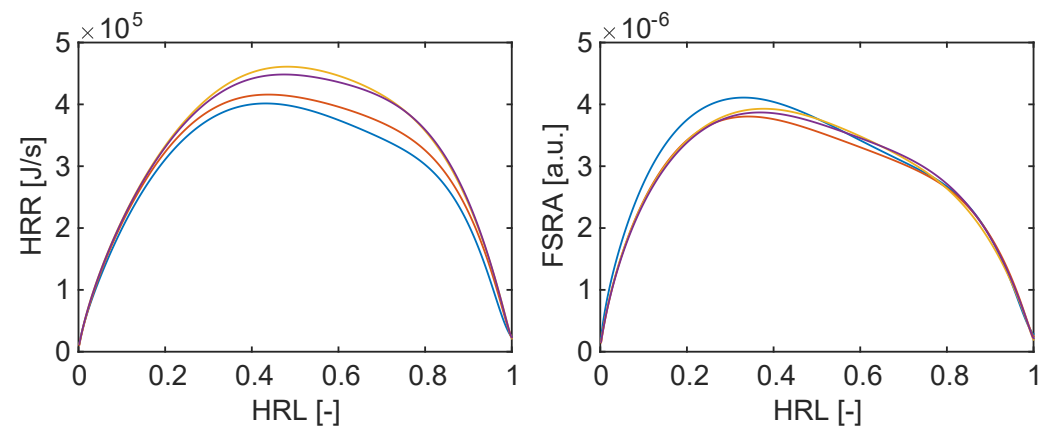

Figure 6.56. Comparison among the HRR and the FSRA obtained for a $F_{\text {app }}$ variation at Point 2000@17 operated with different $F_{\text {app }}$ values.

$$
5^{\text {th }} \text { step: : } A^{*}[\text { a.u. }]=F S R A[a . u .] / N^{f}[\text { a.u. }]
$$

Once the FSRA is obtained, it is important to take into account that this parameter results from the combination of the FSR (representative of the turbulence level existing inside the cylinder) and the theoretical combustion area without the wrinkling effect of the turbulence. As widely known, the turbulence intensity can be scaled with the engine speed, and according to the Borghi diagram (Figure 2.3, page 22), if the engine is operated in the wrinkled flames region, the influence of the engine speed is directly proportional to the turbulence intensity [12]. Therefore, the FSRA can be divided by the engine speed in order to make all the curves obtained at different engine speeds comparable among them. In order to follow the same philosophy as in the previous equation definition (Eq. 6.14), the parameter related to the engine speed has been defined as $N^{f}$, where the exponent $f$ has to be optimized following the same methodology as for the previous step. Once some tests at different engine speed have been selected, the optimization process has been carried out, and the best $f$ value found has been $f=1$, thus confirming that the FSR is scaled directly with the engine speed (see Figure 6.57). 
This new parameter will be referred as $A^{*}$, and it is representative of a constant value multiplying the theoretical geometric area of the combustion flame front $\left(k \cdot A_{g e o}\right)$, which, by this means, is experimentally obtained.
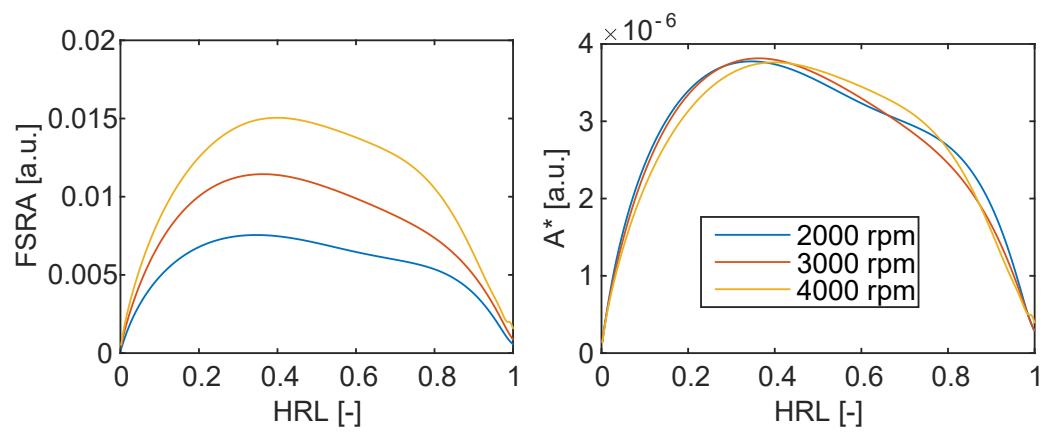

Figure 6.57. Correction of the engine speed. Left - FSRA values without any correction. Right - The same values corrected with $f=1$.

As a summary of the methodology presented, in Figure 6.58, the different described steps have been represented for a test at Point 2000@17, in order to give a graphical view of the described analysis. It is worth to indicate that, in the figure, the many different lines at each plot correspond to the 250 cycles registered during a test.

Once reached this point, it is worth to compare the results of the methodology proposed up to now for three different correlations for the laminar flame speed: the correlation for isooctane presented by Metghalchi, the correlation for common gasoline presented by Rhodes, and the correlation obtained in the frame of the current research, already shown before in this chapter. To perform this comparison, a selection of 14 tests with their corresponding 250 cycles has been used. This selection includes information of different engine speeds, a variation of the apparent Fr between 0.5 and 1, and some tests operated with EGR up to a rate of $20 \%$.

The result of this comparison can be observed in Figure 6.59, where the values for the standard deviation were $\sigma=1.8161$ for the isooctane correlation, $\sigma=0.3578$ for the gasoline correlation and $\sigma=0.1405$ for the correlation adapted to this engine. These values show that the isooctane correlation is far from being reliable in these conditions. Regarding the gasoline correlation, it is more reliable than the previous one, but yet compared with the correlation proposed in the current work, the scattering of the curves is still 2.5 times higher. Consequently, the proposed correlation, which was specifically adapted to this particular engine, provides the best results, as expected. The main 

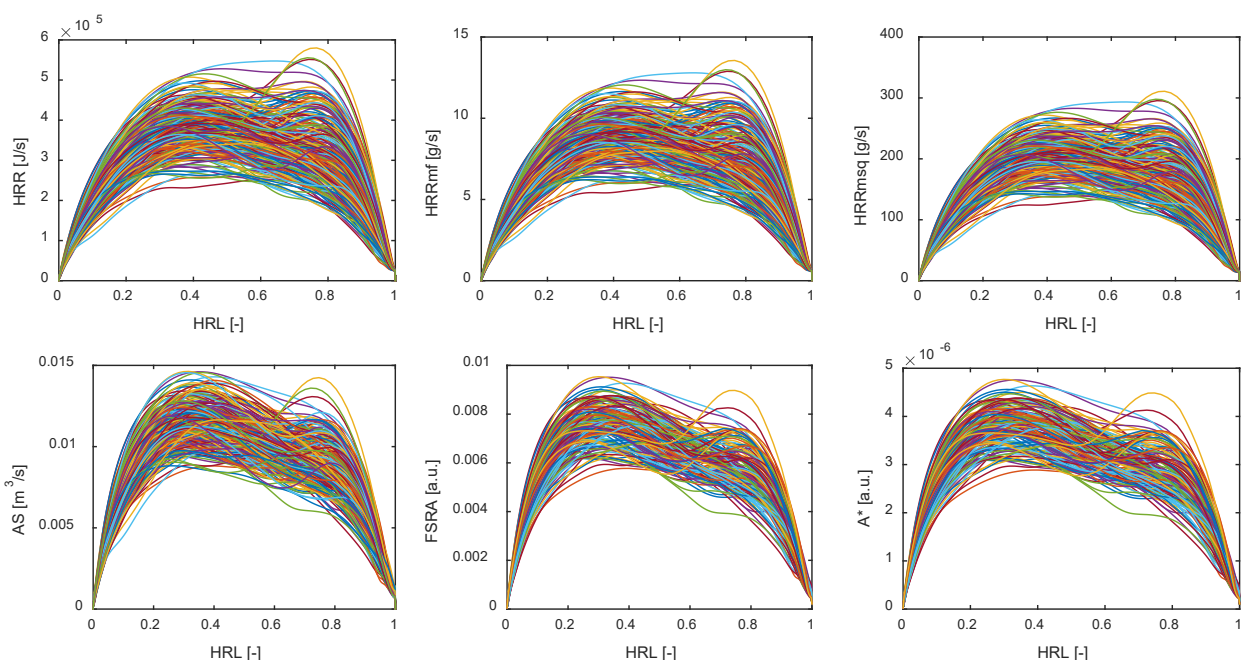

Figure 6.58. Calculation of the $A^{*}$ for a Point $2000 @ 17$ following the steps previously described.

reason for the lower reliability of the gasoline correlation is now going to be investigated.
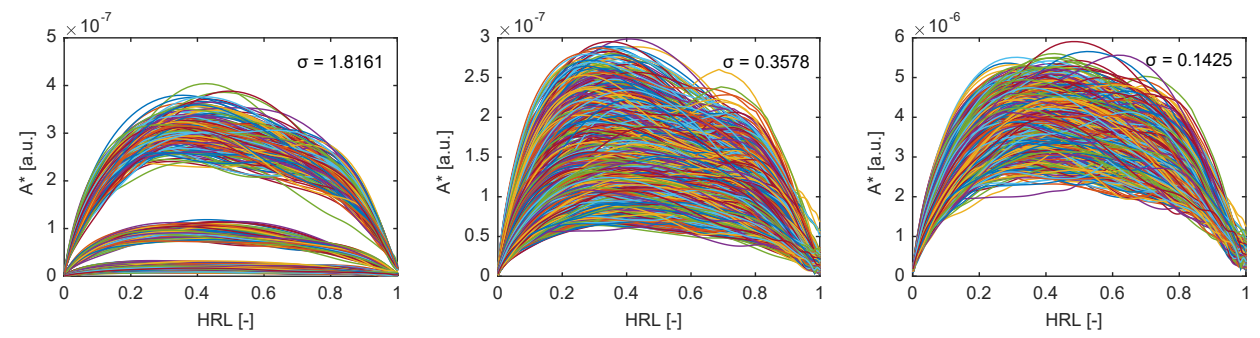

Figure 6.59. Representation of the $A^{*}$ calculation for the three correlations of the laminar combustion speed, from left to right: isooctane correlation, gasoline correlation and proposed correlation.

As stated, the main limitation of the already existing correlations presented above, is the limited Fr validity range. To illustrate this problem, the correlations of gasoline presented by Rhodes and the adapted correlation proposed in this work are going to be used to calculate the $A^{*}$ value of different Point 2000@17 tests, where only the $\mathrm{Fr}_{\text {app }}$ has been variated (the isooctane 
correlation has been omitted for this comparison, since the previous results have already shown that it was clearly the worst option). In this case, three sets of points have been selected: the first one includes $\mathrm{Fr}_{\mathrm{ap}}$ 's from 0.5 to 1 , the second from 0.6 to 1 , and the third from 0.7 to 1 . The results are shown in Figure 6.60. It can be observed that the gasoline correlation loses significantly its accuracy when the $\mathrm{Fr}_{\text {app }}$ range is increased, moving from values of $\sigma=0.1198$ when the minimum $\mathrm{Fr}_{\text {app }}$ is 0.7 , to values of $\sigma=0.3685$ when the minimum $\mathrm{Fr}_{\text {app }}$ is 0.5 . On the contrary, the correlation proposed here for this engine has kept the standard deviation under control despite the increase of the $\mathrm{Fr}_{\text {app }}$ range, thus showing its better suitability in the context of lean mixtures.
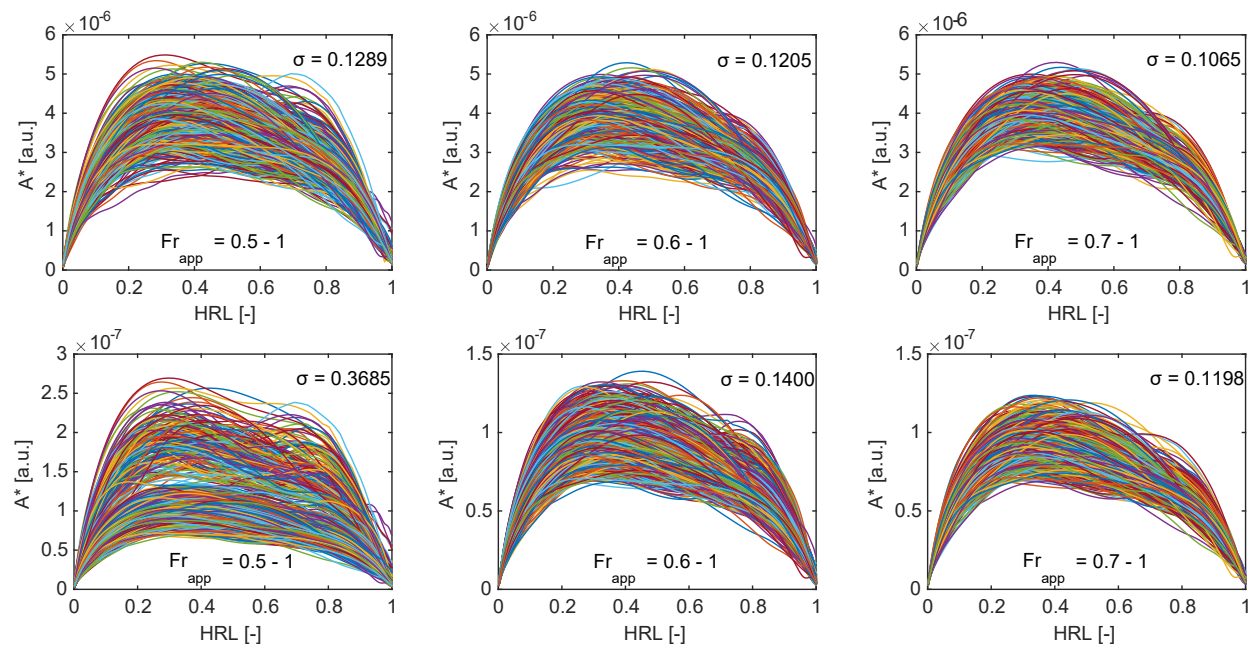

Figure 6.60. Comparison for different $F r_{a p p}$ ranges of the gasoline correlation and the correlation proposed in this work. Above - the proposed correlation. Below - the gasoline correlation.

\section{$6^{\text {th }}$ step: Definition of a standard curve}

The application of the previously explained steps has led to the $A^{*}$ value (in fact, curve), where the influence of the different conditions during the combustion process were intended to be removed. Now, if this parameter is calculated for a larger number of tests representative of the SI combustion mode, the average of all the obtained results should be indicative of a standard curve, representative of the SI combustion in this engine. This curve is 
presented in Figure 6.61. The shape of this curve indicates three trends during the combustion process: first, a fast increase of the theoretical surface of the flame front during the initial development of the combustion, before reaching the chamber walls; after that, once the flame front reaches the wall, $A^{*}$ stagnates, and starts to decrease slowly; finally, once only the last fractions of the mixture remain in the chamber, $A^{*}$ drops much faster, until the flame front reaches the end part of the unburned mixture.

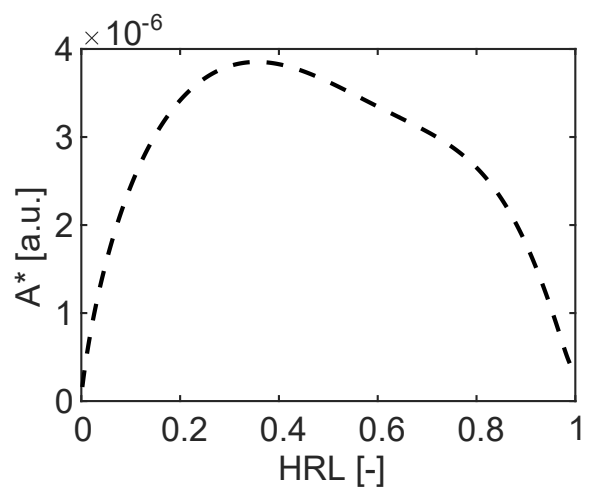

Figure 6.61. Representative $A^{*}$ value (standard curve) for the SI combustion evolution in this engine.

For the calculation of this representative "pattern" of the SI combustion, the operating points chosen have been the same as those already shown in Figure 6.59. From now on, this standard curve will be referred as "SI pattern".

$7^{\text {th }}$ step: Evaluation of the different operating points

Once the SI pattern and all the calculations are defined, any operating point of the engine can be processed and compared with the SI pattern in order to evaluate the differences between what can be considered as an ideal SI combustion and an individual engine operation case.

Now, the way to present the results is going to be explained. Two different graphs will be presented for each case (see, e.g. Figure 6.62): the first graph will allow a qualitative comparison, whereas the second will allow a more quantitative one. The first one shows the evolution of $A^{*}$ against the nondimensional HRL. Inside this graph, several plots are represented: first the SI pattern (blue dashed line) and, second, the processed operating point. Three different curves are given for the processed point: the averaged $A^{*}$ 
for the registered cycles (red continuous line), and the same curve plus and minus a standard deviation of the individual cycles (orange dashed lines). On the second graph, the quantitative difference between a given test and the SI pattern is illustrated. The black horizontal line would represent the perfect match between both cases (Difference $=0$ ). There is also a red circle, representing the average difference between the SI pattern and the test processed (calculated as indicated in Eqs. 6.18 and 6.19; in this computation, $\mathrm{n}$ cycles are considered, and $A_{i, j}^{*}$ and SIpattern $_{j}$ are the vectors representing the different curves). This Difference presents also an error bar plotted together with the red circle, which defines the standard deviation of that Difference value estimation (see Eq. 6.20; it is worth to note that this parameter is a standard deviation of the average difference of the $\mathrm{n}$ cycles, which justifies the $\mathrm{n}-1$ term dividing the usual equation for a standard deviation). However, the value obtained for the standard deviation ${ }^{6}$ is so small due to the big number of cycles taken into account that it is almost invisible compared to the ordinate axis scale of the graph.

$$
\begin{gathered}
\text { Difference }_{i}=\frac{\sum_{j=1}^{m} \frac{A_{i, j}^{*}-\text { SIpattern }_{j}}{\text { SIpattern }_{j}}}{m} \\
\text { Difference }=\frac{\sum_{i=1}^{n} \text { Difference }_{i}}{n} \\
\sigma_{\text {Difference }}=\frac{\sqrt{\frac{\sum_{i=1}^{n}\left(\text { Difference }_{i}-\text { Difference }^{2}\right.}{n}}}{\sqrt{n-1}}
\end{gathered}
$$

Now, as stated, the SI pattern will be the reference to evaluate the different tests, either taking the average cycle or some individual cycles. If the test shows a similar shape and scale, it would mean that the combustion has been developed as a standard SI combustion. On the contrary, if some differences are found, that will be indicative of some changes in the combustion development.

\footnotetext{
${ }^{6} 2 \sigma$, being representative of $68.3 \%$ of the total "population" of points of the relative difference between the two curves.
} 

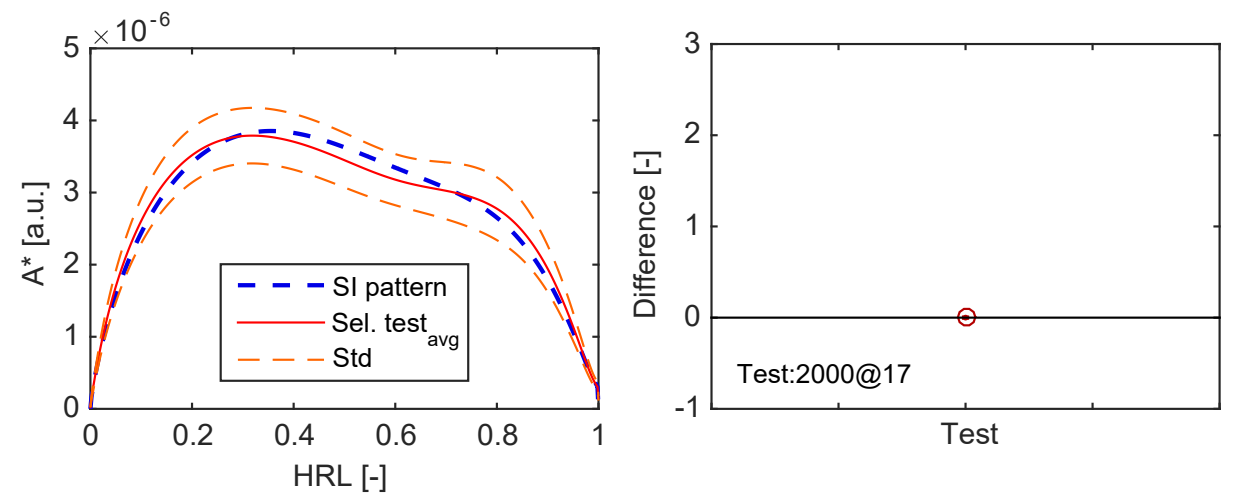

Figure 6.62. Final output data for the combustion analysis. Left - Comparison between the SI pattern and the selected test to analyze. Right - Difference parameter, representative of the similarity of the analyzed test compared to the SI pattern.

\subsubsection{Results}

The defined methodology should be capable to be used in any operating point of the engine, since the obtained SI pattern has been defined removing the effects of the load degree, the engine speed and the combustion conditions. In this subsection, the methodology will be used, first, to analyze the SI combustion on this engine for different points and conditions. After that, some CAI tests will be processed, to see the results obtained by this analysis. And, finally, the hybrid modes will be also studied with this analytical tool. This last point results very interesting, because during the combustion process, the two combustion modes have taken place, and it's very difficult to define how the process has been developed.

For the SI conditions, some tests with different engine speeds and different Fr's are chosen. The results obtained are represented in Figure 6.63, showing that they fit very well with the defined SI combustion reference. The shape of the combustion evolution is very similar, and the calculated difference between the SI pattern and the tests is almost zero. These results do give a positive feedback about the analysis methodology performance, indicating that the different SI tests can be successfully processed and compared.

It is known that this engine has a high cyclic variability. Therefore, if the data is taken cycle by cycle, most of the cycles differ slightly from the average cycle, meaning that there have been slight differences in terms of combustion speed. These differences might have different origins: by the natural variability 

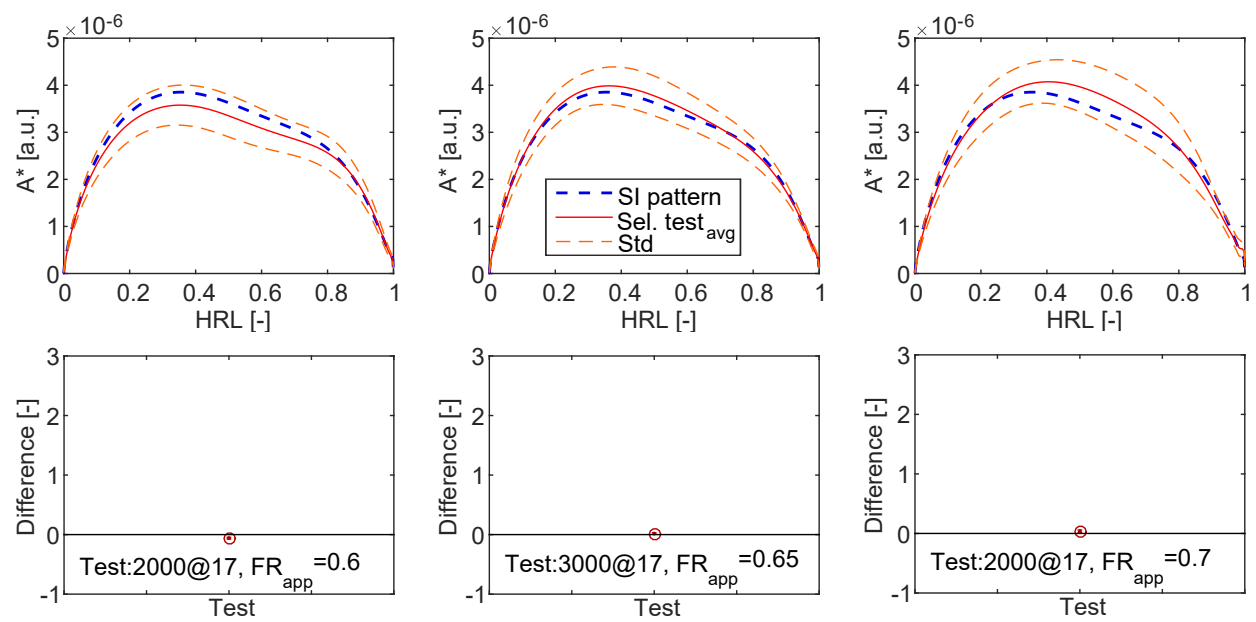

Figure 6.63. Results of different SI tests processed.

of the combustion development in SI engines caused by the ignition process and the local turbulence, by inaccuracies of the laminar combustion speeds calculated, or due to the mixture heterogeneities during the combustion. These slight differences do not present relevant information (at least for the present work) and are not going to be further analyzed. However, there are other cycles, more singular in shape and dimensions, that possess a relevant difference with the reference pattern. These singular cycles can be analyzed in order to understand the difference respect to the theoretical combustion that should have happened.

Figure 6.64 shows the $A^{*}$ values of a given test at Point 2000@17, and in a dashed black line the SI pattern. Some of the cycles of this test are going to be analyzed individually, in order to see the different situations that can be found with this combustion analysis if a SI test is processed. The chosen cycles are $\# 60$, \#150 and \#18, since the first one is equivalent to the SI pattern (see Figure 6.65 to the right), cycle \#150 presents a different shape during the last part of the HRL (see Figure 6.65 to the left), and cycle \#18 shows the same shape, but the scale is higher (see Figure 6.67).

The first two cycles (\#60 and \#150) are plotted individually in Figure 6.65. Cycle \#150 is out of the main trend of the whole cycle population of this test: it presents a big increase on $A^{*}$ from the $60 \%$ of the heat release. If the corresponding pressure trace is examined (Figure 6.66), it can be said that the 


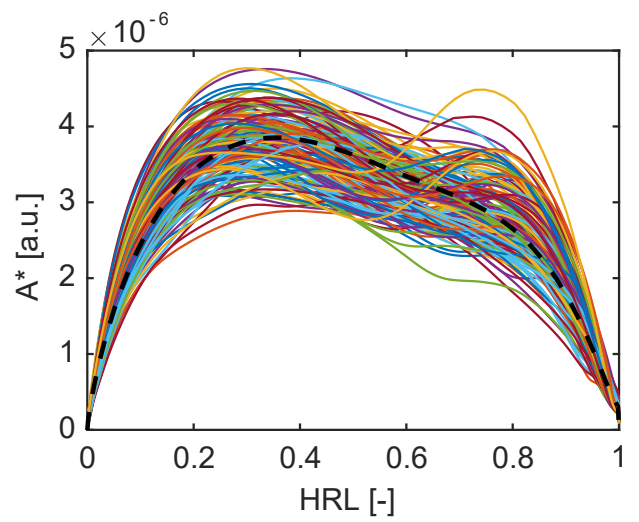

Figure 6.64. Representation of the $A^{*}$ values for all the individual cycles in a test at Point 2000@17.

origin of this big increase can be associated to the knock appearance during the last stage of the combustion. This statement is supported by the final big pressure raise and the oscillations generated after that event. Consequently, when $A^{*}$ starts to be higher than the SI pattern, is because a change on the combustion speed has taken place, meaning that the theoretical area of the flame front has been increased faster than expected. This fact can be indicative of an autoignition event during the final phase of the combustion process (leading, in this case, to knock).
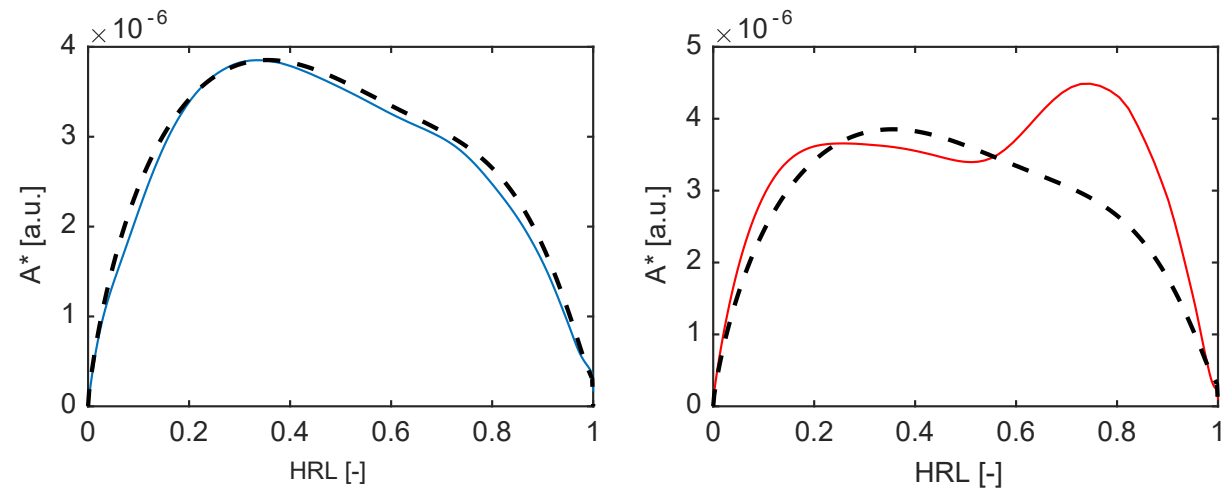

Figure 6.65. Representation of $A^{*}$ of cycles \#60 (left) and \#150 (right). 


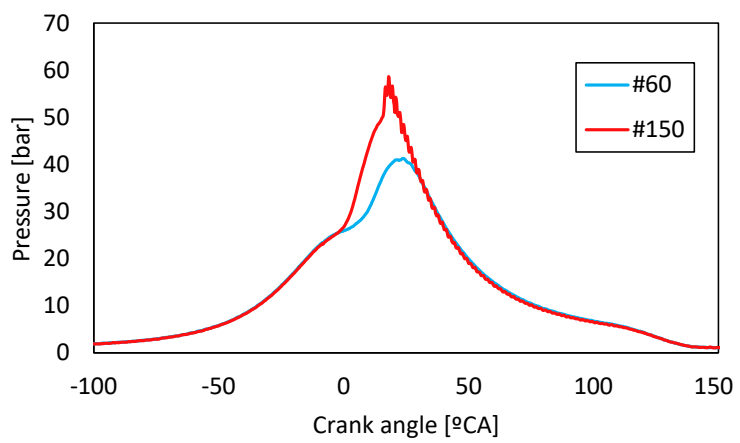

Figure 6.66. Cylinder pressure for cycles \#60 and \#150.

If these cycles are compared by means of the CTCM presented in Chapter 5 , the values obtained for the main combustion parameters, shown in Table 6.2, indicate that the combustion has been more advanced and fast in the case of cycle $\# 150$, leading to the appearance of knock, due to the high pressures and temperatures reached during the combustion process, resulting in a MAPO increment up to 2 bar.

\begin{tabular}{llll}
\hline Data & Cycle \#60 & Cycle \#150 & Cycle \#18 \\
\hline \hline CA50 [ ${ }^{\circ}$ ATDC] & 18.95 & 12.95 & 12.2 \\
CA75 [ ${ }^{\circ}$ ATDC] & 25.45 & 16.7 & 16.2 \\
CA25 [ ATDC] & 13.45 & 7.7 & 8.2 \\
comb dur [ $\left.{ }^{\circ} \mathrm{CA}\right]$ & 12 & 9 & 8 \\
MAPO [bar] & 0.096 & 1.96 & 0.7621 \\
Fr [-] & 0.73 & 0.73 & 0.72 \\
\hline
\end{tabular}

Table 6.2. Different values for cycles \#60, \#150 and \#18.

The other cycle, $\# 18$ has been chosen because the $A^{*}$ values have resulted abnormally high, even though presenting the characteristic shape of the SI pattern, standing out above the other cycles. In Figure 6.67 this cycle is presented together with the corresponding pressure trace, and in Table 6.2, some values of the combustion performance can be seen. In this case, the combustion has been developed faster than the previously shown cycles, and 
it has been more advanced compared to cycle\#60 . Some knock seems to have appeared, but the value of the MAPO is still inside the acceptable limits. Therefore, this cycle has an abnormally high speed of combustion, but it is not easy to find the reason for this behavior with the available data (maybe a slight autoignition event at the beginning of the combustion process).
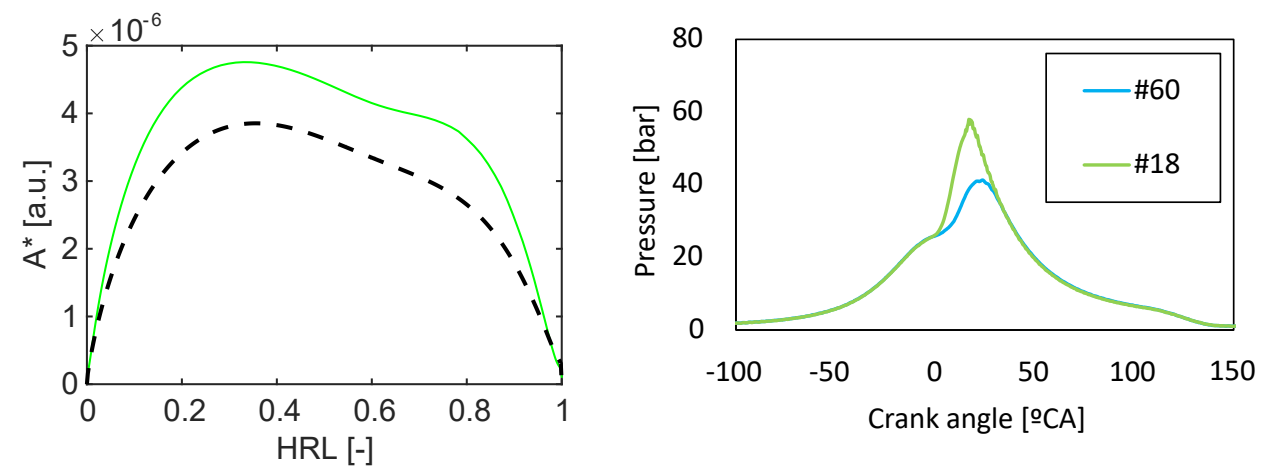

Figure 6.67. Representation of $A^{*}$ and the cylinder pressure of cycle\#18.

In order to get more information to explain these events, the cycles just before the one studied can be analyzed, to try to see if there has been any influence coming from them. Concerning cycle \#150, the previous cycles do not show any particular trend (see Figure 6.68). Using the CTCM, the compression temperatures at $15^{\circ}$ BTDC and the instantaneous Fr's and IGR ratios have been calculated (Table 6.3), to see if the cause of this knock is related to the initial conditions of the mixture, but they have remained almost constant. The only parameter that has changed (but erratically) during this sequence is the combustion phasing. This effect can be simply attributed to the variability of the combustion progression originated by the spark ignition process.

Now if cycle \#18 is analyzed, the corresponding information is shown with the same structure as in the previous analysis (Figure 6.69 and Table 6.4). The compression temperatures, Fr and IGR values have shown to remain almost constant. However, the combustion phasing has been advanced progressively till reaching the conditions of cycle \#18, where the combustion has turned to be faster than usually.

The combustion analysis of the SI combustion has shown to be valid to fix a reference of the "normal combustion development", to evaluate the different cases and to discover the abnormal cases. 

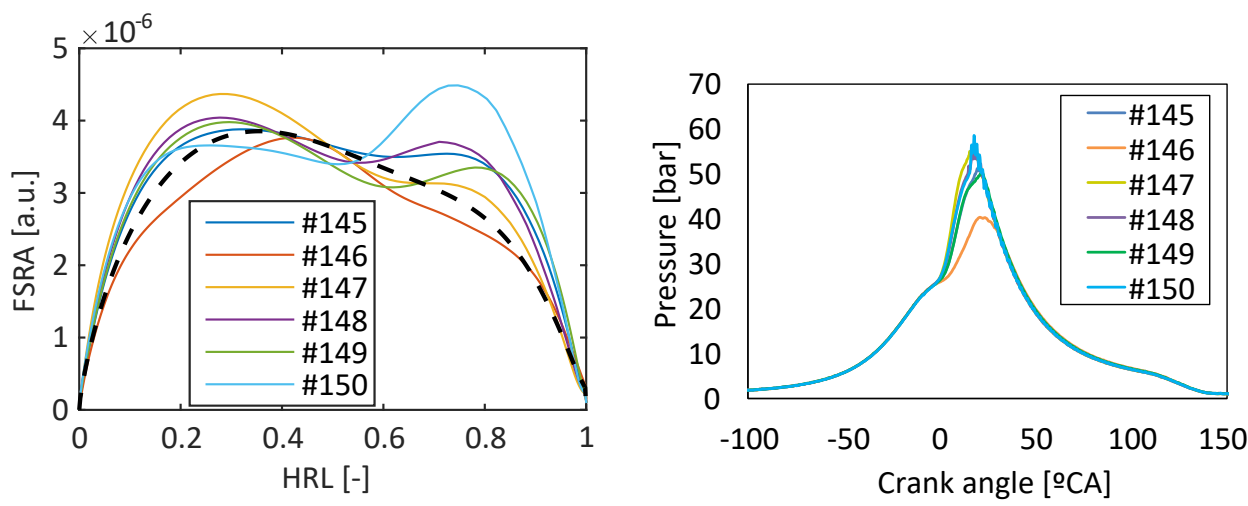

Figure 6.68. Analysis of the cycles before \#150.

\begin{tabular}{lllll}
\hline & $\begin{array}{l}\text { Compression } \\
\text { temperatures at } \\
\end{array}$ & Fr [-] & IGR [-] & $\begin{array}{l}\text { CA50 } \\
{\left[{ }^{\circ} \text { ATDC }[\mathrm{K}]\right.}\end{array}$ \\
\hline \hline Cycle \# 145 & 496 & 0.70 & 0.10 & 15.7 \\
Cycle \# 146 & 497 & 0.72 & 0.11 & 25.45 \\
Cycle \# 147 & 498 & 0.73 & 0.12 & 14.7 \\
Cycle \# 148 & 496 & 0.77 & 0.15 & 23.45 \\
Cycle \# 149 & 497 & 0.72 & 0.11 & 14.7 \\
Cycle \# 150 & 495 & 0.73 & 0.12 & 13.2 \\
\hline
\end{tabular}

Table 6.3. Estimated instantaneous combustion parameters for the cycles before \#150.

\section{CAI combustion}

The CAI combustion follows a different combustion pattern. Its evolution is defined by the chemical mechanisms, resulting in a faster combustion process, where there is not a defined single flame front consuming the unburned mixture. These differences should be appreciated if a CAI point is processed and compared to the SI pattern. The operating Point 2000@4 has been selected as representative, because it is a stable CAI point, operated in Region III of the engine map. 

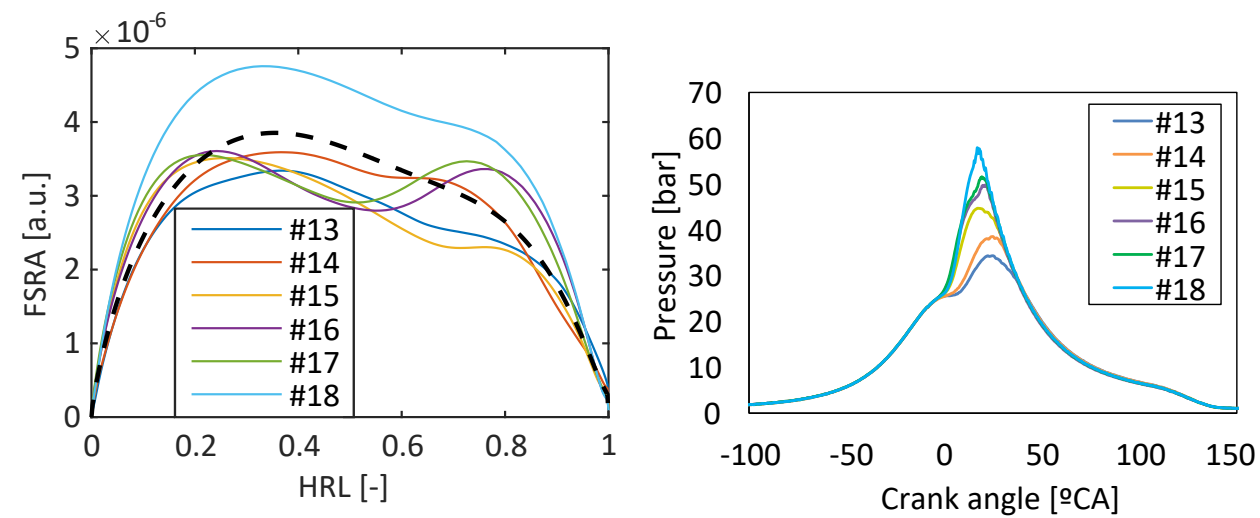

Figure 6.69. Analysis of the cycles before \#18.

\begin{tabular}{lllll}
\hline & $\begin{array}{l}\text { Compression } \\
\text { temperatures at } \\
\text {-15 }{ }^{\circ} \text { ATDC [K] }\end{array}$ & Fr [-] & IGR [-] & $\begin{array}{l}\text { CA50 } \\
{\left[{ }^{\circ} \text { ATDC] }\right.}\end{array}$ \\
\hline \hline Cycle \# 13 & 499 & 0.72 & 0.12 & 23.2 \\
Cycle \# 14 & 494 & 0.73 & 0.12 & 20.7 \\
Cycle \# 15 & 497 & 0.72 & 0.11 & 15.45 \\
Cycle \# 16 & 495 & 0.71 & 0.11 & 13.95 \\
Cycle \# 17 & 498 & 0.73 & 0.13 & 13.7 \\
Cycle \# 18 & 497 & 0.73 & 0.12 & 12.2 \\
\hline
\end{tabular}

Table 6.4. Estimated instantaneous combustion parameters for the cycles before \#18.

The result of this analysis shows, in Figure 6.70, many differences respect to the SI pattern (which represents the theoretical combustion development at these conditions assuming SI operation). The most striking difference is the huge separation of the $A^{*}$ values from the SI reference, resulting in an equivalent theoretical surface of the flame front much higher during the combustion evolution. There is also a significant difference in shape between the two curves (the SI pattern and the average cycle): the shape is now more symmetric. The difference between the two curves calculated from all the HRL 

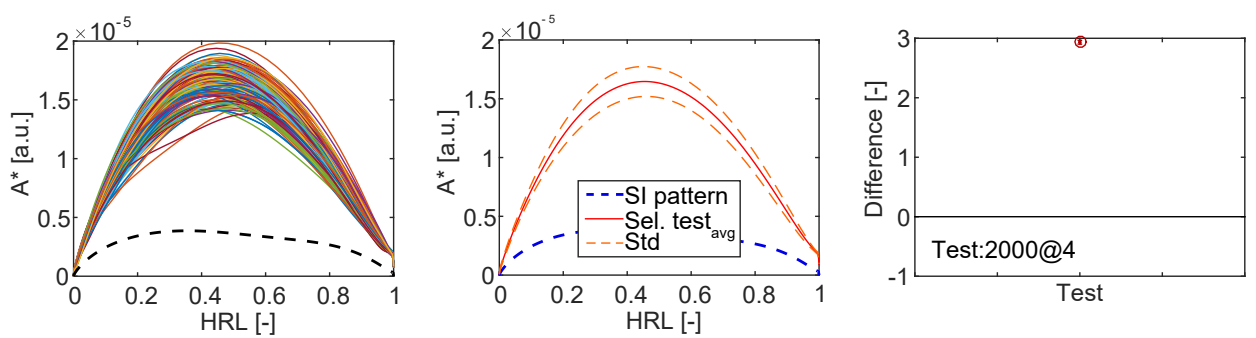

Figure 6.70. Combustion analysis of Point 2000@4 operated in CAI conditions.

shows that the theoretical flame front surface of the CAI combustion has been developed 4 times $^{7}$ higher compared to the one corresponding to SI conditions. This means that, in this case, the combustion process has been 4 times faster, in average, because of its CAI nature.
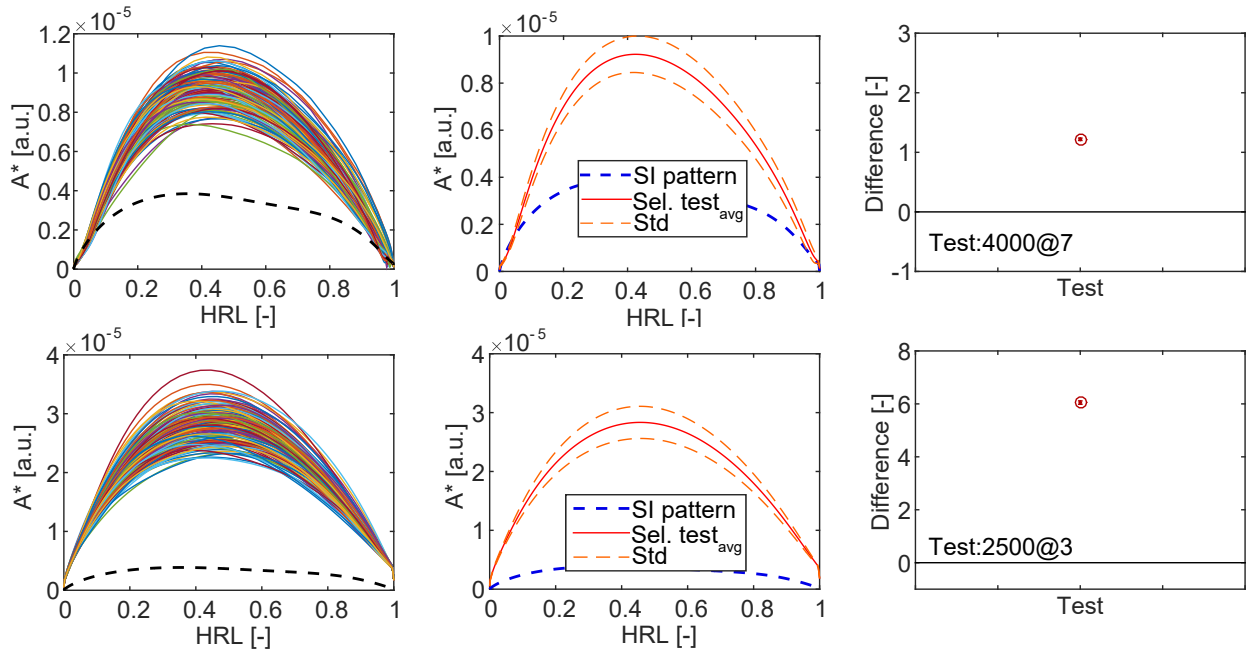

Figure 6.71. Combustion analysis of Points 4000@7 (above) and 2500@3 (below) operated in CAI conditions.

These differences are repetitive for the different CAI operated points, no matter the load degree, the engine speed or the combustion conditions. Then,

\footnotetext{
${ }^{7}$ The number 4 comes from the following reasoning: based on the figure, the relative difference is $3\left(S_{C A I}-S_{S I}\right) / S_{S I}$. To obtain $S_{C A I} / S_{S I}$, it is required to add 1 to the previous expression, thus being 4 .
} 
this methodology offers an analytical way to differentiate CAI combustion from SI combustion. As an example, two other operating points (see Figure 6.71) have been considered, to repeat the same analysis as the one already presented previously (Figure 6.70). With these new points, a higher load and a lower load respect to the previous point, have been explored. In Figure 6.72, a summary of the effect of the engine load on the CAI to SI difference is presented. It can be seen that, as the load is decreased, the difference between CAI and SI combustion is higher, since the SI combustion for low loads results worsened due to the excessive dilution (i.e. very low $\mathrm{YO}_{2}$ ), and the lower temperatures and pressures. It can be concluded that the CAI mode enhances combustion velocity, and the lower the load, the higher the enhancement.

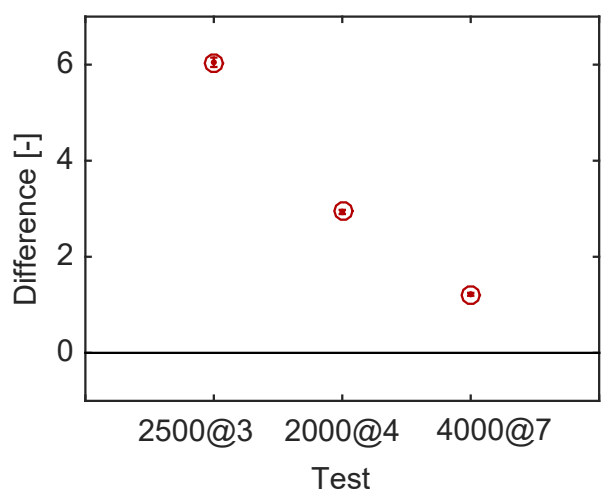

Figure 6.72. Evolution of the Difference parameter with the load increase.

\section{Hybrid modes, CAISI combustion}

The combustion defined as hybrid modes combines an initial part of the combustion developed by a SI flame front with a CAI combustion that consumes the rest of the unburned mixture at the end of the combustion process. In the previous lines the results obtained of SI and CAI combustions have been analyzed, showing the different trends and values obtained for these different combustion modes. Now, it would be very interesting to see the results obtained if this hybrid combustion is analyzed, in order to see how the evolution of the combustion is performed during the cycle, and to check if both events can be differentiated. To illustrate this combustion mode and try to evaluate the combustion performance, a set of tests at Point 2000@5 have been chosen and presented in Figure 6.73. This set of tests is a Fr variation, starting with lean mixtures and increasing the Fr progressively. By this means, the combustion starts being operated as SI to finish the tests with a CAI operated point. 

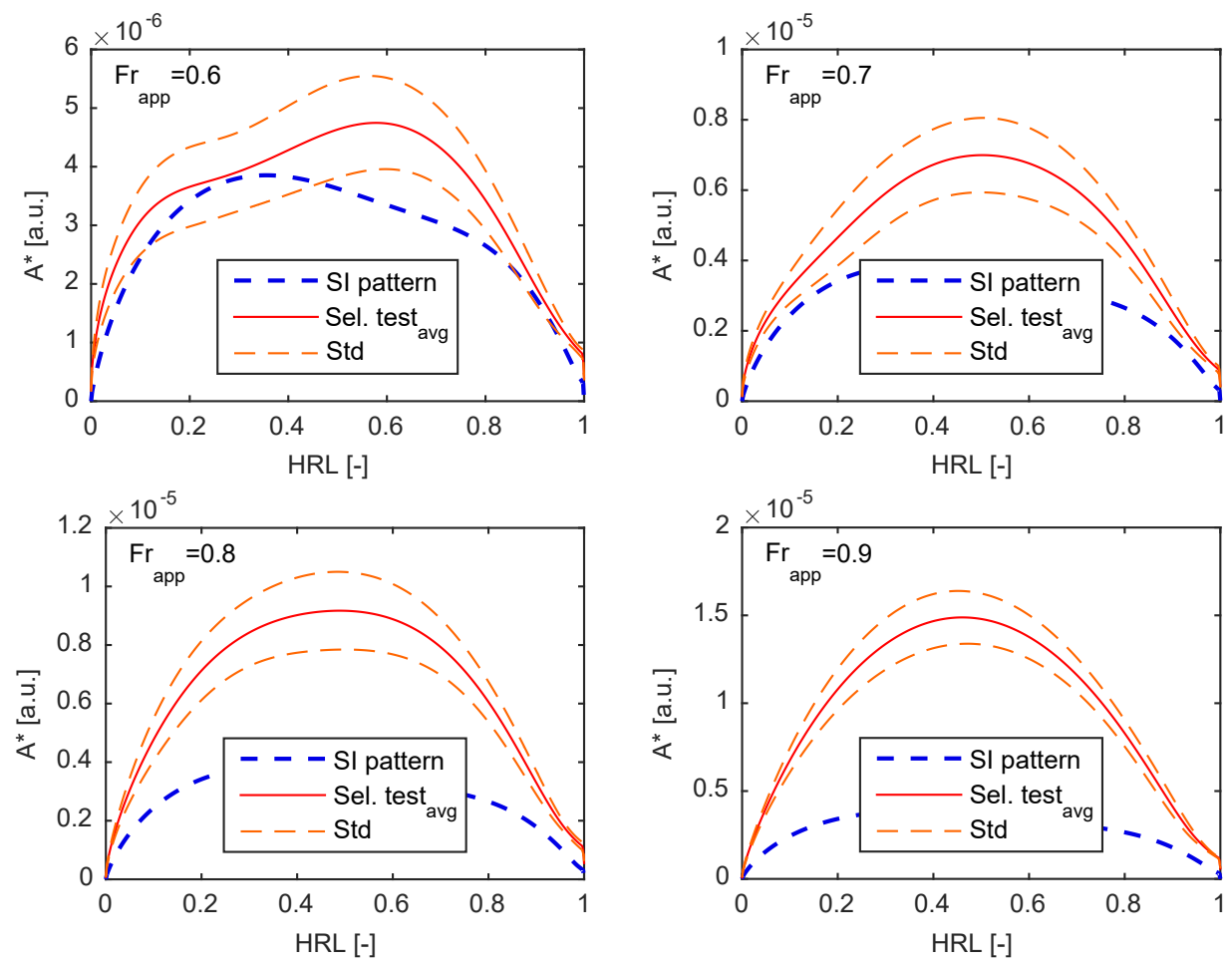

Figure 6.73. Results of the combustion analysis for a Frapp swept at Point 2000@5.

The leaner Fr was expected to be a SI combustion test. This one shows a start of combustion very similar to the SI pattern, but from the $30 \%$ of the combustion approximately, the $A^{*}$ values start to increase faster than the SI pattern, meaning that from that moment part of the mixture has been autoignited. Consequently, this point can be considered to burn under a hybrid combustion mode. However, the transition to CAI conditions takes place relatively late, and a significant part of the mixture is burnt in SI conditions. As the $\mathrm{Fr}$ is increased, if attention is paid to the $\mathrm{Fr}=0.7$ case, it also shows a combustion start very similar to the SI pattern, but from a very early HRL value ( $10 \%$ approx.), the $A^{*}$ value starts to increase very fast, acquiring the CAI combustion characteristics. This is probably the most interesting point of the hybrid combustions, since the start of the combustion has been governed by the SI process and very early it has changed to a CAI combustion.

The other two tests with higher Fr values are CAI combustion, losing the influence of the spark and therefore the control on the combustion onset. In 
Figure 6.74, the value of the calculated Difference is plotted for all these tests. It can be seen how the combustion development is changing steadily and getting more CAI.

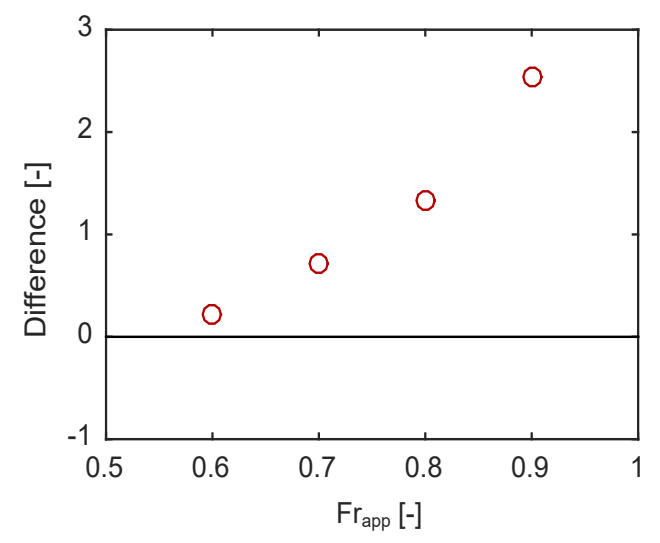

Figure 6.74. Difference between the SI pattern and the different processed tests of the $\mathrm{Fr}_{\text {app }}$ swept at Point 2000@5.

The results obtained with this methodology have shown to be very useful to characterize the hybrid combustions. As expected, the SI part of the combustion follows the SI pattern, and when the combustion is changed to $\mathrm{CAI}$, the $A^{*}$ value indicates this change moving beyond the SI pattern. This makes possible the differentiation of the two combustion events and the characterization of the combustion transition during the cycle.

\subsection{Conclusions}

Along this chapter the SI and CAI combustion modes have been studied from an experimental point of view using a two-stroke single cylinder engine. Now the main findings along the chapter are going to be summarized.

\section{Conclusions of the SI mode}

The lean operation gives some advantages with respect to the stoichiometric conditions: better combustion phasing, improved combustion efficiency, less heat loses and better pollutant emissions values. Nevertheless, if the Fr is decreased excessively, all these benefits will be lost, since the $\sigma$ IMEP and the combustion efficiency will be lost. 
The IGR is always present during the engine operation to a greater or a lesser extent. This component is not beneficial for the SI operation, since it increases the compression temperatures and therefore the knock intensity, forcing to delay the combustion phasing, and it generates a dilution degree in the combustion chamber that affects the combustion rates and the correct combustion development.

The trapping ratio (characteristic parameter of $2 \mathrm{~S}$ engines) limits the maximum load of the engine, since the intake mass flow cannot be retained properly inside the engine. This effect makes that the maximum load degrees have to be operated with too high in-cylinder richness values. In that case, the knock is raised, and the only solution is to delay the combustion, making impossible to translate the extra amount of fuel in extra power. The increase of the exhaust pressure has been tested, but it is not a valid strategy to solve this problem. The density of the charge is increased and the trapped mass is higher, but the IGR ratio is also increased, since the charge composition is not modified by this strategy. Therefore, the same IGR ratios and an increased pressure at the start of the compression leads to a higher knock intensity.

Finally, with the load reduction, the scavenging process is worsened, and the IGR ratio is increased. As a consequence, the charge dilution is increased progressively, worsening the $\sigma \mathrm{IMEP}$ and the combustion efficiencies. This effect makes that the engine won't be very efficient at partial loads.

\section{Conclusions of the CAI mode}

The CAI combustion mode can be operated at partial loads. Compared to the SI mode, this combustion has shown to be more repetitive, stable (better $\sigma$ IMEP), with high combustion speeds, and a better combustion efficiency. Thanks to all those changes the fuel efficiency is improved at partial loads. The emissions are also improved, $\mathrm{NO}_{\mathrm{x}}$ and soot thanks to the lower temperatures and Fr's, and $\mathrm{HC}$ and $\mathrm{CO}$ thanks to an improved combustion efficiency.

This combustion mode is achieved through the increase of the mixture reactivity until the charge is autoignited. The key parameters to adjust this reactivity are:

- The IGR ratio: with the control of the hot residual gases retained inside the cylinder, the temperature of the charge can be adjusted. This IGR ratio depends on the scavenging process. The load degree has a high influence on the IGR ratios, and the configuration of the Fr and the VVT position can be used to vary the amount of hot residuals retained during the engine operation. 
- Fuel injection: in this case two parameters can be adjusted: the SOI and the DOI (of the fuel+air injection). The SOI has to be advanced sufficiently to homogenize the fuel properly, and once defined the positions for which the homogenization is acceptable, it can be finely adjusted to control the time during which the fuel is inside the cylinder, since this time, combined with the autoignition delay, can be used to adjust the combustion onset. Regarding the DOI adjustment, the variation of this parameter modifies the amount of air mixed with the fuel. This air has a cooling effect on the charge and increases the fuel dispersion. So there is an optimum configuration for this parameter, defined by Eq. 5.18, where the amount of air introduced with the fuel gives the best combustion efficiency values.

- The EGR: this additional tool can be used to reduce the knock intensity, since the dilution of the charge with cooled residual gases decrease the combustion rates. By this means, the maximum achievable load in CAI conditions is increased. Nevertheless, the use of EGR deteriorates the combustion efficiency and the $\sigma \mathrm{IMEP}$, since the higher dilution of the cylinder charge hinders the combustion process.

Once studied the CAI combustion in this engine the operating region in CAI conditions has been defined. This region starts at very low loads ( 1 bar IMEP) until the $35 \%$ of the max load without the use of EGR and up to $50 \%$ of the maximum load with the EGR addition. These results show that it is possible to improve the part-load region of the engine, and operate it in CAI conditions in a big part of the engine map, and not only in a narrow operating region. This fact increases the interest of this combustion mode to be implemented in commercial engines.

\section{Conclusions of the hybrid mode CAISI}

This mode combines the CAI combustion with the initial development of the combustion as a spark assisted. In this way, the CAI efficiencies and benefits can be achieved, and the combustion initiation can be better adjusted. Apart from this main difference, in these conditions, the engine can be operated in CAI combustion with leaner Fr's and less IGR, achieving higher efficiencies and lower combustion rates, since the mixture reactivity is smaller, and the air excess is slightly higher.

These points have shown to be useful to operate when the CAI combustion results over advanced, due to the reactivity excess. In this way, the combustion can be better positioned. 


\section{Conclusions of the combustion analysis}

Through this last part of the chapter, a methodology to analyze the HRR has been defined to get more detailed information of the combustion development when the engine is operated. This work has offered the results summarized in the following lines.

An adapted new correlation for the laminar combustion speed for the engine has been defined. This correlation has allowed to better characterize the effect of the apparent $\mathrm{F} / \mathrm{A}$ equivalence ratios and the $\mathrm{YO}_{2}$ on the combustion velocity. The results have shown to be a more suitable $S_{L}$ correlation compared to some other correlations taken from the literature. But it has to be noted that this correlation is specifically adapted for this particular engine. To use it in other engines, most probably the exponents have to be adapted accordingly.

The methodology has shown to be valid to define a standard SI combustion for different conditions, and compare it with the experimental data to get info about the combustion performance, to identify irregularities during the combustion, and to detect anomalous cycles. Taking this SI reference, the CAI combustion can be processed, and therefore the differentiation between both modes can be made. The results have shown that the CAI cycles present higher $A^{*}$ values during all the combustion development, as well as a different shape compared to the SI pattern, allowing to differentiate them. This tool has also shown to be very useful in the case of CAISI tests, since the combustion process can be characterized, indicating the moment and the burned mass fraction when the combustion changes from SI to CAI.

Finally, the limitations of this methodology are identified:

- The inaccuracies at low loads to estimate the exact Fr's and mass flows for each individual cycle lead to deviations in the results difficult to solve just with corrections.

- The effect of the piston position affecting the geometry of the combustion chamber, and therefore the evolution of the flame front, is not considered. This additional improvement could help to homogenize the different tests in a best way, and get a higher quality information.

- Another limiting factor is the competition of this method with the CFD. This other tool is much more complex, precise and offer a high amount of information. But it needs much more processing capacity and time. So, each tool should be used for different purposes: the tool proposed here is recommended when a lot of data needs to be analyzed, and not much 
time is available; whereas CFD is probably more suitable when few data needs to be analyzed, and a lot of time is available for the analysis.

\section{A Effect of the power stroke increase on the BSFC due to the VVT delay}

Along the lines around the reference to this appendix, it was stated that the improvement on the BSFC when the VVT (and therefore EVO) was delayed, was mainly due to the modification of the IGR ratio of the in-cylinder charge. But, nevertheless, when the EVO is delayed, the effective power stroke is also increased, thus improving theoretically the BSFC. So, the question that arises is: which of both effects is more important?

To clarify this question, a simulation by a $0 \mathrm{D}$ thermodynamic predictive model has been performed in order to isolate the increase of the expansion stroke effect on the BSFC. This model is called SICICLO, and its detailed description can be found in [13]. To configure this 0D model, the dimensional characteristics of the engine have been introduced. Afterwards, a simulation trying to reproduce an experimental result at the operating conditions close to the ones that are intended to be analyzed has been carried out. This simulation has been used to verify the accuracy of the model. Finally, two simulations have been performed in the same operating conditions as before, imposing the same HRL in both of them, and introducing a variation in the EVO position as the only difference between these two cases. By this way, the effect of the increase in effective power stroke can be analyzed isolatedly.

The results are shown in Table 6.5. Based on these simulations, the increase in indicated efficiency associated to the increase of the power stroke has been $2.1 \%$.

\begin{tabular}{llll}
\hline $\begin{array}{l}\text { VVT position } \\
{\left[{ }^{\circ} \mathrm{CA}\right]}\end{array}$ & IMEP [bar] & $\begin{array}{l}\text { Indicated effi- } \\
\text { ciency [\%] }\end{array}$ & ISFC [g/kWh] \\
\hline 161 & 12.36 & 37.65 & 250 \\
\hline 166 & 12.62 & 38.45 & 244.79 \\
\hline
\end{tabular}

Table 6.5. Results obtained from the SICICLO simulation.

Now that the effect of the increase in effective power stroke has been quantified, it will be compared with the observed experimental result, where 
both effects (IGR and power stroke) take place together. These experimental results are shown in Figure 6.75.
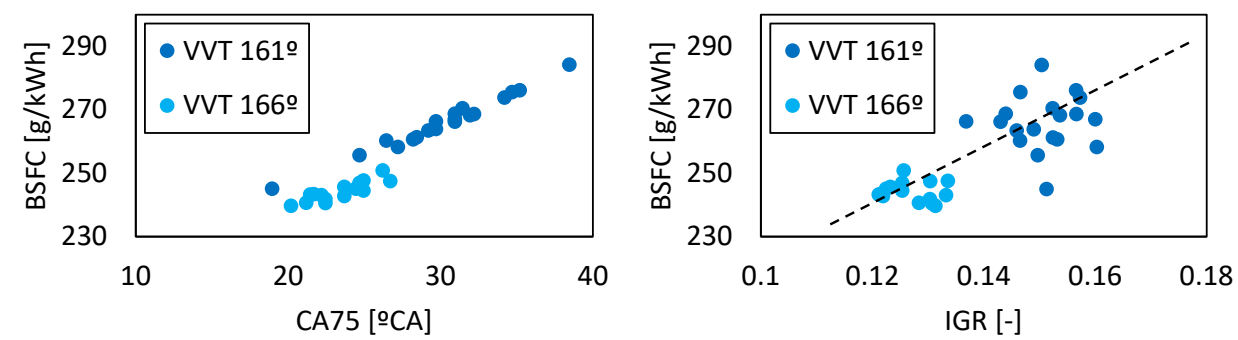

Figure 6.75. Left - Evolution of BSFC with CA75. Right - Correlation for the same tests between BSFC and IGR ratio.

Since for each VVT position there is a cloud of values presented in the figure, the averaged value of all those values is going to be calculated. The experimental improvement will be assumed to be the one defined with the averaged values. The results obtained are shown in Table 6.6, where the ISFC improvement has shown to be $9.6 \%$. It has to be noted that the ISFC values have been taken to perform the comparison, because the brake values are not available in SICICLO.

\begin{tabular}{lll}
\hline $\begin{array}{l}\text { VVT position } \\
{\left[{ }^{\circ} \mathrm{CA}\right]}\end{array}$ & BSFC $[\mathrm{g} / \mathrm{kWh}]$ & ISFC $[\mathrm{g} / \mathrm{kWh}]$ \\
\hline 161 & 282.29 & 261.54 \\
\hline 166 & 256.57 & 236.42 \\
\hline
\end{tabular}

Table 6.6. Experimental results obtained.

Finally, taking into account all these results, it can be concluded that the improvement in BSFC is governed mainly by the IGR ratio modification coming from the VVT variation rather than by the variation of the effective power stroke. 


\section{B HRL refinement}

Along this appendix, the calculation details to suppress the anomalous slopes at the beginning and the end of the HRL are given. To explain the followed methodology, a specific cycle measured at Point 2000@5, shown in Figure 6.76, will be used.

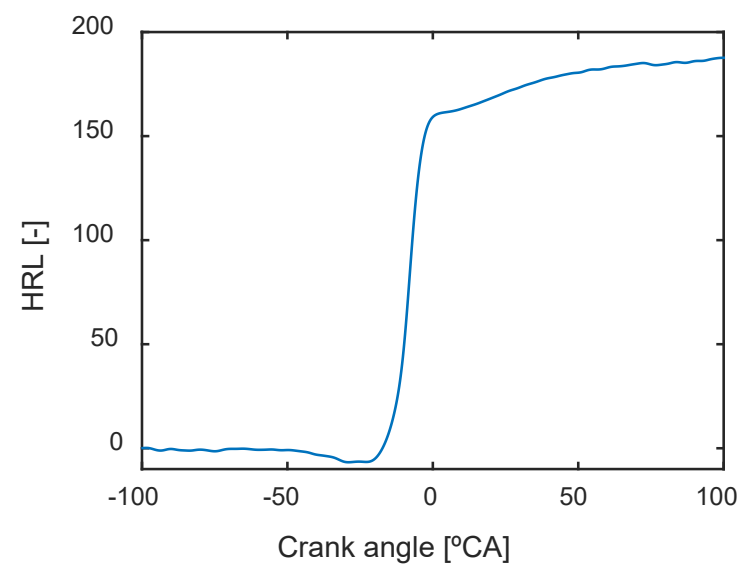

Figure 6.76. Initial calculated HRL.

\section{Lower part}

The first part of this methodology works with the lower part of the HRL, and the objective is to remove the initial slope observed before the combustion start. The followed steps are:

- Estimation of the HRL initial part without combustion.

To this end, an equation of a line that passes through two points is calculated for the 25 and the $75 \%$ of the HRL (black line in Fig. 6.77), and the crank position where this line crosses the HRL $=0$ is found. From this position, the HRL initial part without combustion is defined from the crank angle $=-100^{\circ}$ to the determined crossing point minus $10{ }^{\circ} \mathrm{CA}$.

- Calculation of the slope of this initial part.

The next step is to calculate the slope of that initial part without combustion, in such a way to define a line with that inclination (see Fig. 6.77, red dashed line) that later will be removed from the HRL (Fig. 6.78). 


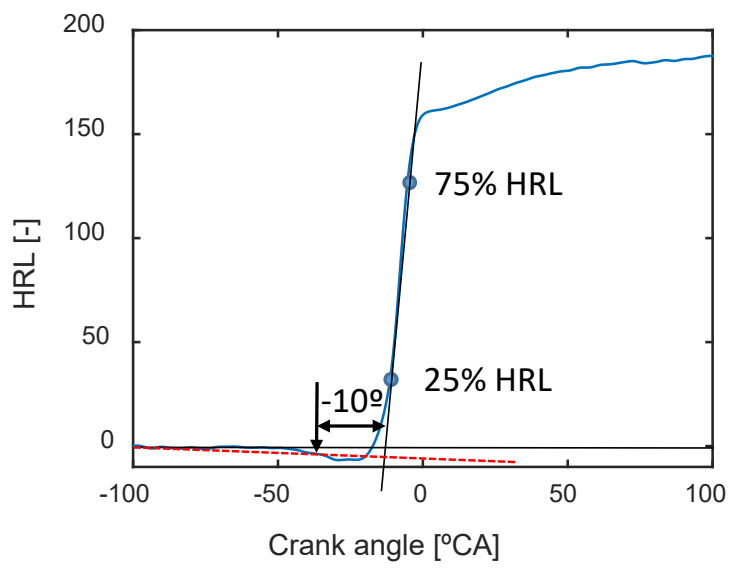

Figure 6.77. Operations on the initial calculated HRL.

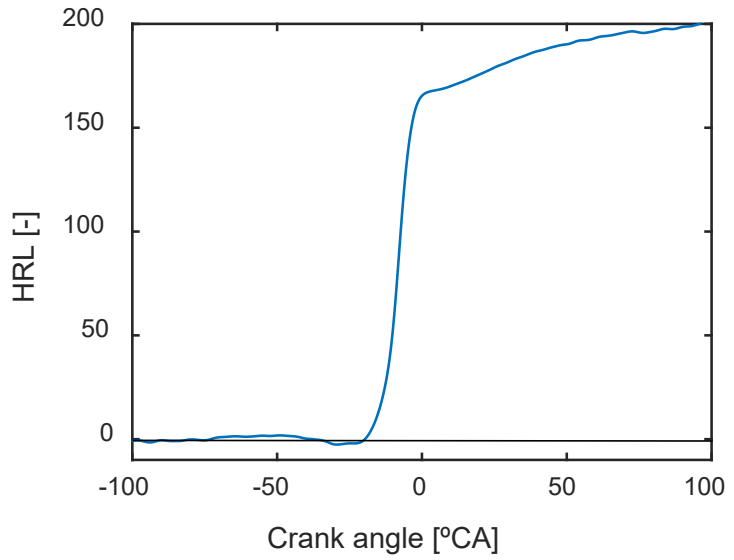

Figure 6.78. HRL with the initial inclination removed.

- The following step is to add an extra negative inclination to the HRL, in order to define the SOC by the search of the minimum HRL value (Fig. 6.79). The definition of the necessary inclination has been manually optimized and fixed for all load degrees, since it was checked that the error on the SOC estimation was lower compared to a variable inclination as a function of the load degree. The procedure to search this optimal inclination to remove, was based on two aspects: first, the minimization of the different estimated SOCs (individual cycles) dispersion for a 
measured test; and second, the minimization of the deviation between the SOC estimated through the averaged cycle diagnostics and the SOC obtained from the average of all the individual SOCs. With both references, the best compromise for different operating points and load degrees was taken as the best choice to define the inclination to remove.

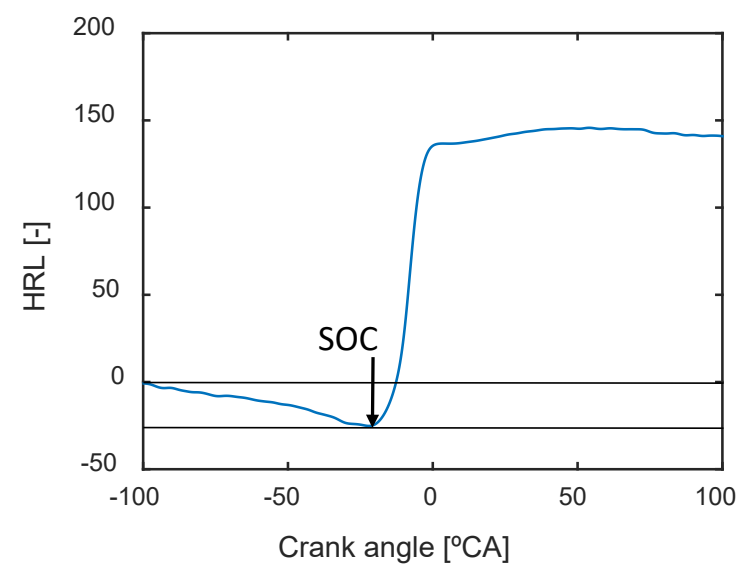

Figure 6.79. Inclination of the HRL to find the SOC angle.

- The operations presented up to now have been useful only to determine the SOC position. Now, the corrected HRL will be based on the initial one, where the HRL value for the SOC will be set to 0 (the curve will be shifted in the vertical axis accordingly), and all the initial part, from $-100^{\circ}$ to the SOC position will be removed (set to 0) (Fig. 6.80).

\section{Upper part}

The correction of the upper part follows a very similar procedure as the lower part. The final slope of the HRL is suppressed, to leave this last part horizontal, and finally an extra slope is subtracted to locate the EOC. In this case, the determination of an optimum for this inclination becomes more difficult, since there are more deformations at the end of the HRL than at the beginning. Therefore the search of the optimum cut-off point is a significantly difficult task. To assist during this determination, the appropriate slope is defined with the help of the HRR/HRL chart. By means of this graphical information the choice of the appropriate slope to find the end of the combustion can be assessed. The main idea is that the start and the end of the HRR should cross the HRL axis on the values 0 and 1 . The definition of 


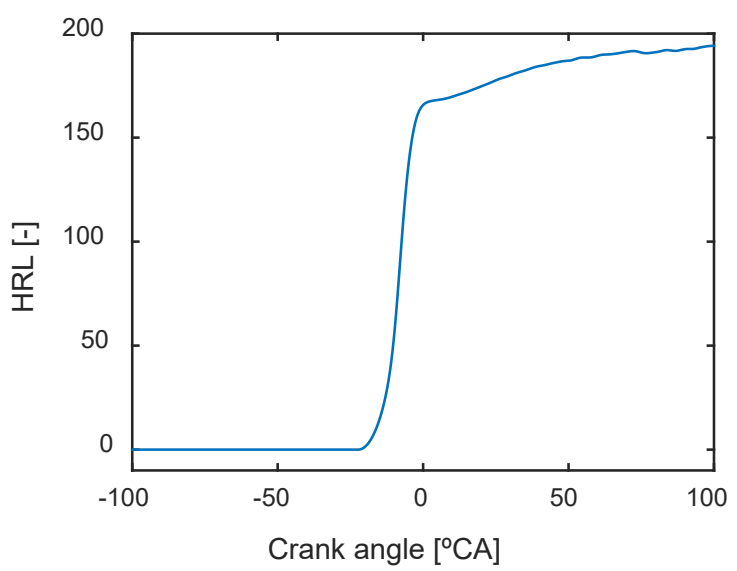

Figure 6.80. Final HRL with the lower part corrected.

this slope is also manually performed for each processed test, and the slope is applied to all the individual cycles.

To illustrate how the use of this chart can be really useful for this purpose, in Figures 6.81, 6.82, and 6.83, the three possible situations are represented: in the first case, a delayed estimation of the EOC is shown, and the HRR curve reaches the HRL axis to early (at 0.9 instead of 1); in the second case, a properly estimated EOC is shown; and, finally, a case where the EOC is over estimated is shown, where at $\mathrm{HRL}=1$, the HRR is still far from being 0 . This procedure shows to be very sensitive to validate the correct choice of slope. In fact, it is used as a way to check this choice during the pre-processing of the HRL's.

\section{Bibliography}

[1] Collins N.R. and Twigg M.V. "Three-way catalyst emissions control technologies for spark-ignition engines - Recent trends and future developments". Topics in Catalysis, Vol. 42-43 n 1-4, pp. 323-332, 2007.

[2] Caton J.A. "Combustion phasing for maximum efficiency for conventional and high efficiency engines". Energy Conversion and Management, Vol. 77, pp. 564-576, 2014.

[3] Zhang Y. and Zhao H. "Investigation of combustion, performance and emission characteristics of 2-stroke and 4-stroke spark ignition and CAI/HCCI operations in a DI gasoline". Applied Energy, Vol. 130, pp. 244-255, 2014.

[4] Desantes J. M., Bermúdez V., López J. J. and López-Pintor D. "Correlations for the ignition characteristics of six different fuels and their application to predict 

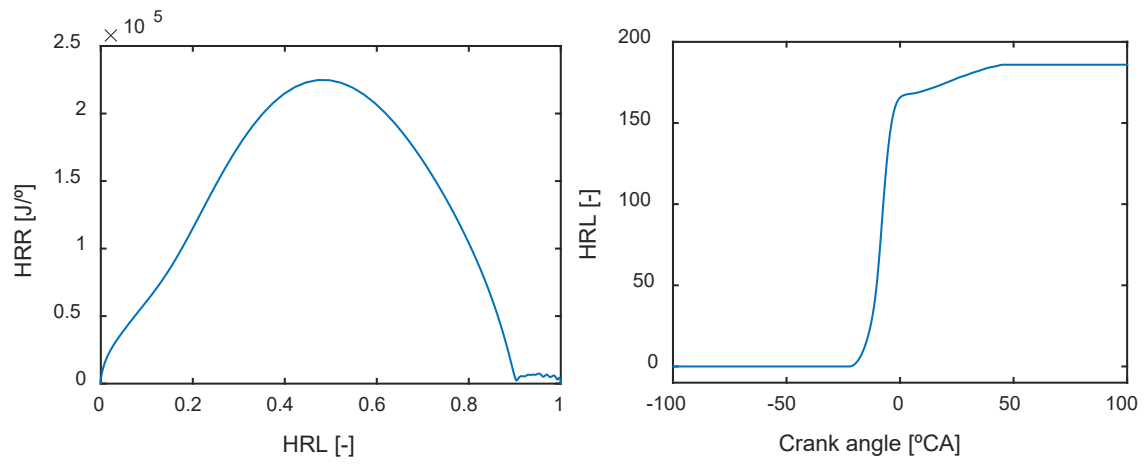

Figure 6.81. Delayed estimation of the EOC.
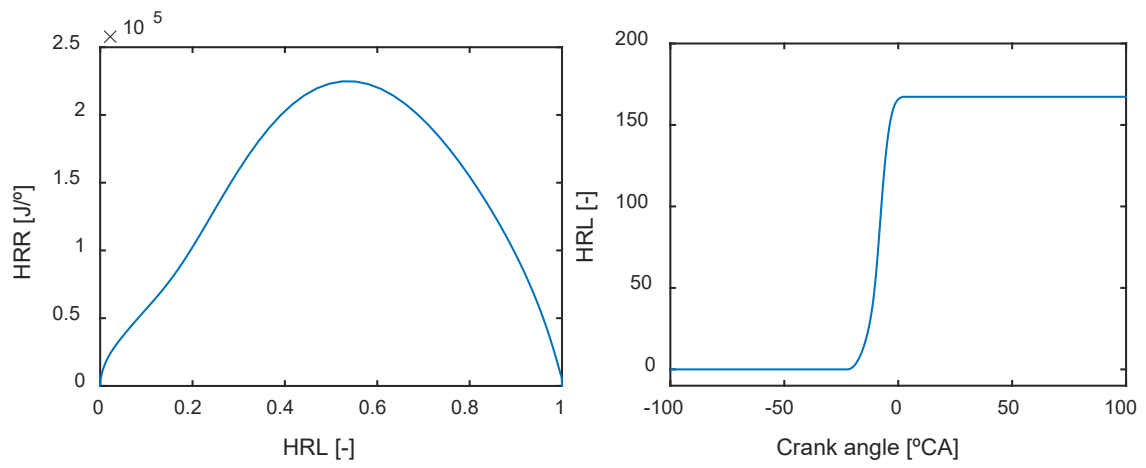

Figure 6.82. Properly estimation of the EOC.
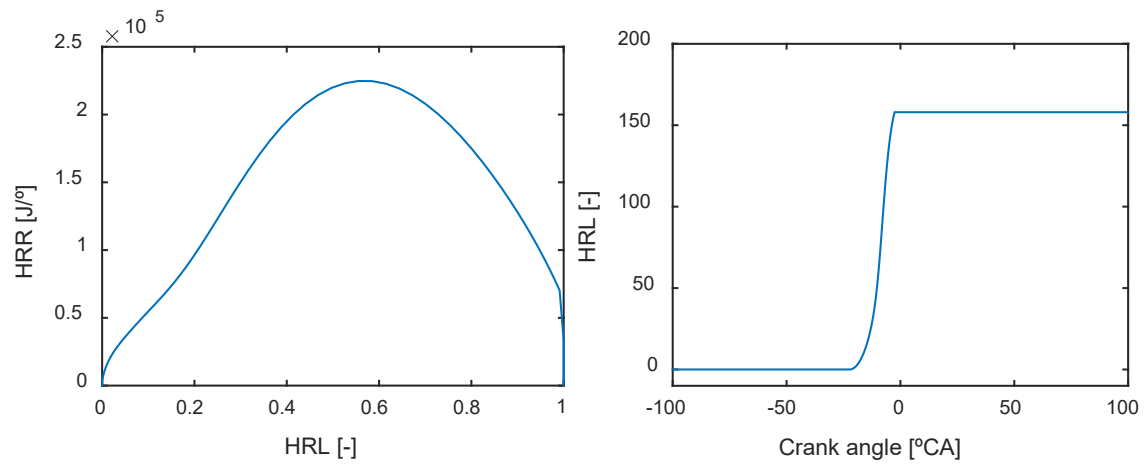

Figure 6.83. Advanced estimation of the EOC. 
ignition delays under transient thermodynamic conditions". Energy Conversion and Management, Vol. 152, pp. 124-135, 2017.

[5] Grandin B., Angström H., Stalhammar P. and Olofsson E. "Knock suppression in a turbocharged SI engine by using cooled EGR". SAE Technical Paper n. 982476, 1998.

[6] Wang Z., Wang J.-X., Shuai S.-J., Tian G.-H., An X. and Ma Q.-J. "Study of the effect of spark ignition on gasoline HCCI combustion". Proceedings of the Institution of Mechanical Engineers, Part D: Journal of Automobile Engineering, Vol. $220 \mathrm{n}^{\circ} 6$, pp. 817-825, 2006.

[7] Manofsky L., Vavra J., Assanis D. and Babajimopoulos A. "Bridging the gap between HCCI and SI: Spark-assisted compression ignition". SAE 2011 World Congress and Exhibition, 2011.

[8] Wijesinghe J.S. and Hong G. "Effect of spark assistance on autoignition combustion in a small two-stroke engine". Proceedings of the Institution of Mechanical Engineers, Part D: Journal of Automobile Engineering, Vol. $225 \mathrm{n}^{\circ}$ 1, pp. 115-126, 2011.

[9] Metghalchi M. and Keck J.C. "Burning velocities of mixtures of air with methanol, isooctane, and indolene at high pressure and temperature". Combustion and Flame, Vol. $48 \mathrm{n}^{\circ}$ C, pp. 191-210, 1982.

[10] Rhodes D.B. and Keck J.C. "Laminar burning speed measurements of indolene-airdiluent mixtures at high pressures and temperatures". SAE Technical Paper $n$. 850047 , 1985.

[11] Heywood JB. Internal combustion engine fundamentals. McGraw-Hill, 1988.

[12] Bopp S., Vafidis C. and Whitelaw J.H. "The effect of engine speed on the tdc flowfield in a motored reciprocating engine". SAE Technical Paper n. 860023, 1986.

[13] Payri F., Olmeda P., Martín J. and García A. "A complete 0D thermodynamic predictive model for direct injection diesel engines". Applied Energy, Vol. 88 n $^{\circ} 12$, pp. 4632-4641, 2011. 



\section{Chapter 7}

\section{Conclusions and future works}

\section{Contents}

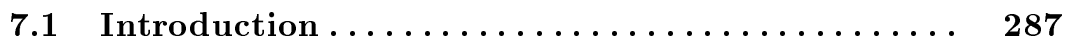

7.2 Achievements obtained in the $\mathrm{PhD}$ thesis ...... 287

7.3 The engine potential, a brief analysis ........ 292

7.4 Future works ..................... 295

7.A Estimation of the theoretical results of the performance of the twin cylinder engine in standard cycles $\ldots \ldots \ldots \ldots \ldots \ldots \ldots \ldots \ldots \ldots \ldots, 298$ 



\subsection{Introduction}

This final chapter will be the closing of this $\mathrm{PhD}$ thesis. Along this, the most remarkable obtained conclusions are presented. Additionally, a brief study of the engine potential when operating in standard cycles is included. Finally, some future works and ideas to continue this work are proposed.

\subsection{Achievements obtained in the $\mathrm{PhD}$ thesis}

Looking back to the beginning of this work, the main objective guiding the development of this $\mathrm{PhD}$ thesis has been to study the lean SI and CAI combustion processes in an engine that presents a combination of the different advances achieved in SI engines up to now.

To accomplish this main objective, it was divided in several specific objectives. These were: first, to explore the potential of $2 \mathrm{~S}$ architectures equipped with the latest technologies. Second, to implement and analyze the results obtained from CAI and lean SI combustion modes operation; additionally, an EGR system was installed to reduce $\mathrm{NO}_{\mathrm{x}}$ emissions and to study its potential on the combustion control. Third, the combustion diagnostics and the methodologies to analyze the results obtained have been reviewed. On the one hand, the combustion diagnostics was approached cycle by cycle, and, on the other hand, the combustion analysis based on the HRL estimation was studied in order to get deeper results focused on lean SI and CAI combustion. Finally, thanks to this work and the consecution of the different objectives, a complete engine solution combining lean burn and CAI combustion will be analyzed.

\section{The engine}

The engine selected can be operated in both combustion modes, SI and CAI, depending on the chosen engine configuration and the load degree. For low and mid loads, the engine is operated as a CAI engine (except for the very low loads, as the idle point), and at high loads the engine operates as a SI under lean combustion conditions.

By the fact of being a $2 \mathrm{~S}$ engine, it has a more complex scavenging process compared to a $4 \mathrm{~S}$ engine, and this is a key point for the engine management and the operation of the different combustion modes. The charge that will be enclosed inside the cylinder will be a mixture between the portion of fresh trapped air (or a mixture of air and EGR, if EGR is introduced) and the hot residual gases (IGR) that have remained from the previous cycle. This IGR is 
found "naturally" to a greater or lesser extent depending on the load degree, the $\mathrm{F} / \mathrm{A}$ ratio and the VVT position, which are the main instruments to adjust and optimize the scavenging process.

Furthermore, the fuel injection system selected for this engine is not the most usual one nowadays. It is an air-assisted direct injection system. By this way, a mixture of fuel and air is introduced into the engine, offering a better spray homogenization with lower fuel injection pressures. The most remarkable finding around this fuel injection system during the present research is that there is an optimum value for the so-called IAR (Injected Air Ratio), which represents the ratio between the injected amount of air and the total amount of fresh air trapped in the cylinder. This parameter has shown to present a single optimum value for the different operating points of the engine.

\section{The combustion modes, SI lean conditions and CAI operation}

First, the lean SI combustion mode will be summarized. This one offers some benefits with respect to the one under stoichiometric conditions: better combustion phasing, improved combustion efficiency, less heat loses and better pollutant emissions values. Nevertheless, if the Fr is decreased excessively, all these benefits will be lost, since both the $\sigma \mathrm{IMEP}$ and the combustion efficiency will be deteriorated.

During the study of this combustion mode in this engine, some findings can be remarked.

- The presence of IGR has shown to be detrimental for this combustion mode, since it increases the compression temperatures and, therefore, the knock intensity, thus forcing to delay the combustion phasing. Additionally, it generates a dilution degree in the combustion chamber that affects the combustion rates and the correct combustion development.

- The trapping ratio has shown to limit the lean operation of this engine at very high loads since the fresh air cannot be retained inside the cylinder. Therefore, the Fr needs to be increased and the benefits of the lean operation are lost. Besides, with the raise of the knock caused by the Fr increase, the maximum achievable load is limited.

- Finally, with the load reduction, the scavenging process is worsened, and the IGR ratio is increased. As a consequence, the charge dilution is increased progressively, worsening the $\sigma \mathrm{IMEP}$ and the combustion efficiencies. This effect makes that the engine won't be very efficient at partial and low loads under SI conditions. 
Second, the CAI combustion mode will be synthetized. This combustion mode has shown an operation range from low to mid loads. Compared to the SI mode, this combustion has shown to be more repetitive, stable (better $\sigma$ IMEP), with higher combustion speeds and better combustion efficiencies. Thanks to all those changes the fuel efficiency is improved at partial loads. The pollutant emissions are also improved: $\mathrm{NO}_{\mathrm{x}}$ and soot, thanks to the lower combustion temperatures and the low Fr's, and $\mathrm{HC}$ and $\mathrm{CO}$, thanks to an improved combustion efficiency.

This combustion mode is achieved through the increase of the mixture reactivity until the charge is autoignited. The key parameters to adjust this reactivity in the engine are two: the IGR and the fuel injection. The IGR ratio has shown to be the main parameter to adjust the charge reactivity and to achieve CAI combustion. By means of the IGR ratio adjustment, the temperature of the charge can be increased up to the autoignition conditions. And, to a lesser extent, the fuel injection configuration has shown to influence the fuel homogenization and the residence time inside the cylinder, parameters that also significantly affect the autoignition process of the fuel.

Additionally, there is a third combustion mode, which could be understood as a mixture between the two previous combustion modes: it has been referred as a hybrid mode (CAISI). This mode combines the initial development of the combustion as a spark assisted to continue with the rest of the combustion in CAI conditions. In these conditions, the engine can be operated in CAI combustion with leaner Fr's and less IGR than a pure CAI combustion, achieving higher efficiencies and lower combustion rates, since the mixture reactivity is smaller and the air excess is slightly higher. Another important benefit of this combustion mode is the possibility to better adjust the combustion initiation, since the initial development is governed by the spark plug. However, the operation range of this mode has shown to be very narrow.

Finally, after seeing all these statements, it can be remarked that the IGR ratio has shown to be a key parameter for the optimization of the engine operation in both SI and CAI conditions.

\section{The EGR introduction on lean SI and CAI combustion}

The EGR strategy has been chosen, apart from reducing $\mathrm{NO}_{\mathrm{x}}$ emissions, as an additional parameter to adjust the charge thermodynamic conditions and, above all, its reactivity. Under SI conditions, depending on the engine load, the use of EGR has led to different results. At high loads, it has shown a strong capacity to reduce $\mathrm{NO}_{\mathrm{x}}$ and, additionally, it has helped to improve the performance of the engine thanks to the decrease in the knocking tendency, thus allowing a better combustion positioning. At lower loads, however, this 
extra benefit has not been observed. During CAI operation, this strategy can be used to reduce also the knock intensity, since the dilution of the charge with cooled residual gases decrease the combustion rates. By this means, the maximum achievable load in CAI conditions can be increased. Nevertheless, the use of EGR deteriorates both the combustion efficiency and the $\sigma$ IMEP, since the higher dilution of the cylinder charge hinders the combustion process.

\section{Combustion diagnostics cycle by cycle}

The analysis of all the measured cycles individually instead of a single averaged cycle has shown to provide a large amount of detailed information about all the different cycles recorded during the test measurement. In this way, some specific phenomena occurring during the combustion process can be studied, and the anomalous cycles can be isolated and studied separately. This methodology has shown to be more suitable for engines with high cycle to cycle deviation, as the one presented in this work, since the averaging of a pressure cycle for the combustion diagnostics can lead to a wrong representative cycle in most of the cases. However, for combustion processes without cyclic deviation (e.g. in diesel engines), the high amount of information obtained through the CTCM is not useful at all, since it results in a large amount of redundant information. The required processing effort is much greater, and therefore a longer calculation time and a greater amount of resources are required, as well as a greater effort to deal with this large amount of data.

Finally, it should be noted that this type of methodologies are going to be necessary in new engine concepts where, for example, the engine will be operated in HCCI or CAI conditions, since a greater degree of detail for the analysis of the combustion is needed.

\section{Analytical approach to the different combustion modes}

The work performed to go deeper in the combustion analysis has led to different outcomes.

The first has been obtaining an adapted new correlation for the laminar combustion speed determination at the combustion conditions available at this engine. This correlation has allowed to better characterize the effect of the F/A ratio and the $\mathrm{YO}_{2}$ in a range wider than usual.

And secondly, the methodology has shown to be valid to define a standard SI combustion at the different operating conditions, to compare it later with the experimental data so as to get information about the combustion performance. Taking this SI reference, the CAI combustion cases can be processed in the same way, and therefore the differentiation between both modes can be performed. This tool has also proven very useful in the case of CAISI tests, 
since the combustion process can be characterized, indicating both the instant and the mass burned fraction when the combustion changes from SI to CAI.

\section{Complete engine solution}

Once the different combustion modes in this engine have been studied, the operating strategies and the optimum combustion regions have been defined. The combination of lean SI and CAI combustion has shown to possess a high potential to cover a complete engine map in a $2 \mathrm{~S}$ engine. Both combustion modes complement each other, since in the regions where CAI combustion is not possible (mainly high loads) the lean SI combustion offers a good solution, whereas in the regions where the SI operation efficiency is worsened (mid and low loads) the CAI operation has proven to be a good choice to operate efficiently the engine. Finally the proposed engine map is presented in Figure 7.1

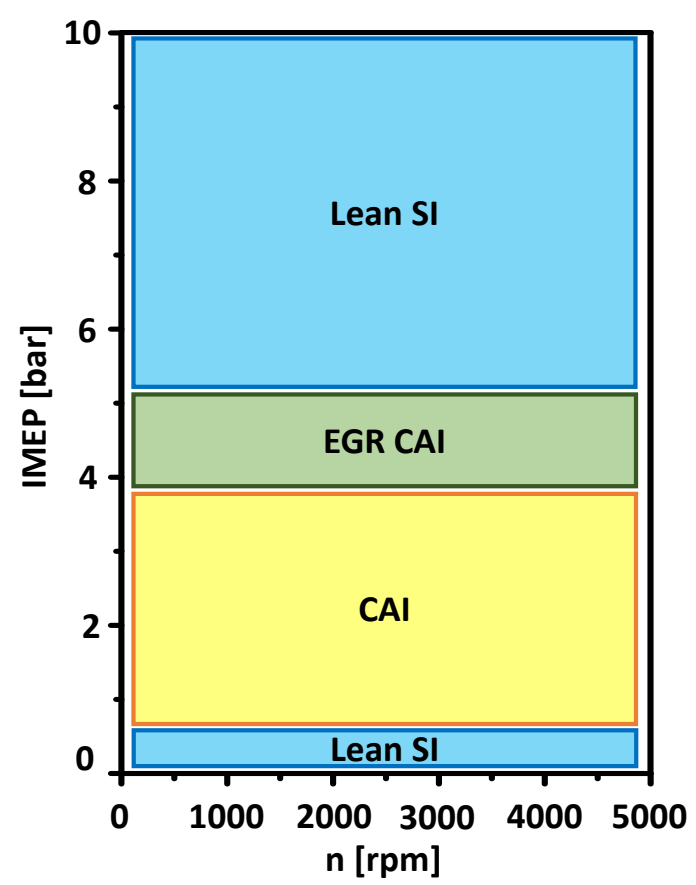

Figure 7.1. Final distribution of the different combustion modes in the engine map.

These results show that it is possible to improve the part-load region of the engine, operating it under CAI conditions in a big part of the engine map, and not only in a narrow operating region. This fact increases the interest of this combustion mode to be implemented in commercial engines. Nevertheless, 
the lower part of the engine cartography is necessarily SI operated, and this considerably increases the number of transitions between CAI and SI modes (e.g. each idle time during the engine operation).

\subsection{The engine potential, a brief analysis}

As an extra information of all this work, a brief analysis of the engine potential is going to be shown through the simulation of the theoretical results that this engine would achieve in different standard cycles. As already known, the result of a standard cycle is obtained not only for an engine, but also for a vehicle. Consequently, the engine has to be installed inside a vehicle, and the final result comes from the combination of these two factors. For this particular case, the vehicle designed for this engine is a light vehicle of approximately $700 \mathrm{~kg}$, the maximum speed of which will be above the maximum speed of any of the driving cycles (consequently, the complete cycle will be simulated in all cases). All details about the procedure to estimate the results on a standard cycle are included in Appendix 7.A.

First, the best results obtained in terms of BSFC and $\mathrm{NO}_{\mathrm{x}}$ emissions for the main points of the engine map (those appearing throughout the whole study) are shown in Table 7.1. These values are given as an extra information of the final fuel efficiency and $\mathrm{NO}_{\mathrm{x}}$ emissions reached for the interested readers. In that way this data could be compared with other results of different works in the future.

Now, the results obtained for different standard cycles are going to be presented. The different considered cycles are: the Bharat cycle, which is the main target of the initial development of this engine; the NEDC cycle, which is (or, at least, it was during the development of the project with Renault) the current standard cycle in Europe; the Artemis cycle, which is considered a more realistic and complete driving cycle, and therefore more demanding than the NEDC ${ }^{1}$; and, finally, the WLTP cycle, which is the driving cycle recently implemented, replacing the NEDC. For all the results presented here, the engine parameters (mainly BSFC and $\mathrm{BSNO}_{\mathrm{x}}$ ) are estimated from the ones experimentally known at a set of 17 different operating points distributed along the whole engine map.

\footnotetext{
${ }^{1}$ This diving cycle is usually employed as an internal reference for the car manufacturer, since the different parts of the driving test can be configured. By this means, the Artemis can be configured to be similar to another driving cycle, and the level of stringency can be also adjusted.
} 
Without EGR

\begin{tabular}{lllll}
\hline \hline Point & $\mathrm{n}$ & BMEP & BSFC & BSNO $_{\mathrm{x}}$ \\
\hline$[-]$ & {$[\mathrm{rpm}]$} & {$[\mathrm{bar}]$} & \multicolumn{2}{l}{$[\mathrm{g} / \mathrm{kWh}][\mathrm{g} / \mathrm{kWh}]$} \\
\hline $2000 @ 17$ & 2000 & 8.2 & 250 & 14 \\
$4000 @ 5$ & 4000 & 2 & 295 & 0.6 \\
$2000 @ 5$ & 2000 & 2.1 & 285 & 0.5 \\
$2500 @ 3$ & 2500 & 0.7 & 420 & 0.2 \\
\hline \hline
\end{tabular}

With EGR

\begin{tabular}{lllll}
\hline \hline Point & $\mathrm{n}$ & BMEP & BSFC & BSNO $_{\mathrm{x}}$ \\
\hline$[-]$ & {$[\mathrm{rpm}]$} & {$[\mathrm{bar}]$} & \multicolumn{2}{l}{$[\mathrm{g} / \mathrm{kWh}][\mathrm{g} / \mathrm{kWh}]$} \\
\hline $2000 @ 17$ & 2000 & 8.2 & 250 & 6 \\
$4000 @ 5$ & 4000 & 2 & 300 & 0.4 \\
$2000 @ 5$ & 2000 & 2.1 & 290 & 0.3 \\
$2500 @ 3$ & 2500 & 0.7 & 420 & 0.2 \\
\hline \hline
\end{tabular}

Table 7.1. Best values obtained for the selected Points without and with EGR.

Firstly, the results have been calculated without the use of EGR. This consideration has been made paying attention to the initial idea coming from the ULCGE project to achieve an ultra-low $\mathrm{NO}_{\mathrm{x}}$ engine for the Indian market. In Table 7.2 these results are shown. As it can be seen, the current Bharat standard cycle (equivalent to EURO IV) can be fulfilled with a properly defined engine calibration. Therefore, the initial goal coming from the ULCGE project can be achieved. However, the rest of the standard cycles are not fulfilled. The main reason of this huge difference in terms of $\mathrm{NO}_{\mathrm{x}}$ emissions is the higher speeds tested on these other driving cycles, which make the engine to work with higher loads during more time.

Secondly, the estimation of the results for the standard cycles is also performed with the optimized engine map, now with EGR, configured to fulfill all $\mathrm{NO}_{\mathrm{x}}$ limitations for the standard cycles defined (see Table 7.3). In this case, all the different cycles can be fulfilled (in fact, the choice of the optimized engine map was carried out paying attention to fulfill the most stringent cycle, 


\begin{tabular}{llll} 
& Fuel cons. & $\mathbf{N O}_{\mathbf{x}}$ & \\
\hline Cycle & {$[1 / 100 \mathrm{~km}]$} & {$[\mathrm{mg} / \mathrm{km}]$} & \\
\hline Bharat & 3.58 & 82.0 & Limit: $80 \mathrm{mg} / \mathrm{km}$ \\
\cline { 2 - 3 } NEDC & 3.87 & 209.2 & \\
Artemis & 4.2 & 405.9 & Limit: $60 \mathrm{mg} / \mathrm{km}$ \\
WLTP & 3.85 & 298.5 & \\
\hline
\end{tabular}

Table 7.2. Results in the standard cycles obtained without EGR addition.

the Artemis in this case). However, it can be seen how the fuel efficiency has been worsened in favor of the $\mathrm{NO}_{\mathrm{x}}$ emissions reduction thanks to the EGR introduction and the selection of different operating points without their best fuel efficiency but with low $\mathrm{NO}_{\mathrm{x}}$ emissions.

\begin{tabular}{llll} 
& Fuel cons. & $\mathbf{N O}_{\mathbf{x}}$ & \\
\hline Cycle & {$[1 / 100 \mathrm{~km}]$} & {$[\mathrm{mg} / \mathrm{km}]$} & \\
\cline { 2 - 3 } Bharat & 4.18 & 30.8 & Limit: $80 \mathrm{mg} / \mathrm{km}$ \\
\cline { 2 - 3 } NEDC & 4.47 & 47.5 & \\
Artemis & 4.92 & 59.0 & Limit: $60 \mathrm{mg} / \mathrm{km}$ \\
WLTP & 4.38 & 52.8 & \\
\hline
\end{tabular}

Table 7.3. Results in the standard cycles obtained with EGR addition.

Finally, the announced results of different car manufacturers for similar vehicles are shown in Table $7.4^{2}$. If the fuel efficiencies published by different car manufacturers are compared to the estimated results obtained in the EURO VI WLTP standard cycle for the engine under study, it can be seen that this engine offers better fuel efficiency compared to the others (compared to the averaged fuel consumption of the selected group, the other engines need $19 \%$ more fuel, in average). Thus, it can be concluded that this engine concept is able to bring an extra improvement in fuel efficiency and can be a competitive solution against current SI, and also CI, small engines.

\footnotetext{
${ }^{2}$ The source of all this collected information is the one published on the different car manufacturers websites.
} 


\begin{tabular}{|c|c|c|c|c|}
\hline Vehicle & Standards & $\begin{array}{l}\text { Engine } \\
\text { installed }\end{array}$ & $\begin{array}{l}\text { Fuel } \\
\text { consumption }\end{array}$ & Difference \\
\hline $\begin{array}{l}\text { Ford } \\
2019\end{array}$ & Euro VI & $\begin{array}{l}\text { SI engine, } 1.19 \\
\text { TI-VCT }\end{array}$ & $\begin{array}{l}5.9[1 / 100 \mathrm{~km}] \\
\text { WLTP }\end{array}$ & $+35 \%$ \\
\hline $\begin{array}{l}\text { Ford } \\
2019\end{array}$ & Euro VI & $\begin{array}{l}\text { Diesel engine, } \\
\text { 1.5 TDCI }\end{array}$ & $\begin{array}{l}4.7[1 / 100 \mathrm{~km}] \\
\text { WLTP }\end{array}$ & $+7 \%$ \\
\hline $\begin{array}{l}\text { Renault } \\
\text { Twingo } \\
2019\end{array}$ & Euro VI & $\begin{array}{l}\text { SI engine, } 0.9 \\
\text { TCe }\end{array}$ & $\begin{array}{l}5.3-5.6 \quad[1 / 100 \\
\mathrm{km}] \text { WLTP }\end{array}$ & $+24 \%$ \\
\hline $\begin{array}{l}\text { Peugeot } 108 \\
2019\end{array}$ & Euro VI & $\begin{array}{l}\text { SI engine, } 1.0 \\
\text { VTi }\end{array}$ & $\begin{array}{l}4.8[1 / 100 \mathrm{~km}] \\
\text { WLTP }\end{array}$ & $+10 \%$ \\
\hline $\begin{array}{l}\text { Toyota } \\
\text { Aygo } 2019\end{array}$ & Euro VI & SI engine, 1.0 & $\begin{array}{l}4.8[1 / 100 \mathrm{~km}] \\
\text { WLTP }\end{array}$ & $+10 \%$ \\
\hline $\begin{array}{l}\text { VW } \\
2019\end{array}$ & Euro VI & SI engine, 1.0 & $\begin{array}{l}5.5[1 / 100 \mathrm{~km}] \\
\text { WLTP }\end{array}$ & $+26 \%$ \\
\hline
\end{tabular}

Table 7.4. Fuel consumptions for different compact cars sold in Europe.

\subsection{Future works}

Once having seen all the developed work, the main future work to be performed step by step is the implementation of CAI combustion on SI engines, and little by little define the CAI engine as an engine solution suitable for industrialization. If this ambitious task is intended to be related to this engine, some ideas come to mind to continue improving the engine and the study and optimization of these combustion modes. Being a two stroke engine, the scavenging process (especially in this engine) is very complex and, therefore, the implementation of a fully Variable Valve Actuation system could help to better control the trapping ratio and the scavenging process. With this new system, the possibilities to study the lean SI and the CAI combustion would be further increased, since the IGR ratio could be better adjusted independently of the apparent F/A equivalence ratio and the load degree. Nevertheless this improvement would increase the engine complexity, moving it away from a suitable industrialization. So, the best compromise or the best system to 
improve the scavenging process is, at the moment, an unknown for the author of this work.

Another possible and "necessary" improvement for this type of engines is the implementation of a variable compression ratio (VCR) technology. The CAI combustion requires high compression ratios to get an optimum process, and this need is also variable with the load degree. However, the SI combustion mode does not need those higher compression ratios (unfortunately due to the knock raise), and with a higher CR the maximum achievable load of this engine is limited. This improvement has also the same problem as the VVA: the excessive complexity and the question about which would be the best solution.

Seeing these two proposals, as well as the problems faced along the whole work, it is clear that the future engines implementing these combustion modes need more flexibility to adjust the charge reactivity at all times.

Apart from the "engine hardware future works" just proposed up to now, another field with different possible tasks to be performed would be what it can be referred as "the engine operation". Along the work performed during this $\mathrm{PhD}$ thesis, one of the main lacks detected could be the definition of the reactivity concept. It would be very convenient to clarify the different influences on the reactivity, as well as try to define a measurable standardized parameter to better quantify and control this concept during the engine operation. In this way, the definition and optimization of the different operating points could be faster. Another work could be the implementation of an effective online knock prediction system, as well the necessary strategies to avoid this phenomenon, since knock has been a big and constant issue during all the work, greatly limiting the potential of this engine. And to finish with these "engine operation future works" part, the attempt to get an idle operation under CAI combustion mode would be a great improvement for this engine operation, since a big percentage of the CAI-SI-CAI transitions would be removed. Nevertheless this last improvement may be also related to the initially stated necessary improvements in the engine hardware.

Finally, regarding the combustion analysis methodology developed in this $\mathrm{PhD}$ thesis (presented in Section 6.3), the next step to complete this analysis, in view of the results, would be to characterize a CAI pattern. In this way, it would be possible to try to define the instants when SI and CAI combustion are taking place at the same time. And if this situation is observed, try to calculate the fraction of burned mixture consumed by each mode. The expected result should be similar to the one presented in Figure 7.2 for illustration. This is a combination of the results already presented in Section 6.3, and more specifically in Figure 6.73. The following curves are represented in the figure: 
the curve of the $\mathrm{Fr}_{\mathrm{app}}=0.7$ case, which has been taken as the one under analysis (labeled as "selected"); the "SI pattern", which is the one obtained in the frame of the present work; and the $\mathrm{Fr}_{\mathrm{app}}=0.9$ case, which has been taken as the "CAI pattern", since the whole combustion has developed in CAI conditions. With this information, the fuel fraction burnt in each combustion mode can be obtained based on the distance of the case under analysis to both patterns. In this "virtual" example, however, it has to be noted that the combustion conditions for the "Selected" and the "CAI pattern" are not the same. This plot has been built just to give an idea of the results that could be obtained if a CAI pattern would be also established.

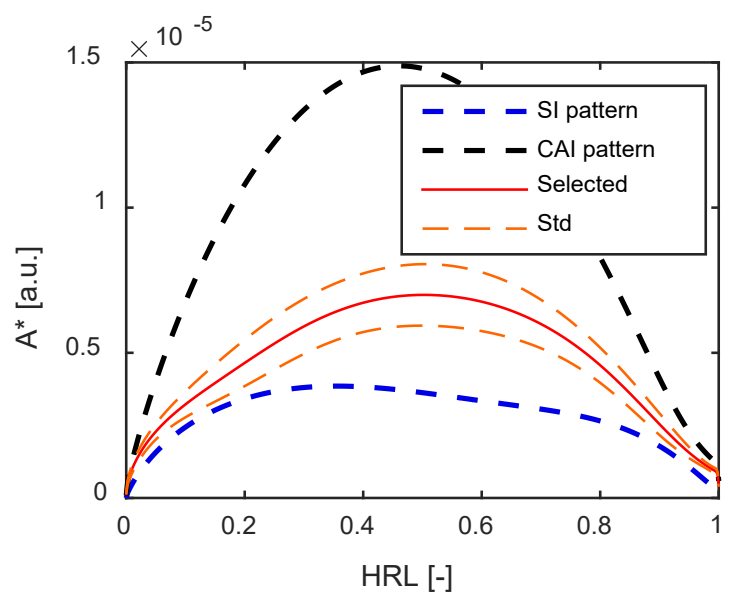

Figure 7.2. Illustrative result of the combustion analysis assuming that a CAI pattern is available.

Another additional future work around this combustion analysis methodology could be the in-cylinder pressure prediction for a SI combustion under the defined operating conditions, in order to enrich the data coming from the analysis and to use it as a combustion prediction and optimization tool. More precisely, the idea would be to use the SI pattern as the starting point to predict the real HRR in some given operating conditions (of course, assuming that the engine is working under SI conditions), as well as the in-cylinder pressure. 


\section{A Estimation of the theoretical results of the performance of the twin cylinder engine in standard cycles}

This estimation methodology tool has been developed to approach the theoretical results of this engine in a standard cycle from an engine map obtained in the test cell. The aim of this work is to give an approximated idea of the final efficiency of this engine inside a given vehicle. And with this information, it can be evaluated if this developed new engine concept is a valid solution to meet the market requirements in the future, and if it has enough potential compared to the current engine solutions.

Along the following lines this methodology is going to be described.

- Getting the necessary information to define the driving cycle in the engine map

The driving cycles are defined as a test for a vehicle in which, during a defined period of time, it will be running emulating a driving path (Fig.7.3) in a chassis dynamometer. During this test, the emissions and the fuel consumption are measured to obtain later the final results along this standardized driving cycle.

DRIVING CYCLES: NEDC

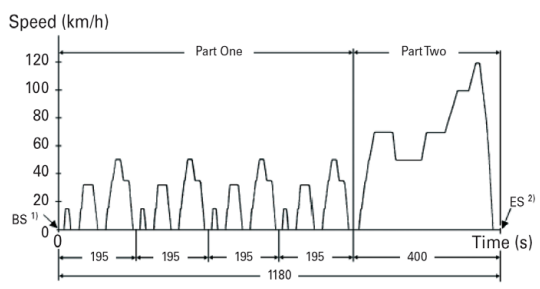

DRIVING CYCLES: WLTC

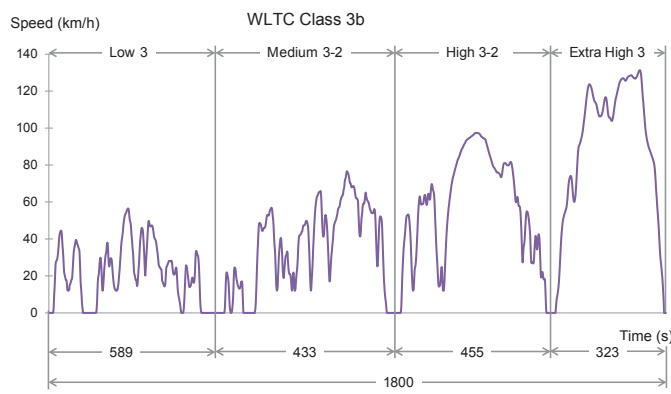

Figure 7.3. Detail of the velocity profile for the NEDC and the WLTC standard cycles.

During this test, the engine will be operating at different operating points depending on the specifications of the vehicle (weight, gearbox, selected 
7.A. Estimation of the theoretical results of the performance of the twin cylinder engine in standard cycles

gear, size of the wheels, etc.) and the required vehicle speed during the driving cycle. Therefore, this test can be discretized as a set of engine operating points (that will be referred as cycle points - BMEP@ $\mathrm{N}^{3}-$ ) and the corresponding "residence time" at each of these points $\left(\Delta t_{i}\right)$. During this discretization, in order to obtain a set of cycle points representative of the driving conditions, the necessary BMEP has to take into account the mechanical loses from the engine crankshaft to the wheels ${ }^{4}$. Finally, Figure 7.4 is included in order to show these cycle points (green crosses) on the engine operating map.

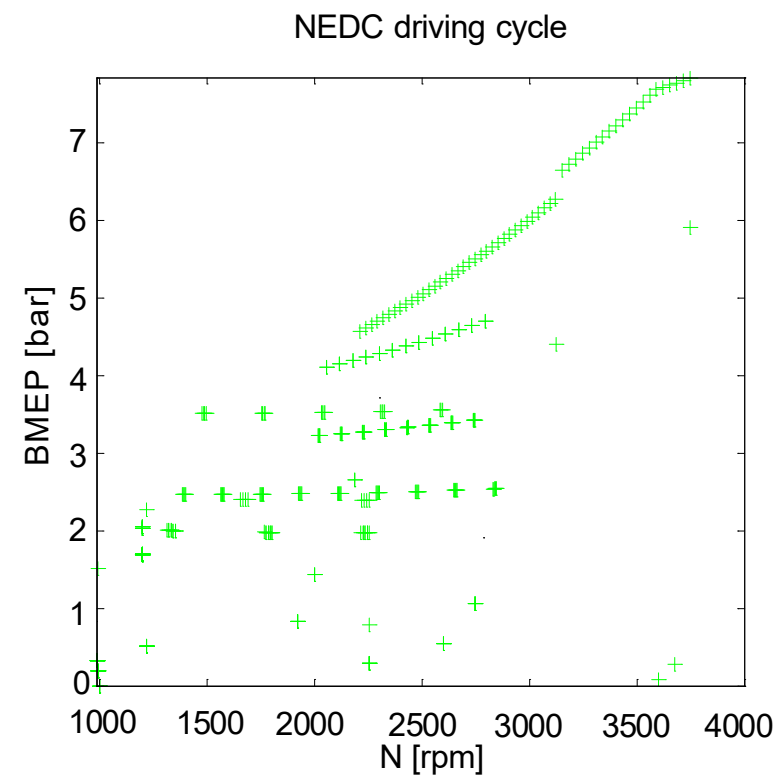

Figure 7.4. Representation of the cycle points set to define the NEDC driving cycle on the engine operating map.

\section{- Equation to estimate the results at a given standard cycle}

For this step, Eq. 7.1 is suggested. With this equation, the fuel consumption along the whole cycle (or the $\mathrm{NO}_{\mathrm{x}}$ emissions if the BSFC values are replaced by the $\mathrm{BSNO}_{\mathrm{x}}$ values) is calculated as follows:

\footnotetext{
${ }^{3}$ BMEP is the Brake Mean Effective Pressure and $\mathrm{N}$ is the engine speed.

${ }^{4}$ These mechanical loses depend on the vehicle considered. In this case Renault provided directly the cycle points to perform the corresponding calculations. Therefore the power loss from the engine to the wheels was already included in the given set of cycle points.
} 


$$
\frac{\sum B S F C\left[\frac{g}{k W h}\right] \cdot N e[k W] \cdot \Delta t[s] \cdot \frac{1000[\mathrm{mg}]}{1[\mathrm{~g}]} \cdot \frac{1[\mathrm{~h}]}{3600[\mathrm{~s}]}}{\sum v\left[\frac{\mathrm{km}}{\mathrm{h}}\right] \cdot \Delta t[\mathrm{~s}] \cdot \frac{1[\mathrm{~h}]}{3600[\mathrm{~s}]}}=x\left[\frac{\mathrm{mg}}{\mathrm{km}}\right]
$$

The above equation could be written as a single summation, but it is more convenient to perform the summation appearing in the numerator and in the denominator separately. The reason for this separation is due to the cycle points where $v=0$, since if the contribution of each cycle point is determined separately, there will be some points with a division by 0 . Thus, the best way to proceed is the following: on the one hand, to compute the $\mathrm{g}$ of fuel (or $\mathrm{NO}_{\mathrm{x}}$ ) consumed (or emitted) each second, and to perform the summation of all these values. With this, the total amount of fuel (or $\mathrm{NO}_{\mathrm{x}}$ ) in $\mathrm{g}$, consumed (or emitted) by the engine along the whole cycle is determined. On the other hand, to compute the distance traveled each second, and to perform the summation of all these values. With this, the total distance travelled by the vehicle is determined and the final fuel consumption and $\mathrm{NO}_{\mathrm{x}}$ emissions can be determined in $\mathrm{g} / \mathrm{km}$ or liters $/ 100 \mathrm{~km}$.

This equation can be also separated in two terms: on the one hand, the necessary energy and the distance travelled during the whole driving cycle, since these are constant for a given cycle and a given vehicle. With this, $K_{\text {cycle }}$ is obtained, see Eq.7.2.

$$
K_{\text {cycle }}=\frac{\sum N e[k W] \cdot \Delta t[s] \cdot \frac{1000[\mathrm{mg}]}{1[\mathrm{~g}]} \cdot \frac{1[\mathrm{~h}]}{3600[\mathrm{~s}]}}{\sum v\left[\frac{\mathrm{km}}{\mathrm{h}}\right] \cdot \Delta t[\mathrm{~s}] \cdot \frac{1[\mathrm{~h}]}{3600[\mathrm{~s}]}}
$$

And, on the other hand, the "unknown term", the mean BSFC (or $\mathrm{NO}_{\mathrm{x}}$ ) during the whole driving cycle. This term is calculated as the summation of the BSFC values of each cycle point $\left(B S F C\left(C y P_{i}\right)\right)$ multiplied by a weight term $\left(W\left(C y P_{i}\right)\right)$, representative of the influence of each cycle point on the complete driving cycle.

$$
B S F C_{a v g}\left[\frac{g}{k W h}\right]=\sum B S F C\left(C y P_{i}\right)\left[\frac{g}{k W h}\right] \cdot W\left(C y P_{i}\right)[-]
$$


7.A. Estimation of the theoretical results of the performance of the twin cylinder engine in standard cycles

How this term is calculated will be discussed in the next paragraph. With these two terms, the fuel consumption (or $\mathrm{NO}_{\mathrm{x}}$ emitted) along the whole cycle could be calculated as shown in Eq. 7.4:

$$
\text { Fuel }_{\text {cons.cycle }}\left[\frac{m g}{k m}\right]=K_{\text {cycle }} \cdot B S F C_{\text {avg }}
$$

- Calculation of the $B S F C_{a v g}$ from the defined engine map

Since the BSFC and the $\mathrm{NO}_{\mathrm{x}}$ for each cycle point are unknown, these have to be estimated from the engine map created with a set of cartography points, see Figure 7.5.

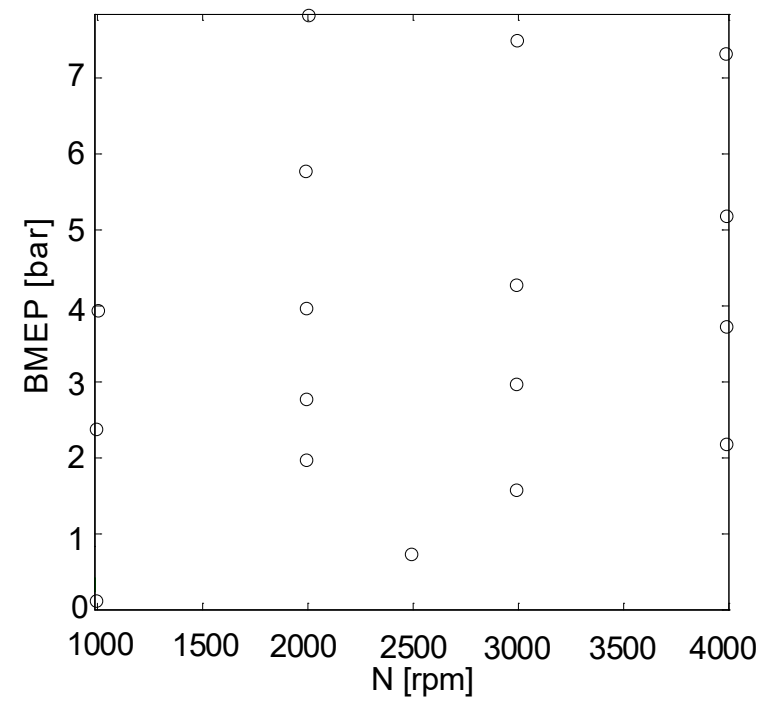

Figure 7.5. Representation of the set of cartography points to define the engine operating map.

Once the cartography points have been defined, the next step is to obtain the fuel consumption and the $\mathrm{NO}_{\mathrm{x}}$ emissions of the cycle points based on the values of the cartography points. For this purpose the methodology chosen is a linear interpolation (by triangulation), to find the influence of each cartography point on each cycle point (see Fig. 7.6). In that way, each cycle point will be defined as the sum of the influences of its closer cartography points. And the smaller the distance, the higher the proportion of the influence that has to be assigned to that point. 


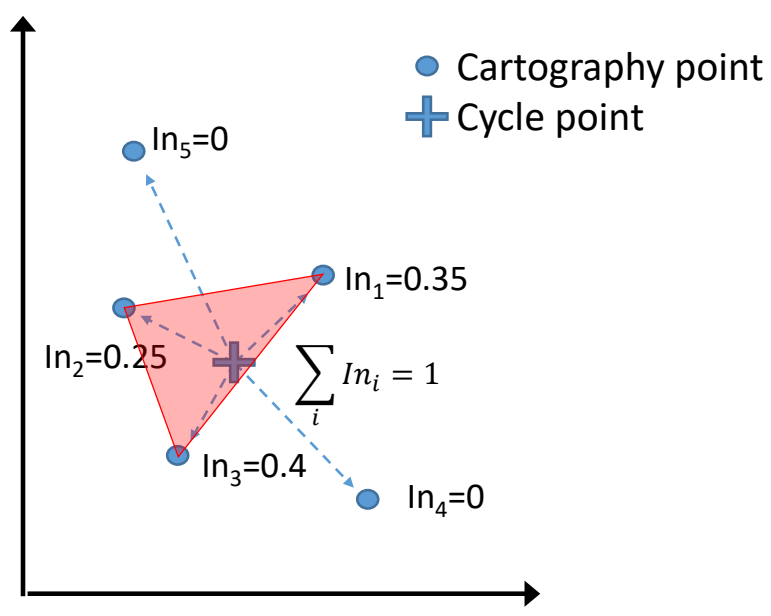

Figure 7.6. Graphical scheme of the influence estimation of the different cartography points on a cycle point.

The influence of each cartography point (referred as $I n$ ) on a given cycle point is computed as follows: a virtual function that takes the value 1 at the cartography point under consideration, and 0 at the rest, is used, and the value at the cycle point is interpolated/extrapolated using Matlab (linear interpolation/extrapolation). It is worth to indicate that the value obtained corresponds directly to the searched In: the influence of that particular cartography point on the cycle point. To get an accurate interpolation/extrapolation, the two axes need to have a similar scale. For this purpose, both axes are divided by the maximum BMEP and N, respectively, in such a way that their values oscillate between 0 and 1 .

In Equation 7.5, the BSFC for a cycle point $\left(C y P_{i}\right)$ is estimated from the determined influence $(\mathrm{In})$ of the cartography points $(\mathrm{CaP})$ and their corresponding BSFC value. The same equation can be used for the $\mathrm{NO}_{\mathrm{x}}$ emissions estimation.

$$
B S F C\left(C y P_{i}\right)=\sum \operatorname{In}\left(C a P_{i}\right) \cdot B S F C\left(C a P_{i}\right)
$$

Once the $B S F C\left(C y P_{i}\right)$ values are calculated, the next step to obtain the $B S F C_{a v g}$ is to calculate the $W\left(C y P_{i}\right)$ values (weights). This will be done as follows. 
7.A. Estimation of the theoretical results of the performance of the twin cylinder engine in standard cycles

The contribution of each cycle point in the final results along the whole driving cycle can be defined as a relative weight from 0 to 1 , in which the sum of all the cycle points weights complete the total cycle (weight=1). Taking into account Eqs. 7.1 and 7.2, it can be demonstrated that the weight of each cycle point in the whole cycle has to be defined as the energy consumed of that point $\left(N e \cdot \Delta t_{i}\right)$, divided by the total power consumed.

$$
W\left(C y P_{i}\right)=\frac{N e_{i} \cdot \Delta t_{i}}{\sum N e_{i} \cdot \Delta t_{i}}
$$

\section{- Estimation of the driving cycle results}

Once the three previous steps have been fulfilled (i.e. the weighs of the cycle points have been defined, the influences of the cartography points in each cycle point have been determined, and the values of the BSFC and the $\mathrm{NO}_{\mathrm{x}}$ emissions for each cycle point have been estimated), the result of the driving cycle can be obtained from the cycle points as already shown in Equation 7.4.

However, initially the only points where everything is known are the cartography points, and thus the estimation of the driving cycle results from the cartography points would be much faster. To this end, it is very convenient to directly relate the cartography points with the driving cycle. In this case, the weight of each cartography point in the total driving cycle $\left(W\left(C a P_{i}\right)\right)$ can be simply determined by Equation 7.7:

$$
W\left(C a P_{i}\right)=\sum \operatorname{In}\left(C y P_{i}\right) \cdot W\left(C y P_{i}\right)
$$

Finally, the equations for the estimation of the total fuel consumed and the total $\mathrm{NO}_{\mathrm{x}}$ emitted would be the followings:

$$
\begin{aligned}
& \text { Fuel }_{\text {cons.cycle }}=K_{\text {cycle }} \sum \cdot W\left(C a P_{i}\right) \cdot B S F C\left(C a P_{i}\right)\left[\frac{m g}{k m}\right] \\
& N O_{x \text { emiss.cycle }}=K_{\text {cycle }} \sum \cdot W\left(C a P_{i}\right) \cdot N O_{x}\left(C a P_{i}\right)\left[\frac{m g}{k m}\right]
\end{aligned}
$$





\section{Bibliography}

Aakko P. and Nylund N. .

Particle emissions at moderate and cold temperatures using different fuels.

SAE Technical Paper n. 2003-01-3285, 2003.

(cited in p.33)

Aceves S.M., Flowers D.L., Martinez-Frias J., Smith J.R., Westbrook C.K., Pitz W.J., Dibble R., Wright J.F., Akinyemi W.C. and Hessel R.P.

A sequential fluid-mechanic chemical-kinetic model of propane HCCI combustion.

SAE Technical Paper n. 2001-01-1027, 2001.

(cited in p. 76)

Aceves S.M., Flowers D.L., Westbrook C.K., Smith J.R., Pitz W., Dibble R., Christensen M. and Johansson B.

A multi-zone model for prediction of HCCI combustion and emissions.

SAE Technical Paper n. 2000-01-0327, 2000.

(cited in p. 76)

Aceves S.M., Martinez-Frias J., Flowers D.L., Smith J.R., Dibble R.W., Wright J.F. and Hessel R.P.

A decoupled model of detailed fluid mechanics followed by detailed chemical kinetics for prediction of iso-octane HCCI combustion.

SAE Technical Paper n. 2001-01-3612, 2001.

(cited in p. 76)

Akihama K., Takatori Y., Inagaki K., Sasaki S. and Dean A.M.

Mechanism of the smokeless rich diesel combustion by reducing temperature.

SAE Technical Paper n. 2001-01-0655, 2001.

(cited in p. 48)

Akihisa D. and Daisaku S.

Research on Improving Thermal Effiiency through Variable Super-High Expansion Ratio Cycle.

SAE Technical Paper n. 2003-32-0039, 2010.

(cited in p. 37)

Albayrak çeper B., Yildiz M., Akansu S.O. and Kahraman N.

Performance and emission characteristics of an IC engine under SI, SI-CAI and CAI combustion modes.

Energy, Vol. 136, pp. 72-79, 2017.

(cited in pp. 54, 64)

Alger T., Chauvet T. and Dimitrova Z.

Synergies between high EGR operation and GDI systems.

SAE Technical Paper n. 2008-01-0134, 2009.

(cited in p. 173)

Allen J. and Law D.

Production electro-hydraulic variable valve-train for a new generation of I.C. Engines.

SAE Technical Paper n. 2002-01-1109, 2002.

(cited in p. 39) 
Amorim R.

Combustión por difusión de baja temperatura en motores Diesel de pequeña cilindrarada. PhD thesis. Universitat Politècnica de València, Departamento de Máquinas y Motores Térmicos, 2010. (cited in p. 13)

Anbari Attar M., Herfatmanesh M.R., Zhao H. and Cairns A.

Experimental investigation of direct injection charge cooling in optical GDI engine using tracer-based PLIF technique.

Experimental Thermal and Fluid Science, Vol. 59, pp. 96-108, $2014 . \quad$ (cited in p. 51)

Andersen F.H. and Mayer S.

Parametric study of the scavenging process in marine two-stroke diesel engines.

ASME 2015 Internal Combustion Engine Division Fall Technical Conference, ICEF 2015, Vol. 1, 2015.

(cited in p. 108)

Andersen J., Karlsson E. and Gawell A.

Variable turbine geometry on SI engines.

SAE Technical Paper n. 2006-01-0020, 2006.

(cited in p. 36)

Andwari A.M., Abdul Aziz A., Muhamad Said M.F. and Abdul Latiff Z.

An experimental study on the influence of EGR rate and fuel octane number on the combustion characteristics of a CAI two-stroke cycle engine.

Applied Thermal Engineering, Vol. 71 n $^{\circ}$ 1, pp. 248-258, 2014.

(cited in p. 69)

Andwari A.M. and Aziz A.A.

Homogenous Charge Compression Ignition (HCCI) technique: A review for application in two-stroke gasoline engines.

Applied Mechanics and Materials, Vol. 165, pp. 53-57, $2012 . \quad$ (cited in pp.68, 69)

Andwari A.M., Aziz A.A., Muhamad Said M.F. and Abdul Latiff Z.

Controlled auto-ignition combustion in a two-stroke cycle engine using hot burned gases.

Applied Mechanics and Materials, Vol. 388, pp. 201-205, 2013.

(cited in p. 69)

Andwari A.M., Aziz A.A., Said M.F.M. and Latiff Z.A.

A converted two-stroke cycle engine for compression ignition combustion.

Applied Mechanics and Materials, Vol. 663, pp. 331-335, 2014.

(cited in p. 69)

Andwari A.M., Aziz A.A., Said M.F.M., Latiff Z.A. and Ghanaati A.

Influence of hot burned gas utilization on the exhaust emission characteristics of a controlled auto-ignition two-stroke cycle engine.

International Journal of Automotive and Mechanical Engineering, Vol. $11 \mathrm{n}^{\circ}$ 1, pp. 23962404, 2015.

(cited in p.69)

Aoyama T., Hattori Y., Mizuta J. and Sato Y.

An experimental study on premixed-charge compression ignition gasoline engine.

SAE Technical Paper n. 960081, 1996.

(cited in p. 50)

Armas O.

Diagnóstico experimental del proceso de combustión en motores Diesel de inyección directa. PhD thesis. Universitat Politècnica de València, Departamento de Máquinas y Motores Térmicos, 1998.

(cited in pp. 74, 126)

Auer P.

Advances in Energy Systems and Technology, Vol.3.

Academic Press, Vol. 3, 1982.

(cited in p. 46) 
Bai H., Hu C., Hou S., Liu N. and Li Z.

Comparison of spray characteristics of air-assisted direct injector using kerosene and gasoline.

Ranshao Kexue Yu Jishu/Journal of Combustion Science and Technology, Vol. $21 \mathrm{n}^{\circ}$ 5, 2015.

(cited in p. 160)

Bai H., Li Z., Li J., Lai W. and Hu C.

Experiment on spray characteristics with air-assisted injector of direct-injection gasoline engine.

Neiranji Xuebao/Transactions of CSICE (Chinese Society for Internal Combustion Engines), Vol. $31 \mathrm{n}^{\circ}$ 1, pp. 38-44, 2013.

(cited in p.160)

Baratta M., D'Ambrosio S., Spessa E. and Vassallo A.

Analysis of cyclic variability in a bi-fuel engine by means of a 'cycle-resolved' diagnostic technique.

2005 Fall Technical Conference of the ASME Internal Combustion Engine Division, pp. 175$191,2005$.

(cited in p. 74)

\section{Baratta M. and Misul D.}

Development and assessment of a new methodology for end of combustion detection and its application to cycle resolved heat release analysis in IC engines.

Applied Energy, Vol. 98, pp. 174-189, 2012.

(cited in p. 74)

Baratta M., Spessa E., D'Ambrosio S. and Vassallo A.

Cycle-resolved detection of combustion start in SI engines by means of different in-cylinder pressure data reduction techniques.

Proceedings of the Spring Technical Conference of the ASME Internal Combustion Engine Division, pp. 303-316, 2006.

(cited in p. 74)

Barron M.B. and Powers W.F.

The role of electronic controls for future automotive mechatronic systems.

IEEE/ASME Transactions on Mechatronics, Vol. $1 \mathrm{n}^{\circ}$ 1, pp. 80-88, $1996 . \quad$ (cited in p.6)

Belarte E.

Estudio del proceso de combustión premezclada controlada por la reactividad del combustible en un motor de encendido por compresión.

PhD thesis. Universitat Politècnica de València, Departamento de Máquinas y Motores Térmicos, 2015.

(cited in p.13)

Benajes J., Novella R., De Lima D., Tribotté P., Quechon N., Obernesser P. and Dugue V.

Analysis of the combustion process, pollutant emissions and efficiency of an innovative 2stroke HSDI engine designed for automotive applications.

Applied Thermal Engineering, Vol. 58 n $^{\circ}$ 1-2, pp. 181-193, 2013. $\quad$ (cited in pp. 130,132)

Beretta G. P., Rashidi M. and Keck J. C.

Turbulent flame propagation and combustion in spark ignition engines.

Combustion and Flame, Vol. $52 \mathrm{n}^{\circ}$ C, pp. 217-245, 1983.

(cited in p. 23)

Bernstein L., Bosch P., Canziani O., Chen Z., Christ R. and Riahi K.

Synthesis Report. Intergovernmental Panel on Climate Change $200 \%$.

2007.

(cited in p.6)

Bhave A., Kraft M., Mauss F., Oakley A. and Zhao H.

Evaluating the EGR-AFR operating range of a HCCI engine.

SAE Technical Paper n. 2005-01-0161, 2005. 


\section{Bird G.L.}

Ford 2.5 liter direct injection naturally aspirated diesel engine.

Proceedings of the Institution of Mechanical Engineers. Part D, Transport engineering, Vol. $199 \mathrm{n}^{\circ}$ 2, pp. 113-122, 1985.

(cited in p.6)

Blundell D., Turner J., Duret P., Lavy J., Oscarsson J., Emanuelsson G., Bengtsson J., Hammarstrom T., Perotti M., Kenny R. and Cunningham G. Design and evaluation of the elevate two-stroke automotive engine. SAE Technical Paper n. 2003-01-0403, 2003.

(cited in p.69)

Bopp S., Vafidis C. and Whitelaw J.H.

The effect of engine speed on the tdc flowfield in a motored reciprocating engine.

SAE Technical Paper n. 860023, 1986.

(cited in p. 256)

Boronat V.

Dual-fuel dual-mode combustion strategy to achieve high thermal efficiency, low NOx and smoke emissions in compression ignition engines.

PhD thesis. Universitat Politècnica de València, Departamento de Máquinas y Motores Térmicos, 2018.

(cited in p. 13)

BP. Pundir.

Engine emissions: pollutant formation and advances in control technology.

Narosa Publishing House, New Delhi, 2007.

(cited in p. 49)

Braisher M., Stone R. and Price P.

Particle number emissions from a range of European vehicles.

SAE Technical Paper n. 2010-01-0786, 2010.

(cited in p. 33)

Brandi F.K., Wünsche P. and Gschweltl E.

Design strategies for low noise engine concepts.

SAE Technical Paper n. 9110\%0, 1991.

(cited in p.6)

Brunt M.F.J. and Platts K.C.

Calculation of heat release in direct injection diesel engines.

SAE Technical Paper n. 1999-01-0187, 1999.

(cited in p. 72)

Brunt M.F.J., Rai H. and Emtage A.L.

The calculation of heat release energy from engine cylinder pressure data.

SAE Technical Paper n. 981052, 1998.

(cited in pp. 70, 71, 72)

Bybee K.

Reliable electronics for high-temperature downhole applications.

JPT, Journal of Petroleum Technology, Vol. $52 \mathrm{n}^{\circ} 7$, pp. 56-57, $2000 . \quad$ (cited in p. 6)

Callahan T.J., Yost D.M. and Ryan III T.W.

Acquisition and interpretation of diesel engine heat release data.

SAE Technical Paper n. 852068, 1985.

(cited in p. 72)

Cao L., Zhao H., Jiang X. and Kalian N.

Mixture formation and controlled auto-ignition combustion in four-stroke gasoline engines with port and direct fuel injections.

International Journal of Engine Research, Vol. 6 n$^{\circ}$ 4, pp. 311-330, $2005 . \quad$ (cited in p. 61) 
Cao L., Zhao H., Jiang X. and Kalian N.

Numerical investigation into effect of fuel injection timing on $\mathrm{CAI} / \mathrm{HCCI}$ combustion in a four-stroke GDI engine.

International Journal of Computational Methods in Engineering Science and Mechanics, Vol. $7 \mathrm{n}^{\circ} 1$, pp. 41-57, 2006.

(cited in p.61)

Carnot S.

Réflexions sur la puissance motrice du feu et sur les machines propres à développer cette puissance.

Bachelier, 1824

(cited in p.4)

Cathcart G. and Tubb J.

Application of air assisted direct fuel injection to pressure charged gasoline engines.

SAE Technical Paper n. 2002-01-0705, 2002.

Cathcart G. and Zavier C.

Fundamental characteristics of an air-assisted direct injection combustion system as applied to 4 -stroke automotive gasoline engines.

SAE Technical Paper n. 2000-01-0256, 2000.

(cited in p.110)

Caton J.A.

Combustion phasing for maximum efficiency for conventional and high efficiency engines. Energy Conversion and Management, Vol. 77, pp. 564-576, $2014 . \quad$ (cited in p. 204)

Caton P.A., Song H.H., Kaahaaina N.B. and Edwards C.F.

Residual-effected homogeneous charge compression ignition with delayed intake-valve closing at elevated compression ratio.

International Journal of Engine Research, Vol. 6 n$^{\circ}$ 4, pp. 399-419, 2005. （cited in p.60)

Çinar C., Uyumaz A., Polat S., Yilmaz E., Can Ö. and Solmaz H.

Combustion and performance characteristics of an HCCI engine utilizing trapped residual gas via reduced valve lift.

Applied Thermal Engineering, Vol. 100, pp. 586-594, 2016.

(cited in p.60)

Çinar C., Uyumaz A., Solmaz H., Sahin F., Polat S. and Yilmaz E.

Effects of intake air temperature on combustion, performance and emission characteristics of a HCCI engine fueled with the blends of $20 \%$ n-heptane and $80 \%$ isooctane fuels.

Fuel Processing Technology, Vol. $130 \mathrm{n}^{\circ}$ C, pp. 275-281, 2015.

(cited in p.64)

Chen T., Xie H., Li L., Zhang L., Wang X. and Zhao H.

Methods to achieve HCCI/CAI combustion at idle operation in a $4 \mathrm{VVAS}$ gasoline engine.

Applied Energy, Vol. 116, pp. 41-51, 2014.

(cited in p. 50)

Chen Z. and Mitsuru K.

How to put the HCCI engine to practical use: Control the ignition timing by compression ratio and increase the power output by supercharge.

SAE Technical Paper n. 2003-01-1832, 2003.

(cited in p. 51)

Cheung H.M. and Heywood J.B.

Evaluation of a one-zone burn-rate analysis procedure using production SI engine pressure data.

SAE Technical Paper n. 932749, 1993.

(cited in pp. 71,72 )

Choi S., Lim J., Ki M., Min K. and Choi H.

Analysis of cyclic variation and the effect of fuel stratification on combustion stabilityin a Port Fuel injection (PFI) CAI engine.

SAE Technical Paper n. 2009-01-0670, 2009.

(cited in p.61) 
Christensen M., Hultqvist A. and Johansson B.

Demonstrating the multi fuel capability of a homogeneous charge compression ignition engine with variable compression ratio.

SAE Technical Paper n. 1999-01-3679, 1999.

(cited in p. 59)

Christensen M. and Johansson B.

Influence of mixture quality on homogeneous charge compression ignition.

SAE Technical Paper n. 982454, 1998.

(cited in p. 51)

Christensen M. and Johansson B.

Homogeneous charge compression ignition with water injection.

SAE Technical Paper n. 1999-01-0182, 1999.

(cited in p.67)

Christensen M. and Johansson B.

Supercharged homogeneous charge compression ignition (HCCI) with exhaust gas recirculation and pilot fuel.

SAE Technical Paper n. 2000-01-1835, 2000.

(cited in p. 51)

Christensen M., Johansson B. and Einewall P.

Homogeneous Charge Compression Ignition (HCCI) using isooctane, ethanol and natural gas - A comparison with spark ignition operation.

SAE Technical Paper n. 972874, 1997.

(cited in pp. 56, 64)

Christian R., Knopf F., Jasmek A. and Schindler W.

A new method for the filter smoke number measurement with improved sensitivity.

MTZ Motortechnische Zeitschift, Vol. 54, pp. 16-22, 1993.

(cited in p. 126)

Clerk Dugald.

The gas engine.

Longmans Green, 1887.

(cited in p. 73)

Collins N.R. and Twigg M.V.

Three-way catalyst emissions control technologies for spark-ignition engines - Recent trends and future developments.

Topics in Catalysis, Vol. 42-43 $\mathrm{n}^{\circ}$ 1-4, pp. 323-332, $2007 . \quad$ (cited in p. 200)

Coltman D., Turner J. W. G., Curtis R., Blake D., Holland B., Pearson R. J., Arden A. and Nuglisch $\mathbf{H}$.

Project Sabre: A close-spaced direct injection 3-cylinder engine with synergistic technologies to achieve low $\mathrm{CO} 2$ output.

SAE Technical Paper n. 2008-01-0138, 2009.

(cited in p. 35)

Coskun G., Delil Y. and Demir U.

Analysis of an HCCI engine combustion using toluene reference fuel for different equivalence ratios - Comparison of experimental results with CFD and SRM simulations.

Fuel, pp. 217-227, 2019.

(cited in p. 77)

Curran H.J., Gaffuri P., Pitz W.J. and Westbrook C.K.

A comprehensive modeling study of iso-octane oxidation.

Combustion and Flame, Vol. $129 \mathrm{n}^{\circ}$ 3, pp. 253-280, 2002.

(cited in pp. 76, 193)

Curto-Risso P. L., Medina A., Calvo Hernández A., Guzmán-Vargas L. and Angulo-Brown $\mathbf{F}$.

On cycle-to-cycle heat release variations in a simulated spark ignition heat engine.

Applied Energy, Vol. 88 n $^{\circ}$ 5, pp. 1557-1567, 2011.

(cited in p. 73) 


\section{Szczepanski}

Factors influencing NOx emissions at Tarong and Stanwell power stations.

PhD-Thesis. The University of Queensland, 1998.

(cited in p. 32)

D'Ambrosio S., Ferrari A. and Galleani L.

In-cylinder pressure-based direct techniques and time frequency analysis for combustion diagnostics in IC engines.

Energy Conversion and Management, Vol. 99, pp. 299-312, 2015.

(cited in p. 74)

D’Ambrosio S., Misul D., Spessa E. and Vassallo A.

Evaluation of combustion velocities in bi-fuel engines by means of an enhanced diagnostic tool based on a quasi-dimensional multizone model.

SAE Technical Paper n. 2005-01-0245, 2005.

(cited in p. 75)

De Bellis V., Bozza F., Siano D. and Valentino G.

A modeling study of cyclic dispersion impact on fuel economy for a small size turbocharged SI engine.

SAE Technical Paper n. 2016-01-2230, 2016.

(cited in p. 74)

\section{de Lima D.}

Analysis of combustion concepts in a poppet valve two-stroke downsized compression ignition engine designed for passenger car applications.

PhD thesis. Universitat Politècnica de València, Departamento de Máquinas y Motores Térmicos, 2016.

(cited in p.12)

Demir U., Yilmaz N., Coskun G. and Soyhan H.S.

Evaluation of zero dimensional codes in simulating IC engines using primary reference fuel. Applied Thermal Engineering, Vol. 76, pp. 18-24, 2015.

(cited in p. 77)

Dempsey A.B., Das Adhikary B., Viswanathan S. and Reitz R.D.

Reactivity controlled compression ignition using premixed hydrated ethanol and direct injection diesel.

Journal of Engineering for Gas Turbines and Power, Vol. $134 \mathrm{n}^{\circ}$ 8, 2012. （cited in p.67)

Desantes J. M., Bermúdez V., López J. J. and López-Pintor D.

Correlations for the ignition characteristics of six different fuels and their application to predict ignition delays under transient thermodynamic conditions.

Energy Conversion and Management, Vol. 152, pp. 124-135, 2017.

(cited in pp. $25,56,223$ )

Desantes J.M., Bermúdez V., López J.J. and López-Pintor D.

A new method to predict high and low-temperature ignition delays under transient thermodynamic conditions and its experimental validation using a Rapid CompressionExpansion Machine.

Energy Conversion and Management, Vol. 123, pp. 512-522, $2016 . \quad$ (cited in p. 56)

Desantes J.M., García-Oliver J.M., Vera-Tudela W., López-Pintor D., Schneider B. and Boulouchos $\mathrm{K}$.

Study of the auto-ignition phenomenon of PRFs under HCCI conditions in a RCEM by means of spectroscopy.

Applied Energy, Vol. 179, pp. 389-400, 2016.

(cited in p. 56)

Desantes J.M., López J.J., García-Oliver J.M. and López-Pintor D.

Experimental validation and analysis of seven different chemical kinetic mechanisms for ndodecane using a Rapid Compression-Expansion Machine.

Combustion and Flame, Vol. 182, pp. 76-89, 2017. 
Desantes J.M., López J.J., Molina S. and López-Pintor D.

Validity of the Livengood and $\mathrm{Wu}$ correlation and theoretical development of an alternative procedure to predict ignition delays under variable thermodynamic conditions.

Energy Conversion and Management, Vol. 105, pp. 836-847, 2015.

(cited in p. 56)

Desantes J.M., López J.J., Molina S. and López-Pintor D.

Theoretical development of a new procedure to predict ignition delays under transient thermodynamic conditions and validation using a Rapid Compression-Expansion Machine. Energy Conversion and Management, Vol. 108, pp. 132-143, $2016 . \quad$ (cited in p. 56)

Ding Y., Li J., Xiang L. and Zhang Y.

Two-zone simulation modeling of gas exchange process of super-long-stroke low-speed diesel engine.

Journal of Harbin Engineering University, Vol. $40 \mathrm{n}^{\circ}$ 1, pp. 210-216, 2019.

(cited in p. 108)

Douaud A. M. and Eyzat P.

Four-octane-number method for predicting the anti-knock behavior of fuels and engines. SAE Technical Paper n. 780080, 1978.

(cited in p. 26)

Duret P., Dabadie J.-C., Lavy J., Allen J., Blundell D., Oscarsson J., Emanuelsson G., Perotti M., Kenny R. and Cunningham G.

The air assisted direct injection ELEVATE automotive engine combustion system.

SAE Technical Paper n. 2000-01-1899, 2000.

(cited in p.69)

Duret P. and Venturi S.

Automotive calibration of the IAPAC fluid dynamically controlled two-stroke combustion process.

SAE Technical Paper n. 960363, $1996 . \quad$ (cited in pp. 57, 58)

Egnell R.

Combustion diagnostics by means of multizone heat release analysis and NO calculation. SAE Technical Paper n. 981424, 1998.

(cited in pp. 71, 72)

Eichenberger D. A. and Roberts W. L.

Effect of unsteady stretch on spark-ignited flame kernel survival.

Combustion and Flame, Vol. $118 \mathrm{n}^{\circ}$ 3, pp. 469-478, 1999.

(cited in p. 21)

EPA U.S.

The benefits and costs of the clean air act from 1990-2010. 1999 .

(cited in p. 6)

Epping K., Aceves S., Bechtold R. and Dec J.

The potential of HCCI combustion for high efficiency and low emissions.

SAE Technical Paper n. 2002-01-1923, 2002.

(cited in pp. 49, 50, 51)

Eriksson L.

Requirements for and a systematic method for identifying heat-release model parameters. SAE Technical Paper n. 980626, 1998.

(cited in pp. 71, 72)

Fitton, J. Nates R.

Knock erosion in spark-ignition engines.

SAE Technical Paper n. 962102, 1996.

(cited in p. 25) 


\section{Franca $\mathbf{O}$.}

Impact of the Miller Cycle in the Efficiency of an FVVT (Fully Variable Valve Train) Engine During Part Load Operation.

SAE Technical Paper n. 2009-36-0081, 2009.

(cited in p. 40)

Fuerhapter A., Piock W.F. and Fraidl G.K.

CSI - Controlled auto ignition - The best solution for the fuel consumption - Versus emission trade-off?

SAE Technical Paper n. 2003-01-0754, 2003.

(cited in p. 59)

\section{Galloni E.}

Analyses about parameters that affect cyclic variation in a spark ignition engine.

Applied Thermal Engineering, Vol. 29 n ${ }^{\circ}$ 5-6, pp. 1131-1137, 2009. (cited in p. 74)

Gatowski J.A., Balles E.N., Chun K.M., Nelson F.E., Ekchian J.A. and Heywood J.B.

Heat release analysis of engine pressure data.

SAE Technical Paper n. 841359, 1984.

George S., Morris G., Dixon J., Pearce D. and Heslop G.

Optimal boost control for an electrical supercharging application.

SAE Technical Paper n. 2004-01-0523, 2004.

(cited in p. 36)

Ghojel J. and Honnery D.

Heat release model for the combustion of diesel oil emulsions in di diesel engines.

Applied Thermal Engineering, Vol. 25 n $14-15$, pp. 2072-2085, 2005.

(cited in pp. 71, 72)

Glahn C., Kluin M., Hermann I. and Koenigstein A.

Cooled external egr as a key technology for high-efficient gasoline combustion systems.

FISITA 2016 World Automotive Congress - Proceedings, 2016.

Glahn C., Kluin M., Konigstein A. and Cloos L.K.

Cooled External EGR - System Optimization of the Cooling and Charging System on a 3-Cylinder Gasoline DI T/C Engine.

24th Aachen Colloquium Automobile and Engine Technology, pp. 189-204, 2015.

(cited in p. 36)

Goering C.E. and Fry B.

Engine durability screening test of a diesel oil/soy oil/alcohol microemulsion fuel.

Journal of the American Oil Chemists Society, Vol. 61 n $^{\circ}$ 10, pp. 1627-1632, 1984.

(cited in p.6)

Gomez A. J. and Reinke P. E.

Lean burn: A review of incentives, methods, and tradeoffs.

SAE Technical Paper n. 880291, 1988.

(cited in p. 46)

Goto S. and Fukuda T.

Study on NOx, formation and reduction of lean-burn spark ignition gas engine.

JSAE Review, Vol. $19 \mathrm{n}^{\circ}$ 4, pp. 351-354, 1998.

(cited in p. 31)

Gould L.A., Richeson W.E. and Erickson F.L.

Performance evaluation of a camless engine using valve actuators with programmable timing. 
Gowthaman S. and Sathiyagnanam A.P.

Experimental investigation on performance and emission characteristics of homogeneous charge compression ignition (HCCI) engine fuelled by biodiesel.

International Journal of Applied Engineering Research, Vol. $10 \mathrm{n}^{\circ}$ 11, pp. 10134-10139, 2015.

(cited in p. 51)

Grandin B. and Angström H.

Replacing Fuel Enrichment in a Turbo Charged SI Engine: Lean Burn or Cooled EGR. SAE Technical Paper n. 1999-01-3505, 1999.

Grandin B., Angström H., Stalhammar P. and Olofsson E.

Knock suppression in a turbocharged SI engine by using cooled EGR.

SAE Technical Paper n. 982476, 1998.

(cited in pp. 43, 44, 173, 237)

Guezennec Y.G. and Hamama W.

Two-zone heat release analysis of combustion data and calibration of heat transfer correlation in an I. C. engine.

SAE Technical Paper n. 1999-01-0218, 1999.

(cited in p. 72)

Hacohen J., Ashcroft S. J. and Belmont M. R.

Lean burn versus EGR S.I. engine.

SAE Technical Paper n. 951902, 1995.

(cited in pp. 42, 43, 172)

Hadia F., Wadhah S., Ammar H. and Ahmed O.

Investigation of combined effects of compression ratio and steam injection on performance, combustion and emissions characteristics of HCCI engine.

Case Studies in Thermal Engineering, Vol. 10, pp. 262-271, $2017 . \quad$ (cited in p. 49)

Haenel P., Seyfried P., Kleeberg H. and Tomazic D.

Systematic approach to analyze and characterize pre-ignition events in turbocharged directinjected gasoline engines.

SAE Technical Paper n. 2011-01-0343, 2011.

(cited in p. 129)

Hanson R.M., Kokjohn S.L., Splitter D.A. and Reitz R.D.

An experimental investigation of fuel reactivity controlled pcci combustion in a heavy-duty engine.

SAE Technical Paper n. 2010-01-0864, 2010.

(cited in p. 54)

Haraldsson G., Tunestal P., Johansson B. and Hyvönen J.

HCCI combustion phasing in a multi cylinder engine using variable compression ratio.

SAE Technical Paper n. 2002-01-2858, 2002.

(cited in p. 59)

Herbst F., Stöber-Schmidt C. ., Eilts P., Sextro T., Kammeyer J., Natkaniec C., Seume J., Porzig D. and Schwarze H.

The potential of variable compressor geometry for highly boosted gasoline engines.

SAE Technical Paper n. 2011-01-0376, 2011.

(cited in p. 36)

Hermann F., Zeuch T. and Klingmann J.

The effect of diluents on the formation rate of nitrogen oxide in a premixed laminar flame. In Proceedings of the ASME Turbo Expo 2004, volume 1, pp. 559-566, 2004.

(cited in p. 31)

Heywood JB.

Internal combustion engine fundamentals.

McGraw-Hill, 1988.

(cited in pp. 34, 70, 71, 73, 108, 254) 
Hill J., Polasky S., Nelson E., Tilman D., Huo H., Ludwig L., Neumann J., Zheng $H$. and Bonta $D$.

Climate change and health costs of air emissions from biofuels and gasoline.

Proceedings of the National Academy of Sciences of the United States of America, Vol. 106 $\mathrm{n}^{\circ}$ 6, pp. 2077-2082, 2009.

(cited in p.6)

Hill P. G. and Zhang D.

The effects of swirl and tumble on combustion in spark-ignition engines.

Progress in Energy and Combustion Science, Vol. 20 n $^{\circ}$ 5, pp. 373-429, 1994.

(cited in p. 24)

Hiroyuki Oda, Yasuyuki Morita, Toshimitsu Fujishima and Masashi Marubara. Investigation of High-Compression Lean Burn Engine.

SAE Technical Paper n. 871215, 1987.

(cited in p. 46)

\section{Hirst, S.L. Kirsch L.J.}

The application of a hydrocarbon auto-ignition model in simulating knock and other engine combustion phenomena, in: Combustion modeling in reciprocating engines.

New York: Plenum, 1980.

(cited in p. 25)

Hou J., Qiao X., Wang Z., Liu W. and Huang Z.

Characterization of knocking combustion in HCCI DME engine using wavelet packet transform.

Applied Energy, Vol. 87 n $^{\circ}$ 4, pp. 1239-1246, 2010.

(cited in p. 49)

Hu T., Liu S., Zhou L. and Zhu C.

Combustion and emission characteristics of a homogeneous charge compression ignition engine.

Proceedings of the Institution of Mechanical Engineers, Part D: Journal of Automobile Engineering, Vol. 219 n $^{\circ}$ 9, pp. 1133-1139, 2005.

(cited in p. 51)

Hung N.B., Lim O. and Iida N.

The effects of key parameters on the transition from SI combustion to HCCI combustion in a two-stroke free piston linear engine.

Applied Energy, Vol. 137, pp. 385-401, 2015.

(cited in p.69)

\section{Hunicz J.}

An experimental study of combustion phasing control in CAI gasoline engine with in-cylinder fuel reforming.

SAE Technical Paper n. 2011-24-0052, 2011.

(cited in pp. 59, 62)

Inagaki K., Fuyuto T., Nishikawa K., Nakakita K. and Sakata I.

Dual-fuel PCI combustion controlled by in-cylinder stratification of ignitability.

SAE Technical Paper n. 2006-01-0028, 2006.

(cited in pp. 53, 54)

Iwabuchi Y., Kawai K., Shoji T. and Takeda Y.

Trial of new concept diesel combustion system - Premixed compression - ignited combustion

SAE Technical Paper n. 1999-01-0185, 1999.

(cited in pp. 49, 51, 52)

Iwashiro Y., Tsurushima T., Nishijima Y., Asaumi Y. and Aoyagi Y.

Fuel consumption improvement and operation range expansion in HCCI by direct water injection.

SAE Technical Paper n. 2002-01-0105, 2002.

(cited in p.67) 
Jang J., Lee Y., Cho C., Woo Y. and Bae C.

Improvement of DME HCCI engine combustion by direct injection and EGR.

Fuel, Vol. 113, pp. 617-624, 2013.

(cited in p.67)

Jiao Q. and Reitz R.D.

Modeling soot emissions from wall films in a direct-injection spark-ignition engine.

International Journal of Engine Research, Vol. 16 no 8, pp. 994-1013, 2015.

(cited in p. 51)

John J. E. A.

Lean burn engine concepts-emissions and economy.

SAE Technical Paper n. 750930, 1975.

(cited in p. 46)

Kaahaaina N.B., Simon A.J., Caton P.A. and Edwards C.F.

Use of dynamic valving to achieve residual-affected combustion.

SAE Technical Paper n. 2001-01-0549, 2001.

(cited in p. 59)

Kaimai T., Tsunemoto $H$. and Ishitani $H$.

Effects of a hybrid fuel system with diesel and premixed DME/methane charge on exhaust emissions in a small di diesel engine.

SAE Technical Paper n. 1999-01-1509, 1999.

(cited in p. 59)

Kaiser E.W., Yang J., Culp T., xu N. and Maricq M.M.

Homogeneous charge compression ignition engine-out emission-does flame propagation occur in homogeneous charge compression ignition?

International Journal of Engine Research, Vol. $3 \mathrm{n}^{\circ}$ 4, pp. 185-195, $2002 . \quad$ (cited in p. 63)

Kalghatgi G. T.

Spark ignition, early flame development and cyclic variation in I.C. engines.

SAE Technical Paper n. 870163, 1987.

(cited in p. 20)

Kamimoto T., Minagawa T. and Kobori S.

A two-zone model analysis of heat release rate in diesel engines.

SAE Technical Paper n. 972959, 1997.

(cited in pp. 71, 72)

Kamo R., Bryzik W. and Glance P.

Adiabatic engine trends-worldwide.

SAE Technical Paper n. 870018, 1987.

(cited in p. 6)

Kaneko N., Ando H., Ogawa H. and Miyamoto N.

Expansion of the operating range with in-cylinder water injection in a premixed charge compression ignition engine.

SAE Technical Paper n. 2002-01-1743, 2002.

(cited in p. 52)

Karjalainen P., Pirjola L., Heikkila J., Lahde T., Tzamkiozis T., Ntziachristos L., Keskinen J. and Ronkko T.

Exhaust particles of modern gasoline vehicles: A laboratory and an on-road study.

Atmospheric Environment, Vol. 97, pp. 262-270, $2014 . \quad$ (cited in p. 38)

Kelly-Zion P.L. and Dec J.E.

A computational study of the effect of fuel type on ignition time in homogeneous charge compression ignition engines.

Proceedings of the Combustion Institute, Vol. $28 \mathrm{n}^{\circ}$ 1, pp. 1187-1194, 2000.

(cited in p. 55) 
Kimura S., Aoki O., Ogawa H., Muranaka S. and Enomoto Y.

New combustion concept for ultra-clean and high-efficiency small di diesel engines.

SAE Technical Paper n. 1999-01-3681, 1999.

(cited in p. 50)

Kleinschmidt P. and Schmidt F.

How many sensors does a car need?

Sensors and Actuators: A. Physical, Vol. $31 \mathrm{n}^{\circ}$ 1-3, pp. 35-45, $1992 . \quad$ (cited in p.6)

Knop V.

Analysis of mixture structure and of its influence on combustion in a CAI engine.

International Journal of Engine Research, Vol. $19 \mathrm{n}^{\circ}$ 4, pp. 393-410, 2018.

(cited in p. 55)

Knop V. and Essayem E.

Comparison of PFI and DI operation in a downsized gasoline engine.

SAE Technical Paper n. 2013-01-1103, 2013.

(cited in pp. 37, 38)

Ko Y., Arpaci V. S. and Anderson R. W.

Spark ignition of propane-air mixtures near the minimum ignition energy: Part II. A model development.

Combustion and Flame, Vol. 83 n ${ }^{\circ}$ 1-2, pp. 88-105, 1991.

(cited in p. 21)

Kohany T. and Sher E.

Using the 2nd law of thermodynamics to optimize variable valve timing for maximizing torque in a throttled SI engine.

SAE Technical Paper n. 1999-01-0328, 1999.

(cited in p.6)

Kokjohn S.L., Hanson R.M., Splitter D.A. and Reitz R.D.

Experiments and modeling of dual-fuel HCCI and PCCI combustion using in-cylinder fuel blending.

SAE Technical Paper n. 2009-01-2647, 2010.

(cited in p. 53)

Konig, G. Maly R.R. Bradley D. Lau A.K.C. Sheppard C.G.W.

Role of exothermic centres on knock initiation and knock damage.

SAE Technical Paper n. 902136, 1990.

(cited in p. 25)

Konig, G. Sheppard C.G.W.

End gas auto-ignition and knock in a spark ignition engine.

SAE Technical Paper n. 902135, 1990.

(cited in p. 25)

Konrad R.

Dieselmotor-Management im Überblick. 2nd edition.

Springer, 2014.

(cited in p. 108)

Koopmans L. and Denbratt I.

A four stroke camless engine, operated in homogeneous charge compression ignition mode with commercial gasoline.

SAE Technical Paper n. 2001-01-3610, 2001.

(cited in pp. 59,60,63)

Krieger R.B. and Borman G.L.

The computation of apparent heat release for internal combustion engines.

ASME Paper 66-WA/DGP-4, 1966.

(cited in p. 72)

Kyrtatos N.P. and Koumbarelis I.

A three-zone scavenging model for two-stroke uniflow engines.

Journal of Engineering for Gas Turbines and Power, Vol. $110 \mathrm{n}^{\circ}$ 3, pp. 531-537, 1988.

(cited in p. 108) 
Lacey J.S., Filipi Z.S., Sathasivam S.R., Cannella W.J. and Fuentes-Afflick P.A. HCCI operability limits: The impact of refinery stream gasoline property variation. Journal of Engineering for Gas Turbines and Power, Vol. $135 \mathrm{n}^{\circ}$ 8, 2013. (cited in p. 59)

Ladommatos N., Abdelhalim S. and Zhao H.

Control of oxides of nitrogen from diesel engines using diluents while minimising the impact on particulate pollutants.

Applied Thermal Engineering, Vol. 18 n $^{\circ}$ 11, pp. 963-980, 1998.

(cited in p. 32)

Lancaster David R., Krieger Roger B., Sorenson Spencer C. and Hull William L. Effects of turbulence on spark-ignition engine combustion.

SAE Technical Paper n. 760160, 1976.

(cited in p. 20)

\section{Lapuerta $M$.}

Un modelo de combustión fenomenológico para un motor Diesel de inyección directa rápido.

PhD thesis. Universitat Politècnica de València, Departamento de Máquinas y Motores Térmicos, 1988.

(cited in p. 126)

Lapuerta M., Armas O. and Bermúdez V.

Sensitivity of diesel engine thermodynamic cycle calculation to measurement errors and estimated parameters.

Applied Thermal Engineering, Vol. 20 n $^{\circ}$ 9, pp. 843-861, 2000.

(cited in p.126)

Lapuerta M., Armas O. and Hernandez J.J.

Diagnosis of DI Diesel combustion from in-cylinder pressure signal by estimation of mean thermodynamic properties of the gas.

Applied Thermal Engineering, Vol.19 no5, pp.513-529, 1999.

(cited in p.126)

Lavoie G.A., Martz J., Wooldridge M. and Assanis D.

A multi-mode combustion diagram for spark assisted compression ignition.

Combustion and Flame, Vol. $157 \mathrm{n}^{\circ}$ 6, pp. 1106-1110, 2010.

(cited in p. 65)

Lavy J., Dabadie J.-C., Angelberger C., Duret P., Willand J., Juretzka A., Schäflein J., Ma T., Lendresse Y., Satre A., Schulz C., Krämer H., Zhao H. and Damiano L.

Innovative ultra-low NOx controlled auto-ignition combustion process for gasoline engines: The 4-SPACE project.

SAE Technical Paper n. 2000-01-1837, 2000.

(cited in pp. 50, 59, 69)

Law D., Kemp D., Allen J., Kirkpatrick G. and Copland T.

Controlled combustion in an IC-engine with a fully variable valve train.

SAE Technical Paper n. 2001-01-0251, 2001.

(cited in pp. 50, 59)

Leach B., Zhao H., Li Y. and Ma T.

Control of CAI combustion through injection timing in a gdi engine with an air-assisted injector.

SAE Technical Paper n. 2005-01-0134, 2005.

(cited in p.65)

Lee K., Cho S., Kim N. and Min K.

A study on combustion control and operating range expansion of gasoline HCCI.

Energy, Vol. 91, pp. 1038-1048, 2015.

(cited in p. 67)

Li H., Cheng P., Tan M.-Z., Gu Y.-H., Wang H., Peng Y.-P. and Guo Y.-N. CAI combustion comparison between NVO strategy and EGRB strategy. Jilin Daxue Xuebao (Gongxueban)/Journal of Jilin University (Engineering and Technology Edition), Vol. $41 \mathrm{n}^{o}$ SUPPL. 1, pp. 47-52, 2011. 
Li J., Zhao H., Ladommatos N. and Ma T.

Research and development of Controlled Auto-Ignition (CAI) combustion in a 4-stroke multicylinder gasoline engine.

SAE Technical Paper n. 2001-01-3608, 2001.

(cited in pp.60,65, 69)

Li N., Xie H., Chen T., Li L. and Zhao H.

The effects of intake backflow on in-cylinder situation and auto ignition in a gasoline controlled auto ignition engine.

Applied Energy, Vol. 101, pp. 756-764, 2013.

(cited in p.60)

Li W., Liu Z., Wang Z. and Xu Y.

Experimental investigation of the thermal and diluent effects of EGR components on combustion and NOx emissions of a turbocharged natural gas SI engine.

Energy Conversion and Management, Vol. 88, pp. 1041-1050, 2014.

(cited in p.64)

Li Y., Zhao H., Brouzos N. and Leach B.

Managing controlled auto-ignition combustion by injection on a direct-injection gasoline engine.

Proceedings of the Institution of Mechanical Engineers, Part D: Journal of Automobile Engineering, Vol. $221 \mathrm{n}^{\circ}$ 9, pp. 1125-1137, 2007.

(cited in p.66)

Li Y., Zhao H., Brouzos N., Ma T. and Leach B.

Effect of injection timing on mixture and CAI combustion in a GDI engine with an airassisted injector.

SAE Technical Paper n. 2006-01-0206, 2006.

(cited in pp.65, 160)

Litak G., Kaminski T., Czarnigowski J., Sen A. K. and Wendeker M.

Combustion process in a spark ignition engine: Analysis of cyclic peak pressure and peak pressure angle oscillations.

Meccanica, Vol. $44 \mathrm{n}^{\circ}$ 1, pp. 1-11, 2009.

(cited in p. 73)

López J.J., García-Oliver J.M., García A. and Domenech V.

Gasoline effects on spray characteristics, mixing and auto-ignition processes in a CI engine under Partially Premixed Combustion conditions.

Applied Thermal Engineering, Vol. 70 n $^{\circ}$ 1, pp. 996-1006, 2014.

(cited in p. 52)

López J.J., Novella R., Valero-Marco J., Coma G. and Justet F.

Evaluation of the Potential Benefits of an Automotive, Gasoline, 2-Stroke Engine.

SAE Technical Paper n. 2015-01-1261, 2015-April. (cited in p.11)

Lü X., Han D. and Huang Z.

Fuel design and management for the control of advanced compression-ignition combustion modes.

Progress in Energy and Combustion Science, Vol. 37 n 6 , pp. 741-783, 2011.

(cited in p. 59)

Lü X.-C., Chen W. and Huang Z.

A fundamental study on the control of the HCCI combustion and emissions by fuel design concept combined with controllable EGR. Part 2. Effect of operating conditions and EGR on HCCI combustion.

Fuel, Vol. $84 \mathrm{n}^{\circ}$ 9, pp. 1084-1092, 2005.

(cited in p. 59)

Luján J.M., Climent H., Novella R. and Rivas-Perea M.E.

Influence of a low pressure EGR loop on a gasoline turbocharged direct injection engine. Applied Thermal Engineering, Vol. 89, pp. 432-443, 2015.

(cited in p.173) 
Lumsden G., Eddleston D. and Sykes R.

Comparing lean burn and EGR.

SAE Technical Paper n. 970505, 1997.

(cited in pp. 44, 45)

Manofsky L., Vavra J., Assanis D. and Babajimopoulos A.

Bridging the gap between HCCI and SI: Spark-assisted compression ignition.

SAE 2011 World Congress and Exhibition, 2011.

(cited in pp.65, 241)

Mardi M.K., Abdolalipouradl M. and Khalilarya Sh.

The effect of exhaust gas recirculation on performance and emissions of a SI engine fuelled with ethanol-gasoline blends.

International Journal of Engineering, Transactions A: Basics, Vol. $28 \mathrm{n}^{\circ} 1$, pp. 133-138, 2015 .

(cited in p.171)

Martín J.

Diagnóstico de la combustión en motores Diesel de inyección directa.

PhD thesis. Universitat Politècnica de València, Departamento de Máquinas y Motores

Térmicos, 1998.

(cited in p. 126)

Martins M. and Zhao $\mathrm{H}$.

Experimental studies of a 4-stroke multi-cylinder gasoline engine with controlled autoignition (CAI) combustion.

SAE Technical Paper n. 200\%-01-2609, 2007.

(cited in p.64)

Matekunas F.A.

Engine combustion control with ignition timing by pressure ratio management, 18 Nov. 1986.

US Pat A4622939, 1986.

(cited in p. 74)

Mathis U., Mohr M. and Forss A. .

Comprehensive particle characterization of modern gasoline and diesel passenger cars at low ambient temperatures.

Atmospheric Environment, Vol. 39 n $^{\circ}$ 1, pp. 107-117, 2005.

(cited in p. 33)

Megaritis A., Yap D. and Wyszynski M.L.

Effect of water blending on bioethanol HCCI combustion with forced induction and residual gas trapping.

Energy, Vol. $32 \mathrm{n}^{\circ}$ 12, pp. 2396-2400, 2007.

(cited in p.67)

Mehl M., Chen J.Y., Pitz W.J., Sarathy S.M. and Westbrook C.K.

An approach for formulating surrogates for gasoline with application toward a reduced surrogate mechanism for CFD engine modeling.

Energy and Fuels, Vol. $25 \mathrm{n}^{\circ}$ 11, pp. 5215-5223, 2011.

(cited in pp. 72, 127)

Mehl M., Pitz W.J., Westbrook C.K. and Curran H.J.

Kinetic modeling of gasoline surrogate components and mixtures under engine conditions. Proceedings of the Combustion Institute, Vol. $33 \mathrm{n}^{\circ}$ 1, pp. 193-200, 2011.

(cited in p. 127)

Metghalchi M. and Keck J.C.

Burning velocities of mixtures of air with methanol, isooctane, and indolene at high pressure and temperature.

Combustion and Flame, Vol. 48 n ${ }^{\circ}$ C, pp. 191-210, 1982.

(cited in pp. 76, 252) 
Michaels H. C. and Fulper B. K.

Nitrous oxide emission factors for mobile sources USEPA.

In AWMA emissions inventory conference, New Orleans, USA, 1998., 1998.

(cited in p.32)

Miklanek L., Vitek O., Gotfryd O. and Klir V.

Study of unconventional cycles (Atkinson and Miller) with mixture heating as a means for the fuel economy improvement of a throttled SI engine at part load.

SAE Technical Paper n. 2012-01-1678, 2012.

(cited in p. 40)

\section{Milpied J. and Jeuland N.}

Which fuel properties for improved CAI combustion? Study of fuel impacts on the operating range of a CAI PFI engine.

SAE Technical Paper n. 2009-01-1100, 2009.

(cited in p.61)

Mohr M., Forss A. . and Lehmann U.

Particle emissions from diesel passenger cars equipped with a particle trap in comparison to other technologies.

Environmental Science and Technology, Vol. $40 \mathrm{n}^{\circ}$ 7, pp. 2375-2383, 2006.

(cited in p. 33)

Mori S. and Shimizu R.

Analysis of EGR cyclic variations in a direct injection gasoline engine by using raman scattering method.

SAE Technical Paper n. 2002-01-1646, 2002.

(cited in p. 37)

Najt P.M. and Foster D.E.

Compression-ignited homogeneous charge combustion.

SAE Technical Paper n. 830264, 1983.

(cited in pp. 50, 58)

Nates, R.J. Yates A.D.B.

Knock damage mechanisms in spark-ignition engines.

SAE Technical Paper n. 942064, 1994.

(cited in p. 25)

Nishijima Y., Asaumi Y. and Aoyagi Y.

Premixed lean Diesel Combustion (PREDIC) using impingement spray system.

SAE Technical Paper n. 2001-01-1892, 2001.

(cited in p. 50)

Noguchi M., Tanaka Y., Tanaka T. and Takeuchi Y.

A study on gasoline engine combustion by observation of intermediate reactive products during combustion.

SAE Technical Paper n. 790840, 1979.

(cited in pp. 49, 68)

Oakley A., Zhao H., Ladommatos N. and Ma T.

Experimental studies on controlled auto-ignition (CAI) combustion of gasoline in a 4-stroke engine.

SAE Technical Paper n. 2001-01-1030, 2001.

(cited in pp. 56, 57)

Odell P. R.

Why carbon fuels will dominate the 21st century's global energy economy.

Geopolitics of Energy, Vol. 26 n $^{\circ}$ 3-4, pp. 2-8, 2004.

(cited in p. 32)

Oh H. and Bae C.

Effects of the injection timing on spray and combustion characteristics in a spray-guided DISI engine under lean-stratified operation.

Fuel, Vol. 107, pp. 225-235, 2013. 
Ohgami E., Ohsawa N. and Saito T.

Nissan's new V8 and L4 aluminum cylinder block - Design and production.

SAE Technical Paper n. 910431, 1991.

(cited in p.6)

Okude K., Mori K., Shiino S. and Moriya T.

Premixed compression ignition (PCI) combustion for simultaneous reduction of nox and soot in diesel engine.

SAE Technical Paper n. 2004-01-1907, 2004.

(cited in p. 52)

Olesky L.M., Martz J.B., Lavoie G.A., Vavra J., Assanis D.N. and Babajimopoulos A.

The effects of spark timing, unburned gas temperature, and negative valve overlap on the rates of stoichiometric spark assisted compression ignition combustion.

Applied Energy, Vol. 105, pp. 407-417, 2013.

(cited in pp. 76, 77)

Olsson J.-O., Tunestal P. and Johansson B.

Closed-loop control of an HCCI engine.

SAE Technical Paper n. 2001-01-1031, 2001.

(cited in p. 59)

Onishi S., Jo S.H., Shoda K., Jo P.D. and Kato S.

Active Thermo-Atmosphere Combustion (ATAC) - A new combustion process for internal combustion engines.

SAE Technical Paper n. 790501, 1979.

(cited in pp. 49,68)

Ouellette P., Douville B., Hill P. G. and Ursu B.

NOx reduction in a directly injected natural gas engine.

American Society of Mechanical Engineers, Internal Combustion Engine Division (Publication) ICE, Vol. 31-33 n ${ }^{\circ}$ 3, pp. 59-71, 1998.

(cited in p. 32)

Ozdor N., Dulger M. and Sher E.

Cyclic variability in spark ignition engines a literature survey.

SAE Technical Paper n. 940987, 1994.

(cited in p. 74)

Pairy F. and Desantes J.M.

Motores de combustión interna alternativos.

Editorial Reverté and Editorial UPV, 2011.

(cited in pp. 19, 22, 23, 26, 27, 29, 31, 35, 40, 48, 109)

Park C., Kim S., Kim H. and Moriyoshi Y.

Stratified lean combustion characteristics of a spray-guided combustion system in a gasoline direct injection engine.

Energy, Vol. $41 \mathrm{n}^{\circ}$ 1, pp. 401-407, 2012.

(cited in p. 45)

Patterson D. J.

Cylinder pressure variations, a fundamental combustion problem.

SAE Technical Paper n. 290016, 1966.

(cited in pp. 21, 73)

Payri F., Armas O., Desantes R. and Leiva A.

Modelo termodinámico para el diagnóstico experimental del proceso de combustión en motores Diesel de inyección directa (ID).

III Congreso Iberoamericano de Ingeniería Mecánica, La Habana, 1997. （cited in p. 71)

Payri F., Olmeda P., Martín J. and García A.

A complete $0 \mathrm{D}$ thermodynamic predictive model for direct injection diesel engines.

Applied Energy, Vol. 88 n $^{\circ}$ 12, pp. 4632-4641, 2011.

(cited in p. 276) 
Peng Z., Zhao H. and Ladommatos N.

Effects of air/fuel ratios and EGR rates on HCCI combustion of N-heptane, a diesel type fuel.

SAE Technical Paper n. 2003-01-0747, 2003.

(cited in p. 51)

Peng Z., Zhao H. and Ladommatos N.

Visualization of the homogeneous charge compression ignition/controlled autoignition combustion process using two-dimensional planar laser-induced fluorescence imaging of formaldehyde.

Proceedings of the Institution of Mechanical Engineers, Part D: Journal of Automobile Engineering, Vol. 217 n $^{\circ}$ 12, pp. 1125-1134, 2003.

(cited in p. 56)

Persson H., Hultqvist A., Johansson B. and Remón A.

Investigation of the early flame development in spark assisted HCCI combustion using high speed chemiluminescence imaging.

SAE Technical Paper n. 2007-01-0212, 2007.

(cited in p. 76)

\section{Peters N.}

Laminar flamelet concepts in turbulent combustion.

Symposium (International) on Combustion, Vol. $21 \mathrm{n}^{\circ}$ 1, pp. 1231-1250, 1988.

(cited in p. 22)

Peters N. and Williams F. A.

Premixed combustion in a vortex.

Symposium (International) on Combustion, Vol. $22 \mathrm{n}^{\circ}$ 1, pp. 495-503, 1989.

(cited in p. 22)

Price P., Stone R., Oudenijeweme D. and Chen X.

Cold start particulate emissions from a second generation di gasoline engine.

SAE Technical Paper n. 2007-01-1931, 2007.

(cited in p. 38)

Qin J., He B., Xie H. and Zhao H.

Auto-ignition and heat release correlations for controlled auto-ignition combustion in gasoline engines.

Transactions of Tianjin University, Vol. $13 \mathrm{n}^{\circ}$ 5, pp. 328-333, $2007 . \quad$ (cited in p. 54)

Qin J., Xie H., Zhang Y., Chen T., He B.-Q. and Zhao H.

Experimental study on CAI gasoline engine equipped with 4-variable valve actuating system. Neiranji Xuebao/Transactions of CSICE (Chinese Society for Internal Combustion Engines), Vol. $25 \mathrm{n}^{\circ}$ 4, pp. 316-321, 2007.

(cited in p.66)

Qin J., Xie H., Zhang Y. and Zhao H.

Study on CAI combustion heat release model in 4-stroke gasoline engine.

Neiranji Xuebao/Transactions of CSICE (Chinese Society for Internal Combustion Engines), Vol. $24 \mathrm{n}^{\circ} 3$, pp. 242-249, 2006.

(cited in p.64)

R. Maly.

Initiation and Propagation of Flame Fronts in Lean CH4-Air Mixtures by the Three Modes of Ignition Spark in Fuel Economy in Road Vehicles Powered by Spark-Ignition Engines. Hilliard, J. C. and Springer, G. S. Plenum Press, New York, $1984 . \quad$ (cited in p. 20)

R. Maly.

Spark Ignition: Its Physics and Effect on the Internal Combustion Engine in Fuel Economy in Road Vehicles Powered by Spark-Ignition Engines.

Hilliard, J. C. and Springer, G. S. Plenum Press, New York, 1984.

(cited in p. 20) 
Ra Y. and Reitz R.D.

A combustion model for IC engine combustion simulations with multi-component fuels.

Combustion and Flame, Vol. $158 \mathrm{n}^{\circ}$ 1, pp. 69-90, 2011.

(cited in p. 52)

Radu, B. Martin G. Chiriac R. Apostolescu N.

On the knock characteristics of LPG in a spark ignition engine.

SAE Technical Paper n. 2005-01-37r73, 2005.

(cited in p. 26)

Ramesh N. and Mallikarjuna J.M.

Evaluation of in-cylinder mixture homogeneity in a diesel HCCI engine - a CFD analysis. Engineering Science and Technology, an International Journal, Vol. $19 \mathrm{n}^{\circ}$ 2, pp. 917-925, 2016.

(cited in p. 48)

Rassweiler G.M. and Withrow L.

Motion pictures of engine flames correlated with pressure cards.

SAE Technical Paper n. 380139, 1938.

(cited in p. 71)

Reuss D.L., Kuo T.-W., Silvas G., Natarajan V. and Sick V.

Experimental metrics for identifying origins of combustion variability during spark-assisted compression ignition.

International Journal of Engine Research, Vol. $9 \mathrm{n}^{\circ}$ 5, pp. 409-434, $2008 . \quad$ (cited in p. 76)

Reyes M., Tinaut F. V., Giménez B. and Pérez A.

Characterization of cycle-to-cycle variations in a natural gas spark ignition engine.

Fuel, Vol. 140, pp. 752-761, 2015.

(cited in p. 74)

Rhodes D.B. and Keck J.C.

Laminar burning speed measurements of indolene-air-diluent mixtures at high pressures and temperatures.

SAE Technical Paper n. 850047, 1985.

(cited in pp. 76, 252)

Richter M., Engström J., Franke A., Aldén M., Hultqvist A. and Johansson B. The influence of charge inhomogeneity on the HCCI combustion process.

SAE Technical Paper n. 2000-01-2868, 2000.

(cited in p. 51)

Rivas M.

Assessment of fuel consumption reduction strategies on a gasoline turbocharged direct injection engine with a cooled EGR system.

PhD thesis. Universitat Politècnica de València, Departamento de Máquinas y Motores Térmicos, 2016.

(cited in p. 12)

Ryan III T.W. and Callahan T.J.

Homogeneous charge compression ignition of diesel fuel.

SAE Technical Paper n. 961160, 1996.

(cited in p. 51)

Ryu J., Kim H. and Lee K.

A study on the spray structure and evaporation characteristic of common rail type high pressure injector in homogeneous charge compression ignition engine.

Fuel, Vol. $84 \mathrm{n}^{\circ}$ 18, pp. 2341-2350, 2005.

(cited in p. 51)

Saito H., Shirasuna T. and Nomura T.

Extension of Lean Burn Range by Intake Valve Offset.

SAE Technical Paper n. 2013-32-9032, 2013.

(cited in pp. 44, 45) 
Santodonato J., Basu D. and Howard P.

Health effects associated with diesel exhaust emissions, literature review and evaluation. National Academy of Sciencies, Engineering and Medicine, ${ }^{\circ}$ EPA/600/1-78/063, 1978-11.

(cited in p.6)

Sawamoto K., Kawamura Y., Kita T. and Matsushita K.

Individual cylinder knock control by detecting cylinder pressure.

SAE Technical Paper n. 871911, 1987.

(cited in p. 74)

Senecal P.K., Richards K.J., Pomraning E., Yang T., Dai M.Z., McDavid R.M., Patterson M.A., Hou S. and Shethaji T.

A new parallel cut-cell cartesian CFD code for rapid grid generation applied to in-cylinder diesel engine simulations.

SAE Technical Paper n. 2007-01-0159, 2007.

(cited in p. 127)

Sher E. and Keck J. C.

Spark ignition of combustible gas mixtures.

Combustion and Flame, Vol. $66 \mathrm{n}^{\circ}$ 1, pp. 17-25, 1986.

(cited in p. 20)

Siebers D.L.

Scaling liquid-phase fuel penetration in diesel sprays based on mixing-limited vaporization.

SAE Technical Paper n. 1999-01-0528, 1999.

(cited in pp. 48, 53)

Simescu S., Ryan III T.W., Neely G.D., Matheaus A.C. and Surampudi B.

Partial pre-mixed combustion with cooled and uncooled EGR in a heavy-duty diesel engine.

SAE Technical Paper n. 2002-01-0963, 2002.

(cited in p. 52)

Sluder C.S. and Wagner R.M.

An estimate of diesel high-efficiency clean combustion impacts on FTP-75 aftertreatment requirements.

SAE Technical Paper n. 2006-01-3311, 2006.

(cited in p. 49)

Soltic P. and Hausberger S.

On-Road Emission Measurements and emission modeling results for a tractor-semi trailer in Trans-Alpine operation.

13th International Scienfftic Symposium Transport and Air Pollution Boulder, September 13-15, 2004.

(cited in p. 32)

Splitter D., Kokjohn S., Rein K., Hanson R., Sanders S. and Reitz R.

An optical investigation of ignition processes in fuel reactivity controlled PCCI combustion.

SAE Technical Paper n. 2010-01-0345, 2010.

(cited in p. 54)

Standing R., Kalian N., Ma T., Zhao H., Wirth M. and Schamel A.

Effects of injection timing and valve timings on CAI operation in a multi-cylinder di gasoline engine.

SAE Technical Paper n. 2005-01-0132, 2005.

(cited in p.65)

Stanglmaier R.H. and Roberts C.E.

Homogeneous charge compression ignition (HCCI): Benefits, compromises, and fut ure engine applications.

SAE Technical Paper n. 1999-01-3682, 1999.

(cited in pp. 50, 51)

Steinhilber T. and Sattelmayer T.

The effect of water addition on HCCIdiesel combustion.

SAE Technical Paper n. 2006-01-3321, 2006. 
Stevens E. and Steeper R.

Piston wetting in an optical DISI engine: Fuel films, pool fires, and soot generation.

SAE Technical Paper n. 2001-01-1203, 2001.

(cited in p. 34)

Sturm S., Schmidt S. and Kirchberger R.

Overview of Different Gas Exchange Concepts for Two-Stroke Engines.

SAE Technical Paper n. 2018-32-0041, 2018.

(cited in pp. 108, 149)

Superchargers Rotrex.

Rotrex Technical Handbook.

Official technical handbook for Rotrex C-type superchargers, $2014 . \quad$ (cited in p. 110)

Syaiful, Nuryasin M. and Bae M.-W.

Effect of hot EGR on performance and exhaust gas emissions of EFI gasoline engine fueled by gasoline and wet methanol fuel blends.

ARPN Journal of Engineering and Applied Sciences, Vol. $11 \mathrm{n}^{\circ}$ 6, pp. 4065-4069, 2016.

(cited in p. 171)

Tanaka S., Ayala F., Keck J.C. and Heywood J.B.

Two-stage ignition in HCCI combustion and HCCI control by fuels and additives.

Combustion and Flame, Vol. $132 \mathrm{n}^{\circ}$ 1-2, pp. 219-239, 2003.

(cited in p. 56)

Technologies Delphi.

Worldwide emissions standards, Passenger cars and light duty vehicles.

Delphi informative booklet, 2018/2019.

(cited in pp. 7,8 )

Thring R.H.

Homogeneous-Charge Compression-Ignition (HCCI) engines.

SAE Technical Paper n. 892068, 1989.

(cited in p. 50)

Turkcan A., Ozsezen A.N., Canakci M., Coskun G., Soyhan H.S. and Demir U. An experimental and modeling study to investigate effects of two-stage direct injection variations on HCCI combustion.

Combustion Science and Technology, Vol. $187 \mathrm{n}^{\circ}$ 4, pp. 642-658, 2015. (cited in p. 77)

Turner J.W.G., Head R.A., Wijetunge R., Chang J., Engineer N., Blundell D.W. and Burke $P$.

Analysis of different uniflow scavenging options for a medium-duty 2-stroke engine for a U.S. light-truck application.

ASME 2018 Internal Combustion Engine Division Fall Technical Conference, ICEF 2018, Vol. 2, 2018.

(cited in p. 108)

Turner J.W.G., Popplewell A., Patel R., Johnson T.R., Darnton N.J., Richardson S., Bredda S.W., Tudor R.J., Bithell C.I., Jackson R., Remmert S.M., Cracknell R.F., Fernandes J.X., Lewis A.G.J., Akehurst S., Brace C.J., Copeland C., Martinez-Botas R., Romagnoli A. and Burluka A.A.

Ultra Boost for Economy: Extending the Limits of Extreme Engine Downsizing.

SAE Technical Paper n. 2014-01-1185, 2014.

(cited in p. 35)

\section{Uyumaz A.}

An experimental investigation into combustion and performance characteristics of an HCCI gasoline engine fueled with n-heptane, isopropanol and n-butanol fuel blends at different inlet air temperatures.

Energy Conversion and Management, Vol. 98, pp. 199-207, 2015.

(cited in p.66) 
Valero-Marco J., Lehrheuer B., López J.J. and Pischinger S.

Potential of water direct injection in a CAI/HCCI gasoline engine to extend the operating range towards higher loads.

Fuel, Vol. 231, pp. 317-327, 2018.

(cited in pp. 59, 60, 67)

W. Pulkrabek Willard.

Engineering Fundamentals of the Internal Combustion Engine.

Upper Saddle River, New Jersey 07548, 1997.

(cited in pp. 20, 25)

\section{Wandell J.L.}

Shot peening of engine components.

American Society of Mechanical Engineers, Internal Combustion Engine Division (Publication) ICE, Vol. 29, pp. 101-108, 1997.

(cited in p.6)

Wang X., Ma J. and Zhao H.

Analysis of scavenge port designs and exhaust valve profiles on the in-cylinder flow and scavenging performance in a two-stroke boosted uniflow scavenged direct injection gasoline engine.

International Journal of Engine Research, Vol. $19 \mathrm{n}^{\circ}$ 5, pp. 509-527, 2018.

(cited in p. 108)

Wang $\mathrm{X}$. and $\mathrm{Zhao} H$.

A High-Efficiency Two-Stroke Engine Concept: The Boosted Uniflow Scavenged DirectInjection Gasoline (BUSDIG) Engine with Air Hybrid Operation.

Engineering, Vol. $5 \mathrm{n}^{\circ}$ 3, pp. 535-547, 2019.

(cited in p. 108)

Wang X., Zhao H., Xie H. and He B.-Q.

Numerical Study of the Effect of Piston Shapes and Fuel Injection Strategies on In-Cylinder Conditions in a PFI/GDI Gasoline Engine.

SAE Technical Paper n. 2014-01-2670, 2014.

(cited in p.62)

Wang Z., He X., Wang J.-X., Shuai S., Xu F. and Yang D.

Combustion visualization and experimental study on spark induced compression ignition (SICI) in gasoline HCCI engines.

Energy Conversion and Management, Vol. $51 \mathrm{n}^{\circ}$ 5, pp. 908-917, 2010. (cited in p.64)

Wang Z., Liu H. and Reitz R.D.

Knocking combustion in spark-ignition engines.

Progress in Energy and Combustion Science, Vol. 61, pp. 78-112, 2017. （cited in p.129)

Wang Z., Wang J.-X., Shuai S.-J., Tian G.-H., An X. and Ma Q.-J.

Study of the effect of spark ignition on gasoline HCCI combustion.

Proceedings of the Institution of Mechanical Engineers, Part D: Journal of Automobile

Engineering, Vol. $220 \mathrm{n}^{\circ}$ 6, pp. 817-825, 2006.

(cited in pp.65, 241)

Warnatz J., Maas U. and Dibble R.W.

Combustion: Physical and chemical fundamentals, modeling and simulation, experiments, pollutant formation.

2006 .

(cited in p. 26)

Wärtsilä Finland Corporation.

Wartsila 50DF Engine Technology.

Brochure - Wärtsilä Co., 2015.

(cited in p. 45) 
Watanabe I., Kawai T., Yonezawa K. and Ogawa.T.

The New Toyota 2.0-Liter Inline 4-Cylinder ESTEC D-4ST Engine - Turbocharged Direct Injection Gasoline Engine.

23rd Aachen Colloquium Automobile and Engine Technology, 2014. $\quad$ (cited in p.37)

Westbrook, C.K. Pitz W.J. Leppard W.R.

The autoi-gnition chemistry of paraffinic fuels and pro-knock and anti-knock additives: a detailed chemical kinetic study.

SAE Technical Paper n. 912314, 1991.

(cited in p. 25)

Whitaker P., Kapus P., Ogris M. and Hollerer P.

Measures to Reduce Particulate Emissions from Gasoline DI engines.

SAE Technical Paper n. 2011-01-1219, 2011.

(cited in p. 38)

Wijesinghe J. and Hong G.

Effect of spark assistance on improving cyclic stability of auto-ignition at light load in a small two-stroke engine.

SAE Technical Paper n. 2009-32-0021, 2009.

(cited in p.68)

Wijesinghe J. and Hong G.

Study of the autoignition combustion operating region of a small two-stroke engine.

Proceedings of the Institution of Mechanical Engineers, Part D: Journal of Automobile Engineering, Vol. $223 \mathrm{n}^{\circ}$ 5, pp. 651-659, 2009.

(cited in p. 68)

Wijesinghe J.S. and Hong G.

Effect of spark assistance on autoignition combustion in a small two-stroke engine.

Proceedings of the Institution of Mechanical Engineers, Part D: Journal of Automobile Engineering, Vol. $225 \mathrm{n}^{\circ}$ 1, pp. 115-126, 2011.

(cited in pp.68, 241)

Williams F. A.

An approach to turbulent flame theory.

Journal of Fluid Mechanics, Vol. $40 \mathrm{n}^{\circ}$ 2, pp. 401-421, 1970.

(cited in p. 22)

Xie H., Li L., Chen T. and Zhao H.

Investigation on gasoline homogeneous charge compression ignition (HCCI) combustion implemented by residual gas trapping combined with intake preheating through waste heat recovery.

Energy Conversion and Management, Vol. 86, pp. 8-19, 2014.

(cited in p. 58)

Xie H., Yang L., Gao R., He B.-Q. and Zhao H.

Influence of spark discharge on CAI combustion process.

Neiranji Xuebao/Transactions of CSICE (Chinese Society for Internal Combustion Engines), Vol. $23 \mathrm{n}^{\circ}$ 5, pp. 410-416, 2005.

(cited in p. 65)

Xiong Y., Roberts W. L., Drake M. C. and Fansler T. D.

Investigation of pre-mixed flame-kernel/vortex interactions via high-speed imaging.

Combustion and Flame, Vol. 126 n $^{o}$ 4, pp. 1827-1844, 2001.

(cited in p. 21)

\section{Yamaguchi J.}

Honda readies activated radical combustion two-stroke engine for production motorcycle. Automotive Engineer, pp. 90-92, SAE publications, January 1997, 1997. (cited in p. 49)

Yanagihara H., Satou Y. and Mizuta J.

A simultaneous reduction of NOx and soot in diesel engines under a new combustion system (Uniform Bulky Combustion System - UNIBUS).

17th Int. Vienna Motor Symposium, 1996.

(cited in p. 50) 
Yang C. and Zhao $\mathrm{H}$.

In-cylinder studies of $\mathrm{CAI} / \mathrm{HCCI}$ combustion with negative valve overlap in a direct injection gasoline optical engine.

Combustion Science and Technology, Vol. $183 \mathrm{n}^{\circ}$ 5, pp. 467-486, $2011 . \quad$ (cited in p. 59)

Yang C., Zhao H. and Megaritis T.

Investigation of CAI combustion with positive valve overlap and enlargement of CAI operating range.

SAE Technical Paper n. 2009-01-1104, 2009.

(cited in pp. 59, 60)

\section{Yang J.}

Expanding the operating range of homogeneous charge compression ignition-spark ignition dual-mode engines in the homogeneous charge compression ignition mode.

International Journal of Engine Research, Vol. $6 \mathrm{n}^{\circ}$ 4, pp. 279-288, 2005. （cited in p.66)

Yang J., Culp T. and Kenny T.

Development of a Gasoline Engine System using HCCI Technology - the Concept and the Test Results.

SAE Technical Paper n. 2002-01-2832, 2002.

(cited in p. 50)

Yoshizawa K., Teraji A., Miyakubo H., Yamaguchi K. and Urushihara T.

Study of high load operation limit expansion for gasoline compression ignition engines.

Journal of Engineering for Gas Turbines and Power, Vol. $128 \mathrm{n}^{\circ}$ 2, pp. 377-387, 2006.

(cited in p.67)

Yu C., Kim T., Yi Y., Lee J., Noh S. and Choi K.

Development of kmc 2.41 Lean burn engine.

SAE Technical Paper n. 950685, 1995.

(cited in pp. 45, 47)

Yu H., Guo Y., Li D., Liang X., Shu G.-Q., Wang Y., Wang X. and Dong L. Numerical Investigation of the Effect of Spray Cone Angle on Mixture Formation and $\mathrm{CO} /$ Soot Emissions in an Early Injection HCCI Diesel Engine.

SAE Technical Paper n. 2015-01-1070, 2015.

(cited in p. 51)

Yu H., Liang X., Wang Y. and Zhang $H$.

Effect of the nozzle diameter variation on the mixture formation and combustion characteristics in an HCCI-DI engine using an early injection strategy: CFD modeling. ASPACC 2015 - 10th Asia-Pacific Conference on Combustion, 2015. (cited in p. 51)

Zhang H.F., Seo K. and Zhao H.

Combustion and emission analysis of the direct DME injection enabled and controlled autoignition gasoline combustion engine operation.

Fuel, Vol. 107, pp. 800-814, 2013.

(cited in p. 70)

Zhang Y., Dalla Nora M. and Zhao $\mathbf{H}$.

Comparison of Performance, Efficiency and Emissions between Gasoline and E85 in a TwoStroke Poppet Valve Engine with Lean Boost CAI Operation.

SAE Technical Paper n. 2015-01-0827, 2015.

(cited in pp.66, 70)

Zhang Y., Dallanora M. and Zhao H.

Investigation of Valve Timings on Lean Boost CAI Operation in a Two-stroke Poppet Valve di Engine.

SAE Technical Paper n. 2015-01-1794, 2015.

(cited in p. 70)

Zhang Y., He B.-Q., Xie H. and Zhao H.

The combustion and emission characteristics of ethanol on a port fuel injection HCCI engine.

SAE Technical Paper n. 2006-01-0631, 2006.

(cited in p.69) 
Zhang Y., Jia M., Liu H., Xie M., Wang T. and Zhou L.

Development of a new spray/wall interaction model for diesel spray under PCCI-engine relevant conditions.

Atomization and Sprays, Vol. $24 \mathrm{n}^{\circ}$ 1, pp. 41-80, 2014.

(cited in p. 51)

Zhang Y., Xie H. and Zhao $\mathbf{H}$.

Investigation of SI-HCCI Hybrid combustion and control strategies for combustion mode switching in a four-stroke gasoline engine.

Combustion Science and Technology, Vol. $181 \mathrm{n}^{\circ}$ 5, pp. 782-799, 2009. (cited in p. 65)

\section{Zhang Y. and Zhao $\mathbf{H}$.}

Measurement of short-circuiting and its effect on the controlled autoignition or homogeneous charge compression ignition combustion in a two-stroke poppet valve engine.

Proceedings of the Institution of Mechanical Engineers, Part D: Journal of Automobile Engineering, Vol. $226 \mathrm{n}^{\circ}$ 8, pp. 1110-1118, 2012.

(cited in p.69)

\section{Zhang $\mathbf{Y}$. and Zhao $\mathrm{H}$.}

Investigation of combustion, performance and emission characteristics of 2-stroke and 4stroke spark ignition and CAI/HCCI operations in a DI gasoline.

Applied Energy, Vol. 130, pp. 244-255, 2014.

(cited in pp.63, 64, 70, 220)

Zhang Y., Zhao H., Ojapah M. and Cairns A.

Effects of injection timing on CAI operation in a $2 / 4$-stroke switchable GDI engine.

SAE Technical Paper n. 2011-01-1773, 2012.

(cited in pp.60,61)

Zhang Y., Zhao H., Peckham M. and Campbell B.

Direct in-cylinder CO2 measurements of residual gas in a GDI engine for model validation and HCCI combustion development.

SAE Technical Paper n. 2013-01-1654, Vol. 2, 2013.

(cited in p. 70)

Zhao F.-Q., Lai M.-C. and Harrington D.L.

A review of mixture preparation and combustion control strategies for spark-ignited directinjection gasoline engines.

SAE Technical Paper n. 970627, 1997.

(cited in p. 45)

Zhao H.

HCCI and CAI Engines for the Automotive Industry.

Woodhead Publishing Limited, 2007.

(cited in pp. 49, 54, 56, 58, 69)

Zhao H., Li J., Ma T. and Ladommatos N.

Performance and analysis of a 4-stroke multi-cylinder gasoline engine with CAI combustion.

SAE Technical Paper n. 2002-01-0420, 2002.

(cited in pp. 50, 54, 63, 69)

Zhao H., Peng Z. and Ladommatos N.

Understanding of controlled autoignition combustion in a four-stroke gasoline engine.

Proceedings of the Institution of Mechanical Engineers, Part D: Journal of Automobile Engineering, Vol. 215 n $^{\circ}$ 12, pp. 1297-1310, 2001.

(cited in p. 55)

Zhao H., Peng Z. and Ma T.

Investigation of the HCCI/CAI combustion process by 2-D PLIF imaging of formaldehyde. SAE Technical Paper n. 2004-01-1901, 2004.

(cited in p.69)

Zhao H., Zhang L., Xie H., Xie L., Wang X. and Chen T.

Influence of intake backflow on HCCI auto-ignition timing.

Ranshao Kexue Yu Jishu/Journal of Combustion Science and Technology, Vol. $19 \mathrm{n}^{\circ}$ 3, pp. 206-212, 2013.

(cited in p. 70) 
Zhen X., Wang Y., Xu S., Zhu Y., Tao C., Xu T. and Song M.

The engine knock analysis - An overview.

Applied Energy, Vol. 92, pp. 628-636, 2012.

(cited in pp. 129, 181)

Zheng J. and Caton J.A.

Second law analysis of a low temperature combustion diesel engine: Effect of injection timing and exhaust gas recirculation.

Energy, Vol. 38 n ${ }^{\circ}$ 1, pp. 78-84, 2012. 